
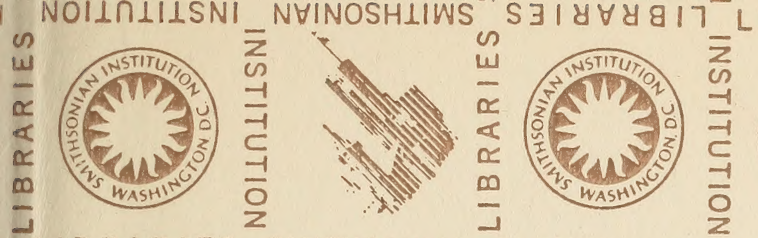

SMITHSC

LIBRARIES SMITHSONIAN
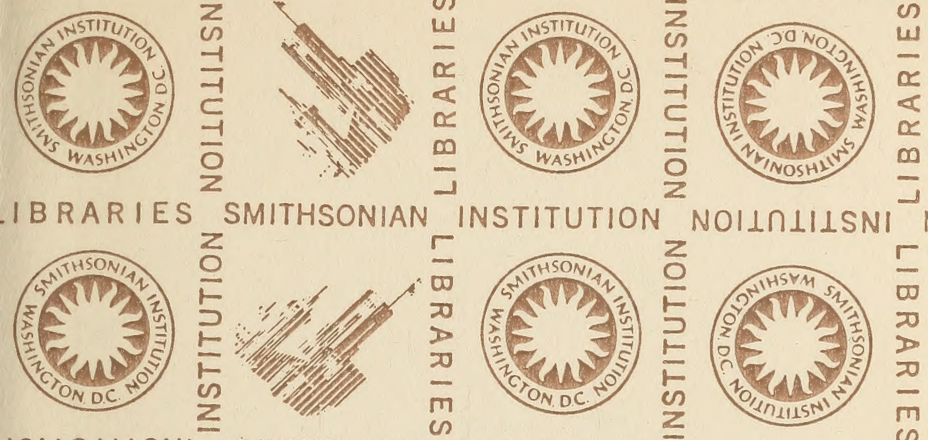

)

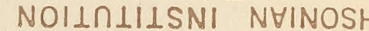
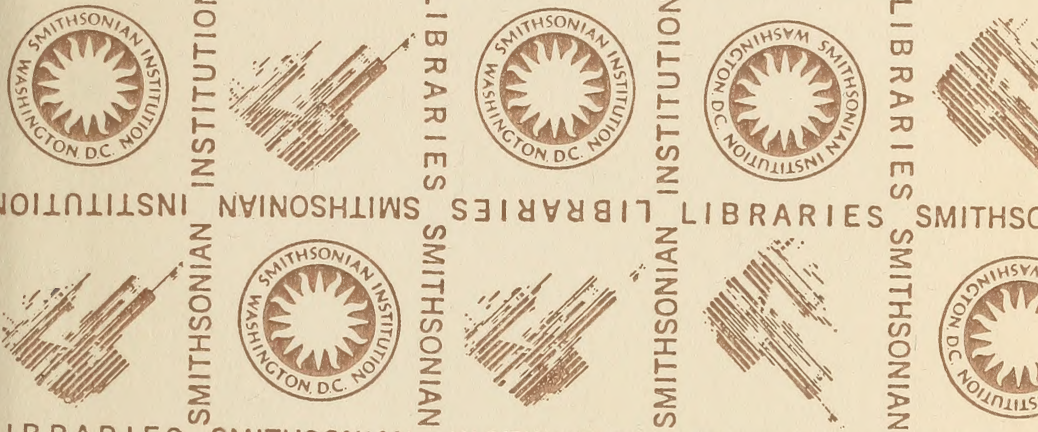

LIBRARIES SMITHSONIAN

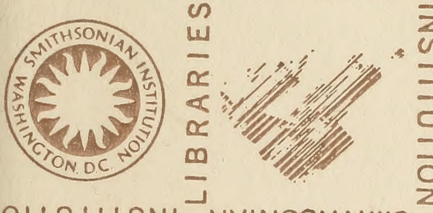

INSTITUTION

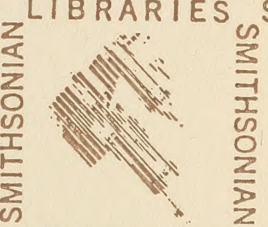

SMITHSC
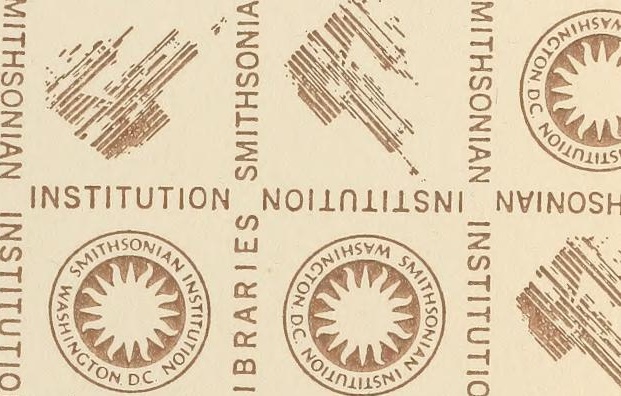

NHINOSH

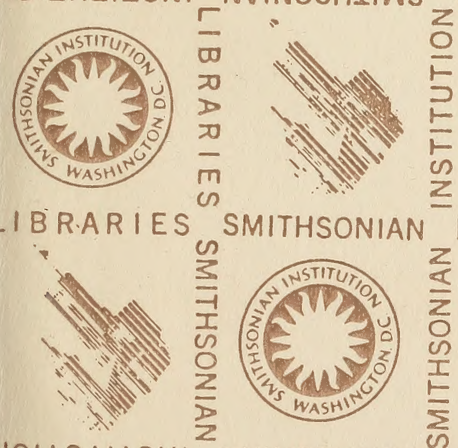

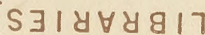
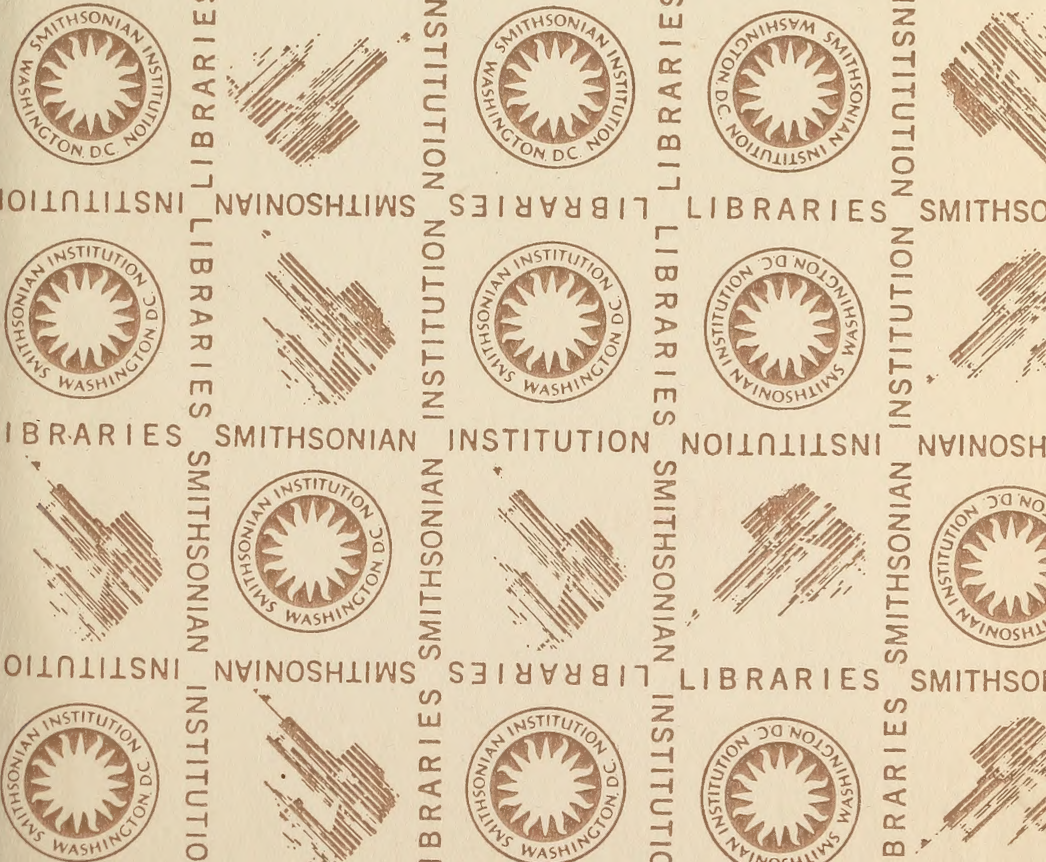

NHINOSH
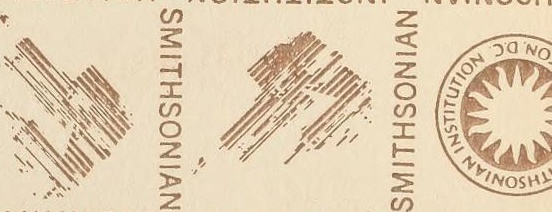

LIBRARIES SMITHSOI 






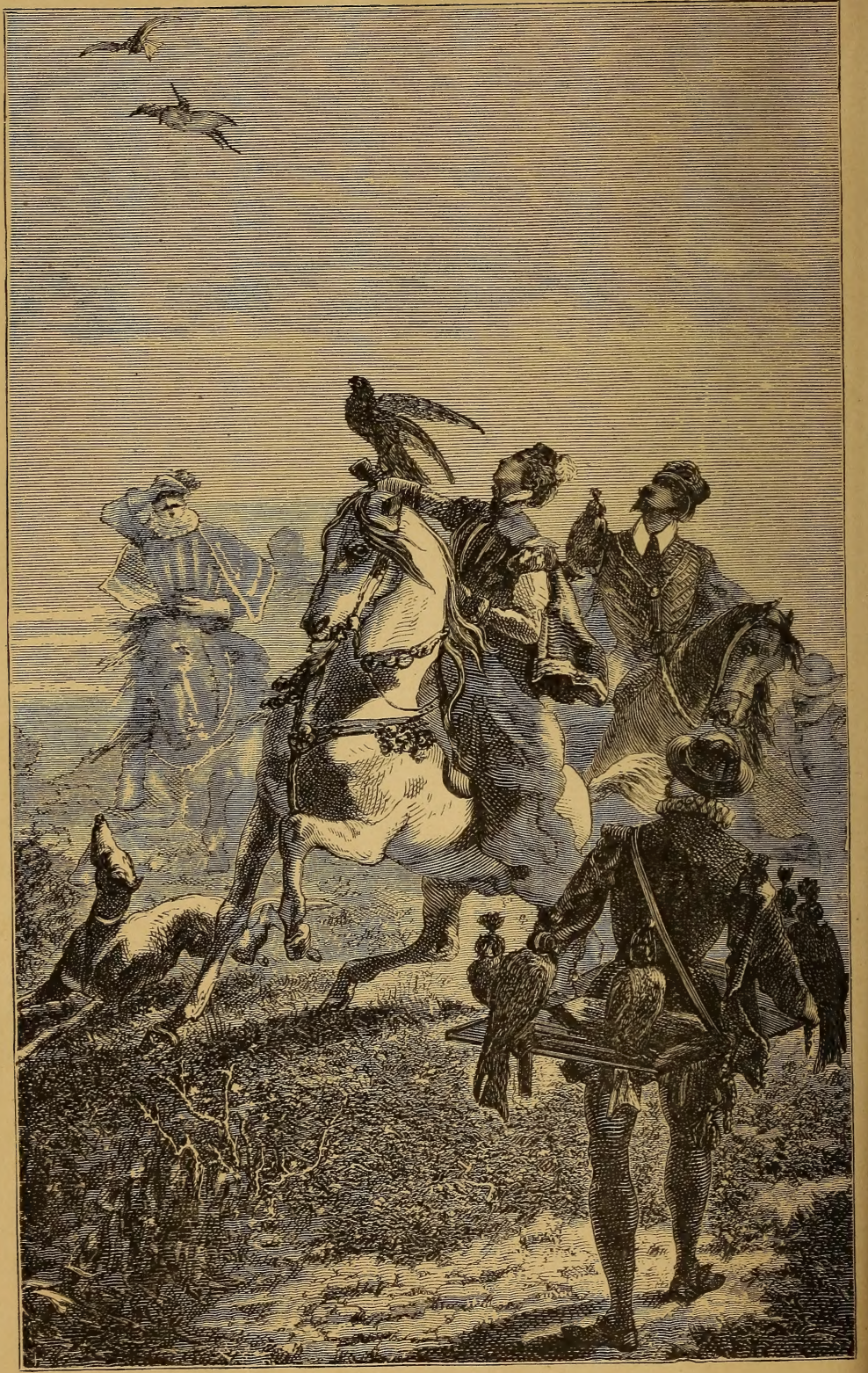




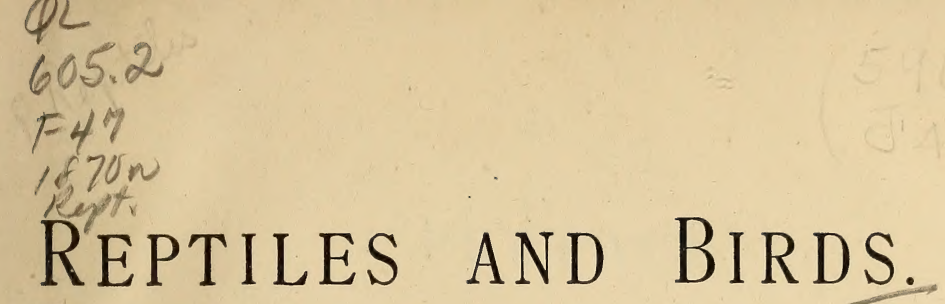

A Fopular Arrount of

\section{THEIR VARIOUS ORDERS,}

WITH A DESCRIPTION OF THE HABITS AND ECONOMY OF THE MOST INTERESTING.

FROM THE FRENCH OF

$$
\text { LOUIS FIGUIER. }
$$

NEW EDITION, REVISED BY

P A R K E G I L L M O RE.

("UBIQUE.")

IHith 307 Tlumfrations.

SMITHSONIAN

JAN 221979

D. A P P L E T O N

LIBRARIES

NEW YORK. 


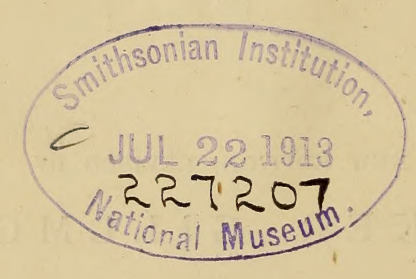




\section{PREFACE.}

IN presenting to the public this Second Edition of the English version of LOUIS FIGUIER's interesting work on Reptiles and Birds, I beg to state that the whole has been most carefully revised, and where alterations and additions have been made, my object has been that the style and matter should be suited to the present state of general - knowledge, and that all classes should be able to obtain useful information and amusement from the pages which I have again the honour and pleasure of presenting to them.

On originally commencing my undertaking I was not aware of the immensity of the labour to be done, and fear that I must have relinquished my arduous task but for the kind encouragement of FrANK BUCKLAND, Esq., Inspector of Salmon Fisheries, and HENRY LEE, Esq., F.L.S., F.G.S., \&c., to both of whom I return my sincere thanks.

\section{PARKER GILLMORE}

Fanuary, 1873 . 



\section{O N T E N T S.}

\section{REPTILES.}

INTRODUCTORY CHAPTER

CHAPTER 1 .

AMPHIBIA, OR BATRACHIANS.

Structural Distinctions

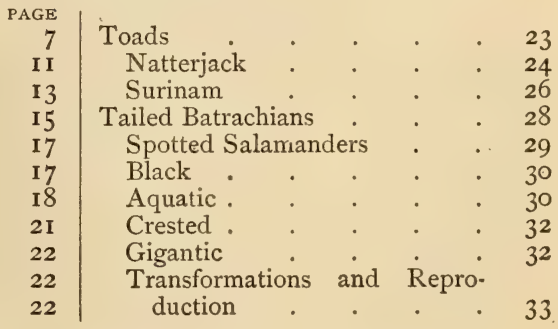

CHAPTER II.

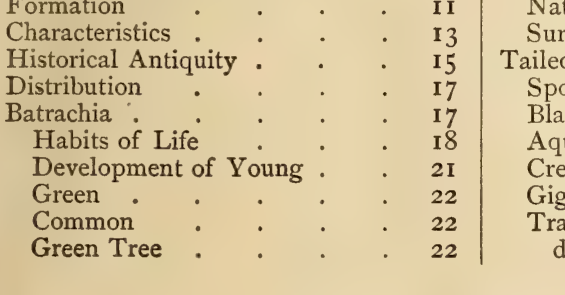

OPHIDIAN REPTILES, OR TRUE SNAKES.

Snakes

Burrowing . . . . 39

Ground . . . . . 39

Tree . . . . . 39

Fresh-water . . . . 39

Sea . . . 40

Innocuous Snakes . . . 42

Blind

Shield-tail : $\quad: \quad 4 \quad 43$

Black . : : . 44

Rat . . . . 45

Ringed . . . . 45

Green and Yellow : . $\quad 47$

Viperine . . . 47

Desert . . . . 47

Whip . . . 49

Blunt-heads . . . . 5 I

Boas

Diamond
Carpet . . . . 54

Rock . . . . . 55

Natal Rock . . . . 55

Guinea Rock . . . . 55

Royal Rock . : . . . 55

Aboma . . . . 56

Anaconda . . . 59

Venomous Snakes . . . 64

Cobra . . . 65

Asp . . . . 70

Bungarus . . . . 7 I

Pit Vipers . . . . 73

Fer-de-lance . . . . 73

Trimeresurus . . . . 75

Rattle . . . . 76

Copperhead . . . 76

Tic-polonga . . . 82

Puff Adders : . . 83

Common Adder . . $\quad 83$ 
CHAPTER III.

THE ORDER OF LIZARDS-SAURIANS.

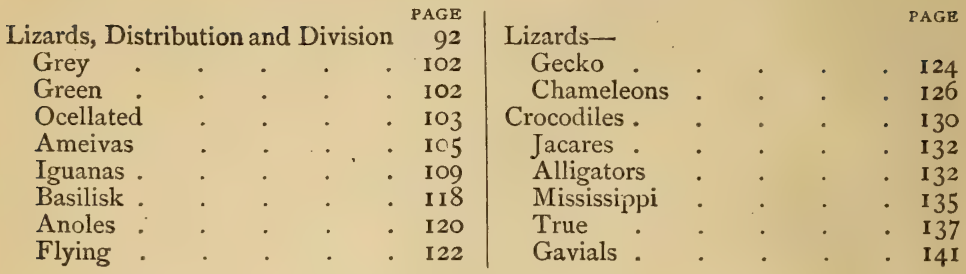

\section{CHAPTER IV.}

CHELONIANS, OR SHIELDED REPTILES.

Formation .

- 142

Distribution and Classification . 144

Tortoises

Land

Margined

Moorish.

Greek

Elephantine

Genus Pyxis

Ditto Kinixys

Homopodes
Elodians, or Marsh Tortoises Mud

Emydes .

Pleuroderes

Potamians, or Rizer Tortoises

Trionyx .

Thalassians, or Sea Tortoises

Green

Hawk's-bill

Loggerhead

Leather-back .
147

149

I 49

I 49

I 50

150

I 56

162

162

163

I63

\section{BIRDS.}

INTRODUCTORY CHAPTER.

Anatomy . . . . . 165

Plumage . . . . . 170

Feet .

. 173

$\begin{array}{lllll}\text { Beaks } & \cdot & \cdot & & \mathbf{1} 74 \\ \text { Digestive Organs } & \cdot & . & . & \mathbf{1} 76\end{array}$

Powers of Sight
Vocal Organs

Nests

Reproduction

Longevity .

Utility

Classification
179

181

185

187

189

191

\section{CHAPTER I.}

THE NATATORES, OR SWIMMING BIRDS.

\section{Divers}

Great Northern

Black-throated

Red-throated .

Penguins

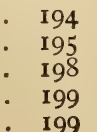

Grebes

Crested .

Horned .

American

Guillemots 
CHAPTER II.

DUCKS, GEESE, SWANS, AND PELICANS.

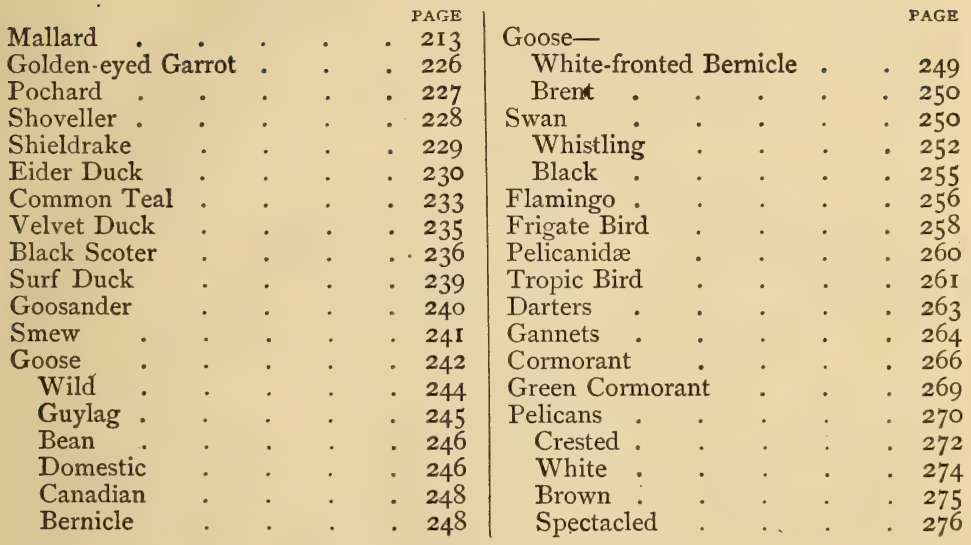

CHAPTER III.

THE LARIDA.

Longipennes . . . . $277 \mid$ Lesser Tern . . . 280 Terns

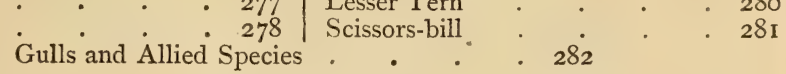

CHAPTER IV.

GRALLATORES, OR WADING BIRDS.

Palmidactyles

Macrodactyles

Longirostres

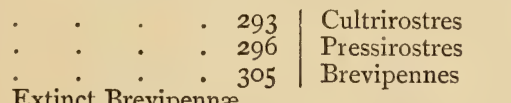

Extinct Brevipennæ

367

CHAPTER V.

GALLINACEOUS BIRDS.

Tetraonidæ

Perdicides .

Tinamides .

Chionidx

Megapodinæ
$37 \mathrm{I}$

375

393

394

394

Phasianidæ

Columbidæ

397

$42 \mathrm{I}$

Colombi-Gallines

Colombes .

Colombars

430

CHAPTER VI.

SCANSORES OR CLIMBERS.

Parrots

Toucans

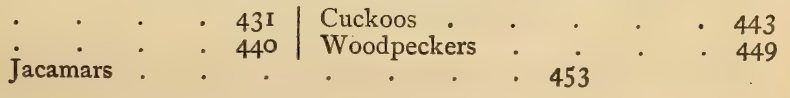


CHA P T R VII.

PASSERINES.

Syndactyles

Tenuirostres

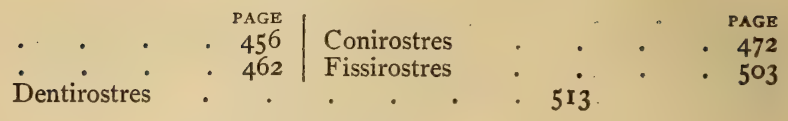

CHAPTER VIII.

RAPTORES, OR BIRDS OF PREY.

Nocturnal Birds of Prey

Horned Owls

Hornless Owls Vultures

- 545

- 547

. 553

\section{Diurnal Birds of Prey} Falconidæ . 560 Sea Eagles 561

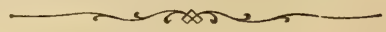

\section{FULL-PAGE ILLUSTRATIONS.}

PLATE

Hawking in the Midde Ages (Frontispiece).

I. SNake Charmers .

II. Chased by an Alligator

III. Capturing Turtles

IV. Gathering EgGs in the Faroe Islands

V. Flight of Wild Ducks

VI. Shooting over Decoy Ducks

VII. DUCK-Shooting From A Hut

VIII. Duel between Ruffs .

IX. Ruffas in their Nuptial Plumage

X. Woodcock Shooting

XI. The OSTRICH .

XII. The Emu, or Australian Cassowary

XIII. QUAILS AND YOUNG

XIV. QuaIl Shooting

XV. PARTRIDGe Shooting

XVI. COMMON PARTRIDGe AND Young

XVII. Red-LEgGed Partridge Shooting

XVIII. Pheasant Shooting

XIX. Golden Pheasants

$\mathrm{XX}$. ARGUS

XXI. Cochin China Fowls 


\section{REPTILES AND BIRDS.}

\section{INTRODUCTORY.}

THERE is little apparent resemblance between the graceful feathered warbler which makes the woods re-echo with its cheerful song and the crawling reptile which is apt to inspire feelings of disgust-between the familiar swallow, which builds its house of clay under the eaves of your roof, or the warbler, whose nest, with its young progeny, is carefully guarded by the father of the brood in the silent watches of the night, and the serpent which threatens them, its huge mouth disclosing fearful fangs, and against which the despairing parents have nothing but their slender bills to oppose. "Placed side by side," says Professor Huxley, "a humming-bird and a tortoise, or an ostrich and a crocodile, offer the strongest contrast; and a stork seems to have little but its animality in common with the snake which it swallows." Nevertheless, unlike as they are in outward appearance, there is sufficient resemblance in their internal economy to bring them together in classifying the animal kingdom. The air-bladder which exists between the digestive canal and kidneys in some fishes, becomes vascular, with the form and cellular structure of lungs in reptiles; the heart has two auricles, the ventricle in most is imperfectly divided, and more or less of the venous blood is mixed with the arterial, which circulates over the body; but, retaining their gills and being transitional in structure, they are also cold-blooded. In birds, the lungs are spongy, the cavity of the air-bags becoming obliterated by the multiplication of vascular cellules; the heart is four-chambered, transmitting venous blood to the lungs and pure arterial blood to the body; the temperature is raised and maintained at $90^{\circ}$ to $100^{\circ}$ Fahr.

Thus reptiles, like birds, breathe the common air by means of 
their lungs, but respiration is much less active. "Although," remarks Professor Owen, "the heart of Birds resembles in some particulars that of Reptiles, the four cavities are as distinct as in the Mammalia, but they are relatively stronger, their valvular mechanism is more perfect, and the contractions of this organ are more forcible and frequent in Birds, in accordance with their more extended respiration and their more energetic muscular action." It is true, as Professor Huxley informs us, that the pinion of a bird, which corresponds with the human hand or the forepaw of a reptile, has three points representing three fingers : no reptile has so few.* The breast-bone of a bird is converted into membrane bone : no such conversion takes place in reptiles. The sacrum is formed by a number of caudal and dorsal vertebræ. In Reptiles the organ is constituted by one or two sacral vertebræ.

In other respects the two classes present many obvious differences, but these are more superficial than would be suspected at a first glance; and Professor Huxley believes that, structurally, "reptiles and birds do really agree much more closely than birds with mammals, or reptiles with amphibians."

While most existing birds differ thus widely from existing reptiles, the cursorial or struthious genera, comprising the Ostrich, Nandou, Emu, Cassowary, Apteryx, and the recently extinct Dinornis of New Zealand, come nearer to the reptiles in structure. All of these are remarkable for the shortness of their wings, the absence of a crest or keel upon the breast, and peculiarities of the skull, which bring them nearer to the Reptilian order. But the gap between Reptiles and Birds is only slightly narrowed by these examples, and is somewhat unsatisfactory to those who advocate the development theory, which asserts that all animals have proceeded, by gradual modification, from a common stock.

Traces had been discovered in the Mesozoic formations of certain ornitholites, which were too imperfect to determine the affinities of the bird. But the calcareous mud of the ancient sea-bottom, which has hardened into the famous lithographic slate of Solenhofen, revealed to Hermann von Meyer, in $\mathrm{I} 86 \mathrm{I}$, first the impression of a feather, and, in the same year, the independent discovery of a skeleton of the bird itself, which Von Meyer had named Archcoopteryx lithographicus. This relic of a far-distant age now adorns the British Museum.

The skull of the Archæopteryx is almost lost, but the leg, the foot,

*Vide, however, p. 8.-ED. 
the pelvis, the shoulder-girdle, and the feathers, as far as their structure can be made out, are completely those of existing birds. Two digits of the Manus have curved claws, and, to all appearance, the metacarpal bones are quite free and disunited, exhibiting, according to Professor Huxley, closer approximation to the reptilian structure than any existing bird. Mr. Evans has even detected that the mandibles were provided with teeth.

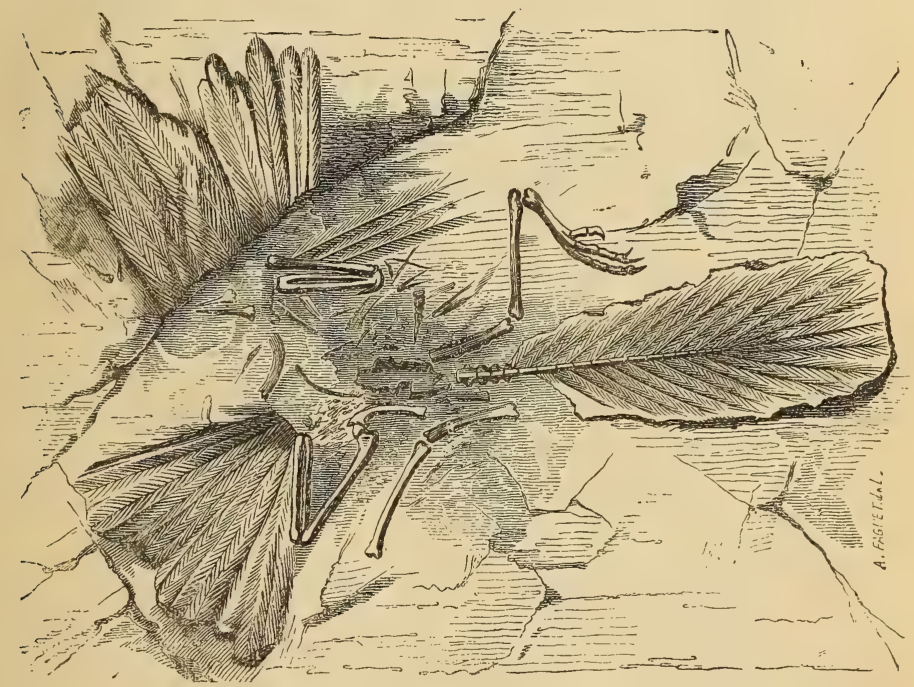

Fig. 1.-Archæopteryx lithographicus.

On the other hand, the same writer points out certain peculiarities in the single reptile found also among the Solenhofen slates which has been described and named Compsognathus longipes by the late Andreas Wagner. This reptile he declares "to be a still nearer approximation to the missing link between reptiles and birds," thus further narrowing the gap between the two classes.

While we think it proper to point to these structural resemblances of one class of the animal creation to others very different in their external appearance, it is necessary to guard our readers from adopting the inferences sometimes deduced; that "these infinitely diversified forms are merely the final terms in an immense series of 
changes which have been brought about in the course of immeasurable time by the operation of causes more or less similiar to those which are at work at the present day." Domestication and other circumstances have no doubt produced alterations in the form of many animals ; but none from which this inference can be drawn, except in the imagination of ingenious men, who strain facts to support a preconceived hypothesis. In spite of the innumerable forms which the pigeon assumes by cross-breeding and domestication, it still remains a pigeon ; the dog is still a dog; and so with other animals. Nor does it seem necessary, or calculated to advance our knowledge of natural history, to form theories which can only disturb our existing systems without supplying a better. Systems are necessary for the purpose of arrangement and identification; but it should never be forgotten that all classifications are artificial-a framework or cabinet, into the partitions of which many facts may be stowed away, carefully docketed for future use. "Theories," says Le Vaillant, "are more easily made and more brilliant probably than observations; but it is by observation alone that science can be enriched." A bountiful Creator appears to have adopted one general plan in the organisation of all the vertebrate creation; and, in order to facilitate their study, naturalists have divided them into classes, orders, and genera, formed on the differences which exist in the structure of their vital functions. The advantages of this are obvious, but it does not fathom what is unfathomable, or explain what is inexplicable in the works of God.*

In previous volumes of this seriest we have endeavoured to give the reader some general notions of the form, life, and manners of the branches of the animal kingdom known as Zoophytes, Mollusca, Articulata, and Pisces. We now continue the superior sub-kingdom (to which the fishes also belong) of the vertebrated animals, so called from the osseous skeleton which encircles their bodies, in which the vertebral column, surmounted by its appendage the cranium, forms the principal part.

The presence of a solid frame in this series of animals admits of their attaining a size which is denied to any of the others; while their nervous system is also more developed. There is, consequently, a more exquisite sensibility in them than in the classes whose history

* This, however, is a subject upon which naturalists of the highest rank hold different opinions, many of those most highly qualified to form a correct judgment advocating the tenets propounded by Mr. Charles Darwin. - ED.

$\dagger$ "The Ocean World," from the French of Louis Figuier. "The Insect World," from the French of the same author. 
we have hitherto discussed. They possess five senses, a heart, a circulation, with red blood.

We have now to deal with a class advanced above that of fishes, that of Reptilia, which is divided as follows :-

\section{AmpHibia-(Batrachia, Cuv.)}

Animals having ribs or processes, or short, slight, and free vertebræ, forming a series of separate centrums, deeply cupped at both ends, one of which is converted by ossification in the mature animal into a ball, which may be the front one, as in the Surinam Toad, Pipa; or the hind one, in the Frogs and Toads, Rana. The skin is nude, limbs digitate, gills embryonal, permanent in some, in most lost in metamorphosis, to be succeeded by pulmonary respiration, or both ; a heart with one ventricle and two auricles. 'They consist of :-

I. OPHIOMORPHA.

Cæciliadæ or Ophiosomæ.

II. ICTHYOMORPHA.

Proteidæ or Sirens, Proteus, Newts, and Salamanders.

III. Theriomorpha.

Aglossa . . Pipa or Surinam Toads.

Ranida . . Frogs.

Hylide . . . Tree Frogs.

Bufonide . . Toads.

\section{Chelonia, or Turtles.}

Distinguished by the double shield in which their bodies are enclosed, whether they are terrestrial, fresh-water, or marine.

The Turtles, Chelonia, have the limbs natatory.

$\left.\begin{array}{l}\text { Mud Turtles, Trionyx, } \\ \text { Terrapens, Emys, }\end{array}\right\}$ limbs amphibious.

Tortoises, Testudo, limbs terrestrial.

\section{LACERTILIA.}

Having a single transverse process on each side, single-headed ribs, two external nostrils, eyes with movable lids; body covered with horny sometimes bony scales.

Lacerta-the Monitors, Lizards; having ambulatory limbs. Anguis-Ophisaurus, Bimanus, Chalcides, Seps ; limbs abortive ; no sacrum. 


\section{OpHIDIA.}

Having numerous vertebræ with single-headed hollow ribs, no visible limbs, eyelids covered by an immovable transparent lid; body covered by horny scales. It includes :-

Viperine-the Vipers and Crotalidæ.

Colubrinu - the Colubers, Hydridæ, and Boidæ.

\section{Crocodilia.}

Teeth in a single row, implanted in distinct sockets; body depressed, elongated, protected on the back by solid shield; tail longer than the trunk, compressed laterally, and furnished with crests above. The several families are :-

Crecodilida-the Gavials, Mecistops, Crocodiles. Alligatorida-Jacares, Alligators, Caiman.*

* By some naturalists the Amphibia are considered as a distinct class, by others as a sub-class either of Reptilia or of Pisces. Of the Reptiles proper (at present existing), the arrangement into the orders Testudinata (or Tortoises), Sauria (or Lizards), and Ophidia (or Snakes), is the one most generally adopted; but De Blainville elevates the Loricata (or Crocodiles) to the rank of an order, and others have adopted a division of corresponding rank, Saurophida, for the Anguis series above referred to ; but the latter are merely limbless Lizards (or with abortive limbs) akin to the Scinques.-ED. 


\section{CHAPTER I.}

\section{AMPHIBIA, OR BATRACHIANS.}

Those geographers who divide the world into land and sea overlook in their nomenclature the extensive geographical areas which belong permanently to neither section-namely, the vast marshy regions on the margins of lakes, rivers, and ponds, which are alternately deluged with the overflow of the adjacent waters, or are parched from the exhalations produced by summer heat; regions which could only be inhabited by beings capable of living on land or in water-beings having both gills (through which they may breathe in water) and lungs (through which they may breathe on land.) The first order of Reptiles possesses this character, and hence

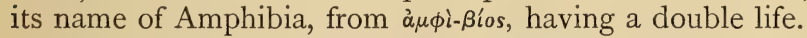

The transition from Fishes to Reptiles is described by Professor Owen, with that wonderful power of condensation which he possesses, in the following terms:- "All vertebrates, during more or less of their developmental life-period, float in a liquid of similar specific gravity to themselves. A large proportion, constituting the lowest organised and first developed forms of this province, exist and breathe in water, and are called fishes. Of these a few retain the primitive vermiform condition, and develop no limbs; in the rest they are 'fins' of simple form, moving by one joint upon the body, rarely adapted for any other function than the impulse or guidance of the body through the water. The shape of the body is usually adapted for moving with least resistance through the liquid medium. The surface of the body is either smooth and lubricous or it is covered with overlapping scales; it is rarely defended by bony plates or roughened by tubercles. Still more rarely is it armed with spines." Passing over the general economy of Fishes we come to the heart. " "The heart," he tells us, "consists of one auricle receiving the venous blood, and one ventricle propelling it to the gills or organs submitting that blood in a state of minute subdivisions to the action of aerated water. From the gills the aërated blood is carried over the entire body by vessels, 
the circulation being aided by the contraction of the surrounding muscles."

The functions of gills are described by the Professor with great minuteness. "The main purpose of the gills of fishes," he says, "being to expose the venous blood in this state of minute subdivision to streams of water, the branchial arteries rapidly divide and sub-divide until they resolve themselves into microscopic capillaries, constituting a network in one plane or layer, supported by an elastic plate, covered by a tesselated and non-ciliated epithelium. This covering and the tunics of the capillaries are so thin as to allow chemical interchange and decomposition to take place between the carbonated blood and the oxygenated water. The requisite extent of the respiratory field of capillaries is gained by various modes of multiplying the surface within a limited space." "Each pair of processes," he adds, "has its flat side turned towards contiguous pairs, and the two processes of each pair stand edgeway to each other, being commonly united for a greater or less extent from their base ; hence Cuvier describes each pair as a single bifurcated plate, or 'feuillet.' "

The modification which takes place in the respiratory and other organs in Reptilia is described in a few words. "Many fishes have a bladder of air between the digestive canal and the kidneys, which in some communicates with an air-duct and the gullet; but its office is chiefly hydrostatic. When on the rise of structure this air-bladder begins to assume the vascular and pharyngeal relations with the form and cellular structure of lungs, the limbs acquire the character of feet: at first thread-like and many-jointed, as in the Lepidosiren; then bifurcate, or two-fingered, with the elbow and wrist joints of land animals, as in Amphiuma; next, three-fingered, as in Proteus; or four-fingered, but reduced to the pectoral pair, as in Siren."

In all Reptiles the blood is conveyed from the ventricular part of the heart, really or apparently, by a single trunk. In Lepidosiren the veins from the lung-like air-bladders traverse the auricle which opens directly into the ventricle. In some the vein dilates before communicating with the ventricle into a small auricle, which is not outwardly distinct from the much larger auricle receiving the veins of the body. In Proteus the auricle system is incomplete. In Amphiuma the auricle is smaller and less fringed than in the Sirens, the ventricle being connected to the pericardium by the apex as well as the artery. This forms a half spiral turn at its origin, and dilates into a broader and shorter bulb than in the Sirens. 
"The pulmonic auricle," continues the learned Professor, "thus augments in size with the more exclusive share taken by the lungs in respiration; but the auricular part of the heart shows hardly any outward sign of its diversion in the Batrachians. It is small and smooth, and situated on the left, and in advance of the ventricle in newts and salamanders. In frogs and toads the auricle is applied to the base of the ventricle, and to the back and side of the aorta and its bulb."

In the lower members of the order the single artery from the ventricle sends, as in fishes, the whole of the blood primarily to the branchial organs, and in all Batrachians at the earlier aquatic periods of existence. In the Newt, three pairs of external gills are developed at first as simple filaments, each with its capillary loop, but speedily expanding, lengthening, and branching into lateral processes, with corresponding looplets, these blood-channels intercommunicating by a capillary network. The gill is covered by ciliated scales, which change into non-ciliated cuticle shortly before the gills are absorbed. In the Proteus anguinus, three parts only of branchial and vascular arches are developed, corresponding with the number of external gills. In Siren lacertina the gills are in three pairs of branchial arches, the first and fourth fixed, the second and third free, increasing in size according to their condition.

Thus, the Amphibia have, at some stage of their existence, both gills and lungs co-existent ; respiring by means of branchiæ or gills while in the water, and by lungs on emerging from it.

All these creatures seem to have been well known to the ancients. The monuments of the Egyptians abound in representations of Frogs, Toads, Tortoises, and Serpents. Aristotle was well acquainted with their form, structure, and habits, even to their reproduction. Pliny's description, however, presents some amount of error and exaggeration. Darkness envelops their history during the Middle Ages, from which it gradually emerges in the early part of the sixteenth century, when Belon and Rondeletius in France, Salviani in Italy, and Conrad Gesner in Switzerland, devoted themselves to the study of natural history with great success. In the latter part of the same century Aldrovandi appeared. During fifty years he was engaged in collecting objects and making drawings, which were published after his death, in 1640, being edited by Professor Ambrossini, of Bologna, the reptiles forming two volumes: in these volumes, twenty-two chapters are occupied by the Serpents. But the first arrangement which can be called systematic was that produced by John Ray, who based his system 
upon their mode of respiration, the volume of their eggs, and their colour.

Numerous systems have since appeared in France, Germany, and England; but we shall best consult the interest of our readers by briefly describing the classification adopted by Professor Owen, the learned principal of the British Museum, in his great work on the vertebrata.

The two great classes Batrachians and Reptiles, include a number of animals which are neither clothed with hair, like the Mammalia, covered with feathers like the Birds, nor furnished with swimming fins like Fishes. The essential character of Reptiles is, that they are either entirely or partially covered with scales. Some of them-for instance, Serpents-move along the ground with a gliding motion, produced by the simple contact and adhesion of the ventral scales with the ground. Others, such as Tortoises, Crocodiles, and Lizards, move by means of limbs ; but these, again, are so short, that the animals, with very few exceptions, appear only capable of crawling slowly. Again, some of this class are only furnished with feet in the pectoral region; but this is the exception. The locomotive organs in Serpents are the vertebral column, with its muscles, and the stiff epidermal scutes crossing the under surface of the body. "A Serpent may, however, be seen to progress," says Professor Owen, "without any inflection, gliding slowly and with a ghost-like movement in a straight line; and if the observer have the nerve to lay his hand flat in the reptile's course, he will feel, as the body glides over the palm, the surface pressed as it were by the edges of a close-set series of paper knives successively falling flat after each application." In some, as in various Lizards, the limbs acquire considerable strength.

There is one genus of small Lizards, known as the Dragons (Draco), whose means of progression present an exception to the general rule. Besides their four feet, these animals are furnished with a delicate membranous parachute, formed by a prolongation of the skin on the flanks, and sustained by the long slender ribs, which permits of their gliding through the air upon their prey from a considerable height.

Batrachians, again, differ from most other Reptilia by being naked; moreover, most of them undergo certain metamorphoses. In the first stage of their existence they lead a purely aquatic life, and breathe by means of gills, after the manner of fishes. Young Frogs, Toads, and Salamanders, which are then called tadpoles, have at that stage no resemblance whatever to their parents in structure. They are little creatures with slender, elongated bodies, destitute of 
feet and fins, but with large heads. In stagnant ponds they are frequently found in numbers, where they live and breathe after the manner of fishes. By degrees, however, they are transformed, their limbs and air-breathing lungs commence to develop, when they disappear, till the day arrives that they find themselves organised for another existence, when they leave their liquid retreat and betake themselves to dry land. "The tadpole, meanwhile being subject to a series of changes in every system of organs concerned in the daily needs of the coming aërial and terrestrial existence, still passes more or less time in water, and supplements the early attempt at respiration by pullulating loops and looplets of capillaries from the branchial vessels." (Owen.)

Nevertheless, they do not altogether forget their native element ; thanks to their webbed feet they can still traverse the waters which sheltered their infancy; and when alarmed by any unusual noise, they rush into it as a place of safety. To the Proteus and the amphibious Sirens, where the limbs are confined to the pectoral region, swimming is most natural. They are truly amphibious, and they owe this double existence to the persistence of their gills; for in these perenni-branchiate Batrachians, arteries are developed from the last pair of branchial arches which convey blood to the lungs: while, in those having external deciduous gills, the office being discharged, they lose their ciliate and vascular structure and disappear altogether. The skull in Reptiles generally consists of the same parts as in the Mammalia, though the proportions are different. The skull is flat, and the cerebral cavity, small as it is, is not filled with brain. The vertebral column commences at the posterior part of the head, two condyles occupying each side of the vertebral hole (Fig. 2). The anterior limbs are mostly shorter than the posterior, as might be expected of animals whose progression is effected by leaps. Ribs there are none. The sternum is highly developed, and a large portion of it is cartilaginous; it moves in its mesial portions the two clavicles and two coracoid bones, which fit on to the scapula, the whole making a sort of hand which supports the anterior extremities, and an elongated disc which supports the throat, and assists in deglutition and respiration. The bone of the arm (humerus) is single, and long in proportion to the fore arm. In the Frogs (Rana), the iliac bone is much elongated, and is articulated in a movable manner on the sacrum, so that the two heads of the thigh bones seem to be in contact. The femur or thigh is much lengthened and slightly curved, the leg joined together so as to form a much-elongated single bone. 
The respiration of Reptiles and some of the Batrachians, like that of Birds and Mammals, is aërial and pulmonary, but it is much less active. Batrachians have, in addition, a very considerable cutaneous respiration. Some of them, such as Toads, absorb more oxygen through the skin than by the lungs. Their circulation is imperfect, the structure of the heart only representing one ventricle ; the blood, returning after a partial regeneration in the lungs, mingles with that which is not yet revivified: this mixed fluid is launched

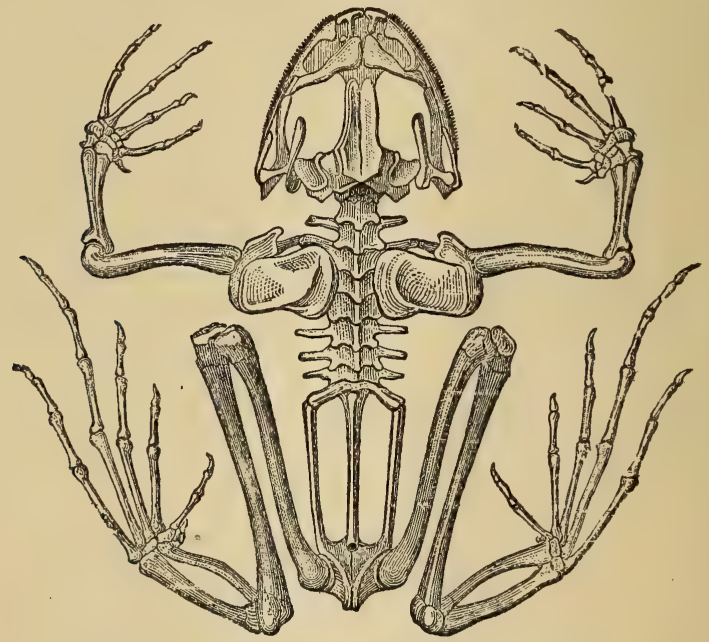

Fig. 2.-Skeleton of a Frog.

out into the economic system of the animal. Thus Reptiles and Batrachians are said to be cold-blooded animals, more especially the former, in which the respiratory organs, which are a constant source of interior heat, are only exercised very feebly. Owing to this low temperature of their bodies, Reptiles affect warm climates, where the sun exercises its power with an intensity unknown in temperate regions; hence it is that they abound in the warm latitudes of Asia, Africa. and America, whilst comparatively few are found in Europe. This is also the cause of their becoming torpid in our latitudes during the winter, not having sufficient heat in themselves to produce reaction against the external cold, re-awakening only 
when the temperature permits of their activity. Serpents, Lizards, Tortoises, Frogs, are all subjected to this law of their being. Some hybernate upon the earth, under heaps of stone, or in holes; others in mud at the bottom of ponds. The senses are very slightly developed in these animals; those of touch, taste, and smell, being very imperfect; hearing scarcely so much so; but not so with sight, for their large eyes are provided with contractile eyeballs, which enables certain reptiles-such, for instance, as the geckos-to distinguish objects in the dark. Most Reptiles and Batrachians are almost devoid of voice ; Serpents, however, utter a sharp hissing sound, and Crocodiles howl; again, Geckos are particularly noisy, and Frogs possess the well-known croak. Reptiles and Batrachians can, it is true, be tamed; but although they seem to know individuals, they do not appear susceptible of affection; this may be attributed to the slight compass of their brain, as also that insensibility to pain which enables them to support mutilations that would prove immediately fatal to other animals. For instance, the Common Lizard frequently breaks its tail in its abrupt movements. Nor does this curtailment affect him ; for complaisant Nature renews its growth as often as it becomes necessary. In the Crocodiles and Monitor Lizards, however, a mutilated part is not renewed, and the renovated tails of other Lizards do not develop bone. In some instances, the eyes may be put out, or the animal otherwise seriously injured. In the course of time, without the animal having ceased to perform any of its functions, they will be renewed. A Tortoise will continue to live and walk for six months after it is deprived of its brain; and a Salamander has been seen in a very satisfactory state, although its head was, so to speak, isolated from the trunk by a ligature tied tightly round its neck. There is another curious peculiarity in the history of Reptiles and Batrachians : each year, as they awake from their state of torpor, they slough their old covering, or in other words cast their skin. Their growth is slow, and continues almost through the whole duration of their existence; they are, moreover, endowed with remarkable longevity. This is not very astonishing, if we consider that (at least in our latitudes) they remain torpid for several months yearly ; thus using up less of the materials of life, and, consequently, ought to attain a more advanced age. The activity of organisation in Reptiles and Batrachians is so slight that their stomachs feel less of the exigencies of hunger; hence they rarely take nourishment, and digest their food very slowly. With the exception of the Land Tortoises, whose regimen is herbivorous, most reptiles feed on living prey. Some, such as Lizards, Frogs, and Toads, subsist on worms, 
insects, small terrestrial or aquatic molluscs; others, such as Ophidians and Crocodiles, attack Birds, and even Mammals. Large Serpents, owing to the distensibility of their œsophagus, frequently swallow animals broader than themselves at the moment of seizing their prey.

Reptiles, whether Batrachians, Ophidians, or Chelonians, are mostly oviparous, sometimes ov'o-viviparous, and generally very prolific. The eggs of some are covered with a calcareous envelope, as in the turtle. Sometimes they are soft, and analogous to the spawn of fish, as in the Batrachians. Most species do not hatch their eggs by sitting upon them, but bury them in the sand, trusting to the heat of the sun, which hatches them in due course. To this the Pythons form a partial exception. Batrachians content themselves with diffusing their spawn or eggs in marshy waters or ponds, or they bear them on their backs until the time of hatching approaches. On leaving the egg young Tortoises have to provide immediately for their own wants, for the parents are not present to bring them nourishment or to defend them against enemies. Parental affection, so manifest among the superior animals, does not exist in oviparous species, except in those that hatch their eggs in the body of the mother. The young are consequently, so to speak, produced in a living state, and fully prepared for the battle of life. The loves of these animals present none of that character of mutual affection and tender sympathy which distinguishes the Mammalia and Birds.* When they have ensured the perpetuity of their species, they separate, and betake themselves again to their solitary existence.

Some Reptiles attain dimensions truly extraordinary, which render them most formidable. Turtles are met with which weigh as much as $\mathrm{I}, 600$ pounds; and carapaces have been found that measured as much as six feet in length. Although the average length of the Crocodile is about eight to nine feet, they have been seen twentyfour and even thirty feet long.

In Chelonians the surface of the skull is continuous without movable articulations. The head is oval in the Land Tortoises, the interval between the eyes large and convex, the opening of the nostrils large, the orbits round. The general distinguishing characteristic of Tortoises is the external position of the bones of the thorax, at once enveloping with a cuirass or buckler the muscular portion of the frame, and protecting the pelvis and shoulder bones. The ribs

* Birds, however, are ovip rrous, and nevertheless manifest the strongest parental affection. - ED. 
are inserted by means of sutures into these plates, and united with each other. A three-branched shoulder and cylindrical shoulderblade are characteristic of the Tortoises.

In tropical regions enormous Serpents are found, which are as

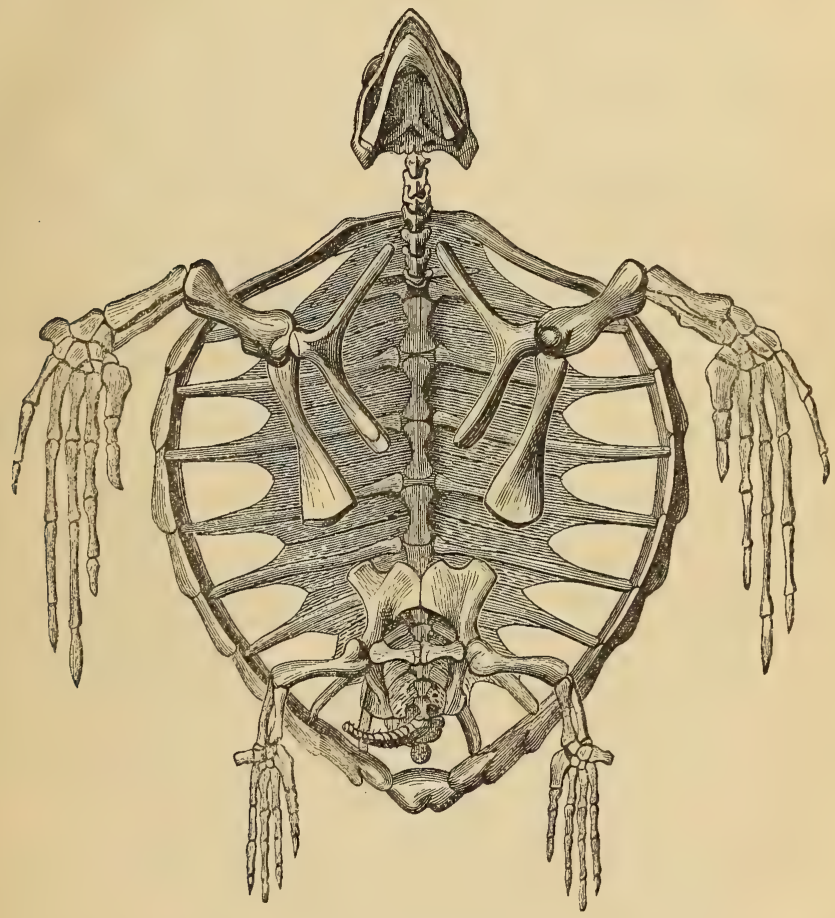

Fig. 3.-Skeleton of a Turtle.

large in diameter as a man's thigh ; and some are reported to have almost reached forty feet in length. Roman annals mention one forty feet long, which Regulus encountered in Africa during the Punic Wars, and which is fabulously said to have arrested the march of his army. These gigantic Reptiles are not, however, enemies which man has most cause to fear, for their very size draws attention to 
them, enabling them to be avoided. Not so with the more minute poisonous Snakes, which glide after their prey without attracting attention, strike it, and puncture the wound with venom, which produces death with startling rapidity. Doubtless this fatal power was the cause of barbarous nations of old worshipping certain Reptiles; even at the present time these animals are venerated by some barbarous races of men. The whole class of Reptiles are for the most part calculated to inspire feelings of repugnance, and such has been the prevailing sentiment in all ages. There are people who cannot suppress a movement of fright at the sight of an ordinary Snake, Lizard, or Frog, notwithstanding that they are most inoffensive animals. Several causes concur to produce this aversion. In the first place the low temperature of their bodies, contact with which communicates an involuntary shudder in the person who touches them; then the moisture which exudes from the skins of Frogs, Toads, and Salamanders, their fixed and strong gaze, all combine to impress one painfully, while the odour which some of them exhale is so disgusting, that it has often been known to produce fainting; add to this the fear of a real though often exaggerated danger, and we shall have the secret of the sort of instinctive horror which is felt by many people at the sight of most reptiles. Nevertheless, the poisonous species are exceptional amongst Reptiles, and among Batrachians there are none, for it is altogether a mistake to take for venom the fluid which the Toad discharges. ${ }^{*}$ Although these animals are repulsive in appearance, we can nevertheless recognise their services in the economy of Nature. Inhabitants of slimy mud and fotid swamps, they are incessantly destroying worms and insects which abound there, and which ultimately would become most injurious to animal and vegetable life; while, in their turn, they find implacable enemies in the Birds, which check an excessive increase in their race. In this manner the equilibrium of Nature is maintained.

Some of the animals which now occupy our attention render a direct service to man, being utilised by him for food. Frogs are eaten in the south of France, Italy, and many other countries; and Adders, under the name of "hedge-eels," are not despised in some localities. We know the favour in which Turtles are held by us, where soup made from them is considered a dish only fit for merchant princes. In other countries, Iguanas, Crocodiles, and even

* The Necturus, a siren-like animal inhabiting the lakes of North America, has a series of small fang-like teeth above and below, which are stated to give an envenomed bite.-Proceedings of the Zoological Society for 1857, p. 61. For poison-organs in certain fishes, vide the same publication for 1864, p. 155.-ED. 
Serpents are eaten. But viper-broth, which was known to Hippocrates, we believe, is not to be found now as an article of food.

As we have already remarked, the peculiar nature of their organisation leads Reptiles and Batrachians to seek the warmer regions of the earth. It is in those regions that they attain the enormous dimensions which distinguish certain Serpents; there, too, they secrete their most subtle poisons and display the most lively colours, which, if less rich than those of Birds and. Fishes, are not less startling in effect. Many Serpents and Lizards glitter with radiant metallic reflections; and some of them present extremely varied combinations of colour. Chameleons are found in the same localities, but in the Old World only; these and some other Lizards are remarkable for changing their colour, a phenomenon which is also seen among the Frogs, but in a smaller degree.

Reptiles and Batrachians were numerous in the early ages of our globe. It was then that those monstrous Saurians lived, whose dimensions even are startling to our imagination. The forms of the Reptiles and Batrachians of the early ages of the earth were much more numerous, their dimensions much greater, and their means of existence more varied than those of the present time. Our existent Reptiles are very degenerate descendants of those of the great geological periods, unless we except the Crocodiles and the gigantic Boas and Pythons. Whilst the Reptiles of former ages disported their gigantic masses, and spread terror amongst other living creatures, alike by their formidable armature and their prodigious numbers, we are happy to say that now they are reduced to fewer varieties. There are now but little more than r,500 species of Reptiles and Batrachians described, and only 100 of these belong to Europe.*

\section{BATRACHIA.}

Animals which compose this class have long been confounded with Reptiles, from which they differ in one fundamental peculiarity in their organisation. At their birth they respire by means of gills, and consequently resemble Fishes. In a physiological point of view, at a certain time in their lives these animals are Fishes in form, habits, and organisation. As they progress in age they undergo permanent metamorphosis-they acquire lungs, and thenceforth an aërial respiration. It is, then, easy to understand that these animals hold a doubtful rank among Reptiles, which are animals with an

* Vide subsequent notes on this subject, in p. $28, \&$ c. 
aërial respiration, and so ought to form a separate class of Vertebrates.*

Batrachians establish a transitional link between Fishes and Reptiles - they are, as it were, a bond of union between those two groups of animals. In the adult state Batrachians are cold-blooded animals with incomplete circulation, inactive respiration, and the skin bare. In the introductory section to this chapter we have given the general characteristics which belong to them. The Frogs-Tree Frogs, Toads, Surinam Toads, Salamanders, and Newts-are the representatives of the principal families of Batrachians of which we propose giving the history.

The Frogs (Rana) have suffered injury by their resemblance to Toads. This circumstance has given rise to an unfavourable prejudice against these innocent little Batrachians. Had the Toad not existed, the Frog would appear to us as an animal of a curious form, and would interest us by the phenomena of transformation which it undergoes in the different epochs of its development. We should see in it a useful inoffensive animal of slender form, with delicate and supple limbs, arrayed in that brilliant colouring which is so pleasant to the eye, and which mingles so harmoniously with the carpeting of our fields.

The body of the Edible Frog, Rana esculenta (Fig. 4), sometimes attains a length, from the extremity of the muzzle to the end of the hind feet, of six to eight inches. The muzzle terminates in a point ; the eyes are large, brilliant, and surrounded with a circle of gold colour. The mouth is large; the body, which is contracted behind, presents a tubercular and rugged back. . It is of a more or less decided green colour on the upper, and whitish on the under parts. These two colours, which harmonise well, are relieved by three yellow lines, which extend the whole length of the back, and by scattered black marblings. It is, therefore, much to be regretted that prejudice should cause some at least of us to dislike this pretty little creature. For ourselves, we cannot see the banks of our streams embellished by its presence and animated with its gambols without pleasure. Why should we not follow with our eyes their movements in our ponds, where they enliven the solitude without disturbing its tranquillity. Frogs often leave the water, not only to seek their nourishment, but to warm themselves in the sun. When they repose thus,

* They are regarded by some naturalists as a sub-class of Fishes rather than as Reptiles; as piscine forms, certain of which develop to a parallelism with the ordinary reptitian condition of advancement ; their reproduction especially favour ing this view.-ED. 
with the head lifted up, the body raised in front and supported upon the fore feet, the attitude is more that of an animal of higher organisation than an humble Batrachian. Frogs feed on larvæ, aquatic insects, worms, and small molluscs: They select their prey from living and moving creatures, for which they watch, and, when

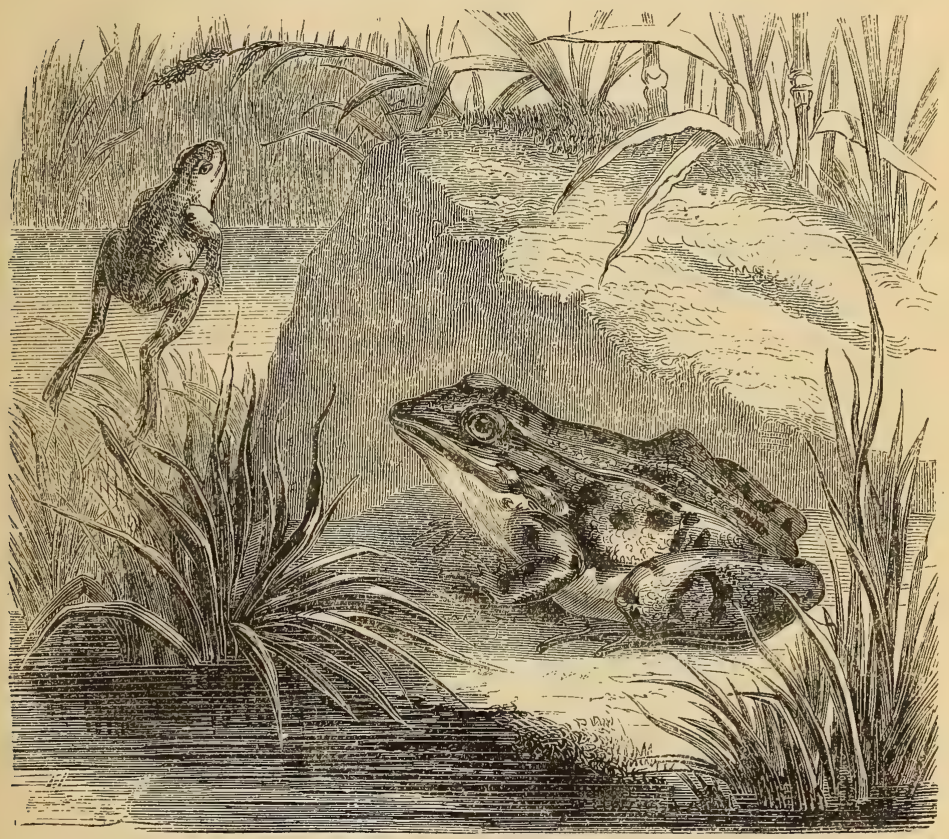

Fig. 4.-The Edible Frog.

within proper distance, they spring on them with extraordinary rapidity. A large Indian species ( $R$. tigrina), has been seen to prey occasionally upon young sparrows. Far from being dumb, like many oviparous quadrupeds, frogs have the gift of voice. The females only produce a peculiar low note, caused by the air which vibrates in the interior of two vocal pouches placed on the sides of the neck; but the cry of the male is sonorous, and heard at a great distance : it is a croak which the Greek poet Aristophanes endeavoured to imitate by the 
inharmonic consonants, brekekexkoax, coax! It is principally during rain, or in the evenings and mornings of hot days, that frogs are to be heard. Under the feudal system, during the "good old times" of the Middle Ages, the country seats of many of the nobility and country squires were surrounded by ditches half full of water, and, as might be expected, inhabited by a population of frogs. Vassals and villeins were ordered to beat the water in these ditches morning and evening in order to keep the frogs from croaking and disturbing the sleep of the lords and masters of the houses. Independent of the resounding and prolonged cries of which we have spoken, at certain times the male frog calls the female in a dull voice, so plaintive that the Romans described it by the words "ololo," or "ololygo." "Truly," says Lacépède, "the accent of love is always mingled with some sweetness."

When autumn arrives Frogs lose their voracity, and cease to eat. To protect themselves from the cold, when the season has advanced, they bury themselves deeply in the mud, troops of them joining together in the same place. Thus hidden, they pass the winter in a state of torpor. This state gives way early in spring. During the month of March they begin to awake and move about; soon after, their breeding season commences. Their race is so prolific, that a female can produce from 600 to I, 200 eggs annually. These eggs are globular, and are in form spheroid, glutinous and transparent, in the centre of which is a little blackish globule; the eggs float on the surface of the water, and at a distance look like froth or air bubbles.

All who have observed the small ponds and ditches in the country at this season, will have seen these light glutinous formations swimming on the surface of the water. After a few days, more or less according to the temperature, the little black spot, which is the embryo of the egg, and which has developed itself in the interior of the glairy mass which envelops it, disengages itself and shoots forth into the water-this is the tadpole in its earliest stage.

The body of the tadpole at birth is oval in shape, destitute of legs, and terminates in a long flat tail, which forms a true fin; on each side of the neck are two large gills, in shape like a plume of feathers ; these gills soon begin to wither, without aquatic respiration ceasing, for, besides these, the tadpole possesses interior gills like those of a fish. Soon after, the legs begin to show themselves, the hind legs appearing first; which acquire a considerable length before the fore feet show themselves. These are developed under the skin, which they pierce through. When the legs have appeared, the tail begins 
to fade, and, little by little, withers away, until in the perfect animal it entirely disappears. About the same time the lungs become developed, and assume their functions. In Fig. 5 may be traced the successive phases of its transformation from the egg to the tad-
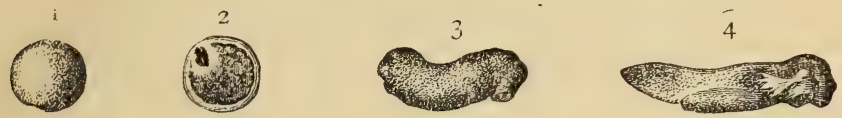

5

6
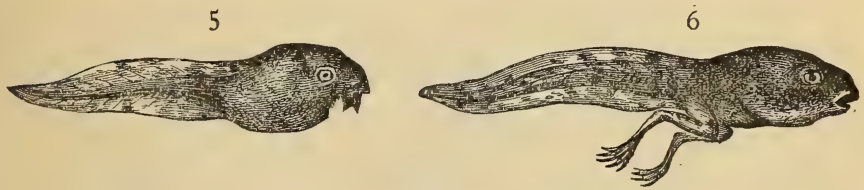

7
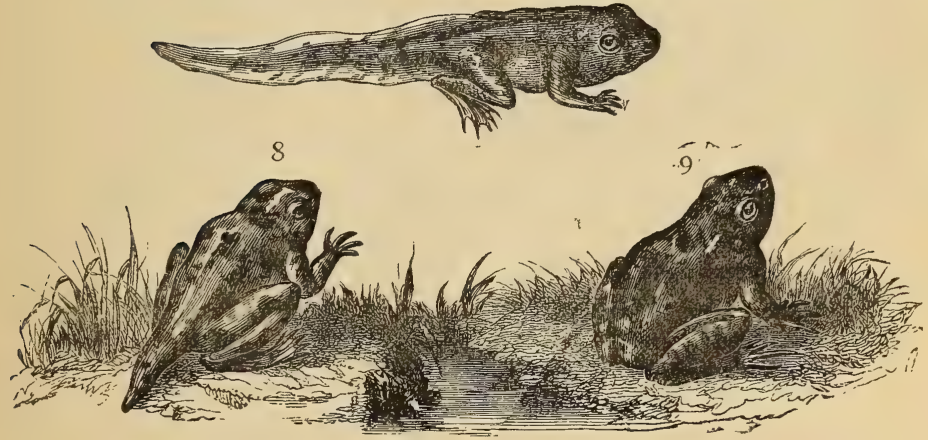

Fig. 5.-Development of the Tadpole.

x. Egg of the Frog. 2. The egg fecundated, and surrounded by its visicule. 3. First state of the Tadpole. 4. Appearance of the breathing gills. 5. Their development. 6. Formation of the hind feet. 7. Formation of the fore feet, and decay of the gills. 8. Development of the lungs, and reduction of the tail, 9. The perfect Frog.

pole, till we finally reach the perfect Batrachian. Through these admirable modifications we see the fish little by little becoming a Batrachian. In order to follow this strange metamorphosis, it suffices to gather some Frogs' eggs, and place them with some aquatic herbs in an aquarium, or in a globe with gold and silver fish. It there constitutes a most interesting spectacle, and we 
advise our readers to give themselves this instructive and easy lesson in natural history.

At present there exist two species of Frog in Europe : the Green or Edible Frog, and the Common Frog. The Green Frog is that which we have described, and of which we have given a representation in Fig. 4. They are found in running streams and stagnant waters. It is this species to which $\mathrm{La}$ Fontaine alludes in one of his fables. Common Frogs are smaller than the preceding; they inhabit damp places in fields and vineyards, and only return to the water to breed or to pass the winter.

The flesh of the Edible Frog is very tender, white, and delicate. As an article of food it is highly esteemed by some, and deservedly so. Prepared in the same manner, Green Frogs closely resemble very young fowls in taste. In almost all parts of France Frogs are disdained as articles of food; it is only in the south that a taste for them is openly avowed, and there Frogs are sought for and brought to market. Therefore, I never could comprehend how the notion popular in England, when it is wished to express contempt for Frenchmen, should be to call them frog-eaters. It is a reproach which might be addressed to Provençals and Languedocians, like the author of this work, but not at all to the majority of Frenchmen.

The Green Tree Frog (Hyla) is easily distinguished by having little plates under its toes. These organs are a species of sucker, by means of which the animal is enabled, like the house-fly, to cling strongly to any surface, however smooth and polished it may be. The smoothest branch, even the lower surface of a leaf, forms a sufficient hold and support to these delicate organs.

The upper part of the body is of a beautiful green, the lower part, where little tubercules are visible, is white. A yellow line, lightly bordered with violet, extends on each side of the head and back, from the muzzle to the hind legs. A similar line runs from the jaw to the front legs. The head is short, the mouth round, and the eyes raised. Much smaller than the ordinary Frog, they are far more graceful. During the summer they live upon the leaves of trees in damp woods, but pass the winter at the bottom of stagnant pools of water, which they do not leave till the month of May, having previously deposited their eggs. They feed on small insects, worms, and molluscs. During the glare of the sun they remain hidden amongst the leaves, but when twilight approaches they become more active. We must repeat of these Green Tree Frogs what we have already said of Frogs : get rid of all prejudice towards their kind, and then you will examine with pleasure their brilliant 
colouring, which harmonises so well with the green leaves they frequent; remark their tricks and ambuscades; follow them in their little hunting excursions; see them suspended in a manner which appears marvellous to those who are not aware of the organs that enable them to adhere to the smoothest bodies; and it will give as much pleasure to the student of Nature as can be derived from the plumage, habits, and flight of Birds. The croak of the Green Tree Frog is less sharp and more agreeable than that of the other species; it can be pretty well translated by the syllables caraccarac, pro-

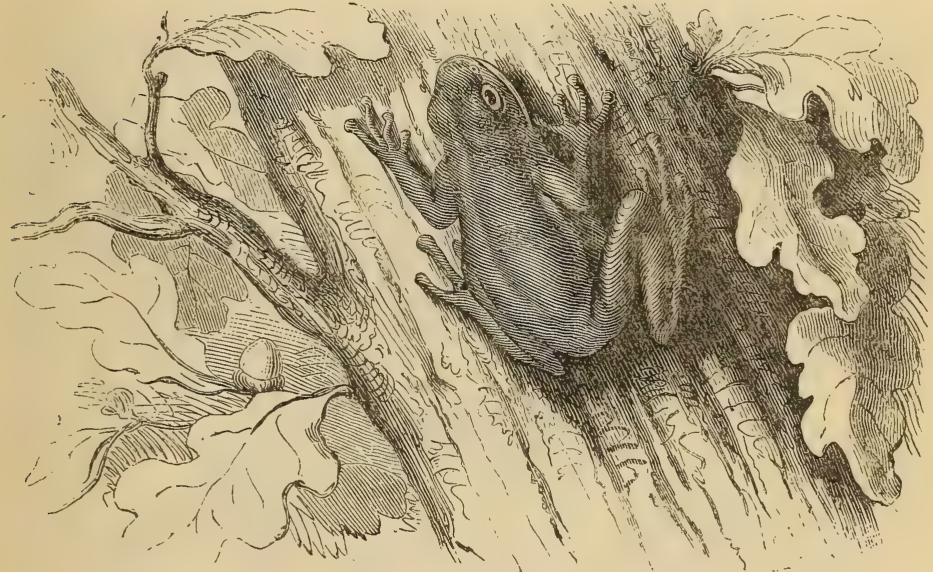

Fig. 6.-Green Tree Frog.

nounced from the throat. It is principally heard in the morning and evening; and when one frog commences to pipe, all the others imitate it. In the quiet night the voices of these little Batrachians can be heard a long way off.

Toads (Bufo) are heavy and ungraceful in shape. It is difficult to comprehend why Nature, while it has been so kind to the Frogs and Tree Frogs, has stamped the Toad with so ungainly a form. These much despised beings are very universally distributed, and occupy an important place in the order of Nature. In colour they are usually of a livid grey, spotted with brown and yellow, and disfigured by a number of pustules or warts. A thick and hard skin covers a flat back; its large belly always appears to be distended to 
an unnatural size; the head is broader than the rest of its body; the mouth and the eyes are large and prominent. It lives chiefly in ditches, especially in those where stagnant and corrupt water has lain a long time. It is found in dung-heaps, caves, and in swampy portions of woods. One has often been disagreeably surprised on raising some great stone to discover a toad struggling to avoid the notice of the intruder. It is in obscure and sometimes foetid places of refuge that the toad secretes itself during the day; only going out in the evening in search of food, when the common species employ

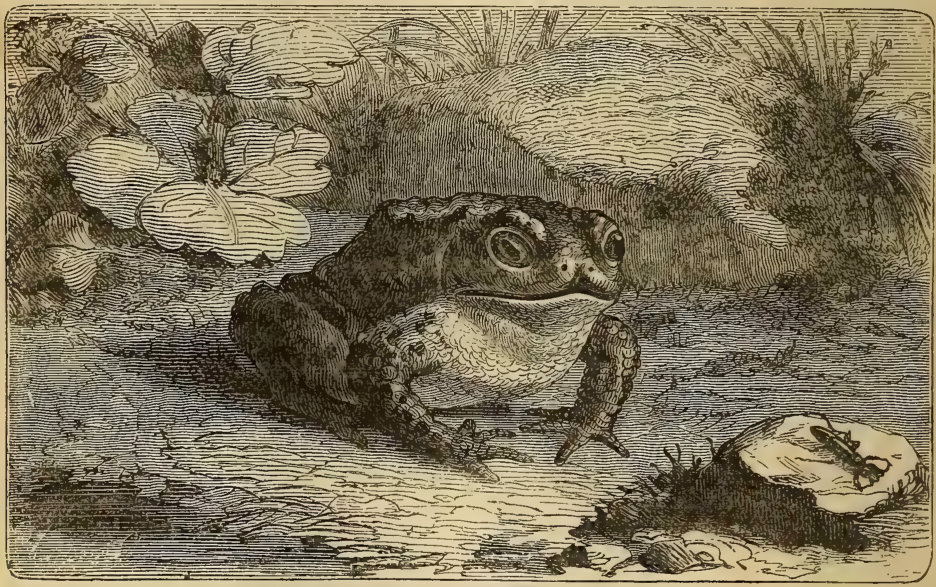

Fig. 7. -The Common Toad.

short hops as its means of locomotion; another, the Natterjack Toad (Bufo calamita), is only capable of crawling. When seized, it voids into the hand a quantity of limpid water exuded through the pores of its skin; but if more irritated, a milky and venomous humour issues from the glands of its back.

One peculiarity of its structure offers a defence from outward attacks. Its very extensible skin adheres feebly to the muscles, and, at the will of the animal, a large quantity of air enters between this integument and the flesh, which distends the body, and fills the vacant space with an elastic bed of gas, by means of which it is less sensible to external injuries. Toads feed upon insects, worms, and 
small molluscs. In fine evenings at certain seasons they may be heard uttering a plaintive monotonous sound. They collect in ponds, or even puddles, to breed and deposit their eggs. When hatched, the young Toads go through the same metamorphosis as do the tadpoles of the Frogs.

Though very inactive, they are nevertheless very enduring; they respire little, are susceptible of hybernation, and can remain for a considerable time shut up in confinement so restricted as to produce astonishment.

It is proper, however, to caution the reader against believing all that has been written about the longevity of Toads. Neither must implicit faith be given to the discovery of the living animal (Fig. 7) in the centre of stones. "That toads, frogs, and newts, occasionally issue from stones broken in a quarry or are discovered in sinking wells, and even taken from coal-strata at the bottom of a mine," is true enough; but, as Dr. Buckland observes, "the evidence is never perfect to show that these Amphibians were entirely enclosed in a solid rock; no examination is made until the creature is discovered by the breaking of the mass in which it was contained, and then it is too late to ascertain whether there was any hole or crevice by which it might have entered." These considerations led Dr. Buckland to undertake certain experiments to test the fact. He caused blocks of coarse oolitic limestone and sandstone to be prepared with cells of various sizes, in which he enclosed toads of different ages. The small toads enclosed in the sandstone were found to die at the end of thirteen months; the same fate befell the larger ones during the second year; they were watched through the glass covers of their cells, and were never seen in a state of torpor, but at each successive examina tion they had become more meagre, until at last they were found dead. This was probably too severe a test for the poor creatures, the glass cover implying a degree of hardness and dryness not natural to half amphibious toads. This animal, the Common Toad (Bufo vulgaris), is badly provided with means of progression, is timid and solitary in habits, and shuns the sight of man, as if it comprehended the repugnance with which it is regarded. It is, nevertheless, susceptible of education, and has been tamed. Pennant the zoologist relates some curious details respecting a poor toad which took refuge under the staircase of a house. It was accustomed to come every evening into a dining-room near the place of its retreat. When it saw the light it allowed itself to be placed on a table, where the host furnished it with worms, wood-lice, and various insects. As no attempt was made to injure it, there were no signs of irritation when it was 
touched, and it soon became, from its gentleness, the object of general curiosity; even ladies came to see this strange animal. The poor Batrachian lived thus for thirty-six years; and it would probably have lived much longer had not a tame crow, living in the house, attacked it, and put out one of its eyes. From that time it languished and died.

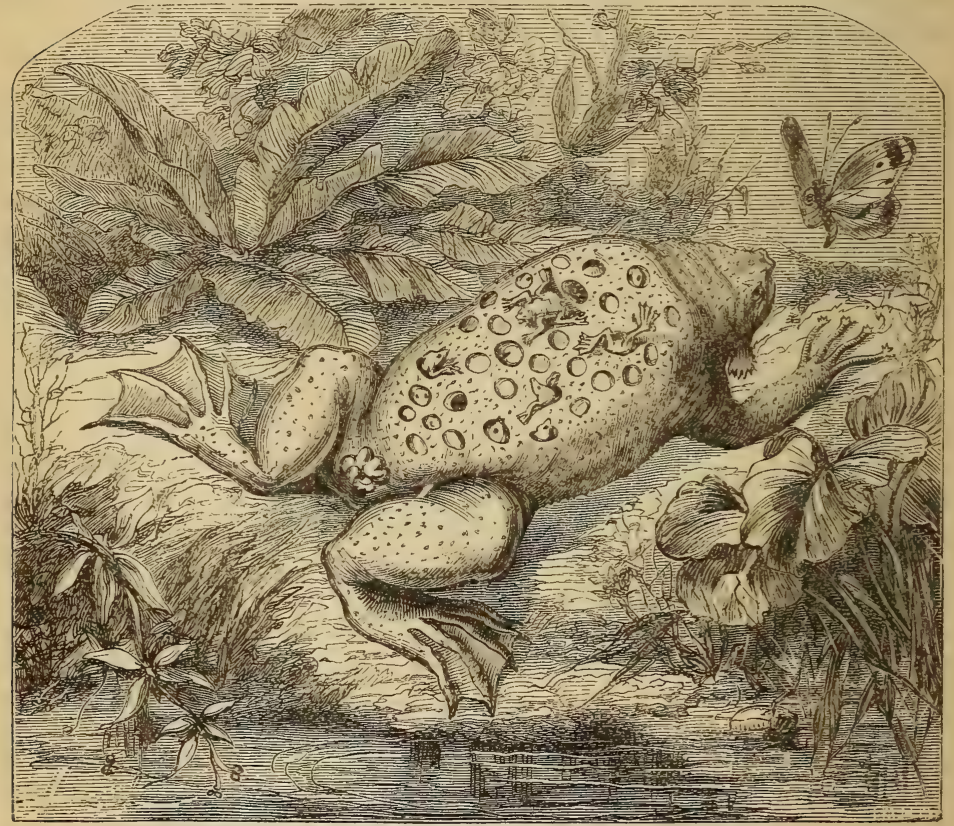

Fig. 8.-Surinam Toad.

Nearly allied to the Toads (Bufo), the Surinam Toad (Pipa monstrosa) holds its place (Fig. 8). Its physiognomy is at once disagreeable and peculiarly odd: the head is flat and triangular, a very short neck separates it from the trunk, which is itself depressed and flattened; its eyes are extremely small, of an olive, more or less bright colour, dashed with small reddish spots; it has no tongue. There is only one species of Pipa, viz., the American Pipa, 
which inhabits Guiana and several provinces of Brazil. The most remarkable feature in this Batrachian is its manner of reproduction. It is oviparous: and when the female has laid her eggs, the male takes them, and piles them on her back. The female, bearing the fertilised ova, reaches the marshes, and there immerses herself; but the skin which supports her future progeny soon becomes inflamed, erysipelatous inflammation follows, causing an irritation of the integument, which continues till all are absorbed into the skin.

The young are rapidly developed in these dorsal cells, and are extricated at a less advanced stage than almost any other vertebrate animal. After extrication, they grow rapidly, and the chief change of form is witnessed in the gills. As to the mother Batrachian, it is only after she has got rid of her progeny that she abandons her aquatic residence.**

The Batrachians differ essentially from all other orders of Reptilia. They have no ribs; their skin is naked, being without scales. The young, or tadpoles, when first hatched, breathe by means of gills, being at this stage quite unlike their parents. These gills, or branchiæ, disappear in the tailless Batrachians, as the Frogs and Toads. In the tadpoles the mouth is destitute of a tongue, this organ only making its appearance when the fore limbs are produced. The habits also change: the tadpole no longer feeds on decomposing substances, and cannot live long immersed in water; the branchiæ disappear one after the other, by absorption, giving place to pulmonary vessels. The principal vascular arches are converted into the pulmonary artery, and the blood is diverted from the largest of the branchiæ to the lungs. In the meantime the respiratory cavity is formed, the communicating duct advances with the elongation of the œsophagus, and at the point of communication the larynx is ultimately developed. The lungs themselves extend as simple elongated sacs, slightly reticulated on the inner surface backwards into the abdominal cavity. These receptacles being formed, air passes into and expands the cavity, and respiration is commenced, the fore limbs are liberated from the branchial chambers, and the first transformation is accomplished.

The alleged venomous character of the Common Toad has been altogether rejected by many naturalists; but Dr. Davy found that

* The same phenomena occur, with certain variations, in some other American Batrachians, as the Nototrema marsupiatum of Mexico, and the Notodelphys ovifera of Venezuela. In the Alytes obstetricans of France, Switzerland, and the Rhine district, the ova (about sixty in number) adhere to the hind-legs of the male parent !-ED. 
venomous matter was really contained in follicles in the true skin, and chiefly about the head and shoulders, although also distributed over other portions of the body. He also pronounced it to be extremely acrid, but innocuous when introduced into the circulation. A chicken inoculated with it was unaffected ; thus, Dr. Davy conjectures that this acrid liquid is the animal's defence against carnivorous mammalia. A dog, when urged to attack one, will drop it from its mouth in a manner which leaves no doubt that it has tasted the secretion.

In opposition to these opinions a story is told in France of a lad who had thrust his slightly-wounded hand into a hole, intending to seize a lizard which he had seen enter. In place of the lizard he brought out a large toad. While holding the animal, it discharged a milky yellowish-white fluid, which got introduced into the sore, and this poison occasioned his death; but it is not stated whether the boy was previously healthy or not.

Warm and temperate regions with abundant moisture are the localities favourable to all the Batrachians. Extreme cold, as well as dry heat, and all sudden changes, are alike unfavourable to them. In temperate climates, where the winters are severe, they bury themselves under the earth or in the mud at the bottom of pools and ponds, and there pass the season without air or food, till returning spring calls them forth.

The species of this family are very numerous. MM. Duméril and Bibron state that the Frogs (Rana) number fifty-one species, the tree frogs (Hyla) sixty-four, and the Toads (Bufo) thirty-five. They are found in all parts of the world, the least variety of the race being found in Europe, and the largest in America. Oceania is well supplied with the Tree Frogs. There are several curious forms in Australia, and one species only is known to inhabit New Zealand. The enormous fossil Labyrinthodon, of a remote geological era, is believed to have been nearly related to these comparatively very diminutive Batrachians.*

\section{TAILED Batrachians,}

Sometimes called Urodeles, from où $\alpha$, "tail," $\delta \hat{\eta} \lambda o s$, "manifest." The constant external character which distinguishes these Amphibians in

* In Dr. Günther's Catalogue of the Batrachia salientia (as Dr. Gray terms them) in the collection of the British Museum, published in $185^{8}$, and which includes all the ascertained species up to the time of publication, as many as 282 are enumerated, which are arranged under twenty-five groups holding the rank of families.-ED. 
a general manner is the presence of a tail during the whole stage of their existence. Nevertheless they are subject to the metamorphoses to which all the Amphibians submit. "The division, therefore, of Reptiles," says Professor Rymer Jones, "into such as undergo metamorphoses and such as do not, is by no means philosophical, although convenient to the zoologist, for all Reptiles undergo a metamorphosis, although not to the same extent. In the one the change from the aquatic to the air-breathing animal is never fully accomplished; in the tailed Amphibian the change is accomplished after the embryo has escaped from the ovum."

Salamanders have had the honour of appearing prominently in fabulous narrative. The Greeks believed that they could live in fire, and this error obtained credence so long, that even now it has not been entirely dissipated. Many people are simple enough to believe from the Greek tradition that these innocent animals are fire-proof. The love of the marvellous, fostered and excited by ignorant appeals to superstition, has gone even further than this : it has been asserted that hottest fire becomes extinguished when a Salamander is thrown into it. In the Middle Ages this notion was held by most people, and it would have been dangerous to gainsay it. Salamanders were necessary animals in the conjurations of sorcerers and witches; accordingly painters, among their symbolical emblems, represented Salamanders as capable of resisting successfully the most powerful heat. However, naturalists and philosophers have taken the trouble to prove by experiment the absurdity of these tales.

The skull of the Land or Spotted Salamander (Salamandra maculosa, Fig, 9) is well described by Cuvier as being nearly cylindrical, wider in front so as to form the semi-circular face, and also behind for the crucial branches, containing the internal ears. The cranium of the aquatic Salamander differs from the terrestrial in having the entire head more oblong.

In the Land Salamander the body is black and warty, with large irregular yellow spots distributed over the head, back, sides, feet, and tail. They affect retired and moist places, and only issue from their retreat in the night or morning, walking slowly, and dragging themselves with difficulty along the surface of the ground. They live upon flies, beetles, snails, and earth-worms. They remain in the water to deposit their eggs; the young are born alive, and furnished with fully-developed gills. Salamanders are gifted with the power of discharging an acrid and milky humour from the surface of its body, with a very strong odour, which serves as a defence against animals 
which would otherwise attack it. It has been proved by experiment that this liquid, when introduced into the circulatory system by a small wound is a very active poison, and causes certain death to the smaller animals. This species is found in most parts of Europe, but not in the British Islands.

The Black Salamander (Triton alpestris) has no spots ; it is found on the loftier European mountains, but principally on the highest Alps.

Newts, or Aquatic Salamanders, have not a round conical tail like the terrestrial species, but have that appendage compressed or

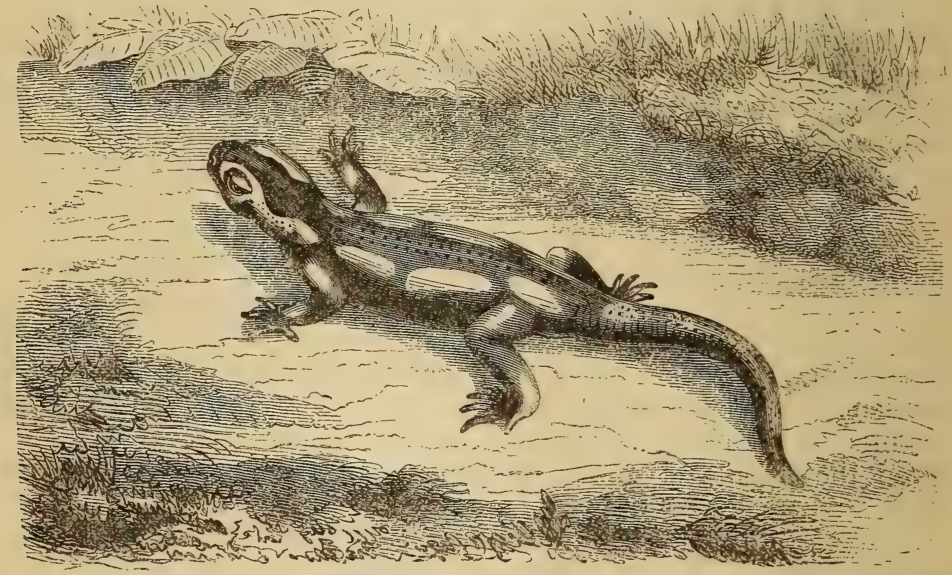

Fig. 9.-Land Salamander.

flattened laterally. The males (during the breeding season only) are recognised chiefly by the membranous serrated ridge or crest which extends along the whole length of the back, from the head to the extremity of the tail, as represented in Fig. Io. Newts are found in ditches, marshes, and ponds, which after the breeding season they leave for any moist places they can find on land, often then finding their way into drains and cellars. They are carnivorous, feeding upon different insects and on the spawn of frogs, not even sparing individuals of their own species. The females deposit their eggs singly, fixing them on the under surface of the leaves of aquatic plants. "Some Newts," says Professor Owen, "deposit their eggs upon aquatic plants, such as Polygonum persicaria, folding the 
leaf by means of the hind feet in such a way that its under-surface is turned inwards and the fold made to stick by the adhesive coating of the egg, which she inserts in the fold." The young are hatched fifteen days after. These animals give utterance to a very peculiar noise, and when touched emit a disagreeable odour.

It has been ascertained that Newts can live for a long time, not only in very cold water, but even in the midst of ice, being sometimes taken in blocks of ice which are formed in the ditches and ponds which they inhabit. When the ice-flakes melt they seem to

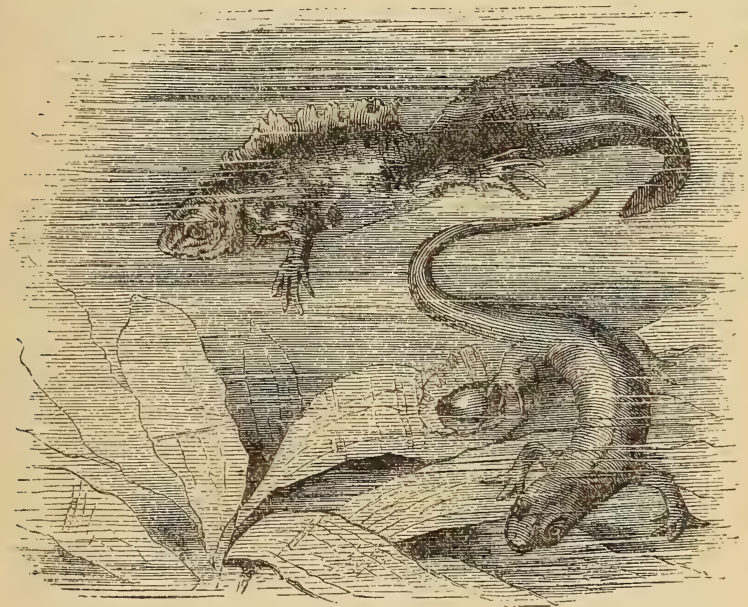

Fig. 10.-Newts, or Aquatic Salamanders.

awaken from their torpor, and betake themselves to their accustomed movements uninjured from their previous loss of liberty. Lacépede states that he found Aquatic Salamanders during summer in pieces of ice obtained from the ice-dealers, where they had remained without movement or nourishment from the time in which they had been enclosed.

Newts present another remarkable feature in the facility with which Nature repairs any mutilations they may have undergone. Not only do their tails grow again when broken off, but even their feet are reproduced in the same manner; and the process may be many times repeated. 
The Crested Newt (Triton cristatus) is frequently found in the neighbourhood of Paris; the skin of its back is rough and warty, of a brownish colour, with large black spots and white projecting points ; the belly has black spots upon an orange ground.

The Dutch traveller, Sieboldt, has introduced a species of Aquatic Salamander, which inhabits the mountain lakes of Japan. This species is remarkable for its gigantic growth. Instead of being the size of those indigenous to Europe, this Batrachian is four feet and a half in length, and weighs fifty pounds.

Magnificent specimens of this gigantic Salamander, the Sieboldtia maxima, may be seen by the visitors to the London Zoological Gardens. The largest of them measured and weighed as above (March 3, I869). An analogous large fossil species was described as the homo diluvii testis!

The transformation of the tailed Batrachians, from the tadpole condition to the air-breathing and four-footed state, is one of the most interesting exhibitions of Nature, and one which every one may witness. We cannot in our brief description have a more trustworthy guide than Professor Rymer Jones, who selects the water newt (Triton cristatus) as an example :-

"Immediately before leaving the egg," he says, "this tadpole presents both the outward form and internal structure of a fish. The flattened and vertical tail, fringed with a broad dorsal and oval fin; the shape of the body and gills, appended to the side of the neck, are all apparent; so that were the creature to preserve this form throughout its life the naturalist would scarcely hesitate in classing it with fishes properly so called.

"When first hatched it presents the same fish-like body, and rows itself through the water by the lateral movement of the caudal fin. The only appearance of legs as yet visible consists in two minute tubercles, which seem to be sprouting out from the skin immediately behind the branchial tufts, and which are, in fact, the first buddings of anterior extremities. Nevertheless, to compensate to a certain extent for the total want of prehensile limbs, which afterwards become developed, two supernumerary organs are provisionally furnished in the shape of two minute claspers on each side of the mouth; by means of these the little creature holds on to the leaves which are under water.

"Twelve days after issuing from the egg, the two fore-legs, which at first resembled two little nipples, have become much elongated, and are divided at their extremity into two or three rudiments of fingers; the eyes, which were before scarcely visible, being covered 
by a membrane, distinctly appear. The branchiæ, at first simple, are divided into fringes, wherein red blood now circulates; the mouth has grown very large, and the whole body is so transparent as to reveal the position of the viscera within. Its activity is likewise much increased; it swims with rapidity, and darts upon minute aquatic insects, which it seizes and devours.

"About the twenty-second day the tadpole for the first time begins to emit air from the mouth, showing that the lungs have begun to be developed. The branchiæ are still large. The fingers upon the fore-legs are completely formed. The hind-legs begin to sprout beneath the skin, and the creature presents, in a transitory condition, the same external form as that which the Siren lacertina permanently exhibits.

"By the thirty-sixth day the young Salamander has arrived at the development of the Proteus anguinus; its hind-legs are nearly completed; its lungs have become half as long as the trunk of the body, and its branchiæ more complicated in structure.

"At about the forty-second day the tadpole begins to assume the form of an adult Newt. The body becomes shorter, the fringes of the branchiæ are rapidly obliterated, so that in five days they are reduced to simple prominences covered by the skin of the head; and the gills, opening at the sides of the neck, which allowed the water to escape from the mouth, as in Fishes, and were, like them, covered with an operculum formed by a fold of the integument, are gradually closed; the membranous fin of the tail contracts, the skin becomes thicker and more deeply coloured, and the creature ultimately assumes the form and habits of the perfect Newt, no longer possessing branchiæ, but breathing air, and in every particular the reptile."

But however curious the phenomena attending the development of the tadpoles of the Amphibian Reptiles may be to the observer who merely watches the changes perceptible from day to day in their external form, they acquire tenfold interest to the physiologist who traces the progressive evolution of their internal viscera; more especially when he finds that in these creatures he has an opportunity afforded him of contemplating, displayed before his eyes as it were upon an enlarged scale, those phases of development through which the embryo of every air-breathing vertebrate animal must pass while concealed within the egg or yet unborn.*

* In the British Museum Catalogue (1850) these Amphibians are styled Batrachic Gradientia, and are distributed under three families, comprising fifty-two 
recognised species. The class Amphibia is divided by Dr. Gray into five orders, viz., Batrachia, Pseudosauria, Pseudophidia, Pseudichthyes, and Meantia. Of these the first, or the Batrachia, are divided into the sub-orders Salientia and Gradientia, the latter consisting of three families, Salamandrida, Molgida, and Plethodontida. The second order, Pseudosauria, comprises the families Protonopside (which contains the Sieboldtia maxima) and Amphiumida. The third order, Pseudophidia, consists of only one family, Caciliida. The fourth order, Pseudichthyes, also contains one family only, the Lepidosirenida. The fifth order, Meantia comprises the two families Proteidee and Sirenida. Twenty-four ascertained species are distributed amongst the last four of these orders; but the limits of this work do not permit of a more detailed notice of these various groups of Batrachia Gradienta. More recently, Dr. Günther, in his work on the Reptiles of the Indian region, has pointed out certain structural characters connected with the generative system which show that the Pseudophidia clo not properly belong to the Batrachia; nor is their place in the system as yet quite satisfactorily determined. They seem rather to be a very humble form of Reptile; while the Psendichthyes should rather be subordinated to the class Pisces: though, as we have seen, there are naturalists who would refer all of the Batrachia to the Fish class, certain forms amongst them rising to a parallelism of development with Reptilia, but still not constituting true reptiles. The mode of reproduction especially is in favour of this view. Both Pseudophidia and Psendichthyes are intertropical or subtropical animals, whereas the rest of the Batrachia Gradientia belong almost exclusively to the northern temperate zone, any exceptional case occurring probably in very elevated regions. Of sixty-six ascertained species, forty-nine are American, and there are five from Japan, inclusive of the Sieboldtia maxima. But more species have been discovered since the catatogue cited has been drawn up, and of course there must be many yet to be discovered. Five species are referred to the Pseudophidia, and three only to the Pseudichthyes.-ED. 


\section{CHAPTER II.}

\section{OPHIDIAN REPTILES, OR TRUE SNAKES.}

REPTILES are, as has been said in the preceding chapter, vertebrated animals, breathing by lungs, having red and cold blood-that is to say, not producing sufficient heat to render their temperature superior to that of the atmosphere; destitute of hairs, of feathers, of mammary glands, and having bodies covered with scales.

Snakes, properly so called, have the tympanic bone, or pedicle of the lower jaw, movable, and nearly always suspended to another bone analogous to the mastoid bone, which is attached to the cranium by muscles and ligaments, a conformation which gives to these animals the vast power of distension they possess. Their trachea is long, their hearts placed far back, and the greater number have one very long lung and vestiges of a second. They are divided into non-venomous and venomous; and the latter are sub-divided into venomous with maxillary teeth, and venomous with isolated fangs.

The Snakes prey almost exclusively on animals of their own killing; the more typical species attacking such as are frequently larger than themselves, and the maxillary apparatus is, as we have seen, modified so as to permit of the requisite distension. According to Professor Owen's clear and intelligible description, the two superior maxillary bones have their anterior extremities joined by an elastic and yielding fibrous tissue with the small and single intermaxillary bone; the lower maxillary rami are similarly connected. The opposite extremity of each ramus is articulated to a long and movable vertical pedicle formed by the tympanic bone, which is itself attached to the extremity of a horizontal pedicle formed by the mastoid bone, so connected as to allow of a certain yielding movement upon the cranium. The other bones have similar loose movable articulations, which concur in yielding to the pressure of large bodies with which the teeth have grappled. 
The class of Reptiles is divided into three orders :- the OpHIDIANS, comprehending the Snakes; the SaURIANS, the Lizards and Crocodiles; and the Chelonians, the Turtles and Tortoises.

\section{OpHIDIANS.}

In Ophidians, commonly known under the name of Snakes, the body is long, round, and straight. They have neither feet, fins, nor other locomotive extremities. Their mouths are furnished with pointed hooked teeth. In the Boas and Pythons the teeth are slender, curved, bending backwards and inwards above their base of attachment. In others each maxillary bone has a row of larger ones, which gradually decrease in size as they are placed further back. These teeth are not contiguous, being separated by considerable intervals. The smaller non-venomous Serpents, such as the Colubrida, have two rows of teeth in the roof of their mouth. Each maxillary and mandibular bone includes from twenty to twentyfive teeth. In the Rattlesnakes and some other typical genera of poisonous Snakes, the short maxillary bone only supports a single perforated fang. Their lower jaw is highly distensible; the opening being longer than the skull. They have no neck; their eyelids are immovable; their skin is coriaceous, highly extensible, and scaly or granulous, covered with a thin caducous epidermis, which detaches itself in one entire piece, and is reproduced several times in one year. Their movements are supple and varied. In consequence of the sinuosity of their bodies-for, though scale-clad, Snakes are without apparent means of progression-they make their way with the utmost facility.

The very numerous species of the genus inhabit either arid or moist ground, bushes or trees. Some pass much of their time in the water, and one family (that of the Hydrophida) is exclusively aquatic, even pelagic in the instance of one very widely diffused species, the Pelamis bicolor. In the arboreal Snakes the tail is very long, and highly prehensile; in others, as the Vipers, it is short and without any prehensility. In the Sea Snakes (Hydrophida), it is laterally much compressed. Like other true Reptiles, Snakes abound more especially in warm climates, and there are many kinds of them in Australia; but the order has not a single representative in New Zealand.

Most of the Snakes feed on living animals, only a few on birds' eggs. Several kinds of them prey habitually on other Snakes, as the genera Hamadryas, Bungarus, and Elaps, even Psammophis 
occasionally; and there are rare instances of non-venomous Snakes preying upon poisonous ones. The venomous kinds first kill their victim by poison; others by smothering it between the coils of their body. As they do not possess organs for tearing their prey to pieces, nor a dentition fit for mastication, the prey is swallowed entire ; and in consequence of the great width of the mouth, and of the extraordinary extensibility of the skin of the gullet, they are able to swallow animals of which the girth much exceeds their own. The Sea Snakes prey mostly upon fishes, and the ordinary Water Snakes (Homolopsida, \&c.) on Frogs and other Batrachians. Certain swallowers of birds' eggs have peculiar spinous processes proceeding from the vertebræ of the neck, the object of which is to fracture the shell of an egg during the process of deglutition.

Most of the Ophidian Reptiles are oviparous, but many are ovo-viviparous. The Pythons alone (so far as ascertained) perform a sort of incubation, which has been repeatedly observed in captive specimens of these huge Serpents.

Many Snakes are remarkable for their great beauty of colouring or for the pattern of their markings; but on account of the poisonous property so many possess, the whole order is popularly regarded with horror and apprehension, and the most foolish tales are current respecting various species of them. Thus many people suppose that there are Snakes which rob cows of their milk; and the skeleton of a child being found in the same hollow with a number of harmless Snakes (the North American Coryphodon constrictor), it was concluded, as a matter of course, that the serpents must have both killed the child and stripped off its flesh, a thing which no snake could possibly do. People are prone to exaggerate, and commonly evince a fondness for the marvellous, which induce those of hot countries more especially, where the species of Ophidians are numerous, to declare every snake met with to be the most venomous one in their country; and thus travellers often come away with exceedingly erroneous impressions on the subject. The Indian region surpasses every other part of the globe in the number and variety of its Ophidians ; and almost every investigation of a limited but previously unexplored district, is tolerably sure to add largely to our previous knowledge of them. What, however, the late Sir J. Emerson Tennent asserts of those inhabiting Ceylon is equally applicable to other parts of the Indian region. "During my residence in Ceylon," he remarks, "I never heard of the death of a European which was caused by the bite of a snake; and in the returns of coroners' inquests made officially to my department, such accidents 
to the natives appear chiefly to have happened at night, when the reptiles, having been surprised or trodden on, inflicted the wound in self-defence. For these reasons the Cingalese, when obliged to leave their houses in the dark, carry a stick with a loose ring, the noise of which, as they strike it on the ground, is sufficient to warn the snakes to leave their path."

In some parts of the vast Indian region the natives regard the innocuous Chameleon as venomous; in other parts various Geckos or other Lizards. In Bengal there is a current notion regarding a terrifically poisonous Lizard, which is termed the bis-cobra, but which has no existence except in the imagination of the nativeswho bring the young of the Monitors and occasionally other wellknown Lizards as specimens of the object of their dread. Again, the little Burrowing Snakes (Typhlops), which, superficially, have much the appearance of earth-worms, are there popularly regarded as highly poisonous, though not only are they harmless, but physically incapable of wounding the human skin. Strangers who are little versed in zoology are commonly led astray by such errors on the part of natives of those countries, and, unfortunately, there is a number of stock vernacular names which are applied to very different species in different localities. Thus, Europeans in India are familiar with the appellation "Carpet Snake," as denoting a very deadly reptile, but nobody can there point out what the Carpet Snake really is; and the one most generally supposed to bear that name is a small innocuous Snake (Lycodon aulicus), which is common about human dwellings. In the Australian colony of Victoria, however, the appellation Carpet Snake is bestowed upon a terribly venomous species (Hoplocephalus curtus); while in the neighbouring colony of New South Wales, a harmless and even useful creature (Morelia spilotes) is habitually known as the Carpet Snake.

With regard to the poison of venomous Snakes, attention has lately been directed to the virtue of ammonia or volatile alkali. This should be administered internally, mixed with alcoholic spirit and water, in repeated doses; and it should also be injected into a vein-about one drachm of the liquor ammonice of the shops being mixed with two or three times that quantity of water. The patient should be kept moving as much as possible, and the effects of a galvanic battery should also be tried in cases where animation is nearly or quite suspended. By these means it is asserted that quite recently some very remarkable cures have been effected in Australia.

The Ophidia have many enemies among mammalia, such as the vell-known Mungoose, also swine, and various ruminating quadrupeds, 
as deer and goats. In the Bird class, the famous Serpent-eater, or Secretary-bird of South Africa, is one of their chief destroyers; and there are various other snake-devouring birds of prey, besides the great African Ground Hornbill-even the Peafowl, sundry Storks, and other waders, seldom fail to attack them when opportunity offers. Comparatively large birds of the Kingfisher family prey chiefly upon Snakes and Lizards in Australia ; and of Reptiles, besides those Snakes which prey upon others, the Monitor Lizards frequently seize and devour them.

The series of Ophidians is arranged by our most eminent herpetologist, Dr. A. Günther; into five subordinate groups, which he characterises as follows :-

I.-Burrowing Snakes, living under ground, only occasionally appearing above the surface. They are distinguished by a rigid cylindrical body, short tail, narrow mouth, small head not distinct from the neck, little teeth in small number, and by the absence or feeble development of the ventral shields. They feed chiefly on small invertebrate animals. Not any of them are venomous.

II.-Ground Snakes, or species which live above ground, and only occasionally climb bushes or enter the water; their body is more or less cylindrical, very flexible in every part, and of moderate proportions. Their ventral shields are broad. They feed chiefly on terrestrial vertebrate animals. By far the greater number of Snakes belong to this category, and it is represented by many variations in all of the three sub-orders to be noticed presently.

III. - Tree Snakes, or species passing the greater part of their life on bushes and trees, which they traverse with the utmost facility. They are distinguished either by an exceedingly slender body, with broad, sometimes carinated, ventral shields, or by a prehensile tail. Many of the species are characterised by their vivid colouring, of which green forms the principal part. We shall see, in the sequel, that the first and third sub-orders offer numerous instances of Tree Snakes; the Tree Snakes of the second sub-order being confined to tropical Africa. They feed on animals which have a mode of life similar to their own; only a few species on eggs.

IV.-Fresh-water Snakes, distinguished by the position of the nostrils, which are placed on the top of the snout, and by a tapering tail. They inhabit fresh waters, and are, therefore, excellent swimmers and divers; only a few species (which also in external characters approach the following group, that of the true Sea Snakes) venture out to sea. They feed on fishes, frogs, crustaceans, and other water animals, and are viviparous. Not any of them are venomous. 
V.-Sea Snakes, distinguished by a strongly-compressed tail, and by the position of the nostrils, which are placed as in the last group. They live in the sea, only occasionally approaching the land, feed on marine fishes, are viviparous and venomous. One genus only (Platurus) has the ventral shields so much developed as to be able to move on land. No oceanic serpent is known of gigantic dimensions, such as is currently alleged to have been seen by unscientific observers.

"Although these five groups," remarks Dr. Günther, "are not separated from each other by defined lines of demarcation, and frequently pass into one another by intermediate forms, yet a family and genus which should be composed of species of several of these groups would be a very unnatural assemblage of heterogeneous forms."

It is also remarked by the same naturalist that there is no sharp boundary line between the order of Snakes and that of Lizards. There are various limbless Saurians of Ophidian appearance, but the systematic position is decided by the structure of their jaws. The Common Orvet, or Slow-worm, is a familiar instance. On the other hand, certain Ophidians remind us, by several characteristics, of the Saurian type-as the Snakes constituting the families Typhlopida, Tortricida, Xenopeltide, and Uropeltida, which are distinguished by polished, closely adherent, rounded, sub-equal scales, much resembling the smooth scales of various Scincoid Lizards; most of them have a very narrow mouth, unlike the enormous gape of the typical Serpents ; and some are without that longitudinal fold in the median line of the chin which is so characteristic of most Ophidians ; moreover, most of them have rudiments of the bones of a pelvic arch. "The reason," alleges Dr. Günther, "why we adopt the view of those systematists who refer such Reptiles to the. Ophidians, instead of associating them with the limbless Scincoid Lizards, is the loose connection of the jaw-bones, a character which must be considered as peculiar to the Ophidians, and which is only somewhat less developed in the families mentioned than in the typical forms; the two halves of the lower jaw in Ophidians, namely, are not united by a bony symphysis, but by an elastic ligament. The peculiar mobility of the jaw bones enables the Snakes to extend the gape in an extraordinary degree, and to work their prey down through the collapsed pharynx."

The same naturalist classifies the Ophidia into three sub-orders, in which the venomous snakes are separated from the others; but 
to some herpetologists this arrangement must appear rather forced, as his Venomous Colubrine Snakes have certainly a much nearer resemblance in other respects to the Colubride than they have to the Viperine Snakes. For the most part, these Reptiles are provided with numerous teeth, which are lengthened, conical, thin, and pointed like a needle, and more or less bent backwards.

In Dr. Günther's first sub-order, that of Non-venomous Snakes, the teeth are either entirely smooth, or only the last of the maxillary series is provided with a faint longitudinal groove, which is not intended to convey a virus into the wound, the groove appearing rather to increase the strength of the tooth. Many of them have long teeth in front of the jaws or of the palate, but these are never grooved or perforated, and only serve to afford a firmer hold on the living and struggling prey.

"The structure of the venom-tooth is not the same in all poisonous Snakes : in some it is fixed to the maxillary bone, which is as long, or nearly as long, as in the non-venomous Snakes, and generally bears one or more ordinary teeth on its hinder portion. The venomtooth is fixed, more or less erect, not very long, and its channel is generally visible as an external groove. The poisonous Snakes with such a dentition have externally a more or less striking resemblance to the non-venomous Serpents, and on this account they are designated as Venomous Colubrine Snakes, forming our second sub-order." Two very distinct families are here brought together-viz., the Elapida (which comprises the Cobras and many others), and the Hydrophide (or Sea Snakes).

"In the other venomous Snakes, composing the third sub-order, the maxillary bone is extremely short, and does not bear any teeth except an exceedingly long fang, with a perfectly closed externally invisible channel in its interior. Although this tooth also is fixed to the bone, the bone itself is very mobile, so that the tooth, which is laid backwards when at rest, can be erected the moment the animal prepares to strike. This tooth or fang, like all the other teeth, is not only occasionally lost, but appears to be shed at regular intervals. From two to four other venom-fangs, in different stages of development, destined to replace the one in action, exist between the folds of the gum, and are not anchylosed to the bone." The more characteristic venomous Snakes appertain to this sub-order-viz., the two families Crotalida (comprehending the Rattlesnakes, the Fer-de-Lance, \&c.) and Viperide (comprising the Vipers, Puff Adders, \&c.)

Let it be particularly borne in mind that the supposed distinguishing characters of all poisonous Snakes, as assigned by sundry 
mischievously ignorant writers, are those of the third of the foregoing sub-orders almost exclusively. Even the broad, flat, and lanceolate form of head is exemplified in certain Tree Snakes of the non-venomous genus Dipsas, and not in the Cobras and others that are quite as deadly-e.g., Hoplocephalus, Bungarus, Naja, Elaps, and others constituting the Colubriform family Elapida.

\section{First SUB-ORDER.}

\section{Ophidii Colubriformes (Günther), Innocuous Snakes.}

These are distributed by Dr. Günther under numerous families, of which we can only notice the more prominent and some of the more conspicuous species, in a popular exposition.

The Typhlopida, or Blind Snakes, comprise forms which are the most remote from the true Ophidian type. They live underground, their rigid body and short curved tail being adapted for burrowing. After showers of rain they occasionally appear above ground, and then they are tolerably agile in their serpentine movements. The eye, which is scarcely visible in many species, can give to them only a general perception of light. They feed on worms and small insects, the tongue being forked, and, as in other Snakes, frequently exserted. They are oviparous. The smallest species of Snakes belong to this family, some of them being only half the size of a common earthworm, to which they bear a superficial resemblance. Such, indeed, are the small vermiform Snakes already referred to as being foolishly considered venomous by most natives of India. Species of this family inhabit almost every country within and near the tropics.

The Tortricide are akin to the Typhlopida, and have rudiments of hind limbs hidden in a small groove on each side of the vent, also a longitudinal fold at the chin. The Coral Snake of Demarara (Tortrix scytale) appertains to this family; and the genus Cylindrophis, different species of which inhabit the great Asiatic archipelago, with the island of Ceylon.

The family Xenopeltide consists of a single species only, so far as hitherto known, the Xenopeltis unicolor, which is common in the Indo-Chinese and Malayan countries. It grows to three or four feet in length, and when alive is along the back a steel-blue colour, most beautifully iridescent, beneath white; but the blue fades to brown after long immersion in spirits. Young examples have a white collar. Mr. W. Theobald remarks of it that "this snake is common in Lower Pegu and the Tenasserim provinces, and is very malignly beautiful, though of repulsive physiognomy. The skin is loose and 
thick, and its habits are nocturnal. The following illustrates its ferocious nature:-I once remarked a Colubrine Snake (Ptyas mucosa), some five feet in length, in the hedge of the Circuit-house of Bassein. On running down-stairs, the snake had vanished, but on searching for it I saw its tail sticking out of a hole beneath a wooden plant-case. Do what I might I could not drag it out, as it seemed held fast within. I therefore, with some trouble, overturned the plant-case, and then saw that the unlucky Colubrine Snake was firmly pinned by a large Xenopeltis, into whose hole it had unwittingly entered. The Xenopeltis seemed about four feet in length; but, on perceiving itself uncovered, released its hold of the Ptyas, and made its escape." The Xenopeltis preys chiefly on small mammalia, which it hunts for in their subterranean holes; and in some respects it approximates the Pythonida.

The Uropeltide, or shield-tails, constitute a very curious family of Burrowing Snakes, which bear considerable resemblance to the Typhlopida, but have a very peculiar, short, strong, posteriorly shielded tail, adapted for working their way below the surface. The species are mostly small, and hitherto they have been found chiefly in Ceylon, a few only in the peninsula of India. In that island they are by no means scarce, but escape observation from their peculiar mode of life. Dr. Kelaart remarks that "they are timid creatures, seldom making their appearance above ground ; living chiefly in anthills or dunghills, sometimes also several feet deep in rich loamy soil. They feed on ants, small earth-worms, and the larvæ of insects, and at least one species has been ascertained to be viviparous. Five genera and eighteen species of them are recognised.

The Calamarida form an extensive family of diminutive slender snakes, from one to two feet in length, many species of which inhabit both the Old World and the New, though the same kinds are not found East and West. They keep to the ground, beneath stones, fallen trees, \&c. ; and their food appears to consist chiefly of insects. They are gentle, and never attempt to bite ; they not uncommonly become the prey of the smaller Elapida, certain of which bear considerable resemblance to the family, but are readily distinguished by possessing the poison-fangs.

The Oligodontida are another extensive family of small GroundSnakes, which are peculiar to South-eastern Asia and its great archipelago. They conduct to the terrene genera of the great family Colubrida.

The Colubridæ are divided by Dr. Günther into Ground Colubrines (Coronellina), True Colubrines(Colubrince),Bush Colubrines(Dryadina), 
and Fresh-water Colubrines (Natricine) ; and he remarks that "they are found in every part of the temperate and tropical regions, but are only scantily represented in Australia and in the islands of the Pacific. The species are so numerous, and show such a gradual passage between extreme forms, that, although genera can be easily characterised, it is almost impossible to distinguish wider groups by definite characters." Among them the Coronelline approximate to the immediately preceding families, and, like them, live on the ground, and are not generally of brilliant colouring, though a few species which frequent grassy plains are of a bright green colour. The Coluthince "form, as it were," writes Dr. Günther, "the nucleus of the whole sub-order of innocuous Snakes; they are typical forms, not characterised by the excessive development of some particular organ, but by the fairness of the proportions of all parts. Yet some of them have a more slender body than others which always live on the ground; they are land Snakes, but swim well when driven into the water, or climb when in search of food. They are of moderate or rather large size." In the Dryadina the form is elongate and somewhat compressed, indicating their climbing propensities; they have the body not so excessively slender as in the true Tree Snakes, to which they lead off. They are much more numerous in the New World than in the Old, and their ground-colour is very commonly green. The Natricince are generally not very elongate or compressed, and most of them have keeled scales. They freely enter the water in pursuit of their food, which consists chiefly of frogs and fishes. All the Snakes of the preceding three sub-families overpower their prey by throwing some coils of the body round it, and commence to swallow the victim after it has been smothered. The Natricina swallow their prey immediately after they have seized it.

Of the sub-family Coronelline, one species of the typical genus Coronella is widely diffused over Europe, and has only of late years been recognised as an inhabitant of the British Islands, the Coronella austriaca. Another, C. girondica, occurs in Italy. Others are found in Africa, America, and Australia. The C. austriaca has somewhat the appearance of the Common Adder, for which it is often mistaken; but it is non-venomous, though rather fierce, biting and holding on to whatever is placed in its way. As it occurs in Malta (where no venomous species is known to exist), it is doubtless the Viper which seized the apostle Paul. Several other genera are recognised.

Of the Colubrine Rhinechis scalaris, Coluber asculapii, C. quadrilineatus, Elaphis quater-radiatus, and three species of Zamenis inhabit Europe ; in North America there are to be found five species 
of Coluber, as well as the well-known Black Snake (Coryphodon constrictor) of the Anglo-Americans. Other species of Coryphodon or Ptyas inhabit south-eastern Asia, such as the Rat Snakes of Anglo-Indians, of which Ptyas mucosus is particularly common in Hindostan, where it is encouraged by sensible people on account of its animosity to the troublesome Brown Rat (Mus decumanus).

The Dryadince are chiefly American, and do not call for particular attention; but the Natricince are numerous, and of them three species are to be found in Europe-viz., Tropidonotus natrix, T. hydrus, and T. viperinus. Dr. Günther gives as many as twenty-one species of this genus as inhabitants of the Indian region alone, and there is reason to believe that that number is far from being complete. Others inhabit North America and North-western Australia, and some generic groups have been detached that are not very conspicuously separable.

The Ringed Snake (Tropidonotus natrix, Fig. II) is often found in fine seasons near human habitations. It deposits its eggs, which are fifteen to twenty in number, commonly in dunghills, in one agglutinated mass. If exposed to the air, these eggs soon shrivel and dry, and the embryos within perish. The Ringed Snakes (Tropidonotus natrix) found near rivers and meadows, by the side of watercourses, into which they love to plunge, are sometimes called Water Serpents, Swimming Serpents, Hedge Eels, and other provincial synonyms. They sometimes attain to a yard in length. The summit of their head is covered with nine large scales, disposed in four rings. The upper part of the body is of a more or less darkish grey colour, marked on each side with irregular black spots. Between the two rows of spots are two other longitudinal rows, which extend from the head to the tail. The belly varies from black to a bluish white. Upon the neck are two whitish or pale yellowish spots, which form a kind of half collar or ring, from which its name is derived; these two spots become much more apparent from being contrasted with two other very dark triangular spots placed near them. They prey upon lizards, frogs, and mice, and they even surprise young birds, and devour eggs : they climb trees with facility. Towards the end of the autumn they seek the most sheltered retreats, approaching even houses; or they retire into holes at the bottom of hedges when in such an elevated position as to secure them from inundations. The Ringed Snake is found in nearly all European countries, and can be handled without danger. Lacépède gives some interesting details, showing the gentleness of its habits. They are easily tamed, and can be kept in houses, where they soon accustom themselves to those who 
have the care of them. At a sign from their keeper, they will twist themselves round his fingers, arms, and neck, insinuate their heads between his lips to drink his saliva, and to hide and warm themselves under his clothes. In their wild state the adult Ringed Snake lives in the fields; and, when full-grown, shows great irritation if attacked. When exasperated, they open their mouths, erect themselves with great activity, and even bite the hand which attempts to lay hold of them.

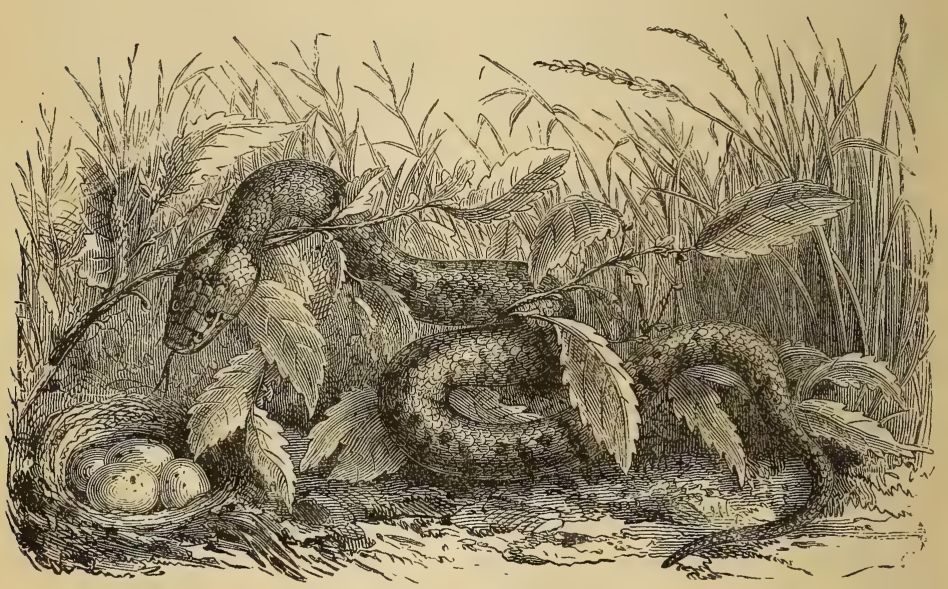

Fig. Ir.-Ringed Snake.

[This Ringed Snake is the Natrix torquatus of Ray. The female is larger than the male. Its food consists principally of frogs, which are generally seized by the leg and swallowed alive.

When the skin has just been cast, the Ringed Snake presents beautiful markings when seen swimming across some clear running stream, its head and neck raised above the limpid water and the sun shining on its bright enamelled back. It has been supposed that this Snake casts its skin at fixed intervals ; this, Mr. Bell considers to be a mistake. He has always found that this depended on the temperature of the atmosphere and on their state of health. "I have known the skin thrown off," he adds, "four or five times during the year. It is always thrown off by reversing it, so that the transparent 
covering of the eyes and that of the scales are always found in the exuviæ. Previous to this curious phenomenon, the whole cuticle becomes somewhat opaque, the eyes dim, and the animal is evidently blind ; it also becomes more or less inactive, until at length, when the old skin is ready for removal and the new skin perfectly hard underneath, the animal bursts it at the neck, and creeping through some dense herbage or low brushwood, leaves it detached, and comes forth in brighter and clearer colours than before."

The Ringed Snake begins to hybernate about the end of autumn, when they coil themselves up, sometimes in numbers, till the spring again calls them forth. Many instances are told of this Snake being tamed. Mr. Bell had one which knew him from all other persons ; it would come to him when let out of its box, crawl under the sleeve of his coat, and every morning visit him for a draught of milk.]

The Green and Yellow Snake is also about a yard in length, and is common in the south and west of France; they have been taken in the forest of Fontainebleau. The beautiful colours in which they are clothed causes them to be easily distinguished from the Viper. The eyes are edged with golden-coloured scales; the upper part of the body is of a very dark greenish colour, upon which is extended a large number of radiating lines, composed of small yellowish spots of different shapes, some long, others lozenge shape, giving it a chequered appearance. These chequers extend from the head to the tail. The belly is yellowish; the large plates which cover it have a black spot at each end, and are bordered with a very thin black line. This inoffensive reptile is extremely timid, and generally hides itself from observation, taking to flight at the least alarm. They are said to be easily tamed.

The Viperine Snake (Tropidonotus viperinus, Fig. I2) has the body of a greyish or dirty yellow colour, having on the middle of the back a series of blackish spots so close to each other as to give the idea of one small continuous wavy line from head to tail. The sides are covered with isolated spots, forming lozenge-like figures, the centres of which are of a greenish tint. This is the smallest of all the European Colubrida, and, like the others, it is found in most parts of Europe.

[The Psammophida, or Desert Snakes, are akin both to the Colubrida and to the Tree Snakes of the next family; but the latter, remarks Dr. Günther, may always be distinguished either by their green coloration, by the horizontal pupil of the eye, or the absence of a long anterior maxillary tooth. In the Psammophidae the pupil 
of the eye is round or vertical. Most of the species of this family belong to the fauna of tropical Africa, which also produces a slender form (Psammophis elegans). The other species are of a stouter habit, frequenting plains, or at all events living on the ground. Ot the Indian Psammophis condanarus, Dr. Jerdon procured one which had killed and was swallowing a small viper (Echis carinata), this being one of the few instances in which a non-venomous Snake has been known to overpower a poisonous one.* We have heard the

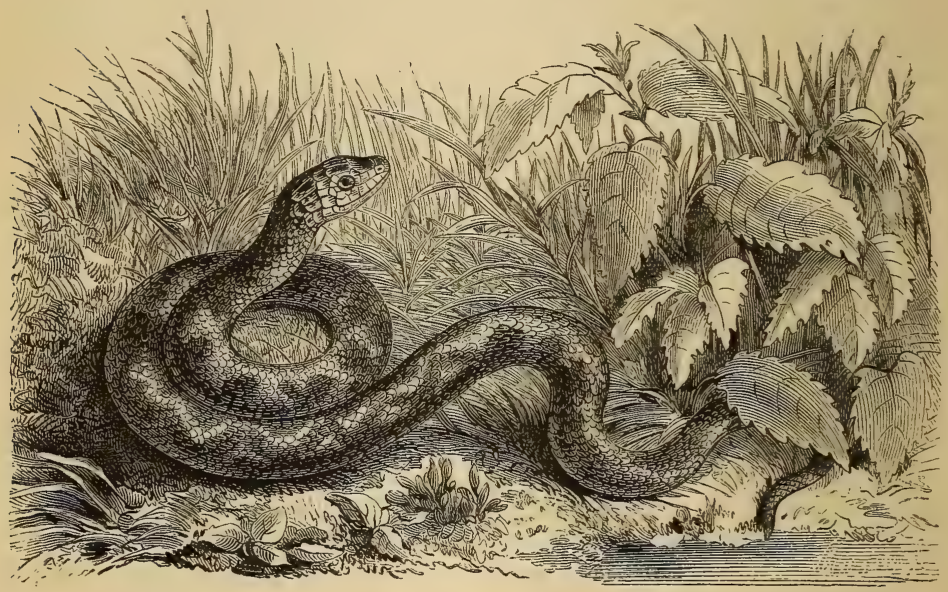

Fig. 12.-Viperine Snake.

same of a small boa-like Serpent (Chilabothrus?) in the West Indies, which is said to prey upon the formidable Crotalida. The Psammodynastes pulverulentus has a wide geographical range over southeastern Asia and its islands. Although innocuous, it has the aspect of a venomous species.

In a kindred African family, the Rachiodontida, the species of Dasypeltis have the maxillary teeth minute and few in number (four to seven); but they have also some remarkable gular teeth, which are formed by the elongated inferior spinous processes of the hinder

* The Black Snake of North America undoubtedly preys upon the formidable Rattlesnake.-ĖD. 
cervical vertebræ. The object of the latter is to crush the shells of birds' eggs, upon which the snakes in question habitually feed.

Of the more characteristic Tree Snakes, the Dendrophida have the budy and tail much compressed, or very slender and elongated; the head generally lengthened, narrow, flat, and distinct from the slender neck; the snout rather long, obtuse or rounded in front; cleft of the mouth wide; and the eye of moderate size, or large, with round pupil. These are diurnal Snakes, which live entirely upon trees, where they prey chiefly on arboreal lizards and frogs. Species of them inhabit all tropical countries. They are generally of great beauty; the Indian Chrysopelea ornata is excessively so, being variegated with yellow and crimson upon a black ground, but the crimson soon fades when a specimen is immersed in spirit. Others are very variable in their colouring, as the African Bucephalus capensis and the Indian Dendrophis picta.

The next family of Dryiophida, or the Whip Snakes, have a still more slender and elongated body, which has been aptly compared to the thong of a whip. The head is very narrow and long, with tapering snout, ending in a protruded rostral shield, which is sometimes modified into a flexible appendage ; the eyes are of moderate size, and all the Asiatic species have the pupil of the eye horizontally linear, and a long fang-like tooth in the middle of the maxillary. The whole of this group are provided with a posterior grooved tooth. They are chiefly nocturnal, and their movements are wonderfully rapid and graceful among the branches of trees. They are numerous almost everywhere in tropical countries. In general the various Whip Snakes are of a bright leaf-green colour, with two white stripes on the belly, so that they are difficult to discern among the foliage. In the genus Langaha, which is peculiar to Madagascar, the muzzle is elongated into a fleshy appendage, which is covered with small scales, constituting about one-third of the total length of the head. This appendage is dentated in one species ( $L$. crista-galli), and not so in another ( $L$. nasuta). In the Indian genus, Passerita, the snout is long and pointed, terminating in a flexible appendage. The name of Whip Snake is applied by Anglo-Indians to all of the species of Dendrophidie and of Dryiophida; and the erroneous notion prevails that they are highly venomous, and that they spurt venom into people's eyes. The same is believed in South Africa of the Bucephalus capensis. Even Gordon Cumming asserts that one night a snake which his servant had tried to kill with his loading-rod flew up at his eye, and "spat poison into it. Immediately," he adds, "I washed it 
well at the fountain. I endured great pain all night, but next day my eye was all right." *

Of a beautiful green species (Philodryas viridissimus), appertaining to the family of Dendrophide, in Brazil, Dr. Wurcherer writes :- "I am always delighted when I find that another Tree Snake has settled in my garden. You look for a bird's nest, the young ones have gone, but you find their bed occupied by one of these beautiful creatures, which will coil up its body, of two feet in length, within a space not larger than the hollow of your hand. They appear to be always watchful ; for at the instant you discover one, the quick playing of the long black forked tongue will show you that you too are observed. On perceiving the slightest sign of your intention to disturb it, the snake will dart upwards through the branches and over the leaves, which scarcely appear to bend beneath the weight. A moment more, and you have lost sight of it." Some of the true Whip Snakes attain to six or seven feet in length, or even more; and with reference to the vague application of vernacular names (vide p. 38), it may here be remarked that the "little Whip Snake" of the Australian colony of Victoria denotes a poisonous Snake of a very different family (the Hoplocephalus flagellum).

The Dipsadida are a numerous family of tropical Tree Snakes, which also have a much compressed body, but short and triangularshaped head, which is broad behind; the eye large, having generally a vertical pupil. Some of them attain to six or seven feet in length, and all live on warm-blooded animals. It is remarkable that certain of the species prey on birds solely, whilst others attack only mammalia. Their coloration varies a good deal; and species of them inhabit most tropical and sub-tropical countries.

The Lycodontida are an extensive family of small Ground Snakes, inhabiting Africa and tropical Asia, which have the body generally of moderate length, rather slender, and the head long and wide, with generally a depressed, flat, and somewhat elongated muzzle ; maxillary with a fang-like tooth in front, but without a posterior grooved tooth. The African species feed on mice and other smaller nocturnal

* “A Hunter's Life in South Africa," vol. ii., p. I33. Vide also Chapman's "Travels in the Interior of South Africa," vol. ii., p. 34. We have personally captured or assisted in capturing various species of both families, and it is no easy matter to do so sometimes, from the rapidity of their movements among the branches of trees and bushes; but most assuredly we never saw one of these most beautiful reptiles attempt to dart or to spurt at anybody, and as they have no poison fangs, the latter must needs be an error.-ED. 
Mammalia; while the Indian species (which has a vertical pupil) prey chiefly, if not wholly, on the smaller Scincoid Lizards, which they follow into their places of retreat. Lycodon aulicus is also a common Snake in India, and is quite harmless, though often ignorantly supposed to be dangerous.

The Amblycephalida, or Blunt Heads, comprise a few species of moderate or small size, akin to the Dipsadida, the narrow mouth of which necessitates their feeding on insects, and they live on trees and bushes, or under the roofs of huts. Of the Indo-Chinese and Malayan Amblycephalus boa, Dr. Günther remarks that "the head of this most singular snake resembles much that of a mastiff, the lips being arched and tumid. It climbs with great facility, frequenting the roofs of the natives' huts in pursuit of its insect food. It attains to a length of three feet, the tail being a third." Of a second genus, Pareas, three species inhabit the same region.

The Pythonida, or Pythons, and Boas, are celebrated for the enormous magnitude to which some of the species attain. These are emphatically the great Constrictor Serpents, to all of which the name of Boa Constrictor is popularly applied, although this appellation refers properly to one only which is peculiar to South America. Various genera of them inhabit Africa, south-eastern Asia and its islands, Australia, tropical America, and the West Indies.]

The Pythons are large serpents of Asia and Africa. They live in marshy places and near the margins of rivers. They are nonvenomous, but possessed of immense muscular power, which enables some of the species to kill by constriction animals of much larger circumference than themselves.

Aristotle tells us of immense Lybian serpents, so large that they pursued and upset some of the triremes of voyagers visiting that coast. Virgil's "Laocoon," so vividly represented in the well-known marble group, owes its origin, no doubt, to the descriptions current of constricting serpents. Quoting Livy, Valerius Maximus relates the alarm into which the Roman army, under Regulus, was thrown by an enormous serpent, having its lair on the banks of the Bagradus, near Utica. This serpent Pliny speaks of as being I 20 feet long. Without multiplying instances to which time has lent its fabulous aid, but coming to more modern times, Bontius speaks of serpents in the Asiatic islands as being so various that he despairs of even enumerating them all. "The great ones," he says, "sometimes exceed thirty-six feet, and have such capacity of throat and 
stomach, that they swallow entire boars." He adds that he knew persons who had partaken of a hog cut out of the stomach of a serpent of this kind. "They are not poisonous," he adds, "but they strangle by powerfully applying their folds round the body of their prey." Mr. M'Leod, in his interesting "Voyage of the Alceste," states that during a captivity of some months at Whidah, on the coast of Africa, he had opportunities of observing serpents double this length, one of which engaged a negro servant of the Governor of Fort William in its coil, and very nearly succeeded in crushing him to death. There can be no doubt that the length is here much exaggerated. About thirty feet is the utmost length attained by the most gigantic serpents of which we possess accurate knowledge.

The body of the Python is large and round. They live on trees in warm damp places, on the banks of streams or watercourses, and attack the animals which, to slake their thirst, have the mishap to pass near them. Attached by their tail to the limb of a tree, they remain immovable in their ambush until their opportunity comes, when they dart upon their prey with amazing rapidity, wrap their bodies round it, and crush it in their powerful folds. Animals as large as gazelles, and even larger, thus become their victims. Their jaws are extremely distensible, for, having neither breast-bone nor false sides, they can easily increase the diameter of the opening to an almost incredible extent.

The Ophidians (as we have seen) surpass all other Reptiles in the number of their vertebræ, with incomplete hæmal arches; these constitute the skeleton of the long, slender, limbless trunk. All these vertebræ coalesce with one another, and are articulated together by ball-and-socket joints. Besides this articulation to the centrum, the vertebræ of Ophidians articulate with each other by means of joints which interlock by parts reciprocally receiving and entering one another, like the tenon-and-mortise joint in carpentry. "The vertebral ribs have an oblong articular surface, concave above and almost flat below, in the Python. They have a large medullary cavity, with dense but thin walls, with a fine cancellated structure at their articular ends. Their lower end supports a short cartilaginous membrane, closing the hæmal arch, which is attached to the broad and stiff abdominal scute. These scutes, alternately raised and depressed by muscles attached to the ribs and integuments, aid in the gliding movement of serpents."

The peculiar motion of snakes was first noted by Sir Joseph Banks, and commented on by Sir Everard Home. Sir Joseph was observing a Coluber of unusual size, and thought he saw its ribs come forward 
in succession, like the feet of a caterpillar. To test this, he placed his hand under the animal; the ends of the ribs were distinctly felt pressing upon the surface in regular succession, leaving no doubt that the ribs form so many pairs of levers, by means of which it moves its body from place to place.

The muscles which bring forward these ribs, according to Sir Everard, consist of five sets:-One from the transverse process of each vertebra and the rib immediately behind it, which rib is attached to the next vertebra; the next set goes from the rib near the spine, and passes over two ribs, sending a slip to each, and is inserted into a third, a slip connecting it with the next muscle in succession; under this is a third set, issuing from the posterior side of each $r i b$, passing over two ribs, and sending a lateral slip to the next muscle, and is also inserted in the third rib behind. And so on throughout the five sets of muscles.

On the inside of the chest there is a strong set of muscles attached to the anterior surface of each vertebra, and, passing obliquely forward over four ribs, is inserted into the fifth one only in the centre. From this part of each rib a strong flat muscle comes forward on each side, before the viscera, forming the abdominal muscles, and uniting in a middle tendon, so that the lower half of each rib which is beyond the origin of this muscle, and which is only laterally connected to it by a loose cellular membrane, is external to the belly of the animal, and is used for the purpose of progressive motion, while that half of each rib which is next the spine, as far as the lungs extend, is employed in respiration.

These observations of Sir Everard Home apply to all Snakes; but the muscles were compared with a skeleton of the Boa Constrictor in the Hunterian Museum, which is thirteen feet nine inches in length. The habit of attaching themselves to trees, and holding on by the tail, their heads and bodies floating listlessly over some sedgy river, is explained by the structure of the tail. Dr. Meyer has minutely described the manner in which they hook themselves to a tree, which gives them the power of a double fulcrum. The apparatus which gives this power is a spur or nail on each side of the vent in the Pythonida, in which the anatomist discovered the elements of an unguinal phalanx articulated with another bone much stronger, which is concealed under the skin.

Following the arrangement of the Pythonidae adopted by Dr. J. E. Gray in the catalogue of the British Museum, we find :-

I.-Morelia, having a strong prehensile tail, distinct head, truncate 
muzzle, crown of the head with small shield-like plates. Of this genus there are two species:- the Diamond Snake ( $M$. spilotes), a native of Australia, and of a bluish-black colour; and the Carpet Snake $(M$. variegata), from Port Essington and Swan River. It is whitish, with irregular black-edged olive spots and an olive head, with two or three white spots in the centre of the crown.

II.-Python, having the crown shielded to behind the eyes.

Of this genus there are two species, which have sometimes been referred to the Boas. The Pythons bear the same general appearance. Upon their bodies is traced a sort of blackish-brown chain, presenting nearly quadrangular links upon a clear yellowish ground, extending from the nape of the neck to the extremity of the tail. The suscephalous region is partly covered by a large brownish-black spot. Upon each side of the head is a black band, which frequently extends from the nostril, passing by the eye as far as the corners of the lips.

$P$. reticulatus, the Ular Sawad of the Malay countries, found also in Burmah and Siam, has the four front upper labial plates pitted; the frontal plate simple; the head has a narrow, longitudinal, brown stripe. This is one of the most handsomely-marked species of the whole family, its body being covered with a gay lacing of black and golden yellow. It is said to attain the great length of thirty feet, and is stout in proportion. In its native wilds the powers of this gigantic reptile are said to be enormous, being able to subdue a full-grown buffalo; and even men have been said to become its prey. A Malay proa had anchored for the night under an island of the Celebes. One of the crew had gone ashore in search of the favourite betel nut, and is supposed on his return to the beach to have fallen asleep. In the dead of the night his comrades were roused by his screams; they pulled ashore with all expedition, but came too late; the cries had ceased, and the wretched man had breathed his last in the folds of one of these enormous Serpents. They killed the creature, cut off the head, and carried it, together with the lifeless body of their comrade, to the vessel. The right wrist of the corpse bore the mark of the serpent's teeth, and the disfigured body showed that the man had been crushed by the constrictive folds of the reptile round the head, breast, and thighs. The Ular Sawad arranges its eggs by placing them in a group, which is covered by the body. This statement, first made by Mr. Bennett, has been confirmed by the observations of M. Lamare Picquot, and by observations on other species of Python in the Jardin des Plantes, Paris, and in the London Zoological Gardens. 
The Rock Snake of India and Ceylon ( $P$. molurus) is another species to which the name of Boa Constrictor has been given. It has the two pairs of front upper, and three hind lower labial shields pitted, and the frontal plates double. Of this gigantic Serpent several specimens are generally to be seen in the Zoological Gardens.

III.-Hortulia, having the upper and lower labial shields deeply pitted; muzzle and forehead with symmetrical shield; nostrils lateral. They are natives of Africa, and three species are known, namely, the Natal Rock Snake, having the lower labial shields deeply pitted, the muzzle and forehead with symmetrical shields, the nostrils lateral; the Guinea Rock or Fetish Snake (H.Seba), closely resembling the last in many structural points; and the Royal Rock Snake (H. regia), having the four pairs of the upper front labials pitted, the upper ocular plate single, and lower labial shields four in number and broad.

The Royal Rock Snake inhabits Western Africa. It is black in colour, marked on the middle of the back with a series of oblong white spots, the sides being marked by another series of large white spots, with one or two black spots in the upper part; the head black, with a streak over the nostrils and the top of the eyes.

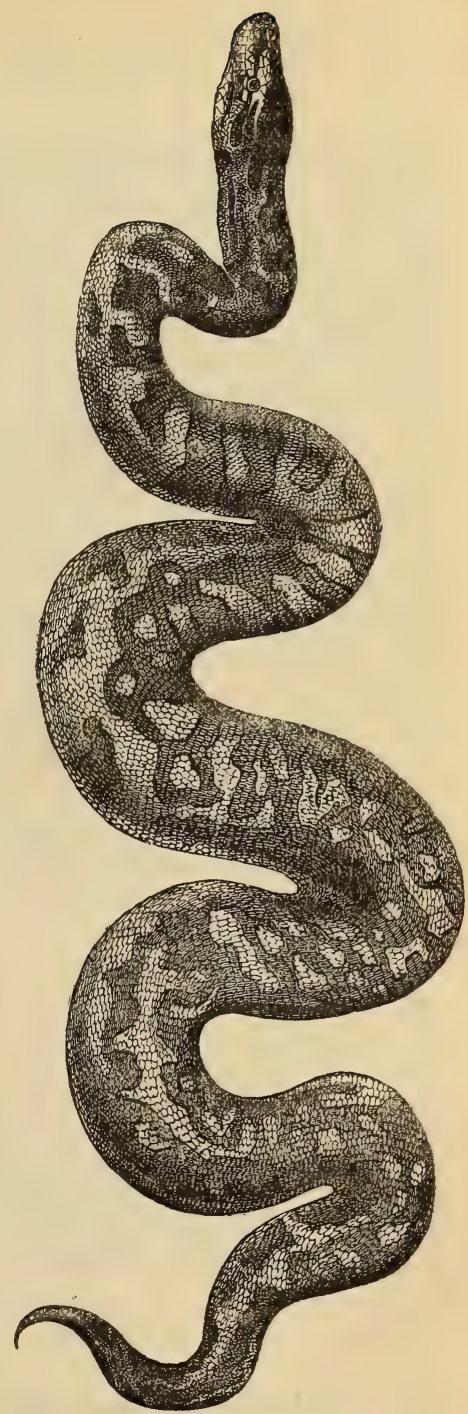

Fig. I3.-Natal Rock Snake. 
The Natal Rock Snake (H. natalensis, Fig. I3) is described by Sir Andrew Smith as being gigantic in size, he having seen a skin measuring twenty-five feet, although part of the tail was absent. "It feeds," he says, "on small quadrupeds ; and for some days after swallowing one it remains in a torpid state, when it may be easily destroyed." Of this opportunity, however, the South Africans never avail themselves; they have a horror of the reptile, but believe that it has an influence over their destinies, and affirm that no one has ever been known to kill one and prosper.

The Guinea Rock or Fetish Snake (H. Sebce, Fig. I4) is typical of the genus, and has also been referred to the Boa Constrictor, and closely resembles the Natal Rock Snake.* It is a native of the warmer parts of Africa. A living specimen at the Zoological Gardens is estimated to weigh a hundredweight.

Of the genera Liasis and Nordoa there are five species, very imperfectly known.

IV.-Epicrates, an American and West Indian species, having the crown scaly, the forehead with symmetrical shields.

The Aboma (E. cenchria, Fig. I5) is one of the largest of the group, sometimes attaining dimensions quite gigantic. It is yellowish in colour, with a row of large brown rings running the whole length of the back, and variable spots on the sides; these are generally dark, with a whitish semi-lunar mark. This formidable reptile has all the habits of its congeners ; it is found in the marshy swamps of tropical America and near the rivers, where it lies in wait for its prey.

The Boas, properly so-called, have the scales smooth; labial shields smooth, not pitted; the body compressed, tapering to the tail, which is long and prehensile; the head is comparatively small, being enlarged behind and contracted towards the muzzle, which is rather short. The crown is covered with scales; the nostrils lateral, between two plates. Four species of this genus are recognised by naturalists, all of which have been described by travellers as the true Boiguacu, or boa constrictor of Linnæus. This species has the scaly circle of the orbit separated from the upper labial plates by one or two series of scales. A large chain consisting of blackish hexagonal spots, alternating pale oval stains, notched and jagged, extending the whole length of the back, and forming a very elegant design. This species seems to be strictly confined to tropical America. Humboldt found it in Guiana, and the Prince de Wied observed it

* A variety very similar to this is known in China.-ED. 
in Brazil. All the specimens in the British Museum are from that part of the New World. This is supposed to be the Tlicoatl and

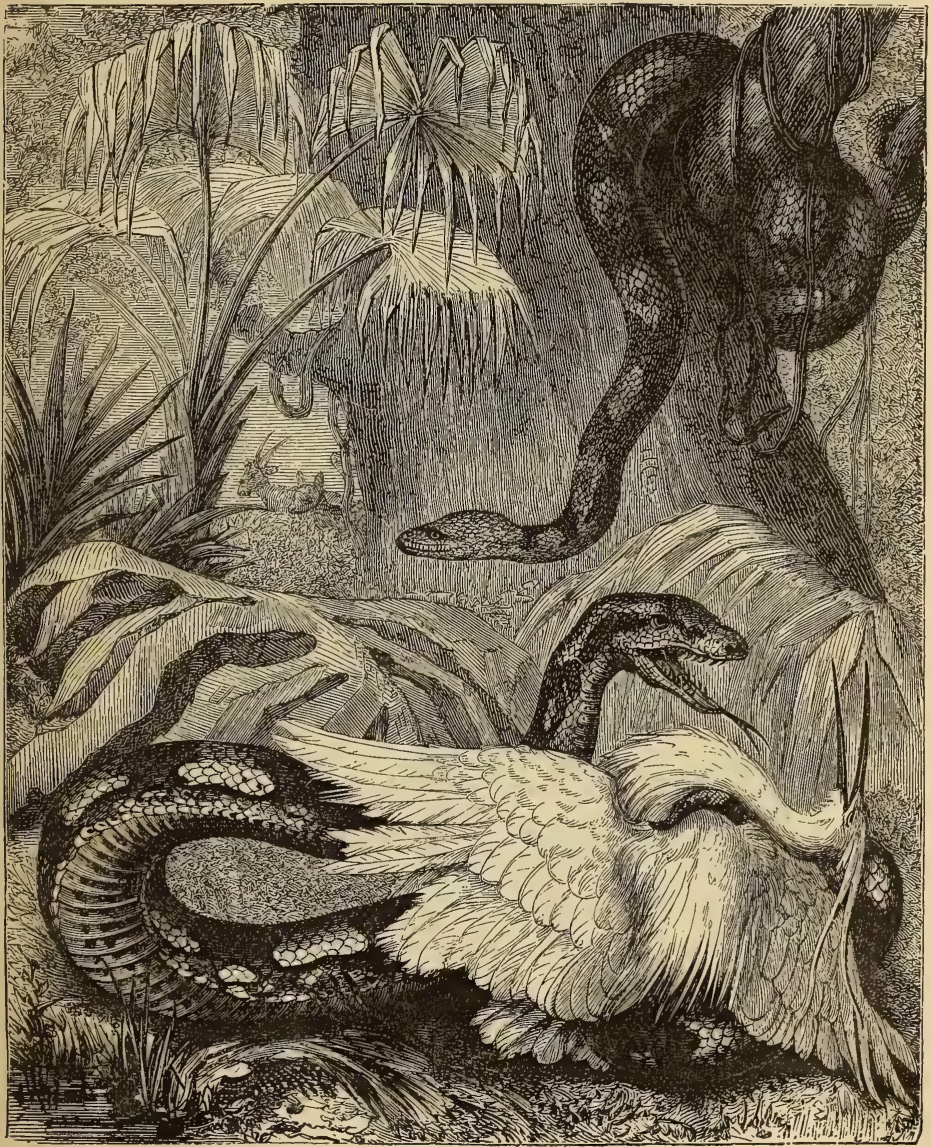

Fig. 14.-Guinea Rock Snake.

Temacuilcahuilia (the words meaning "fighting with five men") described by Hernandez, the latter name being derived from its size 
and strength. "It attacks," he says, "those it meets, and overpowers them with such force, that if it once ccils itself round their

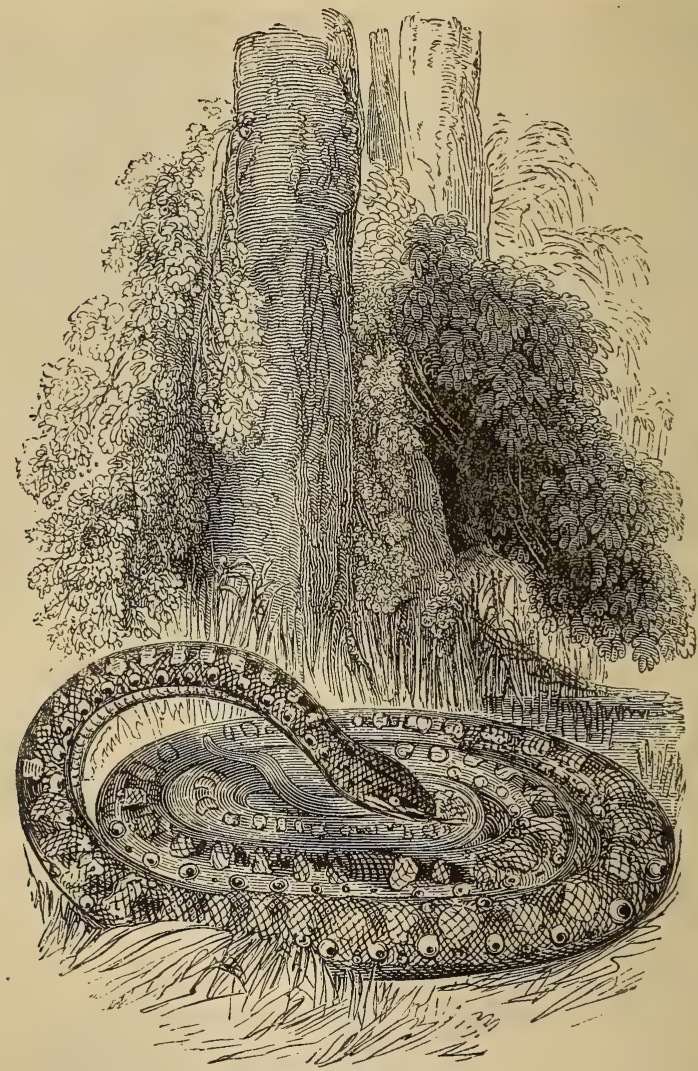

Fig. 15.-Aboma.

necks, it strangles and kills them, unless it bursts itself by the violence of its own efforts." The same author states that he has seen serpents as thick as a man's thigh, which had been taken when young by Indians, and tamed. That this Boa attains an immense 
size is a well-established fact. Shaw mentions a skin in the British Museum, in one of his lectures, which measured thirty-five feet in length.

Three other species-the Lamanda ( $B$. diviniloqua), from Santa Lucia; the Emperor ( $B$. imperator), a native of Mexico; and $B$. eques, the Chevalier Boa of Peru-are all to be occasionally seen in the Zoological Gardens.

The Boa anaconda, more properly Eunectes murinus (Fig. I6), is also a native of tropical America. The name of Anaconda has become well known through Mr. Lewis's celebrated tale so called, in which its predatory habits are displayed in such a manner as to enthral and fascinate the reader, as the author makes the reptile fascinate its victim. The name, Mr. Bennett tells us, is of Cinghalese origin, and is popularly applied to all very large serpents. This species is of a brownish tint, with a double series of colours extending from head to tail; the sides are covered with annular spots with white discs surrounded by blackish rings. Seba has represented this creature lying in wait for mice; but this is probably the prey of the young Anaconda. Another provincial name, "El Troga Venado" (the deer swallower), is probably applied to the matured reptile.

The following description of the actions of one of these large non-venomous serpents, which accompanied a specimen sent to the United Service Museum, by Sir Robert Ker Porter, is probably a fair description of the habits of all the large Pythonida:- "This species is not venomous, nor is it known to injure man (at least not in this part of the New World) ; however, the natives of the plain stand in great fear of it, never bathing in waters where it is known to exist. Its common haunt, or rather domicile, is invariably near lakes, swamps, and rivers ; likewise close to wet ravines produced by inundations of the periodical rains. Animals which repair there to drink, and even fishes, are its prey. The creature lurks watchfully under cover of the water, and, while the unsuspecting animal is satisfying its thirst, suddenly makes a dash at its nose, and with a grip of its back-reclining range of teeth, never fails to secure the terrified beast. In an instant the sluggish waters are in turbulence and foam. The whole form of the serpent is in motion; its huge and rapid coilings soon encircle the struggling victim, and but a short interval elapses ere every bone in the body of the expiring prey is broken." Sir Ra,bert then describes the manner in which the prey is swallowed, being previously lubricated by the serpent's saliva; but Professor T. Bell, after carefully watching the constricting serpent's mode of swallowing its prey, asserts that this is a delusion. "The 
mucus is not poured out till it is required to lubricate the dilated jaws and throat for the seemingly disproportionate feat."

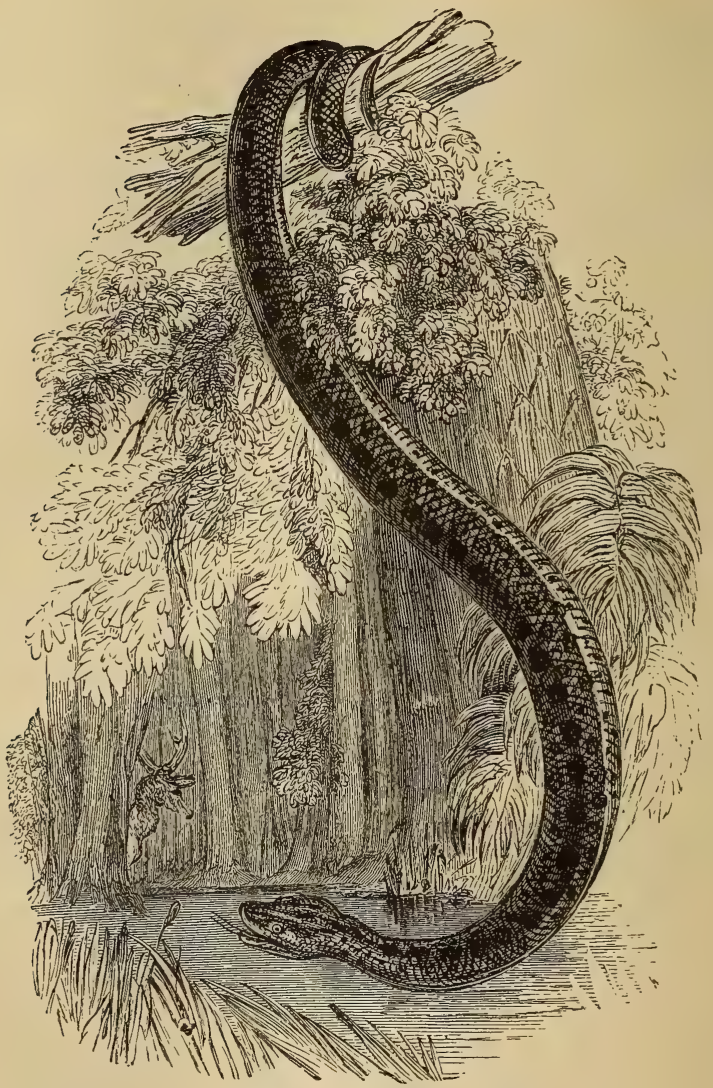

Fig. r6.-Anaconda.

[The small, but very distinct family of Erycida have the body of moderate length, cylindrical, covered with small and short scales; the tail very short, with only a single series of subcaudal scales; head somewhat elongate; eye rather small, with vertical 
pupil. Adult individuals have, like the Pythons, a short conical prominence in a groove on each side of the vent; this being the extremity of a rudimentary hind limb. "The snakes of this family," remarks Dr. Günther, "show great similarity to the Pythons and Boas with regard to their internal structure as well as to their external characters. But their tail is very short, not flexible, and much less prehensile; and whilst the serpents just mentioned are more or less arboreal, frequenting marshy places with luxuriant vegetation, the Erycida inhabit dry, sandy, or stony plains, burrowing with the greatest facility below the surface, and entering crevices and holes in search of their prey, which consists of mice, lizards and other burrowing snakes. Probably they are semi-nocturnal, and able to see in dark places as well as in the night. They are found in Northern Africa, in the islands of the Mediterranean, in the arid parts of India, and probably in Arabia: two species are known to have been brought from Sikhim."

The Cursoria elegans is said to be from Afghanistan; Eryx jaculus inhabits Greece and Egypt; and there is also E. thebaicus in the latter country, and $E$. Johnii in India. Another Indian species is the Gongylophis conicus, which the natives erroneously persist in declaring to be venomous. The Eryx Johnii is frequently found in the possession of the serpent-charmers of its native country, who mutilate the end of its short thick tail in such a manner that the scarred extremity somewhat resembles the form of the head. Such specimens are shown as deadly two-headed snakes, and, as such, are occasionally brought alive to Europe. An example of this species lived in the London Zoological Gardens for about eight years, and fed regularly on young mice. The keeper assured Dr. Günther that it frequently covered its prey with saliva. It always kept itself hidden below the gravel at the bottom of its cage. This species attains to a length of nearly four feet, the tail measuring but four inches.

The Acrochordida constitute a very remarkable small family, of which one genus is terrene and another highly aquatic in its habits. Whether a third genus, the Javanese Xenodermus, should be referred to it, is doubtful, in the opinion of Dr. Günther. These snakes have the body of moderate length, rounded or slightly compressed, and covered with small wart-like not imbricate tubercular or spiny scales; tail rather short, prehensile; head rather small, not distinctly separated from the neck, and covered with scales like those of the body; nostrils close together at the top of the snout; teeth short, but strong, of nearly equal size, and situate both in the jaws 
and on the palate. These serpents are viviparous. One of them, Acrochordus javanicus, inhabits Java and the Malayan peninsula, where it is considered rare. It grows to a length of eight feet, and its habits are terrene. The late Dr. Cantor justly compares its physiognomy to that of a thorough-bred bull-dog; a female in his possession brought forth no fewer than twenty-seven young in the course of about twenty-five minutes. At birth they were active, and bit fiercely. Hornstedt found a quantity of undigested fruits in the stomach of this Serpent! upon which Dr. Günther remarks that no opportunity of making further observations on the habits of this remarkable Snake should be lost. The aquatic member of this family, Chersydrus granulatus, is to be found from the coasts of India to New Guinea and the Philippine Islands. Sometimes it is met with at a distance of three or four miles from the shore. Mr. W. Theobald remarks that it is plentiful in the Bassein River (in British Burmah), in salt water below Gnaputau, and, with various other Sea Snakes, is frequently swept by the tide into the fishing baskets of the natives. The ebb-tide, running like a sluice, sweeps various fishes, crustaceans, snakes, and even porpoises occasionally, into the broad mouths of those baskets, where they are at once jammed into a mass at the narrow end of the creel. "The Chersydrus," he adds, "is more nearly connected with the Hydrophide than with the next family, being as essentially aquatic as any of the former, to which, save from its wanting the poison-gland, it might be appropriately referred. Indeed, it has been erroneously asserted by some authors to be venomous."

The Homalopside are an extensive family of Snakes, of thoroughly aquatic habits, which are only occasionally found on the margins of rivers; several of them enter the sea, and in some parts of their organisation they approximate to the true marine Snakes. They may be easily recognised by the position of the nostrils on the top of the snout, which enables them to breathe by raising only a very small portion of the head out of the water, an arrangement which is likewise seen in the hippopotamus, the crocodile, the sea snakes, and other aquatic animals. Many of them have a distinctly prehensile tail, by means of which they hold on to projecting objects. Their food consists either entirely of fishes, or (some species) of crustaceans. All appear to be viviparous, and the act of parturition is performed in the water. Not any of them attain a larger size than three or four feet in length. In captivity they refuse to feed. All the Asiatic species of this family have a grooved fang at the hinder extremity of the maxillary bone. The species are numerous, 
and are arranged into many generic divisions. The majority are from the grand Indian region, extending to China and to Australia, but there are also several from the New World. The Herpeton tentaculatum, of Siam, is very remarkable from its snout terminating in two flexible, cylindrical, scaly tubercles, which are supposed to be employed as organs of touch under water-perhaps to discern its food, which as yet has not been ascertained. The largest known example of this curious Snake is only twenty-five inches long, of which the tail measures six inches.

We now proceed to the first family of Poisonous Snakes, that of

\section{The Sea Snakes (Hydrophidce),}

which are very distinct from all that follow, though less so from certain of the harmless species appertaining to the two families last treated of. Some of their distinctions have been already noticed (p. 40), but they are especially characterised by their highly compressed tail, indicative of their thoroughly aquatic habits.* According to Dr. Günther, there is no other group of Reptiles the species of which are so little known, and the synonymy of which is so much confused, as that of the Sea Snakes. Most naturalists who have worked on them have been misled by the idea that the species were not nearly so numerous as they actually are. Mr. W. Theobald makes out as many as twenty-five inhabiting the Bay of Bengal and the adjacent seas, to which area this group of reptiles is mainly confined, a few species extending to northern Australia, and one, the most emphatically pelagic, the Pelamis bicolor, even to the Pacific Ocean. One genus only, Platurus, approaches the Land Snakes in several of its characters; having much the physiognomy of an Elaps, with the cleft of the mouth not turned upwards behind, as in other Sea Snakes; the eye also is rather small, nor is the tail at all prehensile. There are two species of this particular form, one of which, $P$. scutatus, is rather common, and its geographic range extends from the Bay of Bengal and the China seas to the coasts of New Zealand; the distribution of the other, $P$. Fischeri, being nearly as extensive. The great genus Hydrophis has the posterior part of the body highly compressed; and most of the species are more or less of a bluish lead-colour, like that of the sea,

* Varieties of this family are extremely numerous in the southern Chinese Sea, the Straits of Banka, Malacca, and Sunda; but from being known to be extremely poisonous, are seldom molested.-ED. 
or black, banded with white or yellowish white. They are so abundant in the Indian seas that some of them are taken with every haul of a fishing-net, and they are helpless and seemingly blind when out of the water, the fishermen commonly seizing them one after the other by the nape and throwing them back into the sea. Some of them (Microcephalophis of Lesson) have the head very small and the neck exceedingly slender, while the compressed body is large and thick.

\section{The Colubrine Venomous Snakes.}

These are comprised under the one family, Elapida, all of which have an erect, immovable, grooved, or perforated fang, in the forepart of the maxillary bone. There is little in their external appearance to distinguish them from the harmless Colubrine Snakes, to which they are more nearly akin - in all but their poison-fangs - than they are to the Rattlesnakes and Vipers; yet some of the most poisonous of Ophidians appertain to this family, as exemplified by the well-known Cobras of the Indian region and of Africa, and also by some of the worst Snakes that inhabit Australia. In the colony of Victoria alone as many as ten species of Snakes are known, one only of which, Morelia variegata, is harmless ; and one only of them, the formidable Death Adder (Acanthopis antarctica), belongs to the sub-order of the Viperine Snakes. The rest are included among the Colubriform Venomous Snakes, and most of the accidents from poisonous Snakes in that colony are due to what is there known as the Carpet Snake (Hoplocephalus curtus), while the Snake that bears the same name in the adjacent colony of New South Wales is the innocuous Morelia spilotes, which is a small Serpent of the family of Pythonida. Of the total number of Snakes known in all Australia, by far the greater number are venomous, which is the reverse of what occurs elsewhere. Only about five species, however, are really dangerous throughout the great island-continent, for in many of them the poison is by no means virulent. Thus, of Diemansia psammophis, which sometimes exceeds four feet in length, Mr. Kreftt remarks that "its bite does not cause any more irritation than the sting of a bee." Also, that "the bite of Hoplocephalus variegatus is not sufficiently strong to endanger the life of a man. I have been wounded by it several times," writes Mr. Krefft, "and experienced no bad symptoms beyond a slight headache; the spot where the fang entered turning blue to about the size of a shilling for a few days." Again, of Brachysoma diadema, "This very handsome little snake is venomous, but never offers to bite, and may be handled with 
impunity." Far otherwise, however, is the venom of Hoplocephalus curtus, and also of some others. $H$. curtus is one of the worst Snakes of Australia, where it inhabits the more temperate parts of the country from east to west. Its bite is almost as deadly as that of the Indian Cobra, to which it is considerably allied. "A goodsized dog bitten became paralysed within three minutes, and was dead in fifty minutes afterwards ; a goat died in thirty-five minutes; a porcupine ant-eater (Echidna hystrix) lived six hours; and a common tortoise, an animal which will live a day with its head cut off, died in five hours after being bitten." The $H$. superbus replaces it in Tasmania.

The Cobras (Naja) are widely known, alike from the virulence of their poison and for their remarkable dilatable disc or "hood" on the nape, the ribs which support this hood being much elongated. Two species are commonly recognised, the Cobra di Capella of Southern Asia, Fig. I7 (Naja tripudians), and the Asp (N. haje) of Africa but there are marked local varieties of both species, and the $N$. sputatrix of the Malay countries should probably be recognised as a third species. Those of India, with Ceylon, have a mark like a pair of spectacles upon the hood; while those of Burmah and the neighbouring countries eastward, have only an oval black spot upon it. In India the commonest colour of this formidable reptile is uniform brown, though many are of a pale yellowish straw colour; and there are others of every shade between that and black. It grows to a length of about five feet, seldom more. "Almost every writer on the natural productions of the East Indies," remarks Dr. Günther, "has contributed to the natural history of this snake, which has been surrounded by such a number of fabulous stories, that their repetition and contradiction would fill a volume." It is very generally diffused over the Indian region, though, as $\mathrm{Mr}$. Theobald notices, from its nocturnal habits, it is less often seen than many harmless species. "This snake is, I believe," he adds, "of inoffensive habits, unless irritated, but is, of course, a dangerous neighbour to have in a house.* Not only in Burmah, where the respect for animal life is greatest, but in India also, I have known a cobra enticed or forced into an earthen jar, and then carried by two men across a river, or some distance from the village, and liberated.

* Although the Cobra di Capella is so plentiful in India, we could never hear of one instance of a European being bitten by one during a residence of many years in that country. They prey chiefly on rats-the presence of which is the attraction which brings them about human habitations-occasionally upon young chickens, and commonly upon toads.-ED. 
Dr. Günther remarks that, 'singuiarly enough, it has never been obtained in the Valley of Nepâl.' This is very easily accounted for," continues Mr. Theobald, "since few would venture to kill a cobra, even for scientific purposes, in the rigorously Hindu State of Nepâl. In British India, decent Hindus will not kill a cobra; and if one has taken up his abode in a house, it is permitted to remain, or else carefully inveigled into an earthen pot, and carried away as described. Of course only the orthodox Hindu is so careful to abstain from injuring the cobra, and their reverential feeling is now perhaps rather the exception than the rule." A fine example of the more formidable Cobra (Hamadryas elaps), to be noticed presently, was obtained from an earthen pot which had floated out to sea.

The late Sir J. Emerson Tennent mentions that "the Cinghalese remark that if one cobra be destroyed near a house, its companion is almost certain to be discovered immediately after-a popular belief which I had an opportunity of verifying on more than one occasion. Once, when a snake of this description was killed in a bath of the Government House at Colombo, its mate was found in the same spot the day after ; and again, at my own stables, a cobra of five feet long having fallen into the well, which was too deep to permit its escape, its companion, of the same size, was found the same morning in an adjoining drain.* On this occasion the snake, which had been several hours in the well, swam with ease, raising its head and hood above water ; and instances have repeatedly occurred of the Cobra di Capella voluntarily taking considerable excursions by sea" (or by rivers, as the writer has personally witnessed).

Cobras are much dreaded, for they instil the most subtle poison into their victims. Their manners are very singular. When at rest the neck of the animal is no larger in diameter than the head; but when under the influence of passion and irritation, it raises the front part of its body vertically, holding it straight and rigid as an iron bar, the neck swelling at the same time. The lower part of the body rests upon the ground, and serves as a support to the upper part, which is movable and capable of locomotion. This faculty of dilating the neck is as striking a trait in the organisation of the Cobras as the rattle is in Crotalus. The ancient inhabitants of Egypt adored them; they attributed to their protection the preservation of grain, and allowed them to live in the midst of their cultivated

* "Pliny," remarks Sir J. E. Tennent, " notices the affection that subsists between the male and female Asp (or African Cobra); and that if one of them happens to be killed, the other seeks to avenge its death."-LIB. viii., c. 37. 



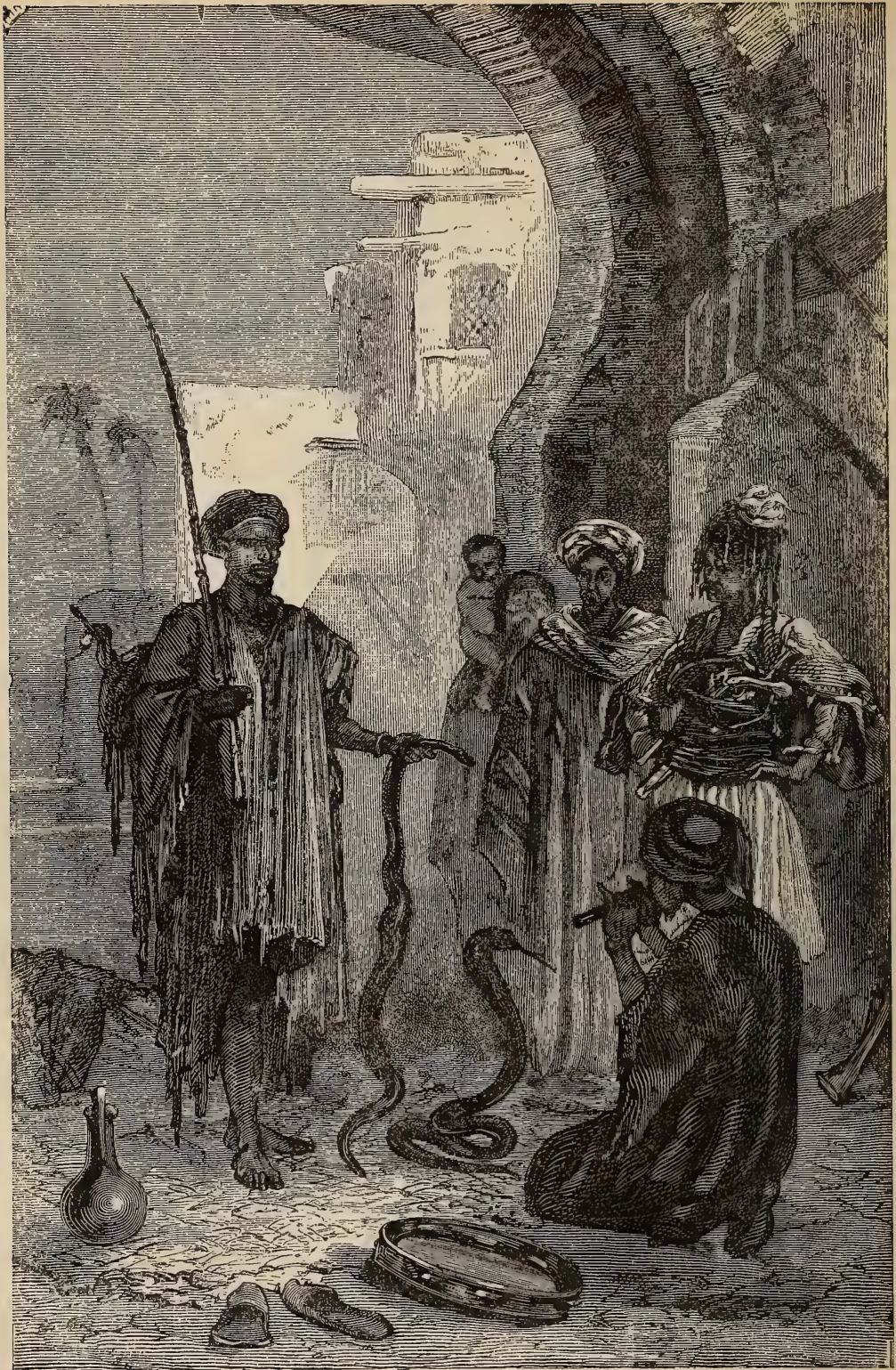

I.-Snake-charmers. 
fields. It is the serpent chiefly used by snake-charmers, terribly fatal as its bite is known to be.

The action of the snake-charmer is as follows: he takes in his hand a root, the virtue of which is supposed to preserve him from the venomous effects of the bite of the Cobra. Drawing the reptile from

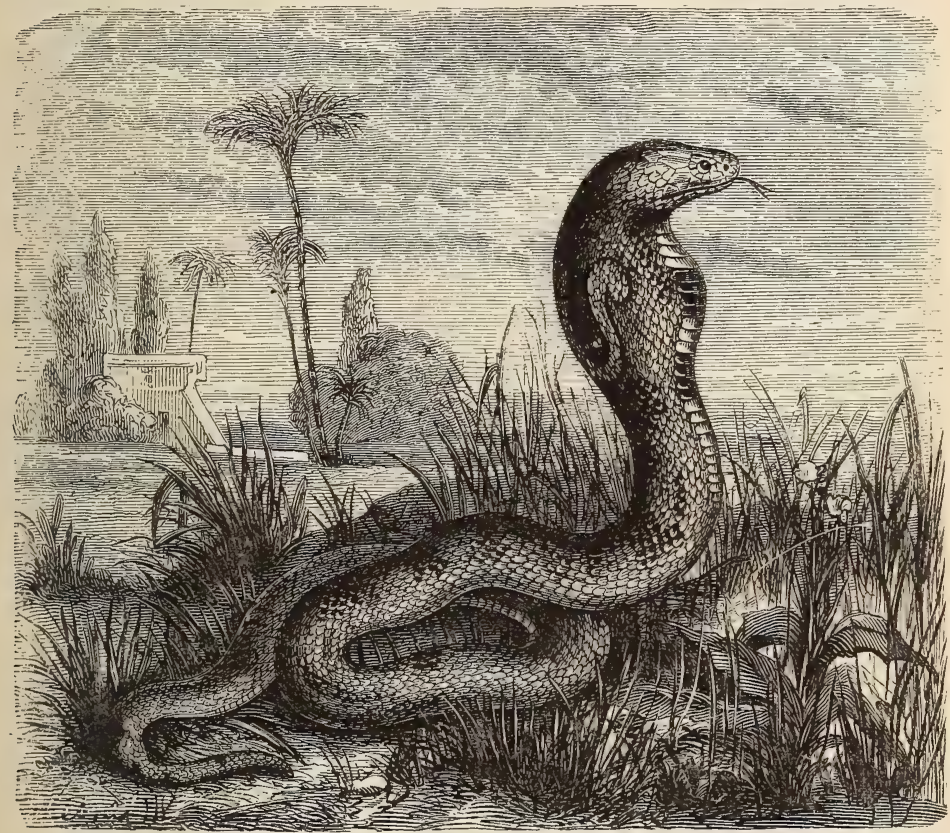

Fig. 17.-Cobra di Capella.

the cage in which he keeps it confined, he irritates it by presenting a stick to it ; the animal immediately erects the fore part of its body, swells its neck, opens its jaws, extends its forked tongue, its eyes glitter, and it begins to hiss. Then a sort of battle commences between the serpent and the charmer; the latter, striking up a monotonous sort of song, opposes his closed fist to his enemy, sometimes using his right hand and sometimes his left (Plate I.) The animal fixes its eyes upon the fist which threatens it, follows all its movements, 
balances its head and body, and thus simulates a kind of dance. Other charmers induce the Cobra to make a variety of movements of the neck and head by playing upon a whistle or flute. It is said that these mysterious jugglers are able, by some sympathetic action they possess, to plunge these dangerous enemies into a sort of lethargy and death-like rigidity, and to bring them at will out of this momentary torpor. It is certain, at any rate, that they handle these animals, whose bite is extremely dangerous, with considerable impunity. It is supposed by some that these charmers take the precaution of exhausting the venom of the Cobra every day by forcing it to bite something several times before exhibiting it, or by drawing its poisonous fangs.

The Asp (Naja haje) has a less dilatable neck; it is of a greenish colour, and marked with brownish spots. It is smaller than the former; is found in the west and south of Africa ; and is especially common in Egypt. It was said to have been this reptile which caused the death of Cleopatra.

[The genus Hamadryas of Cantor (Ophiophagus of Günther) differs very little from the true Cobras, but has a less developed hood, and a single small tooth placed at some distance behind the fang. The only species (H. elaps) attains to thirteen feet in length, and is proportionately formidable, being much less timid and retiring in its habits than the Cobras of the genus Naja. It preys habitually on other Snakes, and seems to be more plentiful eastward of the Bay of Bengal than it is in India. In Burmah it is styled the Gnán; and Mr. Theobald tells us that its venom is fatal in a few minutes. "One of these snakes," he adds, "was brought in alive, and a snakecharmer came up to display his command over the animal. At first, (as I am told) the snake seemed cowed by the authoritative 'Hah' of the man; but suddenly, through some carelessness on his part, the snake struck him on the wrist. The poor fellow at once ran off home to get an antidote, but fell down before reaching his own door, and died in a few minutes. When at Tonghu," continues Mr. Theobald, "I heard a case of an elephant being killed by one of these snakes, which I have no reason for doubting. The elephant was a fine powerful male, and was pulling down with his trunk some creepers or boughs, when a large Gnàn, which was disturbed in the tree, struck the elephant on the trunk between the eyes. The elephant at once retreated, became faint, and died in about three hours." This terrible Snake would appear to be not uncommon in the Andaman Islands, and its range of distribution extends through the Malay countries to the Philippines and to New Guinea. 
The genus Bungarus is so called from the vernacular appellation of Bungarum, which is applied to one of the species on the Coromandel coast. Some of them are very like Cobras without the hood, as the Kerait ( $B$. caruleus), which is a much-dreaded snake in India, but the geographic range of which extends neither to the countries eastward nor to Ceylon. The Snakes of this genus have a row of broad hexagonal scales along the middle of the back. The Kerait grows to four feet and a half in length, and has the upper parts of a bluish or brownish black, either uniform or more generally marked with numerous narrow white cross-lines, which mostly radiate from a white vertebral spot. In its habits it resembles the Cobra, preying on small mammalia, lizards, toads, and probably other snakes occasionally. The Raj-sámp (literally, Lord Snake) is a larger and thicker species than the Kerait, beautifully marked throughout with alternate broad rings of black and golden-yellow. This one is found almost generally throughout the Indian region, and would seem to prey entirely on other Snakes, especially of the Tropidonotus genus. It is of very sluggish habits, and frequents moist places and the vicinity of water. A species or local variety (B. ceylonicus), takes its place in Ceylon, and there is also a kindred species ( $B$. semifasciatus) in China and Formosa. According to Cantor, the Bungarums are capable of darting nearly the anterior half of the body. Their bite is very dangerous ; but " the magnitude of the danger," remarks Dr. Günther, "depends, as in other venomous snakes, on many circumstances-chiefly on the size and energy of the individual snake and on the place of the wound. As the fangs of the Bungarums are comparatively short, the wound is always superficial, and can be easily excised and cauterised; also, experiments made on some of the lower animals show that the general effect on the whole system becomes visible only after a lapse of time."

Of poisonous snakes akin to the Bungarums, there are the Xenurelaps bungaroides, founded on a single specimen received from the Khásya hills (north of Sylhet); and the Megarophis flaviceps, which inhabits the Indo-Chinese and the Malayan countries, but not India. The latter attains to more than six feet in length, and when alive or fresh the head and neck are vivid blood-red, which soon fades to a pale buff hue in specimens immersed in spirit, and hence the faulty name of flaviceps. As many as seven genera-Glyphodon, with two ascertained species; Diemansia, with four; Hoplocephalus, with eight; Pseudechis, with one; Pseudo-naja, with one; Brachysoma, with three; and Vermicalla, with one-are peculiar to Australia with 
Tasmania, making twenty known species of Colubriform Venomous Snakes in that range of territory, where others doubtless remain to be discovered; and there is one described as Pseudo-elaps superciliaris, which is suspected to be a second species of Pseudo-naja. The Cyrtophis scutatus of South Africa is a sort of hoodless Cobra, without any small teeth behind its fangs. In America there is only the genus Elaps, with numerous species, which are mostly of small size, and in some instances are very brightly coloured, as one of the Coral Snakes* of Brazil ( $E$. corallinus), which is beautiful coral-red, with the body encircled by equidistant black rings. The genus Elaps in America is represented in Africa by Homorelaps, in the Indian region by Callophis, and in Australia by Vermicalla. In general these are small and slender snakes, too much so to be held in much dread. What Dr. Günther remarks of the species of Callophis will apply, as we believe, equally to the others:- "They appear to prefer hilly countries to the plains, live constantly on the ground, and are slow in their movements. In their habits, in their form, and in their powerless muscular organisation, they show the greatest similarity to the Calamarice; and this is why the Callophides feed almost entirely on the latter, the venomous snake being able to overpower the nonvenomous. Both of these genera have also the same geographical distribution; and Ceylon, where we do not find the Calamaria, is not inhabited by a single Callophis. If we are allowed to judge from the number of individuals of both genera brought to Europe in collections, the Calamarice are about twice as numerous as the Callophides. Cantor, who had opportunities of observing them, states that they are generally seen lying motionless, with the body thrown into many irregular folds, but not coiled. Although they are diurnal, their sight, from the minuteness of the pupil, appears to be as defective as their sense of hearing, and they may be closely approached without apparently being aware of danger. $\mathrm{He}$ never observed them to strike voluntarily, even when provoked, and he had difficulty in making an adult $C$. gracilis bite a fowl, although, of course, the venom of these Snakes is as virulent as that of a Viper, the animals used for the experiments having died in the course of from one to three hours after they had been wounded. Therefore the greatest caution should be observed in catching or handling these Snakes. The shortness of their fangs and the small quantity of their poisonous fluid, however, will always give a very fair chance of recovery if the proper remedies be applied, should an accident occur. Two or three

* This name is also applied to the harmless Tortrix scytale (vide p. 42.) 
species of this genus inhabit India, and the rest are found in the Indo-Chinese and Malayan countries, one of the most common of them ( $C$. intestinalis) having likewise been received from the Philippines. The $C$. nigrescens of the mountains of southern India attain to four feet in length, but they are mostly about half that size, or even smaller.

Lastly, we arrive at

\section{The Viperine Snakes,}

which have a long, perforated, erectile fang on the maxillary bone, which is extremely short and bears no other teeth. This is described in greater detail subsequently (pp. 87 and 88). They are arranged under the two families, Crotalidee and Viperida.

The Crotalide, or Pit Vipers, have the body robust, the tail of moderate length, or rather short, sometimes prehensile; head broad, sub-triangular, frequently scaly above or imperfectly shielded; a deep pit on the side of the snout, between the eye and nostril; the eye of moderate size, with vertical pupil. They are viviparous. The Pit Vipers are found only in Asia and America; those of the New World surpassing the Asiatic species in size, and therefore they are much more dangerous. Some live in bushes, others on the ground. A rudiment of the curious caudal appendage of the American Rattlesnake is found as a simple spine-like scale in the Asiatic species, constituting the genus Halys.

Some have the head covered with scales, having small shields on the edge of the forehead and brows; the cheeks are scaly, and the tail ends in a spine. Of these the American genus Craspedocephalus and the Asiatic genus Trimeresurus have the sub-caudal plates tworowed to the tip.

The genus Craspedocephalus comprises the terrible Fer-de-Lance of certain islands in the West Indies and of the mainland of South America, where four other species are recognised-one of them being found as far north as Mexico.]

The Fer-de-Lance (C. lanceolatus, Fig. I8) attains to a length of nearly six feet; its colour generally yellow, sometimes greyish, or even marbled with brown; the head, which is large, is remarkable for a triangular space, the three angles of which are occupied by the muzzle and the two eyes.

This space, raised at its front edge, represents the head of a lance, large at its base and slightly rounded at the summit. On each side of the upper jaw, one, sometimes two, and even three, fangs are visible; all of which the animal makes use of for the pur- 
pose of wounding and discharging his venom. Of the poison fangs of the Fer-de-Lance, Professor Owen remarks, "that they (in common with the Rattlesnake and Viper) are coated with a thin layer of a sub-transparent and minutely cellular cement. This disposition of the dentinal tubes is obedient to the general law of verticality, and

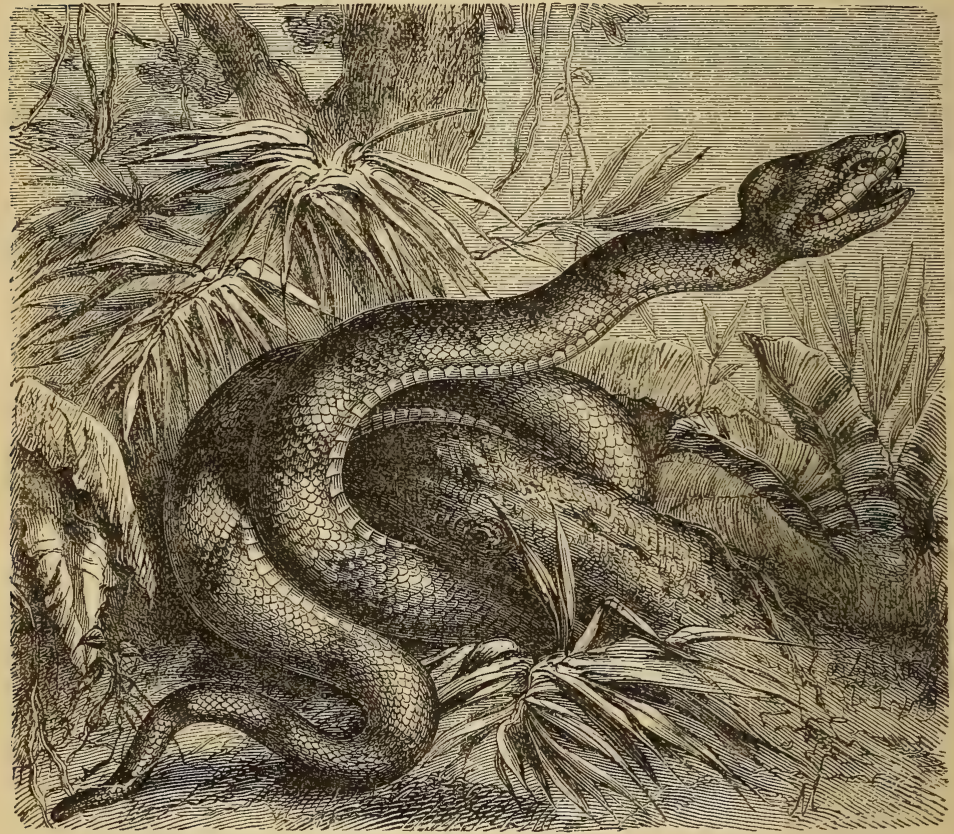

Fig. I8.-Fer-de-Lance.

the external surface of the tooth can be exposed to no other pressure than that of the turgescent duct with which it is in contact." It feeds on lizards and the smaller mammals, especially rats, but it is capable of killing large animals, such as oxen. The negroes working among the sugar-cane, and soldiers in the Martinique service, often become victims to the Fer-de-Lance. This snake is, unfortunately, very prolific ; and its venom is so subtle, that animals bitten 
by it invariably die within a few hours of becoming inoculated with the poison. The wound produces extreme pain, and is immediately followed by more or less livid swelling; the body becomes cold and insensible, the pulse and respiration slower, the head confused, coma appears, and the skin turns bluish; sometimes extreme thirst and spitting of blood are experienced, till paralysis attacks the whole system.

Other species are known in South America, viz., C. brasiliensis, $C$. bilineatus, $C$. elegans, and $C$. atrox. All of these are most highly formidable and dangerous Snakes, and are held in especial dread.

Ten or more species of Trimeresurus occupy their place in the woodland districts of tropical Asia and its islands. In them the hinder labial shields are the smallest. The head is triangular, covered above with small scales, except the foremost part of the snout and the superciliary region, which generally are shielded; the body possesses more or less distinctly-keeled scales, in from seventeen to twenty-five series; while the tail is prehensile. These reptiles are more or less arboreal, as is indicated by this latter peculiarity, and by their green or varied coloration. "In general," remarks Dr. Günther, "they are sluggish, not attempting to move out of the way, and as they very closely resemble the branch on which they rest, they are frequently not perceived until they prepare to dart, vibrating the tail, and uttering a faint hissing sound, or until they have struck the disturber of their rest. Accidents caused by them, therefore, are not of uncommon occurrence, and it is a fortunate circumstance that comparatively few of them attain to a size of more than two feet, so that the consequences of their bite are less to be dreaded than that of various other poisonous snakes. Indeed, numerous cases are on record which show that the symptoms indicating a general effect on the system were of short duration, extending only over from two to forty-eight hours, and confined to vomiting, retching, and fever. After the pain and swelling of the bitten member or spot have subsided, the vicinity round the wound becomes discoloured, mortifies, and is finally thrown off as a black, circular slough, after which health is speedily restored. The bite of larger specimens, from two to three feet long, is more dangerous, and has occasionally proved fatal ; so that the greatest care should always be observed in the immediate treatment of the patient. When roused, these snakes are extremely fierce, striking at everything within their reach; and Cantor states that in the extreme of fury they will fix their fangs in their own bodies. Frogs, small mammalia, and birds, form their food, and I have never found a lizard or snake in their stomach." 
Three or more of the species inhabiting India and Burmah are of a beautiful leaf-green colour, which changes to dull blue after long immersion in spirit. The commonest of them, $T$. carinatus, varies remarkably in colouring in the Andaman and Nicobar islands; if, indeed, the species be quite the same. These grow to over three feet in length. The kindred genus, $P$. eltopelor, is founded on a single species inhabiting the mountains of Southern India, $P$. masrolepis, which is remarkable for the very large scales with which its head and body are covered. The Lachesis, with two species, is another kindred genus in South America, in which the end of the tail has four rows of scales underneath. The Calloselasma rhodostoma is a very formidable reptile of this same series, which inhabits the Malay countries. It has a remarkably broad head, and grows to three feet or more in length. Dr. Günther states that "it is one of the most beautiful and most dangerous of venomous snakes. Feeding on frogs, it frequents grassy plains, and approaches gardens and human dwellings. Kuhl was eyewitness to a case where two men, bitten by one and the same snake, expired five minutes after." Another Malayan species is known as the Atropos acouba. The genus Halomys is characteristic of the fauna of Central Asia, the species being found in Tartary, on the northern side of the Himalayas, in China, in Japan, and in Formosa. One of them occurs in the Western Himalaya, at an altitude of 9,000 feet, and another has been referred to this genus from the mountains of Southern India. The "carawalla" of Ceylon (Hypnale nepa) is likewise found on the mountains of Southern India. It is a small species, but a good deal dreaded, " although," remarks Dr. Günther, " its bite is but exceptionally fatal to man, and in such cases death does not occur before the lapse of some days. There is therefore some hope of restoring the patient by a timely application of proper remedies." Its crown is more shielded than is usual with Snakes of this family and it varies much in colouring.

The rest of the Crotalide are American, and consist of the famous Rattlesnakes and their immediate kindred. In the genus Cenchris the tail ends with a spine, and the tip of the tail has several rows of scales beneath. The well-known Copperhead $(C$. contortrix) belongs to this genus, and the Black Water Viper ( $C$. piscivorus). The last has bred repeatedly in the London Zoological Gardens, and is rather a large species, of very aquatic propensities. "The Copperhead," according to Dekay, " is a vicious reptile, and its venom is justly dreaded, being considered as deadly as that of the Rattlesnake; and an instance is recorded in which a horse, 
struck by one of these reptiles, died in a few hours. Its motions are sluggish, and when approached it assumes a threatening aspect, raising its head and darting out its tongue. It chiefly occurs in pastures and low meadow grounds, where it feeds on field-mice, frogs, and the smaller disabled birds." The poison of the Black Water Viper is equally to be dreaded.

The true Rattlesnakes have the tail furnished with the extraordinary appendages at its tip which will be described presently. According to differences in the shields and scales covering the head, Dr. Gray arranged them into three genera-Crotalophorus, with three species; Uropsophus, with one; and Crotalus also with one, $C$. horridus, which appears to be the only one known in South America. Of the Common Northern Rattlesnake (Uropsophus durissus), Dekay remarks that, "Although furnished with such deadly weapons, the rattlesnake can scarcely be termed a vicious animal, for he rarely strikes unless almost trodden upon. When suddenly disturbed, he throws himself into a coil, and warns the aggressor by rapidly vibrating his rattles, which, however, can scarcely be heard beyond the distance of a few yards. This is most usually the case, but they occasionally strike without the slightest warning. At the moment the snake strikes, he ejects the venom forcibly into the wound. In an instance of a very large rattlesnake from Florida ( $C$. horridus), which was irritated, he struck violently against the iron wire on the side of the cage, and spurted the venom to the distance of three feet."* The fibulæ, or rattles, seldom exceed fifteen in number, and are rarely so many.]

The Common Northern Rattlesnake (Uropsophus durissus, Fig. I9) sometimes attains to six feet in length, the middle being about the size of a man's leg; $\uparrow$ the colour of the back is grey, mixed with yellow. Upon this foundation extends a longitudinal row of black spots, bordered with white; towards the muzzle the flat head is covered with six scales larger than the others, and disposed in three transverse rows, each formed of two scales. The males are smaller, much more brightly and markedly coloured than the other sex. The very long and visible fangs are situated in front of the upper jaw. The scales on the back are oval, and raised in the middle by a bone which extends in the direction of their greatest diameter.

* We have seen a Cobra thus spurt its venom against the plate-glass cover of the box in which it was kept. - ED.

† That the Timber Rattlesnake of the United States sometimes grows to the length of seven or eight feet we have no doubt; the Prairie Rattlesnake, however, seldom exceeds two feet.-ED. 
The under part of the body is furnished with a single row of large plates. The Rattlesnake owes its name to a remarkable peculiarity in its structure; the extremity of the tail is furnished with horny cells, articulated one into the other. When the animal is irritated it causes its tail to vibrate, which produces a sound like the dry husks

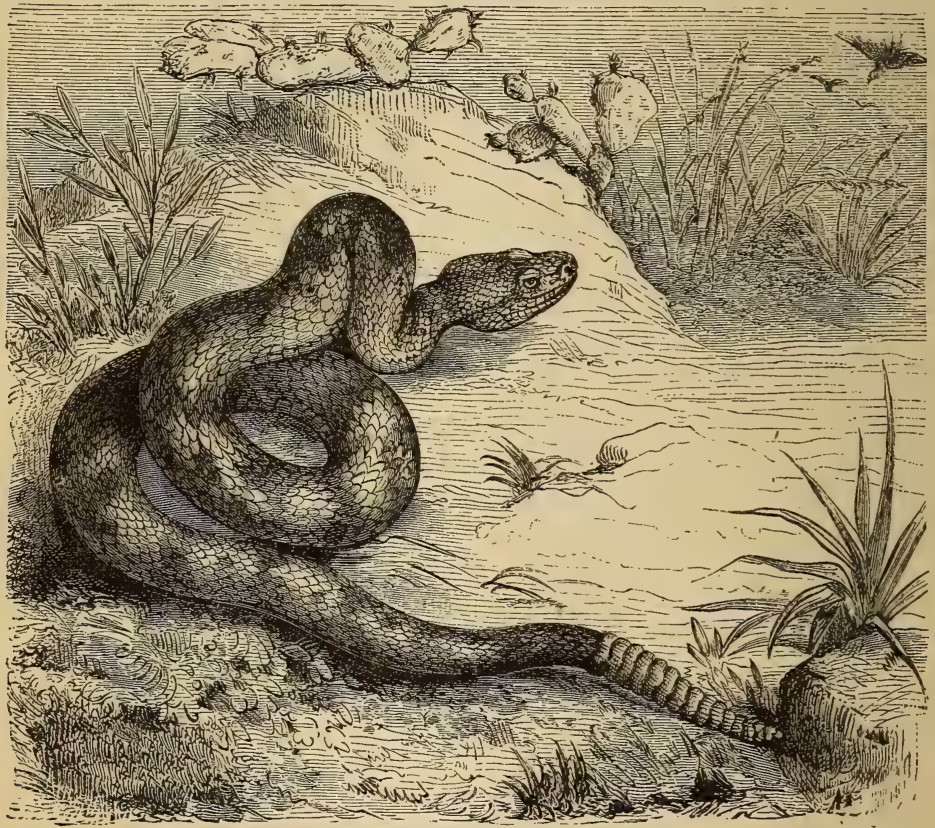

Fig. 19.-Northern Rattlesnake.

of beans which still retain their seeds being shaken by the wind, thus giving warning of the proximity of this terrible enemy. The sibilant rattle of these appendages is not very loud, but it may be heard ten paces off.

Rattlesnakes feed on small mammals, or upon other reptiles. They are oviparous; and, for some time after they are hatched, the young are said to seek a refuge in the mouth of their mother. Woodland or prairie are selected by them, according to the species they 
belong to, but never cultivated land if uncultivated can be found. The shadow of an old fallen tree is often a lurking-place chosen by them. Audubon, the celebrated ornithologist, says that he has often met with rattlesnakes rolled up in a state of torpor when the temperature was low. Rattlesnakes are revered by some of the American aborigines, who know how to lure them from their houses; for it is a singular fact that this terrible animal is not insensible to the sound of music. Chateaubriand's remarks will be read with interest:- "In the month of July, I79r," says this celebrated writer, "we were travelling in upper Canada with some savage families of the Ounoutagnes. One day, when we had stopped in a plain on the banks of the river Genedie, a rattlesnake entered our camp. We had a Canadian amongst us who played on the flute; wishing to amuse us, he approached the animal with this new kind of weapon. At the approach of his enemy, the splendid reptile at once coiled itself up spirally, flattened its head, puffed out its cheeks, contracted its ears, and showed its envenomed fangs, while its forked tongue moved rapidly, and its eyes burned like red-hot coals; its body became inflated with rage, rose and fell like a pair of bellows; its dilated skin bristled with scales; and its tail, which produced a sinister sound, oscillated with lightning rapidity. The Canadian now began to play upon his flute. The snake made a movement expressive of surprise, gradually drew its head backwards, closed its inflamed mouth, and, as the musical sounds struck it, the eyes lost their sharpness, the vibration of its tail relaxed, and the noise which it made became weaker, and finally died away altogether; the coiled-up line became less perpendicular, the orbs of the changed snake opened, and in their turn rested in wider concentric circles on the ground. The scales of the skin were also lowered, and immediately recovered their wonted brilliancy, and, turning its head slowly towards the musician, it remained immovable in an attitude of pleased attention. At this moment the Canadian walked away a few steps, drawing low and monotonous tones from his flute; the reptile lowered his neck, opened a way among the fine grass with its head, and crawled in the steps of the musician who thus fascinated him, stopping when he stopped, and following him when he began to move away. The snake was thus conducted from our camp in the midst of a throng of spectators-as many Redskins as Europeans-who could hardly believe their eyes."

It is generally agreed that rattlesnakes only attack men in selfdefence, but it is at all times a dangerous neighbour, and it is important to know how to keep them at a distance in countries where 
they abound.* The pig is an excellent auxiliary in obtaining this result. In the western and southern States of North America, when a field or farm is infested by these poisonous reptiles, it is usual to put a sow with her young brood there, and the snakes, it is said, will soon be destroyed. It appears that owing to the fatty matter which envelops the body of this animal it is safe from the venomous bite. Besides, it likes the flesh of the snakes, and eagerly pursues them. According to Dr. Franklin, when a pig sees a rattlesnake, it smacks its jaws, and its hairs bristle up ; the snake coils itself up to strike its enemy; the pig approaches fearlessly, and receives the blow in the fold of fat which hangs upon the side of its jaw. Then it places a foot on the tail of the snake, and with its teeth he begins to pull his enemy to pieces, and eats it with evident enjoyment. $\uparrow$ The pig is not the only animal employed to destroy rattlesnakes. Dr. Rufz de Lavison, who has long resided in the French Antilles, and who has since been manager of the Jardin d'Acclimatation, of Paris, has published a highly interesting work, in which he relates the very important services which certain birds, especially the Secretary-bird, or Serpent-eater (imported from South Africa), render by destroying rattlesnakes in the West Indies. We have said that the Crotalide are some of the most dangerous of any Snakes; let us mention some facts which show the frightful power of their venom. A Crotalus, about three feet in length, killed a dog in about fifteen minutes, a second in two hours, and a third in about four hours. Four days after it bit another dog, which only survived thirty seconds; and another, which only struggled four minutes. Three days afterwards it bit a frog, which died at the end of two seconds; and a chicken, which perished at the end of eight minutes.

An American, named Drake, arrived at Rouen with three live rattlesnakes. In spite of the care which he had taken to preserve them from cold, one of them died. He put the cage which contained the other two near to a stove, and excited them with a small stick, to assure himself that they were alive and in health. As one

* It is currently believed in parts of the United States, that it a ring of the bark of the white ash tree be placed around a camp, that these reptiles will not cross it.

+ Dekay, in his "Natural History of New York," remarks that it is a popular belief that hogs are particularly destructive to rattlesnakes; but neither their bristly hide nor their thick teguments afford them perfect immunity from the stroke of this reptile. I was informed by a respectable farmer that he lost three hogs in one season by the poison either of the Copperhead or Rattlesnake. 
of the snakes made no movement, Drake took it by the head and tail and approached a window, to see if it was dead; the animal turned its head quickly, and bit the unfortunate man on the back of his left hand; as he replaced it in the cage he was bitten anew in the palm of the same hand. "A doctor! a doctor!" cried the unhappy man. He rubbed his hand upon some ice which was close by, and two minutes after he bound the wrist tightly with a cord. Four hours later a doctor arrived, and cauterised the wound; but alarming symptoms soon appeared. Syncope, noisy respiration, scarcely any pulsation, and involuntary evacuations, followed ; the eyes closed, their pupils contracted; the limbs became paralysed, and the body cold. Drake died at the end of nine hours. ${ }^{*}$

Some experiments made by a friend of Dr. Bell seem to present different results. This gentleman had received a living rattlesnake from America, intending to try the successive effects of its bite upon some rats. He introduced one into the cage with the snake: it immediately struck the rat, and the latter died in two minutes. Another that was placed in the cage ran to the farthest corner, uttering cries of distress. The snake did not attack it immediately; but after about half an hour, on being irritated, it struck the rat, which, however, exhibited no signs of being poisoned for several minutes; nor did it die for about twenty minutes after the bite had been inflicted. A third rat, remarkably large, was then introduced into the cage, and exhibited no signs of terror, nor did it seem to be noticed by its dangerous companion: after watching some time, the gentleman retired to bed, leaving the rattlesnake and rat in the cage together. In the morning the snake lay dead, and the rat had supped on the muscular part of its backbone. Unfortunately, Dr. Bell does not remember at what season this experiment took place, but thinks it was not in very warm weather. $t$

The climate of France, differing only slightly from that of the United States, is consequently well adapted for the production of rattlesnakes. If a living male and female of these dangerous Crotalide were to escape from a menagerie, their progeny would soon infest the country. It is for this reason that public exhibitions of rattlesnakes are forbidden in France. Nevertheless, two or three may be seen in the collection of the Museum of Natural History at Paris, enclosed in a double cage, every measure of precaution being taken which prudence demands.

* This is unusual, for we have known both men and animals bitten by them, and although they suffered most acutely, they in all cases recovered.-ED.

$\dagger$ Summer is the season when their bite is most severe.-ED. 
It is a remarkable fact that the poison is secreted after death. Dr. Bell, in his " History of British Reptiles," adduces the following as evidence of the facts:- He was dissecting very carefully and minutely the poison glands of a large rattlesnake, which had been dead some hours; the head had been taken off immediately after death; yet, as Dr. Bell continued his dissection, the poison continued to be secreted so fast as to require to be dried up occasionally with a sponge or rag: and his belief is, that there could not be less than six or eight drops of the poison. It is obvious that such experiments require the utmost caution, seeing that preserved specimens are not without danger.

[The family of the Viperida, or true Vipers, are peculiar to the Old World, inclusive of Australia, with the sole known exception of one species in Peru. They have generally a robust body, with nonprehensile tail; the head broad or thick, generally scaly above or incompletely shielded; the eye of moderate size, with vertical pupil, and they are at once distinguished from the Crotalide by the absence of the pit below the eye. The scales are keeled except in one genus (Acanthopis). For the most part, these reptiles inhabit exposed and arid situations, though perhaps all of them will take to the water on occasions, as does the common British Adder.

They are divided, firstly, into those which have a depressed head, rounded on the sides, and covered with acutely-keeled scales. Some of these have large nostrils in the centre of a ring-like shield, edged with a large scale above. Such are the genera Daboia in the warmer parts of Asia, and Clotho, which is peculiar to Africa-both genera are extremely venomous.

The famous Tic-polonga of Ceylon (Daboia elegans) is also widely diffused over India and Burmah. It is beautifully marked with three rows of white-edged, oblong, brown spots. Occasionally the spots forming the middle row are connected like the beads of a necklace, whence the name Cobra monil (literally Colwber moniliger), applied to the young of this Viper by the Indo-Portuguese, and now corrupted into "cobra de manilla," which bears the reputation of being a highly poisonous Snake of diminutive size ; it attains, however, to a length of nearly five feet, the tail then measuring about eight inches, with considerable thickness of body. It is nocturnal, and preys chiefly on mice. In Burmah this formidable Viper is dreaded almost as much as the Hamadryas. It has been obtained in the Himalayas at an elevation of 5,500 feet, at Almorah, and elsewhere. Mr. Theobald has known one to kill a bull-terrier in twenty minutes. The $D$. xanthina is a second species of this form inhabiting Asia Minor. 
The genus Clotho consist of the terrible Puff Adders of Africa, of which there are at least four or five species. Among the best known of them are the ordinary Puff Adder (C. arietans), and the Berg Adder (C. atropos) of the Cape colonists. The Rhinoceros Puff Adder $(C$. nasicornis of Guinea) has the scales over the nostrils of the male produced into a long re-curved spine ; and in the Horned Puff Adder (C. cormuta, Fig. 20) of South Africa there is a group of small hornlike scales over each eye. Examples of the Common and of the

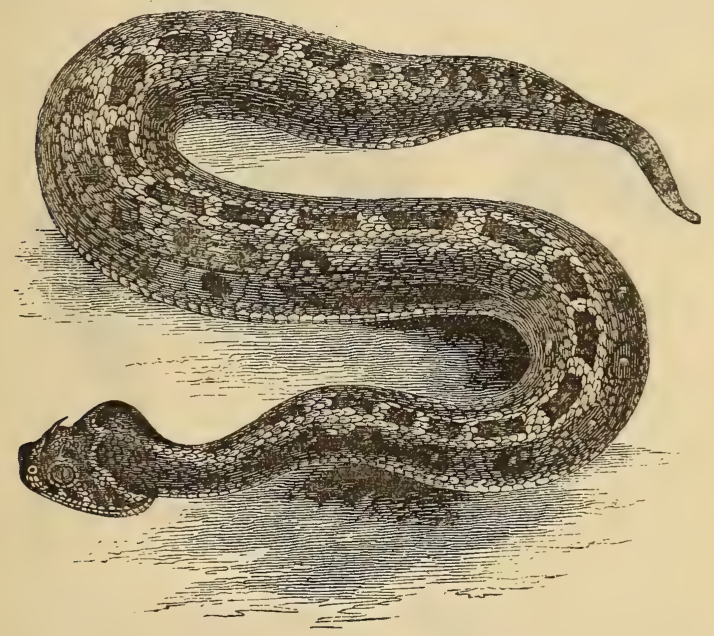

Fig. 20. - The Horned Puff Adder.

Rhinoceros Puff Adders may generally be seen in the reptile house of the London Zoological Gardens. The last-mentioned is a huge Viper of wondrous beauty, both of colouring and in the complex pattern of its markings, especially as seen when it has newly shed its epidermis; but the aspect of its surprisingly broad, flat, and triangular-shaped head, unmistakably betokens its terrific powers. Its head is remarkably massive. One peculiarity of the Puff Adders is that they sometimes hold on to their victim by their long fangs. Thus, of the common $C$. arietans Sir A. Smith remarks that "although generally inactive, it is by no means so when attacked-its movements are then bold and energetic, and when once it seizes the ob- 
noxious object, it retains its hold with great determination, and some considerable exertion is often necessary to detach it."* The traveller Burchell remarks of this snake that its venom is said to be most fatal, taking effect so rapidly as to leave the person who has the misfortune to be bitten no chance of saving his life, but by instantly cutting out the flesh surrounding the wound. Although I have often met with this snake," he adds, "yet, happily, no opportunity occurred of witnessing the effects of its poison; but, from the universal dread in which it is held, I have no doubt of its being one of the most venomous species of Southern Africa. There is a pecu-

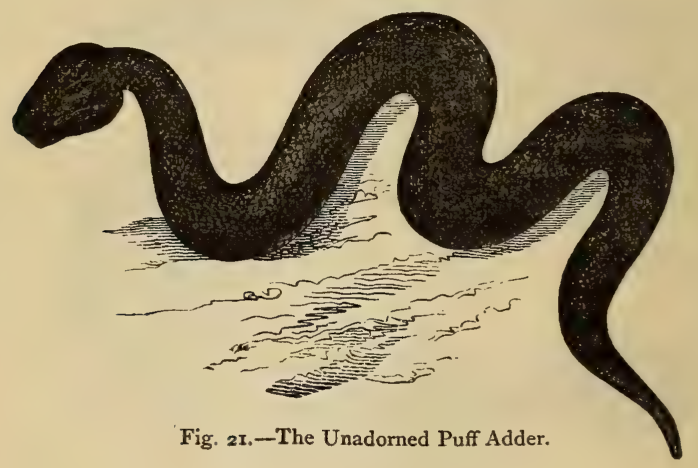

liarity which renders it more dangerous, and which ought to be known to every person liable to fall in with it. Unlike the generality of Snakes, which make a spring or dart forward when irritated, the Puff Adder, it is said, throws itself backwards, so that those who should be ignorant of this fact would place themselves in the very direction of death, while imagining that by so doing they were escaping the danger. The natives, by keeping always in front, are enabled to destroy it without much risk. The Snakes of South Africa, as of Europe, lie concealed in their holes in a torpid state during the

* In "Chapman's Travels in the Interior of South Africa" (vol. ii., p. 59), we read-"May I9th. I lost my best dog, Cæsar. He had seized a large Puff Adder by the tail, and shook it. When the snake was released it darted at the dog's face, and having fixed its fangs in its cheek, stuck there like a bull-dog until it was killed. The dog only survived ten minutes."-ED. 
colder part of the year. It is, therefore, only in the hottest summer months that the traveller is exposed to the danger of being bitten." Dr. Gray refers doubtfully to this genus both the Echidna inornata (Fig. 2I) of Sir A. Smith, and the E. mauritanica of Duméril and Bibron, from Algeria; likewise a Peruvian species named Echidna ocellata by Tschudi, which is the only known instance of a member of this family inhabiting the New World. The appellation Echidna, however, belongs properly to the Porcupine Ant-eaters, of the class Mammalia.

The species of Cerastes and of Echis have the nostrils much smaller than the preceding, and are Vipers of less formidable size. In the two species of Cerastes, or Horned Viper, the eyebrows of the male bear commonly a sort of horn. C. Hasselquistii is common in Egypt ; and the other, C. Richii, inhabits Tripoli. Of Echis there is one species in Egypt and North Africa, E. arenicola; and another in India, $E$. carinata. The latter grows to about twenty inches long, of which the tail measures two inches and a third. These Vipers commoniy lie half-buried in the sand, which they much resemble in colour. They feed upon Centipedes (Scolopendra), and no case is known of their bite having proved fatal.

The remaining Viperida have the head more or less shielded. They are divided by Dr. Gray into Vipera (with two European species, not found in Britain- $V$. aspis from the Alps, and $V$. ammodytes from the countries bordering on the Mediterranean); Pelias, which contains only the common British Adder, P. berus; Sepedon, with one species only, from South Africa, S. hamachates; Causus, with also only one African species, C. rhombeatus; and finally Acanthopis, founded on the Death Adder of the Australian colonists, $A$. antarctica, which is the only member of the family $V i p e r i d a$ known to inhabit Australia, where the poisonous Colubrine Snakes are so numerous. It is also the only known species the scales of which are smooth or not keeled. It seldom exceeds thirty inches in length, and varies a good deal in colour. Like other Viperida, it is sluggish in its movements, but when irritated it flattens itself out generally in the form of the letter $\mathrm{S}$, turning round to one side or the other with astonishing rapidity, but never jumping at its enemy or throwing itself backward, as the Puff Adders are described to do. The Death Adder is found in almost every part of Australia northward of the thirty-sixth parallel of south latitude.]

The Common Adder (Pelias berus, Fig. 22), is not improbably the "Exis of Aristotle, and the Vipera of Virgil, as it is the Manasso of the Italians, the Adder of the country-people in England and 
Scotland, and the Vipere of France. It is found in all these countries, and in Europe generally.

The Common Adder varies from thirteen or fourteen inches to sometimes double that length; and from two to three or even four inches in girth.

Its general colour varies considerably: in some it is olive, in others reddish-brown, sometimes of an ashy-grey; at other times it is greyish-black. A waving brown or blackish line runs along the back. A row of unequal spots of the same colour is observable

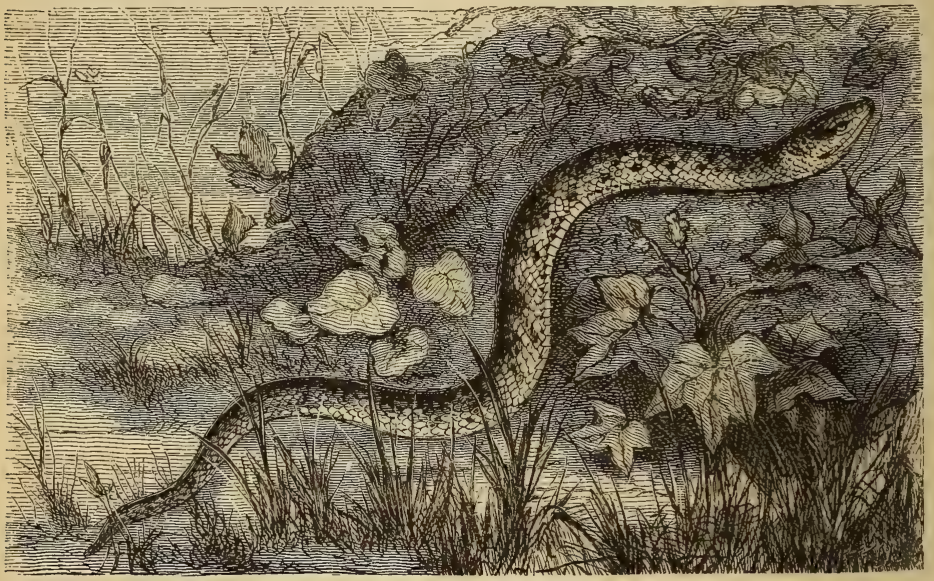

Fig. 22,-The Common Adder.

on the flanks; the belly is slate-coloured ; the head nearly triangular, a little larger than the neck, obtuse and truncated in front, and covered with granulated scales. Six small plates cover the muzzle, two of which are perforated for the nostrils, which are lateral, forming a blackish spot. Above is a sort of $\mathrm{V}$ shape, formed by two black bands. The upper jaw is a white ground, spotted with black; the lower jaw is yellow. The eyes are small and sharp, edged with black. The tongue is long, grey, and forked.

Adders are met with in the wooded, stony, and mountainous regions of southern and temperate Europe-in France, Italy, England, Germany, Prussia, Sweden, Poland, and even Norway. 
They are also occasionally found on the heaths near London and in the neighbourhood of Paris ; they are met with at Montmorency, and in the forest of Fontainebleau. They feed upon lizards, frogs, molluscs, worms, insects, and small mammalia, such as field-mice, shrews, and moles. They pass the winter and early spring in deep hollows, in a state of torpor, where they are sheltered from the cold. It is not unusual to find several adders coiled up together in one heap, entwined and interlaced together.*

The movement of Adders is abrupt, slow, and irregular. They appear to be shy and timid creatures, shunning the day, and only seeking their food in the evening. The young come into the world alive; so long as they are maintained within the mother, they are enclosed in eggs with membranous shells. Soon after their birth the young Vipers, whose length does not exceed six or seven inches, are abandoned by the parent, and left to shift for themselves. They do not, however, acquire their full development till they are six or seven years old. Adders are justly considered objects of fear and horror both to men and to other animals, as they bear with them a formidable apparatus, of which it is important that both the structure and the mode of action should be known. This venomous apparatus is composed of three parts-the secreting glands, the canal, and the hooked fangs.

The gland is the organ which secretes the venom; it is situated upon the sides of the head, behind and a little beneath the globe of the eye it is formed of a number of inflated bladders, composed of a granulous tissue, and disposed with great regularity along the excretory canal, not unlike the barbs of a pen-feather. This arrangement, however, is only visible through a microscope. The tube destined to conduct the secreted venom through the gland is straight and cylindrical ; after being filled, in its short journey it ends in two peculiar hook-like teeth, called fangs, tapering to a point, and horn-like. They are much longer than the others, and placed one to the right, the other to the left, of the upper jaw. The adder, then, is furnished with two of these poison-fangs ; they are curved and sharppointed, convex anteriorly, and furnished with a straight duct which commences in one part by a slit placed at the anterior part of its base, terminating by a second and smaller cleft towards its point, and on the same side. This last cleft is like a little trench or fine furrow, which extends the whole length of its convexity. These hooked teeth are surrounded by a fold of the gums, which receives

* In the Highlands of Scotland I have twice observed this.-ED. 
and partly hides them, like a sheath, when they are at rest. They are attached to the upper maxillary bones, which are small and very mobile, and are put in motion by two muscles. Behind them are dental germs, intended to replace them when they fall out. The other teeth in the roof of the mouth belong to the palate, where they form two rows.

Such are the terrible weapons of the Viper group. It is not, therefore, as many persons still believe, with the tongue that the Adder inflicts its wound; the forked, projecting tongue serves them as a feeler, and to drink with, but cannot inflict a wound. We have said that when in a state of repose the hooked teeth are hidden; when the animal wishes to use them, they issue from

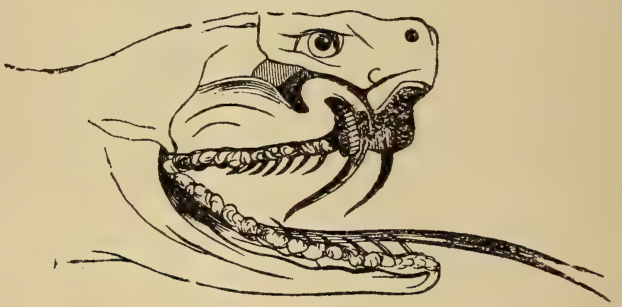

Fig. 23-Fangs and tongue of an Adder.

their fleshy sheath, somewhat in the same manner as the claws of a cat when about to be used as weapons of offence.

Adders use their fangs to seize the small animals which serve as their prey. They do not voluntarily attack a man. But if he imprudently places his foot on or attempts to seize them, they will defend themselves vigorously. Let us note how this reptile takes its prey. In this case it may be supposed to act without passion, merely obtaining food, when it simply seizes, sinking its fangs into the body of its victim. In proportion as these penetrate the body of the animal the poison flows into the canal, which again conducts it to the fangs under the influence of the contracting muscles, by which they are raised and made to press upon the gland; causing the venom to be injected into the wound.

Adders bite in this manner when seized by the tail or middle of the body; but when they are at liberty, and become irritated, they strike rather than bite. At first they coil themselves up into several 
superposed circles, then they will uncoil themselves to their whole length with excessive quickness, extending their bodies like a spring, drawing it out with the rapidity of lightning, and gliding over a space equal to their own length, for they never leave the ground. They will now open their jaws wide, erect their fangs, and strike, first throwing back their heads, by which means they contrive to strike as with a hammer.

Dr. Bell expresses doubts, in his "History of British Reptiles," of the existence of any well-authenticated case in this country of an adder bite terminating fatally.* At the same time he cautions all persons against running any risks in the heat of summer and autumn, when the poison is most virulent. The remedy applied to such a bite is to rub the part with olive oil, over a chafing dish of coals, and to take a strong dose of ammonia (spirit of hartshorn) internally. $\dagger^{-}$

Open copses, dry heaths, new woodland clearings, and sandy wastes, are the usual haunts and hibernaculum of the adder.

It was long supposed that Aciders, and Snakes generally, exercised a sort of magnetic action-a power which has been called fascination. This impression has been attributed, not without reason, to a less mysterious cause; namely, the sentiment of profound terror which these creatures inspire. This terror manifests itself in animals by tremblings, spasms, and convulsions. The sight of a venomous snake sometimes renders its victims immovable, incapable of flight, and as if it were paralysed, and thus allow themselves to be seized without opposing the slightest resistance. M. Duméril, while pursuing experiments in the Museum of Natural History demonstrative of the sudden and mortal action of the bite of a viper on little birds, saw a goldfinch which he held in his hands die suddenly merely at the sight of one.

In warm countries wounds produced by the larger species of these terrible reptiles are extremely dangerous-they swell, become red and ecchymose, and sometimes livid; the wounded person is seized with syncope, fever, and a series of morbid symptoms, which often terminate in death. The remedy is to bind immediately a ligature above the wound with a band, such as a rolled handkerchief, a cord, or a string, so as to stop all communication of the blood with the rest of the body, and thus prevent the absorption of the venom into

* A few cases have been known.-ED.

+ Subsequent experiments with the virus of the Indian Cobra have conclusively proved that ammonia is not a sufficient antidote-ED. 
the system till more effectual means can be adopted. It is well to suck the wound and make it bleed; it is necessary also to make an incision, so as to expose the internal parts, and then to cauterise the wound immediately, either with a red-hot iron or by means of a caustic agent. For this purpose the following composition may be employed :-

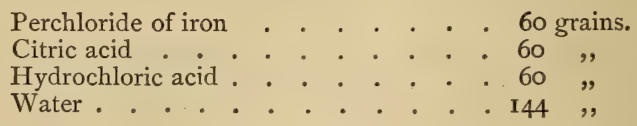

A few drops of this is poured on the wounded part, which is then covered with a small piece of lint. Iodine or iodinet of potassium can also be employed. M. Viand-Marais has substituted the following composition for this compound with great success :-

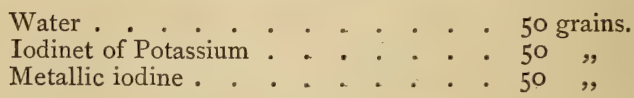

To facilitate the introduction of caustic into the wound, the same naturalist has invented a little bottle closed with emery ; the stopper, which is long and conical at the lower end, plunges into the liquid. By means of this stopper the medicated substance can be made to penetrate by drops as far as the bottom of the wound, which has been previously enlarged by the bistoury. This little apparatus will replace with advantage the bottle of volatile alkali with which viperhunters are usually furnished. But all these means are only useful when applied immediately. The limbs and round about the wound must, besides, be rubbed with ammoniacal liniments. Afterwards emollient poultices should be used to lower the swelling and reduce the chances of congestion; while tonics, sudorifics, and sometimes ammoniacal potions, should be given internally.

It is a remarkable fact that this venom, which is one of the most virulent poisons known, can be taken internally with impunity. It is neither acrid nor burning, and only produces a sensation on the tongue analogous to that caused by greasy matter. But if introduced into a wound in sufficient quantities, it enters into the blood, and causes death with frightful rapidity. This is a characteristic common to all morbid and venomous virus.

The strength of the venom varies according to the species of Snake, and likewise the condition of the animal. The same species is more dangerous in hot than in cold or temperate regions. The bite 
is serious, according as the poison is more or less abundant in the glands, and probably with the degree of rage experienced by the animal, as Professor Owen supposes.

[Of snakes in general it has been remarked that "all strangers in countries where these reptiles abound are apt to exaggerate their danger; but in a year or two they think as little of them as we do in England. I never knew an instance of a snake attacking a person unless it was trodden upon or molested, and even then they almost always give warning by hissing, or endeavour to effect their escape. During my residence in the Cape colony I have at different times trodden on them or kicked them in the grass unintentionally, but was never bitten." "**]

* Moodie's “Ten Vears in South Africa," vol. i., p. $3^{18} 8$. 


\section{CHAPTER III.}

\section{THE ORDER OF LIZARDS.-SAURIANSS.}

THIs is the second order of the great section of scaly reptiles (Squamata), as distinguished from the shielded reptiles (Cataphracta). The name Saurian, Zaúpos, given by Aristotle to the genus of lizards, has been more comprehensively applied to a group of reptiles which have the body elongated, covered with scales, or having the skin rough like shagreen. They have, for the most part, four feet, the toes of which are furnished with hooked claws; the eyelids are movable, and their jaws armed with encased teeth; they have a distinct tympanum, a heart with two auricles and a single ventricle, sometimes partially valved, having sides and a sternum. They are not subject to metamorphosis, and, finally, they are furnished with a tail.

["By far the greater number of the Saurians," writes Dr. Giunther, "are easily distinguished from the other orders of Reptiles by their elongated form, by their movable thorax covered with skin, by the presence of legs, and by their general integuments, which are either folded into scales, or granular, or tubercular, or shielded; still, there are many Saurians which, at a superficial glance, might easily be taken for members of the preceding order, that of the Snakes; and it cannot be denied that there is a gradual transition from one of these orders to the other. On the part of the Saurians, we allude to those which have no externally visible limbs, and which combine with a greatly elongated, cylindrical body, the peculiar kind of locomotion we observe in Snakes. Yet the greater affinity of these Reptiles to the ordinary Lizards is indicated by another character, which is in intimate connection with their mode of life. The Snakes, having movable maxillary bones, and mandibles not joined by a symphidis, are enabled to swallow other animals of apparently greater bulk than their own. In the Saurians the maxillæ are fixed and immovable, and the mandibles are joined by an 
osseous suture, so that the cleft of the mouth can be dilated only in the usual vertical direction. Moreover, in these limbless Saurians we always find bones of the shoulder hidden below the skin, whilst no trace of them can be discovered in the true Snakes. The motions of some Lizards are extremely slow, whilst those of others are executed with very great but not lasting rapidity. Many of them have the power of changing their colours, which depends on the presence of several layers of cells loaded with different pigments; these layers the animal compresses by more or less inflating its lungs, whereby the changes in the coloration are effected."

Dr. Günther does not follow Dr. Gray in arranging all true Reptiles into the two grand divisions of Shielded Reptiles (Cataphracta) and Scaly Reptiles (Squamata); but he includes the Crocodilidae among the Saurians as a first grand division of them, Emydosauri; and the other Lizards constitute his second grand division of them, Lacertini. These latter are again primarily divisible according to the structure of the tongue. Thus, in the series of Leptoglossa, the tongue is elongated, forked, and exsertile, much as in the Ophidians; in that of Pachyglossa the tongue is short, thick, attached to the gullet, and is not exsertile ; and in the Vermilingues it is worm-like, club-shaped in front, and very exsertile.

The various genera of Saurians which have either not a trace of external limbs, or have them more or less diminutive and rudimentary - either the usual two pairs or one pair only, and in the latter case sometimes the fore and sometimes the hind pair being deficientare included among the Leptoglossa, or the series which have a forked and protrusile tongue; and so far as is practicable, we will commence by noticing the different serpentiform genera; only, in a classification which is not confessedly superficial, it will be found that the various snake-like Saurians appertain to several distinct natural families, most of the other genera belonging to which have, in sundry cases, limbs that are well developed. Some of them, therefore, will have to be noticed as the different families to which they belong are successively treated of ; and there will yet remain the curious serpentiform family of Amphisbcenida, which Dr. Gray refers to his grand series of Shielded Reptiles (Cataphracta).

The same naturalist divides the Leptoglossa into two tribes, which he styles Geissosaura and Cyclosaura; and, as constituting particular division of the former, he includes under it the family Typhlopida. which Dr. Günther refers, as we have seen, to the order of Ophidians. In the series of Geissosaura, the scales of the belly and (almost 
always) of the back and sides are quincuncial, rounded, and imbricate; the tongue is narrow, short, flat, and but slightly forked; and the head is of a conical shape, and is covered with regular shields.

Of the families thus characterised, some only have distinct eyelids, as the families Acontiade, Ophiomorida, Sepside, and Scincida; while others have the eyelids rudimentary and the eyes exposed, as the families Lialisida, Aprasiadce, Pygopodida, and Gymnopthalmida. In the Acontiada the nostrils are placed in the enlarged rostral plate, with a longitudinal slit behind. The form of the body much resembles that of our common Orvet, or Blind-worm, and their limbs, when present, are so rudimentary that they can aid little in locomotion. One genus, Acontias, is without limbs, and the eyes are furnished with a lower lid, while the upper eyelid is rudimentary. Of this, one species, A. meleagris, inhabits South Africa ; and another, A. Layardii, has been discovered in Ceylon. The genus Nessia has four rudimentary limbs, and the rostral shield is large, sub-conical, and depressed. In one species, $N$. monodactyla, the limbs are diminutive, the posterior placed far apart from the anterior, all being very short, weak, and undivided into toes. In another, $N$. Burtoni, each foot is divided into three minute toes. Both species are peculiar (so far as known) to Ceylon, and the habits of this family are much the same as those of our common Orvet (Anguis fragilis).

The family of Ophiomorida is founded on a single genus and species, Ophiomorus miliaris, which inhabits North Africa. As remarked by Dr. Gray, this reptile seems to be intermediate to the Acontiade and the Scincida, and makes it appear as if the large rostral shield of the former was formed of the united rostral, supranasal, and nasal shields of the present family, and of the Scincida. It has an elongate, cylindrical body, without external limbs, and the ears are hidden under the skin; the eyes are distinct, with valvular eyelid; and the scales of the body and somewhat elongate tail are hexagonal.

The Sepsida differ from the preceding, and also from the great family of the Scincida, by having the nostrils placed in the front edge of a small shield, in a notch at the hinder side of the rostral plate, which latter is rather large and square. The eyes are distinct, the lower eyelid scaly, or with a transparent disc; body fusiform or sub-cylindrical, elongate. These reptiles burrow in dry sand, and are peculiar to the anciently-known continents and certain islands. Some have a wedge-shaped head, with prominent rostral plate. Of these the genus Sphenops has more developed limbs, 
each dividing into four toes, and the only species, S. sepsoides, inhabits Egypt and other parts of North Africa. Sphenocephalus has a more slender and elongate shape, and the limbs are placed more distantly apart; the anterior minute, and fitting into a groove, the posterior as large as in Sphenops, and each of them having but three toes, of which the innermost and next are subequal, and the outer much shorter. The only known species, S. tridactylus (Fig. 24), is common in Afghanistan. In Scelotes the

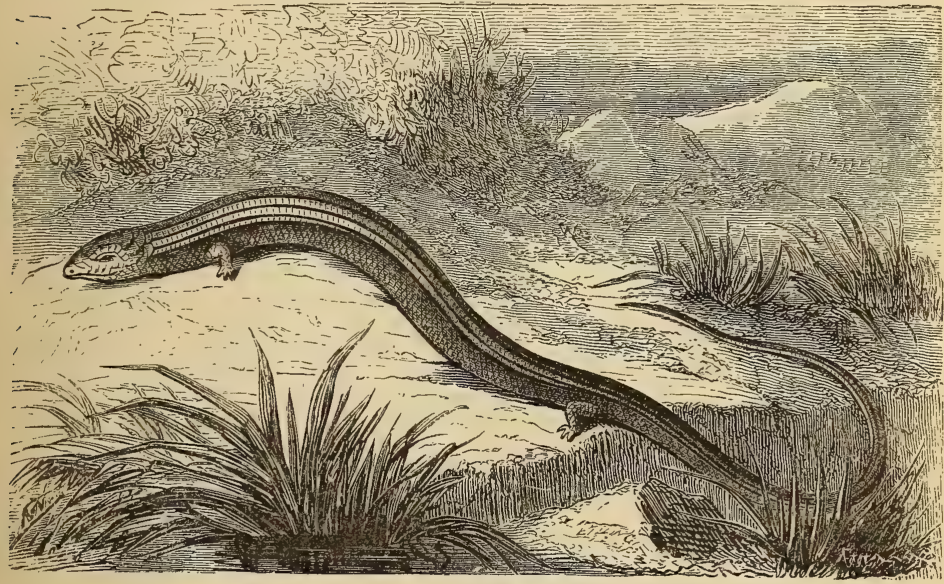

Fig. 24.-Seps tridactylus.

anterior limbs disappear altogether; and the only known species, $S$. bipes, inhabits South Africa. Other genera have a pyramidal head, with the rostral plate erect, and rounded in front. Such are the five following, each founded on a single species:-Gongylus ocellatus, from North Africa and the borders of the Mediterranean; Thyrus Bojeri, from the Mauritius; Amphiglossus astrolabi, from Madagascar; Seps tridactylus from the south of Europe and north of Africa; and Heteromeles mauritanicus, from North Africa. The last has only two toes to the fore-feet, three to the hind; and Seps has three toes to each foot, while the other three genera have five to each foot. In general these animals are found in dry and elevated spots, where they hide themselves in the sand or under stones. 
The Scincida have the head covered with shields, which are symmetrically arranged. Tongue slender, free, exsertile, terminating in two pointed lobes. Scales on the back rounded, quincuncial, imbricate; those on the belly similar to those on the back and on the sides. No fold across the throat or along the side; no femoral or inguinal pores. Tail generally long, rounded, fragile. Eyes and eyelids well developed. Nostrils in a separate plate, between the frontal and labial shields. Generally four limbs, moderately developed, sometimes feeble or hidden below the skin. The species of this family are exceedingly numerous, and inhabit almost every part of the tropical regions, some extending into the temperate zones. They are thoroughly land lizards, preferring dry ground, and hiding themselves in the sand, under stones, fallen leaves, \&c., very few of them entering the water. They do not attain to any considerable size, only a few species of Australia and the West Indies growing to the thickness of a man's wrist, and exceeding a foot in length. Some of them are viviparous, others deposit from eight to twelve globular eggs. Dr. Gray divides them into the sub-families of Scincina, or those which have the scales thin, smooth, and neither striated nor keeled; the nostrils in a single smooth plate, without any lunate groove behind; and the tail round, tapering, unarmed; and Tropidophorine, or those which have the scales thick, bony, rugous, striated, and with one or more keels upon each of them; the rostral plate rounded in front, and the body fusiform, with well-developed limbs, which terminate always in the full complement of toes. A few species of the Scincince have no external limbs, thus approximating in their appearance to certain of the burrowing Ophidians.]

The Orvet, or Blind-worm (Anguis fragilis, Fig. 25), is small, cylindrical in shape, about eleven or twelve inches in length, and having the exterior appearance of Snakes. The scales which cover the body are small, smooth, and shining, being red in the middle, and edged with white, of a silvery yellow on the upper part, and dusky beneath; the sides somewhat dusky brown, and the throat slightly marbled with white, black, and yellow. Two larger spots appear, one above the muzzle, the other upon the back of the head; from this point two blackish longitudinal rays start, which extend to the tail, as well as two other nut-brown rays, which start from the eyes, the markings vary, however, in different countries, and probably with age and sex.

The Blind-worm is found in woods, and on dry, sandy, and stony 
wastes. They are timid, harmless creatures, retiring into holes, and concealing themselves in moss at the foot of trees, to hide themselves from observation. They feed upon worms, insects, and the smaller molluscs. Although perfectly harmless, the country-people are strongly prejudiced against them, believing their bite to be a deadly poison. This animal is extremely brittle. Laurenti and others assert that when captured it throws itself into a position of such rigidity that it sometimes breaks in two, and that a smart blow of a switch will at any time divide it.

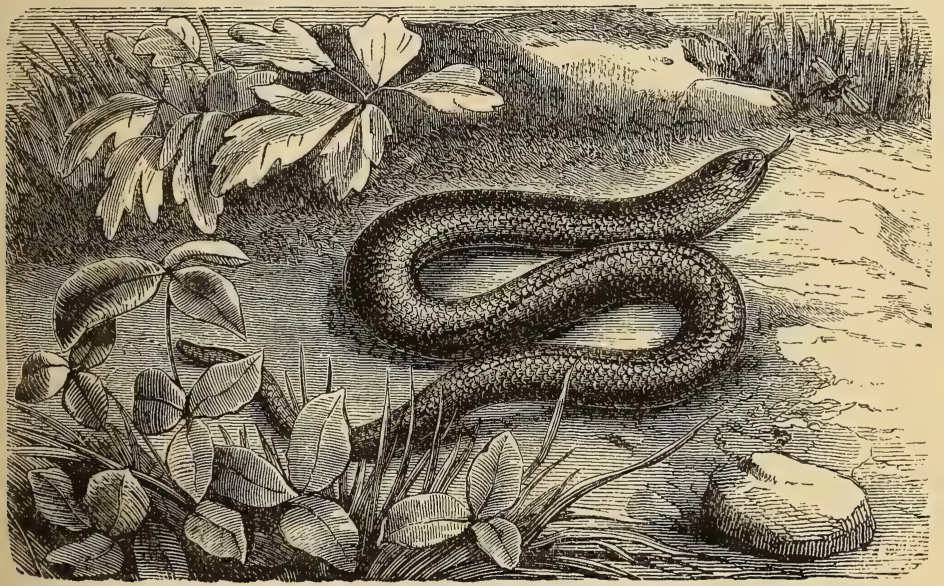

Fig. 25.-Blind-worm.

[There are little-known species of Anguis in India and South Africa, which are at least provisionally so considered, and certainly do not differ essentially; and next we come to forms in which the limbs are successively more developed. Such are the Ophiodes striatus of Brazil, which has two short, flattened, undivided, and one-pointed limbs, corresponding to the usual hind pair; the Brachymeles bonite of the Philippines, in which there are two pairs of short and rudimentary limbs, the fore bearing two minute claws, while the hind are undivided; Venira bicolor, of the same archipelago, has very short limbs, the fore and hind being placed distantly apart, but in this genus all have five distinct toes; Chiamelea lineata, from 
some part of India, and Hagria Vosmaërï, from Bengal, are kindred forms which conduct to the genus Eumeces, the species of which are very numerous, and spread over nearly all the different countries between or near the tropics, and in certain of them (as the Burmese $E$. anguinus) the limbs are still remarkably diminutive, and (as in $E$. isodactylus of Cambodia) the fore and hind limbs are placed very far apart, the body and tail being long and anguiform. In various other species of Eumeces, however, the proportions are more those of an ordinary Scink, as again in the kindred genera Mabonia and Plestiodom, which are widely distributed.

In other series of Scinks, the distinctions of which are far from beirig conspicuous, we again have limbless genera, or nearly so, as the Australian Soridia lineata, which has one pair of small, posterior, undivided extremities, while in another Australian form, the Rhodona punctata, the anterior pair of limbs are simple and undivided, while the hinder divide into two unequal toes, and the two pairs of limbs are situate as distantly apart. And thus we may continue to trace the successive gradations, in sundry genera, until we arrive at the Scincus officinalis of North Africa, a well-known reptile, the geographical range of which extends eastward into Afghanistan, and which was formerly in considerable request for its supposed medicinal properties. Indeed, this notion still prevails in Hindustan, into which country dried specimens of both this reptile and of Sphenocephaius tridactylus (p. 95) are brought by Afghan traders, and are sold in the bazaars. Both of these are Sand Lizards, which burrow into the sand with great rapidity.

We now come to the Tropidophorinx, or second sub-family of Scinks indicated by Dr. Gray (vide p. 96), which have always welldeveloped limbs, the body only moderately elongated, and the scales variously keeled. Several species of larger size appertain to this series, as the Cyclodus gigas of Australia, and the curious stump-tail lizards, Trachydosaurus rugosus and T. asper, of the same insular continent, which latter have most prominently rugous scales, and the tail literally appearing like the short and abrupt stump of one. Egernia Cunninghami and Tropidolesma (of different species) are other comparatively large Australian Lizards ; and examples of most of those that have been mentioned may generally be seen alive in the London Zoological Gardens, where the Cyclodus gigas has bred and proves to be viviparous. Of the species of Euprepes, of which several inhabit the Indian region, some (as the very common $E$. $\mathrm{ru}$ fescens) are viviparous, and others (as E. multicarinata) are oviparous. These have three more distinct though not prominent keels upon 
each scale; and the different species inhabit both the Old World and the New, as well as Australia. The Galliwasps (Celestus) of the West Indies, and sundry other genera, do not greatly differ. Of Tropidophorus, which has exceedingly rugged scales, the species inhabit the Indo-Chinese countries, and one ( $T$. cocinsinensis) is found likewise in the Philippines; while of another (T. Berdmorei), in Burmah, Mr. Theobald remarks that "its scales are dull and lustreless, and the coloration peculiar for a Scink. It harbours under half-immersed stones, and enters the water freely." In several of this family of Lizards the scales are beautifully iridescent, and many of them show longitudinal pale or white lines, or are otherwise variegated.

Nearly akin to the extensive family of Scincide, there are three small families (as classed by Dr. Gray), the species of which are peculiar to Australia. They have small, undivided posterior limbs only, or are quite limbless. These families are the Lialisida, founded on three or more species of a single genus, Lialis; the Aprasiada, founded upon one species only--Aprasia pulchella, which is limbless; and the Pygopodida, comprising the two genera Pygopus and Delma, the former containing two, the latter only one ascertained species. The Gymnopthalmide constitute still another small family, quadrupedal, but with the limbs small and weak. Of seven genera referred to it, five are Australian, one is European, and one belongs to South America. Ablepharus pannonicus is a small Lizard of this family; inhabiting Eastern Europe, with a congener, $A$. bivittatus, in the Caucasus; and Gymnopthalmus lineatus found in Brazil and the Island of Martinique.

In the second tribe of Leptoglossa, entitled Cyclosaura, the scales of the belly are square, in cross bands; those of the back and tail are rhombic and imbricate, or circular and subgranular; the tongue is lengthened, and more or less conspicuously furcate; and the eyes are diurnal, having two valvular lids. The limbs are generally well developed; but in several genera they still are more or less rudimentary, or even absent.

There are four small families in which the sides are rounded and covered with scales like the back. Of these, that of Chamcesaurida is founded upon the South African Lacerta anguina of Linnæus, now Chamesaura anguina, which has the limbs quite rudimentary. In the American families of Cercosaurida, Chirocolide, and Anadiada, the limbs are moderately developed, and have each five toes. The two last-mentioned families are founded each upon a single species, Chirocolus imbricatus and Anadia ocellata; and the other contains 
the two genera Circosaura and Lepisoma-of which the first comprises some two or three species only. All of these reptiles have exceedingly long tails, though not so inordinately long as in the Lacertida of the genus Tachydromus.

Certain other families have a distinct longitudinal fold, covered with small granular scales on each side. These are the families Chalcida, Holaspida, and the more extensive one of Zonurida. The Chalcida have the head covered with regular many-sided shields, and the lateral fold is indistinct; limbs small and rudimentary, and the hind feet are undivided in the genera Chalcis and Bachia, with three tubercles in place of toes in Microdactylus, and with four clawed toes in Brachypus. Each of these genera is founded on a single species, and all are doubtless peculiar to the New World. The Holaspida is also founded on one species only, the Holaspis Guentheri, which again is supposed to be South American. It has four well-developed limbs, a double row of plates along the back and upper surface of the tail, and the latter organ is curiously serrated laterally.

The Zonurida constitute a considerable family, to which some eighteen or twenty genera are assigned, and which present considerable modification of form. The ears are distinct, whereas, in the Chalcida they are hidden under the skin. The head is pyramidal, or depressed, and covered with regular many-sided shields; eyes with two valvular lids. Limbs mostly well-developed, but short in some, and rudimentary, or even wanting, in the so-called Glass Snake which constitute the sub-family Pseudopodince. There is no external trace of them in the North American Glass Snake, Ophisaurus ventralis; and in the Old World genus, Pseudopus, there is only one pair, posterior, rudimentary, and undivided. These Reptiles are long, and serpentiform in shape; whilst in other Saurians the whole skin of the belly and of the sides is extensible, the extensibility is limited in the Glass Snakes to a separate part of the skin; and, as Dr. Günther remarks, "the scaly covering of the upper and lower parts is so tight that it does not admit of the same extension as in Snakes and other Lizards; and the Pseudopus, therefore, could not receive the same quantity of food in its stomach as those animals, were it not for the expansible fold of the skin running along each side of its trunk." One species of Pseudopus, the P. Pallasii, inhabits Asia Minor and the south-east of Europe ; and there is another, P. gracilis, in the IndoChinese countries (or those lying eastward of the Bay of Bengal). A second sub-family, Gerrhonotina is peculiar to America, and consists of more ordinarily-shaped Lizards, which are ranged in four genera. 
Together with the Ophisaurus, or American Glass Snake, they are the only known Zonurida that inhabit the New World. The great mass of this family and all of its most characteristic species are African, and these are arranged by Dr. Gray under the sub-families Cicignina and Zonurince. In the first of these sub-families the tail is smooth or unarmed, and in the second it is spinous: The Cordules; Cordylus, Zonurus, \&c., are very characteristic Lizards, chiefly of southern Africa, several species of which have been figured by Sir Andrew Smith. They are mostly of shortish form, and the neck is more or less spinous ; the body-scales in some (as Zonurus cataphractus) being extraordinarily rugous. These lizards squeeze themselves into crevices in the rocks, in which they hold on so firmly by their nuchal spines that it is next to impossible to dislodge them, the tail commonly giving way if it be attempted to pull them forth by means of it.

The family of Lacertida, comprising our ordinary European Lizards, have no longitudinal fold along the sides, but generally one across the throat ; the tail is very long, rounded, with its scales arranged in rings; the head is covered with shields, which are symmetrically arranged; scales on the back granular or rhombic, on the sides granular, on the belly largely quadrangular or rounded, and arranged in cross bands ; eyes diurnal, with eyelids ; the tympanum distinct; limbs always four, and well developed ; it is also fragile. This group of Lizards has no representative in America or (so far as known) in Australia.

The sub-family of Tachydromina is included by Dr. Gray in the family Zonurida. These are Asiatic Lizards, with a most inordinate length of tail, the fore and hind limbs being not placed distantly apart, as in the various anguiform Lizards already treated of ; there is an indistinct collar, and the toes are not serrated or keeled. Two genera have been distinguished, Tachydromus and Tachysaurus, the latter founded on a Japanese Lizard, $T$. japonicus. At least three species are known of Tachydromus, two of which inhabit China, T. septentrionalis and T. meridionalis; the third belonging to the Indo-Chinese countries, $T$. sex-lineatus. In an example of the last, measuring fourteen inches long, the tail occupies eleven inches and a half. It is the longest-tailed creature, in proportion to its other parts, that we have any knowledge of ; indeed, something quite wonderful to behold and muse over.

The rest of the Lacertida are chiefly from Africa and the south of Europe ; there are probably more of them to be discovered in central Asia, and only three or four species are known to inhabit the Indian region. Fifteen or more genera are recognised. In temperate Europe 
(inclusive of the British Islands) two species are common-the Zootica vivipara and the Lacerta agilis. The former, as its name imports, is viviparous, whereas the other genera belonging to the family are (so far as known) oviparous. Others occur in the south of Europe.]

The common Grey or Sand Lizard (L.agilis) sometimes attains the length of from eight to ten inches, of which the tail occupies more than half. These little inoffensive creatures, so common in southern Europe, are slender and active; their movements are so rapid that they escape the eye as quickly as a bird. They require a mild temperature, and seek shelter among ruins. When the sun strikes with its meridian force upon a wall, they may be seen basking in its rays, enjoying themselves upon the heated surface. It is commonly said that the Lizard is the friend of man, since far from flying at his approach, they seem to regard his appearance with pleasure.* They pass the winter at the bottom of small holes which they have hollowed out of the earth, in which they become torpid. At the commencement of spring they issue from their hiding-place and seek a mate; they go in pairs, it is said, for many years, sharing between them the domestic arrangements, which comprise hatching the young and nursing them in their helplessness, carrying them to warm and sunny places, and sheltering them from cold and damp.

Lizards feed chiefly upon insects, and especially flies. All who have watched the actions of the Grey Lizards must have observed that the caudal vertebræ are so extremely fragile that they separate on the slightest touch, the tail remaining in the hand of any one attempting to seize it. These tails sometimes grow again. When an attempt is made to seize a Grey Lizard on the wall it lets itself fall to the ground, and remains there for a moment immovable before attempting to run, evidently simulating death.

Grey Lizards are easily tamed, and appear happy in captivity. From their extreme gentleness they soon become familiar with their keepers, and return caress for caress, approaching mouth to mouth, and suck the saliva from between their master's lips with a grace that few people would allow them to display.

In the Green Lizard (L. viridis, Fig. 26), the scales of the temple are many-sided and unequal, with a central layer; back granular and oblong, with shelving sides; throat fold distinct. Nothing can be more brilliant than the variegated colouring with which it is orna-

Very doubtful-our experience of them in the wild state having been quite the reverse.-ED. 
mented. Its favourite locality is a slightly elevated woody place, where the sun's rays readily penetrate. It is also found in sunny meadows. It feeds upon small insects, and shows no alarm at the presence of man, but stops to look at him. Snakes, on the contrary, they seem to fear much; but when they cannot avoid them they fight courageously. In length they are about eighteen inches.

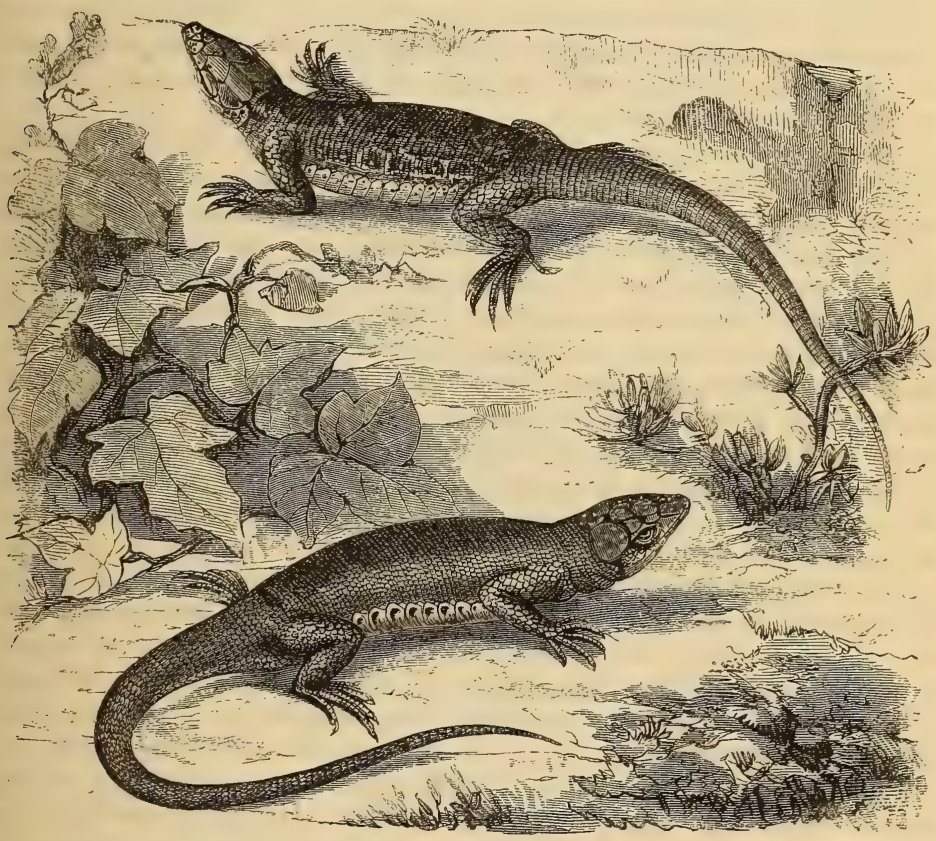

Fig. 26.-Green Lizard and Ocellated Lizard.

Green Lizards are found on the African coast of the Mediterranean, in Jersey and Guernsey, and other warm countries of Europe, and they are not rare in France.

How often have we admired their magnificent colours in the neighbourhood of Montpellier, where they rival the green of the meadows, and glitter in the sun like so many living emeralds.

In the Ocellated Lizard (L. ocellata, Fig. 26), the upper part of the 
body is green, variegated, spotted, and reticulated or ocellated with black, having large round blue spots upon the flanks ; the under-part of the body is white, frosted with green; in size it is about twenty inches. They are found at Fontainebleau, in the south of France, and in Spain. They secrete themselves in hard sand, often between two beds of calcareous rock, upon some steep declivity, more or less directly exposed to the south ; they are also found between the roots of old stems, either in hedgerows or vineyards. They feed almost exclusively on insects ; but are said to attack mice, shrews, frogs, and even snakes, and to destroy the eggs of the partridge. They have sometimes been tamed.

[In the genus Ophiops, two species of which inhabit Asia Minor, and one of them the shores of the Mediterranean, the eyelid is rudimentary and the eye exposed, whence the name, signifying "snake eye." So far as known, the habits of the various Lizards which constitute the family of Lacertida are much the same.

The family of Teida is peculiar to the New World, and some of the species attain to the length of several feet. In these Lizards the head is pyramidal, and is covered with regular many-sided shields; supra-orbital plate horny; the teeth solid and well rooted; tongue elongate, flat, free (rarely slightly sheathed at its base); the scales of the back are regular and keeled, and of a rhombic shape; sides flat, and covered with small granular scales; the throat scaly, with a double collar, rarely indistinct.

In some the throat has two cross-folds, with large six-sided scales within ; and of these some have the ventral shields small, long, and smooth, while others have them much broader. The former are known as the Teguexins (Teius and Callopistes), and the latter as the Ameivas (Ameiva, and three other genera). One species of Teguexin, Teius teguexin, may commonly be seen alive in the London Zoological Gardens. This is a large and powerful Lizard, exceeding five feet in length when full grown, and extremely active. It feeds on small living animals of any kind, and will even devour poultry or their eggs, for which latter it manifests an especial liking. Sometimes it has been known to prey on kindred lizards, as the Ameivas. The teeth of this species are strong, and they can bite with much severity. It is a bold and determined combatant when attacked, and if it succeeds in seizing its foe, retains its hold with pertinacity. Its flesh is eaten by some people, who consider it excellent. Together with a second species, T. nigropunctatus, it inhabits Brazil, and two species of Callopistes are also South American, one of them occurring as far south as Chili. The species of this family, although strong and agile, never ascend 
trees, but range the hot sandy plains or the dense and damp underwood on the margins of lakes and rivers, into which they plunge when alarmed, and remain below the surface until the danger has passed away, their capacious lungs and peculiar circulation permitting them to endure a long immersion without inconvenience.

The Ameivas have a long whip-like tail, and peculiarly elongated toes on their hind feet. The species of Ameiz'a and Cnemidophorus are numerous, and the genera Dicrodon and Acrantus are founded each of them upon a single species. In general these are Lizards which correspond with the ordinary Lacertide of the Old World. One species only, Cnemidophorus sex-lineatus, inhabits the Southern States of North America; there are at least four others in Mexico; and the rest belong to South America and the Antilles. "The Ameiva dorsalis," writes Mr. Grosse, "is one of the most common of the reptiles of Jamaica, and is as beautiful as abundant. Its colours are striking, but not showy, and its countenance has a very meek expression. All its motions are elegant and sprightly; when it is proceeding deliberately, its body is thrown into latent curves the most graceful imaginable; but when alarmed, its swiftness is so excessive that it appears as if it literally flew over the ground, and the observer can scarcely persuade himself that it is not a bird. It is very timid, and though its toes are not formed, as in the Geckos and Anoles, for holding on against gravity, I have seen a large Ameiva run with facility on the side of a dry wall, along the perpendicular surfaces of the large stones."

A second series occurs in those Teide which have a collar of large shields on the throat. As many as five genera of them have been established, each upon a single species, and are all from intertropical America. In Crocodilurus lacertinus the two rows of crests along the tail recall to mind the Crocodiles, hence the name bestowed. Others have been styled dragons, as the Great Dragon, Ada guianensis, and the Smaller Dragon, Custa bicarinata. All bear a certain amount of superficial resemblance to the Crocodiles, and the Great Dragon grows to six feet in length, and is found in many parts of South America. This large reptile runs up the trunks of trees with facility, is quick when on the ground, and it also swims well. It preys upon small animals, and chiefly frequents inundated savannahs and marshy localities, where it is seen basking in the sunshine. There is considerable difficulty in capturing this Lizard, as, if alarmed, it rushes for its burrow, and bites desperately in self-defence. Its flesh is eaten, and is considered a delicacy. Its eggs, also, of which each female lays some dozens, are much esteemed. 
The family of Fielodermida is founded on a very remarkable Lizard from Mexico, the $H$. horridum, which is of the same size as the Great Dragon, and in some respects approximates to the Old World family of Varanido. Its back and sides are covered with oblong, hexagonal, very convex and shield-like scales, and the belly with oblong, rather convex plates; the tail is cylindrical, with oblong, convex scales above, and flat, elongate, thin plates beneath. The head is somewhat flattened, and is covered with polygonal, convex shields; the muzzle is rounded; and the teeth are incurved on the inner side of the jaws, with a groove on the front of "their inner side. The bite of this reptile is said to be severe.

The family of Varanide inhabit south-eastern Asia and its islands, Africa, and Australia. In this family are comprised the largest of existing Lizards, with the exception of the Crocodilida. They are very commonly miscalled Iguanas by Europeans and their descendants, in the countries where they are found. These reptiles have a pyramid-shaped head, more or less elongated, and covered with small and scale-like, but not imbricate, shields. Their teeth are acute and compressed. The tongue is elongate, slender, terminating in a long fork, and is retractile into a sheath at its base. Their scales are small, equal on the sides and on the back, and arranged in cross rings; those on the belly and tail are square, in cross bands. Tail long, and generally more or less compressed. The feet are well developed, with five toes on each, which are armed with strong claws. Most of them live near water, and they are excellent swimmers, their long and compressed tail serving as a propeller. Their movements on land are not much less rapid than in the water. Several of the species climb trees, and they are more or less nocturnal in their time of action. They are exclusively carnivorous, feeding on the different water animals, and on the eggs of birds, and likewise on those of other reptiles; some of them are also destructive to ducklings, and to various snakes. Dr. Günther remarks that "their external nasal opening leads into a spacious cavity situated in the snout; when the animal dives, it closes the nasal aperture, and retaining a certain quantity of air in that pouch, or rather in the two pouches, it is enabled to remain under water for a prolonged period without the necessity of rising to the surface in order to breathe. It is the same plan of structure as that with which a large northern seal (Cystophora borealis) is provided." In like manner, the air-bag connected with the one developed lung of the Ophidians retains the necessary supply of air during the tedious process of deglutition or swallowing. The nostrils are variously placed, either midway between the eye and 
muzzle, or nearer to one or to the other; and according to this and some other differences, Dr. Gray divides the Varanide into as many as seven genera, Dr. Günther into two. When the tail of these lizards is mutilated, the lost portion is never renewed; whereas in the preceding families of the Zonurida, Lacertida, and Teide a new tail or portion of one is produced-but this renewed portion contains no bony vertebræ, and remains smooth externally; when the fracture is cleft, as sometimes happens, two new tails are put forth. Another family of lizards in which the tail is thus commonly renewed is that of the Geckos; but never in the Iguanida, the Agamida, and the Chameleonida, any more than in the Varanida. The species of this family defend themselves vigorously, when attacked, by lashing with the tail, as do also the Crocodiles and the larger Isuanida.

In the genus Varanus, the nasal apertures form an oblique slit, in, or nearly in, the middle, between the eye and the tip of the snout. The scales are elliptic and small; those on the back and on the sides are not imbricate, each of them being surrounded by a small, circular, granular fold. The tail possesses a low crest, formed by two or four series of strongly keeled scales. The throat has a transverse fold. The $V$. draiana, very common in India and Ceylon, grows to a length of five feet, the tail being longer than the body. These reptiles live in holes, and in midday they come forth to seek their food, which consists chiefly of the smaller reptiles and insects. In many parts of India, and in. Ceylon, their flesh is eaten by the natives. The late Dr. Kelaart states that soup made from it tastes like that from hare. At Trincomali, he tells us, they are hunted down by dogs, and sold in the market for sixpence each. This species climbs walls, and holds on so firmly with its strong claws, that it is actually used by housebreakers in India to surmount obstacles : the robber retaining hold of the creature's tail, while in its endeavour to escape it draws him upwards. It lays twenty or thirty eggs, which in texture and appearance resemble those of many snakes, being similarly agglutinated together by a viscid mucus. Sir J. E. Tennent remarks that "one of the earliest, if not the first, remarkable animal to startle a stranger on arriving at Ceylon, whilst wending his way from Point de Galle to Colombo, is this large lizard, which may be seen at noonday searching for ants and other insects in the midst of the highway and along the fences. When disturbed, but by no means alarmed, by the approach of man, it moves off to a safe distance; and, the intrusion being at an end, it returns again to the occupation in which it had been interrupted. It lives in any convenient hollow, such as a hole in the ground, or the deserted nests of the termites; and some 
small ones, which frequented my garden at Colombo, made their retreat in the heart of a decayed tree."

Of another species, $V$. flavescens, which inhabits Lower Bengal, and to the eastward in Burmah, \&c., Mr. Theobald remarks that "large specimens are not often procurable by Europeans, as they are much sought after by both Burmese and Karéns as choice articles of food. They are chiefly hunted with dogs, whose scent enables them to discover the Varans in the hollow trees in which they habitually shelter themselves. A Burman, though ordinarily a lazy man, to obtain such a bonne bouche will think nothing of the labour of cutting down and breaking up a large tree in which one of these creatures has sought refuge. The Varanida deposit their eggs on the ground, usually selecting a deserted White Ant's nest. The eggs are cylindrical, with tapering ends, of a dirty white colour with a covering of leathery texture (those of $V$.dracana are two inches long), and, being esteemed an uncommon luxury by the Burmese, sell dearer than fowls' eggs. They are oily and feculent-looking, though devoid of any nauseous odour, and some Europeans eat them with pleasure.

A well-known African species, the $V$. or Psammosaurus scincus, extends to the extreme desert region of the north-west of India, habitually frequenting dry localities. In this species the nasal apertures are placed very near the eyes.

In the genus Hydrosaurus, the nostrils are more or less rounded, and are situated near the extremity of the snout. These animals are more aquatic than the preceding, and some of the species grow to seven or even eight feet in length. Such is the H. giganteus of Australia, where three, if not four, species are found. In all southeastern Asia and its islands, its range extending to Lower Bengal but not to India proper, although found in Ceylon, the $H$. salvator is a common species, which, according to the late Dr. Cantor, is "very numerous in hilly and marshy localities of the Malayan peninsula. During the day it is commonly observed on the branches of trees overhanging rivers, preying upon birds, their eggs, and smaller lizards, and, when disturbed, throws itself into the water from a considerable height. It will courageously defend itself by teeth, claws, and blows with its tail.

We have now to treat of the

\section{Pachyglossa.}

These have the tongue short, thick, attached to the gullet, and not exsertile. They are divided into two very distinct tribes-the 
Strobilosaura and Nyctisaura of Dr. Gray, or the tribe of the Iguanas and their kindred, and that of the Geckos and their kindred. The tribe of

\section{STROBILOSAURA}

Have the scales of the back and sides imbricate, generally rhombic, and those of the lower parts imbricate and of small size. Tail with more or less distinct whorls of scales. The eyes diurnal, with round pupil, and valvular lids. Feet with toes of very unequal length. Many of these Reptiles have a row of spines or spine-like scales along the back and tail, which in some are very long, while others have high dorsal and caudal crests, and an expansile gular pouch. Like the Varans among the Leptoglossa (p. 107), these Lizards do not renew the tail, or a portion of it, after mutilation. There are two great families of them-one peculiar to the Old World and Australia, the other to the New World; but they do not differ much, and might very well be retained as varieties of the same extensive family.

In the family of Iguanida, all of which-inhabit America or its islands, the teeth are round at the root, dilated and compressed at the tip, and toothed at the edge; they are placed in a simple series on the inner side of the jaws, just below the margin, and are covered on the inner side by the gums; as they fall out they are replaced by others, which grow at the base of their predecessors. Probably not fewer than I50 species are now recognised, which are distributed under more than fifty genera. We can only notice a few of the most remarkable of these Lizards, some of the larger of which attain a length of five or six feet, with proportionate bulk of body. As a general rule, the larger species are principally herbivorous, while the smaller are generally insectivorous, though many of the latter also devour fruit. As most of them are remarkable for their rapid changes of colour, the name of chameleon is often misapplied to them, in the supposition that the chameleons are the only lizards in which that curious phenomenon is observable. Of one remarkable species, the Spharops anomalus, inhabiting Brazil, it is stated that the eye nearly resembles that of the true chameleons, it is also one of those which are particularly celebrated for changing its hue.

The name Iouana was given by Laurenti to a heterogeneous group of Saurians, various forms being included which were first separated by Daudin. The Iguanas, as thus restricted, are characterised by a very large thin dew-lap under the neck, a double row of small palatal teeth, and a crest on the back and tail ; the latter long, slender, com- 
pressed and covered with small imbricated and carinated scales. Messrs. Duméril and Bibron describe the genus, thus modified, as principally remarkable for the cutaneous prolongation which constitutes the deep and thin dew-lap, or pouch, the free border of which describes a curved line, and is dentated at the part nearest the chin.

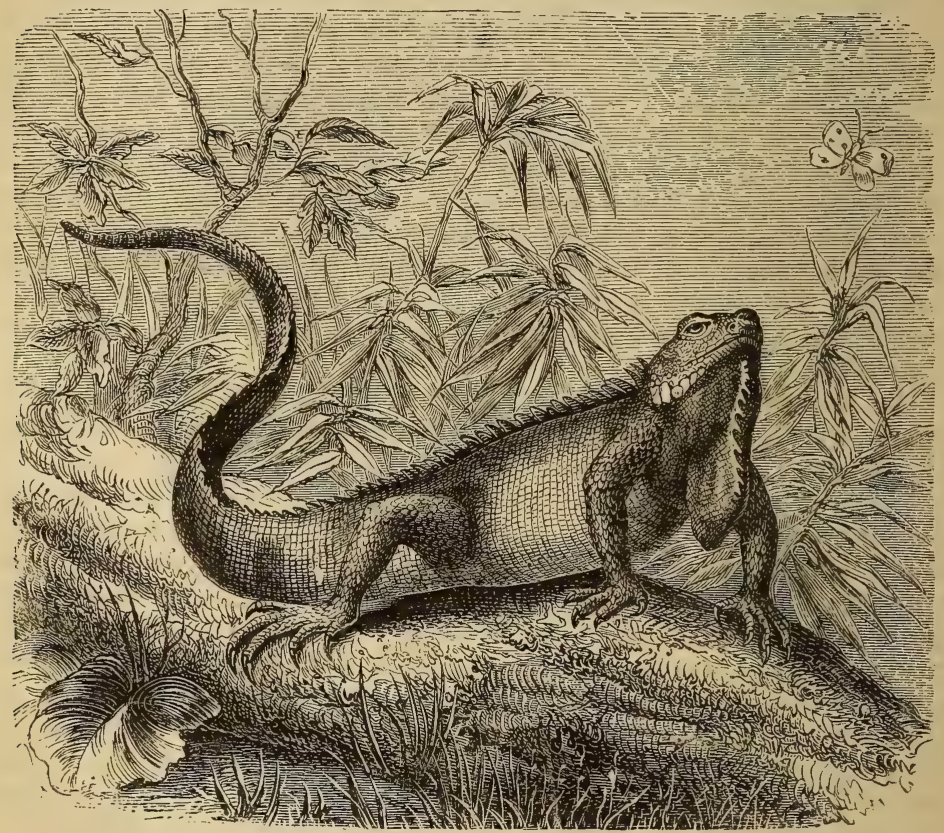

Fig. 27.-Common Iguana.

The head is moderately long, and has the form of a pyramid with four faces. The neck is slightly compressed, the limbs long, the toes unequal and sometimes denticulate on the edge. The five toes of the posterior feet are graduated; the tail, which is long and slender, is slightly flattened from right to left. The Iguanas live chiefly on trees, but they take readily to the water, and swim with great facility.

There are numerous species, all of which are found in South America and the Antilles. In the Island of Isabella, Sir E. Belcher 
found swarms of them which he had reason to consider omnivorous, feeding voraciously on birds' eggs and the intestines of birds and insects.

The Common Iguana (1. tuberculata, Fig. 27), which inhabits a great part of South America, is one of the best known of this family. These Reptiles are easily recognised from the large pouch underneath the neck, and the dentated crest which extends from the head to the extremity of the tail. The tail, feet, and body are covered with small scales. On the upper part their colour is a more or less decided green, sometimes becoming blue, at others slate-coloured; the lower part is of a yellowish green. The sides present zigzag, roundish, brown scales, edged with yellow; frequently a yellow line is traced obliquely in front of the shoulder, and some specimens are sprinkled with brown; others have the limbs spotted with brown on a black ground. The tail is surrounded with brownish rays alternating with others of green and yellow. When full grown it attains the length of four feet, but the more ordinary length of the animal is about thirty inches. They are very gentle creatures, and perfectly harmless, feeding almost exclusively on vegetables. They are hunted for their flesh, which is excellent; and they are most numerous in Surinam and Brazil.

[Of a kindred species, Metopoceros cornutus, which is common in the Antilles, an excellent description has been published by Lieutenant Tyler,* which we must endeavour to condense. This Reptile attains a length of five, and sometimes even six feet, the tail being about twice and three-quarters the length of the body. When first hatched it measures four inches. The mouth is large, and is armed with two rows of maxillary and two of palatal teeth, which appear simply to be intended to crop grass and to provide the stomach with vegetable food. Each maxillary tooth is a little double-edged saw, and they are so lapped over each other that the reptile, in closing its mouth upon a leaf, cuts through it completely. The tongue is curiously used by the animal to draw food into the mouth, and to forward it down the gullet, or to repel it at will, and the only use of the palatal teeth appears to be to secure the food while the tongue moves forward to afford fresh assistance in its journey down the throat. The tongue is always covered by a glutinous secretion, the gland which secretes it being perceptible when the mouth is open. Between the lower jaw and the chest is a pouch, which the animal draws in or extends simultaneously with the compression or swelling out of the body when

" "Proceedings of the Zoological Society" for I850, p. 106. 
enraged or excited. The portion of the gular pouch attached to the jaw is inflatable, and food is sometimes retained in it for a considerable period, but the lower part is merely extensible.

"Whilst always retaining the same colours, this Iguana has the power of considerably changing its hues; but these alterations are gradual. The colours become more dull as the period for the change of cuticle approaches-which is not, however, frequent. Each scale has its own tint, and the colours being thus irregularly blended, an appearance is given, particularly to the younger reptiles, very much like that of worsted-work.

"These Iguanas live principally on trees, and near the windward coast of the island" (St. Lucia). "They are not much seen, excepting in the months of February, March, and April, when they quit their hiding-places and repair to the sea-shore or other sandy places to lay their eggs in the sand. The older females lay a great number of eggs. I have known an instance of one in confinement laying five in one day, and thirty-two within the space of ten minutes five days afterwards, making thirty-seven in all. Younger females are much less prolific, according to their size. The eggs are very liable to destruction by ants, which fact probably accounts for their being usually deposited in sea-sand. They are soft, and without any white, and their shell resembles the most beautiful light straw-colour kid leather used for French gloves. These eggs are about the size of a domestic pigeon's, but rather longer ; still they vary in dimensions according to the age and size of the iguana.

"This Iguana is not averse to water, when not too cold, taking to it only when the sun is shining; in fact, not moving about much at any other time. Its mode of swimming differs from that of other Lizards, inasmuch as it places its four legs close by the side of its body, and swims entirely with its tail. It dives with great facility, and remains sometimes for a considerable time under water. I believe that it never ventures into the sea. The tail is a very valuable limb; for, besides being the sole means of swimming possessed by the animal, it is of great use in climbing trees, although not prehensile: and it is a more important weapon of defence, a blow from it being frequently sufficient to inflict a severe wound. In fact, this Reptile is rather formidable when brought to bay in the woods. It is hunted by the natives with dogs trained for the purpose. The dog, immediately upon scenting it, gives tongue, and, if on the ground, the dog seizes it by the back, and either kills it or maims it, which makes its capture easy ; if in a tree, the Iguana is either shaken down-a matter ordinarily of no small difficulty-or the branch is cut off. It is almost 
useless to attempt to find these Reptiles without dogs, as the resemblance of their colour to that of the trees which they inhabit prevents them from being easily seen. Few dogs but those accustomed to the sport will touch them, as, in addition to the blows which they inflict with the tail, they bite and scratch furiously; and when once they lay hold of anything with their teeth, they can only be made to let go by an inducement to bite some more attractive object offered to them. They run into holes when chased, if an opportunity offers, and when their eyes are hidden from view they fancy that their whole body is safely covered. The flesh, particularly of the female, is a great delicacy ; it is cooked in various ways, sometimes in a fricassee with the eggs whole, sometimes roasted or stewed. The eggs have a very glutinous consistence. The flesh is said to disagree with some constitutions.

"Unless when caught young, it is very difficult to induce these reptiles to feed in confinement, and particularly when watched. Their disposition is sulky and savage, and I have known some of them," continues Lieutenant Tyler, "to die in confinement from starvation, rather than feed. This has caused me to try the following plan, which I find very successful, of affording them nourishment :I hold them by the lower part of the body with one hand, and with the other I irritate them until they open their mouth and attempt to bite, when I insert food; and by annoying them in this way, I have not only made them eat their natural food, but I have killed some of them by forcing them to eat corn and leaves, which appear to have disagreed with them. By some of the natives this Iguana is said to eat lizards and insects; but I have opened several, and I have never succeeded in finding any but vegetable matter in the stomach."

Of the habits of a kindred species of Iguana, the Cyclura lophura, inhabiting Jamaica, Mr. Gosse has given an elaborate description; and he tells us that the gular pouch in the Iguanida "is extensible, but not inflatable," as is the current opinion. Holbrook and others have remarked the same; and Professor Thomas Bell describes the fold of skin as being drawn down by a peculiar arrangement of the lingual bone and a singular cartilage fixed to it and attached also to the skin. These parts are moved by delicate muscles, so that, when the cartilage is drawn down, the skin of course is distended, and follows it "in the same way that the silk is stretched over the whalebone of an umbrella." "In fact the skin," writes Professor Holbrook, "when distended in life by the animal, does not resemble the inflated vocal sacs of the Frogs and Toads, which are round, but 
looks like a fola of the skin, pinched and drawn down, the two portions of it being in contact, like a dewlap." It appears that the Cyclura also is exclusively herbivorous; and Mr. Gosse remarks upon the severe wounds it can inflict with its sharply-serrated tail. In general, the larger species of this family are solely vegetablefeeders, while the smaller kinds (such as the Anoles) are more or less insectivorous; and there are some, of intermediate size, which even prey occasionally upon the kindred Anoles and other small animals. The genera of these Reptiles are exceedingly numerous, as we have seen, and amongst so many there must be considerable variety in the habits; but we can only notice a very few of them. Within the limited area of the small archipelago of the Gallapagos, situated under the equator about ten degrees west of South America, there are two remarkable species of Iguanida, of which the habits have been described and commented upon by Mr. Darwin in his volume of the "Voyage of H.M.S. Beagle." One of these is particularly so, because, as that naturalist observes, it is the only existing Saurian which can properly be said to be a marine animal. In the whole of that group of islands, as he tells us, there is only one rill of fresh water; yet this Reptile frequents the sea-beaches, and no other parts of the islands. $\mathrm{He}$ adds that it is the only known existing Lizard that feeds exclusively on aquatic productions. Although he refers both species to the genus Amblyrhynchus, the aquatic sort now constitutes the genus Oreocephalus of Dr. Gray, and it bears the name of $O$. cristatus. This lizard, according to Mr. Darwin, "is extremely common on all the islands throughout the archipelago of the Gallapagos. It lives exclusively on the rocky sea-beaches, and is never found-at least, I never saw one-even ten yards inshore. It is a hideous-looking creature, of a dirty black colour, stupid and sluggish in its movements. The usual length of a full-grown one is about a yard, but there are some even four feet long. I have seen a large one which weighed twenty pounds. On the Island of Albemarle they seem to grow to a greater size than on any other. These Lizards were occasionally seen some hundred yards from the shore swimming about; and Captain Colnett, in his 'Voyage,' says, 'they go out to sea in shoals to fish.' With respect to the object, I believe that he is mistaken; but the fact stated on so good an authority cannot be doubted. When in the water the animal swims with perfect ease and quickness, by a serpentine movement of its body and flattened tail-the legs, during this time, being motionless and closely collapsed on its sides. A seaman on board sank one, with a heavy weight attached to it, 
thinking thus to kill it directly; but when, an hour afterwards, he drew up the line, the lizard was quite active. Their limbs and strong claws are admirably adapted for crawling over the rugged and fissured masses of lava which everywhere there form the coast. In such situations, a group of six or seven of these ugly reptiles may oftentimes be seen on the black rocks, a few feet above the surf, basking in the sun with outstretched legs. I opened the stomachs of several," continues Mr. Darwin, "and in each case found it largely distended with minced sea-weed of that kind which grows in thin foliaceous expansions of a bright green or dull red colour. I do not recollect having observed this sea-weed in any quantity on the tidal rocks; and I have reason to believe that it grows at the bottom of the sea, at some little distance from the coast. If such is the case, the object of these animals occasionally going out to sea is explained. The stomach contained nothing but the sea-weed. Mr. Bynoe, however, found a piece of a crab in one; but this might have got in accidentally. The intestines were large, as in other herbivorous animals."

The food of this Lizard, equally with its compressed form of tail, and the certain fact of its having been seen voluntarily swimming out at sea, absolutely prove its aquatic habits; nevertheless, as we are told by Mr. Darwin, "there is in this respect one strange anomaly, namely, that when frightened it will not enter the water. From this cause, it is easy to drive these lizards down to any little point overhanging the sea, where they will sooner allow a person to catch hold of their tail than jump into the water. They do not seem to have any notion of biting; but when much frightened they squirt a drop of fluid from each nostril. One day I carried one to a deep pool left by the retiring tide, and threw it in several times as far as I was able. It invariably returned in a direct line to the spot where I stood. It swam near the bottom, with a very graceful and rapid movement, and occasionally aided itself over the uneven ground with its feet. As soon as it arrived near the margin, but still being under the water, it either tried to conceal itself in the tufts of sea-weed, or it entered some crevice. When it thought the danger was passed, it crawled out on the dry rocks, and shuffled away as quickly as it could. I several times caught this same lizard by driving it down to a point, and, though possessed of such perfect powers of diving and swimming, nothing would induce it to enter the water; and as often as I threw it in it returned in the manner above described. Perhaps this singular piece of apparent stupidity may be accounted for by the circumstance that this Reptile 
has no enemy whatever on shore, whereas at sea it must often fall a prey to the numerous sharks. Hence, probably urged by a fixed and hereditary instinct that the shore is its place of safety, whatever the emergency may be, it there takes refuge. I asked several of the inhabitants if they knew where it laid its eggs : they said, that although well acquainted with the eggs of the other kind, they had not the least knowledge of the manner in which this species is propagated - a fact, considering how common an animal this lizard is, not a little extraordinary. During our visit (in October) I saw extremely few small individuals of this species, and none, I should think, under a year old. From this circumstance it seems probable that the breeding season had not commenced."

The terrene species (Amblycephalus subcristatus), unlike the aquatic one, is confined to the central islands of the Gallapagos archipelago, where they inhabit both the higher and damp, as well as the lower and sterile parts; but in the latter they are much more numerous. "I cannot give a more forcible proof of their numbers," relates Mr. Darwin, "than by stating that, when we were left at James Island, we could not for some time find a spot free from their burrows on which to pitch our tent. These Lizards, like their brothers of the sea-kind, are ugly animals; and, from their low facial angle, have a singularly stupid appearance. In size perhaps they are a little inferior to the latter, but several of them weighed between ten and fifteen pounds each. The colour of their belly, front legs, and head (excepting the crown, which is nearly white) is a dirty yellowish orange; the back is of a brownish red, which, in the younger specimens, is darker. In their movements they are lazy and halftorpid. When not frightened, they slowly crawl along, with their tails and bellies dragging on the ground. They often stop and doze for a moment, with closed eyes, and hind legs spread out on the parched soil. These Iizards inhabit burrows; which they sometimes excavate between fragments of lava, but more generally on level patches of soft volcanic sandstone. The holes do not appear to be very deep, and they enter the ground at a small angle ; so that when walking over one of these lizard zvarrens, the soil is constantly giving way, much to the annoyance of the tired pedestrian. This animal, when excavating its burrows, alternately works the opposite sides of its body. One front leg for a short time scratches up the soil, and throws it towards the hind foot, which is well placed so as to heave it beyond the mouth of the hole. This side of the body being tired, the other takes up the task, and so alternately. I watched one for a long time," continues Mr. 
Darwin, "till half of its body was buried; I then walked up and pulled it by the tail; at this it was greatly astonished, and soon shuffled up to see what was the matter; and then stared me in the face, as much as to say, 'What made you pull my tail?' They feed by day, and do not wander far from their burrows ; and if frightened, they rush to them with a most awkward gait. Except when running down-hill, they cannot move very fast ; which appears chiefly owing to the lateral position of their legs. They are not at all timorous; when attentively watching any one they curl up their tails, and, raising themselves on their front legs, nod their head vertically, with a quick movement, and try to look very fierce, but in reality they are not at all so ; if one just stamps the ground, down go their tails, and off they shuffle as quickly as they can. I have several times observed small fly-eating Lizards, when watching anything, nod their heads in precisely the same manner; but I do not at all know for what purpose. If the Amblyrhynchus is held, and plagued with a stick, it will bite it very severely; but I caught many by the tail, and they never tried to bite me. If two are placed on the ground, and held together, they will fight and bite each other till blood is drawn. Those individuals (and they are the greater number) which inhabit the lower country, can scarcely taste a drop of water throughout the year but they consume much of the succulent cactus, the branches which are occasionally broken off by the wind. I have sometimes thrown a piece to two or three, when together; and it was amusing enough to see each trying to seize and carry it away in its mouth, like so many hungry dogs with a bone. They eat very deliberately, but do not chew their food. The little birds are aware how harmless these creatures are: I have seen one of the thick-billed finches (peculiar to the Gallapagos) picking at one end of a piece of cactus - which is in request among all the animals of the lower region-whilst a lizard was eating at the other; and afterwards the little bird, with the utmost indifference, hopped on the back of the reptile. The stomachs of several that I opened were full of vegetable fibres and leaves of different trees, especially of a species of Acacia. In the upper region they live chiefly on the acid and astringent berries of the Guayavita, under which trees I have seen these lizards and the huge tortoises feeding together. To obtain the acacia leaves, they crawl up the low, stunted trees; and it is not uncommon to see one, or a pair, quietly browsing whilst seated on a branch several feet from the ground.

" The meat of these animals, when cooked, is white; and by those whose stomachs rise above all prejudices, it is relished as very good 
food. Humboldt has remarked, that in intertropical South America, all Lizards which inhabit $d r y$ regions are esteemed as delicacies for the table. The inhabitants of the Gallapagos say that those inhabiting the damp region drink water, but that the others do not travel up for it from the sterile country, like the gigantic Land Tortoises. At the time of our visit the females had within their bodies numerous large elongated eggs. These they lay in their burrows, and the inhabitants seek them for food."

These two curious Lizards of the Gallapagos agree nearly in general structure, and in many of their habits ; and neither of them has that rapidity of movement which is characteristic of various other Igzanida. The form of the head resembles a good deal that of a Land Tortoise, and we find the same form of head, and again the same disinclination to bite, in certain herbivorous Lizards, such as the Uromastyx and kindred forms, which are referred by Dr. Gray to the corresponding Old World family of Agamida.]

In the family of Iguanas the Basilisk may be noted. According to ancient authors, reproduced by writers of the Middle Ages, the Basilisk, although such a small animal, could produce instant death by its sting. The man whose eyes met theirs was supposed to be at once devoured by an intense fire. Such are the fabulous ideas which tradition has transmitted to us about these animals. It is to be remarked, however, that the Basilisk of modern herpetology is not the $B \alpha \sigma \iota \lambda \iota \sigma \kappa \delta s$, or royal serpent, of the ancients, the cockatrice of Scripture. The Reptile which now bears the name is an inoffensive animal, living in the forests of Guiana, Martinique, and Mexico, and leaping from branch to branch, in order to gather the seeds or seize the insects on which it feeds.

The Basilisk is distinguished from the other iguanian Lizards by the absence of the long and dilatable skin under the throat, and by the presence of an elevated crest which runs along the whole length of the back and tail.

The Hooded Basilisk (B. Americanus, Fig. 28) measures seven or eight inches from the nose to origin of the tail, which is itself nearly three times as long, being nineteen or twenty inches in length. Upon the occiput it has a sort of horn or bag, in shape like a hood, round at the summit and slightly inclined towards the neck. This bag, when distended, is about the size of a pullet's egg. In the male the back and tail are surmounted by a raised crest, such as we have described above, sustained in its thickness by the knotty process of the vertebræ. The general colour is a mixture of sandy brown, slightly marbled on the back and sides, with shades of blue on the upper part, 
and a silvery white underneath. On the throat are larger bands of brown, and on each side of the eye is a white ray bordered with black, which is lost upon the back ; and the tail is so remarkably attenuated towards its extremity as to show the articulations of the vertebræ beneath.

[According to Mr. O. Salvin, the Basilisk is very common about Lanquin, in the province of Guatemala, where it may frequently be seen on the lower branches of bushes, and it is particularly fond ot basking on the boughs of a felled tree near a stream. In some speci-

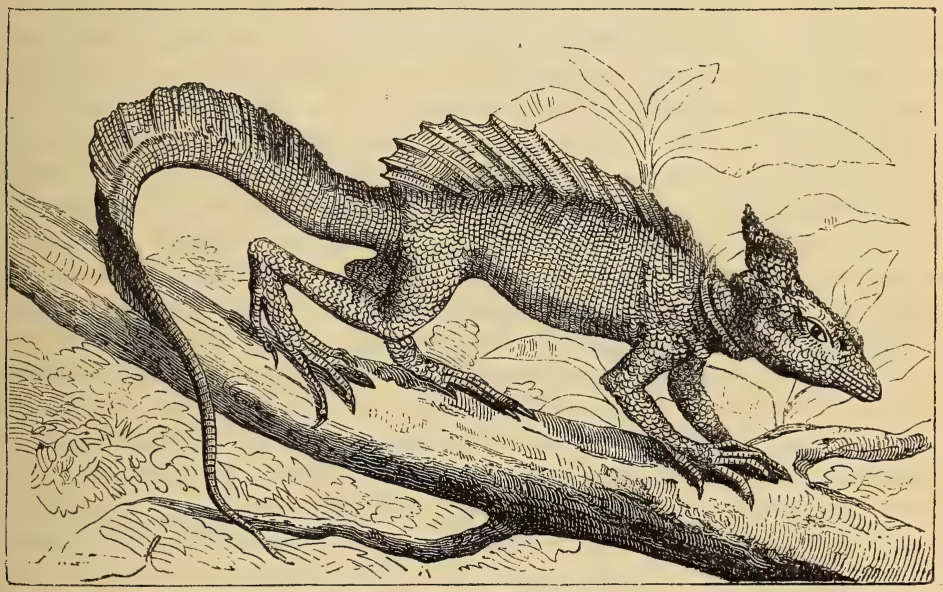

Fig. 28. - Hooded Basilisk.

mens of the males, we are informed, the tail is much more compressed than in others. In a series of the young the crest is shown in all stages of development. We also learn from this naturalist that, notwithstanding the compressed form of its tail, the Basilisk does not habitually enter the water, as most writers have supposed.

The sub-family of Anoles (Anoliina) have mostly the skin of their toes widened (under the ante-penultimate phalanx) into an oval disc, striated crossways underneath, which enables them to attach themselves to various surfaces. They do not attain the large size of the Iguanas; and the habits and characteristics of the various species inhabiting Jamaica are thus vividly described by Mr. P. H. Gosse in 
his "Naturalist's Sojourn" in that beautiful island. " The stranger," he remarks, "walks into the dwelling house. Lizards, still lizards, meet his eye. The little Anoles (A. iodurus, $A$. opalinus, \&c.) are chasing each other in and out between the jalousies, now stopping to protrude from the throat a broad disc of brilliant colour, crimson or orange, like the petal of a flower, then withdrawing it, and again displaying it in coquettish sport. Then one leaps a yard or two through the air and alights on the back of his playfellow; and both struggle and twist about in unimaginable contortions. Another is running up and down on the plastered wall, catching the ants as they roam in black lines over its whitened surface; and another leaps from the top of some piece of furniture upon the back of the visitor's chair, and scampers nimbly along the collar of his coat. It jumps on the table; - can it be the same? An instant ago it was of the most beautiful golden green, except the base of the tail, which was of a soft light purple hue; now, as if changed by an enchanter's wand, it is of a dull sooty brown all over, and becomes momentarily darker and darker, or mottled with dark and pale patches of a most unpleasing aspect. Presently, however, the mental emotion, whatever it wasanger, or fear, or dislike-has passed away, and the lovely green hue sparkles in the glancing sunlight as before."

The green colour of certain of these Anoles so closely resembles that of foliage, that they are apt to be overlooked. Thus, Mr. Gosse was about to throw a net over a butterfly, when, as he remarks, "on a slight rustle among the leaves, I observed that it was fluttering as it unable to get away. My impression was that an invisible spider'sweb was holding it; but, looking closer, I found that a little green Anolis had the butterfly in its mouth. Its colour was so exactly that of the verdant leaves of the bush, that I had not perceived it before, although my eyes were fixed on the spot. I have also observed the same species feeding on ants. On a gateway a number of scattered ants of a small kind were running to and fro, as they very frequently are seen to do; a beautiful male Anolis had stationed himself on the post perpendicularly, with the head downwards, and as the ants one by one came near him he snapped them up. Each capture was the work of an instant; he touched the post with his muzzle, and the ant was gone : they were evidently seized with the lips, not with the tongue. These little creatures are as playful as they are pretty. As they creep about they often catch sight of another of the same species; immediately one suddenly raises and depresses the head and fore-parts, flirts the tail from side to side, and extends the goitre by means of the elastic arched bone in front, till its tip reaches nearly as 
far as the muzzle. The brilliant goitre is thus alternately extended and relaxed several times. After being thus 'signalised' for a few seconds, one darts towards the other, who usually runs away, apparently as if wishing to be caught." Elsewhere Mr. Gosse describes the noosing of an example of a fine Lizard of this Anolis group, the Dactyla Edwardsii, which is also a native of Jamaica, " about a foot long, and of a lively green colour. He was very savage, biting at everything near: presently his colour began to change from green to blackish, till it was of a uniform bluish black, with darker bands on the body, and a brownish black on the tail ; the only trace of green was just around the eyes." He was placed in a cage, and "at night," continues Mr. Gosse, "I observed him vividly green, as at first-a token, as I presumed, that he had in some measure recovered his equanimity. The next day he continued very fierce. I hung the cage out in the sun; two or three times in the course of the day I observed him green, but for the most part he was black. The changes were rather quickly accomplished. The food of this Lizard appears to include both vegetable and animal substances. I was never able to induce one to eat in captivity; but the dissection of several has given me this result. Thus in one I have found seeds and farinaceous substances; in another fragments of a brilliant beetle of the Weevil group. I once observed one deliberately eat the ripe glass-berries munching half of one at a mouthful." *

Thus far we have treated of chiefly arboreal Iguanida; and although a marine Lizard, Trachycephalus cristatus cannot well be so designated, it nevertheless belongs to the same particular series. We have next a long series of mainly terrene genera of the same great American family, in which the body is subtrigonal or depressed. As many as twenty-two genera, with sixty-one species of the terrene Iguanida, were catalogued by Dr. Gray in 1845 , and a good many have since been added. There is a corresponding series in the kindred Old World family of Agancida, and in neither instance are the majority of them ground-frequenting Lizards to any great extent. Thus, of Dr. Gray's first genus Tropidolipis (so named from its large keeled scales), and of which as many as nine species are given from Mexico, a tenth (T. undulatus, of the United States) is described by Professor Holbrook to inhabit chiefly the pine forests, where it is often found under the bark of decaying trees; selecting old fences for its basking-place. "It is exceedingly rapid in its motions, climbing with great facility to the tops of trees, and is hence not taken alive without 
great trouble. Its food consists of insects, especially such as are found under decaying wood." The colouring of this Lizard is remarkably brown, with narrow zig-zag black bands above, and green below, with a white medium stripe bordered with black; throat and breast black, with a broad green band across. Various species of kindred genera were collected by Mr. Darwin, and are figured in the "Zoology of H.M.S. Beagle," and of one of these (probably Lecolanus Darwinii), which he observed at Bahia Blanca, in Northern Patagonia, he remarks that "it lives on the bare sand near the sea-coast, and from its mottled colour, the brownish scales being speckled with white, yellowish red, and dirty blue, can hardly be distinguished from the surrounding surface. When frightened it attempts to avoid discovery by feigning death, with outstretched legs, depressed body, and closed eyes; if further molested, it buries itself with great quickness in the loose sand. This Lizard, from its flattened body and short legs, cannot run quickly." With others these Lizards constitute the sub-family Tropidolepince of $\mathrm{Dr}$. Gray, which are followed by the sub-family Phrynosomine, in which some very singular Lizards find their place. The most extraordinary of them constitute the genus Phrynosoma, four species of which inhabit western North America. These have great spines to the occiput, in these respects resembling the African genus Cordylus (p. Ior), and very toad-like proportions, looking somewhat like toads with short tails; and again they decidedly approximate in appearance to the curious Moloch horridus of Western Australia, which belongs to the corresponding Old World family of Agancida; and, like that strange reptile, they are slow of motion and perfectly harmless, and they may be handled with impunity, as they never attempt to bite.]

\section{Flying Lizards.}

Flying Lizards (Draco) have the head small, the nostrils in a scale, tubular, on the side ridge; tympanum white and opaque. They live on trees, walking with agility with their wings folded by their sides. These wings they expand and use as a parachute when they throw themselves upon their prey" from the tops of trees or other elevated places, but they cannot move them as birds do. These remarkable appendages are also used as a fan to drive off insects.

[The fabulous dragons of the ancient Greeks were serpents or lizards with remarkably piercing sight, which guarded treasures and devoured men. The dragons of mediæval artists were frightful and fantastic beings, one half bat and the other half quadruped or serpent. The little Saurians which now bear the once dreaded name 
are no less interesting, although they are no longer monsters; they are distinguished from all other Reptiles by a kind of wing, which is a large fold of skin, or membrane, on each side of the body. These wings are entirely independent of the other members, being sustained by six false ribs, which do not surround the abdomen, but rather extend horizontally. They are the only existing examples of our day of that organic arrangement which distinguished the Reptiles known under the name of Pterodactyli, and which belonged to the Jurassic period of geology.

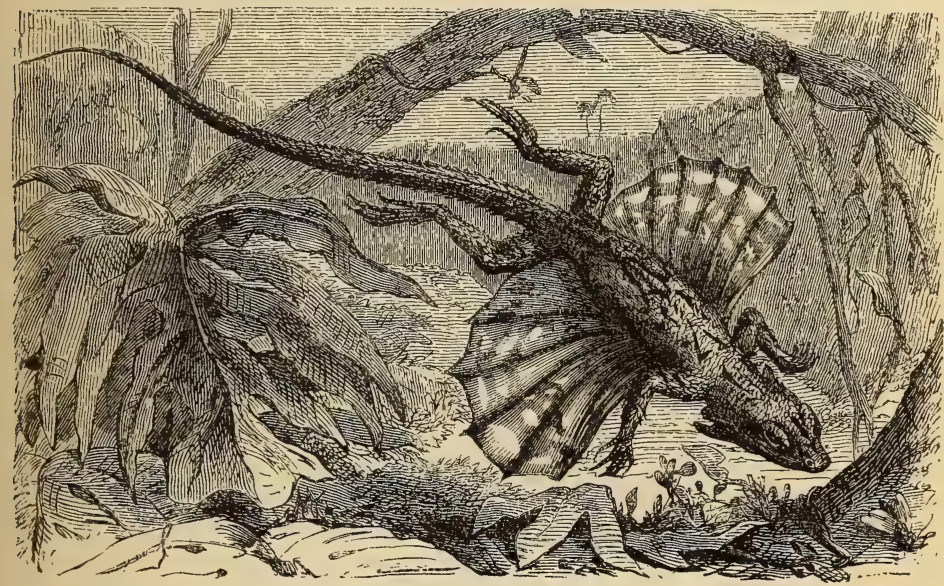

Fig. 29.-Flying Lizard.

Dr. Gray divides the Draconina into three genera, namely :-

I.-Dracos, having the ears naked, nostrils below the fore ridge, of which three species are described-viz., D. volans (the Flying Lizard, Fig. 29), having the scales of the back broad, generally smooth, those of the throat granular; wings grey, fulvous, or brown, spotted and marbled with black, sometimes forming four or five oblique black bands near the outer edge; the sides with a series of large keeled scales : the Timor Flying Lizard (D. viridis timorensis of Schlegel) and the Fringed Flying Lizard ( D. fimbriatus) are also keeled. II.-Draconella, of which there are two species, one $(D$. 
Dussumieri, having the nape crested; and $D$. homatopogon, the Redthroated Dragon, which is without the crest.

III.-Dracunculus, of which five species are described-namely, D. quinquefasciatus, the Banded Flying Lizard, nape not crested, having a longitudinal fold; $D$. lineatus, having the nape crested, the ears slightly concave; $D$. ornatus, wings grey, reticulated with black, and having broad black bands at the edge; the Spotted Winged Dragon (D. maculatus), grey, and the wings black spotted; and $D$. spilopterus, having the wing reddish near the body.]

\section{Geckotide, or Thick-Tongued Lizards.}

This singular family of Saurians have the head wide and flattened, the mouth wide, the nostrils distant and lateral, the eyes large, with short lids ; the tongue short, fleshy, and capable of slight elongation. The body is thick and short, low on the legs, rather squat and depressed, with a belly trailing on the ground, and a back without crest. The skin is defended by granular scales, interlaced with others of a tubercular character. Almost always they are of a sombre colour. Their feet are short, wide apart, and robust; they are furnished on the upper part with imbricated laminæ, which enable them to adhere firmly to the surface of even the smoothest bodies, and to run with rapidity in all directions on a plain surface, and even to remain stationary with the back downwards, like the common house fly. Their hooked and retractile claws, like those of cats, also assist them in climbing, crawling up trees and rocks, on which they will sometimes remain immovable for several hours. Their flexible bodies mould themselves into the depressions of the surface of the earth, their natural colour blending, and being confounded with that of the soil, they become almost invisible. Their eyeballs, which dilate and contract considerably, protect them from the action of the sun's rays, and enable them, it is thought, to see in the dark. They are nocturnal, avoid the sun's light; and catch their food in the chinks of rocks. Their movements are rapid, silent, and sudden. They hibernate, and are provided with fatty masses in the groin which are supposed to be a provision for their nourishment during that period. Geckos emit sounds which resemble the noise an equestrian makes when encouraging his horse. This is produced by smacking their tongues on the palate. They frequent habitations in which they can find food, and are timid, inoffensive, and quite incapable of inflicting injury; but their repulsive appearance makes them objects of general repugnance, and has caused evil properties to 
be attributed to them. There are about sixteen known species of Geckos distributed universally over all tropical and some temperate countries.

[The Geckotida are divided into many genera, according to the construction of the toes. Duméril refers to the comparative shortness and general structure of the feet and conformation of the toes, which he describes and figures in detail. The lower surface and the sole, he states, are very dilatable, and furnished with small plates or

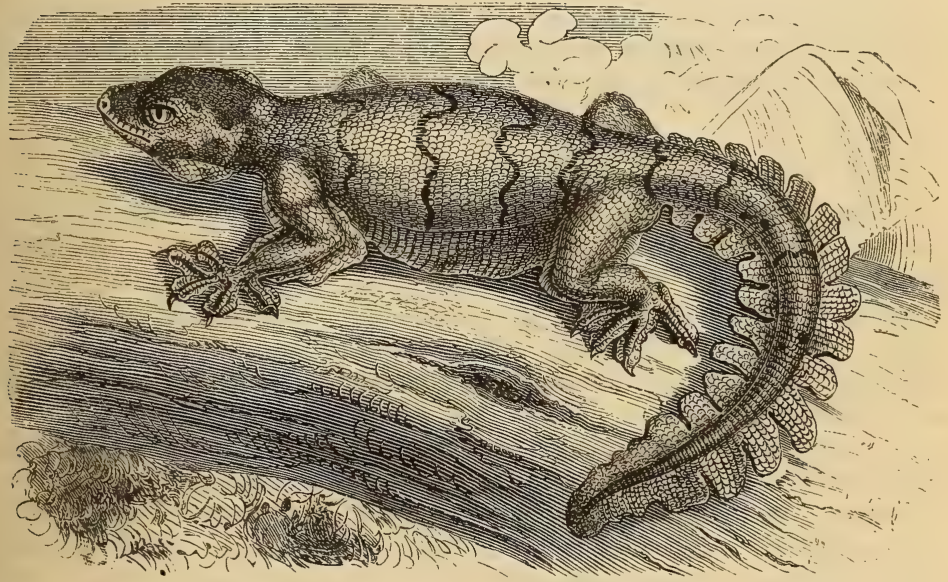

Fig. 30.-Wall Gecko.

lamellæ, following or overlying each other in a mode which varies in the different species. The nails are sometimes wanting on all the toes, but more frequently possess them, when they are hooked, and more or less retractile; the toes sometimes are united at the base, and in Platydactylus the extremity of the toe expands into a fan shape, as in the Tree Frogs. The membranous and soft plates of the lower surface of the toes have various modifications in different genera, which has been made the basis of their arrangement. The Wall Gecko is supposed by Gesner to be the Lizard spoken of by Aristophanes and Theophrastus, and the Tarentula of the Italians; and there is little doubt that it was

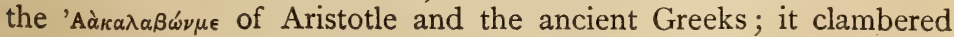


about their walls catching spiders, on which it fed. Schneider has shown it was the Stellio of Pliny. Linnæus mentions three species, which he places with his great genus Lacerta. Modern herpetologists, following Cuvier and Duméril, class them according to the structure under the several genera Ascalabotes, Platydactylus, Hemidactylus, Ptyodactylus, Thecadactylus, Stenodactylus, and Gymnodactylus.]

The Wall Gecko ( $P$. homalocephalus, Fig. 30 ) is of an ashy grey colour, as if powdered on the upper part of the body, and is white underneath. It inhabits the islands of the Mediterranean, as well as the countries which form the basin of that sea, such as Italy, France, Spain, and Africa. They are generally found in old walls; they are, however, sometimes seen running on those of modern habitations. They feed principally on the dipterous insects and Arachnidans.

\section{Chameleo (Laurenti).}

The genus Chameleo, of which ten species are described in the British Museum Catalogue, are natives of Africa and Asia, and naturalised in Southern Europe. They live on trees, clinging to the branches by their feet and prehensile tails; they move slowly and with great caution, feeding upon insects, which they catch with singular dexterity by the rapid elongation of their tongue, which is viscid at the tip.

Certain groundless metaphors, deeply rooted in the popular mind, have singularly distorted the truth in respect to these Reptiles. It is commonly believed that the Chameleon often changes its shape, that it has no fixed colour, but takes that of objects on which it rests. This singular idea has descended from ancient times. According to the reports of Theophrastus and Plutarch, the Chameleon takes all colours in turn; according to Aristotle, it changes colour all over the body; but Elian seems to have had views more in accordance with those of modern observers, for he says when it takes other colours than grey to disguise itself, it covers only certain parts of the body with them. Altogether, the ancients made the Chameleon a very wonderful creature; hence, in the familiar comparisons in literature, they serve as a type to designate unprincipled persons; to paint fawning men, who have neither character nor individuality of their own, but who bend themselves to the will and adopt the opinions of others. Putting aside the imaginary attributes accorded to the Chameleon by the fancies of the ancients, and painting them such as they are, we see in them peculiarities most worthy of observation and highly interesting to the naturalist, as well on account of the singular 
formation of different parts of their bodies as for their remarkable habits of life.

Chameleons have compressed bodies; the back round and projecting, or rather pyramidal; the skin granulated; the head angular, with salient occiput resting on a short and thick neck ; their legs are slender; the toes five in number; the tail prehensile and round. The eyes are very large and protruding, their globes covered by a single shagreen-like eyelid, which the animal can dilate or contract at will, and which almost hides the small aperture in the centre, through which a brilliant eyeball can be perceived. The eyes in the Chameleon, which have a singular mobility, are thus completely enveloped, as if they were too delicate to sustain any glaring light. By certain special muscular arrangements they have the power to direct each eye on different objects even whether they be above or below. It is thus a common saying in France, applied to the Chameleon, "that it could look into Champagne and see Picardy in flames."

The vermiform and retractile tongue is also a most singular organ. It is cylindrical, about six inches long, terminating in a fleshy, dilatable, and somewhat tubular tip, which is covered with a glutinous secretion, by the aid of which it seizes its insect food. The feet have five very long almost equally strong hooked claws, and the skin of the legs extends to their end, and unites them in a very peculiar manner. Not only is this skin attached to each of the toes, but it envelops them, and forms, as it were, two bunches-the one of three fingers, and the other of two. From this structure one can anticipate the extreme difference which exists between the habits of Chameleons and those of Lizards. These two bunches of long toes are placed in such a manner as to enable them to seize the branches of the trees on which they rest both with the fore and after part of the foot in the same manner as woodpeckers, cuckoos, and parrots, while their long and strong prehensile tail serves them as a fifth limb. Chameleons are better able to preserve their equilibrium upon trees than upon the ground; thus doubtless accounting for their preference for the former. Cautious, they move at all times very slowly, particularly when going from one branch to another. Their prey and their enemies they can see from a great distance. The latter they readily avoid. As to the former, when the Chameleon arrives within range of the victim the tongue is projected with unerring precision, returning into the mouth with the prey adhering to the viscous tip. This tongue can be extended to a length sometimes surpassing that of their body. The skin of the Chameleon does not adhere to the muscles everywhere; 
some spaces are left free, into which the air penetrates, causing the skin to expand; this mechanism is voluntary, the animal having the power of inflating or relaxing it at pleasure. Chameleons exhibit great variation in their colours; that is to say, they may be almost white, sometimes yellowish, at other times green, reddish, and even black, either in portions, or all over their bodies. These changes of colour were for a long time attributed to the greater or less distension of the vast lungs they possess, and to the corresponding modifications

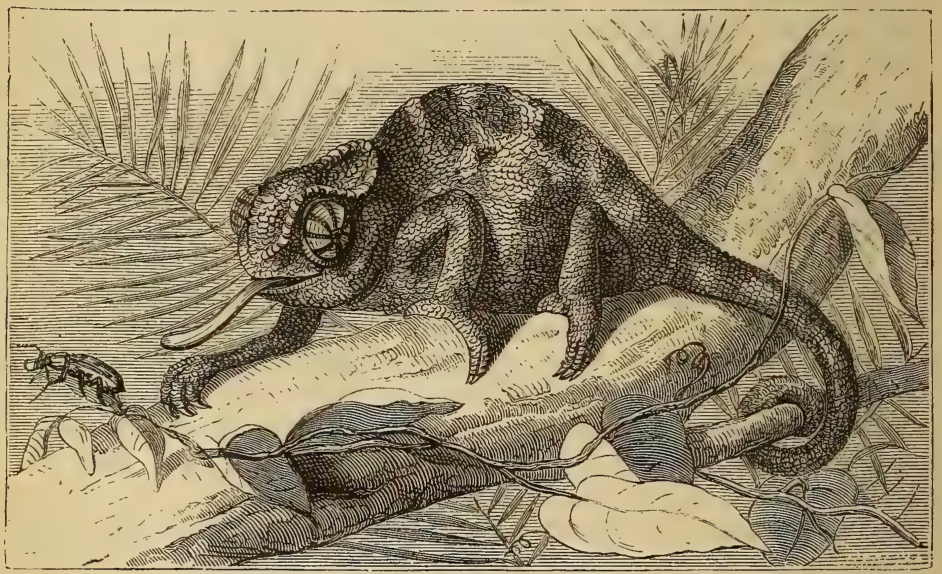

Fig. 3r.-Common Chameleon.

in the quantity of blood sent to the skin ; but this explanation is now abandoned. According to M. Milne-Edwards, the cause of these variations of colour lie in the peculiar structure of their skin, in which there exists two layers of membranous pigment, placed the one above the other, but disposed in such a manner as to appear simultaneously under the cuticle, or at other times to contract so that the one hides the other. Again, occasionally the cuticle is hidden under the superficial pigment.

[Sixteen or seventeen species of Chameleon are described in the British Museum Catalogue.

I.-Having an erect fin on the back, the belly crested; which includes the Fringed Chameleon, $C$. cristatus, a native of Fernando Po. 
II.-Having the back high, and compressed belly and sides, with a toothed crest; including the Side-crested Chameleon, C. laterales, a native of Madagascar.

III.- The back and belly having a toothed crest, the sides simple, the scales small and equal, muzzle simple; including the Common Chameleon, C. vulgaris (Fig. $3 \mathrm{I}$ ), with many synonyms. It is a native of the East Indies, is the recognised type of the family, and the one most commonly brought to England. There are probably two varieties-one from North Africa, which is also found in Sicily and the south of Spain; the other, the East Indian variety, $\boldsymbol{C}$. senegalensis, the Senegal Chameleon, a native of West Africa; $C$. arpelis, from Ashantee and Gaboon; $C$. verrucosus, a native of Bourbon and Madagascar; the Rhinoceros Chameleon, C. rhinoceroceratus, also from Madagascar.

IV.-Having a toothed crest on the back, with the belly and sides simple, the chin and muzzle simple; including C. tuberculiferus, a native of South Africa; $C$. cucullatus, the Hooded Chameleon, a native of Madagascar; C. nasutus, having the chin simple, and the muzzle compressed, and $C$. bifurcus, having the muzzle in the male forked-both natives of Madagascar; C. Tigris, Seychelle Islands; C. ventralis, from South Africa, and C. pumilus, from the Cape of Good Hope.

V.-Having back and belly without crest ; including C. Parsonii, a native of Madagascar; and $C$. Owenii, the Three-horned Chameleon, from Fernando $\mathrm{Po}$, and C. Brookesianus, an adult species, from S. W. Brookes' collection.

\section{EMYdosaurians}

have the head large, covered with a thick skin, ears closed with two valves, gape very wide, tongue short, jaws with a single series of cone-shaped teeth inserted in sockets; back with a hard disc formed of a longitudinal series of square keeled plates of hard bony consistence embedded in the skin; the under surface covered with smooth thin square plates ; legs short, feet webbed, with four to five toes, the three inner toes of each foot only armed with claws.

They are divided into two groups :-

I.-Crocodilida, having the lower canines fitting into a notch in the edge of the upper jaw.

II.-Alligatorida, having the canines fitting into a pit in the upper jaw.] 


\section{Crocodiles.}

The Shielded Saurians, as Duméril designates the largest of living species of that order of Reptiles, have the body depressed, elongated, and protected on the back with a solid carinated shield or buckler; the tail longer than the trunk, compressed laterally, annulated and crested above; possess very short legs ; the toes of the posterior feet united, or web-footed, each foot having three claws only; head depressed and elongated into a muzzle; the gape of the mouth extending back beyond the skull; tongue fleshy, adherent; teeth conical, simple, hollowed at the base or towards the root, unequal in length, and in a single row. Such is a brief summary of the family, by Duméril and Bibron.

If the eagle is the king of the air, the lion the despot of the forest, and the whale the monarch of the deep, the crocodile has for the exercise of his undisputed control the shores of tropical seas and rivers. Living on the confines of land and water, this formidable reptile is the scourge of those human beings who are compelled to reside near its haunts, for it surpasses the tiger, lion, or eagle, in its power of destruction.

Crocodiles have the head depressed and elongated into a muzzle, in the front of which the nostrils are seen close to a fleshy tubercle, and furnished with movable valves. The mouth opens up to the ears; the jaws are of commensurate length, and are armed, as we have seen, with conical-pointed teeth, bent back, and disposed in such a manner that when the mouth is closed they pass one under the other. These teeth are implanted in a single row, and continually maintained perfect by an organic system which ensures their immediate reparation; for, each tooth is hollowed at the base in such a manner as to form the cell or sheath for its successor. The new tooth, presses on underneath the old one, so that the first is developing while the second is decaying. In some species the front teeth of the lower jaw are so long and sharp that they perforate the edge of the upper jaw and appear above the muzzle when the mouth is closed. Baron Cuvier says, "The lower jaw being continued behind the cranium, the upper one appears to be movable." The mouth is without lips, consequently, whether walking or swimming, their teeth are visible.

This conformation gives to the Crocodile a terrible and alarming aspect, increased by its eyes, which are placed obliquely and close together. Its tail is long, tapering, and flat on the sides like an oar; enabling it to direct its course through the water, and swim with 
rapidity. The skin is coriaceous, thick, and resistant ; being covered with plates of different size, according to the parts of the body they protect. On the skull and face the skin adheres to the bone, and there is no trace of scales.

The scales which defend the back and the upper part of the tail are square, and form hard transversal bands possessed of great flexibility, which prevent them from breaking. Down the centre of the back there is a ridge, which adds to the strength of their armour. Thus, Nature has provided for the safety of these animals by covering them with a cuirass capable of resisting anything but fire-arms. The plates which cover the belly, neck, tail, and legs, are also arranged in transversal bands, but are less hard, and not crested. Along the back, the colour of the Crocodile is brown interspersed with black, over which there is a greenish shade, becoming more decided on the head and flanks; the under part of the legs and belly are of a yellowish grey. These shades, however, vary with age and sex, and the nature of the water in which the animals live.

Crocodiles are oviparous. The females of the Nile deposit their eggs where the solar heat soon brings them to maturity. But in certain countries, such as in the neighbourhood of Cayenne and Surinam, the eggs are buried under a mound of leaves and vegetable débris, which the Alligators form. This undergoes a kind of fermentation, the result of which is an increase of temperature, which produces the desired result.

Lacépède describes an egg in the Museum of Natural History in Paris, which was laid by a Crocodile fourteen feet in length, killed in Upper Egypt. This egg is only two inches and five lines in length, and one inch and eleven lines in breadth. It is oval and whitish. Its shell is cretaceous in substance, like the eggs of birds, but not so hard. At the time of birth Crocodiles are only about six inches in length, but their growth is very rapid. They abound in large rivers and in marshes. Being amphibious they often come on shore to watch for their prey. They feed on fish, mammalia, aquatic birds, and reptiles. When they have seized a large object they drag it under the water, where they leave it to macerate before feeding upon it. If a man is carried away by a Crocodile it does not attempt to devour him until the body becomes decomposed.

From the general structure of their framework it is difficult for Crocodiles or Alligators to turn round or move otherwise than forward; thus they can be avoided by the pursued running in a circle or succession of curves. An Englishman was once pursued by an alligator upon the banks of Lake Nicaragua. The animal was gaining 
upon him rapidly, when some Spaniards who witnessed the scene cried out to him to double to and fro. Thus warned he escaped his enemy (Plate II.)

[No specimens of the Crocoditide have been found in Europe, and until very recently none had been found in Australia; but lately they are discovered to be common in the new colony of Queensland; one shot on the banks of the Mackenzie river, which was afterwards exhibited at Rockhampton, was twenty feet long. Crocodiles are found in Africa, Asia, and the West Indies. The Gavials seem to be limited to the Ganges and other large rivers in India. Three other species, namely, $C$. vulgaris, $C$. galeatus, and $C$. bifurcatus; of the first, Siam is its habitat; the others are found in the rivers which debouch into tine Indian Ocean and the Ganges.

The true Crocodiles are indigenous to Africa and India. Their length of head is almost double its breadth. The fourth tooth of the lower jaw is the longest and largest of all, and passes into an indentation hollowed out in the edge of the upper jaw, becoming visible on the outside. The hind feet have on their external edge a dentated crest, and the interstices of their toes externally are palmated.

The principal type is the Common Crocodile (C. vulgaris), which sometimes attains the length of nine or ten feet. The upper part of the body of these Reptiles is of an olive green colour spotted with black, and marbled upon the head, neck, back, and tail, with the same colour; two or three broad oblique black bands are visible upon the flanks of the under part of the body, which is of a yellowish green. Formerly Crocodiles were found in all parts of the Nile, but lately it is said that they are no longer to be met with until the Thebaid and Upper Nile is reached, where they exist in great numbers. They are also found in the rivers Senegal and Niger, also in streams in Caffraria and Madagascar. They also exist in India.

The Crocodile was considered a sacred animal by the ancient Egyptians. In ruins of temples mummies of crocodiles are still found in a perfect state of preservation. The Romans introduced living crocodiles at the national games in the Colosseum. At first only five were imported, under the ædileship of Scaurus. Under the Emperor Augustus thirty-six were killed in the circus of Flaminius. Several ancient medals represent this reptile, the body of which perfectly resembles those now found in the Nile. There is a truly wonderful fact in the natural history of the crocodile. Listen to what Herodotus, the father of history, tells us with regard 


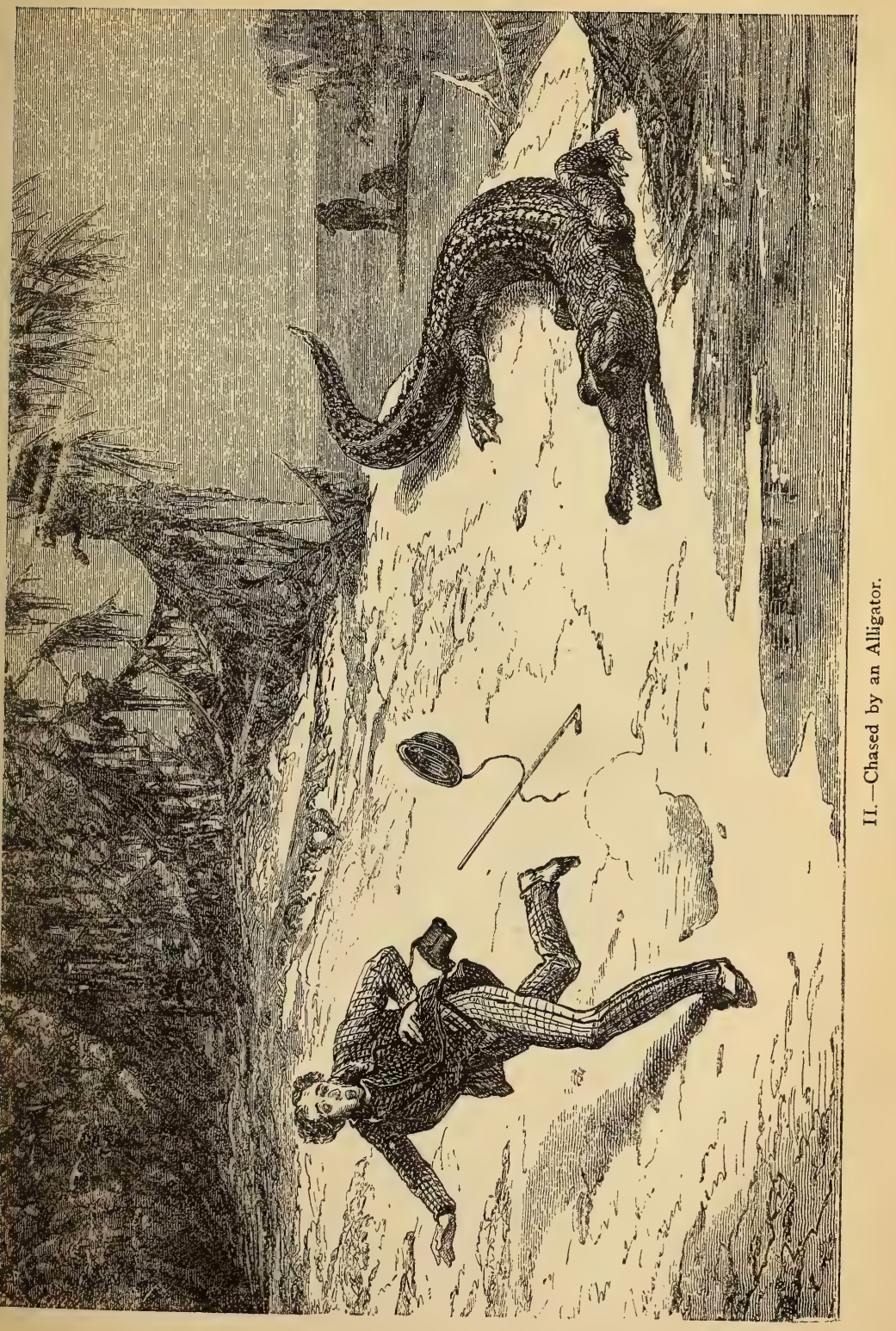



to it:- "When the crocodile takes his food in the Nile, the interior of its mouth is always covered with bdella (flies). All birds, with one single exception, flee from the crocodile; but this one, the Nile Bird, far from avoiding it, flies towards the reptile with the greatest eagerness, and renders it a very essential service. Every time the crocodile goes on shore to sleep, and at the moment when it lies extended with open jaws, the Nile Bird enters the mouth of the terrible animal and delivers it from the bdella which it finds there; the crocodile shows its recognition of the service, by never harming the bird."

This fact, reported by Herodotus, was long considered to be a fable, but the naturalist, Etienne Geoffroy Saint-Hilaire, who formed part of the commission that General Bonaparte took with him in his expedition into Egypt, had on several occasions opportunities of proving the truth of the historian's narrative.

In a memoir read to the Academy of Sciences on the 28 th of January, 1828 , he says : "It is perfectly true that there exists a little bird which flies about, perpetually seeking, even in the mouth of the crocodile, the insects which form the principal part of its nourishment." This bird, which Geoffroy Saint-Hilaire recognised as the Charadrius agyptius of ornithologists, is like a Plover. The fly, which thus torments the Crocodiles, and even excites them to madness, is no other than our European gnat. Myriads of these insects haunt the banks of the Nile, and when these giants of its waters repose on its margin to warm themselves in the sun, they become the prey of these insignificant pigmies. It is like the war between the lion and the mouse, described by La Fontaine. Crocodiles are more voracious than Alligators. Hasselquist asserts that in Upper Egypt they often devour women who come to draw water, or children playing upon the banks of the Nile. Geoffroy Saint-Hilaire says, that in the Thebaid they often met with Arabs mutilated by the crocodiles. Sir Samuel Baker also mentions, in his late work on "The Nile and its Tributaries," the craving of these Amphibia for human flesh, and the dread they are held in by the natives. Livingstone gives the following account of these ferocious animals :-

"The crocodile," says the celebrated traveller, "makes many victims every year among the children who are so imprudent as to play on the banks of the Liambia when their mothers go to fetch water. The crocodile stupefies its victim with a blow from its tail, then drags it into the river, where it is soon drowned. In general, when the crocodile perceives a man it dives, and furtively glides 
away from the side which he occupies. Sometimes, on the other hand, it precipitates itself with surprising agility towards the person it has discovered, which may be noticed from the disturbance caused on the surface of the water. An antelope which is being hunted and takes to the water, in the lagunes of the Barotsé valley, a man or a dog who goes there to seek for game, will scarcely fail to be seized by a crocodile, of whose presence he has not the slightest suspicion. It often happens that, after having danced in the moonlight, the young natives of the river's bank will plunge into the water in order to refresh themselves, when, being seized by an alligator, they perish."

[This mode of attack (striking with the tail) is also one of the methods adopted by the Alligator of America for disabling its prey. A friend, on whose veracity I have much dependence, while shooting wild fowl on one of the tributaries of the Lower Mississippi, had the fortune to witness a fight between a bear and an alligator. $\mathrm{He}$ was called to the scene of the struggle by the noise made by the combatants in the dry cane, that yielded to their pressure as they fought in each other's embrace. Several times both ceased, only to recover breath and fresh energy; at length the alligator missed striking the foe with its tail, Bruin seized the opportunity, and with all his efforts succeeded in turning the amphibian on its back, where he held him for some minutes, at the same time gnawing one of its fore-shoulders. A final struggle of the now-worsted alligator hurled both into the water, where they disappeared, the disturbed surface telling of the dreadful contest that was being prolonged beneath; after the lapse of over a minute the bear came up, evidently much fatigued, and swam ashore, my friend forbearing to wound, or possibly kill, the gallant conqueror.]

Crocodiles, it is said, which have never eaten human flesh, are much less dangerous than those that have acquired a taste for it. Mr. Combes states that he was assured by an inhabitant of Khartoum, who had reached the town with the Egyptian troopsthat is to say, before the horrors committed by the Desterdar, acting with Mehemet Bey, who had been Governor of the Soudan some time before Mr. Combes' voyage - that the Crocodiles appeared to be quite indifferent to human flesh; but after the many executions by drowning ordered by Mehemet Bey, as he was told by a native whom he interrogated- "since the Nile has been loaded with the carcases of my brethren, the monsters which inhabit it have become habituated to substantial food, which they scarcely knew 
before, so that afterwards those swimming in the river, or even bathing on its banks, were exposed to imminent danger."

Natives of Africa shoot the Crocodile, or attack it with a barbed javelin, which is thrown by hand, and aimed at the fore-shoulder. Some Egyptians are reported to be daring enough to swim under the Crocodile, and pierce him in the belly with a dagger. The negroes of Senegal are said to be equally expert. If they surprise the animals in parts of the river where there is not sufficient water for them to swim, they attack the monster with a lance, commencing the assault by aiming with their weapon at their enemy's eyes and throat; then they thrust their arm, encased in leather, into its mouth, hold it open till their enemy is either suffocated or expires under its wounds. Traps are also employed successfully for their destruction. In Egypt the natives dig a deep hole in the ordinary route of the Crocodile, which is easily discovered by the trail they leave in the sand-this is covered with branches and earth, which falls in when trodden upon; the captive is then killed, often with the most brutal cruelty. At other times a thick cord is attached to a tree, at the other end of which a lamb is held by a hook. The cries of the lamb attract the Crocodile, which, in its attempt to carry off the bait, is taken.

Still another method for the destruction of these repulsive-looking creatures has been adopted by Englishmen in India. A dead animal is procured, in its abdomen is placed a loaded shell, to which is attached a wire made fast to an electric battery; when the bait has been seized and carried to the bottom, the shell is exploded, and invariably maims or kills the crocodile.

The Gavials have long narrow cylindrical muzzles, slightly inflated at the extremity; the teeth are almost the same, both in number and shape, on each jaw, the two first and the fourth of the lower jaw pass into notches or indentations in the upper jaw; the hind legs are dentated and palmated. The Gavials are chiefly remarkable for their long head, its type being the Gavial of the Ganges. It is of a deep watery green colour, having on the upper part numerous irregular brown spots; in the young, the back and limbs are transversely banded with black; the lower part is of a pale whitish yellow; the jaws are marked with brown, the claws are of a clear horn colour. This species is not so carnivorous as the others, and is consequently less dreaded.

The Gavial of the Ganges (G. gangeticus) is supposed to be the largest of the existing Saurians; its length, as given by Duméril, is seventeen feet four inches.*

This length is frequently exceeded. 


\section{The Alligatoride}

Include the Jacares, Alligators, and Caimans.

The Jacares have the head oblong and depressed, with a ridge across the face in front of the eyes; teeth unequal, canines of the lower jaw fitting into a pit in the upper jaw; toes only partially webbed, eyelids fleshy, nostrils separated by a cartilage. Five species are described-namely, $J$. fissipes, from tropical America, six feet in length; $J$. sclerops, from the Brazils ; $J$. nigra, also from the Brazils; $J$. punctulatus, with triangular oblong head, muzzle elongated, thin and flat, with a rounded point in front, and a slight enlargement behind the nostrils ; $J$. vallefrons, differing slightly from the above-both natives of the Brazils.

Alligators have the jaws oblong, much depressed, broad and nearly parallel; forehead with a small longitudinal ridge between the orbits; feet fringed, toes half webbed, the outer toes free; nostrils separated by a bony septum rising from the upper edge, muzzle lengthening with age. The species best known is Alligator mississipensis, which is a native of North America; its average length is six to seven feet, although Bartram informs us that in Florida it has been found twenty-three feet long. A. palpebrosus, $A$. sclerops, $A$. punctulatus, and $A$. cynocephalus are natives of South America; and $A$. lucius is found in the southern portion of North America.

The Caimans have the jaws oblong, depressed, rounded, and swollen at the end, without frontal ridges or maxillary pits; teeth unequal, the lower canines fitting into pits in the upper jaw; toes webbed. There are several species described-C. trigonatus, $C$. palpebrosus, and C. goddeceps, all natives of tropical America.

C. acutus is also found in Martinique and San Domingo; $C$. rhombifor, in Cuba.

The principal characteristics of the Alligatoridæ are a head onethird the length, a very short muzzle; teeth unequal in shape and size, the fourth lower tooth buried into the upper jaw when the mouth is closed; the first teeth of the lower jaw piercing the upper at a certain age, so as to appear through the muzzle when closed; the hinder legs and feet rounded, having neither crest nor indentation on their edges ; the intervals of the toes more than half covered with a short membrane, forming semi-palmated feet.

It is generally admitted, as we have stated above, that there are six species of this genera, all American, the type of which 
is the Alligator (A. mississipensis, Fig. 32), belonging to North America, through the whole southern extent of which it is found. They are gregarious, living together in large herds in the Mississippi and its southern tributaries; they are also found in the lakes and marshes of Louisiana, Florida, Georgia, Carolina, and even as far north as thirty degrees of north latitude. Alligators do not appear to leave fresh water. During winter they hibernate in the mud on the margins of their haunts. In the neighbourhood of Bayou Zara, on the Mississippi, vast flats of lakes and marshes stretch away on either bank; every year these reservoirs are flooded by the overflow of the river, when they are visited by myriads of fishes. The heat soon partly dries up these lagoons, leaving only about a few feet deep of water in them, thus exposing a vast amount of prey to the birds and crocodiles. Millions of ibis, herons, cranes, and cormorants come here to feed. In the deepest portions vast quantities of these imprisoned fish accumulate, and these are known in the country as the alligators' holes. Thither these reptiles crowd, and, as evaporation proceeds, soon exterminate all the captives. Alligators principally feed during the night, when they are said to assemble in large herds, driving the fish before them into estuaries, when they force the unfortunates into their mouths by a lateral movement of their tails. On such occasions the clashing of their jaws may be heard at a great distance. Alligators are very numerous in Mexican and Central American waters. In the beautiful transparent waters of I ake Claro they abound, where they are so closely pressed one against the other that they resemble a raft of logs, the resemblance being further increased by the colour of their backs being identical with the bark of a newly-felled tree. In this united and motionless condition, while waiting for their prey, the approach of a boat is disregarded; but they rush with avidity at everything animate which either falls or is thrown into the lake. Many children of poor negro women become a prey to the alligators of this locality. They rarely, however, pursue men, yet they would not hesitate to do so if imprudently thrown within their power.

The natives of Mexico, when they find an isolated alligator asleep, throw a lasso round its body, and, when secured, gag it. After this, the victim's career is terminated by repeated blows on the head. There is another means which the Indians use to capture this animal. They provide themselves with four pieces of hard wood about a foot long, and as thick as a man's finger, and pointed at each end ; round these they tie a cord in such a manner that, supposing the cord to be an arrow, the four sticks would form the 
head of it. Round this is fastened some meat, the end of the cord being secured to a tree. This device is thrown into the water. When the caiman snaps at the prey the points of the sticks, on straining the line, penetrate into its flesh. Having waited till the

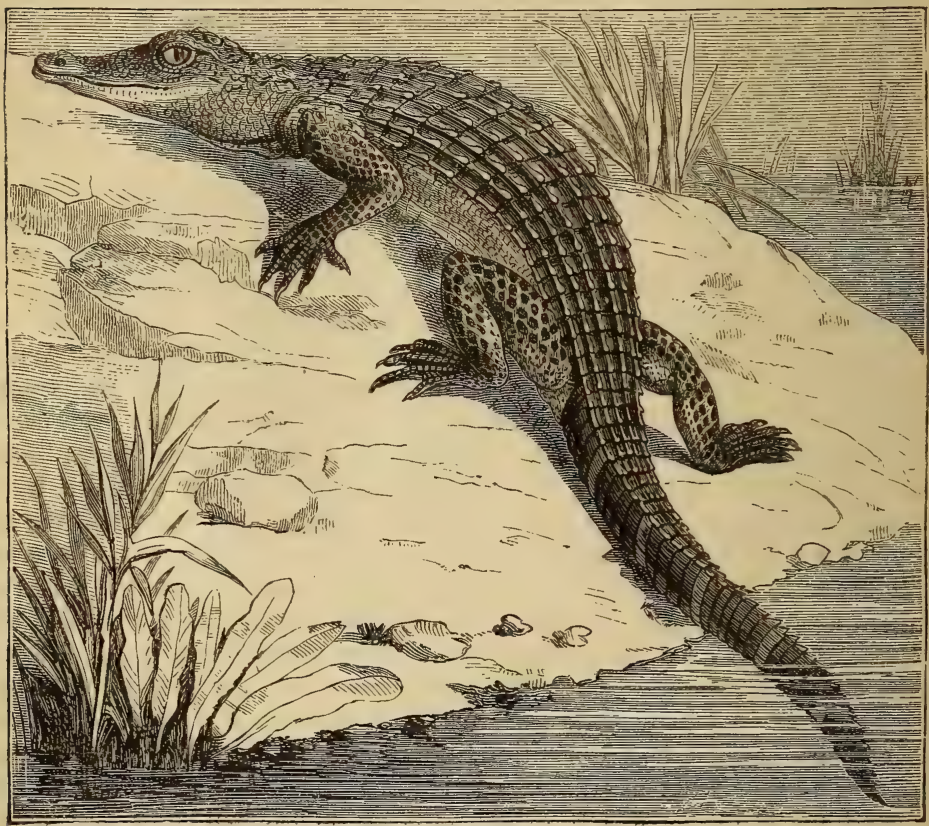

Fig. 32.-Alligator.

captive is dead, it is drawn from the water, when the captors gratify their dislike and spirit of revenge by crushing in its skull.

Another method of capturing Alligators is practised by the residents on the upper waters of the giant river Orinoco. A tree is bent (generally a bamboo is selected, from its elasticity) till the top is brought down to the butt, a bait is then placed on a sharp hook, the line attached to it being fastened securely to the small end of the bent tree, which is caused to relax its position by an ingenious piece 
of mechanism which gives way the moment the least strain is felt upon the line; the tree-point becoming thus released, straightens itself with great velocity, and drags the victim from the water.

Frequently the alligator, from constant pursuit and interruption, becomes excessively wary and difficult to destroy; when such is the case, a live bait is sometimes successfully employed. For instance, a dog with a hook tied to his back is taken in a canoe and dropped in the water ; it is seldom the unfortunate cur is permitted to swim far before being seized.

It is currently believed that Alligators prefer dogs' flesh to all others. The negroes on the plantations in the south-western portion of the United. States, frequently lure these reptiles from their hiding-places by imitating the barking of a dog, when a welldirected bullet terminates their career.

Alligators are very voracious, but, like Serpents and Turtles, they can live a long time without nourishment. In Brown's "Natural History of Jamaica," he asserts that he has known the Caiman to live several months without food. The following experiments have been made in that island: After muzzling a Caiman, it was thrown into a reservoir of water, where it lived several weeks before death supervened. Let us further add that Alligators bred in captivity in the menagerie of Natural History at Paris sometimes live for several months without eating.

The female Alligator takes more care of her young than the female Crocodile properly so called. She conducts them to the water, and disgorges her half-digested food for their nourishment. 


\section{CHAPTER IV.}

\section{CHELONIANS, OR SHIELDED REPTILES.}

["THE body," as described by Dr. Gray, "is covered with square embedded plates, generally forming a dorsal and ventral shield united by their margins, leaving only the head, neck, limbs, and tail free, and (in some species, as the Box Tortoises, Cinasternon, shut up by movable closely-fitting doors) only covered with a scaly skin; the upper shield formed of the ribs united together and adherent to the dorsal vertebræ by a toothed suture, and surrounded by a series of bones forming the edge of the shields; the lower shield or sternum, formed of four pairs and a central anterior, bone; the jaws toothless, covered with a horny bill, rarely hid by fleshy lips; eyelids distinct; drum of the ear visible; legs short and thick; tail conical." "The natural dwelling chamber of the Chelonia consists chiefly," says Professor Owen, "and in the marine species (Chelone) and Mud Turtles (Trionyx) solely, of the floor and the roof; side walls of variable extent are added to the fresh-water species (Emydians) and Land Tortoises (Testudinians). The whole consists of 'osseous plates,' with superincumbent horny plates, or 'scutes,' except in the Soft or Mud Turtles (Trionyx and Sphargis), in both of which these are wanting.*

These animals, to which a portable stronghold is thus given in compensation for inferior powers of locomotion and defence, are recognisable at a glance from the singular armour with which Nature has provided them. A double shield envelopes all parts of their bodies, only permitting the head, neck, legs, and tail to pass through it; moreover, all these organs can be hidden within this double cuirass by means of a retractile power possessed by the animal. This double armour consists of a carapace, or back-piece, and plastron, or breast-plate, composed of a series of small bones or plates closely united together; the first resulting from the union of the sides and dorsal vertebræ the plastron or lower buckler, 
being only a high-developed sternum. These organs are merely portions of the skeleton, which, in place of being lodged in the depths of the soft parts; has become the superfices, which is only covered by a thin dry skin.

This numerous and highly-interesting order of Reptiles, called Chelonia (from $\chi \in \lambda \omega \omega \eta$, a tortoise), are also called Testudinata, from testudo, the Latin name for a tortoise, from the double shield in which the bodies of all, whether terrestrial, fresh-water, or marine, are enclosed.

The skeleton of the Tortoise is perhaps the most extraordinary structure with which we are acquainted. This oddly-organised animal when first seen strikes the beholder with astonishment. The carapace and plastron, with their connecting plates, form a sort of protecting box, in which the animal lives, its head and tail excepted. In the Land Turtles the head and feet, which are comparatively feelingless, can be withdrawn within the protecting armour. The ribs and sternum are both placed quite on the exterior of the body, so as to form a broad dorsal shield on the upper surface, and an equally strong ventral plate; between these, the limbs and the head can be more or less completely retracted. Nevertheless, the modifications in the arrangements of the elements by which these changes are accomplished are of the simplest nature. In the Common Tortoise, the vertebræ of the neck and tail being connected together in the ordinary manner, the neck and caudal region of the spine present their usual flexibility, but the dorsal vertebræ are strangely distorted, the upper arch being disproportionately developed, while the bodies remain almost in a rudimentary state; the spinous processes of these vertebræ are flattened and converted into broad osseous plates, which form a longitudinal series along the centre of the back, and connected together by means of sutures. The ribs are changed into broad flat bones firmly united to each other by sutures, and also to the lateral margins of the spinous processes of the vertebræ, so that they form together a single broad plate; the heads of the ribs are feebly developed, and the intervals between them and the portions of the vertebræ filled up with ligament. The margin of the shield thus formed by the dorsal ribs is further enlarged by a third set of flat bones fixed by sutures around the whole circumference of the carapace.

The plastron or ventral plate is made up of nine pieces, of which eight are arranged in pairs; but the ninth, which is always placed between the four pieces composing the two anterior pairs, is single, and occupies the mesial line. The bones of the shoulder and hip 
are placed within the thorax, and articulated to the sides of the vertebral column.

Of the vertebral column in these extraordinary animals, Professor Owen remarks that the manifold modifications of the framework which render it a portable abode, appear to have been given as a compensation for inferior powers of locomotion, and the absence of offensive weapons. But with all its modifications, the same number of pieces are found in the bony skeleton as in other ordinary vertebratæ, the form and volume of many of these pieces being alone changed.

The skin which covers the body of these animals sometimes preserves its softness, being altogether devoid of scales; but in nearly all the species it is covered with horny scales of great consistency. Upon the plastron and carapace these scales form large plates, the arrangements and appearances of which vary in different species, some of them being often remarkably beautiful. The material which bears the name of tortoise-shell forms an important article of commerce.

Aristotle mentions three groups of Tortoises-namely, Land Tortoises, Sea Tortoises, and Fresh-water Tortoises. Cuvier divides them into five sub-genera:-I, Land Tortoises, Testudo; 2, Freshwater Tortoises, Emyds; 3, Marine Tortoises, Chelque; 4, Chelydes, Testudo fimbriata; 5, Soft Tortoises, Trionyx - in which he is followed by Dr. Gray in the British Museum Catalogue, who makes them the third order of Reptiles in his arrangement, as follows :-

\section{TESTUdINII) E.}

Testudo, Chersina, Kinixys, Pyxis.

\section{EMYDID必.}

Geoemyda, Emys, Cyclemys, Malaclemys, Cistudo, Kinosternon, Chelydra, Platysternum.

\section{Chelydide.}

Sternotherus, Pelomedusa, Hydraspis, Chelymys, Phrynops, Chelodina, Hydromedusa, Chelys, Peltocephalus, Padocnemis.

IV. TRIONYCIDE.

Trionyx, Emyda.

V. Cheloniade. Sphargis, Chelonia, Caretta, Casuana. 
In the valuable "Erpétologie" of Messrs. Duméril and Bibron, the Chelonians are divided into-I. Land Tortoises, Chersites. 2. Marsh Tortoises, Elodites. 3. River Tortoises, Potamites. 4. Sea Tortoises, or Turtles, Thalassites.

This arrangement being the most simple, is adopted as being best adapted to our purpose.]

\section{LAND TORTOISES.}

Terrestrial Tortoises are distinguished by their short, oval, and convex bodies, covered by carapace and plastron; four feet, and the absence of teeth ; short, stumpy, unshapely legs ; nearly equal toes, armed with claws, united by a thick skin, so as to form a clumsy foot, the periphery of which forms a sort of hoof, which seems adapted for the land.

In this group the carapace is very convex, its height sometimes exceeding its breadth; it forms a solid generally an immovable arch, under which the animal can completely conceal its feet and tail. This buckler is covered with large horny plates.

Land Tortoises have been known from the earliest time, representations of them being found on numerous monuments of antiquity. Moreover, ancient writers tell us that the carapace of the tortoise contributed its substance to the formation of the first lyre ; it was consequently sacred to Mercury as the deity of music and inventor of that instrument.

The Land Tortoises are divided into four genera, which Duméril and Bibron again divide into three sub-genera and thirty species. The most interesting species, however, to which we must limit our remarks are-the Marginate Tortoise, Testudo marginata; the Moorish Tortoise, Testudo mauritianica; the Greek Tortoise, Testudo Graca; and the Elephantine Tortoise, Testudo elephantina.

The Marginate Tortoise, which was long confounded with the Greek Tortoise, is found abundantly in Egypt. The carapace is oval in form, oblong, convex, and much dilated at the posterior margin, and nearly horizontal; the plastron is movable behind, which is its chief sub-generic character; the tail is thick, conical, and scarcely issues from the carapace. The plates of the disc are of a blackish-brown, presenting towards the centre certain spots of a beautiful yellow colour; the marginal plates are habitually ornamented with two triangular spots, one yellow, the other black. The under part of the body is of a dirty yellow, with one large triangular black spot upon six or eight of the sternal scales. This Tortoise is of medium size. 
The Moorish Tortoise (Testudo mauritianica, Fig. 33) is com monly found in the neighbourhood of Algiers and along the coast of Morocco, whence they are sent to be sold in the Paris markets.

When shooting in Morocco, scarcely a day would pass without the setters or pointers finding numbers of them, to which they would stand with as much staunchness as game. The scent they emit is so powerful as to be easily detected by a human being. The carapace of this species is also convex; and the sternum

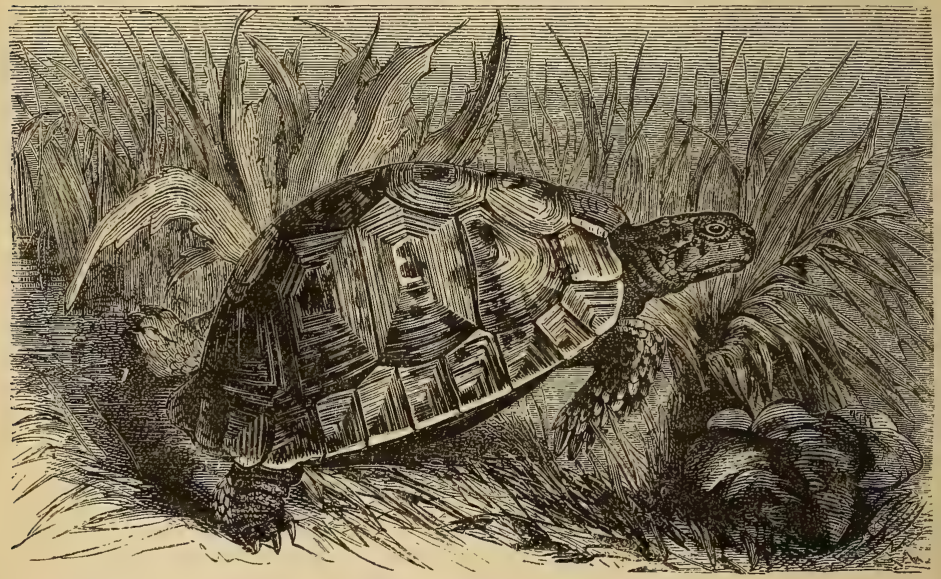

Fig. 33--Moorish Tortoise.

movable: it is generally olive-coloured. The plates of the disc are marked with blackish spots, and sometimes with a buckle of the same colour, which covers their circumference on the front and sides. The plates of the plastron, the ground of which is olive, have each a large black spot in the centre. This species is rather-smaller than the Marginate Tortoise.

The Greek Tortoise (Testudo graca) is of small dimensions, scarcely exceeding twelve inches in length. They inhabit Greece, Italy, and the European shores of the Mediterranean generally. They feed upon herbs, roots, slugs, and lob-worms. Like all their race, they sleep during the winter season in holes which they excavate in the soil. About May they issue from their retreat, 
resorting to some sheltered sandy place, where they bask in the sun's rays. Towards the month of June the females lay from twelve to fourteen white spherical eggs, as large as a small walnut; these are placed in a hole exposed to the sun, and covered over with earth. Thus the operation of hatching is performed. The carapace of this species is oval and very much arched; their marginal plates are twenty-five in number; the plastron, which is almost as long as the carapace, is separated into two great portions by a longitudinal line; the plates of the carapace are spotted with black and greenish yellow, forming a large marbled pattern; the centre of the disc is besides relieved by a small, irregular, blackish, central spot. These three species are held in high estimation on account of their flesh, which is said to make an agreeable soup.

The Elephantine Tortoise (Testudo elephantina), the length of which is more than three feet, inhabits most of the islands situated in the Mozambique Channel. The Museum of Natural History at Paris had a specimen of this Tortoise, which lived more than twelve months after its capture, and weighed about 600 pounds. The flesh of this species is extremely delicate, and much sought after.

In some other Terrestrial Tortoises, from which the genus Pyxis has been formed, the anterior portion of the plastron is movable; and when the head and feet are drawn in, the animal can fasten itself against the sides of the carapace like a door in its case.

In others the carapace is flexible, and can be lowered behind like the plastron ; these are Kinixys. Lastly, we arrive at the Homopodes, which have unguiculated legs.

\section{MARSh TORTOISES.}

Marsh Tortoises (Elodites) occupy a place between Terrestrial Tortoises and those which are essentially aquatic. They have the carapace more or less depressed, oval, and broader behind; their feet have distinct flexible toes supplied with hooked claws, of which the phalanges are united at the base by means of an elastic skin, which enables them to separate one from the other, at the same time preserving their strength and assisting them to grasp a much larger surface. Thus they can walk, swim, or even climb abrupt banks.

These Tortoises are generally small, and are carnivorous. As they exhale a nauseous odour they are not used as human food. Their carapace being neither thick nor handsome, they are consequently little sought after. There are a hundred species of Elodians 
or Marsh Tortoises known, which are spread over all parts of the globe, but principally in warm and temperate regions. Such are the Cistudo, Emydes, and Trionyx.

The Elodians have none of the sluggishness of the Land Tortoises; they swim with facility, and on land they walk with considerable rapidity. Their eggs are white, and nearly spherical, with a calcareous shell, and these are deposited in a hollow dug in the soil or sand, like the Land Tortoises, the place chosen being

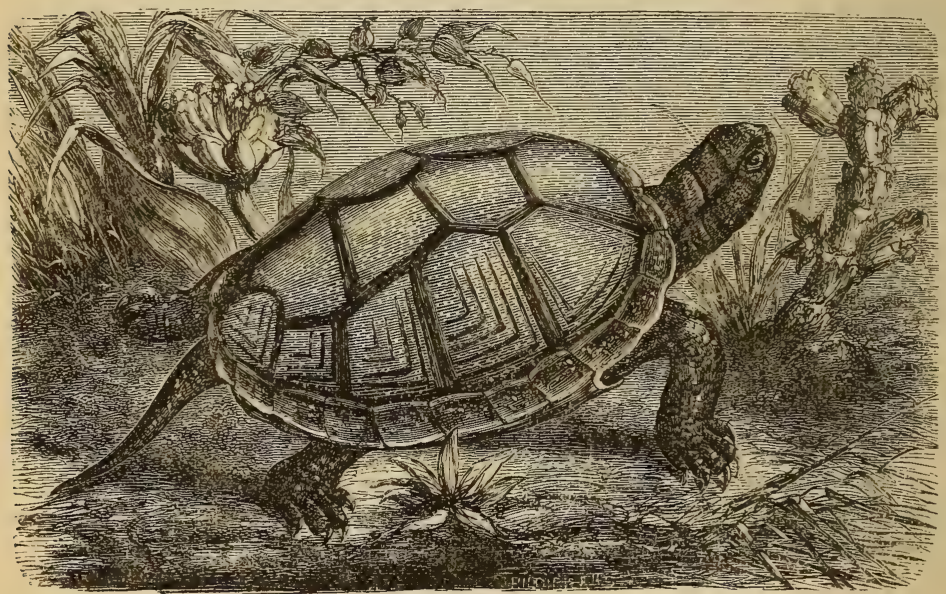

Fig. 34.-Mud Tortoise.

generally situated on the banks of some secluded stream; the number of eggs increasing as the animal approaches maturity.

The Elodians are divided into Cryptoderes and Pleuroderes: the former distinguished from the latter by the retractile power they possess of concealing their cylindrical neck, with its sheath of loose skin, under the middle of the carapace; the head, the width of which is nearly equal to the height at the occiput; the eyes always lateral, and their orbit so large that the diameter of the cavity nearly equals a fourth of the whole cranium ; and the jaws, which are strong, sometimes trenchant, in others are dentated on the edge. In the larger number of species the anterior extremity of the upper 
beak is notched with a strong tooth on each side, producing the appearance of a beak closely resembling that of birds of prey.

The Mud Tortoises (Cistudo europaa, Fig. 34), sometimes called the Yellow Tortoises, are very abundant in Europe. They are found in Greece, Italy, Spain, Portugal, and in the southern provinces of France; also in Hungary, Germany, and as far north as Prussia. They inhabit lakes, marshes, and ponds, at the bottom of which they bury themselves in the mud. They live principally upon insects, molluscs, aquatic worms, and small fishes. Although the flesh of

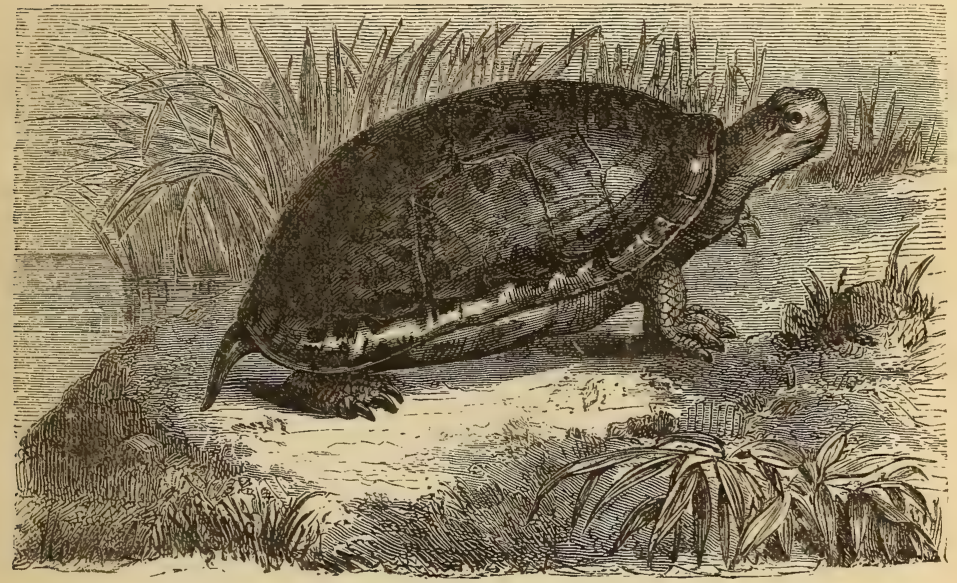

Fig. 35.-Box Tortoise.

the Mud Tortoise is far from being palatable, it is nevertheless eaten in countries where they are common.

The Emydes are divided into four considerable groups-namely, the European group, of which the Box Tortoise (Fig. 35) is typical; the American group, containing twelve or fourteen species, of which the justly celebrated Diamond-backed Terrapin is one; the African, seven species; and Oriental group, about twelve species.

The Pleuroderes have the neck retractile on one side of the carapace, without their having the power of drawing it between their fore feet, and under the buckler and plastron, like the Cryptoderes. The Bearded Tortoise (Chelys 'matamata, Fig. 36), belongs to this 
division. This species lives in stagnant water, and is altogether remarkable for its singular appearance-for its depressed, wide, and triangular nostrils, prolonged into a proboscis ; its wide gape, rounded jaws, and the cutaneous appendages to the chin.

\section{Potamians, or River Tortoises.}

The River Tortoises only rarely come on land; they swim with much ease below and on the surface. The carapace is very broad

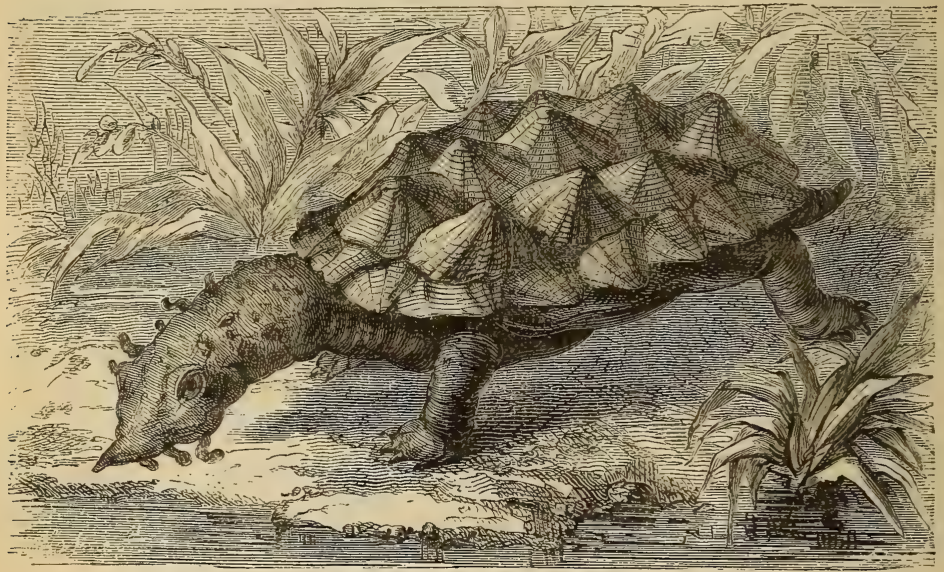

Fig. 36.-Bearded Tortoise.

and flat; the toes are united up to the claws by broad flexible membranes. These membranes change their feet into true paddles. They attain a considerable size, one kept by Pennant for three months weighing twenty pounds, its buckler not reckoned, the neck measuring twenty inches in length. The upper parts of their bodies vary in tint from brown to grey, with irregularly marbled, dotted, or ocellated spots; the under part is a pale white, rosy, or purple tint. Sinuous brown, black, or yellow lines are symmetrically disposed on their right and left sides, but principally on the neck and on the limbs.

During the night the River Tortoises frequently rest on the 
banks and islets, or on floating timber, from which they plunge into the water on the slightest noise. These Tortoises, which accommodate themselves so perfectly to the element they inhabit, being voracious and active, are continually at war with the fishes, reptiles, molluscs, alligators, and other denizens of the rivers they inhabit.

The carapace of the River Tortoise is soft, covered with a flexible cartilaginous skin resting on a greatly-depressed osseous disc; its upper surface is covered with shrivelled sinuosities. As they are destitute of scales these Tortoises are called "soft shelled;" their flesh is much esteemed, and they are angled for with hook and line the bait being small fish, worms, or molluscs. When they seize their victim, or defend themselves, they dart out their head and long neck with great rapidity, biting sharply with their trenchant beak, and holding on till they have bitten out the piece. Persons wading have been known to lose toes from their bite.

M. Lesueur states "that towards the beginning of May the females belonging to this division seek out sunny sandy spots on the river's bank for the deposit of their eggs." "Their eggs are spherical, and more fragile than those of the Marsh Tortoise. They deposit from fifty to sixty at a time." None of this group are found in Europe. The fresh-water lakes and rivers of the warmer regionssuch as the Nile and the Niger, in Africa; the Mississippi, the Ohio, and the Amazon Rivers, in America; the Euphrates and the Ganges, in Asia-are its habitats. Among other remarkable species in the group we here represent Trionyx agyptiacus (Fig. 37), supposed to be the 'E $\mu$ ìs of Aristotle.

No modern naturalist has done more to illustrate the habits of the fresh-water turtle than Mr. Bates, in his highly interesting work, "The Naturalist on the Amazon." "The great freshwater turtle of the Amazon or Orinoco grows," he says, "to an immense size-a fully developed one measuring nearly three feet in length, by two in breadth, and in weight a load for the strongest Indian. Every house (in Ega) has a little pond called a corral or pen in the back-yard, to hold a stock of these animals through the season of dearth-the wet months. Those who have a number of Indians in their employ send them out for weeks, when the waters are low, to collect a stock, and those who have not purchase their supply-this is attended with some difficulty, however, as they are rarely offered for sale. The price of turtles, like that of other articles of food, has risen greatly since the introduction of steam-vessels. 'Thus, when I arrived, in 1850 , a middle-sized tortoise could be bought for ninepence, but when I left, in 1859 , 
they were with difficulty obtained for eight or nine shillings each. Their abundance varies with the amount of diurnal subsidence of the waters. When the river sinks less than the average, they are scarce; but when high waters have prevailed, they are numerous, their haunts being less restricted, and appropriate breeding-places more easily found.

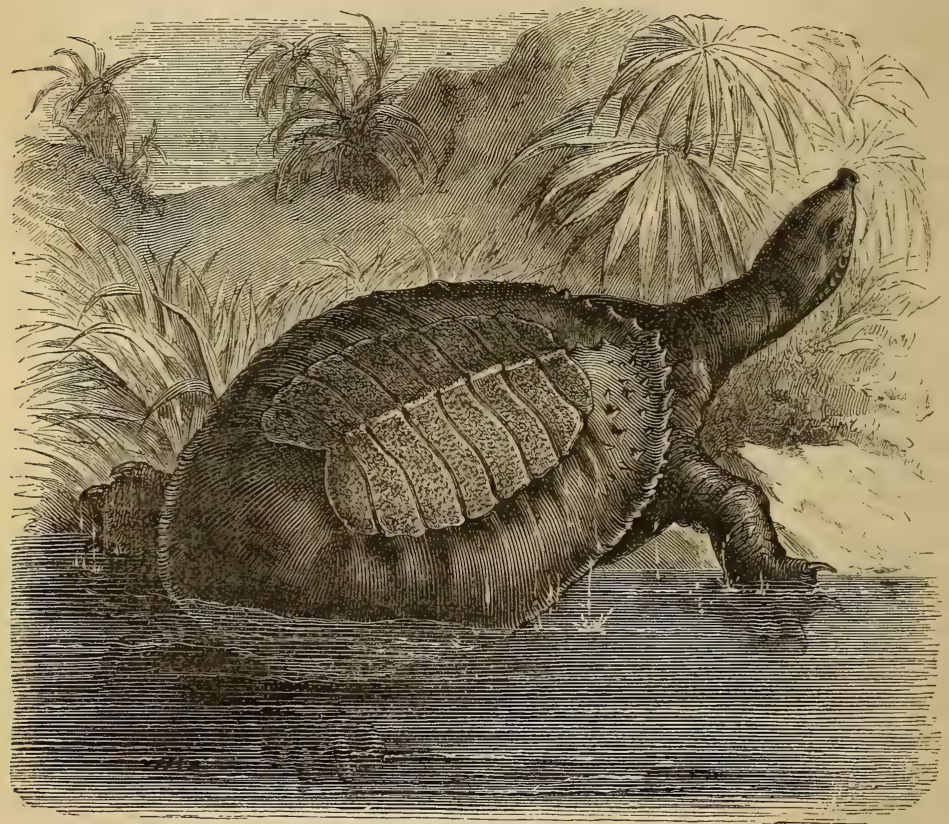

Fig. 37.-Egyptian River Turtle.

"Their flesh is very tender, palatable, and wholesome ; but it is cloying, and every one ends sooner or later by becoming thoroughly surfeited. I became so sick of turtle in the course of two years that I could not bear their smell, although nothing else was to be had; consequently I suffered from actual hunger."

One of the most amusing sketches in Mr. Bates's book is a journey he made on the Solimoens, during which he visited the praias, or 
sand-islands, the turtle-pools in the forest, and the tributaries and lagoons of the great river. His companion was Cardoza, who was a sort of official superintendent of the diggers for turtles' eggs on the sand-banks of Shimuni, the island lying nearest to Ega. There are four or five of these royal praias, as they are called, in the district, each having its commandant, whose business is to see that every inhabitant has an equal chance in the egg-field.

"The pregnant turtles descend from the interior pools of the main river in July and August, before the outlets dry up, and seek their favourite sand-island in countless swarms; for it is only a few praias that are selected by them out of the great number existing. When hatched, the young animals remain in the pools throughout the dry season; for these breeding-places of the turtle then lie from twenty to thirty feet above the level of the river, and are accessible only by cutting a path through the dense forest." On the 26 th of September Mr. Bates left Ega with his companion, who was about to visit the sentinels placed to mark when and where the turtles laid their eggs. Their conveyance was a stoutly-built canoe, or igareté, arranged for two paddlers, with an arched covering in the stern, under which three persons could sleep comfortably. The swift current of the Solimoens carried them rapidly to the large wooded island of Baria, which divides the river into two broad channels. Shimuni lies in the middle of the north-easterly passage. There they were quickly paddled, reaching it an hour before sunset. The island is about three miles long and half a mile broad. The forest which covers it rises to an immense uniform height, presenting all round a compact and impervious front, the uniformity being interrupted by a singular tree, called mulatto wood, the polished dark-green trunk of which is seen conspicuously through the mass of vegetation. The sand-bank lies at the upper end of the island, and extends several miles, presenting an irregular surface of ridges and hollows. At the further shore, to the north-east, where no forest line shuts out the view, the white, rolling, sandy plain stretches away to the horizon; to the south-west a channel, about a mile in breadth, which separates Baria from Shimuni, is situated.

Arrived at this island, Mr. Bates proceeds to describe with great minuteness the operations of the turtles, as well as those of the sentinels placed to watch them.

"We found two sentinels," he says, "lodged in a corner of the praia, where it commences at the foot of the towering forest west of the island, having built themselves a little rancho with poles and palm-!eaves. Great precautions are obliged to be taken to avoid 
disturbing the turtles, which, previous to crawling ashore to lay, assemble in great shoals off the sand-bank. The men during this time take care to warn off any fishermen who attempt to pass near the place; for the passage of a boat, or the sight of a man, or a fire on the sand-bank, would prevent them laying their eggs, and if repeatedly disturbed, they would forsake the praia for some quieter place."

After a night spent under a temporary shed rapidly constructed for himself and companion, Mr. Bates rose from his hammock shivering with cold.

"Cardoza and the men were already watching the turtles on a stage erected on a tall tree fifty feet high; from this watch-tower they are enabled to ascertain the place and date of successive deposits of eggs, and thus guide the commandant in fixing the time for his general invitation to the Ega people. The turtles lay their eggs during the night, leaving the water in vast crowds when all around is quiet, when they crawl to the central and highest part of the praia. The hours between midnight and dawn are those when the turtles excavate, with their broad, webbed paws, deep holes in the fine sand, the animal in each case making a pit about three feet deep; in this pit it lays its eggs, about I20 in number, covering them over with sand; then a second deposit is placed on the top of the first, and so on until the pit is full." This goes on for about fourteen days. "When all have done, the area or taboliero over which they have been digging is only distinguished from the rest of the praia by signs of the sand having been a little disturbed.

"On rising I went to join my friends," he continues, "and few recollections of my Amazonian rambles are more vivid and agreeable than that of my walk over the white sea of sand on this cool morning. The sky was cloudless; the just-risen sun was hid behind the dense woods on Shimuni, but the long line of forest to the west on Baria, with its plumy decorations of palms, was lighted up with his yellow horizontal rays. A faint chorus of singing-birds reached the ears from across the water, and flocks of gulls and plovers were calling plaintively over the swelling banks of the praia. Tracks of stray turtles were visible on the smooth white surface, two of which had been caught, for stragglers from the main body are a lawful prize.

"On arriving at the edge of the forest I mounted the sentinels' stage just in time to see the turtles retreating to the water on the opposite side of the sand-bank. The sight was well worth the trouble of ascending. They were about a mile off, but the surface of the sand was blackened with the multitudes which were waddling 
towards the river; the margin of the praia was rather steep, and many seemed to tumble head first down the declivity into the water."

On the 2nd of October the same party left Ega on a second excursion, the object of Cardoza being to search certain pools for young turtles. The exact situation of these hidden sheets of water are known to few. The morning was cloudy and cool, and a fresh wind blew down the river ; consequently they had to struggle against wind and current. The boat was tossed about, and shipped a good deal of water. Their destination was a point of land twenty miles below Shimuni. The coast-line was nearly straight for many miles, and the bank averaged about thirty feet above the level of the river; at the top rose an unbroken forest. No one could have divined that pools of water existed on that elevated land.

The party cut a path through the timber to the pool, half a mile distant, with their hunting-knives, short poles being laid across the path, over which three light canoes were rolled. A large net, seventy yards in length, was then disembarked. Netting, however, the older Indians considered unsportsmanlike ; and, on reaching the pool, they commenced shooting the turtles with bows and arrows from light stages erected on the shores.

"The pool covered an area of about four acres, and was closely hemmed in by the forest, which, in picturesque variety and grouping, exceeded anything I had seen. The margins for some distance were swampy, and covered with large tufts of fine grass called matupá. These tufts were in many places overrun with ferns, and beyond them was a crowded row of arborescent shrubs growing to a height of fifteen or twenty feet, which formed a green palisade. Around the whole stood the taller forest trees-palmate-leaved Cecropice; slender Assai palms, thirty feet high, with their thin feathery heads crowning their gently curving, smooth stems; and, as a background to these airy forms, lay the voluminous masses of ordinary forest trees, with garlands, festoons, and streamers of leafy parasites hanging from their branches."

The pool which was hemmed in by this gorgeous scenery was nowhere more than five feet deep, and of that one foot was a fine soft mud. Cardoza and the author spent an hour paddling about admiring the skill displayed by the Indians in shooting the turtles. They did not wait for the animals to come to the surface to breathe, but watched for the slightest movements in the water which revealed their presence underneath; that instant an arrow flew from the bow of the nearest man, which never failed to pierce the shell of the 
submerged animal, and by midday about a score of full-grown turtles had been shot. The net was now spread at one extremity of the oval-shaped pool, its side resting on the bottom, while the floats buoyed the other side up on the surface, the cords being held by two Indians. The rest of the party now spread themselves round the pool, beating the water with long poles, in order to drive the turtles towards the centre. When they neared the net, the men moved more quickly, beating and shouting with great vigour. The ends of the net were then seized with vigorous hands, and dragged suddenly forward, bringing them at the same time together, so as to enclose all within a circle. Every man leapt into the enclosure, the boats were brought up, and the captured turtles were thrown in. In this manner about eighty were secured in twenty minutes.

Among these were several male turtles, or capetaris, as they are called by the natives. They are much less numerous than the females, smaller and more circular in shape: their flesh is considered unwholesome.

On the 17 th of October, the day announced for the taboliero or egg-digging, Mr. Bates made a last excursion in Senhor Cardoza's company. Egg-collecting occupied four days. On the morning of the 17 th about 400 persons were assembled on the sand-bank; each family had erected a rude temporary shed of poles and palmleaves to protect themselves from sun and rain. Large copper kettles to prepare the oil, and hundreds of red earthenware jars, were scattered about on the sands. The commandant commenced by taking down the names of all masters of households, with the number of persons each intended to employ; he then exacted from each a tax equal to fourpence a head towards defraying the expense of the sentinels. This being paid, the whole were allowed to go to the taboliero. By the end of the second day it was exhausted, and each household had collected large mounds of eggs around their temporary hut.

\section{Thalassians, or Sea Tortoises.}

The Turtles or Sea Tortoises are distinguished from others by a comparatively flat carapace, long members, the extremities of which terminate in broad paddles, the anterior much longer than the posterior ones; the toes, though formed of distinct pieces, can only act together, thus constituting paddles admirably arranged for swimming. Their carapace, besides being flat, is indented and elongated in front, and contracted behind, being disposed in such a manner that the head and feet can be completely hidden. 
Turtles are the largest of their genus : they swim with great facility, and can remain a long time under water. The external orifice of the nasal canal is furnished with a sort of valve, which the animal raises when it is in the air and closes when submerged; but it rarely leaves the sea except in the breeding season, when Nature prompts it to seek the shore to lay its eggs. Some species, however, frequent the shore in the night, to browse on terrene plants. On land they move with difficulty, and even with pain ; but not so in the sea, where they are remarkably active. Some species feed upon sea-weed and algæ, while others prefer living animals, such as crustaceans, zoophytes, and molluscs, which they seize with their horny jaws, which are hard and trenchant as the beak of a bird of prey.

We have seen how regularly and systematically the Land Tortoises proceed when ready to deposit their eggs; nor is less method adopted by the Turtle. The females, accompanied by the males, frequently traverse hundreds of miles of sea in order to deposit their eggs in some favoured locality, and resort, year after year, with the greatest punctuality, to the same island where they drag themselves ashore sufficiently inland to be safe from the tide. Using their hind flippers as a shovel, they excavate holes about thirty inches deep. Here they: lay frequently a hundred eggs, afterwards covering them with sand. Having carefully levelled the surface, they return to sea, leaving the eggs to be hatched by the solar rays. The eggs are round, slightly depressed at both ends, and furnished with a coriaceous shell. From the high temperature communicated to the sand-bank, they are hatched in about fifteen days. The females seem to have two or three layings in the season, at intervals of two or three weeks. When the young turtles are hatched, their instincts lead them at once to the sea; they are then feeble, white, and about the size of frogs. Under the fostering care of their mother, those which have escaped the birds of prey on their way to the sea and the fishes lying in wait for them, rapidly develop, and attain, under favourable circumstances, an enormous size-some of the Sphargis, or Leathery Turtles, having been known to weigh from I, 500 to $\mathrm{I}, 600$ pounds, -while others, whose carapaces measured more than fifteen feet in circumference and seven feet in length, exceeded $\mathrm{I}, 800$ pounds.

Turtles are met with in herds more or less numerous in all seas in the tropical regions. The shores of the Antilles, the Gulf of Mexico, and the Indian Ocean, are their favourite haunts. Those occasionally found by navigators in the North Atlantic seem to be stragglers who have wandered from their companions.

Of all Chelonians, the Turtle is the most useful to man. In 
countries where they are common, and attain size, their flesh is universally used for food, and their carapace employed as a canoe. The natives even roof their huts with them ; convert them into drinkingtroughs for their cattle and into baths for their children. According to Strabo and Pliny, the ancient inhabitants of the shores of the Indian Ocean and the Red Sea converted the Turtle's carapace into similar uses. The fat of many species, when fresh, is used as

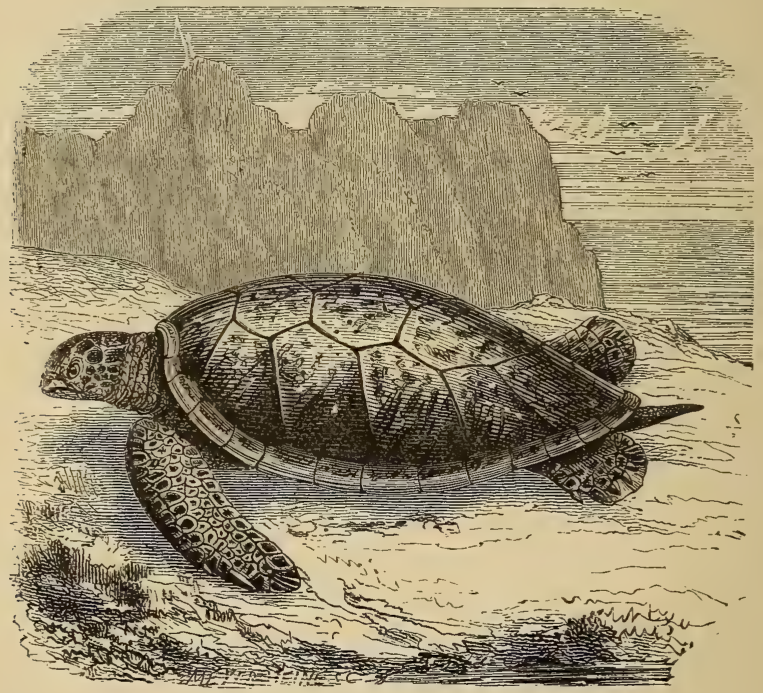

Fig. 38.-Green Turtle.

a substitute for oil and butter, except when pervaded by a musk-like odour, when it is employed in embrocations, in tanning leather, or in lamps. The eggs of nearly all the Turtles are valuable as human food. Finally, the carapace of several species constitutes a valuable material much employed in the arts, and known as tortoise-shell. This is sought after in consequence of its hardness, the fine polish it is susceptible of receiving, and also for the facility with which it is worked. It has a strong resemblance to horn, but is easily distinguished from it. It is formed of parallel fibres, and seems to be the result of the exudation of solidified mucus. Its texture is 



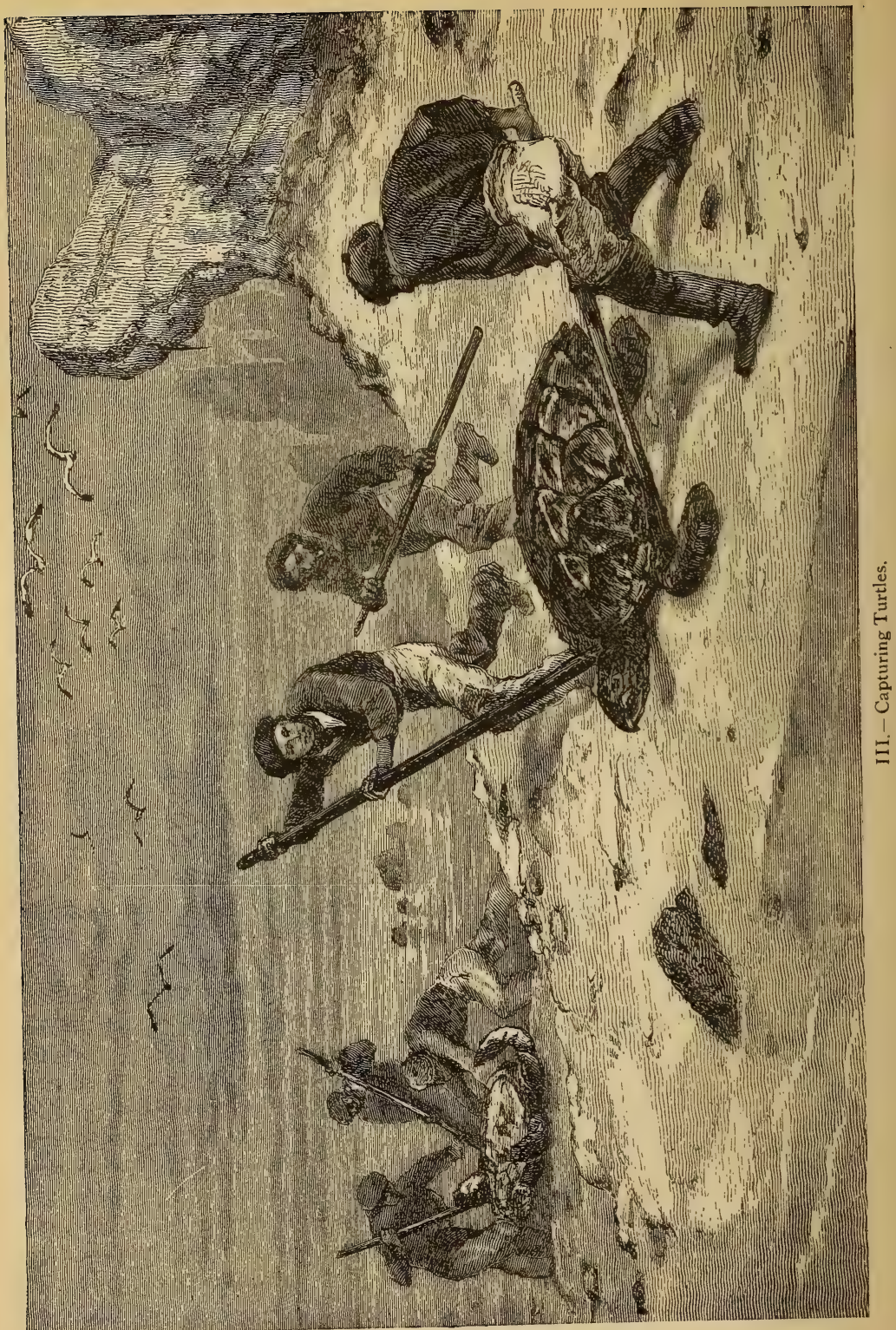


homogeneous ; it can be cut with precision ; and, under the influence of a gentle heat, will soften so that it can be modelled into any fashion dictated by the taste of the moulder; which shape it retains after becoming cool.

While most of the Turtles are highly useful to man, both for food and other purposes, the most valuable is the Green Turtle (Chelonia mydas, Fig. $3^{8}$ ), so called from the reflected green of its carapace. It abounds in the southern Atlantic Ocean, only visiting land in the breeding seasons, when it shows a marked preference for the islands of Ascension and St. Vincent. When sleeping on the surface of the sea, it is easily taken by a noose being placed over its head as the boat containing the captors silently glides past. It is even said to be a practice with Malay fishermen to dive beneath a sleeping turtle, and, attaching a cord to their flippers, take them.

In the regions where this valuable animal breeds, their pursuers follow them by their track on the sands, cut off their retreat, and throw them on their backs ; from their great size, hand-spikes sometimes being necessary to accomplish this. In this position they are helpless, and so remain while their enemies continue their sport, as represented in Plate III. In I802 the crew of a French ship surprised a female turtle on the Island of Lobos. The men had infinite trouble in making good its capture and throwing it on its back, from its immense size and strength. Its head was as large as that of an infant, and its beak four times the size of a macaw's. In its body 347 eggs were found. Turtles are also taken in nets, their beaks and flippers getting entangled in the meshes; thus prevented from coming to the surface for air, they die of asphyxia. Others harpoon them on the open sea. The harpoon is attached to a cord, by which the animal is soon brought to the surface and drawn on board. But the commonest mode of capture is approaching them silently in a boat as they float asleep. When within reach, a back flipper is laid hold of by one of the crew, and by a sudden twist the turtle is thrown on its back, when, becoming helpless for the moment, it is dragged on board.

A very curious mode of fishing for turtle is pursued by means of a species of Echineis remora. These small fish are provided with an oval plate on the head, which consists of a score of parallel plates, forming two series, furnished on their outer edge with an oval disc, soft and fleshy at its circumference ; in the middle of this plate is a complicated apparatus of bony pieces dispersed across the surface, which can be moved on their axis by particular muscles, their free edges being furnished with small hooks, which are all 
raised at once, like the points of a wool-card. When the fishermen see a sleeping turtle they approach it, and throw into the sea one of these Remora, which dives under the turtle, and fixes itself to it by means of their cephalic disc. As the fish is attached to a long cord by means of a ring in its tail, it is drawn on board along with its victim.

The Green Turtle is that from which turtle soup, celebrated for its delicacy and excellence, is made. This dish is of modern in-

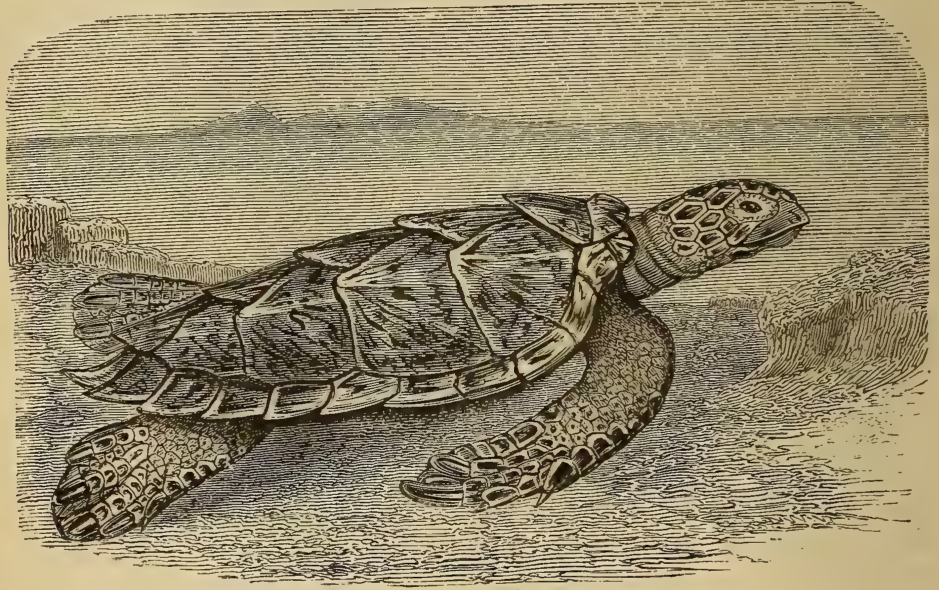

Fig. 39.-Hawk's-bill Turtle.

vention, the first turtle having been brought to London by Admiral Anson in $175^{2}$. It was long very costly, and even is now, although considerably modified by the introduction of steam and other adjuncts to navigation.

Much of the tortoise-shell of commerce comes from the Green Turtle, but by far the finest is produced by the Hawk's-bill Turtle (Chelonia imbricata, Fig. 39). In this species the plates of the disc, thirteen in number, are imbricated, or lapping over each other. The muzzle is long and compressed; the jaws with straight edges, without dentation, curving slightly towards each other at their extremities, with two nails on each fin. It rarely attains the size or weight of the 
former species. The Hawk's-bill Turtle is met with in the Indian Ocean, and also on the American shores. It feeds on marine plants, or molluscs, and small fishes, and is chiefly sought after for its shell, which is the finest known. Its flesh is unpalatable, from its musky flavour. On the other hand, its eggs are excellent when fresh, and are eagerly sought after.

In order to prepare the shell for use, it is softened by means of boiling; it is then flattened by being passed through a press; in

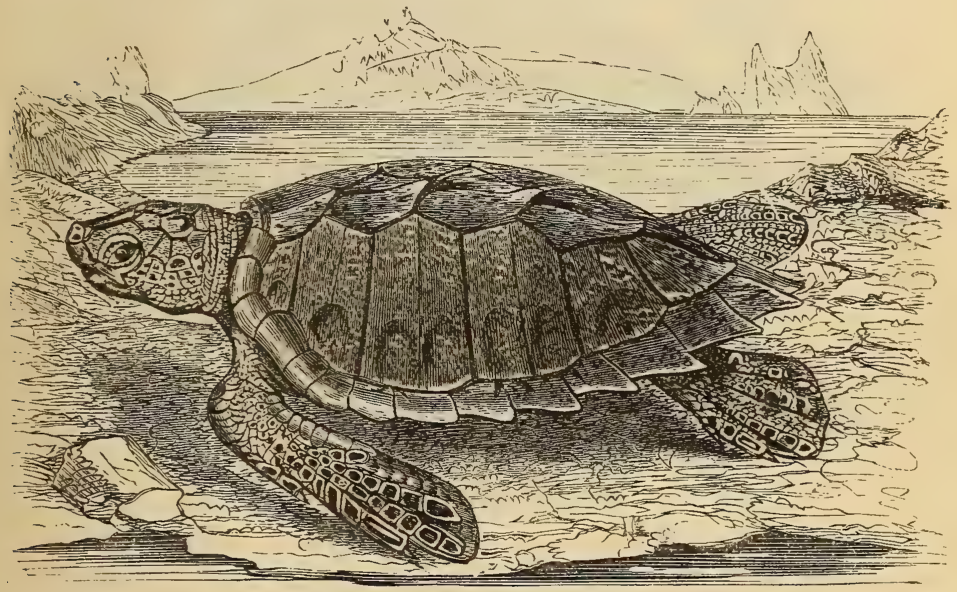

Fig. 40.-Loggerhead Turtle.

this condition it is ready to be manufactured into all sorts of ornamental work. The Loggerhead Turtle (Chelonia caretta, Fig. 40), like the Green Turtle, has its scales placed side by side. Its colour is brownish or deep maroon. It is found incidentally on the French and English coasts, but abounds in the Atlantic and Mediterranean. Its length is about four feet; its weight, from 300 to 400 pounds. It is very voracious, and feeds principally on molluscs. Its shell is much valued, but its flesh is indifferent, and its fat altogether uneatable.

The Leathery Turtle (Sphargis coriacea, Fig. 4I) differs from every other genus, its body being enveloped in a coriaceous hide; tuberculous in the young, perfectly smooth in adults. The feet are with- 
out claws. Seven longitudinal grooves extend from the neck to the tail, which reminds one of the seven chords of the ancient lyre. Only one species is known. It is found in the Mediterranean and Atlantic Ocean, and is, with the Loggerhead Turtle, the only species

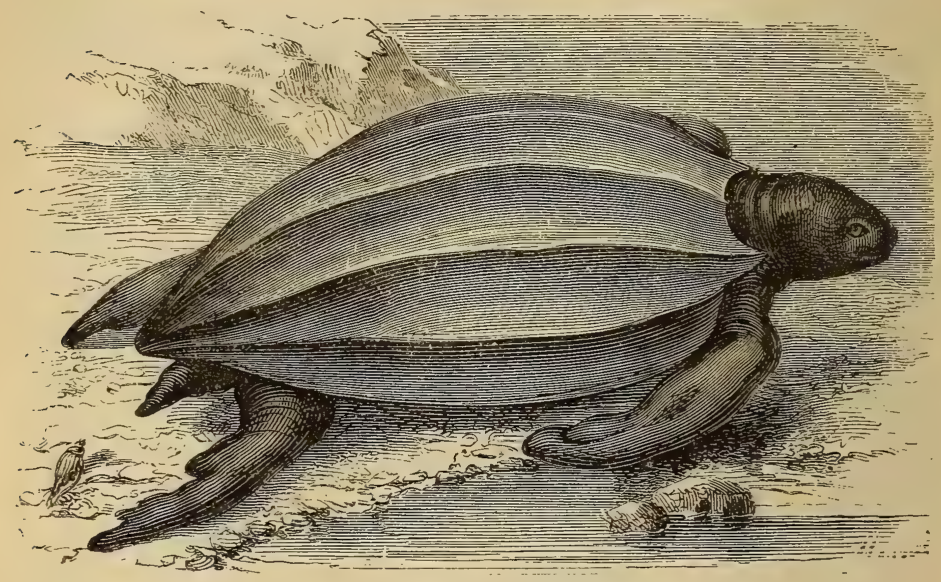

Fig. 4I.-Leathery Turtle.

found on the British coast. Its body is a light brown, with the lines of the carapace fawn-colour; its members black, edged with yellow. It attains the length of six to eight feet, and a breadth of about one-fifth of the length: it sometimes reaches the weight of $I, 400$ to $\mathrm{I}, 600$ pounds. Its flesh is said to be unwholesome, and, on being eaten, to produce severe vomiting with diarrhœa. 


\section{B I R D S.}

\section{INTRODUCTORY CHAPTER.}

BIRDS are the spoilt children of Nature-the favourites of creation. Their plumage often assumes the most resplendent colours. They have the happy privilege of moving in space-now fluttering through the air, hunting the insect which flits from flower to flower; or soaring high aloft, to swoop upon the victim marked for its prey; again cleaving the atmosphere, and performing journeys of vast extent with great rapidity. Mankind cannot fail to admire these winged beings, which charm at once by the elegance of their form, the melody of their song, and the graceful impetuosity of their movements.

Anatomically speaking Birds, by their internal structure, are connected with the Mammifera, as their skeletons are nearly the same, only modified slightly for the purpose of flight. However, in them there is a double circulation. The heart consists of two moieties, or lobes, known as the auricle and ventricle. It is conical in form, and occupies the anterior part of the thorax, its apex passing between the lobes of the liver; but there is little perceptible distinction between auricles and ventricles. Their blood is richer in globules than that of the Mammalia, being more thoroughly permeated by air ; the respiratory function is also more energetic, from the same cause-in fact, they consume a larger quantity of oxygen, and produce a proportionately greater degree of heat; for while their lungs are small, and placed in the upper part of the thorax only, where they are confined on each side to a cavity, bounded above by the ribs, and below by an imperfect diaphragm, they are perforated by tubes, which communicate with membranous cells, distributed over the thoracic and abdominal cavities, between the muscles, and beneath the skin-often 
in all parts of the body. What distinguishes the bird is not the wing; for certain of the Mammalia, and even some fishes, possess them. The diaphragm which arrests the air in Mammalia is scarcely perceptible in Birds, so the external air penetrates into every part of their body by the respiratory tubes, which ramify the whole cellular

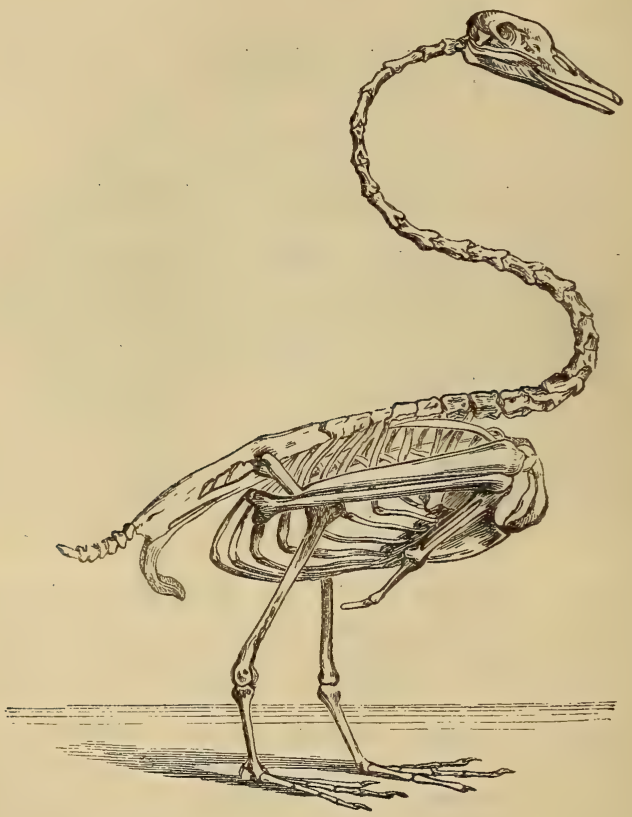

Fig. 42.-Skeleton of the Swan.

tissue, even the interior of the bones, the feathers, and between the muscles. Their forms, thus inflated, lose a proportionate amount of weight, enabling them to float in the gaseous element (See Fig. 42).

Wings alone would fail to support the Bird in space. The position renders a double system of breathing necessary. Vital heat in animals is always in proportion to their respiration, for the oxygen of the air, which penetrates every cell and cavity of their bones, feathers, and body, warming and giving increased activity to 
their circulation and specific lightness to their bodies, from its rich organisation enables Birds to live in the coldest atmospheric regions. In Fig. 43 the respiratory organs of a Pigeon are represented. The trachea or windpipe is composed of many bony rings, varying in different species. In the Falcons it is slightly flattened, and tapers in a small degree; but in many genera it presents dilatations and contractions, and in others it is variously curved, two slender muscles, which run along its sides towards the sternum, serving to contract it. In many of the song-birds several pairs of small muscles are attached to the lower larynx, where the tube bifurcates, by which they are enabled to control this organ, which is the producer of their note.

The trachea carries the air to the lungs in a Pigeon, and separates into two branches in the breast, where it abuts on the aerial sacs, and on the two lungs (Fig. 44). The air carried by the windpipe acts upon the blood through the thin substance of the cells which constitute the pulmonary tissue, which it traverses in an infinity of minute vessels.

The lungs are small, and placed Fig.43--Respiratory organs of a Pigeon in the upper part of the thorax, where they are confined on each side by a cavity bounded above by the ribs and below by an imperfect diaphragm; but they are perforated by tubes which communicate with membranous cells distributed over the thoracic and abdominal cavities, between the muscles, beneath the skin, and in all parts of the body.

The external form of birds is modified so as to be subservient to aërial progression. The vertebral column or spine, along the centre of which runs the spinal cord, is divided into the cervical, dorsal, and sacral regions, terminating in the caudal extremities, the number of vertebræ or pieces varying much in different genera. The body consists of the dorsal, sacral, and caudal parts of the column; laterally, of the ribs and pelvis; and beneath, of the sternum and the soft parts contained in it. Its anterior part, containing heart, lungs, and liver, is named the thorax; the posterior, the pelvis. The sternum, with the clavicles and scapulæ, is perhaps the most curiously 
modified part of the skeleton of Birds. It is a large expanded plate extended over the whole anterior part of the thorax, and even cover-
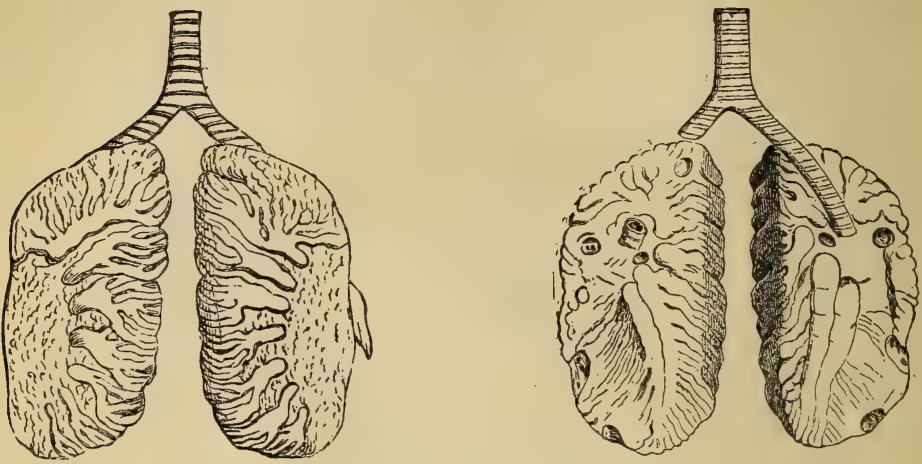

Fig. 44--Lungs of a Pigeon.

ing more or less what may be considered the abdomen. It varies greatly in different genera; but in all it is more or less four-sided, and convex externally, forming the basis for the powerful muscles by

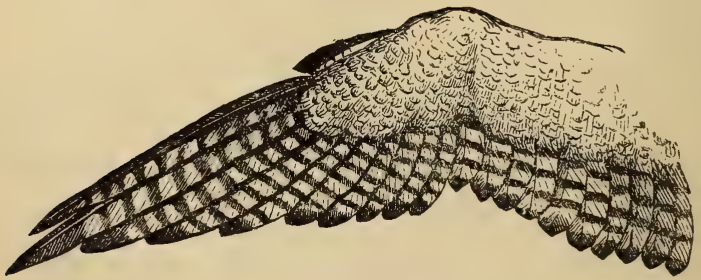

Fig. 45.-Wing of Eagle.

which the wings are moved. These wings serve as arms by which the bird guides itself, ascending or descending, according to the impulse given them. "That the anterior form of birds is modified so as to be subservient to the aërial progression for which these animals are intended," says McGillivray, "is obvious and intel- 
ligible. Their bodies are oval, with the more powerful muscles placed on the breast, so that, when the horizontal position is assumed, the centre of gravity comes between the wings, and is kept near the lower part by the weight of the pectoral muscles. The length and flexibility of the neck enable the bird to make the

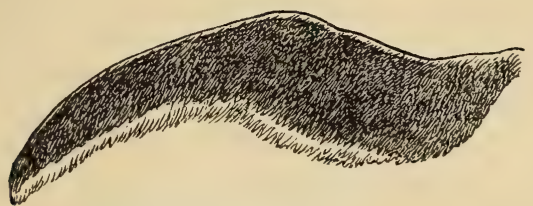

Fig. 46.-Wing of Penguin.

necessary changes in the centre of gravity, while the solidity of the dorsal spine gives advantage to the action of the muscles. The head is terminated by a pointed bill, which aids in cleaving the air; the feet, when short, are drawn up and concealed under the feathers; when long, they are stretched out beneath or behind the tail, which is more or less expanded, and helps to support

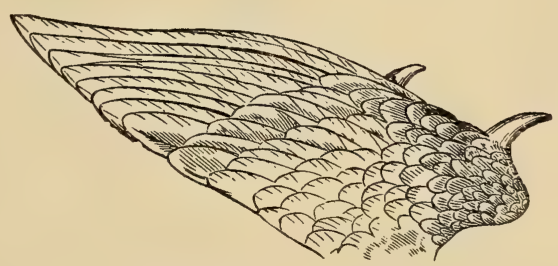

Fig. 47-Wing of Kamichi or Crested Screamer.

the body in the air, as well as, by acting in the manner of a rudder, to change its direction, or, by being expanded, to break its descent."

The wings of Birds (Figs. 45, 46, 47) are acute or obtuse. The more angular the wing of birds-that is to say, the longer the feathers on the edge of the wing-the more rapidly does it propel itself through the air. The tail consists of a number of feathers, to which are attached a series of small muscles, which are capable of depress- 
ing and elevating it in various degrees ; while a series of connections, the fibres of which invest the base of the quills, curve round the edge. Their action is to spread out the tail-feathers, and incline them to the right or left; thus enabling it to perform the part of a helm or rudder.

Besides flight, Birds possess other means of locomotion, being formed for walking, swimming, or flying, according as their habits are aërial, terrestrial, or aquatic. Their general form, though possessing all the characteristics of the class, is modified and adapted to the kind of life they are intended to lead. Where the skin of a bird is closely covered with feathers, it is observed that the true skin, or derma, is thin and transparent; when the reverse, the cuticle is thicker, and even covered with scales, in those parts where feathers are absent.

Before addressing ourselves to the physiological functions of Birds, a few words descriptive of their feathers, beaks, and claws, will not be out of place.

The covering of Birds is known by the general name of plumage, which is composed of many individual feathers. The feathers are horny productions, consisting of a hollow tube or barrel, and a stem rising from it. Chemically, this covering is of the same material as the hair on Mammals and the scales on Reptiles and Fishes, differing only in its mechanical structure. Besides the more conspicuous feathers, most Birds have an underneath covering of smaller ones, known as down. A feather of the ordinary kind consists of the tube or barrel, by which it is attached to the skin, varying in length according to the species; the stcm or shaft, composed internally of a soft, compact, but elastic substance of a whitish colour, and in its buoyancy not unlike cork; the web, which is a lateral prolongation of the external coating of the shaft, and which assumes the form of a thin linear membrane springing from it at an angle more or less acute in different species, called the barb, from which two sets of minute filaments proceed at an angle similar to that of the barb itself in respect to the shaft. These smaller filaments are the barbules, by means of which the barbs are retained in opposition-not by the barbules of one barb interlocking with those of another in the manner of dove-tailing, but by the anterior series of one barb overlapping and hooking into the re-curvate formation of the barb next to it (Figs. 48, 49). The barbules themselves frequently throw out filaments in the same manner, which are called barbicels, the object of which is apparently the same-namely, that of connecting and retaining the barbules in position. These barbules may be observed, 
by the aid of a small magnifying glass, in the quills of a Golden Eagle.

Feathers, then, consist of three parts-the tube, the shaft, and the webs (Figs. 48, 49, 50); the webs being the barbs furnished with barbules, sometimes barbicels. They are convex above, and are thus enabled to resist flexion or fracture from beneath better than from any other direction. They are also elastic ; and this property, combined with their curvature, tends to keep them closer together.

In the feathers of a large portion of birds there is a plumiform

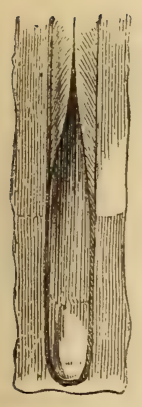

Fig. 48.-Tube.

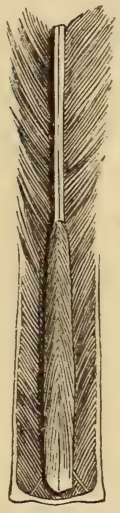

Fig. 49:-Shaft.

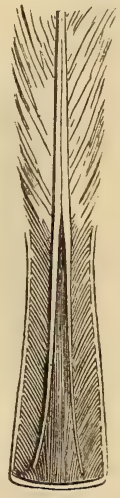

Fig. 50.-Web.

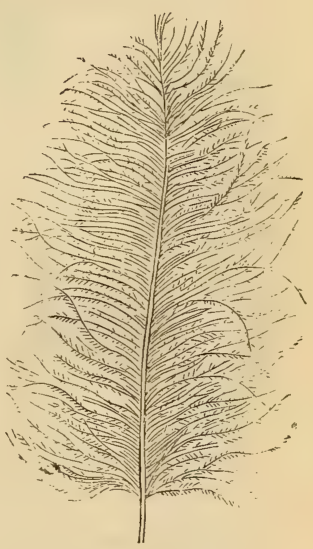

Fig. 5r.-Plume.

formation (Fig. $5 \mathrm{r}$ ). The plumule is conspicuous in gallinaceous birds - for instance, the Pheasants (Fig. 52) ; it springs from the fore part of the tube, just at the commencement of the shafts; it gradually narrows, and is continued in the form of a very delicate, thread-like fibre; from its side proceed two series of barbs, and from the barbs two series of barbules, extremely fine, entirely disunited, and very loose. This plumule seldom exists among aquatic birds, but in gallinaceous fowls it attains the length of two-thirds of the feather, and in the Emu and Cassowary it equals it in length.

Feathers may be divided into those specially employed as the means of locomotion and those intended to protect the Bird from extreme cold. The former are much stronger, more compact, and 
more elongated than the others. The row of feathers bordering the wing behind is known as the alar quills, or wing quills, and those terminating the extremity of the tail, as caudal quills. From the head, backwards to the tail, the body feathers increase in strength and size, also alter in form ; those on the face, or round the base of the bill, being smallest (Fig. 53), the tail-coverts longest (Fig. 54). Immediately covering the base of the wing quills are a row of feathers on both surfaces of the wing; these are the quill coverts.

The most brilliant feathers are found in Birds of warm climates. In many species the brilliant plumage is confined to the males, while that of the females is dark and sombre. In other cases it is the

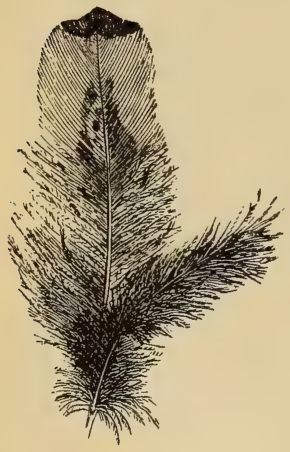

Fig. 52.-Plumule.

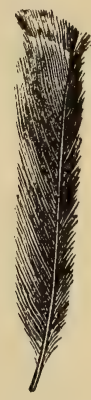

Fig. 53. - Neck covert.

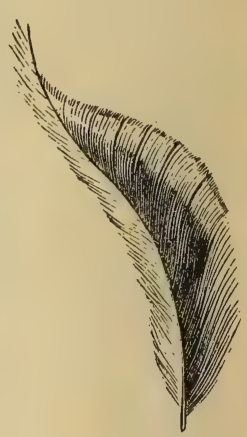

Fig. 54. -Tail covert.

same in both sexes. The young of some species attain the adult appearance after the first moult ; others take several years to acquire their full splendour.

Birds cast their feathers at least once a year. This is called moulting, and usually occurs in the autumn, but sometimes both in spring and autumn. During the moulting season Birds are dull, retiring, and silent; but when they emerge from this state they proudly display their brilliant plumage, which sometimes rivals the gayest flowers.

Among the Gallinaceous Birds, and especially among the aquatic species, there exist over the coccyx certain receptacles which distil the oily substance with which they lubricate their plumage. These receptacles are known as the uropygial glands. On its lower surface 
is a layer of cellular tissue containing a similar fluid, which seems to be connected with the growth of the feathers.

The feet of Birds are as varied in different species as are their wings. In Birds of Prey the claws are powerful and hooked; in others the foot is flat, claws straight and adapted for walking (Figs. 55,

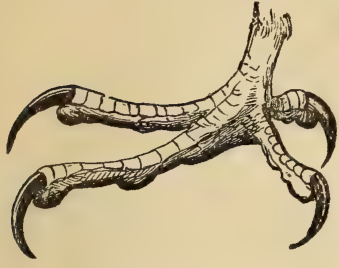

Fig. 55 .

Foot of White-headed Eagle.

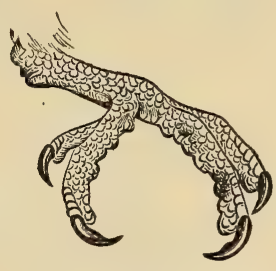

Fig. 56 .

Foot of Honey Buzzard.

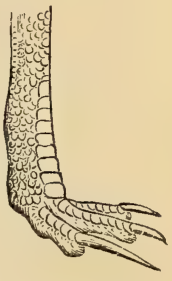

Fig. 57 .

Foot of Cassowary.

56, 57). The great toe is generally the strongest, but this is not an absolute law: a projection which is found on the leg of some species is designated a spur, and is a formidable weapon (Figs. 58, 59). Some birds walk by bringing their feet forward alternately; others by a simultaneous motion, resembling a succession of leaps. Some

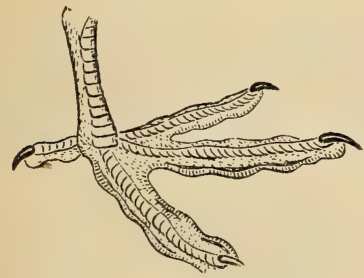

Fig. 58.-Foot of Coot.

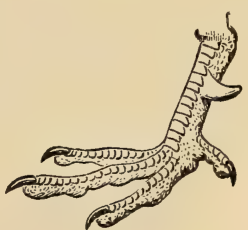

Fig. 59.- Foot of Pheasant.

run with great velocity, while others walk with great difficulty, and then only on a flat surface. Many have their toes joined by thin membranes, which act as paddles by which they propel themselves through the water.

The beak or bill of Birds is composed of two bony pieces, called mandibles, surrounded by a horny substance, differing both in form and thickness, according to the habits of the species. In the 
genus Falco the bill is shorter than the head; the upper mandible, which is furnished at the base with a bare coloured skin, of a peculiar dense texture, called the cere, in outline is slightly convex as far

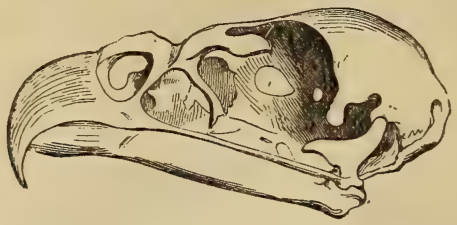

Fig. 6o.-Bill of Eagle.

as the edge of the cere (Fig. 6o), then curved so as to form about the third of a circle, and is evidently destined, in connection with its formidable claws, to tear its prey.

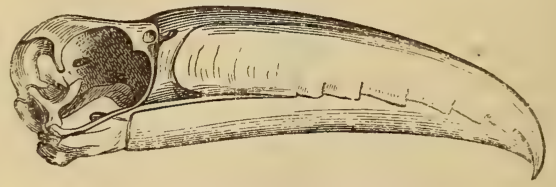

Fig. 61.-Bill of Toucan.

In the Toucans Ramphastidæ the bill is half a foot long, hollow within, thin, and nearly transparent; and the mandibles are so disposed as to combine, with their great bulk, strength and lighiness, and assisting by their digestive power to assimilate both animal and

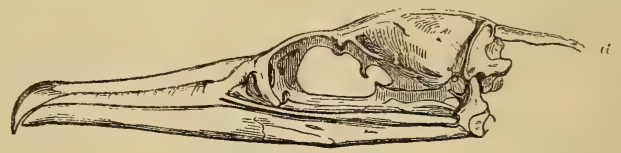

Fig. 62.-Bill of Cormorant.

vegetable food (Fig. 61). In the Pelicanidæ, as in the Common Cormorant, the bill is long, straight, and compound; the upper mandible curved towards the point, the lower compressed; the base inserted in a small membrane which extends under the throat. In the back part of the head is an additional bone (Fig 62, a), 
attached in such a manner to the occiput as to admit of great expansion, which permits of its swallowing plaice and other flat fish of

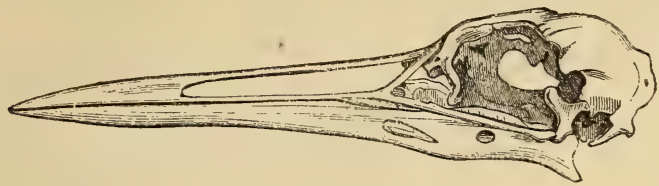

Fig. 63.-Bill of Crane.

considerable size. The Crane (Fig. 63) has the bill rather longer than the head, strong, straight, compressed, and pointed at the extremity; the sides of the mandible deeply channelled with nostrils, and closed backwards by a thin membrane.

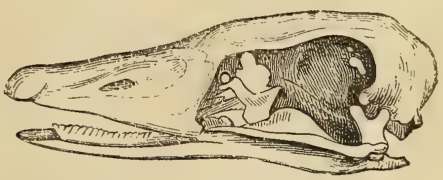

Fig 64.-Bill of Goose.

In the Goose (Fig. 64) we find the bill short, not longer than the head, conical, covered at the base with a cerous skin, with under mandible smaller than the upper. In the Sparrows (Fig. 65) the bill

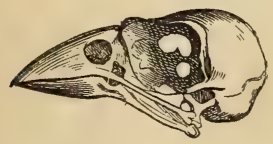

Fig. 65.-Bill of Sparrow.

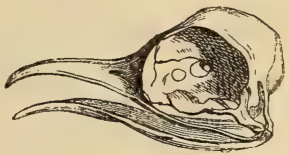

Fig. 66.-Bill of Cuckoo.

is strong and conical, the upper mandible slightly curved, the lower compressed and smaller than the upper; nostrils lateral, basal, round, and partly concealed by the short feathers at the base of the mandibles. In the Cuckoo (Fig. 66) the bill is remarkably small and weak, the sides inflexed and sometimes gaping. 
The tongue, like the bill, however, is only an accessory to the digestive apparatus; for while the beak serves the purpose of prehension and trituration, the tongue assists in deglutition or swallowing. Digestion is so active in some birds, that they get fat in an excessively short space of time. The Ortolan Bunting, and some others, are fattened for the table in five or six days. In the swelling under the throat called the crop

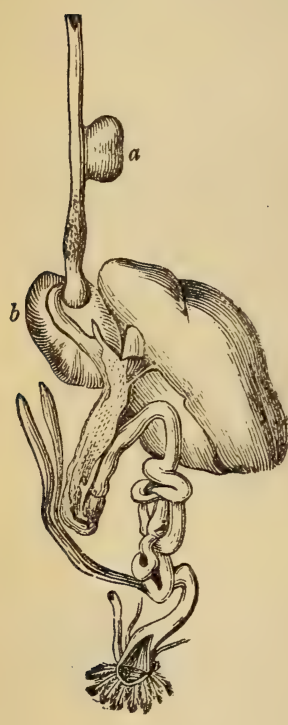

Fig. 67 . Crop and digestive organs. (a, Fig. 67), or first stomach, which is largely developed in some of the granivorous or graineating birds, the food remains for a time, where it undergoes certain modifications which facilitate digestion ; thence it passes into the succenteric ventricle, or second stomach, (b, Fig. $67)$, there it imbibes the necessary amount of gastric juice; being finally transformed into chyme in the gizzard (c, Fig. 67), or third stomach, which is possessed of great muscular power, being capable of acting upon the most solid bodies, triturating even the flints and gravel which the Gallinaceous Birds swallow to aid their digestion.

It is a curious fact that a grain of seed, introduced into the stomach, may be digested without alteration, and when ejected will germinate, if it meets with no obstacle to its vegetation. In this manner trees are frequently found in regions where their species appear to have been previously unknown.

Chyle, which is a milky fluid formed from the junction of chyme and bile, is received by the small intestine, where the bile also flows from the liver and the saliva from the pancreas.

The urinary apparatus consists of the kidneys, two in number, thick and irregular, and distinct one from the other, abutting on the intestine, which terminates in a species of pouch, or cloaca, through which evacuation, alternately of urine, excrement, and eggs, takes place. Such is the general internal anatomy of Birds (Fig. 68).

The senses of touch, of smell, of taste, and hearing are only slightly developed in Birds. Some have spoken of great delicacy of scent in Birds of Prey, which are observed to assemble in great numbers on fields of battle and other places where carcases are exposed. But the opinions of naturalists such as Audubon and Levaillant 
seem to prove that they are attracted rather by the sight than smell.

The organ of sight is, indeed, more highly developed in birds than in any other class of animals. The volume of the eye itself is

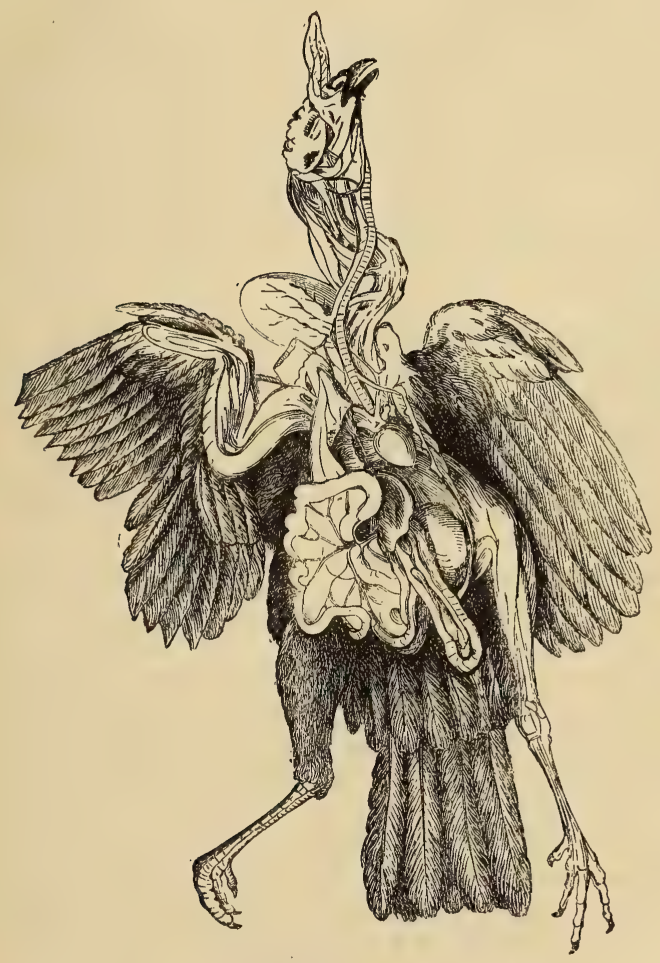

Fig. 68.-Internal Anatomy of Birds.

large compared with the head. It includes an addition which seems to be confined to Birds. This is a black membrane, with many folds, very rich in blood-vessels, and situated at the bottom of the ocular globe, and advancing towards the crystalline. Anatomy has failed to explain the use of this, but it is supposed that by enlarging or 
contracting it, birds obtain additional powers of vision. Other parts of the eye, such as the choroïs, the thin membrane which covers the posterior part of the eye, the iris, the retina, present nothing reremarkable. The white of the eye is surrounded by an osseous or cartilaginous matter, evidently placed there for protection of this delicate and useful organ.

Besides the ordinary upper and lower pupils, Birds possess a third. This consists of an extensive transparent membrane, disposed vertically, which covers the eye like a piece of network, protecting it from the effects of a blaze of light. It is this pupil, or nictating membrane, placed at the internal angle of the eye, between the orb and the external pupil, which the animal uses at will, which permits the eagle to gaze at the sun, and prevents the nocturnal birds of prey from being dazzled when exposed to daylight.

The perfection of 'the sight of Birds seems to be proved from the Vulture, so distant from his prey as to appear a mere speck in the heavens, without deviation flying directly to it; or the Swallow, while on rapid wing, perceiving the smallest insect on which it feeds. According to Spallanzani, the Swift has sight so piercing, that it can see an object only five lines in diameter at the distance of 500 feet.

Birds, of all animal creation, can traverse distances with the greatest rapidity. The fleetest among the Mammifera cannot exceed seven or eight leagues in an hour. Certain Birds easily traverse their twenty leagues in the same interval of time. In less than three minutes we lose sight of a large bird, such as a kite or an eagle, whose extent from wing to wing is almost two yards. It is assumed, from these facts, that these birds traverse more than 1,500 yards each minute, or more than fifty miles in an hour. A falcon of Henri II. strayed from Fontainebleau in pursuit of a bustard; it was taken the next day at Malta. Another falcon, sent from the Canaries to the Duke de Lermes, in Spain, returned from Andalusia to the Peak of Teneriffe in six hours, the flight representing a distance of 250 leagues. In short, the whole organisation gives to a bird that remarkable lightness which contributes so much to its velecity. Not to speak of the feathers with which it is covered, its bones are hollow and form large cells, called aërial sacs, which it is able to fill with air at will, and its sternum is furnished with a bony frame or breastbone, formed somewhat like the keel of a ship, into which the pectoral muscles are inserted-which, besides being largely developed in birds of flight, possess remarkable contractile properties. 
The vocal apparatus in Birds, represented in Fig. 69, is very complicated, and differs from the human larynx and trachea. It consists of a kind of osseous chamber; which, however, is only a swelling in the arterial trachea at the point where it bifurcates and enters the breast to form the bronchial tube. It is this formation, called the lower larynx, which constitutes the organ of song. Five pairs of muscles, attached to the walls of this chamber, stretch or relax the vocal chord, by which means they enlarge or diminish the cavity of the larynx. Whoever has watched a bird singing must have noted the swelling and contracting of its throat
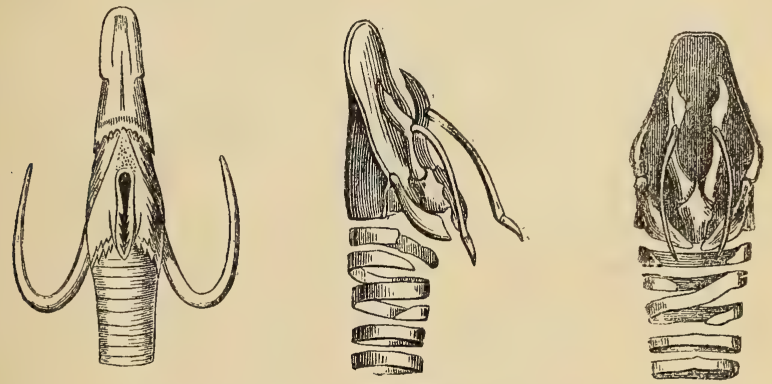

Fig. 69.-Vocal Apparatus contracted and distended.

as it poured out its melody, modifying in a thousand ways the tension of the vocal chords, and producing those marvellous modulations the perfection of which must always be a subject of astonishment and admiration.

The song of Birds must be the expression of some sentiment; for they sing as much for their own pleasure as to charm those who listen to them. While filling the woods with their melodious accents they direct their gaze on all sides, as if proud of their talents, and desirous of gathering the tribute of admiration to which they feel themselves entitled. Their song varies with the season, but it is in the early spring their efforts are most admired for their beauty of harmony. Can anything be more fascinating than the warbling of the linnet, the piping of the goldfinch, or the melodious cadence of the nightingale, as it breaks the silence of the woodland during the serene nights of leafy June?

Our landscapes would be sad and mute indeed without these 
charming songsters, which add so much attraction to country life and solitary rambles. In the silence of night, when Nature sleeps, and life seems suspended, all at once certain notes of harmony rise from under the dense foliage, as if to protest against the universal silence. It is sometimes a plaintive cry, prolonged into a sigh, now a continuous warbling, now a lively song, gay and melodious, which the whole forest re-echoes to.

When the darkness of night gives place to the first dawn of day -when the soft gleam of Aurora has appeared on the horizon, all is transformed, all is vivified on the new-born earth, lately asleep and apparently deserted. The larger birds rise higher and higher in the air, till they are lost in the clouds. The small birds hop from branch to branch with joyous gambols, communicating a feeling of happiness and content to all Nature. What a wonderful variety of music they produce-what dazzling brilliancy decks their plumagewhat a charm pervades the whole scene, enlivened by these living flowers flitting about in intense enjoyment! Be it a titmouse, which seems to spend its life in constant motion; or the fly-catcher, on the other hand, always perched ; the lark, performing its graceful circles in the air as it rises higher and higher, pouring forth its melodious song more vigorously with each circle described; the thrush, which runs along the grassy path, watching for its prey, or the house sparrow chirping from the straw-built roof, or the robin warbling from some leafless bower-how much the little winged wanderers decorate the landscape and improve the picture with their innocent gambols !

Assuredly birds have a language, for when danger threatens them a peculiar cry is uttered by one, and immediately all of the same species hide until their fears are dispelled or confidence restored; or when the presence of a bird of prey is announced by the plaintive voice of the thrush, all the feathered race of the neighbourhood are hushed into silence.

Birds of prey with carnivorous instincts frequent the most solitary places. The eagle lives with its mate in some unapproachable mountain pass, where its nest is placed on the sides of a steeplyscarped precipice, or on the verge of an inaccessible ravine, whence they sally forth in search of prey.

It is very difficult to comprehend the intelligence exhibited by Birds. In the Mammifers, whose organisation approaches nearer to our own, we are enabled partially to comprehend their joys and griefs; but in the case of Birds we are reduced to conjecture in order to arrive at an estimate of their sensations. To explain this 
profound mystery a word has been invented which satisfies easy minds: thus, we call the sentiment which leads birds to perform many admirable actions which are related of them, instinct. The tenderness of the mother for her young-a tenderness so full of delicacy and foresight-is, we say, only the result of instinct. It is agreed on all hands, however, that this instinct singularly resembles the intelligence called reason, and, in the opinion of many, is nothing else.

Reproduction in birds occurs at intervals regulated by Nature, and they are distinguished above all other creatures for the fidelity of their affections. It is frequently observed when a male becomes so attached to a female, that they henceforth live together till separated by death; and many affecting scenes are described of the grief of the survivor for the loss of his or her mate. When the breeding season approaches, the habits of the female are modified. She abandons her former freedom, and, having laid her eggs, she passes her whole time in incubation, defying hunger and other dangers, apparently well knowing that the equal and prolonged heat communicated from her body is necessary to hatch her eggs. During the period of incubation the male, in most instances, watches the female, and supplies her with food; afterwards the little ones are waited on by both parents with the tenderest care until the young are sufficiently old to provide for themselves.

The solicitude of birds for their young is first manifested in the choice of the locality for the nest, and in the care with which this cradle of their progeny is constructed. But all this disappears when the young no longer require the maternal protection.

In spring, when the birds have paired, they commence at once to collect the materials necessary for their nest. Each carries its blade of grass or stem of moss; large birds contenting themselves with coarser materials-chips of wood, or branches of trees interlaced with twigs, lined with hair and other soft substances, are fashioned by them into the necessary shape. But the smaller species really display great art in framing their miniature dwelling, which they line inside with wool, blades of grass, or down-their effort is to make a soft, warm, and solid bed on which to deposit the coming eggs, the male and female labouring in the common work. They have also recourse to all sorts of cunning devices in order to conceal their nest from prying eyes, choosing for this purpose the heart of a leafy bush, the forked limb, the concealed crack or hollow in the trunk of a tree, the chimneys of a house, crevices in a wall or under a roof. Curiously enough, the nests of the same species are fashioned in 
precisely the same manner. The Kinglet, or Golden-crested Wren (Fig. 70), builds its nest among ivy, or dependent from fir branches, generally near some brook; it is neatly formed of moss, nearly

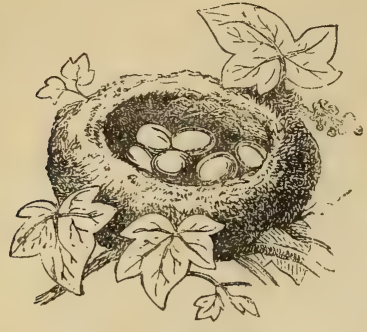

Fig. 70. -Nest of Kinglet.

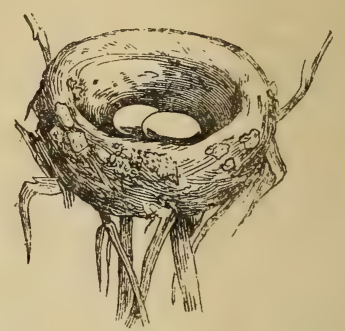

Fig. 71. - Nest of Humming-bird.

covered with leaves, and lined with small feathers, hair, and wool. In this nest it lays six, sometimes more, delicate little eggs, marked with small pink spots. The Humming-birds (Fig. 7I), which flit about in tropical woods, build their nests of grass, lined with feathers.

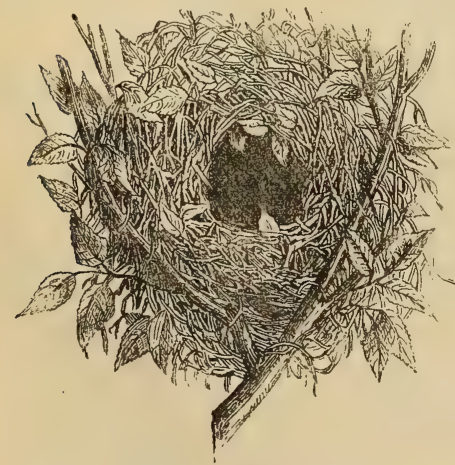

Fig. 72.-Nest of Wren.

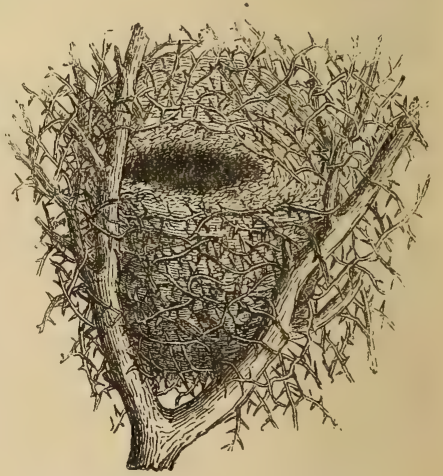

Fig. 73.-Nest of Hedge Sparrow.

The Common Wren, on the other hand, builds a nest like a ball, beautifully constructed with an entrance in the side (Fig. 72). The House Sparrow builds its nest under the eave of some house; while the Hedge Sparrow (Fig. 73) chooses the fork of a hawthorn bush 
in which to locate its children's home. The Magpie, more ambitious, constructs its nest of branches interlaced with twigs, and lined with fine grass, hair, and other soft materials, in the topmost fork of some tall ash, poplar, or elm. It is a large, and consequently a conspicuous fabric, elliptical in form, composed first of rough boughs, on which is laid a quantity of mud, and then a layer of twigs, the whole lined with fibrous roots and other soft material. The Goldfinch builds its nest on trees ; it is composed of grass, moss, and lichens, and lined with the down of various plants and such other soft material as comes in its way, elaborately interwoven with wool and hair (Fig. 74).

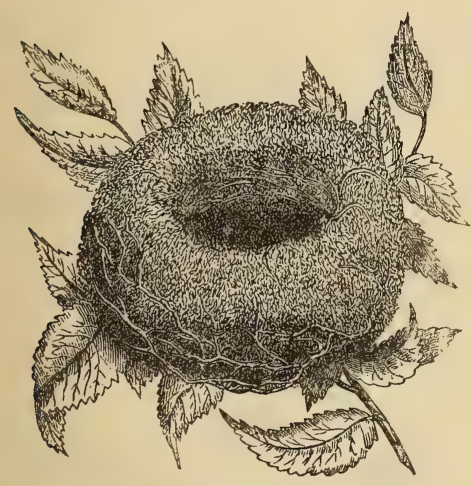

Fig. 74. - Nest of Goldfinch.

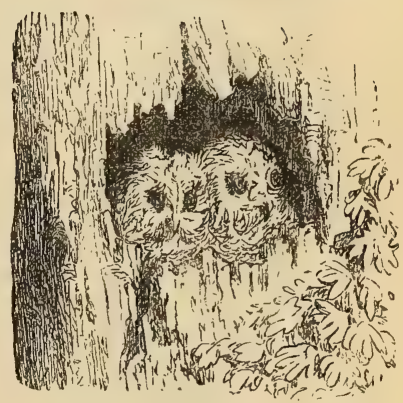

Fig. 75.-Nest of Barn Owl.

The Barn Owl chooses her nest in some obscure nook of an old tower, the steeple of a church, a dovecot, or the hollow of an aged tree (Fig. 75). It is composed of twigs and straw loosely arranged.

Some birds form into a sort of coarse tissue of fibres the materials of which they construct their nest-this has procured them the name of Weaver Birds. The nest of the Tailor Bird is placed in a large leaf, the margins of which are sewn together so as to form a bag (Fig. 76). The Synalaxine Bird builds its nest with grasses, interlacing them in a firm and inextricable web, and in it are found two apartments, the eggs being placed in the inner one. The Baltimore Orioles and Crested Orioles of the New World cannot be passed without noticing therr wonderful skill in nest construction. The nest of the Baltimore Oriole is a perfect pouch, which is suspended from the upper branch of a shrub or tree ; but the nest of the latter consists of dry grasses 
woven into long sacks, gradually increasing in size towards the bottom, with an elongated slit in the side, so constructed as to exclude rain. These wonderful structures are sometimes two yards in length; and when numerous, as they hang suspended from the branches of trees, give a singularly novel aspect to the landscape.

Miraculous indeed is the produce of these little workers. And a fresh wonder is how the birds contrive to enter a nest on the wing when the opening seems scarcely so large as their body, and yet they do so without disturbing a feather. The hut of some savage races is left constantly open, their intelligence not suggesting a protecting

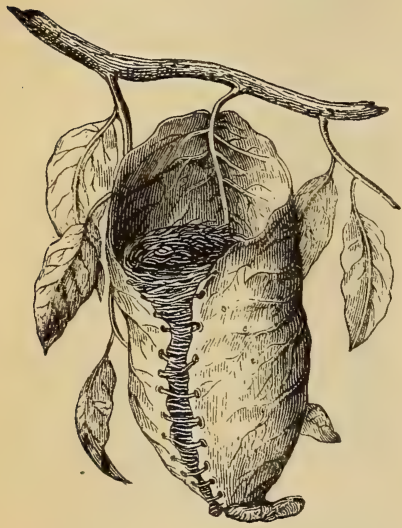

Fig. 76.-Nest of Tailor Bird.

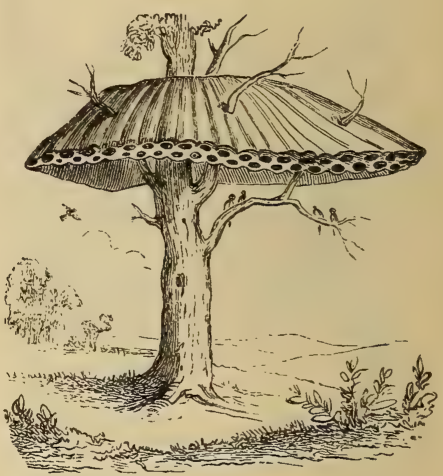

Fig. 77.-Nests of Sociable or Republican Birds.

door. In M. Jeudon's book on the "Birds of India," he speaks of a bird found there which, when the female begins to lay, the male encloses her in their nest by shutting up the door with a thick mud wall, leaving a small opening only sufficient for the female to breathe and receive her food; but we should add that this severe husband is not forgetful of his responsibility, but every few minutes conveys nourishment to the enclosed prisoner.

Sonnerat, in his "Voyage to India," speaks of a Cape Tit, the nest of which is in the form of a bottle, and composed of cotton. While the female hatches the eggs, the male, like a true sentinel, maintains a strict watch on a specially-formed resting-place, built on one of the sides. Finally, for ingenious construction, instigated 
by affection for its progeny, there is nothing to compare to the work of the Sociable Weaver Bird. This Cape bird, also called Republican Bird, which is about the size of and resembles a Sparrow, lives in numerous families, that unite in forming immense colonies. Their dwellings have the appearance of a circular framework or umbrella surrounding the trunk of a tree, as represented in Fig. 77. Levaillant counted as many as 300 cells, which indicate that it is inhabited by 600 birds. These nests are so heavy that Levaillant was compelled to employ a cart with many men in transporting one of their colonies. Again, the esculent nest of the Eastern Swallow, the one so much sought after by gourmands, hangs from cliffs washed by the sea, and is constructed of a fucus or marine plant of the genus Gelidium, which gelatinous substance, cemented by the saliva of the bird, forms a paste, considered by the epicures of some countries to possess a most delicate flavour.

Eggs are generally numerous in inverse proportion to the size of the bird. The Eagle lays two, for instance, while the Wren lays occasionally twelve. After the eggs are laid, the female must submit to the long and painful labour of incubation. While the male watches in the neighbouring bush to defend his embryo brood against any enemy which may present itself, giving battle to much larger animals than himself if they venture to attack his nest, the female only quits her charge for necessary food, and her place is often occupied during her absence by her mate. Among the numerous enemies to be dreaded we may mention birds of prey, quadrupeds, reptiles, and, possibly more unfeeling than all, children with destructive instincts.

If nothing occurs to disturb the repose of the parent birds, the male, perched upon a neighbouring branch, pours out a song expressive of his felicity. The little ones are finally hatched, helpless and incapable, without feathers and with closed eyes, utterly dependent on their progenitors, by whom they are fed until they are capable of providing for themselves. The mother directs their first efforts, uttering a peculiar cry to attract them when she discovers a favourite morsel; defending them courageously, and, with a total abnegation of self, meeting the most formidable enemies; sometimes going so far for their protection as to offer herself a victim. How pitiful are the cries of a swallow whose nest is built under the roof of a house that is on fire! Fearlessly she rushes into the flames, to rescue her young or perish with them in the attempt. Or mark the unhappy partridge which the sportsman has surprised on the nest. She hesitates not to offer herself a sacrifice, rushing almost 
under the intruder's feet, in order to attract his attention from her progeny.

When the young are matured, they abandon the family tie, and soon lose themselves in the great world of Nature, forgetful of their parents' unselfish care. The ingratitude of their first-born does not, however, discourage the forsaken couple. With the returning season they renew their labours, exhibit the same solicitude, the same affection, to meet with the same return. Nature is an unfailing source, an eternal focus, of tenderness and love.

Most families of birds are migratory ; that is, they abandon their summer quarters and undertake long journeys at certain seasons. These migrations occur with the greatest regularity. By their departure from temperate or cold climates they prognosticate the approach of winter, as their return heralds spring. Among the ancient Greeks, as we learn from a passage of Aristophanes on Birds, the arrival of the crane pointed out the time of sowing; the arrival of the kite the sheep-shearing season; and the arrival of the swallow the date for putting off summer clothing. The impulse which causes birds to depart is an instinctive desire to find climatic conditions appropriate to their wants of life. At the approach of winter they desert the regions of the north in search of southern countries with a warmer climate, while others migrate northwards to escape the heat.

Nevertheless, all birds are not migratory; many species remain during their whole lives in the locality where they were hatched, straying but little from their birth-place. The majority of those which migrate perform their journeys annually and with great regularity; a few of them irregularly and accidentally, that is, they do so by necessity, or are forced by atmospheric influences to change their residence; and it is no unusual sight on such occasions to see numerous flocks of birds assembling under the leadership of a chief, and taking their departure. On the 22nd of September, I771, White of Selborne witnessed the flight of a flock of swallows which had rendezvoused the night before in a neighbour's walnut-tree. "At dawn of what was a very foggy day, they arose altogether in infinite numbers, occasioning such a rustling from the strokes of their wings against the hazy atmosphere that the sound might be heard at a considerable distance." In the Old World, choosing a time when the winds are favourable, most migratory birds direct their flight towards the south-east in the autumn, and the north-west in spring. In America the migratory birds take a southerly direction in autumn, and the reverse in spring. These aërial travellers instinctively direct their 
flight to the same regions-often to the same district, which they previously inhabited, and there are good grounds to believe that the same pair frequently find their way year after year to the same nest.

The duration of the life of birds in a state of nature is one of those subjects on which little is known. Some ancient authors-Hesiod and Pliny for example-give to the crow nine times the length of life allotted to man, and to the raven three times that period; in other words, the crow, according to these authors, attains to 720 years, and the raven 240 . The swan, on the same authority, lives 200 years. This longevity is doubtful. Parrots; however, are known to have reached more than a hundred years. Goldfinches, chaffinches, and nightingales unquestionably, even in the confinement of a cage, have lived four-and-twenty. Girardin tells us a heron lived fifty-two years, which was testified by the ring which he bore on one of his legs, and even then he lost his life by an accident, while in full vigour. A couple of storks, moreover, have been known to nestle in the same place for more than forty years. All that we can affirm is that Birds live much longer than the Mammalia.

We can easily fix a circumscribed geographical boundary to any species of Mammalia. They may be limited to a country, or even a district. Can we impose a like boundary on Birds? At first sight this seems difficult : their powerful organs of locomotion permit of their travelling rapidly; and, moreover, their nature, essentially mobile, and their wandering humour, lead them to continual change; and then their organisation adapts them for great extremes of temperature-circumstances which would lead us to consider them quite cosmopolite. Nevertheless, many species reside habitually in countries of very limited range. A sovereign hand has traced on the surface of the globe limits that cannot be passed. How such diminutive creatures are able to perform such distant journeys, has always been a matter of surprise. How can the quail, for instance, with its short wing and plump body, traverse the Mediterranean twice in the year? Hasselquist tells us that small short-winged birds frequently came on board his ship in squally weather, all the way from the Channel to the Levant; and Prince Charles Bonaparte was agreeably surprised by the visit of a party of swallows to the ship Delaware, in which he was a passenger, when 500 miles from the coast of Portugal, and 400 from Africa. Audubon relates a similar occurrence; and numerous instances are recorded in which these migratory birds have taken shelter in the first vessel they met, sometimes so weak as to be hardly able to move a wing. It is therefore 
a fact truly inexplicable, in spite of every hypothesis more or less reasonable which has been advanced by naturalists.

Men have no control over birds, and therefore opportunities of studying their habits in a state of nature are few. Some species may be retained in captivity, and observers have been able to gain a knowledge of them while in that condition; but, except two or three species, it has been impossible to reduce them to a state of domestication. The habits and manners of the feathered race are, therefore, entirely dependent on chance observation.

The Humming-bird we know is confined to certain portions of America. The Nightingale, if a visitor to Scotland, is only found in Berwick and Dumfriesshire in fine seasons, while it is constantly seen in Sweden, a country much colder and much more northerly. The Toucans, so brilliant in plumage, are only found in tropical South America. The Swallow, so rapid on the wing, clearing its twenty leagues an hour when it leaves us for its southern winter quarters, never deviates from the route which seems to have been traced for it by a sovereign master, but the reasons we cannot define.

It may, then, be stated that the great zones of the earth differ as much in Birds as in the Mammifers found in them. We find in climatic regions birds, or groups of birds, of perfectly distinct species, and which are rarely found beyond that particular zone. Glancing at the various countries forming a region, particular types of birds are easily recognised. Africa, for instance, alone possesses the Great Ostrich, while only a small species exists in America, the Rhea; the Emu represents the genus in Australia, and the Cassowary in the Malaccas. Africa has species of birds brilliant as the most precious stones. To America belong exclusively the Hummingbirds, so remarkable for the brilliancy of their plumage. Again, if Africa is the country of the Vulture, to America belongs the Condor.

Nevertheless, the acclimatisation of birds is by no means beyond our power. Experience proves that by carrying a bird far from its native country, and placing it in conditions approaching those to which it has been accustomed, it will live and multiply-acclimate itself, in short, to its new home.

Europe possesses no ornithological type peculiar to it. It is only in Africa and America that we find those rich varieties of form and colour which characterise the feathered race. The Island of Madagascar is the land which possesses the greatest number of ornithological types-simply, perhaps, because that island abounds in 
species whose rudimentary wings do not permit of their wandering away. Whatever the cause, however, the species found there are not obtained elsewhere. There we find the unique Dodo, a form of animal which became extinct in the last century.

There is a wonderful charm of companionship in birds-they give animation to the scene, skipping from bush to bush, or skimming the surface of land and water. They please the eye by their graceful shape and plumage, and they charm our ears by their ceaseless warblings. Even for this we lie under a debt of gratitude to these graceful inhabitants of the air. But this is far from being the limit of the benefits we derive from them. The birds of the poultry-yards furnish our most delicate food ; their eggs form a considerable branch of trade, and are indispensable in the kitchen; and what would become of the country should our birds ever become extinct?-an event by no means improbable, seeing that in the year of grace $\mathbf{1} 868$ the head-dress of every votary of fashion was decorated with the wing of a bird, not confining the demand to Birds of Paradise and Ostriches, but using whatever varieties were obtainable ; but now, thank goodness, the law protects even the harmless sea-fowl, which were destroyed by thousands only for the sake of their wings.

Birds are useful to man by destroying insects, larvæ, and caterpillars which infest cultivated crops. Without their aid agriculture would become impossible. In former times it was a favourite doctrine with the agriculturist that the Passerina were the real destroyers of his crops, and a war of extermination was declared against them; but the observations of more enlightened persons have demonstrated that the chief food of most of these consists of insects, and the havoc among them has consequently been stayed; still much ignorance, and its concomitant, cruelty, exist on this point. Elsewhere, those interested soon discovered that the destruction of small birds led to formidable increase in the numbers of voracious insects - that these lively and joyous creatures, which float in the air and twitter on the bough, are sent us more for good than evil, and that if some of them make the crops pay a tax, they repay it tenfold by keeping down the excess of more destructive ravagers.

While the smaller birds have proved essentially beneficial to man, some of the larger birds exhibit similar tendencies. The Wading Bird clears the earth of serpents and other unclean and venomous animals. The Vultures and Storks consume corrupt carrion and divest the soil of all putrefying objects; thus, in concert with insects, 
birds are the scavengers of the earth, lending their aid to make it $a$ fit residence for man.

In former days falconry afforded a popular and noble sport for the great, in which lords and noble dames assisted. This pastime still exists in England and some portions of the East, especially in Persia, where the falcon is trained to chase the gazelle; while in China and Japan the cormorant and pelican are taught to fish the rivers for their masters. From very ancient times, the carrier pigeon was the bearer of messages now transmitted along the electric wires with lightning speed: the late siege of Paris brought them again into use.

Nor do these benefits comprise all the claims of birds on the gratitude of man. In tropical America the Agami or Trumpeter is domesticated, and so docile in its habits, that it is employed to watch the flocks, which it does with the fidelity and intelligence of a dog. "The Agami," says M. Monocour, "is not only tamed easily, but becomes attached to its benefactor with all the fondness and fidelity of a dog. When bred in the house, it loads the master with caresses, and follows all his motions with affection." It is bold and obstinate, and will attack cats and dogs, fighting a tough battle with one of the latter, however considerable his size. In Cayenne the denizens of the poultry-yard are confided to its care; it leads them to their pasture, prevents them from straying to a dangerous distance, and brings them home in the evening, just as a trained shepherd's dog will do the flocks committed to his care, and it manifests its delight by cries of joy when its master vouchsafes a caress in return for its faithful service. The Cariami, which belongs, like the Agami, to the same order, possesses similar characteristic intelligence. Like the former, it is sociable and susceptible of education, and becomes a most useful auxiliary to the inhabitants of South America.

After these brief remarks on the organisation and habits of Birds, we proceed to describe the more remarkable species, arranged according to a simple and comprehensive classification, placing before the reader the various orders of the class Aves, in the ascending scale which has been adopted in our previous works.

\section{Aves-Birds.}

Warm-blooded, vertebrated, biped animals. Pectoral limbs, forearms or wings organised for flight ; feathery integument; red blood; respiration and circulation double; lungs fixed and perforated. 


\section{Natatores, or Palmipedes.}

Swimming birds, having the toes united by a membrane; legs placed behind the equilibrium; the body covered with a thick coat of down beneath the feathers.

This order, as well as all the subsequent ones, are subdivided into families, genera, species, and even varieties.

The order of Natatores is most extensively represented all over the earth, the Arctic and Antarctic seas, as well as the lagoons and rivers of tropical zones, being the habitats of its different representatives. Their size also varies much, for the Albatross and Petrel, the Swan and the diminutive Teal, are included in it. Among them also is such great dissimilarity of form that the inexperienced in ornithology would never for a moment suppose that the Flamingo, with its long awkward-looking legs and peculiarly shaped bill, belonged to the same order as the active, graceful Tropic Bird or the slendershaped 'Tern.

\section{Grallatores.}

Wading birds, having the legs long and naked from the tibia downwards.

Much that I have said in reference to the former order can be applied to this one, for the diminutive Jack-snipe and the immense Ostrich are both included in it. Again, there is almost as much dissimilarity in some of the bills of members of this order as it would be possible to suppose--for instance, that of the Spoonbill and the Woodcock. Again, among the Grallatores are to be found some of the most valued birds for culinary purposes, while others are entirely unfit for human food.

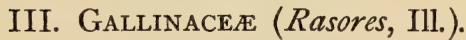

Scratching birds. Feet with strong, obtuse, scratching claws; mandible vaulted; nostrils pierced at the base, covered by a cartilaginous scale. Domestic and Jungle Fowl.

Difference of size is not so conspicuous among the members of this order, although the Pea-fowl and Turtle Dove are both included in it. They are, with few exceptions, natives of tropical and temperate climates.

\section{SCANSORES.}

Climbing birds, with opposing toes in pairs, two behind and two before. 
The majority of Scansores belong to the tropics; a few families, such as Woodpeckers and Cuckoos, visit or permanently reside in temperate climates. Many are possessed of the most brilliant plumage.

\section{PAsserines.}

Outward toe united to the middle one in a more or less extended manner. Cuvier divides them into five families, the first unly being based on the structure of the feet, the others on the formation of the bill. Although arbitrary we shall follow this distribution.

Passerines are to be found in all climates. They also differ much in size and formation - thus, what could be more dissimilar than the Rhinoceros Hornbill and our familiar Robin Redbreast. In this order are not only to be found the most brilliantly-coloured birds, but those possessed of the most graceful plumage. A further attraction some of them possess is that charming power of song that never fails to delight the human ear.

\section{RAPTORES.}

Rapacious birds, with strong, curved, pointed, and sharp-edged beak; legs short and robust, three toes before and one behind, armed with strong crooked talons.

Representatives of this order are to be found in every climate. They are generally possessed of sombre dull plumage, and have, with one exception, no melody in their voice. From their predatory habits they are not favourites with the human family, still many genera are of eminent service to man, for they consume the offal that in tropical climates would be certain to engender disease. 


\section{CHAPTER I.}

THE NATATORES, OR SWIMMING BIRDS.

THE Natatores are devoted, by organisation, to an aquatic life. Their haunts are the ocean, rivers, and lakes. They are characterised by the form of their feet. The toes are united by the extension of webs between them, hence the name of Palmipedes, usually applied to them. These broad palmate feet, acting at the end of a long lever, when fully expanded, are forced against the water, and thus drive the bird forward, and, to repeat its stroke, the toes are relaxed in their forward movement, preparatory to another effort.

Some of the Swimming Birds in their flight are feeble and slow; others are incapable of even rising from the water, being only furnished with rudimentary wings. Again, there are species which possess extraordinary power of traversing the air, their well-developed wings enabling them to pass through space with wonderful rapidity. The Petrels seem to delight in storms and tempests, mingling their wild cry with the roar of the waves. The dread which is experienced by the mariner at the approach of the anticipated gale is unknown to the Sea Gull and Albatross, for they appear to revel in the warring of the elements.

The whole order of Natatores swim and dive without saturation, their plumage being anointed with an oily liquid furnished by certain glands in their skin, which renders them impervious to moisture. This immunity from the effect of water is further assisted by the disposition and structure of their feathers, which, being smooth and three-cornered, with the barbules closely interlaced, cause the water to glide off their polished surface; while the down beneath the feathers protects their bodies from the cold of the most rigorous winters.

The Natatores are numerous both in species and individuals, having their habitat in all countries. According to Prince Charles Bonaparte, one of the most eminent of European naturalists, those which frequent the sea constitute, one-fourteenth part of all the birds on the globe, and the number of species he reckons at 9,400, They 
feed on vegetables, insects, molluscs, and fishes. They seek the coast in the breeding season, where they build their nests on the sand, in nooks and crannies of the rocks, or on the margin of lakes and rivers.

In the spring the sea-birds assemble in large flocks, pair, and proceed to lay; their nests are constructed generally without skill, but always lined or carpeted with down, which forms a soft warm bed for the embryo progeny. Certain localities are frequented by preference, these are occupied by innumerable flocks in the breeding season, all of which seem to live together in perfect harmony. Some of the families of the Natatores are valuable additions to the poultryyard. Ducks and Geese furnish delicate and nourishing food for man; the Swan is gracefully ornamental on our lakes and ponds. The down of all the aquatic birds as an article of commerce is of immense value in northern countries. Their eggs constitute good food, and in many countries the inhabitants consume them in great quantities. Nor does their usefulness end here. Guano, so eagerly sought for by the farmer, is the excrement of aquatic fowls-this has accumulated for ages, until, in the South Pacific Ocean, it has formed whole islands, some of them being covered with this valuable agricultural assistant to the depth of ninety or a hundred yards. Nor is this so marvellous, if it is considered that 25,000 or 30,000 seabirds sleep on these islets night after night, and that each of them will yield half a pound of guano daily, which owes its unrivalled fertilising power to the ammoniacal salts, phosphate of lime, and fragments of feathers of which it is composed.

The order of Natatores or Palmipedes we will form into four families :- I. Brevipennes.

4. Longipennes.

2. Lamellirostres. 3. Totipalmates.

\section{The Divers (Brevipennes).}

Divers, Colymbus; Penguins, Aptenodytes; Auks, Alca; Grebes, Podiceps; and Guillemots, Uria.

The Birds which constitute this family of the Natatores are characterised by wings so thin and short as to be almost useless for the purposes of aërial locomotion. They are also called Brachypteres, from the Greek compound $\beta$ paxiss, short, and $\pi \tau \epsilon \operatorname{c} \rho$, winged. These are all habitual divers and indefatigable swimmers, using their wings as fish do their fins. To raise these after making the down-stroke requires a considerably greater effort than a bird of flight makes in raising its wings in the air, for which reason the second pectoral 
muscle in this and other diving birds has an unusually large development to give further strength. Their plumage is smooth and silky, and impervious to water from its oily nature. They live chiefly on the sea, coming on land in the breeding season.

The Divers (Colymbus) are distinguished from other Brachypteres by their beak being longer than the head, straight, robust, and nearly cylindrical, slightly compressed on the sides, acute, the upper mandible longer than the lower; their toes, in place of being each furnished with marginal membranes, have the three united by a single membrane; their feet being placed far backward and on the same perpendicular line with the tibia-an arrangement very unfavourable for walking, compelling the birds to take a vertical position, rendering their movements on land both painful and difficult.

They are, however, intrepid swimmers, and they dive with such alertness that it requires a quick eye and hand to shoot them. They are inhabitants of northern seas; there they build their nests in some solitary islet or desert promontory, where they lay two eggs, oblong in shape, and more or less in colour of an Isabella white. Fish, particularly the herring, form their principal food; crustaceans and marine vegetables are also eaten by them. Their flesh is tough and leathery, and has a disagreeable taste. In the winter they migrate to temperate countries, where they frequent rivers and lakes, returning to the northern regions when the ice has broken up.

There are three species described: the Great Northern Diver, the Arctic Diver, and the Imber Diver. But there is considerable doubt on this subject, the young of $C$. glacialis of the first and second year being so unlike the parent bird as to have been long supposed a distinct species.

\section{The Great Northern Diver (Colymbus glacialis, Fig. 78).}

The Great Northern Diver is one of those birds which seek their food on the bosom of the great deep. It is not numerous in British waters, and can scarcely be called gregarious, although adults sometimes, and the young more frequently, fish in small parties of five or six. A wanderer on the ocean, it not only frequents the margins of the sea, fishing in the bays and estuaries, but it is also met with many miles from the shore. Narrow channels, firths, coves, sealochs, and sandy bays are, however, its favourite resorts; there it floats, the body deeply submerged in the water. But though swimming deep in the water, it can overtake and shoot ahead of all its more buoyant congeners. But let us watch the actions of a pair of 
these children of the ocean, and listen while Mr. McGillivray describes one of those picturesque scenes in which he delights. "It is now the end of spring, when the returning warmth gives an increase of animation to the wandering tribes of the winged inhabitants of the ocean air; but the Loon makes comparatively little use of his wings, and his great bulk and robust frame would be ill adapted for the hovering flight of the Gulls and Petrels. There he comes, followed by his mate, advancing with marvellous speed. They have rounded the point, and now they stop for a moment to cast a searching glance along the shore, lest an enemy should be lurking there. Forward they start - the smooth water rippling

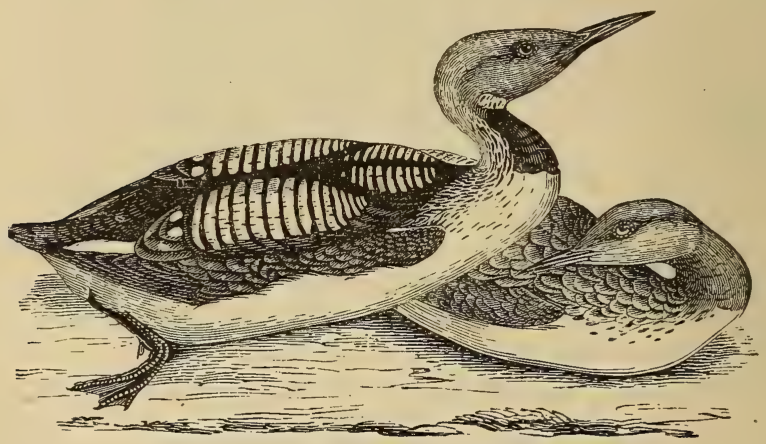

Fig. 78.-Great Northern Divers.

gently against their sides. Small effort they seem to make, and yet powerful must be the strokes of the oars which impel masses so large at so rapid a rate. Now and again they dip their bills into the water; then the head and neck. One glides gently under the surface, without plunge or flutter, and in a few seconds it appears with a fish in its bill, which, with upstretched head and neck, it swallows. The other having also dived, appears with a fish, larger, and less easily managed. It beats it about, plashing the water, and seems unable to adapt it to the capacity of its gullet; but at length, after much striving, it is mastered, and the search is continued. Backwards and forwards, over the clear sand of the shallow bay, they glide in their quiet way, and now they have both dived with their heads towards us. One rises close to the sea-weed, and so near to us, that we might almost count the spots on his 
back. The other, in emerging, has perceived us, and somehow communicates the discovery to her mate. They swim about for a short while with erected necks, then sink into the water, their heads disappearing last; and when we see them again, they are 300 yards distant, standing out to sea, with half-submerged bodies." "If shot at and not wounded," continues this most picturesque of writers on natural history, "it never flies off, but dips into the water and rises at a great distance, and unless shot dead, there is little chance of procuring it, for its tenacity of life is great, and its speed far exceeds that of a four-oared boat."

The great American naturalist, Audubon, has left a most interesting account of this bird in his "Ornithological Biography." After describing the various Transatlantic localities in which he has studied its economy, he describes its nest. "One that I saw," he says, "after the young had left it, on Lake Cayuga, was almost afloat, and rudely attached to the rushes, more than forty yards from the land, though its base was laid on the bottom, the water being only eight or nine inches deep. Others I examined in Labrador were placed on dry land, several yards from the water, and raised to the height of nearly a foot above the decayed moss on which they rested. The nest, however placed, is bulky, and formed of withered grasses and herbaceous plants found in the neighbourhood. The true nest, which is from a foot to fifteen inches in diameter, is raised to the height of seven or eight inches. Of the many nests I have examined, more contained three than two eggs, and I am confident that the former number most frequently occurs."

Of this handsome bird Sir John Richardson remarks, contrary to the generally-received notion, that it is seldom seen either in the Arctic Sea or Hudson's Bay, but that it abounds in all the inland lakes. It is rarely found on land, being ill fitted for walking, but admirably adapted to aquatic habits, swimming with great swiftness and for considerable distances under water; and when it does come up, seldom exposing more than its neck. It flies heavily, but rather swiftly, and in a circle round those who have disturbed it in its haunts, its loud and melancholy cry resembling the howling of the wolf, or the distant scream of a man in distress. When the Loon calls frequently, it is supposed to portend a storm. In the bad weather preceding the advent of winter on the smaller northern American lakes, previous to migration, their wild, weird note is so unnatural, that both the Indians and settlers ascribe to it supernatural powers. 


\section{The Black-Throated Diver (Colymbus arcticus).}

Smaller and more slender than the Great Northern Diver, this species retains many of its characteristic habits. It floats deep in the water, and when alarmed, swims at surprising speed, with outstretched neck and rapid beat of the wings, and little more than its head above the surface. It flies high and in a direct course with great rapidity. Mr. Selby describes an ineffectual pursuit of a pair on Loch Shin, in Sutherlandshire, which was long persevered in. In this case submersion frequently took place, which continued for nearly two minutes at a time, and they generally reappeared at nearly a quarter of a mile distant from the spot at which they went down. In no instance did he ever see them attempt to escape by taking wing. "I may observe," says this acute ornithologist, "that a visible track from the water to the nest was made by the female, whose progress on land is effected by shuffling along upon her belly, propelled from behind by her legs." When swimming, they are in the constant habit of dipping their bill in the water with a graceful motion of the head and neck.

The Black-throated Diver has the beak and throat black; summit of the head ashy grey; the breast and the sides of the neck white, with black spots; the back and rump black; the coverts of the wings with white spots, and all the lower parts pure white. The bird, though rare in England and France, is very common in the north of Europe. It is found on the lakes of Siberia, of Iceland, in Greenland and Hudson's Bay, and sometimes in the Orkney Islands. The women of Lapland make bonnets with its skin dressed without removing the feathers; but in Norway it is considered an act of impiety to destroy it, as the different cries which it utters are said to prognosticate fine weather or rain.

'The, eggs, of which there are two, sometimes three, in the same nest, are of a very elongated oval form, three inches in length, two inches in their greatest girth, and of a brownish olive sprinkled with black or dark-brown spots, and are larger at one end than at the other.

\section{The Red-Throated Diver (Colymbus septentrionalis).}

The Red-throated Diver is smaller than either of the preceding, the plumage is dense and firm, the wings of moderate length, the tail rounded and firm; of blackish plumage, with a red mark on the throat, the belly and lower part of the neck being white. The head is of a changeable black and green colour. When it has young, in 
place of diving under water, as its ordinary habit is when threatened, it boldly attacks its enemies with its beak. Its skin serves the Greenlanders as clothing. It inhabits the Arctic seas of both hemispheres, is abundant about the Hebrides, in Norway, in Sweden, and even on the coast of Scotland. Its appearance on the French coast is very irregular, and only after great storms.

When on a long journey, they keep at a great height, moving rapidly in a direct course with outstretched wings. On these occasions they exceed the speed of most of their congeners. With their long outstretched necks and snow-white breasts, from their comparatively short wings, they present a curious and novel sight. When swimming they are extremely vigilant, and permit nothing to approach them. On the appearance of a boat they glide as it were out of sight under the water, without noise or flutter, and thence pursue their way with great rapidity, using wings as well as feet to propel themselves.

\section{The Penguins (Aptenodytes)}

belong exclusively to cold countries. They ra:ely quit the vicinity of land, yet seldom come ashore except in the breeding season, or when driven by squalls and storms from their favourite element. On shore they are compelled to sit erect. They carry the head very high and the neck stretched out, while their short winglets are advanced like two diminutive arms. When they sit perched in flocks on some lofty projecting rock.they might be mistaken at a distance for a line of soldiers.

At certain periods of the year the Penguins assemble on the beach as if they met preconcertedly for deliberation. These assemblies last for a day or two, and are conducted with an obvious degree of solemnity. When the meeting results in a decision, they proceed to work with great activity. Upon a ledge of rock, sufficiently level and of the necessary size, they trace a square with one of its sides parallel and overlooking the edge of the water, which is left open for the egress of the colony. Then with their beaks they proceed to collect all the stones in the neighbourhood, which they heap up outside the lines marked out, to serve them as a wall to shelter them from the prevailing winds. During the night these openings are guarded by sentinels. They afterwards divide the enclosure into smaller squares, each large enough to receive a certain number of nests, with a passage between each square. No architect could arrange the plan in a more regular manner. 
What is most singular is that the Albatross, a bird essentially aërial and adapted for flight, associates at this period with these half fish, half birds, the Penguins, so that the nest of an Albatross may be seen next the nest of a Penguin, and the whole colony, so differently constituted, appear to live on the best terms of intimacy. Each keeps to its own nest, and if by chance there is a complaint, it is that some Penguin has robbed the nest of his neighbour, the Albatross.

Other sea-birds come to partake of the hospitality of the little

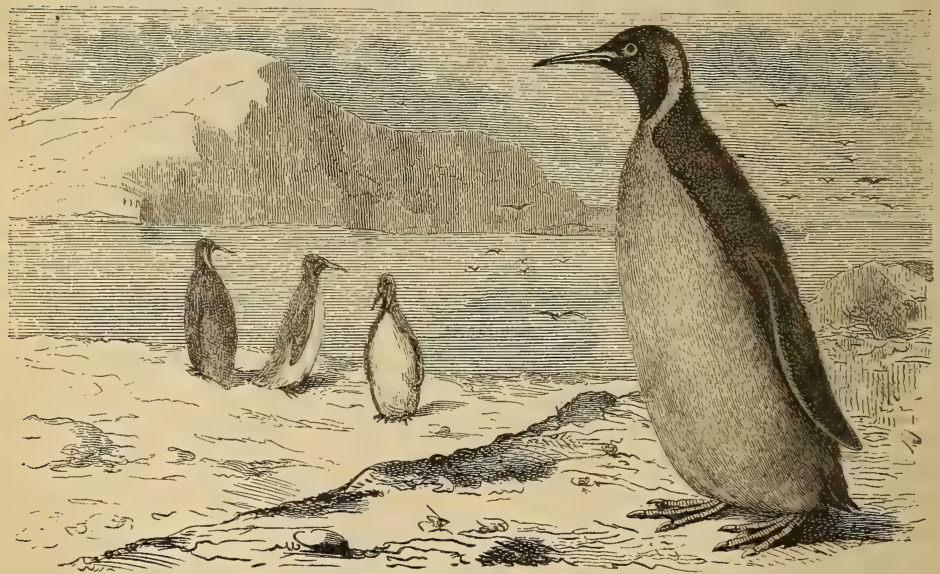

Fig. 79.-King Penguin.

republic. With the permission of the masters of the coterie they build their nests in the vacancies that occur in the squares.

The female Penguin lays but one egg, which she only leaves for a few instants until hatched, the male taking her place while she seeks her food. The Penguins are so numerous in the Antarctic seas, that I 00,000 eggs have been collected by the crew of one vessel.

The King Penguin (A. Pennantii, Fig. 79) has been described by most French naturalists as a distinct species. Of this there is little doubt. They abound in the southern seas. Their short, stunted wings, which quite incapacitate them from flying, are reduced to a flat and very short stump, totally destitute of feathers, being covered 
with a soft down, having something of the appearance of hair, which might be taken for scales. Like all the Penguins, this bird is an excellent swimmer and incomparable diver, and its coating of down is so dense that it even resists a bullet; it is consequently difficult to shoot.

The shape and appearance of the Penguins indicate their adaptation to an aquatic life. Their feet are placed at the extremity of the body-an arrangement which renders them awkward and heavy when ashore, where, in short, they only come to lay and hatch their eggs. They begin to assemble in great numbers at the commencement of October. Their nests are a very simple construction, for they content themselves with a hole in the sand deep enough to contain two eggs, but more often one.

In spite of the limited number of eggs, the quantity of these birds found in the south of Patagonia is something prodigious. When sailors land in these high latitudes they take or kill as many as they choose. Sir John Narborough says, speaking of those at the Falkland Islands, that "when the sailors walked among the feathered population to provide themselves with eggs, they were regarded with sidelong glances." In many places the shores were covered with these birds, and 300 have been taken within an hour; for generally they make no effort to escape, but stand quietly by while their companions are being knocked down with sticks.

In another islet, in the Straits of Magellan, Captain Drake's crew killed more than 3,000 in one day. These facts are not exaggerated. This island, when visited by these navigators, probably had never been pressed previously by a human foot, and the birds had succeeded each other from generation to generation in incalculable numbers, hitherto free from molestation.

The Penguins have no fear of man. Mr. Darwin pleasantly relates an encounter that he had with one of these birds on the Falkland Islands. "One day," he says, "having placed myself between a Penguin and the water, I was much amused by the action of the bird. It was a brave bird, and, till reaching the sea, it regularly fought and drove me backwards. Nothing less than heavy blows would have stopped him. Every inch gained he kept firmly, standing close before me firm, erect, and determined, all the time rolling his head from side to side in a very odd manner, as if the powers of vision only lay in the anterior and basal part of each eye." There are many species of Penguins, the handsomest probably being the Crested Penguin (Eudypes chrysocoma), which is a native of Patagonia, and has a very conspicuous appearance. These birds are 
called by sailors, regardless of species, Jackass Penguins, from their habit, when on shore, of throwing their head backwards, and of making a strange loud noise very like the braying of an ass.

This family all defend themselves vigorously with their beaks when an attempt is made to lay hands upon them; and, when pursued, they will pretend to retreat, and return immediately, throwing themselves upon their assailant. "At other times they will look at you askance," says Pernetty, "the head inclined first on one side, then on the other, as if they were mocking you." They hold themselves upright on their feet, the body erect in a perpendicular line with the head. In this attitude they might be taken for a party of choristers with white surplices and black gowns. Navigators passing these islands of the southern seas might suppose that they were densely inhabited, for the loud roaring voices of these birds produce a noise equal to that of a great crowd. The flesh is most unpalatable, but it is frequently the only resource of ship's crews who find themselves short of provisions in these inhospitable regions. However, their eggs have the redeeming quality of being excellent.

\section{The Auk (Alca)}

is a noble bird, which was once common in our waters, but at this date scarce even in the Arctic Seas; as it is but little known we refer our readers to Fig. 80 for a knowledge of its appearance. In habits and mode of life it strongly resembles the Penguins.

\section{The Grebes (Podiceps).}

The Grebes have the head small, the neck somewhat elongated, the legs attached to the abdomen, the tail rudimentary, the tarsi compressed, the anterior toes united at their base by a membrane slightly lobed in its contracted extent. These birds live on the sea, but they inhabit fresh water by preference, feeding on small fishes, worms, molluscs, insects, and the products of aquatic vegetation. While they dive and swim admirably, they also fly with vigorous wing; but they rarely resort to this unless alarmed or under migrating impulse. If the latter be the case, it is to visit the interior lakes, or to select a breeding-place.

The nest of the Grebe is usually placed in a tuft of rushes on the edge of the water. It is composed exteriorly of large grassy plants roughly interlaced, and the interior is lined with soft broken grasses delicately arranged. The eggs vary from three to seven. On shore 
they cannot walk, but creep, so to speak ; for they must hold themselves nearly upright, supported on the croup, the toes and the tarsi being extended laterally. But ungraceful as they are on shore, so much greater is their elegance on the water. They are covered with a close warm down, so close and so lustrous that muffs are made from their breast.

M. Noury, director of the Museum of Natural History at Elbœuf, who has carefully studied the habits of the Grebes, relates of the Great Crested Grebe, that its nest is a perfect raft, which floats upon

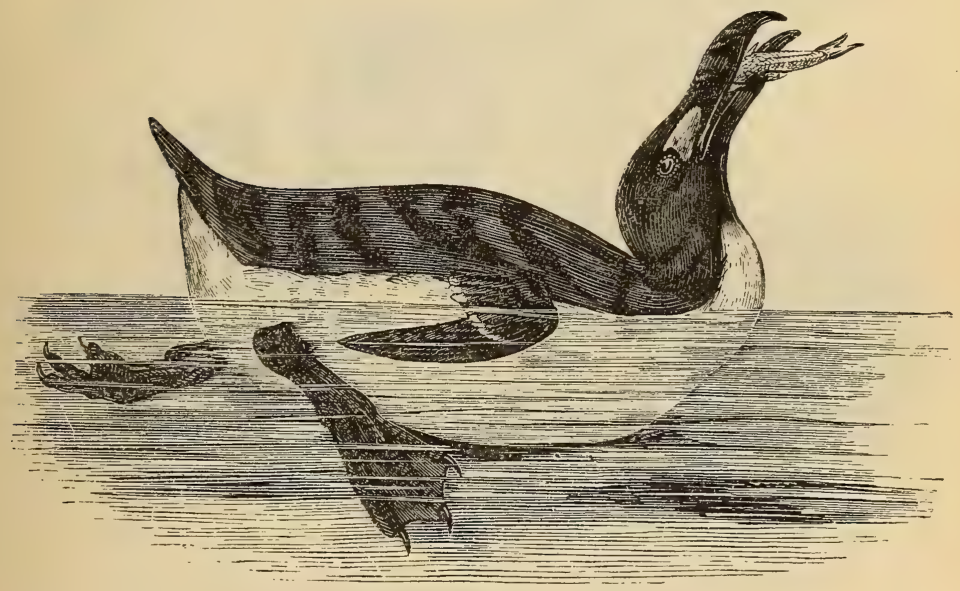

Fig. 8o--Auk.

the surface of our ponds and lakes. It is a mass of thick stems of aquatic herbs closely woven together; and as these materials contain a considerable quantity of air in their numerous cells, and various gases being engendered in decomposition, these aëriform supporters render the nest lighter than the water. In this improvised ship, and upon this humid bed, the female Grebe silently sits and hatches her progeny. But if anything unforeseen disturbs her security, this wild bird plunges one foot into the water, which she employs as an oar to transport her dwelling from the threatened danger.

Grebes are inhabitants of the old and new Continents. Among the European species may be noticed the Crested Grebe (Podiceps 
cristatus, Fig. 8r), about the size of a duck, ornamented with a double black crest; the Horned Grebe $(P$. cornutus), provided with two long tufts of feathers, in form somewhat resembling a horn; the Eared Grebe ( $P$. auritus), distinguished by its beak, the base of which is depressed, while the point is raised upwards. Among the American species may be mentioned $P$. carolinensis and $P$. rubricollis, killed at the Great Slave Lake, associated with $P$. cristatus and $P$. cornutus. $P$. chilensis and $P$. americanus are natives of the warmer parts of America, of St. Thomas, St. Domingo, and the Philippines.

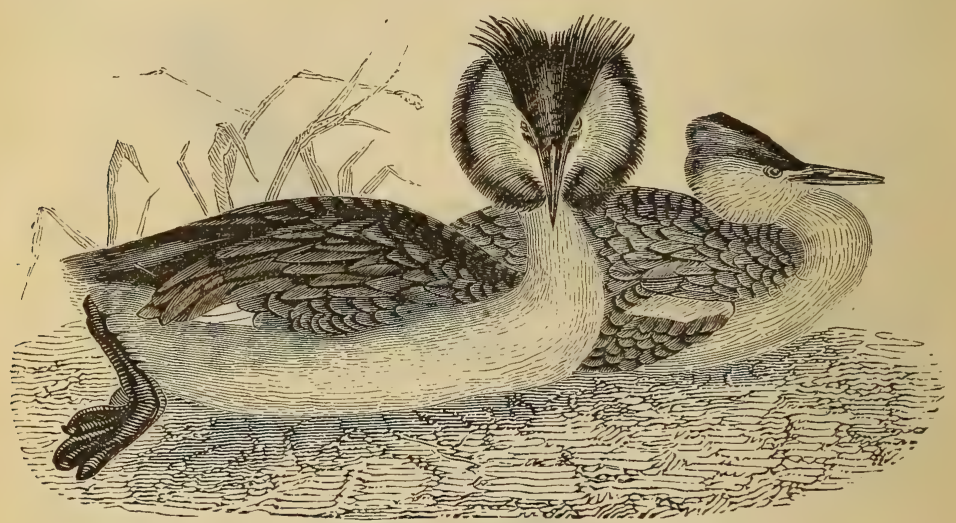

Fig. 81.-The Crested Grebe.

\section{The Crested Grebe (Podiceps cristatus).}

As a representative of the family the Crested Grebe had better be taken. It is found along our coasts and in their estuaries, in limited numbers; but in the splendid lakes of the North American fur countries, according to Dr. Richardson, this species is very abundant. Mr. Audubon says that it returns to the United States from its northern wanderings about the beginning of September, and proceeds south as far as Mexico, a few stragglers only remaining on the lower part of the Ohio, Mississippi, and the neighbouring lakes. "They pass swiftly through the air," says this enthusiastic naturalist, "at the height of about a hundred yards, in flocks of from seven and eight to fifty or more, proceeding in a loose body, and propelling themselves by continual flappings, their necks and feet stretched out to 
their full extent. When about to alight on the water, they glide swiftly downward, with their wings half closed, producing a sound not unlike that of a hawk swooping upon its prey. At this moment their velocity is so great that, on alighting, they slide forward on the surface of the water for twenty or thirty yards, leaving a deep furrow in their wake. They are exceedingly quick-sighted, and frequently elude, by diving, the shot which is aimed at them."

The Guillemots (Uria, Fig. 82) have the beak long, straight, convex above, somewhat angular below, a little curved and hollowed at the extremity of each mandible; the legs are short, compressed, and placed well behind the body; the three anterior toes are united by the same membrane; the claws re-curved and pointed; no hind toe; the wings are straight, and the tail short. These birds, when placed on the ground, raise themselves with great difficulty, owing to the conformation of their legs. They only come ashore when seeking shelter from the storm, or to

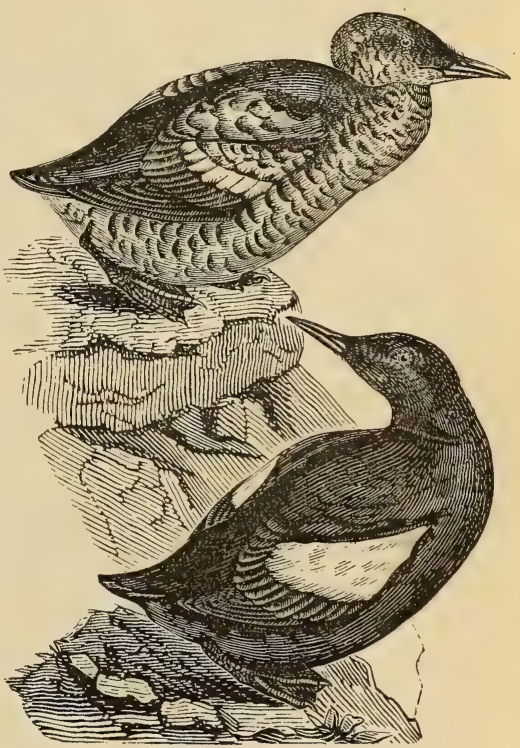

Fig. 82.-Gullemots. breed. For the latter purpose they choose some precipitous coast where the rocks project in ledges, from which they can throw themselves into the sea if they are disturbed. Boldly-scarped cliffs, which rise perpendicularly from the waves, are consequently their favourite resort. Unfortunately, the demand for the wings and down of the Guillemots has reached a point which is not unlikely to lead to their extermination. One London dealer, we are told, has given an order to a resident on Ailsa Craig, on the Clyde, for a thousand sea-birds weekly; and the tacksman of the rock is so intent on supplying the demand, that he spreads his nets while the birds are sitting on the newly-hatched young, which are thus left in thousands to perish, from being deprived of a mother's fostering care. 
Among the Guillemots the female lays only one large egg. They feed on fishes, insects, and on crustacea. They principally inhabit northern regions, visiting our shores and other temperate climates when the ice has invaded their summer home. In their migratory journeys they must trust to their wings-which, however, as already observed, are very short. They are consequently not possessed of long powers of flight, and skim the water, rarely rising much above the surface. Their progress, however, is rapid, but of short duration. The Guillemots during winter are frequently seen in immense numbers on Rockall Bank and on the banks of Newfoundland. So little are they alarmed at the approach of a vessel, that should they be directly in her track, they will only dive to save themselves. These banks are several hundred miles from land.

The whole race of aquatic birds of which we have spoken, whether Divers, Penguins, Grebes, or Guillemots, are, in these northern regions, a valuable source of revenue to the poor people whom lot compels to live there, for they obtain in their feathers, skin, oil, and eggs, clothing, food, and light. But to obtain what they truly consider a blessing from heaven they have to surmount innumerable difficulties, the birds often building their nests in islets almost unapproachable, or on rocks rising perpendicularly out of the water. Slung upon seats hung from the summits of these crags, the courageous islanders suspend themselves, to gather and make, so to speak, a harvest of the sea-fowls' eggs. Others traverse the face of the rocky coast furnished with a conical net attached to the end of a pole, and secure the birds flying around them, much in the same manner as boys catch butterflies in the meadows.

But chasing these graceful swimmers at the foot of their rocky retreat is mere trifling in comparison with the dramatic and dangerous incidents which occur on the summits of the steep giant cliffs. The intrepid inhabitants of the Faroe Islands, which are situated in the Atlantic Ocean, to the north of Scotland, between Norway and Iceland, proceed as follows when in search for eggs : The fowler begins operations by swarming, as schoolboys call it, up a pole, which carries him to the first projecting ledge of rocks which will afford a foot-hold. This point attained, he throws a knotted rope to his companions, who soon join him on his perch. The same manœuvre is performed, stage by stage, until they reach the summit. But this is nothing in comparison to the danger which is to come, viz., visiting the recesses in which the nests are found.

Upon the edge of the rock a beam is run out horizontally; to this beam a two-inch rope, which is not less than 900 feet in 



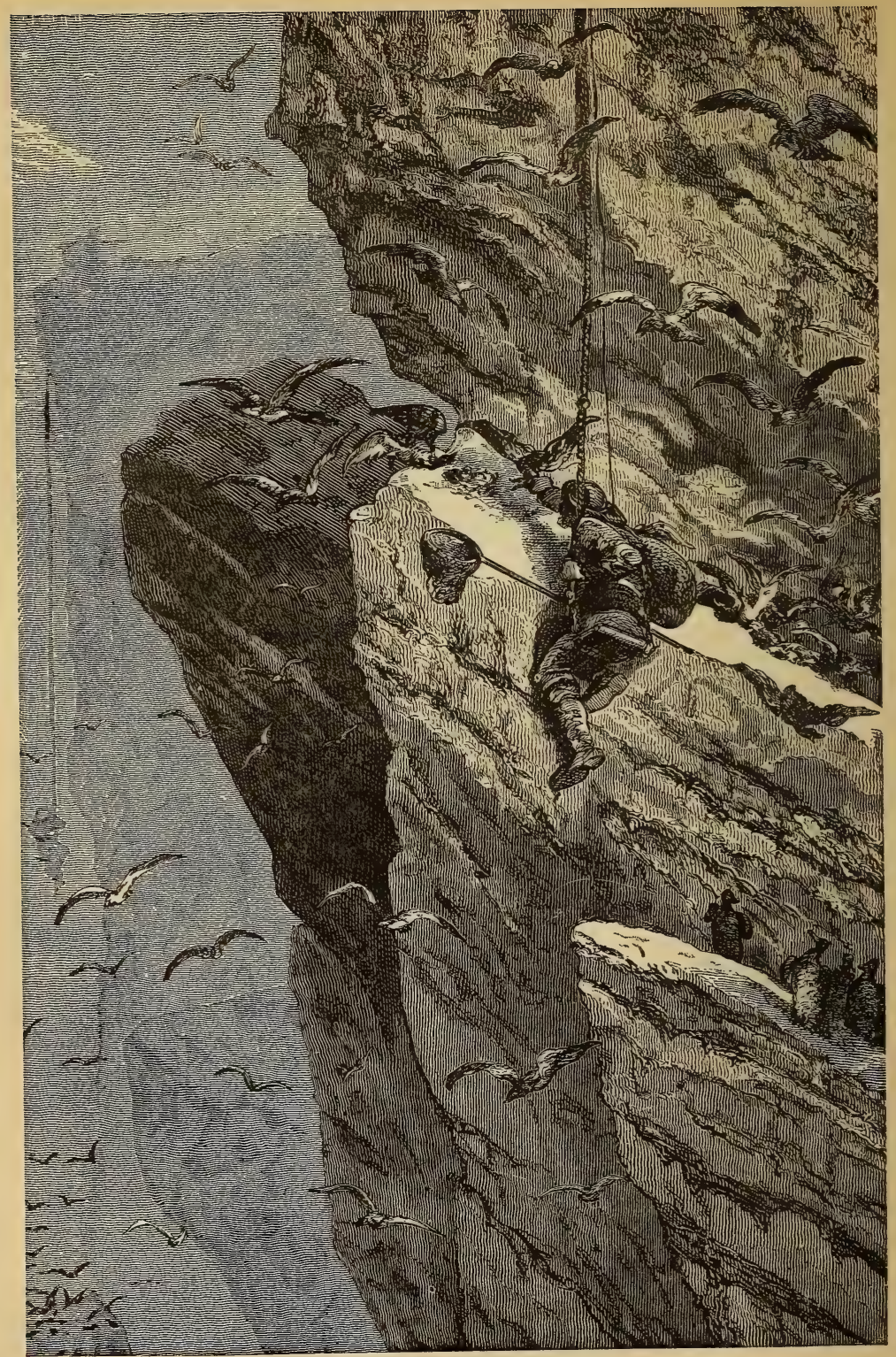

IV.-Gathering Eggs in the Faroe Islands. 
length, is attached. To the end of this immense line a plank is tied, upon which the fowler seats himself. This man holds in his hand a light cord for the purpose of signalling to his companions above. The fowler, thus seated, descends from cliff to cliff, and from rock to rock; he visits every nook and cranny in search of plunder, making an ample harvest of eggs and birds, either taking them by hand, or striking them with the end of his line. The product of his perilous expedition he places in a sort of havresack, which he carries slung from the shoulder. When he wishes to change his place, he gives a preconcerted signal with his cord, imparting an oscillating motion to it in the direction of that part of the rock he wishes to visit. When the harvest is deemed sufficient -when the day's sport is concluded-his companions are notified, and the fowler is hoisted to the summit of the cliff (Plate IV.)

How incredible is the address, and how great the courage, required to induce a man to let himself be suspended by a slender cord over a precipice some hundreds of feet in height; and how hazardous, how frightful the peril! for the cord might be cut by chafing against the sharp rock as he changes his situation from place to place. It has sometimes happened to those above to hear one loud heart-rending shriek, the cry of despair; the men who hold the rope lean forward, they see nothing, they hear only the great voice of the sea, which drowns all other sounds as it breaks against the cliffs ; they hasten to draw up the cord; alas, its reduced weight too plainly tells what has happened! The fowler has been seized with vertigo ; or, probably, he has overreached himself and lost his equilibrium on the slippery stones, and the wave which roars at the base of this wall of rock has closed over him.

It is such accidents as these which induce the inhabitant of the Faroe Islands, when he leaves his house on such an expedition, to bid farewell to his family. Fatal catastrophes, however, are not frequent. Men who live in those climates which Nature seems to have disinherited, become accustomed to struggle with the elements, and almost always to triumph over the dangers which surround them. They go to demand from the abyss food for their wives and children, and this animates and sustains their courage.

\section{The Common Guillemot (Uria Troile).}

Individuals of this species are to be found dispersed over all our seas, in small parties or singly, during the interval between the breeding seasons. In estuaries, bays, and narrows, where herrings 
or other fry are abundant, they congregate in vast numbers, along with Auks, Red-throated Divers, and Gulls of various species. About the end of April great quantities may be seen flying in strings along the coast towards their favourite haunts, which are the precipitous cliffs of Flamborough Head, the Farn Islands, St. Abb's Head, and other well-known spots on the English and Scottish seaboard. No preparation is made by the parent birds for the reception of the eggs, which are deposited in hollows of the rocks and ledges of the cliffs, each female laying a single one, although a great number are often seen so closely packed together as to be possibly covered by one bird.

Where the cliffs are lofty and other birds breed with them, the Guillemot occupies a zone above the Kittiwake and below the Razor-bill. "It is interesting," writes McGillivray, with the enthusiasm of one who has tried it, " to visit one of the great breedingplaces, to row along the foot of the cliffs in a boat, or to stand on a near promontory, and see the multitudes perched on the rocks, or flying out to sea or returning; or to look out from the summit upon the groups in sight; or startle from their stations a whole flock by letting down a large stone ; or to descend by some crevice, clinging with fingers and unshod feet to the little narrow ledges, and creep in among the eggs; or to be let down, dangling on a rope, half trembling between fear and excitement." 


\section{CHAPTER II.}

\section{DUCKS, GEESE, AND SWANS.}

Willoughby distributes the Palmipedes into such as have the back toe, and those in which it is absent; the former, again, into such as have the four toes webbed together, and such as have the back toe separated from the others. These latter he again subdivides into narrow-billed and broad-billed; the former having their bills either hooked at the end or straight and sharp-pointed. The hookbilled have them either even or toothed on the sides. The broadbilled are divided into Ducks and Geese. The Ducks are either sea or pond Ducks. "The Ducks," he adds, "have shorter necks and larger feet, in proportion to their bodies, than Geese. They have shorter legs than Geese, and situated more backward, so that they go waddling; a broader and flatter back, and so a more compressed body; and, lastly, a broader and flatter bill. Their tongue is pectinated, or toothed, on each side, which is common with them and the Geese."

"The Ducks are of two sorts, either wild or tame. The wild, again, are of two sorts :- I. Sea Ducks, which feed mostly in salt waters, dive much in feeding, have a broader bill (especially the upper one), and bend forward to work on the stem; a large hind toe, and then, likely for a rudder, a long train, not sharp-pointed. 2. Pond Ducks, which haunt plashes, have a straight and narrower bill, a very little hind toe, a sharp-pointed train, a white belly, speckled feathers, black, with glittering green on the middle wing, with a white transverse ring on either side."

According to Mr. Yarrell, the first division of Ducks comprises the Wild Duck, Shieldrake, Muscovy Duck, Gadwall, Shoveller, Pintail, Widgeon, Bimaculated Duck, Garganey, and Teals, all of which exhibit length of neck, wings reaching to the end of the tail, tarsi somewhat round, hind toe free or without pendent lobe. They generally frequent fresh water, but pass much of their time on land, feeding on aquatic plants, insects, worms, and sometimes fish. The 
second division includes the Red-crested Duck, Pochard, Ferruginous Duck, Scaup, Tufted Duck, Harlequin Duck, Long-tailed Duck, and Golden Eye; while between the two divisions he places, as possessing some of the characters of each, the Eider Duck, King Duck, Velvet Duck, and Scoter.

McGillivray accepts this arrangement, with some slight variations, remarking that the differences as to habits, as well as structure, are quite obvious; and he gives us a graphic description of the three types. "High in air," he says, "advancing on gently arched and outspread wings, that winnow a passage for them over the far-spreading sea, is seen advancing from the north a flock of large birds, that are observed, as they draw nearer, to be arranged in lines ever undulating and changing figure; while their clear cries seem to express their joy at having escaped the dangers of their long passage over the waste of waters. Now they descend, mingle their ranks, wheel in dislocated bands, unite, sweep along, and, clamorous in their joy, at length alight on the open pasture. Having rested a while and plumed themselves, they begin to move about in search of food, walking sedately and with decurrent necks, stretching their strong bills to the ground, from which they wrench the roots of the grasses and pluck the herbage. Prudent, however-as they well need be in an unexplored tract-and careful of their safety, they neither scatter about at random nor leave themselves subject to surprise. Should a suspicious object present itself, one of them presently erects himself and emits a warning cry, on hearing which they all rise together, raise their necks to their full stretch, and carefully inspect the ground. Should the danger be imminent, they run a few paces forward, spread out their large wings, ascend into the air, and betake themselves to some distant place." These are of the first division, or Cribatores, as Mr. McGillivray calls them-more useful to man than the other aquatic birds, many of them not only affording him savoury food, but feathers, quills, and down; while some have become domesticated, and rival the gallinaceous fowls in utility: these are the Ducks and Geese of the poultry-yards and commons.

These web-footed birds, the Lamellirostra of Cuvier, are distinguished from all others by their laminated bills, which are thick, and have a covering of soft skin, they have also small teeth placed along the edge. The tongue is fleshy, broad, and dentated on the edge. They are aquatic, and principally inhabit the fresh-water lakes and rivers. Their wings being short, and living chiefly on the water, they are badly qualified for a sustained flight. Their food is mostly vegetable. 
Numerous flocks of Ducks of various species frequent the seashores and the rivers of all parts of the world. No family of Birds seems more profusely distributed over the world of waters; and some of them are remarkable for the brilliant colouring of their plumage. On land, the waddling gait of Ducks is anything but graceful, but in the water their appearance is alert and elegant. Look at them as they glide lightly over the surface of the stream, or mark them as they plunge into its bosom with a splash, either to bathe themselves or seek their food. All their movements here are executed with graceful ease, and it is easy to see that they are in their natural element. They love to paddle in the mud, where they find a sufficient supply of fcod to satisfy their voracity. But no description of animal matter comes amiss to them, whether water-insects, worms, slugs, snails, small frogs, bread, fresh or tainted meat, fish living or dead. They are such gluttons, that we have seen two of them fighting and disputing for more than an hour over the skin of an eel, or some other garbage, which one of them had partly swallowed, whilst his antagonist was dragging at the other end. To this division of the Anatidæ belongs the Mallard or Wild Duck, which may be considered typical of the others, and which is generally supposed to be the ancestor of the Domestic Duck.

\section{The Common Wild Duck or Mallard (Anas boschas).}

The plumage of the Wild Duck is dense and elastic. The head, throat, and upper part of the neck of the male are adorned with hues of a bright emerald green, shot with violet; its breast is of a purplish brown; its back is ashy brown, sprinkled with greyishwhite zigzag bars; the four feathers in the middle of the tail, curling up at the end in a semicircle, are of a blackish hue with a green reflection; its length is about twenty-four inches; length of wing, thirty-five inches. The female, which is always smaller than her mate, does not possess the bright colours which adorn the drake. Her plumage is brown and russet grey. Individuals sometimes, though seldom, vary. Sir William Jardine states that he has seen drakes having the upper parts of a bluish grey, decreasing in depth of colouring down the breast; and Mr. Yarrell mentions two instances in which females of this species have assumed, to a considerab'e extent, the appearance and plumage of the Mallard, even to the curling feathers of the tail. On the other hand, the male plumage, according to Mr. Waterton, undergoes a 
singular alteration. About the end of May the breast and back of the drake begin to change colour; in a few days the curled feathers of the tail drop out, and grey feathers begin to appear in the lovely green plumage round the eyes; and, by the 23 rd of June, scarcely one green feather remains. By the 6 th of July all the green feathers have disappeared, and the male has assumed the female garb, but darker in colour. In August this new plumage begins to drop off, and by the middle of October the drake again reappears in all the rich magnificence of its former dress.

The Mallard (Fig. 83) forms the original stock from which our

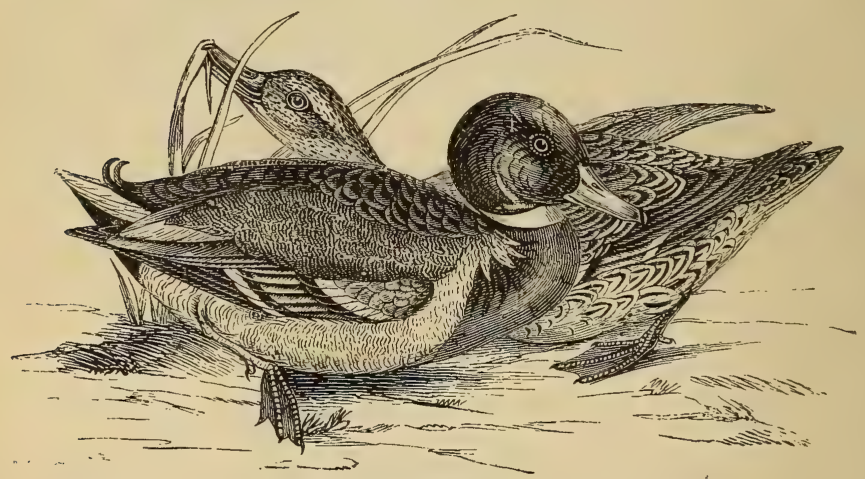

Fig. 83.-Wild Ducks or Mallard.

Domestic Ducks have sprung. Their favourite resorts are to be found in those hyperborean regions whose rigorous climate renders it uninhabitable by man. The rivers of Lapland, Greenland, and Siberia are sometimes literally covered with them; and, in the month of May, their nests are there found in quantities which imagination can scarcely picture. At the first approach of frost their earliest harbingers begin to appear among us, and about the middle of October these travelling bands arrive in increasing numbers.

Wild Ducks have a sustained and rapid flight. With powerful wings they raise themselves either from the land or water, and mount perpendicularly above the summits of the loftiest trees, when they take a more horizontal course, maintaining themselves at a great height, and making long journeys without rest. 'Triangular columns 



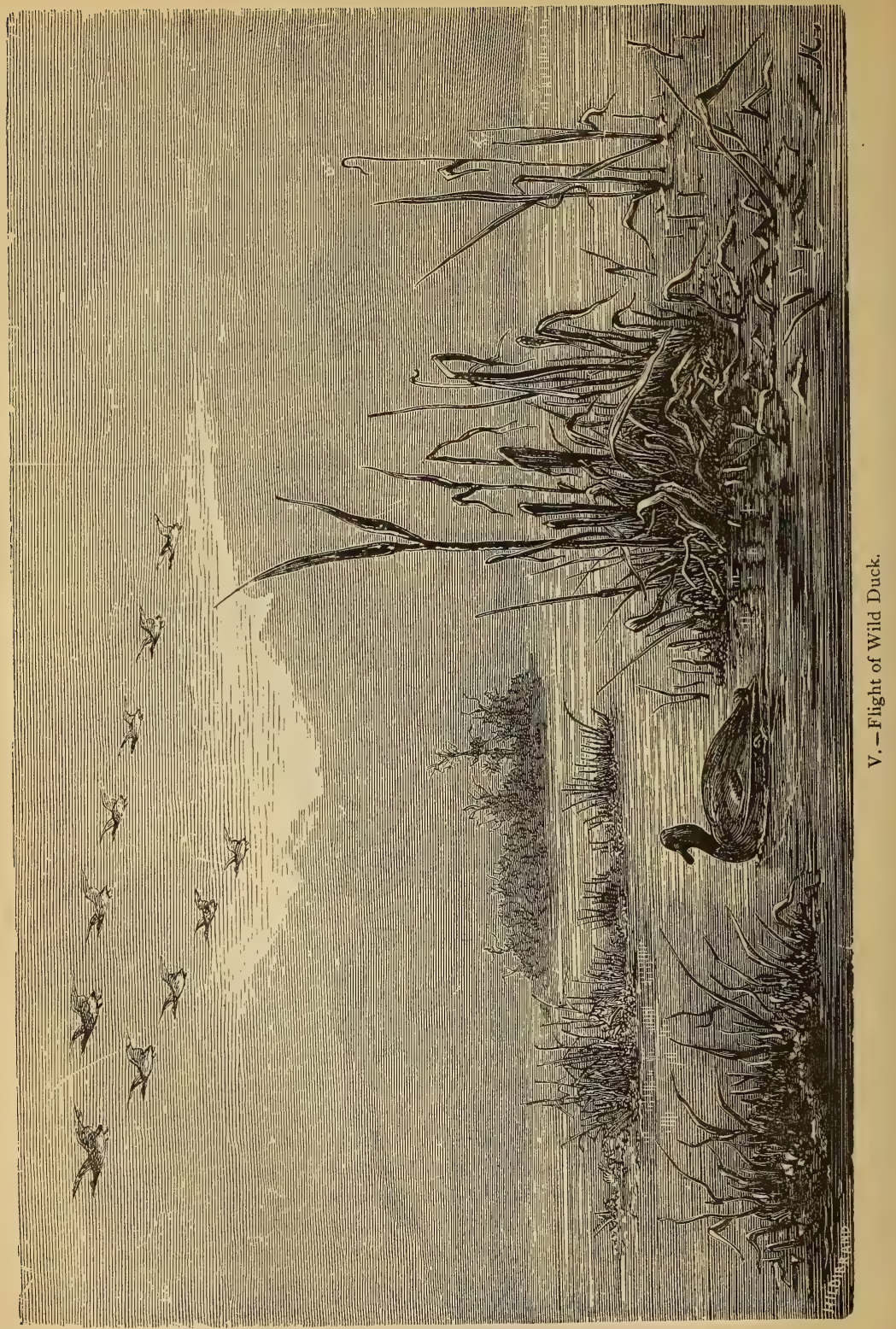


of them may sometimes be seen directing their unerring course towards their destination, the rustling of their wings being heard at considerable distances. The leading bird, which directs the course of the band, and which is thus exposed to the first resistance of the wind, from being foremost to cleave the air, soon becomes fatigued, when it falls back into the second rank, its place in the van being immediately taken by another (Plate V.)

Wild Ducks are extremely suspicious in their nature. When they want to settle down on any spot, or to go from one pool to another, they sweep round in concentric curves, descending and ascending again and again, until they have made a complete survey of their intended halting-place.

The margins of fresh-water lakes, pools, and marshes, are the principal localities frequented by the Wild Duck, so long as the frosts of winter do not prevent their obtaining the water-insects and aquatic weeds on which they feed. But when the ice has covered the stagnant waters, they betake themselves to more temperate climates, invariably following the courses of the rivers and running streams. When they return northward after the great thaw-that is, about the end of February-they disperse in pairs among the rushes, reeds, and sedge-grasses, in search of breeding-places, constructing a bulky nest of weeds, which is simply laid on the ground, and generally near to water.

Much ingenuity of construction is not to be looked for in the nest of the Wild Duck. A favourite situation is a thickly-grown tuft of sedge, from which they pluck off a few of the blades, bend down the other stems so as to form a foundation, the surface being covered with a soft layer of down. Their nests are occasionally found at some distance from water, amidst heath or broom, or even in the fork of a tree, the female having been known to take possession of a magpie or crow's nest, which had been abandoned.

The Duck lays from five to ten eggs, and sometimes more; their colour varies, but is generally a dull greenish white. The female sits alone, and only quits the nest to seek her food, when she covers it up carefully with any rubbish at hand; on her return, the cunning creature alights a considerable distance from it, and glides through the grass, looking in every direction to see that she is not watched; if discovered, she will even feign lameness to induce pursuit, so that she may draw off intruders from her brood.

Incubation lasts about a month. The young ones are then hatched, all generally bursting the egg on the same day. They are covered with a close yellow down, and are quite alert when they 
leave the shell ; and their mother soon leads them down to the water, encouraging them by her example to enter it. They do not return to the nest. At night their mother covers them under her wings, and at first feeds them with the small flies that come within her reach.

The ducklings, although they soon learn to swim, are unable to fly till after the expiration of three months; after that lapse of time wing-feathers are developed sufficiently to enable them to use their pinions. But they are always alert and active on the water, diving and remaining under it for many minutes, sometimes with nothing but the bill above the surface. When danger approaches, the mother utters a peculiar cry, and the young ones immediately conceal themselves. In a ditch full of water, Mr. McGillivray once came upon a whole brood of half-grown ducklings, which disappeared in a moment ; and although he searched everywhere for them, he did not succeed in finding a single one. When the Duck perceives the Great Blackbacked Gull, an enemy of her race, she beats the water with her wings as if to attract the attention of the aggressor; on his approach she darts at him with so much vigour that she frequently compels him to retreat.

Audubon relates a remarkable instance of maternal affection in this bird. The American naturalist had found in the woods a female of this species at the head of her young brood. As he approached, he noticed that her feathers became erect, and that she hissed with a threatening gesture, after the manner of geese. In the meantime the ducklings made off in all directions. His dog, which was perfectly trained, brought the little creatures to him, one by one, without doing them the least injury. But in all his proceedings he was watched by the mother, who kept passing and re-passing in front of him, as if to distract his attention. When the ducklings were all safe in the game-bag, in which they struggled and cried out, the mother came with a sad and troubled air, and placed herself close to the naturalist, as if unable to suppress her despair. Audubon, seeing her intense grief, was filled with pity, and restored her little family before leaving the spot. "When I turned round to watch her," adds he, "I really fancied I could detect an expression of gratitude in her eyes ; and I experienced at that moment one of the most vivid sensations of pleasure I have ever enjoyed."

Whilst the mother is devoting herself to the education of her brood, the father pays but little attention to his progeny. Jaded and thin, he lives a solitary and quiescent life, more sad and wild than ever. He has, in fact, to submit to a most sudden course of moulting. The female also loses her plumage after the young ones are hatched. 



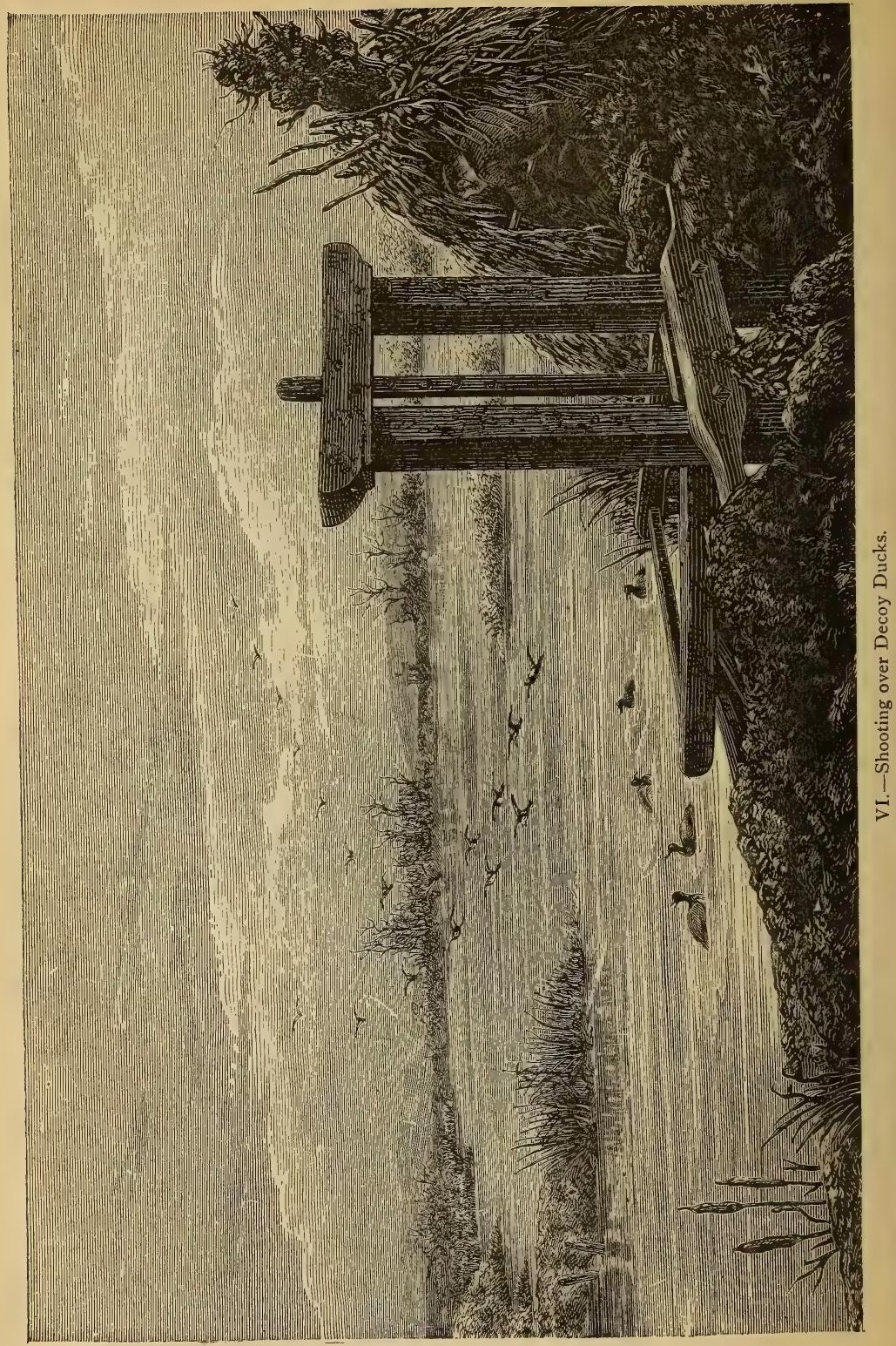


They neither of them regain their more brilliant dress until the end of autumn.

There are numerous instances proving that Wild Ducks are susceptible of attachment to man; and it is certain that they can be easily tamed. They also breed readily with the domestic Duck; and the crossed birds thus produced are said to have a superior flavour, and fatten with facility. Mr. St. John, in his "Wild Sports in the Highlands," remarks that he has frequently caught and brought home

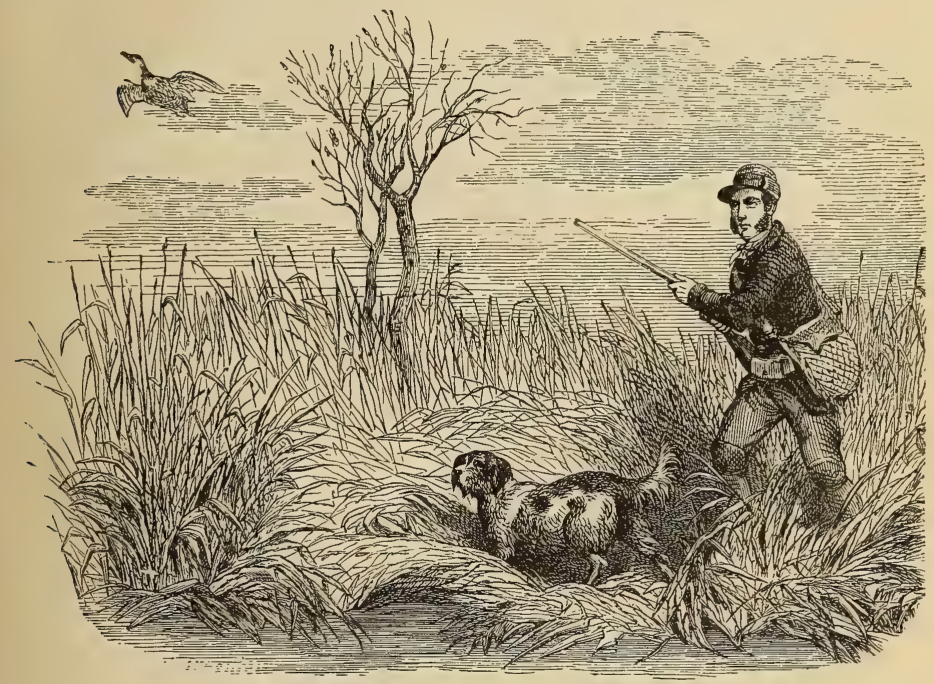

Fig. 84--Open Duck-shooting.

young Wild Ducks. "If confined in a yard with tame birds for a week or two, they strike up a companionship which keeps them from wandering when set at liberty. Some years ago I brought home three, two of which turned out to be drakes. I sent away my tame ducks, and the next season I had a large family of half-bred and wholly Wild Ducks, as the tame and wild bred together quite freely. The Wild Ducks which have been caught turned out the tamest of all, throwing off all shyness, they follow their feeder, and will eat corn out of the hand of any one they know ; while the half-bred birds are inclined to take wing and fly away for the purpose of making their nests at a distance." 
The fiesh of the Wild Duck is much esteemed. But they are birds which are very difficult to approach, in consequence of their suspicious nature ; and in order to get even a long shot at them, it is necessary to have recourse to stratagem. Even when successful in your aim, the shot often fails to penetrate, owing to the thick layers of their downy covering. Various artifices, therefore, are employed to lure them, all of which require some cleverness. Thus they are shot from a watching-place, being attracted to its neighbourhood by employing domestic Ducks, which act as decoys (Plate VI.) They are also shot from huts on the edge of the water. Sometimes they are lured by means of lights, or by imitating their call. Many are taken in nets, in decoy-weirs, and in snares; they are sometimes even taken by means of baited fish-hooks, and many other strange contrivances.

The ordinary open duck-shooting, as represented in Fig. 84, is far from being so productive as some of the former methods, but it is much more attractive. No sport is more uncertain, but occasionally none is more fruitful of success.

Duck-shooting from a hut, as represented in Plate VII., is the method most practised. The sportsmen are hidden in a small hut placed on the edge of some lake or river, or it may be erected in the middle of the water on a heap of stones. Here they lie in wait for the birds in order to get a close shot at them. They generally use fowling-pieces of great length and large calibre, called duck-guns. Shooting from duck-punts is also practised all round the coast, and on the larger lakes, ponds, and estuaries.

On the Saône, the gunners, accompanied by a boatman, take their places in a long, light, narrow, pointed boat, or punt, called a fourquette. The two men, lying down in the bottom of the boat, are hidden by brushwood placed in front of them, the muzzle of the duck-gun protruding through the twigs. Thus floating down the river among the ducks, they get an opportunity of shooting them without being perceived. Sportsmen in France sometimes employ a very odd artifice to baffle the suspicious instinct of these birds : a man disguises himself as a cow by means of an outline of the animal roughly made of common cardboard. Under favour of this disguise he gets near the wild ducks without exciting their fears, if only aware how to make good use of his device; that is, if he describes gentle and graceful curves, so as to advance gradually without alarming the timid Palmipedes. But this sport, though productive enough when skilfully managed, is not unattended with danger. A sportsman, who had dressed himself up in this disguise, happened 


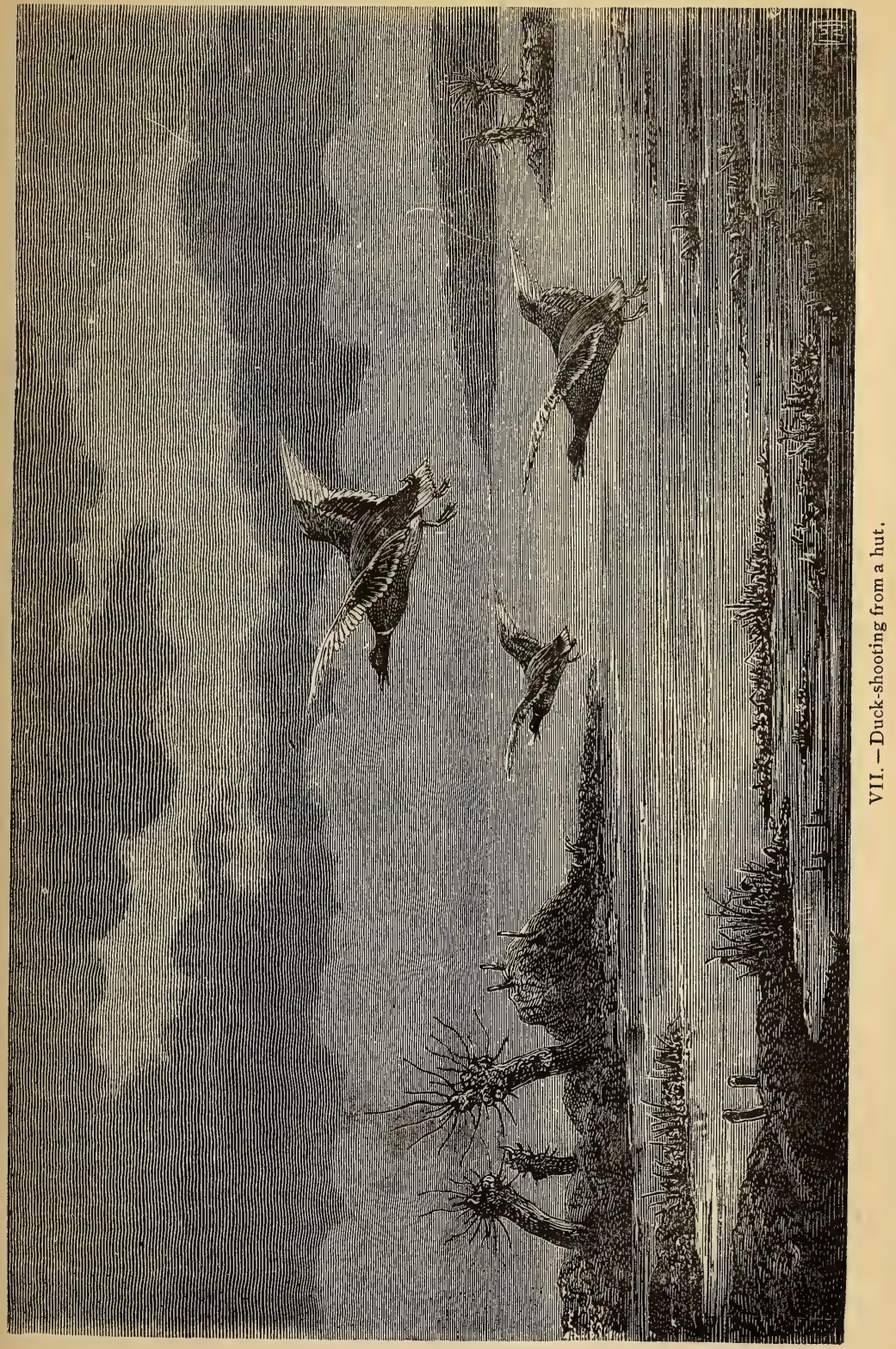



inadvertently to find his way among a herd of cattle, which, detecting the imposture, immediately ran at him and chased him about the meadow. He thought himself fortunate in escaping with the loss of his disguise, which he abandoned to the fury of his horned assailants.

Large numbers of Ducks are taken by means of nets and various snares, which want of space prevents us from here enumerating.

The Domestic Duck (Anas domestica) is a descendant of the Wild Duck, or, as some think, of the Shoveller. The first tame Duck, the ancestor of a family since so prodigiously multiplied, probably proceeded from an egg which had been taken from some reedy marsh, and hatched under a hen.

The Duck, however, has been reduced to a state of domesticity from a very remote period, and has been of incalculable utility to mankind, filling in our poultry-yards no unworthy place. Duck eggs are a wholesome and agreeable article of food, and the flesh of the bird itself is most savoury. Epicures highly prized, and rightly so, the pâtés de foie de canard of Toulouse, Strasbourg, Nérac, and Amiens (we arrange them here in their order of merit, not according to Baron Brisse's dictum, but following our own estimate of their qualities). Their feathers, although not so valuable as those of the goose, are articles of considerable importance in commerce.

Ducks are remunerative to those who rear them, for they are by no means choice in their food; nothing comes amiss to their palate, whether it be the corn scattered about the yard which is disdained by other fowls, or the leavings of the table and kitchen. All that they require as an essential is to have a little water within reach in which they can paddle at will.

Duck eggs are often put under a hen to be hatched. When seeking her food, the hen sometimes leads her little flock to the edge of water, to give them a glimpse of its dangers. But the ducklings, impelled by instinct, rush into the element they are most partial to. The poor mother, anxious for the fate of the young giddy-pates, whom she loves as her own offspring, utters cries of terror. She would resolutely throw herself into the stream, and perhaps get drowned, were she not soothed by seeing them swimming about, happy and active.

There are several favourite varieties of the Domestic Duck, but those of Normandy and Picardy, in France, and the Aylesbury Ducks, in England, are the most profitable. Every nation rears ducks; but the Chinese undeniably most excel in this art. For hatching 
them the Celestials have recourse to artificial heat. They also possess some superb varieties, which have been recently imported into Europe, and are at the present time the glory of our ornamental waters. Magnificent pairs of Chinese Ducks, of which the Mandarin is the most beautiful, may be admired in the Jardin d'Acclimatation at Paris, at the Zoological Gardens of the Regent's Park, and also in the artificial waters in the parks and gardens of our principal cities.

The common Wild Duck or Mallard, which we have described, is the type of the order of Ducks ; but there are about seventy other species. The must remarkable are the Golden Eye, Widgeon, Pochard, Shoveller, Shieldrake, the Eider Duck, the Teal, the Black Diver, and the Merganser.

\section{The Golden Eye (Anas clangula).}

The Golden Eye is sometimes called the Garrot. In some provinces it has received the nickname of the Harlequin Duck, * because its plumage, at a little distance off, looks as if it were composed of black and white feathers only. This variegated appearance, which occurs only in the males, makes a fine show on the dark pools and lakes of the north Highlands and Hebrides, where the scenery in winter is excessively dismal. When undisturbed, they float lightly on the surface; but if alarmed, they are said to sink themselves deeper in the water, diving rapidly, and swimming with great velocity. They fly also swiftly, in a direct manner, their small, stiff, and sharppointed wings producing a whistling sound, which is heard in calm weather at a considerable distance.t They rise easily from the water, striking it with their feet and wings for several yards; but under alarm, or when there is a breeze rippling the surface, they can ascend at once. During winter they are met with in all northern Europe, and in severe weather in the south of England. In Ireland, also, they are constant winter visitors; but they do not seem to breed with us, betaking themselves to the Arctic regions in spring, and returning in October. They are essentially lake ducks ; but they are also found on the open coasts and estuaries. Their flesi is darkcoloured and unsavoury, requiring all the art of the cook to conceal its natural fishy flavour.

* The Harlequin Duck (Clangula histrionica) is a different species from the Golden Eye. - ED.

+ From the noise made by their wings they are in some localities called Whistlers. 
They are generally plentiful in our markets, where the young and females not unfrequently go under the comprehensive name of Widgeons.

The Golden Eye flies low and rapidly. In the month of November it reaches France in small flocks, to remain till the spring. As it is not a shy bird, the sportsmen on the seacoasts of Picardy, Normandy, and the Landes, kill large quantities of them.

\section{The Pochard or Dunbird (Anas ferina).}

The Pochard nearly resembles the American Canvas-back Duck, but is unlike any British species in form. Its body (of the male)

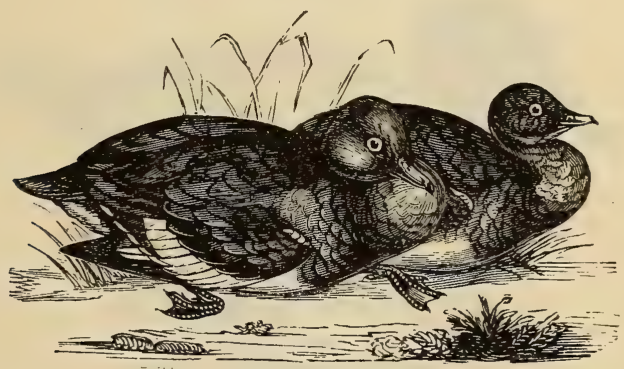

Fig. 85. - Pochard.

is large, full, depressed, and elliptical in form; its neck long and thick ; the head large, oblong, compressed, and rounded above. The plumage is dense, soft, and glossy. The feathers on the fore part of the head are small and stiff; on the remainder of the head and neck, soft, silky, and blended. The wings are short, curved, narrow, and pointed; the bill black to a little behind the nostrils, the intermediate space light greyish blue; the head, and half the neck all round, are of a fine brownish-orange tint.

The Pochard (Fig. 85) is, next to that of the Common Wild Duck, the variety which is most plentiful on our waters. It is almost as large as the latter; it makes its nest in the rushes round pools or lakes, and feeds upon the roots of grasses and aquatic plants, also on worms, molluscs, and small fish. They are plentiful in the eastern counties south of the Humber, and in the fen counties; and it occurs in America, where, as Dr. Richardson states, it breeds in all 
parts of the fur countries, from the fiftieth parallel to their most northerly limits. Audubon found it abundant in winter about New Orleans, in East Florida, and on the Chesapeake Bay. "Although they dive much and to a great depth in our bays and estuaries, yet, when in the shallow ponds of the interior, they prefer dabbling in the mud along the shores, much in the manner of the Mallard."

This bird reaches France in little flocks of twenty to forty in the month of October. It can easily be caught in nets.

The Canvas-back Duck (Anas vallisineria) of America, the most delicious of waterfowl, is next deserving of notice.

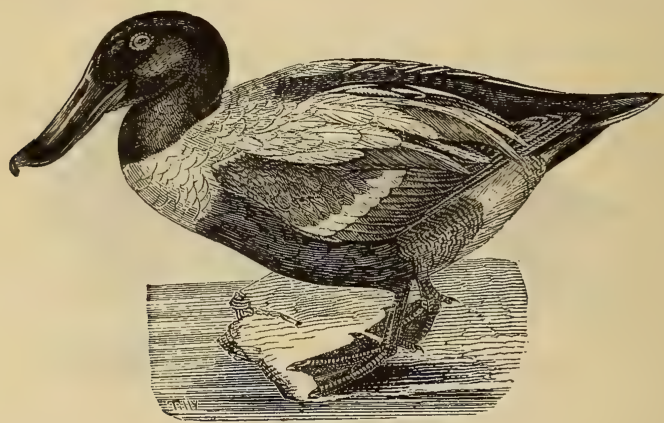

Fig 86. - The Shoveller.

The Shoveller (Anas clypeata).

The Shoveller (Fig. 86) is very common on the Seine and the Marne, where it is called rouge de rivière. It is smaller than the common Wild Duck, and has a very long bill, with the upper mandible of a semi-cylindrical shape, dilated at its extremity, somewhat in the form of a small spoon. This bird is really charming in the brilliancy of its plumage. Its head and neck are of a bright green, and its wings are variegated with streaks of a brilliant pale blue, green, white, and black. It is called "red" because its plumage underneath is of a brownish-red hue. In the month of February it abandons the icy regions of the north, to visit the more southern lakes and rivers of France and Germany. With us it is 
only a straggler, although in former days, when our system of drainage was less perfect, it was a more frequent visitor, and considerable numbers of them remained and bred. It dwells in marshes, on lakes and large rivers, being seldom found near the sea-coast; feeding occasionally on vegetable substances, but chiefly on fresh-water molluscs, worms, and insects, for grubbing up which, and separating them from the sand and mud, its bill is evidently well adapted.

The Shoveller is met with in various parts of Europe, also in Asia, Africa, and America. The nest is constructed on the borders of rushy lakes, and in it the birds lay from eight to twelve eggs. When first hatched, the young ones are excessively ugly, their beaks being almost as large as their bodies. The flesh of the Shoveller is tender and delicate, and preserves its pink colour even after it is cooked.

Before leaving the Anatina, the Wood Duck (Anas sponsa), the most beautiful of this family found in America; also the American Widgeon, or Bald-pate (Anas americana), ought not to be forgotten.

\section{The Shieldrake (Anas tadorna).}

This very beautiful bird is a permanent resident in the British Islands, although it is only met sparingly along our coasts. It resorts in spring and summer to the sandy bays on the west coast of England and Scotland, from the Land's End to the Shetland Islands. In autumn and winter it is found on the eastern coast both of Scotland and England, where many individuals remain to breed. It is generally found in the neighbourhood of sandy marshy land and moist meadows near the sea. It walks with a quickish step, and has a swift flight, something like the Mallard, and with a more rapid beat of the wings than the Goose.

The Shieldrake (Fig. 87 ) is the most remarkable of all the Duck tribe, not only from its size, but from its beauty and the elegant variations of its plumage. It is larger and stands higher on its legs than the common Wild Duck. The plumage is full, soft, and blended; the feathers of the head and upper neck are small and silky. The colours are very brilliant, being of a glossy blackish green on the head and neck, with purplish reflections in some lights; a broad band or ring of white is found on the neck, and lower another of orange-red encircles the fore part of the body. The rest of the under parts are white, with a band of glossy black on the breast and belly; the back white, variegated with black, white, russet, and green. The Shieldrake abounds on the coasts of the 
Baltic and North Sea; it is also found in America, and on the southern coasts of France, as well as on the edge of the Northern Ocean. The nest is usually placed in some indentation in the sand, the female frequently choosing a rabbit's hole, situated in a sandbank. The poor rabbit, thus turned out of its burrow, never ventures to return to it.

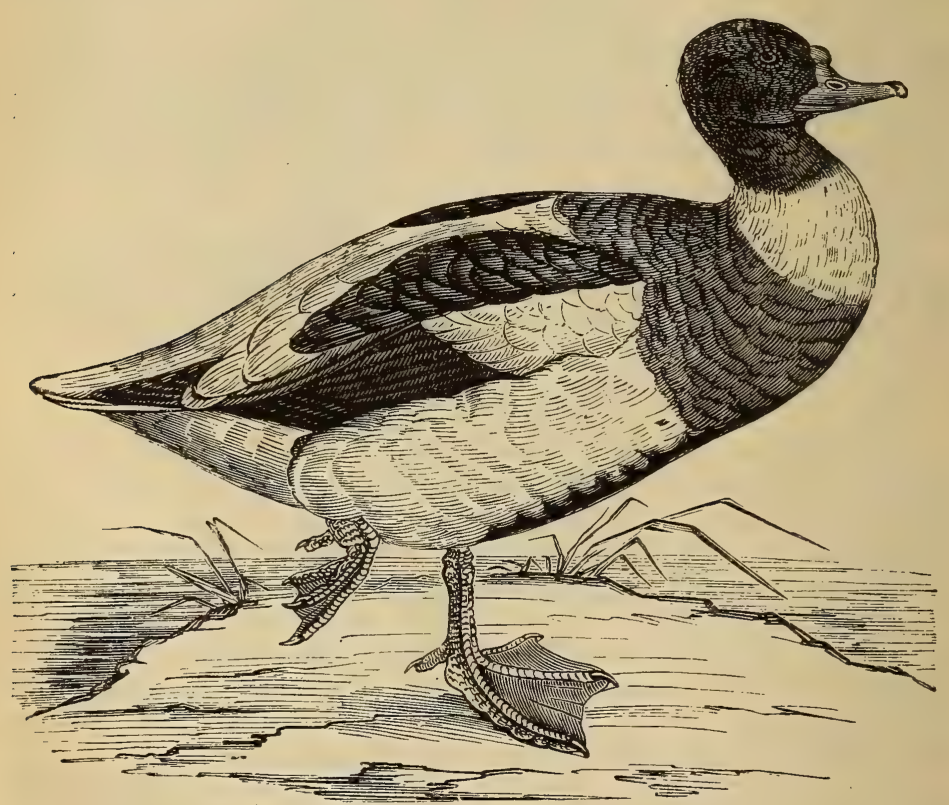

Fig 87.-The Shieldrake.

The Eider Duck (Anas molissima).

The Eider Duck, though remarkable for beauty of plumage, is nevertheless a very clumsy bird. In form it is bulky, depressed, and elliptical, with large, oblong, and compressed head. The plumage is dense and fine; the head-feathers are short, tufted, and rounded, and, blending with the terminal filaments, disunited; the wings diminutive, concave, narrow, and pointed, the tips of which 
extend to the base of the tail, which is short, round, and slightly decurvated.

The Eider Duck is the northern bird which supplies the soft, light, and warm material which is so well known under the name of " eider-down." Its plumage is whitish, but the upper part of the head, its belly, and its tail are black; the side of the head, the throat, and the neck, are white, but the hair-like feathers on the back part of the cheeks and nape are of a delicate pale green; the lower part of the neck is cream-coloured. The black parts, from their glossiness, are conspicuous, while the white look soiled; the head and back are also shaded with a green tint.

The Eider Duck is found in the Arctic and Antarctic regions, occurring in diminished numbers in the latter. In the Outer Hebrides it has many breeding-places, and some nests occur on the Bass Rock, and on the Farn Islands, off the coast of Northumberland, where the eggs have been found in the month of June. The nest is made in some hollow in the turf, and is composed of sea-weed and dried grass, mixed with such marine plants as Plantago maritima and Coronopsis. The eggs, which vary in number, are of a longish oval shape, smooth and glossy, and of a pale greenish grey. When they have been laid, the female is said to pluck the down from her breast and cover them over with it. This down, when shaken out, will occupy a space of nine or ten inches. This peculiar quality of the down, however, caused by its elastic character, belongs to all the Anatidæ, and probably not less so to the Anserinæ.

The principal home of the Eider Duck is on the bleak and frozen coast of Northern Europe ; and its food, which is obtained by diving, is the bivalve mollusca, also crustacea, fishes, and fishspawn, together with aquatic worms. It makes its nest on rocks. Sometimes two females lay in the same nest, which then contains from nine to ten eggs, for each of them lays from four to six. The nest is roughly built. "The eider ducks," as we learn from Willoughby, "build themselves nests on the rocks, and lay good store of very savoury and well-tasted eggs; for the getting of which the neighbouring people let themselves down by ropes dangerously enough, and with the same labour gather the feathers, or eider-dun, our people call them, which are very soft and fit to stuff beds and quilts; for in a small quantity they dilate themselves much, being very springy, and warm the body above any others. 'These birds are wont at set times to moult their feathers, enriching the fowlers with this desirable merchandise." "When its young are 
hatched," adds the English naturalist, "it takes them out to sea, and never looks at land till next breeding-time, nor is seen anywhere about our coasts."

There seems to be some considerable difference between the down taken from the dead bird and that which the female plucks from her breast. The lightness and elasticity of the latter are such that two or three pounds of it squeezed into a ball which may be held in the hand will expand so as to fill a quilt large enough to cover a bed. When the female prepares her nest, she lines it as above mentioned; when she has laid her four or six eggs, which are about three inches in length and two in breadth, she strips herself a second time; should this down be abstracted, as it generally is, and she is unable to supply more, the male submits himself to the same plucking process, his contribution being known by its paler colour.

The haunts of a bird yielding so valuable an article are carefully watched, and proprietors do everything in their power to attract them to their land. In Scotland and Norway the districts resorted to by the Eider Ducks are strictly preserved, everything likely to disturb them being carefully guarded against. Pennant thus records a visit he paid to one of their breeding-places in the Farn Islands on the I5th of July, I769:- "I found the ducks sitting," he writes, "and I took some of the nests, the base of which was formed of sea-plants and covered with the down. After separating it carefully from the plants it weighed only threequarters of an ounce, yet was so elastic that it filled a greater space than the crown of the largest hat. These birds are not numerous on the isles, and it was observed that the drakes kept on the side most remote from the sitting-places. The ducks continue on the nest till you come almost to them, and when they rise, they are very slow fliers. The eggs are of a very pale olive colour, large, glossy, and smooth; they are from three to four, warmly bedded in down." Sir George Mackenzie, in his "Travels in Iceland," says that " the boat in its approach to Vidöe passed multitudes of eider ducks, which hardly moved out of the way; and between the landing-place and the Governor's house it required some caution to avoid treading on the nests, while the drakes were walking about even more familiar than common ducks. The ducks were sitting on their nests all round the house, on the garden wall, on the roof, in the inside of the house, and on the chapel."

The locality where the Eiders make their nests when not in the above semi-tame state is always difficult of access. Nevertheless, 
the inhabitants of Iceland, Lapland, and the coasts of the North Sea invariably secure them. The harvest which is derived from these birds is their principal source of revenue, eider-down being a valuable article of commerce. In inhabited countries the rocks where the Eider Ducks lay their eggs are private property, and are handed down in families just as if they were the most valuable possessions.

\section{The Common Teal (Anas crecca).}

This (Fig. 88) is the smallest of the Duck kind known in the British Isles. It is a remarkably beautiful bird, and in colouring as

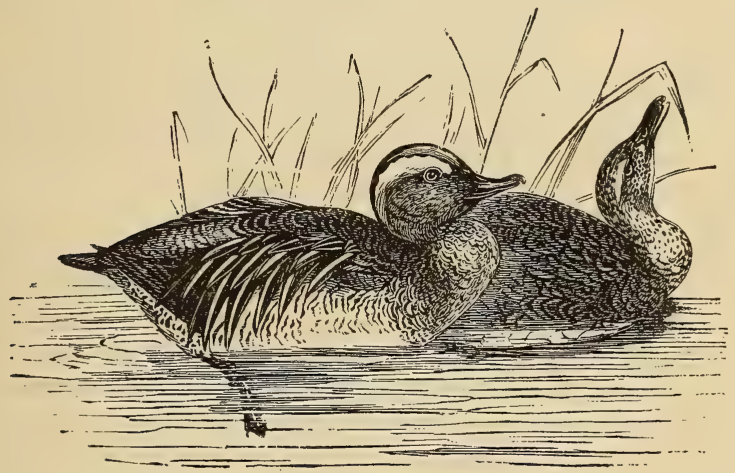

Fig. 88.-The Common Teal.

well as in form closely resembles the Mallard, but is much smaller. It frequents marshy places and the margins of lakes and rivers, seldom betaking itself to estuaries or the sea-coast until frost sets in. It walks with ease, swims with great dexterity, flies rapidly, and is in all respects remarkable for its activity. It rises from the water or the land at once, and shoots away with great rapidity, so that the marksman who would bring it down must be very expert with his gun. It breeds in the long reedy grasses on the margin of lakes, or on upland moors and marshes. Its nest is a mass of decayed vegetable matter lined with down and feathers, in which it lays ten or twelve eggs about an inch and three-quarters in length and an inch and a quarter in breadth. North of the Tay they are 
found occasionally all the year round, returning, according to $\mathrm{Mr}$. St. John, year after year to breed, if left undisturbed in the process of incubation.

"If we compare," says Mr. McGilllivray, "the Common Teal (Anas crecca), with the Garganey (Anas circia), the Gadwall (Anas strepera) and the Pintail Duck (Anas acuta), we find slight differences in the form of the bill, in the elongated lamella of the upper mandible, in the length of the neck and tail; but they are all so intimately connected that, unless each species can be converted into a genus, there can be no reason for separating them." He classes them accordingly under the general name of Teal.

This bird makes its appearance in France in spring and autumn. It breeds in all the temperate climates of Europe, and pushes on towards the south as the winter advances.

According to Columella, in his work "De Re Rustica," the Romans succeeded in domesticating the Teal; but the bird has reverted to an entirely wild state, which is much to be regretted, for it would have formed a valuable addition to the poultry-yard, the flesh of the Teal being held in great estimation.

The group of Ducks usually denominated Teal, Mr. Swainson has formed into the sub-genus Boschas, in which he also includes the Mallard or Wild Duck. "As this is the most numerous group." says this writer, "so it exhibits a greater diversity of form among the species. They are all, however, characterised by a bill longer than the head, the breadth of which is equal throughout, sometimes indeed a little dilated, but never contracted at the tip, while the laminæ of the upper mandible are entirely concealed by the margin of the bill." "The beautiful Anas formosa, which is essentially a Teal, differs," says a writer in the "Penny Cyclopædia," "in the greater length of the tail, thus connecting it more closely with the Pintail and other long-tailed species; while the bill, which is depressed in form in the Mallard as well as in the Domestic Duck, is convex, with projecting laminæ, in the teal. Such is the case with the blue-winged Teal of North America, in which the laminæ of the upper bill project nearly as much as in the Gadwall, while the upper mandible exhibits that sinuosity at the base which is seen in no other Duck except the Shoveller."

Mr. Selby says of the common Teal :- " I am inclined to think that our indigenous breeds seldom quit the immediate neighbourhood of the places in which they are bred, as I have repeatedly observed them to haunt the same district from the time of their being hatched till they separated and paired on the approach of the following 
spring. The Teal breeds in the long rushy herbage about the edges of lakes, or on the boggy parts of upland moors." Very few of them are found, according to Mr. McGillivray, in the south of Scotland during the summer months. In winter, one of his correspondents informs him, it unites in large flocks, the drakes having then a whistle like the plover; but it has not been heard to use this call during the breeding season. The boldness of the female in defence of her young is very affecting. Mr. St. John describes an instance which occurred in Ross-shire. He was riding along when an old Teal, with eight newly-hatched young ones, crossed the road. The youngsters could rot climb the bank, and all squatted flat down while he passed. He dismounted, and carried all the young ones a little distance down the road to a ditch, the old bird fluttering about all the time, and frequently coming within reach of his whip. The part of the road where he found them passed through a thick fir-wood covered with rank heather, and it was a great puzzle to him how such little things, scarcely bigger than a mouse, could have struggled through it. Next day he saw them all enjoying themselves in a pond a little distance off, where a brood of Teal appeared every year.

Teal are less timid than the Wild Duck, and the sportsman, therefore, has not the same difficulty in getting within shot of them. They breed in great numbers in some of the Highland lochs; and Mr. St. John says that in August he has seen perfect clouds of them rise from some calm glassy lake at the report of a gun.

The Scoters (Oidemia, Flemming) have the bill broad, with dilated margins, and coarse lamelliform teeth; a swelling above the nostrils, dividing them into two equal parts, both large and elevated.

\section{The Velvet Duck (Anas fusca).}

This is the largest of the Scoters, and is distinguishable by the white band upon its wing, much-depressed body, thick neck, and large, oblong, and compressed head. They make their appearance in our bays and estuaries towards the end of autumn, and depart about the middle of April. In the evening they proceed out to sea in flocks of fifteen or twenty when the weather is favourable, returning to the shore in the morning. They fly low, but with considerable speed, moving their wings quickly; and on arriving at a suitable place, they relax a little and alight on their hinder end, the body being kept oblique. On settling, they commence forthwith to feed. 


\section{The Black Scoter (Anas nigra).}

The Black Scoter (Fig. 89) arrives on our shores about the middle of autumn in considerable flocks, and is seen on all our western coast during winter, but is still more abundant on the French coast. It closely resembles the American bird of the same name, of which it is probably a variety.

It is almost as large as the common Wild Duck, but is shorter and more thickly made. Its plumage is entirely black; except when young, when it is greyish.

Passing its life on the surface of the water, and never venturing on the land except when driven by

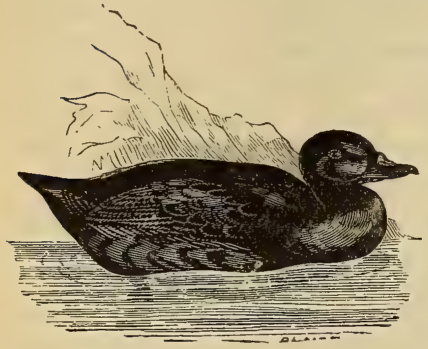

Fig. 89.-Scoter. stress of weather or for the purpose of making its nest in the marshes, it flutters rather than flies over the surface of the sea, and makes no use of its wings, except to escape some danger, or to transport itself from one point to another with more rapidity. Its legs, in flying, hang down, and constantly graze the surface of the water; it always appears as if it regretted to leave its favourite element.

When on land, these birds walk slowly and ungracefully ; but in the water they are active and graceful. They are natives of both the Old and New World. About the month of October, driven by the north and north-west winds, they come down from the northerly countries of Europe, and visit our Atlantic coasts and the Mediterranean.

The salt-water pools adjacent to the sea, and the sheltered creeks on the coast, they delight in ; unfortunately too often to become the objects of the terribly destructive sport of which we are about to speak.

Two or three times during the winter, large placards exhibited in certain towns of the department of Hérault announce that large flocks of these birds (called fouiques in the country) having settled down on some adjacent lake, a day's sport will be had with them on a given date. This day is turned into a real fête by the sportsmen, and an extraordinary concourse of people are brought together. Some come in carriages, some in carts, and the most humble among them on donkeys or on foot. At daybreak they reach the margin of 
the lake, where they embark in boats, provided with a rower. At a given signal the whole flotilla puts off from the shore, and advances slowly towards the portion on which the ducks are resting.

These unusual preparations surprise the birds, which utter plaintive cries of terror as they crowd together. The boats, however, hem them in on all sides, gradually contracting their circle so as to enclose them in a limited space. When closely pressed, they spread their wings and unwillingly take flight over the heads of their enemies. This is the signal for the firing of the first volley. There is now no cessation in the report of guns; for usually no less than 500 sportsmen meet on the not very extensive surface of such lakes as Mauguio or Palavas. The massacre lasts for some hours; in fact, these unfortunate birds, incapable of flying very far, are pursued from place to place by the pitiless boats, which are soon, like the bark of the venerable Charon, laden with the dead. When no birds remain on the lake, the shores are searched, to recover the wounded. Three thousand of these birds will sometimes thus be taken in the space of a few hours. As a matter of course, quarrels often arise among the sportsmen; the cause of dispute frequently being some bird which has been shot at from several boats at the same moment. These disturbances, which usually begin with shouts and abuse, from the warmth of the southern blood, sometimes terminate fatally. In this sport tumult reaches its utmost pitch, and it is as productive of danger as of pleasure. Sometimes a boat capsizes, owing to the excessive eagerness of the rowers; sometimes a sportsman is wounded by an awkward neighbour, or two or three men fall into the water in trying to reach their prey. Such are the exciting scenes that I have often witnessed in my youth; they were the supreme delight of the boys of Clapas (Montpellier). The same sport is practised at Hyères, in the Var, and on the lake of Berre, near Marseilles.

On the coasts of Picardy, where it abounds during winter, very destructive means are used for its capture. Nets are stretched horizontally in the water, above the banks of shell-fish which the sea has left uncovered by its reflux, and on which these birds feed. When they dive to seize their prey they become entangled in the meshes, from which they cannot escape.

This Scoter is also the object of individual sport when it does not arrive in these immense flocks. It is then shot from a boat like other water-fowl.

The Black Scoter is seldom seen on aristocratic tables, for its flesh, which is by no means tender, retains a very decided marshy 
flavour. However, in former times it was much sought after, but not exactly for its culinary qualities. The reason this bird was shown such preference was because people were permitted to eat it in Lent in place of fish. The singular notions on which the Church of Rome founded this toleration-a toleration, however, which still exists in full force even at the present day-is as follows: The Councils of the twelfth century permitted both the clergy and laity to eat this duck during Lent, because it was a generally-accepted idea, founded on the writings of Aristotl, that these birds were not produced from an egg, but had a vegetable origin. The learned of the Middle Ages and the Renaissance, seeing large flocks of them suddenly appear, while nothing was known whence they came, indulged in all kinds of conjectures to explain this mysterious fact. They attributed to them origins which were marvellous; one conjecturing that the feathery appearance in the ciliated tentacles of certain molluscs which inhabit the barnacle shell changed into Scoters; others imagined that these birds were produced from the wood of rotten fir-trees which had been long floating about in the sea, or even from the fungi and marine mosses which cling to the débris of wrecked ships; others, again, went so far as to assert that the north of Scotland, and especi.lly the Orkney Isles, produced a tree the fruit of which, falling into the sea, developed into the bird which was called Anser arboreus, in order to commemorate its origin: this bird they imagined was the Black Scoter.

The naturalists who gave expression to these transcendertal views might certainly boast that they had Aristotle on their side; for this distinguished philosopher believed in the spontaneous gencration of various kinds of animals. He asserted, for instance, that rats sprung from decayed vegetables, and that bees proceeded from the carcase of an ox. Who, for instance, is unacquainted with the fine episode of the fourth book of Virgil's "Georgics," where this poetic fiction is related in beautiful verse?

As a matter of fact, however, Pope Innocent III., better instructed than Aristotle in this department of natural history, passed sentence on all these tales by forbidding its use during Lent; but no one, either in the monasteries, the castles, or the taverns, has ever looked at this interdict of the sovereign pontiff in a serious point of view.

This controverted question, however, at last met with an unexpected solution. Gerard Veer, a Dutch navigator, during one of his voyages to the north of Europe, found some eggs of the Velvet Duck. Being quite ignorant of their nature, he brought them home, and put 
them under a hen, and, when they were hatched, the produce exactly resembled the birds which had been asserted by the ancients to proceed from the decay of vegetable matter. Gerard Veer made the announcement that these birds bred in Greenland, and thus afforded a complete explanation of the entire absence of their eggs in southern countries.

This discovery of the Dutch navigator met with no favourable reception. The custom of eating the Scoter in Lent had been long established; the Church allowed it, and every one was satisfied. Gerard Veer was sent back to his galliot, and all kinds of reasons were found for satisfying the consciences and stomachs of the faithful, which had been justly alarmed.

There was, however, no deficiency in the arguments brought forward. It was asserted that the feathers of this duck were of quite a different nature from those of other birds; that their blood was cold, and that it did not coagulate when shed; that their fat, like that of fishes, had the property of never harlening. The analogy between this bird and the fishes being thus clearly established, the permission of the Councils remained in full force.

Finally, as the writers of the Middle Ages and the Renaissance were but indifferent naturalists, and had very vaguely described the Scoter Duck, the same mode of reproduction was ascribed to several other marsh-birds. As a matter of course, the same toleration in Lent was extended to them. The faithful were thus in the habit of indulging in various other birds, such as the Brent and Bernicle Geese. The opposing claims of devotion and appetite being thus harmlessly satisfied, no one cared to object to a supposition which gave such general satisfaction.

We must add that this confusion of names still exists, for on the sea-coast several varieties of the Duck genus still go by the name of the privileged bird.

There are several varieties of this family, the principal being the species just mentioned, the Velvet Duck (Anas fusca), and the Surf or Black duck (A. perspicellata).

\section{The SURF or Black Duck (Anas perspicellata).}

This bird is rare in our country, the only positive evidence of its occurrence being a female, shot in the Firth of Forth, mentioned by Mr. Gould, and a recently-shot specimen sent to Mr. Bartlett for preservation, and from which Mr. Yarrell derived his description. It is, however, stated by Audubon as being abundant in winter on the 
eastern coast of America as far south as the mouth of the Mississippi. In Labrador he found a female on its nest in a marsh; the nest was snugly placed amidst the tall blades of a bunch of grass, and was raised fully four inches above the roots. It was composed of withered and rotten weeds, the former being circularly arranged over the latter, producing a well-rounded cavity, six inches in diameter and two and a half deep; the border of the inner cup being lined with down from the birds, after the manner of the Eider Duck. In it lay five eggs, the smallest he had ever seen in a duck's nest. They are equally rounded at both ends, about two inches and a half long, and an inch and five-eighths in their greatest breadth; the shell perfectly smooth, and of a uniform yellow colour.

The plumage of the bird is soft, dense, and glossy; the feathers of the head and neck blended and velvety; the wings short, narrow, and pointed; the upper mandible orange red, the protuberance on each side yellowish grey; at the base is a large square patch of black, margined with orange red, with a patch of greyish white in front.

Intimately allied to the Ducks in many respects, and to the Divers and Cormorants in others, are the Goosander, a very distinct family, characterised by a large, elongated, and depressed body; long and slender neck; oblong, compressed head, narrowing anteriorly; bill straight, narrow, and slender, sub-cylindrical outwards, wide at the base, and abruptly hooked at the tip; margins of both mandibles serrated; the teeth directed backwards.

\section{The Goosander (Mergus castor).}

The Goosander is sometimes separated from the Ducks. Prince Charles Bonaparte includes in it two sub-genera, the Smew (Mergus) and the Merganser of Leach, for by this name also this bird is known. It is distinguished by its slender and almost cylindrical bill, armed on the edge with points turning backwards, somewhat resembling the teeth of a saw; yet, in its general appearance, plumage, and habits, this bird bears much resemblance to the Ducks.

The Goosanders rarely come on land ; they are exclusively aquatic, and frequent rivers, lakes, and pools, preferring them to estuaries; but they may be seen in summer fishing in the sea-lochs of Scotland. The Latins gave them the name of Mergus in consequence of their habit of swimming with the body submerged-the head only appearing above the surface of the water. 
These birds feed on fish, of which they destroy an immense number. They also commit serious depredations on the spawning beds. They are able to accumúlate a large quantity of air in the trachea, and therefore can remain some time under water without breathing; this assists them to remain under the water when in search of their prey. Their power of locomotion when submerged is so great that they can traverse a considerable distance before they reappear upon the surface. The activity they display in pursuit of their food is very great; for, in order to accelerate their speed in swimming, they make use of their wings as well as of their feet. The Goosander swallows fish head first; however, it sometimes happens that the body of their prey is too bulky to be easily gorged; they have to submit to the temporary inconvenience of gradual absorption ; thus, sometimes the digestion of the fish's head has commenced whilst the tail is still projecting from the bill.

Their flight is generally without elevation, but rapid and prolonged. On land their gait is awkward and tottering. They generally inhabit temperate regions during the winter, and in spring return to the high latitudes, where are their breeding places. They lay from eight to fourteen whitish-coloured eggs, either on the shore between two large stones, or in thickets of grass on the edge of lakes and rivers : occasionally a hollow in a tree is selected; but their nestingplace is invariably near water, and is composed of dry grass, sedges, fibrous roots, and other similar materials, with a lining of down plucked from their breast.

The Goosander is a regular visitor, in winter, to our coasts and inland lakes. It breeds in North Uist and others of the Outer Hebrides. Its flesh is unedible except when young.

\section{The Smew (Mergus albellus).}

Like its congeners, the Smew (Fig. 90) is a native of the northern regions of both continents, retiring southward as winter approaches, and spreading in great numbers over Germany, France, and Italy, returning northward in April. Montague says it is plentiful on the south coast of England, but that it is not known to breed there. It is of elegant form, smaller than the Goosander, being only fifteen inches in length. The plumage of the head is full, soft, and blended the upper part of the head and nape elongated, forming a gradually narrowing crest ; the wings short, rather narrow, slightly convex, and pointed-when closed reaching to within an inch and a half from the end of the tail. The male bird, at maturity, has a great spot of 
greenish black on each side of the bill, and a longitudinal one on the occiput. The tufted crest, neck, scapulars, small coverts of the wing, and all the lower parts are pure white; the upper part of the back, the two crescents under the sides of the breast, and the edges of the scapulars are deep black; the tail is ash-coloured; sides and thighs are varied with ash-coloured zigzags ; bill, tarsi, and toes are bluish ash; webs black, and the iris brown. In habit the Smew greatly resembles the Goosanders.

The Goose (Anser) forms a special gentis among the Palmipedes.

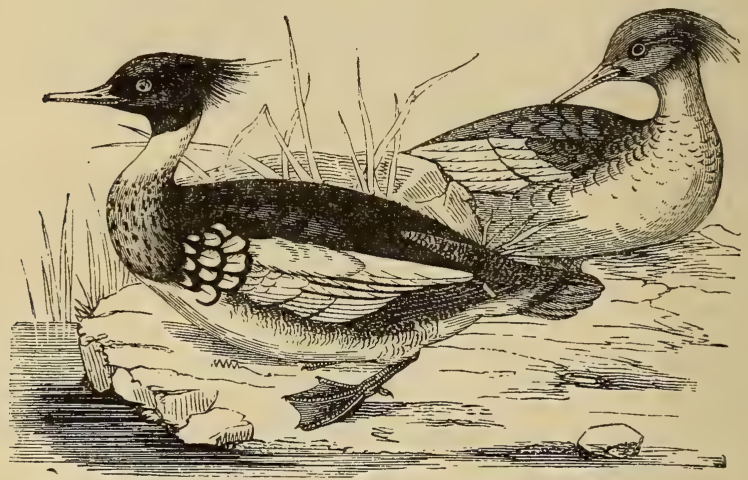

Fig. so-The Smew.

It is a bird which is often spoken of with contempt, though very improperly, for few birds are able to afford mankind a great $\leqslant r$ amount of service.

\section{The Wild Geese (Anser).}

The Wild Goose, though by no means elegant in form, has none of the awkwardness of the Domestic Goose, which is generally supposed to be descended from it. The body of the Grey-lag Goose is large and full ; the neck long, at its upper part slender; the head proportionately small, ovate, oblong, and rather compressed; the feathers of the head are small, short, rounded and blended, of a greyish brown; those of the upper part of the neck small and oblong, and arranged in ridges with deep intervening grooves, gradually getting paler until it fades into greyish white ; the wings are long, reaching 
nearly to the end of the tail, the feathers of the fore part of the back and wings close, broad, and abrupt; the prevailing colour a bluish grey.

Geese in many respects resemble ducks and swans, but they are less aquatic in their habits, keeping often at a distance from large bodies of water, and frequenting, by preference, moist meadows and marshes, where they find herbage and various kinds of seeds, on which to feed. They swim very little, and seldom dive. They make their nests on the ground, and lay from six to eight eggs, which are hatched in rather more than one month. The young ones walk about and find their own food almost as soon as they leave the egg. Geese, especially the male birds, moult twice a year-in June and November.

The noise made by a flock of Geese seeking their food can be heard at a great distance. Their call, which is repeated at regular intervals, somewhat resembles the sound of a trumpet or clarion, and is accompanied by a continuous muttering noise in shorter notes. The hissing common to both Geese and Ducks is produced by two membranes placed in juxtaposition at the lower part of the trachea. These two membranes are situated side by side in the two bony and elongated openings of the internal larynx, from which the two principal bronchia have their origin. A close examination of this structure in the goose is supposed to have contributed to the invention of certain wind instruments, such as the flute, bassoon, bagpipes, clarionet, and even the organ.

When attacked, the Goose makes a hissing noise similar to that of some serpents. Endeavours have been made to express this sound by the three Latin words strepit, gratitat, stridet. The slightest noise wakes them up, when they at once give the signal of alarm, which immediately warns the whole flock of approaching danger. Thus, some authors have maintained that the Goose is more vigilant than the $\operatorname{dog}$; and in proof of this, instance the story of the geese at the Capitol, whose wakefulness saved the Romans from an attempted assault on the part of the Gauls. The Roman people, till the fall of the Empire, were grateful enough to award an annual sum for the maintenance of a certain number of these birds in their Capitol; and on the anniversary of the day when their services had been so valuable, they were in the habit of whipping the dogs in front of the building, as a retrospective punishment for their culpable carelessness.

The Gauls, on the other hand, never pardoned the Goose, for" having baffled their attack. Frenchmen, even in the present day, 
possibly the descendants of the proud companions of Brennus, or of the conquerors of Northern Italy, appear still to inherit this ancestral hatred. At some of the French village fêtes they are in the habit of hanging up geese by the feet in order to cut through their necks with a sword, or to beat them to death by hurling stones and sticks at their heads. At every blow the poor creature must suffer dreadful agony, but it is relieved by death. It is then borne away in triumph, and its mutilated carcase afterwards appears at table to be devoured by its destroyers. The National Assembly of France most properly forbade this brutal and sanguinary amusement, as being dishonourable to a civilised nation.

It is difficult to say why the Goose should have been considered from the earliest ages as the symbol of stupidity. Their sight is sharp and piercing, and they enjoy a remarkable delicacy of hearing. Their watchfulness seems never at fault. When they either sleep or eat, one of their number is placed as a sentinel. With neck stretched out and head in the air, the guard scrutinises the distant horizon in every direction, ready at the slightest alarm to give a signal of danger to the rest of the flock.

The figure formed by a flight of Wild Geese indicates no slight degree of intelligence. They place themselves in two slanting lines, forming a < shaped angle, or sometimes in a single line, if they are not numerous. This arrangement allows each bird to follow the route with the least possible amount of resistance. When the individual which heads the flight begins to be fatigued, it takes its place in the rear, each bird in its turn leading the flock.

Geese being too numerous to travel in large flocks, it appears as if they fixed upon some rendezvous where they separate in order to distribute themselves over various countries. To Europe tiey come principally from Asia. On their arrival, the flocks disperse themselves over different districts. In our land they make their appearance towards the beginning of winter, and depart towards the end of April. Formerly they are said to have been abundant, and to have been even permanently resident; now they are rare, and are seldom known to breed with us. On their arrival they resort to open pastures and cultivated fields, feeding on the roots of aquatic grasses, young corn, clover, and other green herbage. On an alarm being given by the bird on watch, they all erect their necks, run forward, and uttering their loud, grating cry, spring into the air, departing with a heavy, measured, but powerful flight. According to Temminck, "the wild goose inhabits the seas, coasts, and marshes of eastern countries, seldom advancing northward be- 
yond the fifty-third degree; it is abundant in Central Europe ; occasionally halting in Holland during its migrations." Those which visit France are the harbingers of frost; for when they make an early appearance, it is well known that the winter will be severe.

Although they frequent water little, Wild Geese repair every evening to the ponds and rivers in their neighbourhoods to pass the night; so that the Wild Goose visits its aquatic haunts when the Wild Ducks are leaving them. These birds are very difficult to shoot on account of their wariness, for their excessive caution renders nearly useless all the stratagems of the sporstman. The attempt is sometimes made to take them in the evening with nets, the Wild Geese being attracted by means of tame ones, which are trained to act as decoys.

The Ostiacs, on the banks of the Obi, in Siberia, pile up the snow, and, with the addition of branches, construct small huts. Near these they place some stuffed birds; the Wild Geese seeing them, dart on their facsimiles and peck them to pieces. While thus busily occupied, they can easily be shot or captured.

But the most curious and difficult mode of taking them is that followed by the adventurous inhabitants of St. Kilda, a little islet on the west coast of Scotland.* Wild Geese of several species make their nests there in large flocks at the foot of the sea-washed rocks which surround the island. It is very doubtful if the Wild Goose (Anser ferus) is found among these. Both for strength and economy, the inhabitants use a cord made of thongs of twisted cow. hide covered with sheep-skin. With a rope of this description, two men climb to the top of a cliff; there they fasten themselves to either end of the cord; then one lets himself down over the face of the cliff, and the other clings to the rugged points above. The first man fills a sack with the eggs, and suspends by their feet as many young as he can hang to various parts of his person. When he has made his collection, his companion hoists him up by main force, twisting the cord round his own body after the manner of a windlass.

This dangerous sport is said to be very productive. A cow-hide rope forms a large portion of the dowry of a St. Kilda girl, and very often it is the sole dependence of a household. 'The hardy sportsmen have so much coolness and nerve, that accidents very rarely happen.

The Grey-lag Goose (Anser ferus) is the representative of this

* The bird here alluded to is the Gannet or Solan Goose (Sula bassanza), in no way connected with the Anser genus.-ED. 
1ace, and is probably the progenitor of our domestic bird. Its upper $\mathrm{I}$ arts are of an ashen brown, the lower portions of a dark grey. An adult bird is almost three feet long.

The Domestic or Common Goose (Anser sylvestris) has been made the source of great utility and profit. It appears to be the civilised offspring of the Grey-lag Goose, to which it bears the same proportions as other tame animals bear to their prototypes. Mr. Yarrell was of opinion that the White-fronted Goose (Anser albifrons) has concurred, with the Anser ferus, in producing our domestic race.

In our poultry-yards the Domestic Goose begins, in the month of March, to lay from eight to twelve eggs. Incubation lasts for a month. No birds are more easily reared than goslings; they issue from the shell full of life and covered with a delicate down. It is, however, necessary to keep them shut up for the first few days; if the weather permits, they may soon be released. Their first food is a paste formed of barley roughly ground, mixed with bran, moistened, and boiled in milk, with the addition of a few chopped-up, lettuce leaves. When at large, it is necessary to keep them carefully from hemlock and other poisonous plants.

Our ancestors, the Celts, the Gauls, and the Franks, reared a large number of these birds, and carried on a considerable trade in them, especially with Italy. Pliny, in his "Natural History," relates that he has seen immense droves of geese, which were rnaking their way towards Rome from different districts of Gaul, but especially from the country of the Morini (now forming the departments of the Nord and Pas de Calais). The conductors of these feathered flocks were in the habit of placing the tired ones in front, so that, being pushed forward by the whole column behind them, they were forced to move on in spite of themselves. In the present day, numerous Hlocks of geese are driven in the same manner into Spain from the French departments of Lot, Dordogne, Lot-et-Garonne, Gers, Tarn, \&c.

The Goose, in its coarse and somewhat democratic condition, was good enough food for the Romans of the Republic; but at a later period, when the people became more refined in their tastes, they invented a barbarous method of fattening it. By depriving them of water, movement, and light, an extraordinary development of the liver was produced, which gave them a particularly savoury flavour. This invention - the triumph of modern gastronomy-dates as far back as the days of Augustus and Varro; indeed, two persons of consuiar dignity disputed the honour of being its originator.

In order to fatten geese in this way, an abundant supply of food 
is administered, at the same time depriving them of light and exercise. This food consists of balls made up of maize and wheat, with which the poor creatures are crammed three times a day. In some countries they force whole grains of maize down their throats. At the end of about four or five weeks the fattening process is perfect. This is at all events considered to be the case when the wretched Palmipede exhibits signs of suffocation. This is certainly a cruel method of feeding; nevertheless, it is only by this plan that the delicious fat and plump livers so much appreciated by epicures can be obtained. The liver undergoes an alteration which in the end must prove fatal to the bird; in fact, it assumes enormous development; and the epicures, who hold it in such high favour, regard as a dainty this diseased liver !

The introduction of the Turkey has led to the culture of the Goose being more neglected in Europe; nevertheless, the latter bird is a source of prosperity at the present day in many parts of France and in many a rural district in England. In ancient times there was no entertainment or family festival without the traditional goose smoking on the board. In England the goose is still considered a festival bird. A custom intimately associated with their national history still dictates that every true Englishman should partake of goose on Michaelmas Day.

The flesh, and especially the fat, of the goose, keeps perfectly when salted down. In some parts of the world it is much employed for culinary purposes in this state. The enormous succulent livers which are found in these precious birds after their forcible fattening are used to make the delicious Strasbourg pies. Those of Nérac, as well as those of Toulouse, are made more of ducks' livers, for the latter birds can be fattened in very nearly the same way as the goose.

The down and feathers of Geese are objects of considerable trade. Before the invention of steel pens, the only implement that was used for writing was the quill plucked from the wing of the Goose. Great care was necessary in dressing them. This was done by passing the barrel of the quill through hot ashes, or plunging it into boiling water.

From under the neck, the wings, and the breast of the birds, the down is taken. This operation takes place every two months, from March until autumn.

Geese are certainly not so stupid as they are usually said to be. The following facts will perhaps enable us to appreciate the moral qualities which distinguish them :-

In Scotland a goose became so attached to its master, that it followed him about everywhere, just like a dog. One day this gentle- 
man, after mixing with the crowd which was moving about the town he resided in, went into a barber's shop to get shaved. The faithful bird had followed him, and waited at the door until his master came out, in order to attend him in his subsequent movements, and then accompanied him back to his home. This intelligent creature could recognise its master's voice, although clothed in any disguise.

In Germany a gander was in the habit of leading an old blind woman to church every Sunday. It guided her by the skirt of her dress, always conducting her to the seat in the church which she usually occupied. Afterwards it returned into the churchyard to

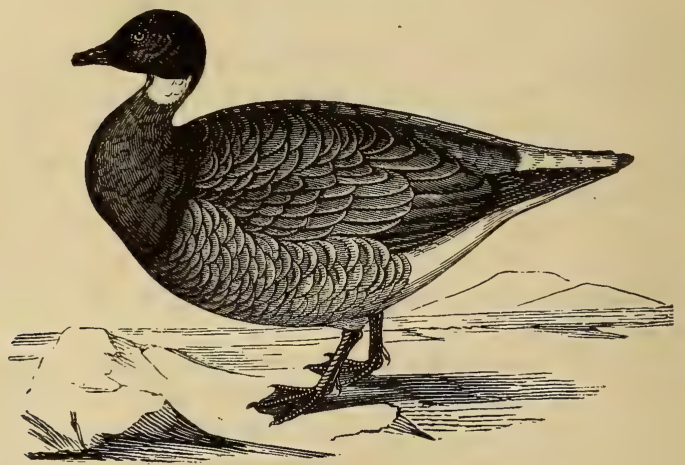

Fig. 9r.-Canada Goose.

browse upon the grass. When the service was over, it waited, just like a faithful dog, to take charge of its mistress. One day, when the minister called upon her and found her from home, he expressed his astonishment that the poor blind woman should venture out alone. "Ah, sir," replied her daughter, "we have no fears about her-the gander is with her." Our blind people would make their fortune if they could replace their traditional dog by a guide of this novel kind.

The Bean Goose (Anas segetum) of most authors differs from the preceding in being somewhat smaller, and having the bill more slender, although not much shorter ; the hind part of the back is also dark brown. In its habits it closely resembles the Grey-lag Goose, for which it has probably been frequently mistaken. Vast flocks of this species frequent the northern waters, such as Montrose Bay, the mouth of the Findhorn, and especially the inland waters of Ross 
and Sutherland - thirty or forty pairs having their nests annually on Lake Laighal. In France this bird is called the Harvest Goose.

The Canadian Goose (Anser canadensis, Fig. 9I) is a handsome bird with white markings about the junction of the head and neck. They are not so large as the Grey-lag Goose, and are very abundant in North America, where they are migratory.

The Bernicle Goose (Anser bernicla) is so called from a foolish tradition of the Middle Ages of their being produced from the barnacle shell which attaches itself to ships' bottoms and timber

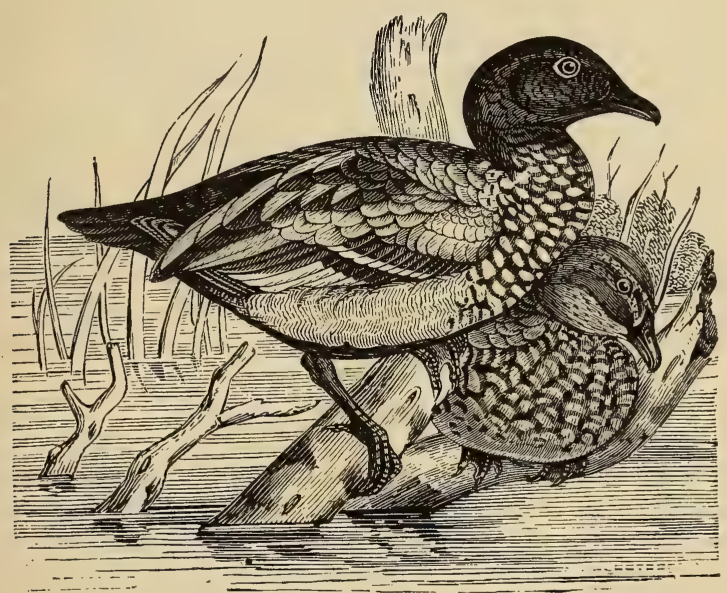

Fig. 92.--White-fronted Bernicle.

floating in the sea. They differ from the true Geese in having the head smaller, the bill shorter and more conical, the breast-feathers much larger, and in the predominance of black in their plumage, bills, and feet. The plumage is full, very soft, and close. There are several species of Bernicla. The one above described, and the Whitefaced Goose (Anser erythropus, Fig. 92), are the best known.

\section{The White-fronted Goose (Anser erythropus).}

In its winter plumage this is a beautiful goose, much smaller than those just described, but with a full body, long neck, and a small, oblong, and compressed head, with soft glossy plumage well blended 
on the head, neck, and breast. It occurs in considerable flocks in the Outer Hebrides, where it arrives in October, and remains till April. A large flock of these birds sitting lightly on the water, advancing with elevated necks, presents a very beautiful spectacle. Nor are they less handsome on the wing as they shoot through the air, now arranged in long undulating ranks, at one time extending in the direct line of their flight, at another flying obliquely, or at right angles to it, and again mingling altogether under some unexplained impulse. Their voice, as it proceeds from a large flock at some distance off, is clear and shrill, producing a pleasant harmony.

The Black-faced Bernicle is much smaller than the White-faced Goose, and easily distinguished from it by the face and head being entirely black. They seem to have visited our shores in great numbers in former years. In the years $1739-40$ these birds were so abundant on the French coast that the people rose en masse to destroy them; and so numerous on the Kentish coast that many were taken in a starving condition. Mr. McGillivray met with large flocks of them in Cromarty Bay, Beauley Firth, and Montrose Easin. Mr. Selby observed them as constant visitors on the shallow waters between Holy Island and the mainland, and other parts of the coast. They are very abundant in North America, and are migratory.

\section{The Swan (Cygmus).}

The Swan, which belongs to the family of Lamellirostral Palmipedes, has been an object of admiration in all ages for its noble and elegant proportions, the graceful curvature of its neck, its small and shapely oval head, its beak so prominent at the base, the gracefullyswelling rotundity of its body, its plumage, and, lastly, its colour of purest white, being in truth the finest and largest of all our aquatic birds. On the water it is a picture of elegant ease; it swims apparently without effort and with great rapidity; on the wing it rises to a great height, but on shore its walk is slow and cumbersome. It is found in Europe, Asia, and America; and in Australia a black swan, for ages the rara avis of the poets, is very abundant. In the wild state it lives on the lakes, rivers, and sea-coasts of both hemispheres, feeding on such seeds, leaves, roots, water-insects, frogs, and worms as come in its way. In its domestic state it is the charm and ornament of our lakes and rivers; but, except in some few instances, it is only kept for show, being jealous and cruel in disposition, and incapable of being tamed.

The ancients thought the voice of the swan musical and har- 
monious, and its gracefully-rounded form and stately neck inspired many poets, who have described it as the bird of gods and god desses. The poetical imagination of the Greeks, in short, associated their most agreeable ideas with its name. It was one of their pleasing fictions that in dying and breathing out its last sigh,

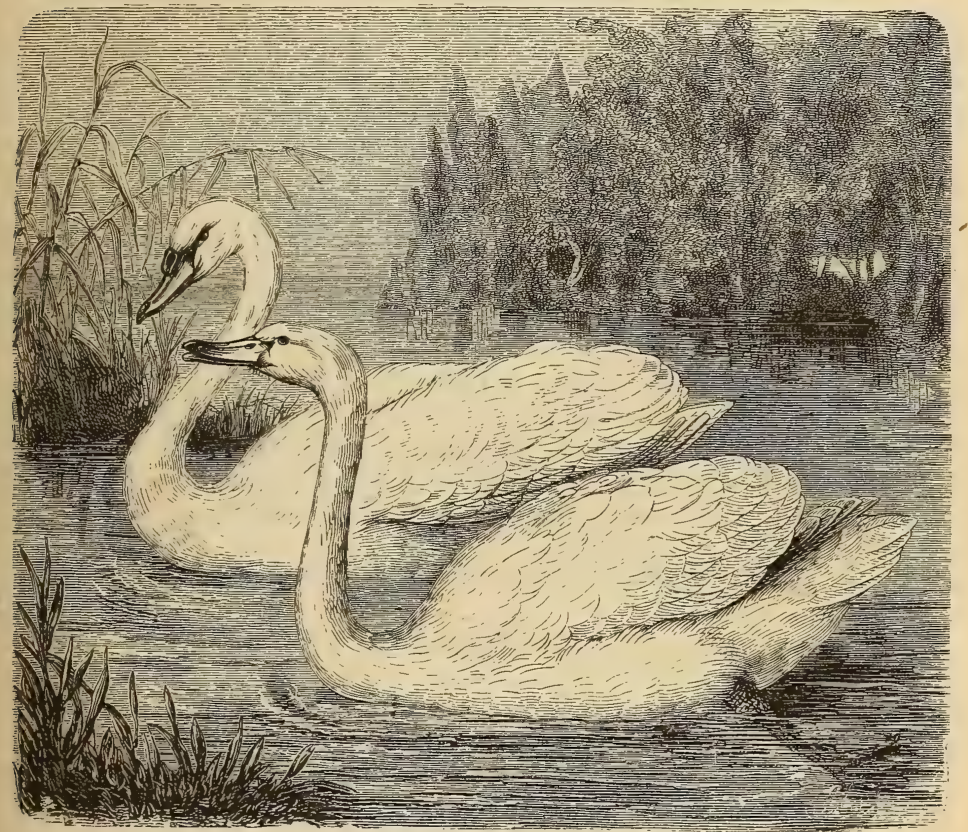

Fig. 93.-Mute and Whistling Swans.

the swan celebrated its death by a melodious song; or, as Eloy Johanneau has it-

"Le Cygne, à la fin de la vie, Fait entendre un touchant accord, Et d'une voix affaiblie, Chante lui-même en mort."

Buffon himself has drawn the portraiture of this bird in words poetical, but certainly untrue :- "The swan," he says, "reigns over 
the water by every claim which can constitute an empire of peace, grandeur, majesty, and kindness. . . . . He lives more in the character of a friend than a monarch amid the numerous tribes of aquatic birds, all of which seem willingly to place themselves under his rule."

The great naturalist allowed himself to be led away by his enthusiasm, and perhaps by his classic recollections; for the swan, although elegant and majestic in form and graceful in its movements on the water, is clumsy and awkward when on land; it is, besides, spiteful and quarrelsome. It attacks every animal, and even man. The swans in the gardens of the Luxembourg at Paris had taken an aversion to all the keepers, and whenever they saw one, they all came out of the water in order to attack him.

The principal strength of the swan does not lie in its beak, but in its wings-a most effective offensive weapon, and which it takes every opportunity to use. In spite of its bad qualities, however, the swan is the most ornamental of all our aquatic birds.

Its song, or rather its cry, is indeed far from being harmonious. It is a dull and harsh sibilation, not at all agreeable to listen to. Some of the poets, however, have not believed the fable which attributes to these birds a sonorous and melodious voice. Virgil perfectly well knew how hoarse the note of the swan really was-

"Dant sonitum rauci per stagna loquacia cygni."

Lucretius says-

"Parvus cygni canor."

The Whistling Swan (Cygnus ferus, Fig. 93).

This is, in all probability, the Swan so celebrated among the ancients. It is found in the northern regions of Europe and Asia; residing in summer within the Arctic circle, and migrating southwards and visiting Holland, France, and the British Islands in winter, although occasionally breeding in the north of Scotland. Southward, it extends to Barbary and Egypt; eastward, it wanders as far as Japan. The note of the Wild Swan is a sort of whoöp, uttered several times in succession-a hoarse, hard, and rather discordant cry - and this has given it the name we have adopted; for it is difficult to imagine the grounds on which the Prince of Canino gave it the name Cygnus musicus.

The peculiar organic distinction of the Swan is the great length of the neck, consisting of twenty-three vertebræ, and the cavity in 
the sternum for the reception of the trachea, which is admirably described by Mr. Yarrell as descending the passage between the two branches of the forked bone called the merrythought to a level with the keel of the breast-bone, which is double, and receives the tube of the trachea between its two sides, which here turns upon itself after traversing the whole length of the keel, and passes upwards and forwards, and again backwards, till it ends in the vertical bone where the two bronchial tubes go off, one to each lobe of the lungs. This is the apparatus through which the cry is produced, which is variously described as a whistle, a whoop, or a song, according to the fancy of the writer. They fly at a great height when on a migratory journey, and in a wedge-like figure, uttering this note as they proceed, and when heard at a distance it is not unmusical. Mr. McGillivray listened to a flock of wild swans coming in from the Atlantic after a gale; their clear, loud, and trumpet-like cries delighted him as they sped their way in lengthened files; but they were too far off for him to decide whether or not they were of this species.

The female lays from six to eight eggs, of a greenish white, and the incubation lasts about six weeks. The cygnets are at first covered with a grey down, and do not put on their adult plumage until the third year. Swans care but little for concealing their broods, as they feel confident of their power to protect them against every enemy. They will fight even with the Fagle itself, harassing it with beak and wings, until the marauder is glad to make a more or less honourable retreat.

In the protection of their young they display extraordinary courage. On one occasion a female swan was sitting on the bank of a river, when she perceived a fox swimming towards her from the opposite bank. Thinking that she would be better able to defend herself in her natural element, she took to the water and went to meet the enemy which was threatening her brood. She soon reached him, and, springing upon him with much fury, gave him such a violent blow with her wing that the fox was disabled, and consequently drowned.

The male swan is equally attentive with the female to their brood, and watches them with a rare devotion. He carries them about on his back, takes them under his wings to warm them, and never abandons them while they are still young. It is a beautiful sight to see him gliding over the water at the head of his young flock, looking forward with an inquisitive eye, and quite prepared to sweep away any opposing obstacle ; whilst the mother keeps some distance behind, ready to protect the rear. How much, too, are they to be admired as they sail majestically along over the surface of some 
solitary lake! If you hide yourself behind the thick reeds so that they have no suspicion of your presence, you may see these noble birds bending their necks into the most graceful curves, plunging their heads into the water, catching it up in their bills, and scattering it behind them, the drops falling round their bodies in glittering rain; or after beating the water with powerful wing and stirring it into a foam, spring forward and glide majestically over the surface, cleaving it before them with their graceful bodies as the ploughman opens a furrow in the ground with his ploughshare.

Sometimes, however, these elegant birds engage in terrible combats with each other, which not unfrequently leads to the death of one of the contestants. The Domestic Swan, a more civilised and educated bird, does not push matters quite so far; but Wild Swans, which live in the regions of the north-in the lakes of Iceland and Lapland-hold most sanguinary tournaments for the favours of their fair ones. A combat between two Wild Swans is a duel to the death, in which both adversaries display not only unequalled strength and fury, but also considerable skill and perseverance. The strife will sometimes last several days, and does not terminate until one of the foes has succeeded in twisting his neck round that of his enemy, and has been able to hold him down under water long enough to drown him.

But let us turn from this warlike spectacle, and admire the Swan at the moment when, impelled by the stimulus of love, it displays all the graces with which Nature has endowed it. Their long and supple necks entwine with one another like garlands of snow, their plumage expanded with gentle undulations, displaying all the splendour of their beauty.

The Swan is certainly conscious of its good looks and grace, for it is constantly busy in cleansing or dressing its feathers, as if its sole idea was to make itself as attractive as possible.

These birds do not afford good sport with the gun, being unapproachable. * In Iceland and Kamschatka, swan-hunting takes place during the season of moulting, because the birds are then unable to fly. Dogs trained to this sport chase and run them down; the birds, being soon worn out with fatigue, are easily overtaken.

The Russians have another mode of killing Swans. When the snows melt, they allure them by means of stuffed geese and ducks. The Swans dart furiously on these decoys. The sportsmen, hidden

* Our experience scarcely agrees with this, for in half an hour last year, on the Chesapeake Bay, in Maryland, I killed three brace of these birds._-ED. 
in a hut constructed of branches of trees and heaps of snow, at short range easily shoot them.

The flesh of the Swan is very indifferent in flavour. Our forefathers ate it, but merely from ostentation, for it was only served up on the tables of the greatest nobles. At the present day, the city of Norwich has a preserve for Swans, which are only eaten at the municipal feasts, or sent as presents to distinguished individuals. In these cases, the birds being young, and tenderly fed, are by no means

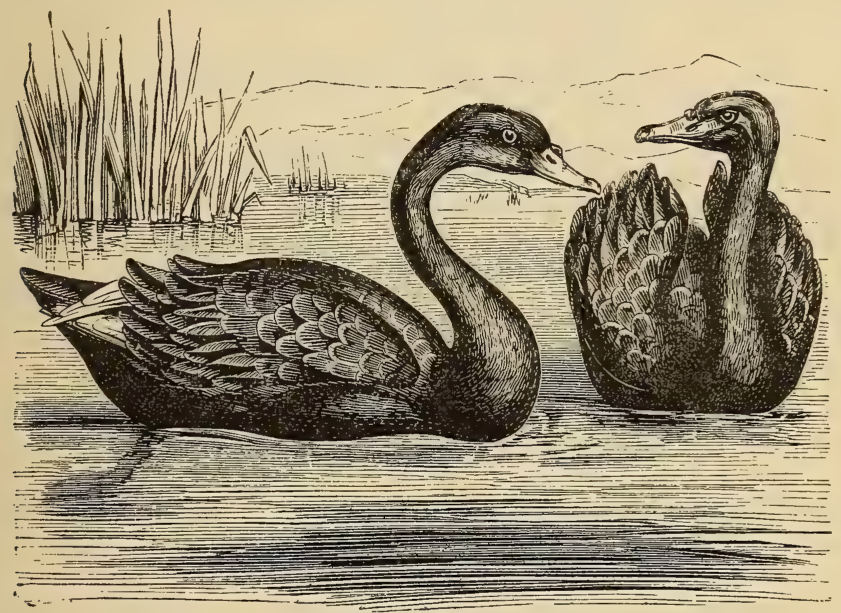

Fig 94,- Black Swans.

a dish to be despised, if properly cooked. The inhabitants of the frozen regions of the extreme north, even with their imperfect system of cuisine, do not entirely disdain it; but the cause for this is apparently something analogous to the philosophical saying, "as there are no thrushes, we eat blackbirds."

The river Thames is remarkable for the number of Swans which live on it. The greater quantity of them belong to the Queen; the others chiefly to the Vintners' and Dyers' Companies of the City of London. but we never heard that these feast their guests on the noble birds. Deputations from the Companies make an annual visit to their preserves, called swan-hopping, or capering - that is, catching the cygnets, and marking them in the presence of the royal swanherd 
with the distinguishing brand of the society to which the parent bird belonged.

Two species of Swans were recognised by Linnæus ; but later naturalists, and notably the Prince of Canino, record four species as known in Europe - designating Cygnus olor, C. immutabilis, C. musicus, and C. Bererickii-besides the American species, namely, C. americamus and C. buccinator. There is another species peculiar to Australia, which is entirely black: efforts have been made suc cessfully to naturalise it in Europe.

\section{The Black Swan (Cygmus atratus).}

We here give a representation (Fig. 94) of the Black Swan of Australia. This bird, which has now become so common in our ornamental waters, in some respects resembles the white species; it is all black, except a few of the secondary feathers, which are white. In a state of Nature, the Black Swans are generally seen floating on lakes in flocks of eight or nine. When disturbed, they fly in single file, and are so shy that it is very difficult to get within gunshot. Their note is less harsh than that of the Whistling Swan.

\section{The Flamingo (Phanicopterus).}

The Flamingoes (Phenicopterus) are one of the most curious of the tribe of Waders. The most fanciful imagination would fail to picture to itself anything more odd than the conformation of this bird. Extremely long legs, supporting quite a small body; a neck corresponding in length with the legs; a bill rather long than otherwise, sharply curved and apparently broken in the middle, contrived probably to discourage those who are tempted to describe it ; wings of a middling size, and a short tail-such are the distinctive features of this remarkable-looking bird. The long legs terminate in equally long feet, with three toes in front; hind toe articulated high up the tarsus, and very short; anterior toes united by a deeply-indented membrane. Add to this a plumage of a rose-colour, warming into a bright red on the back and wings, and we have an object calculated to excite both wonder and admiration.

Ancient writers, struck with the vivid colourings of its wings, gave the Flamingo the designation of Phonicopterus (fiery-winged); this term was popularised in France by the word flambant, or flamant: hence the name by which the bird is universally known. 
Flamingoes inhabit the margins of lakes and ponds, more rarely the sea-shore. They feed on worms, molluscs, and the spawn of fishes, which they capture by the following stratagem: placing their long neck and head in such a position that the upper mandible of their bill is the lowest; they stir the mud about in every direction, thus easily succeed in disturbing the small fish which have settled in it, and capturing them while blended with the thick sediment. They also use their feet for working the ooze and detaching the fry and spawn, to which they are partial. They love company, and live in flocks, which are subject to strict discipline. When they are fishing they draw themselves up into long, straight, and regular files, protected by sentinels whose office it is to give a signal of alarm on the approach of danger. If any cause for uneasiness should arise, the scout-birds give a piercing cry, not unlike the note of a trumpet, and the whole flock immediately wing their way to a place of security.

Flamingoes are very shy and timid, and shun all attempts of man to approach them; the vicinity of animals, however, they disregard. Any one who is acquainted with this fact can take advantage of it, for, by dressing himself up in the skin of a horse or an ox, he can effect immense slaughter among these beautiful creatures. Thus disguised, the sportsman may shoot them down at his ease, so long as their enemy is unrecognised; the noise of the gun only stupefies them, so that they refuse to leave, although their companions are dropping down dead around them.

Some authors have asserted that the Flamingo makes use of its long neck as a third leg, walking with its head resting on the ground like a foot. The fact that has doubtless given rise to this supposition is the position of the neck, necessitated by its peculiar method of seeking food. We are told about a Flamingo reared in captivity which, being accidentally deprived of one of its limbs, found out a remedy for its infirmity by walking on one leg and helping itself along by means of its bill, using the latter as a crutch ; the master of the bird, noticing this, fitted it with a wooden leg, which it used with the greatest success. But this story, which applies very well to a domesticated bird which was maimed, and consequently under peculiar conditions, in no way invalidates our former observations.

The Flamingo makes itself a nest which is as original as its own personal appearance. It consists of a truncated cone, about twenty inches in height, and formed of mud dried in the sun. At the summit of this little hillock it hollows out a shallow cavity, in which the female lays two eggs, rather elongated in shape, and of a dead white colour. When she is incubating she sits astride on this novel 
description of throne, with her legs hanging down on each side. The young ones run about very soon after they are hatched, but it is some time before they are able to fly-not, indeed, until they are clothed with their full plumage. At two years old they assume the more brilliant colours of the adult bird.

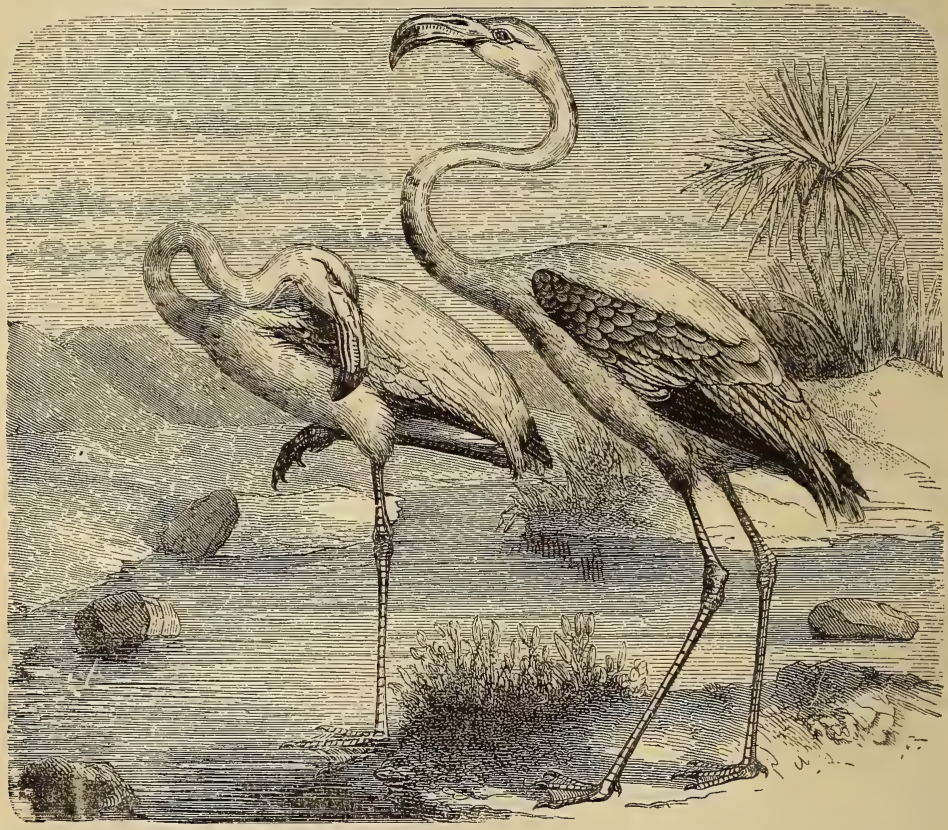

Fig. 95.-Flamingoes.

The Flamingo is found in all the warm and temperate regions of the globe. On certain islands off the American continent they exist in such numbers that navigators have given them the name of the Flamingo Islands. In the Old World they are found spread over a region below the fortieth degree of latitude, principally in Egypt and the Nile tributaries; during the summer they seek a cooler climate, end they are then seen in numerous flocks on the southern coasts of France. The height of these magnificent birds reaches to about 
five feet; when they are flying, in the peculiar formation common to most aquatic birds, with the neck stretched out and the legs prcjecting behind, they look, in the clear sky, like gigantic triangles of fire.

The ancients greedily sought after the flesh of the Flamingo, whicl they regarded as the most choice food. The tongue especially wa: thought to be an exquisite dainty, and the Emperor Heliogabalus appreciated it so highly that a body of troops was exclusively employed in slaughtering Phœnicopteri to satisfy his gastronomical tastes. At the present day we no longer eat the bird; to modern palates its flesh is disagreeable in flavour, and it retains a marshy smell which is far from being pleasant. With regard to the tongue, the Egyptians it is said, are content with extracting an oil from it, which is used to flavour some descriptions of viands. We must add, in order to complete our account of the Flamingo, that it is covered with down like a Swan, which is employed for the same purposes, and that its thigh-bone is used in some countries in the manufacture of flutes. The Flamingo (Phonicopterus ruber, Fig. 95) is the only representative of this family we know.

\section{The Frigate Bird (Atagen aquila).}

The Frigate Bird is principally characterised by a strong, robust, trenchant bill, longer than the head, with mandibles hooked at the point ; nostrils linear; orbits naked ; throat dilatable ; the front of the neck bare of feathers; wings very long and narrow, first two feathers longest ; tail lengthy and forked ; feet short ; toes united by a membrane deeply notched.

The Frigate Bird has a most expansive spread of wing ; its power of flight is, therefore, very great. It inhabits the tropical seas of both the Old and New World; and navigators assure us that they have met with it 200 or 300 leagues from any shore. When a hurricane arises they mount up far above the storm, and remain in those empyrean regions until it is again fine weather. In consequence of their almost disproportionate spread of wing, they can sustain themselves in the air for lengthened periods, without taking or requiring rest.

Their sight is so piercing that, at a distance far beyond that which would render them invisible to us, they can perceive their prey, the principal of which is the flying-fish. From their elevated situation, they dart down upon their favourite food, which has relinquished its native element; and, keeping their neck and feet in a horizontal position, cleave asunder the air and grasp their victim, who little expected to meet with an enemy in the element which it 
sought for safety. It is no unusual thing for it to rob the Gannet of the fish which it has just caught: the unfortunate bird acting as purveyor to this sea-robber.

The Frigate Bird is of such a combative temperament, and has such an unbounded confidence in its strength, that it is not afraid of man. It has been known to dash at a sailor, and to snatch at the fish which he held in his hand. M. de Kerhoënt, a French navigator, relates that, during a residence at the Island of Ascension, a perfect cloud of Frigate Birds surrounded his crew. They hovered about a few feet above the coppers of the open-air kitchen, in order to carry off the meat, without being intimidated in the least by the presence of his followers. Some of them approached so near, that M. de Kerhoënt knocked down one of the impudent intruders with a blow of his stick.

They assemble in large flocks on the islands where they are accustomed to breed. In the month of May they begin to repair their old or construct new nests. They pluck off with their beaks from the bush small dry branches, and with these pieces of stick crossed and re-crossed a foundation is formed. These nests are situated upon trees which hang over the water, or are placed on rocks overjutting the sea; in them they lay one egg of a pure white colour.

These birds are common in the Brazils, in the Island of Ascension, at Timor, the Ladrone Islands, and the Moluccas; in fact, they are to be found in most tropical waters. Navigators, struck with the lightness of their flight and their slender shape, have given them the name they bear, thus comparing them with the fleetest and most elegant of men-of-war. Sir Hans Sloane, who saw numbers of them at Jamaica, describes them under the name- of Man-of-war Birds. " They fly," he says, "like kites, look black, are very large-winged in proportion to their size, and they fight with sea-gulls for their prey." They are eminently raptorial. Ray speaks of their eagle eye, vulturine claws, and cat-like gliding movements, their immense extent of wing, and their dashing swoop.

\section{Pelicanide.}

This family, which Mr. Gray makes the sixth and last of Palmipedes, includes Cuvier's Totipalmes, or birds having the hind toe united to the others by a single membrane. This extensive family comprehends the Tropic Bird (Phaeton), the Darter (Plotus), the Gannets (Sula), the Cormorants (Phalacrocorax), and the Pelicans (Pelicanus). 
The group comprehends those Birds which have the base of the bill denuded of feathers, the nostrils mere slots, in which the opening is scarcely perceptible; the skin of the throat more or less capable of distension ; the tongue small. Some of the group are large and heavy birds, but they are all gifted with powerful wings; they are, at the same time, good swimmers.

\section{The Tropic Bird (Phaeton).}

The Palmipede we are about to notice received from Linnæus the mythological name of Phaeton, in allusion to the son of Apollo and Clymene, who is said to have made an audacious attempt to drive the chariot of the Sun.

These Birds are well known to navigators as the harbingers which foretell the approach to the tropics. They are distinguished by two long, slender tail-feathers, whence their French name of paille en queue. They are gifted with great length of wing, which, with their feeble feet, proclaims them formed especially for flight. They are accordingly swift and untiring in flight, heedlessly going far out to sea ; forming, as Lesson remarks, a well-defined and purely geographical group, their homes being in rocky islands, to which they usually return every night. Nevertheless, he frequently met with them in tracks of ocean far from any land, possibly they having been swept beyond their natural limits by the sudden squalls and hurricanes so frequent in equatorial seas.

The Common Tropic Bird (Phaeton athereus, Fig. 96) seems to confine itself, according to this writer, to the Atlantic Ocean, stopping near the confines of the Indian Ocean; the other species, the Roseate Tropic Bird (Phaeton phonicurus), which is larger than the former, seeming to belong further eastward, both meeting in nearly equal numbers at the Mauritius and other islands of the same group. Their flight is described as calm and quiet, composed of frequent strokes of the wing, interrupted by sudden falls. The bird is about the size of a partridge, with red bill and markings under the lower mandible; in general appearance it resembles the Gulls, but has longer and more powerful wings; the legs and feet are vermilion red, the latter webbed; the tail has two long, narrow feathers. One of their breeding-places is the Bermudas, where the high rocks which surround the island are a protection from the attacks of the fowler.

The Yellow-beaked Phaeton (Phaeton flavirostris), a third species, is distinguished by the colour of its beak. It is a native of the Islands of Bourbon and Mauritius. 
The appearance of these birds announce, as we have said, that the navigators have entered the torrid zone, as they rarely go beyond the limits of this region. It sometimes, however, pushes out to sea to a distance of a hundred leagues. When they are fatigued, aided by their large webbed feet, they rest upon the waves. Like many other ocean birds, their peculiar organisation prevents them settling on the ground from choice. They, therefore, skim continually over the surface, on which they obtain their food, which consists of fish and molluscs. To enjoy a state of quiescence, the immense spread

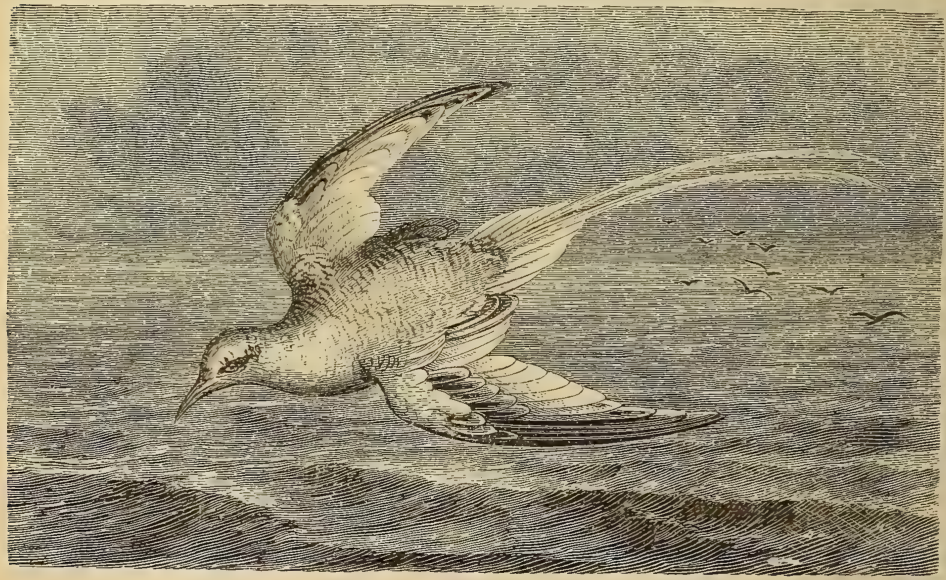

Fig 95.-Tropic Bird.

of their wings forces them to choose an elevated perch, such as the top of a tree or the summit of a rock. When worn-out by fatigue, if they settle on the water, they are forced to wait until they are lifted on the crest of a wave before they can again take flight. Their mode of flying is peculiar, for they communicate to their wings a kind of quivering motion.

These birds seek remote and solitary islands for the purpose of breeding. They build their nests in trees, or in the clefts of rocks, but always in some position difficult of access. They lay two or three eggs. The young ones, when just hatched, owing to their dazzling-coloured down, bear a considerable resemblance to powderpuffs. 


\section{The Darters (Plotus).}

The Darter has a straight and pointed bill, with indentations at the point, turned in a backward direction. Its head is slender and cylindrical, and forms the termination of a slim and excessively long

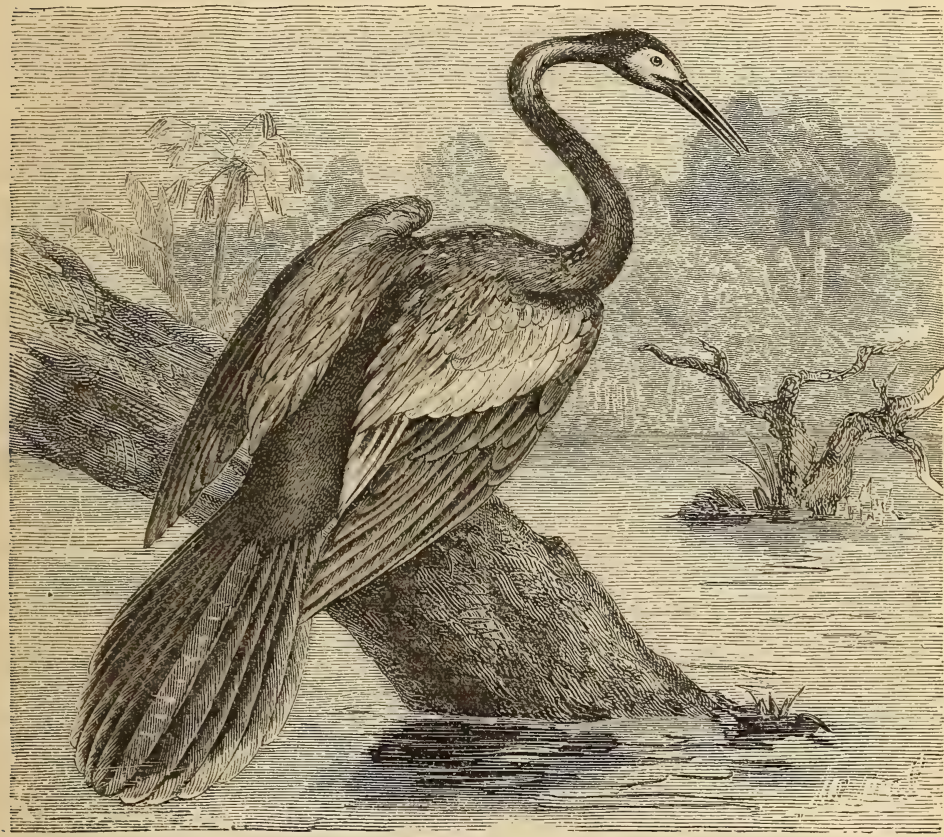

Fig. 97.-Darter.

neck, which gives it much the resemblance of a serpent grafted on a bird. In all its movements this neck is the counterpart of the reptile, and imitates its undulations; therefore, in the United States it has received the name of the Serpent Bird. They are untiring swimmers and excellent divers. When any danger threatens them, they dive under water, and do not come to the surface until they have found some tufts of reeds in which to hide, even should the distance be as much as I,000 feet from the spot where they disappeared 
These birds are of a wild and suspicious nature, confining themselves to solitary haunts. They perch upon trees which grow by the sides of a pool or river, in order to dart upon any unfortunate fish which comes within their reach, which they seize with extraordinary address, swallowing it whole if not too large; but if such should be the case, they carry it to a rock, where they dismember it with their beak and claws.

The Darters build their nests on the topmost branches of trees, constructing them of dried twigs and reeds, and lining them inside with a thick layer of down.

Only two species of Darter are known-the Anhinga (Plotus) Leraillantii, a native of Africa, the plumage of which is black from the breast to the tail ; and the Black-bellied Darter (Plotus anhinga, Fig. 97), an American species.

Levaillant, in his usual lively manner, relates that he was induced to visit a rich proprietor in the Canton of the Twenty-four Rivers by a tempting description he received of two extraordinary birds which haunted the vicinity. They frequented a particular tree, and baffled him more than once by their skill; but at length he got within shot, and killed both of them right and left. He describes them as diving for fish. When they caught a small one it was swallowed; when a large one, it was carried to a rock or the trunk of a tree, when the bird, fixing it beneath its feet, picked it to pieces with its bill. Though the water is its favourite element, it is on trees and rocks, he tells us, that it establishes its nest and brings up its young, taking care to place the nest so that the young may be precipitated into the water as soon as they are able to swim, or when the safety of the family requires it.

\section{The Gannets (Sula).}

The Gannet is a massively-made bird, not of a graceful shape ; it is larger than a Duck, and has white plumage.

One species, the Brown Gannet, has obtained the name of Booby (Sula fusca), from the supposed stupidity which, rightly or wrongly, is attributed to it ; for if a person finds one of these birds standing in his path, the creature offers no resistance, but will allow itself to be killed rather than abandon its position. The Frigate Bird, with audacious rapacity, when it observes the Gannet catch a fish, swoops down upon it and compels it to disgorge its prey. Their somewhat imperfect organisation explains this habit of non-resistance. The shortness of their legs and the excessive length of their wings 
prevent them escaping from their enemies when on shore, nor have they sufficient power of flight to avoid them in the air. But when they are aloft, with their necks stretched out, the tail expanded, and the wings almost motionless, they soar wonderfully. Although they are strong on the wing, they do not venture far from shore, con-

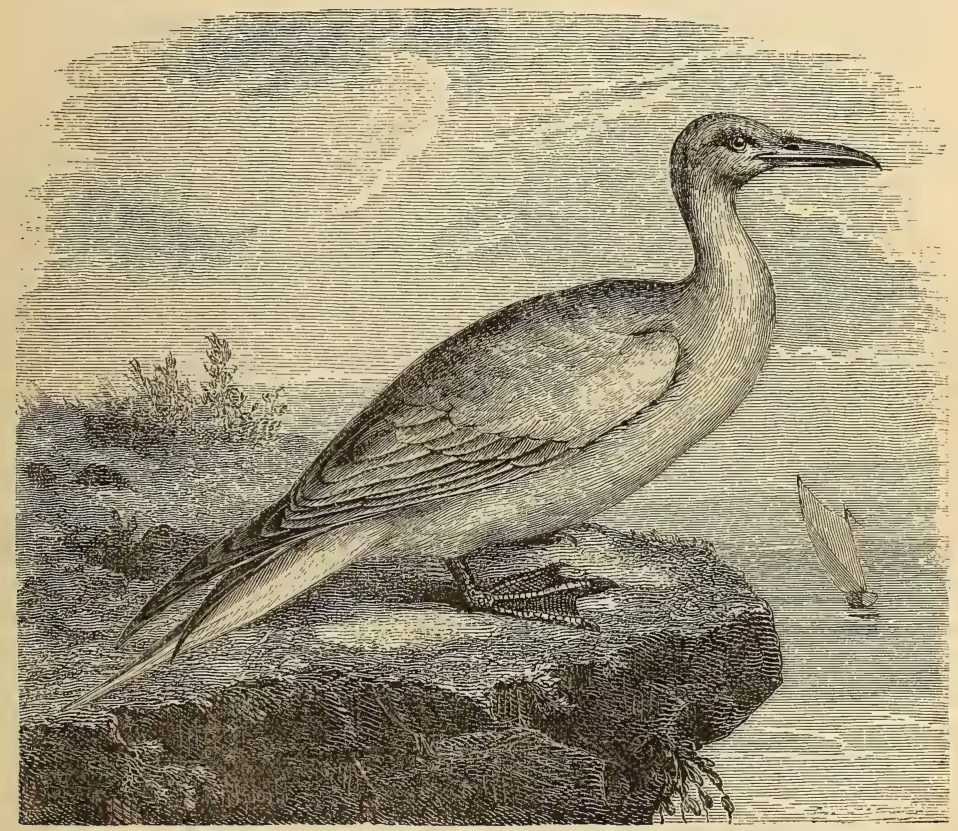

Fig. 98.-Gannet or Solan Goose.

sequently they are never met with more than twenty leagues at sea. Their appearance, therefore, is considered by the mariner as an indication of the proximity of land. In their flight they frequently skim over the sea, catching such fish as swim near the surface. The skin of their throat is so readily distended that they can swallow their prey whole. The Gannet is also an excellent diver, for it is able to remain more than a minute under water when in pursuit of food.

These birds are found in every part of the globe, giving the 
preference, however, to tropical countries ; still they are plentiful in the Hebrides, in Norway, in Scotland, and are even found as far north as Kamtschatka and the Gulf of Bothnia, according to Acerbi. But when residents of high latitudes, they migrate southward on the approach of cold weather. In the winter season they frequent the coast of Cornwall, and are found, in fact, in every part of the British and Irish Channel, generally keeping out at sea. They are constant attendants on the large quantities of herrings and pilchards that frequent our coast late in autumn.

This bird takes its prey by darting down on it with great velocity. When swimming, it floats upon the water with the buoyancy of a Gull, not submerged, as is the case with the Shag, Cormorant, or Northern Diver.

Three species of Sula are known: the Solan Goose or Gannet (Sula bassana, Fig. 98), which is very common on the Bass Rock, a small islet in the Firth of Forth, this is the only European species; the Common Gannet (Sula dactylatra) - vulgarly called mouche de velours-this is smaller than the preceding, and is found about southern tropical and temperate seas; and the Brown Gannet (Sula fusca), which inhabits South America.

\section{The Cormorant (Phalacrocorax).}

The Cormorant is distinguished by a bill straight and compressed, the upper mandible curving downwards, and forming a hook at the termination; lower mandible inserted in a small membrane extending under the throat; feet strong, short, toes three before and one behind, united by a membrane; nail of the middle toe serrated; wings moderate, the first quill longer than the second, the whole being blackish; the upper part of the back and wings ashy brown, or bronzed in the middle, bordered by a large band of glossy greenish black.

The Cormorant (Phalacrocorax carbo, Fig. 99) has a massive and rather awkward body, feet short and drawn back to the abdomen, the head flattened and small, the guttural pouch very small. Their bulk varies. On the south coast of England they are large birds, Pennant having weighed one which exceeded seven pounds, and measured three feet four inches. Their blackish plumage has given the idea of some resemblance existing between them and the crow; hence their name, Cormorant, from Corvus vorans, which signifies a voracious crow.

These birds have a wide geographical distribution, being found 
in all parts of the globe, and always on the sea-coast or at the mouths of rivers. They are excellent swimmers and clever divers, pursuing with extraordinary rapidity the fish on which they feed.

The Cormorant swallows its prey head first; and if it happens to catch it by the wrong end, it will throw it up in the air, and seize it again in its bill as it descends in the proper position. When it has caught an eel, a good half-hour sometimes elapses before it can succeed in swallowing it. It may be seen making the most violent efforts to swallow its prey; and just at the moment when one

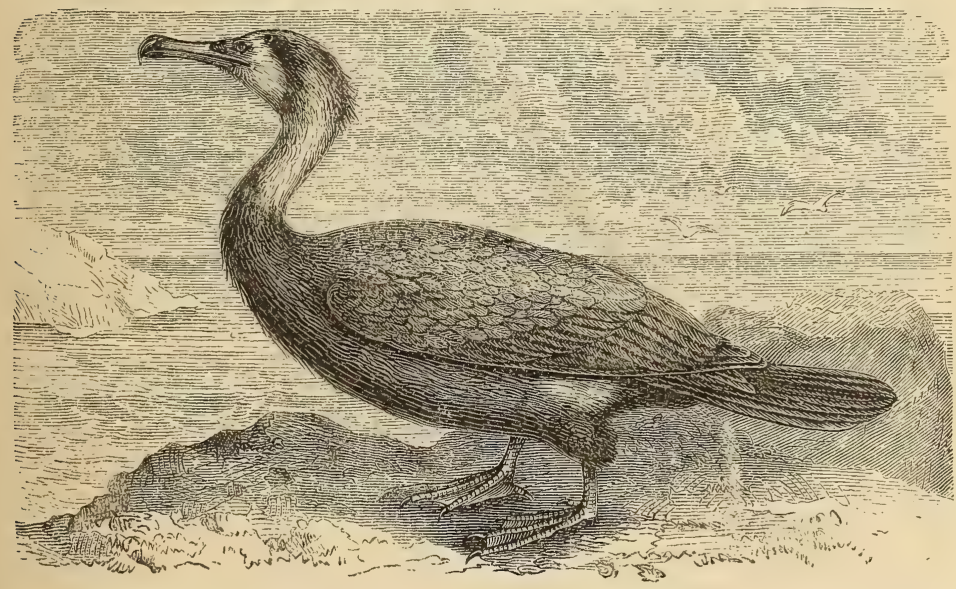

Fig. 93.-Cormorant.

would think that the slippery morsel was successfully absorbed, the fish suddenly reappears again, still struggling to escape; the Cormorant swallows it again ; the eel still resists, and increases its efforts to escape ; worn out at last by its prolonged and useless efforts, the victim is finally compelled to resign itself to fate.

The appetite of the Cormorant is insatiable. The havoc which it commits in rivers is very great, for the consumption of a single bird in one day frequently amounts to six or eight pounds of fish, these it pursues principally under water, for it is an expert diver and most successful hunter. In consequence of the skill displayed by the Cormorant in fishing, and the ease with which it is tamed, it is reared 
in a semi-domestic state in certain parts of Eastern Asia. The Chinese and Japanese are the nations who best know how to utilise their habits. When thus used a ring is placed round their necks to prevent them swallowing the captures they make. Trained to obey their master's voice, and balked in their attempts to swallow by the ring round the neck, they bring to their owner all fish they take. Sir George Stanton, in his embassy to China, having reached Len-tze, famed for its breed of these birds, found them to be a species somewhat resembling the Common Cormorant. They are described by Dr. Shaw as a brown Cormorant with white throat, the body whitish beneath, spotted with brown, the tail rounded, irides blue, and bill yellow, which he named Phalacrocorax sinensis. "On a large lake," Sir George says, "close to this part of the canal, and to the eastward of it, are thousands of small boats and rafts, built entirely for this species of fishery. On each boat or raft are ten or a dozen birds, which, at a signal from the owner plunge into the water; and it is astonishing to see the enormous size of fish with which they return. They appeared to be so well trained that it did not require either ring or cord round their necks to prevent them swallowing their prey, except when they received the permission of their master to do so, as an encouragement for their labours."

The dexterity with which the Cormorant seizes its prey is such that if a dead fish is thrown into the water from a distance, the bird will dive immediately, pursuing its course in a direct line to the spot, never failing to secure it, even before it reaches the bottom. On shore the Cormorant is a dull heavy bird, and it is only in water, and especially while fishing, that it appears to advantage. Now on the surface, next moment below, onward it plunges, with impetuous velocity; then rising suddenly in some unexpected spot after a lengthened dive, it is certain to have the unfortunate fish in its bill.

Another peculiarity which belongs to this species is common with many other aquatic birds - that of violently beating the water with its wings without moving from the spot, followed by a vigorous shaking of the whole body, with the feathers ruffled, and at the same time covering itself with water. After repeating this several times, with short intervals of rest, it will retire to an elevated place on shore, where it will remain with outspread wings until dry.

The flight of these birds is rapid and lasting; but they are as heavy and awkward when on land as they are nimble and active in the water. Their nature being unsuspicious and trustful, they can be easily approached, particularly when resting after their fishing exertions.

The Cormorant is widely diffused both in the Old and New 
World. It is a migratory bird, but is seen on our coast at all seasons. It breeds on the sea-shore, selecting for the purpose crags and inaccessible places. Their nests are composed of sticks and seaweed. The eggs, generally three in number, are of a whitish colour weighing about two ounces.*

In Egypt four species of Cormorants are known. The Common Cormorant is the size of a Goose ; this species is easily domesticated and is frequently met with in France.

\section{The Green Cormorant or Shag (Phalacrocorax cristatus).}

This species is in weight about four pounds; the bill is dusky, and about four inches in length; a bare yellow skin is situated along the sides of the mouth and chin, the latter speckled with black. The whole bird appears black at a little distance, but on nearer examination, the head, neck, breast, and rump are of a glossy green. The feathers of the upper part of the back, scapulars, and wing coverts are pointed, and beautifully glossed with purple, violet, and green, each feather being edged with a velvety black; the under part of the body is less glossed with green; the legs are dusky black; middle claw serrated.

The female weighs over three pounds; the upper part of her body is dark, not so densely glossed as in the male; but the margin of the feathers of the scapulars and wing coverts is black, the under part is dusky, with a mixture of grey.

Such is Colonel Montagu's description of a pair shot from the nest, but they vary in plumage and colour. In habit the Shag is strictly a salt-water bird, breeding on our rocky coasts, where it builds a nest of stick and sea-weed. They resort to the maritime caves of the Hebrides in such vast numbers that they literally cover the sea to a considerable extent when on their passage from the caves of Liuir and Toehead to their fishing-grounds in the Sound. Mr. McGillivray has counted 105 in one flock. This picture Mr. McGillivray makes the text for one of his most delightful descriptions :-

"There is a large cave," he says, "on the west coast of Harris, celebrated for the number of Shags which reside on it, and so lofty that a boat can enter it to a considerable distance without lowering the masts. When we reached the mouth of the cave a considerable

* Sometimes they roost and build on bushes in the vicinity of fresh-water lakes. - ED. 
number appeared conspicuously perched on the little shelving rocks and projections, their dusky figures strongly relieved by the whitened surface of the rocks. Some of them fly overhead as we approach, but more drop into the water like a stone. On looking down we see them rapidly winding their way under the boat, swimming with outspread wings, and not at all in the manner represented by some writers, who say that it propels itself entirely under water by the feet and tail. Glancing aloft, we see many Black Guillemots in the clefts; and above them is the eyrie of the White-tailed Eagle. But our business is with the Shags, which are now seen writhing their long necks as they gaze upon us. Presently a shot is fired, and another; the dead birds drop on the water, the living plunge headlong into it, many advance on the wing, but, being frightened by the upraised oars, dart into the water.

"Advancing a little, we find that many still remain on the rocks; of these we shoot some more. Presently some of those which had escaped return, and perch; and we continue shooting until we have obtained as many as we desire. After all the uproar we have created, several still remain standing near their nests, loath to quit them. Although most of the nests are out of reach, some are accessible. We find them generally bulky, sometimes very scanty, formed of fuci, twigs, heath, and grass, rudely put together, made flat, or with a shallow cavity, containing two, frequently three, sometimes four eggs, never more."

This Bird is smaller than the one preceding, and inhabits the Arctic and Antarctic regions. A bird nearly resembling this (Phalacrocorax Desmarestii) is described by Temminck and figured by Gould, a species which has been observed in Corsica, and is of a blackish green. Montagu satisfies himself that the Crested Cormorant was only a seasonal variety of the Common Cormorant; and probably others of the species described, if carefully examined, would prove to be the same. McGillivray is of opinion, however, if $\mathrm{Mr}$. Gould's figure is correct, the species must be distinct.

\section{Pelicans (Pelicanus).}

The Pelican has the bill long, straight, rather broad, and very much depressed; upper mandible flattened, terminating in a hooked tip much bent and compressed; lower mandible formed of two bony branches united at the point, from which a membranous naked skin is suspended, forming a purse, which can be distended into a voluminous bag. The Pelicans are large, heavy, aquatic birds, with great extent 
of wing, and are excellent swimmers ; their haunts are estuaries, the sea-coast, and the banks of rivers, lakes, and marshes. In its habitat, whenever a fish betrays its presence by leaping or flashing its glittering scales in the sun, the Pelican will be seen sailing towards it.

This bird has an appetite so insatiable and a stomach so capacious that, in one day it devours as much food as would satisfy six men. The Egyptians have nicknamed it the River Camel, because it can imbibe at once more than twenty pints of water. Certainly it only makes two meals a day ; but, oh, what meals they are !

Pelicans often travel in considerable flocks, visiting the mouths of rivers or favourite retreats on the sea-coast. When they have made choice of a suitable fishing-place, they arrange themselves in a wide circle, and begin to beat the water with extended wing, so as to drive the fish before them, gradually diminishing the circle as they approach the shore or some inlet on the coast. In this manner they get all the fish together into a small space, when the common feast begins. After gorging themselves, they retire to the shore, where the process of digestion follows. Some rest with the neck over the back; others busily dress and smoothe their plumage, waiting patiently until returning appetite invites them to fresh exertions. When thus quiescent, occasionally one of these birds empties his well-lined pouch, and spreads in front of him all the fish that it contains, in order to feed upon them at leisure. This pouch, which plays so important a part in the Pelican's life, is composed of two skins, the outer one being a prolongation of the skin of the neck; the inner one is contiguous to the coating of the œsophagus.

In spite of its great size, the Pelican flies easily and to considerable distances. It is no diver, but will occasionally dash down on fish from a considerable height, and with such velocity that it becomes submerged; but its buoyancy instantly brings it again to the surface. It perches on trees, but seems to prefer rocks. Its nest is generally formed of coarse reedy grass, lined with softer material, and placed in the clefts of dry rocks near the water. Here the female deposits two, three, four, sometimes five, white eggs, but most frequently only two. Occasionally they will lay in an indentation in the ground which they have previously roughly lined with blades of grass.

After an incubation lasting from forty to forty-five days, the young ones, covered with a greyish down, are hatched. The female feeds them : she presses the hooked red point of the mandible against her breast, which causes her to disgorge the fish it contains into the bills of the young ones, the male performing the same operation on himself for the benefit of his partner. This is probably the tact that 
has given origin to the absurd fable that the female Pelican is in the habit of piercing her breast in order to nourish her young with her maternal blood. The young birds are easily tamed; it is even asserted that they are susceptible of education, and that, like the young Cormorants, they can be taught to fish for their owners.

The Pelican is more common in tropical regions than in temperate climates. They are very numerous in Africa, Siam, Madagascar, the Sunda Isles, the Philippines; and in the Western Hemisphere they abound from the Antilles to the northern temperate part of the North American continent. It haunts the neighbourhood of rivers and lakes and the sea-coast, being rarely seen more than twenty leagues from the land. Levaillant describes one of those wonderful ornithological scenes which only occur in uninhabited regions. At the entrance of Saldanha Bay, on the south-west coast of Africa, after wading through the surf and clambering up the rocks, "all of a sudden there arose from the surface of the Island of Dassen-Eyland an impenetrable cloud, which formed, at the distance of forty feet above our heads, an immense canopy, composed entirely of aquatic birds-cormorants, sea gulls, sea swallows, pelicans, and I believe the whole winged tribes of this part of Africa were here assembled. Their voices, harsh and discordant, formed a noise so unmusical that I was every moment compelled to cover my head in order to relieve my ears. The alarm we created was so much the more general, inasmuch as the birds disturbed were chiefly sitting females. They had nests, eggs, and young to defend." In this scene the Pelican, from its peculiar appearance, was of course a prominent object. The bestknown species are-I. The Crested Pelican. 2. The White Pelican. 3. The Brown Pelican. 4. The Spectacled Pelican.

\section{The Crested Pelican (Pelzcanus onocrotalus).}

The Crested Pelican (Fig. I00), in common with the White Pelican, inhabits the south-east of Europe and Africa, and is also found in Hungary, Dalmatia, Greece, the Crimea, and the Ionian Islands, as well as in Algeria, and, according to some authors, it is frequently met with in China.*

It has white plumage, with the exception that the ends of the feathers of the back and wings are black. The feathers of the head and upper part of the neck are twisted up so as to form a tolerably

* On the Chinese coast, near Canton, and in the estuaries and creeks of Miers Bay, I have frequently found it.-ED. 
large tuft or crest, hence the name it bears. Its European habitat is principally the marshes round the Black Sea, and the isles adjacent to the mouth of the Danube.

Of their modes of life travellers in those regions give very interesting descriptions. Count Mükle states that they are plentiful on the lakes of Missolonghi and in the marshy grounds near Thermopylæ. In situations difficult of access, such as floating islands

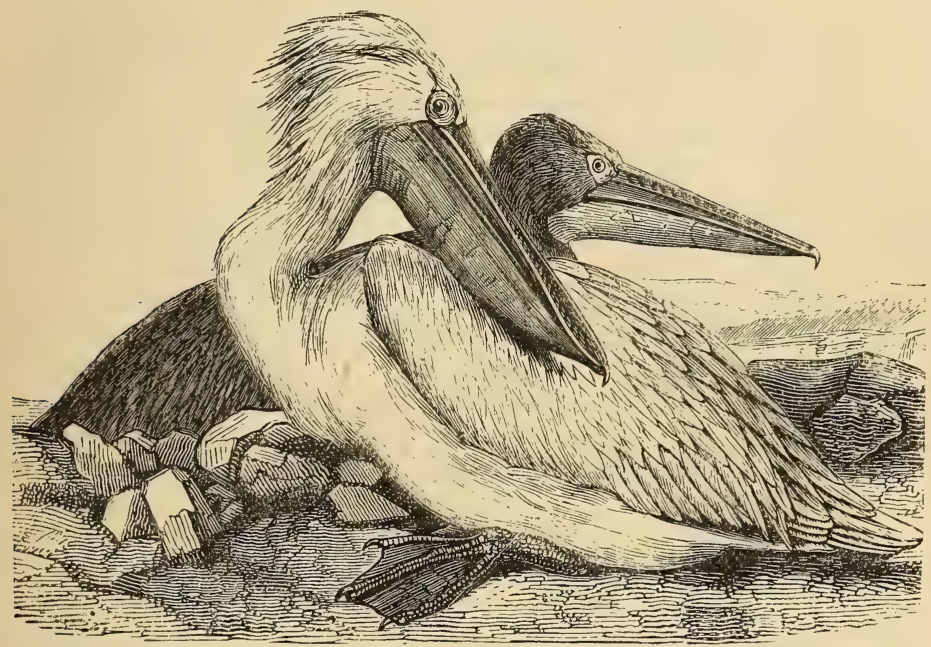

Fig. 1oo.--The Crested Pelican.

scarcely over the water-line, they place their nests, supported by the reeds and rushes. The vicinity of these breeding-places are rendered indescribably offensive by decomposed fish dropped about, and the aisagreeable white dung with which all the neighbourhood is covered. "Time was," says Mr. W. H. Simpson, "and that not so long ago, when Pelicanus crispus* lived in hundreds all the year round, from the rocky promontory of Kourtzalari, hard by the mouth of the Acheloüs, on the western extremity of the lagoon, near the island of Etolico, up the northern arm, and on the east along the great

* Bonaparte's synonym for this species. 
mud flats which mark the limits of the present delta of Phidaris. Nowadays, however, a solitary individual may be seen fishing here and there throughout the vicinity ; the remnant have betaken themselves to the islands which divide the Gulf of Procopanisto from that of Etolico. Here, towards the end of February last, the community constituted a group of seven nests-a sad falling off from the year 1838 , when thirty-four nests were grouped upon a neighbouring islet. As we approached the spot in a boat the pelicans left their nests, and taking to the water, sailed away like a fleet of stately ships, leaving their nursery in possession of the invader. The boat grounded in two or three feet of mud, and when the party had floundered through this, the seven nests were found to be empty. A fisherman had plundered them that morning, taking from each nest one egg, which we afterwards recovered. The nests were constructed in a great measure of old reed palings used by the natives for enclosing fish, mixed with such picces of the vegetation of the islet as were suitable for the purpose. The seven nests were contiguous, and disposed in the shape of an irregular cross, the navel of the cross, which was the tallest nest, being about thirty inches high, the two next in line being about two feet, and the two forming the arms being a few inches lower, the two extremes at either end being about fourteen inches from the ground. .... The eggs are chalky, like others of the Pelicanidæ, very rough in texture, and some of them streaked with blood." *

\section{The White Pelican ( $P$. minor).}

The White Pelican is as large as a Swan. Its bill is about fifteen inches in length. Its plumage is white, with a slightly rosy tint, which is brightest in the breeding season; the primaries and spurious wings are black; the crest and a few feathers on the neck yellowish.

This species received from the ancients the name of Onocrotalus, now allotted to the previous species, because they fancied that they discovered a resemblance in its cry to the braying of an ass. It is very common on the lakes and rivers of Hungary and southern Russia, as well as on the banks of the Danube. If it is seen in France, it is purely accidental. A wild rocky shore, where it can look down on the sea, is the favourite haunt of this Pelican; but it is not uncommon for it to perch on trees. The nest is formed of coarse reedy grass, with a lining of finer quality; it is generally

$$
\text { * “Ibis," vii., p. } 395 \text {. }
$$


made on the ground, and is about eighteen inches in diameter, in which it lays four, sometimes five, white eggs, but more frequently two, slightly oblong, and alike at both ends. Fish forms its principal food, which it captures chiefly in shallow inlets, as it is an indifferent diver. Occasionally its flight is lofty, but generally close to the surface of the water.

\section{The Brown Pelican (P. fuscus).}

The Brown Pelican is an American species, smaller than the preceding, and is described at some length by Nuttall. It has the head and the neck variegated with white and ash-colour; all the rest of the plumage of a brownish grey, with whitish marks on the back; the pouch is of an ashy blue, striped with a reddish hue. It is found in the Larger Antilles, on the coasts of Peru, Florida, and South Carolina.

Although ponderous and heavy-looking on the wing, this species is capable of performing flights of immense distance, and to a certain extent may be considered migratory. In winter they are seldom seen beyond the edge of the tropics, but in summer they are frequently found as far north as the thirty-sixth degree of latitude. Extremely wary and difficult of approach, they are seldom shot, although persistently pursued by fishermen, on account of the immense damage they do to the spawn and young of fish. They are also possessed of the greatest powers of vitality, and resist death when pierced with wounds so serious that it would inevitably kill any other species. From this circumstance doubtless they receive the name of Die-hards from the residents that dwell on the margin of the Gulf of Mexico. When disabled from taking flight, their courage in defending themselves from an assailant is as remarkable as that of the Bittern; but being possessed of superior size and strength to the latter bird, the Brown Pelican can successfully resist the strongest dog. Like the other species of this genus they live in small communities of twenty or thirty members, and build their nests upon the ground closely adjoining each other, and the utmost good fellowship, almost affection for each other, exists between the members of the diminutive coteries. The young birds remain with their parents till the spring following their birth, the old ones driving them off to seek new domiciles, when the advance of the season tells them that they must provide a home for a coming family. As in many other races, the plumage of the young is much darker and less handsomely marked than in the adults. From frequent persecution, the Brown Pelican has of late years much diminished in numbers. 


\section{The Spectacled Pelican (P. conspicillatus).}

The Spectacled Pelican, which is only found in southern climates, is thus named from the naked skin which surrounds its eyes, giving the bird the appearance of having on a pair of spectacles. Its plumage is white, and in habits and mode of life closely resemble the previously described species. One of its principal haunts is along the southern coasts of China, especially in the vicinity of the mouth of the Canton river, and on the bays and estuaries near it. The Chinese regard it as sacred, and nothing would induce them either to rob them of their eggs or young.

Longevity is reported to be one of their characteristics. A very old mandarin, living on the margin of Meers' Bay, pointed out to me a Spectacled Pelican, that he said he could remember since his childhood. This bird was partially tamed; for although it went long distances to fish, it always returned to his village to pass the night. 


\section{H A P T E R III.}

THE LARID $A$.

"Notwithstanding the dissimilarity of the bill," says Mr. Vigors, ${ }^{*}$ "the Sterna and Rynchops most intimately accord in habits and external characters. The Gull-billed Tern of Colonel Montagu conducts us from these genera to the groups which compose the Linnean genus Larus-now divided into two genera, Lestris and Larus. From this group we are led to the genera Diomedece and Haladroma, by the absence of the hind toe, by means of the species Larus tridactylus (Latham), where, though the hind toe is not absolutely different, as might be inferred from its name, there appears but the rudiment of one. The last-mentioned genus, Haladroma, originally belonged to Procellaria, and was separated from it by its tridactyle foot. Even in this character however it forms a connection. from Lar us to the groups that compose the genuine Procellaria, all of which are distinguished by the singular peculiarity of having no true hind toe, but only a nail adhering to the tarsus in its place. We thus arrive at the Petrels, separated into groups of the Procellaria, Pachyptila, Puffinius."

\section{The Longipennes (Cuvier).}

The grands voiliers, or long-winged Birds, are thus named from their powerful and enduring faculty of flight. Mariners meet with them everywhere, and easily recognise them by their long and pointed wings, forked tails, and short legs. In this order the back toe is unconnected with the others, or is wanting, and the membrane which unites the others much notched; their bills are sharp and pointed, and without indentations. They pass their lives at a great distance from land, and do not approach the shore except for breeding purposes. To this sub-order belong the Sea Swallows (Sterna),

* "Linnean Transactions," vol. xiv. 
Scissors-bills or Skimmers (Rynchops), the Gulls (Larida), the Skuas (Stercoraria), the Petrels (Procellaria), Albatross (Diomedea).

\section{The Terns (Sterna).}

There are six species of Sterna, properly so called, described by British naturalists; and six others, according to McGillivray, nearly resembling them in form, colour, and habit. The true Terns have the bill straight, slender, compressed, and tapering, about the length of the head, with the edge sharp, and the tip elongated and pointed; the upper mandible armate ; legs short, slender ; anterior toes small ; membrane emarginate; wings long and pointed; tail forked. These birds are remarkable for their buoyant, graceful, easy flight, and the soft loose texture of their plumage. Their prevailing colours are a pale bluish grey or black, and white.

The Tern or Sea Swallow, on account of its long pointed wings and forked tail, like the Swallow properly so called, appear to possess a perfect immunity from feeling fatigue. They may be seen at one moment soaring in the air at a great height, at another darting down upon their prey, which their piercing sight has enabled them to descry. Often, too, they may be noticed skimming over the surface of the waves with astonishing rapidity, and seizing in their passage any fish which is on the surface. As they rarely swim, their flight seems incessant. When rest is taken it is upon some isolated rock in the ocean. They sometimes congregate in flocks, when they manifest so much attachment for individuals of their own species, that, if one of them be wounded by the sportsman's gun, the others surround it, full of grief and sympathy, nor will they leave it until all hope of helping their comrade is at an end.

These birds in their flight give utterance to shrill and piercing calls, which, when produced by numbers together, cause a most grating, unpleasant effect. But the time, above all others, when their noise is most discordant and shrill is the breeding season. "On going up to one of their breeding-places," says McGillivray, "which may always be discovered from a distance, as some of the birds will be seen hovering over it, one is sure to be met by several of them, which hasten to remonstrate against the intruder's approach by harsh cries and threatened blows. As you draw nearer, more of them leave their nests; and at length they are all on the wing, wheeling and bounding--now high and now low-at times coming quite close, and increasing their cries, which resemble the syllables 'cree-creecree-ae." " 
Like the land swallows, these sea birds arrive on our coasts in the spring. They disperse themselves over our lakes and large ponds, where they feed on any animal substances they meet with-either fresh or putrefied-fish, molluscs, or insects. Montagu says they are found in great abundance on the Sussex and Kentish coasts, particularly about Winchelsea, and in the Romney Marshes towards Dungeness. Mr. Selby found them breeding in the Solway and in the Firth of Clyde. McGillivray met with them in great numbers in South Uist and Long Island; and his correspondents, Messrs. Bailie

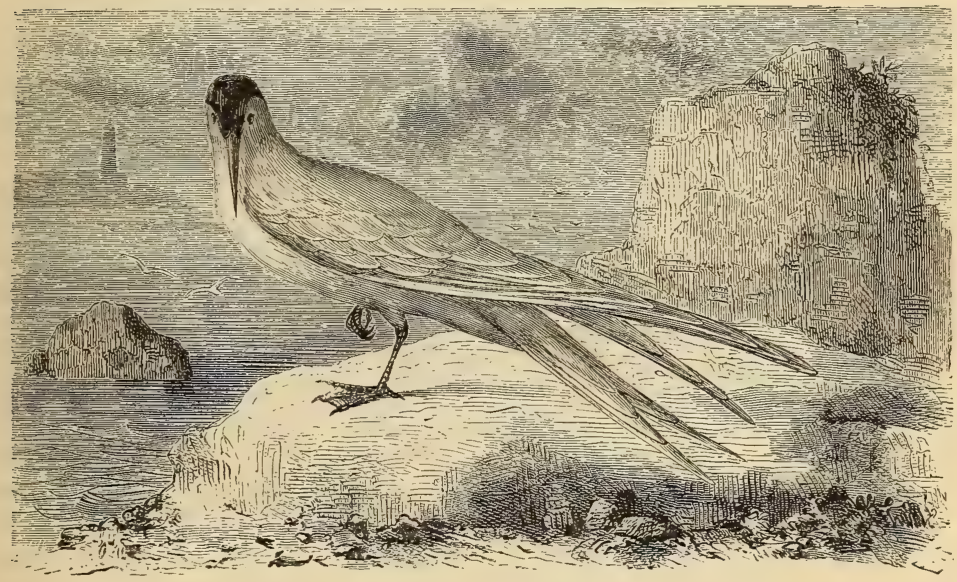

Fig. гог.-The Tern.

and Heddle, noted their annual arrival in the Orkneys in May. "They arrive in straggling flocks in the beginning of May," says McGillivray, "and soon betake themselves to their breeding-places, which are sandy tracts, gravelly or pebbly ridges, rocky ground, sometimes low shelving rocks on the sea-shore, their nests being bits of grass or fragments of sea-weed, placed in a mere depression. In stormy weather they fly less, sometimes sheltering themselves upon the shore. They go to roost very late in the evening; for long after sunset they are still to be seen seeking their sustenance."

Terns at their breeding-time always assemble in flocks on the sea-coast, on the margins of lakes, marshes, or wooded lands near 
the mouths of rivers. Their nests are placed so near to one another, that those sitting actually come in contact. They lay two or three eggs, which hatch in twenty days. These eggs are esteemed as a very delicate viand: in the United States a considerable trade is carried on in them.

The Tern is found in all the regions both of the Old and New World, Australia, and the islands of the Pacific.

The representative species, Sterna hirundo (Fig. IOI), is very common in France, on the shores of the Atlantic, and in the Mediterranean.

\section{The Lesser Tern (Sterna minuta).}

This smallest of the Terns has many habits in common with the Sterna hirundo. "In the elegance of its buoyant flight," says McGillivray, "as it skims over the water or shoots along its way to and from its breeding-place, the tiny creature is an object of admiration to every lover of Nature. You may see a pair coming up from a distance, flying at the height of a few yards over the waves, their long wings winnowing the air and impelling them on by starts as they wind their way in undulating and graceful movements. Suddenly their flight is arrested over a large pool left on the sands by the retreating tide. With quick beats of their wings they hover almost stationary over the water, with downward-pointed bills, intently searching for their prey beneath. One drops with upraised wings, dips for a moment, and rises with a small fish in its bill, the other is equally successful. Onward they proceed, now and then emitting their shrill cry. Far ahead is seen a flock engaged in picking up their prey, and onward the stragglers speed to join their kindred."

The Lesser Tern has the bill slightly longer than the head, and, like the Common Tern, slender, nearly straight, much compressed, tapering, and acute, the eyes and feet small; plumage soft and blended; wings long, narrow, and pointed; tail long and deeply forked; upper part of the head and nape black; neck, back, and wings light greyish blue; hind part of the back and tail white; length to the end of the tail about ten inches; wings twenty-one inches.

This species reaches our shores in the beginning of May, and settles along the whole eastern and southern coast, from the Land's End to the Orkneys, but is rare on the west coast. The Firth of Forth, the sands of Barry, near Dundee, a place at the mouth of 
the Don, and another at the Ythan, are noted as their haunts, as are the sands of Strathbeg Loch, and the sands between Burghead and the mouth of the Findhorn. It is also abundant on the sea-coasts of Holland and France, where it feeds on fish-spawn and small winged insects.

The Noddy (Sterna stolida), which frequents rivers and the borders of lakes, especially marshes, makes its nest among the reeds or bushes: this species is scattered all over the globe. The Sooty Tern (Sterna fuliginosa) inhabits the bays and gulfs of the

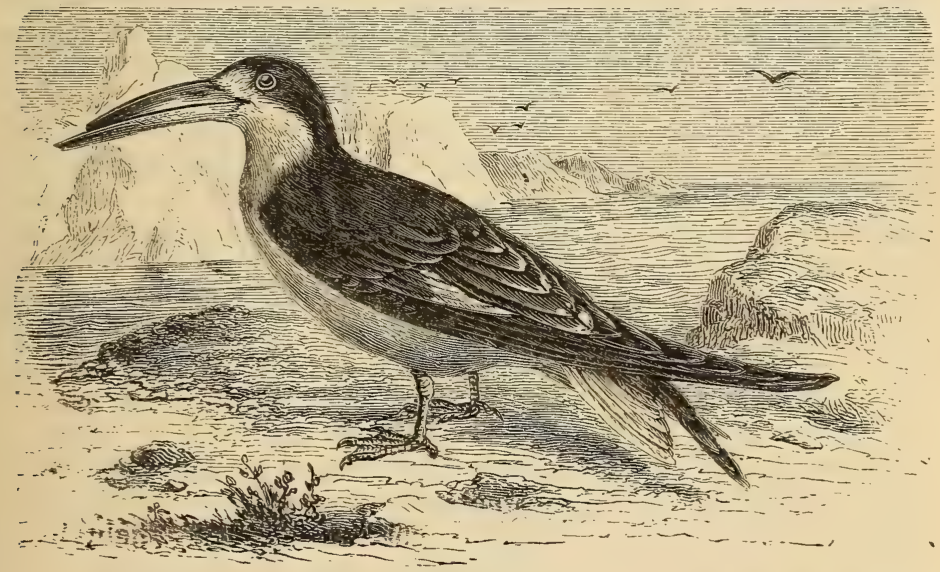

Fig. 102.-The Scissors-bill.

Mediterranean, and is only an accidental visitor to the north of France. The Arctic Tern (Sterna arctica) is a native of the Arctic Circle, and regularly visits the sea-coast of the north of France. We may also mention the Roseate Tern (Sterna paradisea), the Sandwich Tern (Sterna cautiaca), and the Tschegruna, or Caspian Tern (Sterna caspica), all of which either breed upon the British coast or are frequent visitors there, although they rarely reach France.

\section{The Scissors-Bill (Rynchops).}

The Scissors-bill have received their name from the conformation of their beaks, which are flattened laterally into two laminæ fitting 
one on the other, forming two mandibles compressed into cutting blades, the upper being one-third shorter than the lower. In order to pick up the shrimps and small fishes on which they feed, these birds are obliged to skim the surface of the water, dipping the lower mandible of their bill, the upper mandible being kept open and clear of the water till aquatic insects or other small fry have entered upon the lower portion of it.* The singular form of their bills is also of service to them in opening such bivalve shell-fish as come in their way. They frequently watch these molluscs, and when they notice that the shell of the latter is slightly open, they plunge the lower mandible of their long bill into it; and cut the ligaments that hold the opposite sides of the bivalve together. The tenement being thus opened, there is no obstacle to their devouring the inhabitant.

The representative of this species is the Scissors-bill (Rynchops nigra, Fig. IO2), frequently called the Cut-water. It is about the size of a pigeon ; its prevailing colour is white at the top of the head and black shoulders, a white band on the wings. These birds are very numerous in the West Indian seas. Like the Gulls and other sea birds, they occasionally form such dense flocks that they actually darken the sky for the space of a league.

\section{The Gulls and Allied Species.}

This includes the well-known shore birds generally called Gulls, the most familiar of which are the Kittiwake, Common Gull, Blackbacked Gull, and Skua. They are characterised by a light body, more or less compact; neck of moderate length ; head ovate; bill shorter than the head, straight, compressed; convex ridge on upper mandible, nasal groove long; lower mandible with the angle long and narrow ; mouth moderate ; tongue fleshy ; eyes small ; legs generally short; tibia bare; tarsus short, compressed; hind toe small; middle toe longest; fore toe moderate in length and slender; connecting membrane full, margins only concave ; claws generally small, arcuate, acute, and more or less compressed.

These birds inhabit the sea-shore, along which they wander in search of food; the larger species preying on fish, crustacea, and mollusca, and the carcases of cetacea and other marine mammalia

* Catesby says : "These birds frequent near the sea-coast of Carolina. They fly close to the surface of the water, from which they seem to receive somewhat of food." 
cast up by the sea. They all pursue shoals of fish in the open sea, often to great distances from land. Their plumage is full, soft, close, elastic, and well blended; wings long, broad, and pointed ; the tail, of twelve feathers, rounded and forked.

The Kittiwake (Rissa tridactyla) approach the Terns in size, yet have all the characteristics of the Gulls. However, they are of smaller size than the latter, have more slender forms, and their feet and bills are comparatively feebler. Thus we shall describe them under one head, as they have the same generic characteristics.

The Gulls are found in every country, on every coast, out at sea, and sometimes even on fresh waters, lakes, and rivers. These birds literally swarm in certain localities, where they devour every kind of animal food, fresh or decomposed. If they notice the carcase of any animal, either floating on the sea or cast up on the shore, it soon becomes their prey, and is speedily consumed by these "sea vultures," as Buffon calls them. They gorge themselves to their very throats; but their stomachs soon digest the rapidly-decomposing animal diet. They may also be observed in search of fish skimming over the surface of the water, their keen eyes anxiously scanning far and near for this most favourite food.

During the season they visit the breeding-places of other races to feed upon their eggs or young. In spite of the piteous shrieks of the parents and the plaintive cries of their progeny, the whole colony is sacrificed to their gluttony; but, as they are always cowards, whenever these depredators notice the approach of a bird more courageous than themselves, they retreat with all the celerity which their power gives them. The sight of a Skua (Stercoraria) is sufficient to make them disgorge their food. These water scavengers are, however, frequently in want of food, especially during stormy weather. But Nature, in her goodness, has well enabled them to endure hunger.

Sea Gulls are found everywhere, but they are most numerous on the flat and low sea-shores of the north, where the dead bodies of whales and other large fish furnish them with abundant food. They build their nests on inaccessible or desert islands in the northern seas, where they are safe from man's intrusion, laying two or three eggs in a hole scratched in the sand, or in the cleft of a rock.

These birds are easily tamed, and soon take to domestic habits; but their flesh, which is hard and tough, is unfit for human food. In order to render them eatable in cases of emergency, sailors, after having skinned them, hang them up, and leave them exposed to the evening dew for two or three nights. By this means some of the disagreeable sme!l possessed by the carcase is got rid of. 
The most remarkable species of the Sea Gull are the following :-

The Great Black-backed Gull (Larus maximus, Fig. 103) is of a pure white, with a black back. It is very common in northern

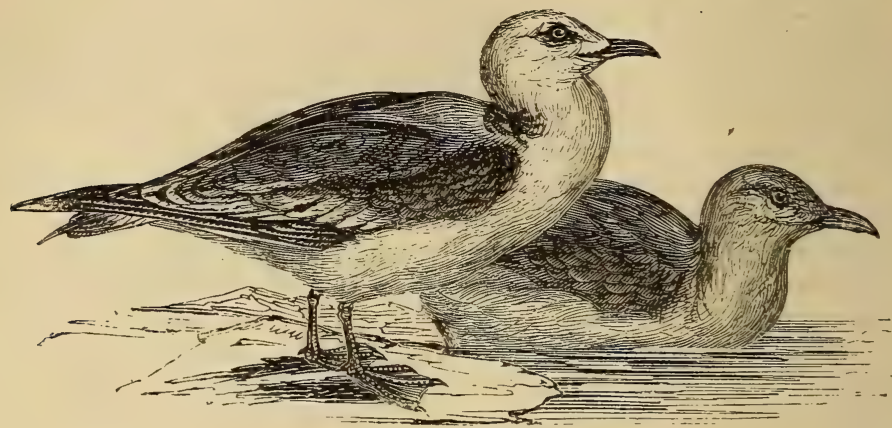

Fig. 103.-Black-backed Gull

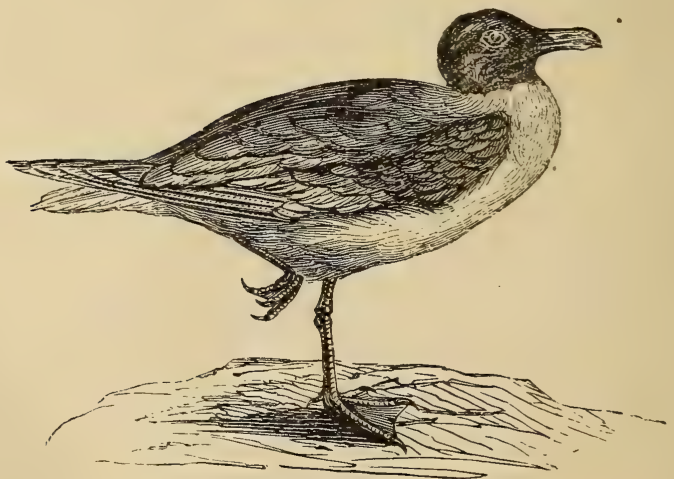

Fig. I04.-Grey Gull.

regions, and habitually visits the shores of the Atlantic to the coast of France.

The Herring Gull (Larus argentatus) is white, with a blue back. It is not so large as the previous bird. It is seen throughout the year on the coasts of the Mediterranean and the Atlantic, frequently associated with the Common Grey Gull (Fig. 104). 
The only species of Rissas necessary for us to describe is the Kittiwake (Rissa tridactyla, Fig. I05), which has the top of the head . black, its neck, tail, and lower parts of a white hue ; its back and wings are bluish grey, and its beak and feet vermilion red. It is called the Laughing Gull, on account of its cry, and is most easily tamed. It is widely spread all over Europe, and builds its nest on the coast at the mouths of rivers. It is only a visitor in France and Germany, but in Holland it is found as a permanent resident. Owing

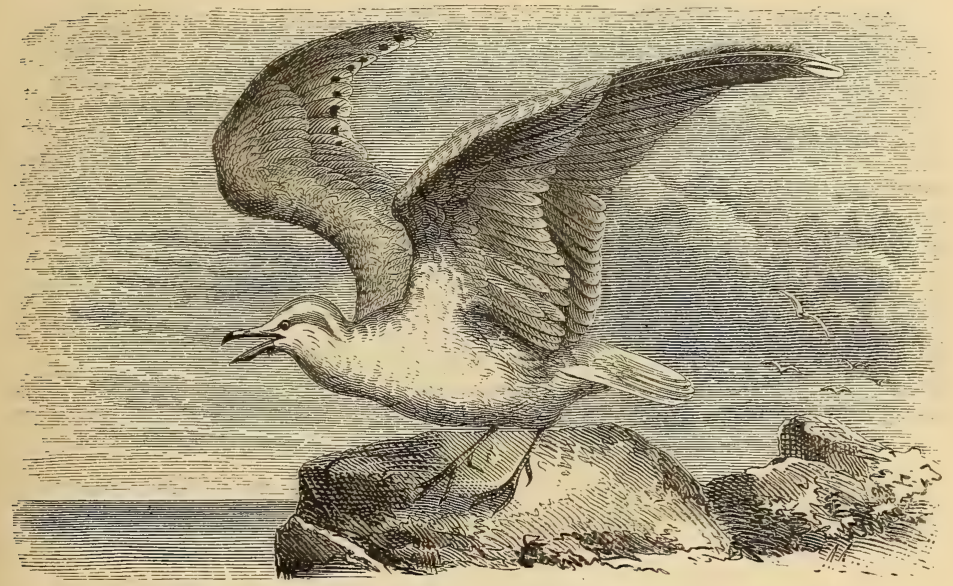

Fig. 105.-Kittiwake.

to this species possessing great diversity of plumage at different ages, this Bird has received several names, and been divided into as many species, which modern research has proved to be erroneous.

The Grey Kittiwake (Larus canus) is often called the Sea Pigeon. Its plumage is of a beautiful white colour, with a grey back. It is common in summer in the regions of the Arctic Circle; in autumn and winter it is found on the sea-coasts of temperate Europe.

The Skua, or Dung-bird (Stercoraria), is remarkable for its stout bill, which is nearly cylindrical, and covered with a membrane from the base as far as the nostrils; the upper mandible is convex, hooked, and armed at the extremity with a crooked point, which almost appears as if it was supplementary. These birds principally 
frequent the sea-shore, but at the time of storms they venture further inland. They fly very rapidly, even against the strongest wind. They pursue the Kittiwakes and Terns most inveterately, and sometimes even Boobies and Cormorants, their aim being to deprive these birds of their prey, or to force them to disgorge or drop their booty, which, before it falls into the sea, is caught by the active persecutor. This singular habit has given rise to the belief that Skuas feed upon the excrement of the Kittiwake, and to this they owe their name of Dung-birds.

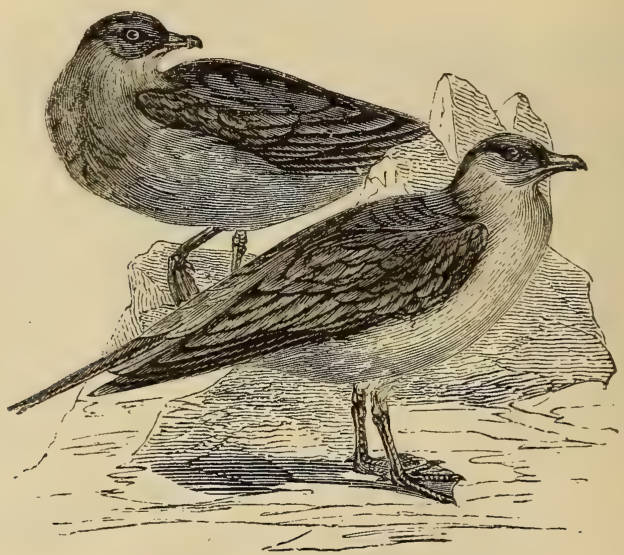

Fig. 106. - Buffou's Skua.

In some countries, as the Shetland Islands, these birds are held in veneration. The care and protection of the sheep are almost entirely entrusted to them, owing to their possessing an inveterate hatred against eagles; for as soon as the monarch of the air appears in view, three or four of them combine together to give him battle. They never attack him in front, but harass him pitilessly until they force him to retreat. In recompense for these services the inhabitants are in the habit of throwing to the Skuas the refuse from their fisheries.

These Birds live much in solitude, so that they may be able to procure a greater abundance of food, which consists of fish, molluscs, eggs, young sea-birds, and small mammals. They inhabit the Arctic regions of Europe and America, and make their nests in the heather; 
they lay from two to four eggs, which are sat upon by the male and female alternately. They are courageous enough to defend their young brood against any kind of animal, and even against man.

There are four European species : the Parasite Skua (Stercorarius parasiticus), which inhabits Greenland, Newfoundland, and Spitzbergen, and visits tolerably often our Atlantic coasts; Buffon's Skua (S. cepphus, Fig. 106), which is very plentiful in Sweden, Norway, Lapland, and North America, remarkable for some elongated feathers in the centre of tail ; the Pomerine Skua (S. pomarinus), which is very common in Newfoundland, Iceland, and the Faroe Islands ; the Common Skua (S. catarrhactes), commonly called the Brown Stoëland.

The Petrels (Procellaria) are characterised by a gibbous beak, the extremity of which is hooked, and seems jointed on to the rest of the upper mandible. These birds never dive, rarely swim, except at night, when they sleep on the waters ; but in their rapid flight they skim over the waves, and actually appear to walk upon them. To this habit they owe the name of Petrel, which simply means "little Peter," in allusion to the miracle of St. Peter, who walked upon the restless waters of the Lake of Genesareth.

The family of the Petrels contains several species of very different appearance. They traverse immense distances in their powerful and rapid flight, although it is rarely elevated above a few feet over the surface. They seldom approach the coast except to build their nests, for which purpose they select a little crevice in some steep rock, in which they deposit a large white egg. While sitting upon it, they keep up a low and continual noise, like that of a spinning-wheel.

Petrels are of a very engaging aspect, and of great importance to the poor people who inhabit the islands in the frigid seas, who are glad to use them as food, although they principally value them for their warm down and the oil which can be extracted from their bodies. The quantity of oil which these birds contain is so large that it is used as an article of diet. In the Faroe Islands candles are made from this oleaginous matter. Often, indeed, the islanders make the bird itself serve as a candle to illuminate their gloomy vigils. This is performed by passing a wick through the Petrel's body when just killed.

These birds appear to glory in tempestuous weather. They glide over the roughest waves, and seem as if they were enjoying themselves as they pass up and down the declivities of the mountains of foam. Sailors, who are confessedly simple and superstitious, take these birds for evil spirits, emissaries of the devil, harbingers of 
storms, and so forth, simply because they more frequently see them during bad weather. Their dark plumage tends to confirm the sailor in his superstition.

When the vessels sent to the whale fishery have passed the Shetland Islands, and entered the northern seas, which are almost always stormy, the Petrels are seen flying about amidst the eddies of foam which are formed by the wake of the ship. They keep in attendance on vessels until something is thrown overboard, for they are extremely voracious, and especially fond of fat. When whalers begin to cut up a whale, the Petrels flock around, to the number of several thousands. They are not afraid to approach so close that they may be knocked down or killed with a blow from a boat-hook. Their plumage is so close that shot fired at them, except at close range, will not penetrate.*

Petrels walk on land with much difficulty. When fatigued, they sleep on the water with their heads placed under their wings, allowing themselves to be borne about at the mercy of the wind.

The most remarkable species are-the Stormy Petrel (Procellaria pelagica), well known upon the coasts of Europe; the Capped Petrel ( $P$. hesitata), marked with a spot of white on the head; Wilson's Petrel ( $P$. Wilsonii), without a forked tail, but much resembling the Forked-tailed Petrel ( $P$. Leachii), which has a white spot at the root of the tail; and the Fulmar Petrel ( $P$. glacialis, Fig. I07), which is principally found in the Arctic regions, but is numerous on parts of the north coast of Scotland.

Under the name of Shear-waters (Puffinius) those species of Petrels are included which have bills as long, and sometimes longer, than their heads, and their nostrils in two distinct tubes. Among these are the Grey Shear-water (Puffinius cinereus), which is very common in the Mediterranean, and builds its nest in Corsica; the English Shear-water (Puffinius anglorum), which inhabits the northern regions of our hemisphere ; the Brown Shear-water ( $P$. aquinoctialis) which inhabits the Southern Ocean, and is frequently met with at the Cape.

The Albatrosst is the largest and most bulky of all the Birds which fly over the surface of the sea. It belongs principally to the

* The author is evidently unacquainted with modern fire-arms. We, for experiment, last season tried a lock-fast Dougall central-fire gun upon petrels, and found that all that was required to kill them, when within fifty yards, or even more, was to hold it straight. - ED.

+ From the Portuguese word Alcatraz, applied by the early navigators of that nation to cormorants and large sea-birds. -ED. 
southern hemisphere. The sailors know it under the name of Cape Sheep, which they give it on account of its enormous size. Its extended wings measure as much as sixteen feet five inches across.* Its plumage is generally white, with the exception of a dark back. Courage is not measured by size. This rule holds good in these birds, for, notwithstanding their wonderful strength and their large, strong, sharp, and hooked bills, they exhibit the most unaccountable cowardice. Even a poor weak Sea-mew will attack an Albatross, the pusillanimous giant finding no better means of getting rid of his enemy than by plunging into the water. Although they are most

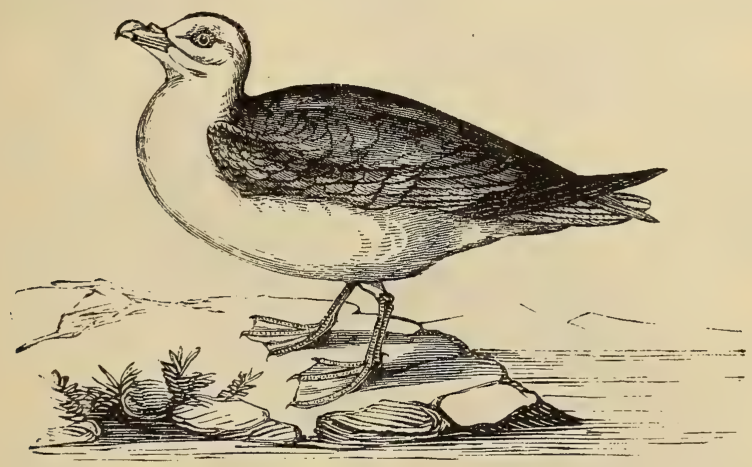

Fig. 107. - The Fulmar Petrel.

gluttonous in taste, they prefer flight to contending for their food. This consists of marine animals, molluscs, mucilaginous zoophytes, and the spawn of fish. When they are filled to repletion, and the prey which they have seized is too large to swallow whole, they may be seen with part of it hanging outside their bill, until the first half is digested. Thus embarrassed, the Albatross has only one mode of escape if it happens to be pursued; namely, by disgorging the food with which its stomach is overloaded.

Gifted with an extraordinary power of flight, these birds venture out to enormous distances from land, more especially in stormy weather. They seem to delight in the warring of the elements. When

* The weight of this bird much varies. A specimen in the Leverian Museum measured thirteen feet from the tip of one wing to the tip of the other. One shot off the Cape of Good Hope was said to be seventeen and a half feet.-ED. 
overcome with fatigue, they repose on the surface of the sea, placing their head under their wings. When in this position they are very easily captured. In order to do this, the sailors have only to approach silently, and knock them down with a boat-hook or spear them with a harpoon.

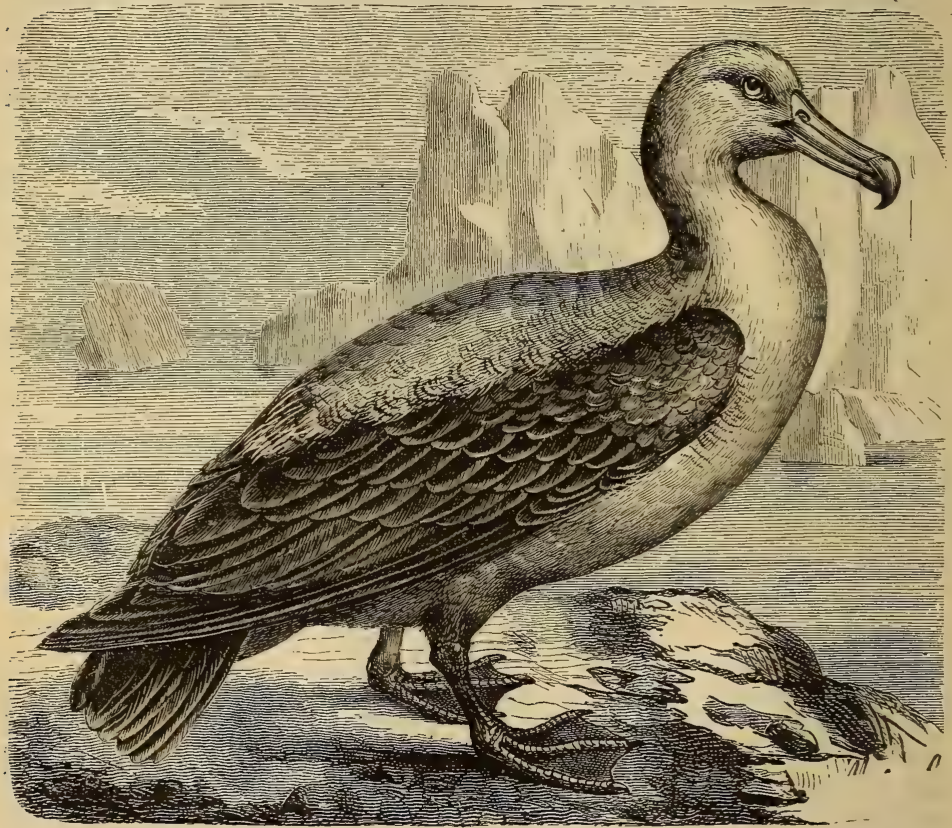

Fig. 108.-The Common Albatross.

Navigators have opportunities of observing these birds in the Antarctic regions, where there is no night at certain seasons of the year, and they assert that the same flocks may be seen hovering around their vessel during many successive days without exhibiting the least signs of exhaustion or the slightest relaxation in their strength. A peculiarity in their mode of flight is that, whether they are ascending or descending, they seldom flap their wings, but do so without an effort. 
To follow in the wake of some passing ship, probably because the agitation of her track brings to the surface the small fry of marine animals which are their principal food, appears to delight them. They pounce upon anything that falls overboard, even man. On one occasion a sailor fell into the sea from a French vessel, and could not be immediately rescued because there was no boat in a fit state to be lowered. A flock of Albatrosses, which followed in the ship's wake, pounced upon the unfortunate seaman, and commenced to peck his head. Being unable to buffet both with the sea and the enemies which surrounded him, the poor sailor perished before the very eyes of his comrades.

The Gulls, the Albatrosses, and Petrels, may be said to be the vultures of the ocean-its scavengers; for they cleanse it of all the putrefied animal substances which float on its surface.

At the breeding season, which varies according to the hemisphere inhabited by them, the Albatrosses congregate at their favourite nesting-places. In the southern hemisphere this is about the end of September, when they assemble in immense numbers on the island of Tristan d'Acunha, in the South Atlantic Ocean. Their nests, which are about three feet in height, are formed of mud.

Their flesh is very hard, and can only be rendered eatable by laying it for a long time in salt, and afterwards boiling it, and flavouring it with some piquant sauce. Nevertheless, sailors, as well as the inhabitants of the desolate southern regions, use it, but only in the absence of better food.

The most remarkable species are, the Common Albatross (Diomedea exulans, Fig. I08), which frequents the seas washing the south of Africa; the Sooty Albatross ( $D$. fulginosa), which also inhabits the seas round the Cape of Good Hope; the Yellow-beaked Albatross (D. chlororhynchus), which, like the preceding species, inhabits the seas of the South Pole.*

* Captain Cook mentions a variety frequently captured by the inhabitants of Kamtschatka and the Kurile Islands. 


\section{CHAP'TER IV.}

\section{GRALLATORES, OR WADING BIRDS.}

THE most striking characteristic of the Waders consists in the nakedness and length of their tarsi, which sometimes attain to really extraordirary dimensions: some of these birds look as if they were mounted on stilts. This peculiarity of conformation is, however, well adapted to their modes of life. They inhabit, for the most part, river-banks, lakes, and marshes, in which they find their sustenance; consequently, they are fearless of water and ooze. The Agami, the Bustard, and the Ostrich, as well as the Emu and other Struthionida, which are placed by naturalists with this family, are not aquatic; they inhabit the interior of the country, and are either herbivorous or granivorous.

The bills of these Birds assume'very various forms. They are generally long; but, according to the species, they may be thick or slender, tapering or flat, blunt or pointed, strong or weak; and in some kinds, such as the Flamingo, the Spoonbill, and the Boatbill, they really defy all description. The neck is always slender, and in perfect harmony with the length of the legs.

Almost all the Waders are Birds powerful on the wing, and twice a year most of them migrate, like Ducks, Geese, and Swans. There are, however, exceptions to this rule. Some of them-the Bustard, for instance-move through the air with difficulty, although their inferiority in this respect does not reach to complete inability; others, as the Brevipennee, are absolutely unable to fly at all: their wings being altogether rudimentary, and are only useful for accelerating their pace in running; and, thus assisted, they are remarkably swift.

The nature of their food varies with the form and strength of the bill and the locality they inhabit; it consists generally of fish, small batrachia, molluscs, worms, and insects ; sometimes of small mammalia and reptiles, and more rarely of grasses and seeds. This kind of sustenance must be wonderfully fitted to develop the savoury qualities of their flesh, for it is among this class that we find our 
most delicately flavoured "game." The mere mention of the Woodcock, Snipe, Plover, Pewit, and Bustard is sufficient to establish their claim upon the epicure. Some kinds, which are utterly devoid of any culinary properties, are furnished with a plumage to which ladies owe many of their most brilliant adornments. The ostrich and marabout feathers, and those of the heron, are much appreciated by many fair ones, whose beauty these adornments are supposed greatly to enhance. In short, this order of Birds possesses two important qualities - ministering to the taste of the most fastidious palate and handsomely decorating our fashionable belles. Gormandism and coquetry alike find satisfaction, and derive from these birds some of their most agreeable pleasures. If they had the additional gift of melody they might lay claim to perfection; however, such is not the case, as their notes are shrill and discordant.

The Waders are monogamous or polygamous, according to their species ; but their history furnishes us with some touching instances of conjugal attachment. They make their nests either on trees, buildings, or the surface of the earth; sometimes even in the middle of the water, among the reeds, sedges, and other aquatic plants. In general, they evince but little care in the construction of the birthplace of their progeny. In most cases they are contented to collect together a variety of substances without much discrimination; sometimes they merely scratch a hole in the ground, in which they deposit their eggs without any further care.

The Waders are usually divided into six great families, which are again divisible into many genera. Following Cuvier's classification, with some slight modification, we propose arranging the group as follows:-I. Palmidactyles. II. Macrodactyles. III. Longirostra. IV. Cultrirostra. V. Pressirostra. VI. Brevipenia.

\section{The Palmidactyles}

have the anterior toes united by a wide membrane; the hind toe is absent, or is small; the legs are long and smooth; from their webbed feet they may appear to belong to the Palmipedes, but the arrangement of their toes is altogether different, constituting the most striking characteristic of this order.

The Avocet (Recurvirostra avocetta, Fig. Iog) is chara terised by a very long and slender bill, flexible, and curved upwards; this latter peculiarity has procured for it the name of Recurvirostra (curved beak). It uses this strange implement to rake up the sand and mud, in order to catch the worms, small molluscs, and fish- 
spawn, which constitute its chief food. Its long legs enable it to travel in safety over swamps and lagoons; it also swims with great ease. It may often be seen looking for its food on the margins of lakes and ponds.

The Avocet stands about twenty inches in height, although its body is but little larger than a pigeon's. It is a pretty bird, of slender make; its plumage is black on the head and back, and white underneath. It is to be met with on both the Continents; the European species is common in Holland and on the French coast. Wild and shy in its nature, it is very difficult of approach, and is clever in avoiding snares, and ingenious in escaping pursuit, either

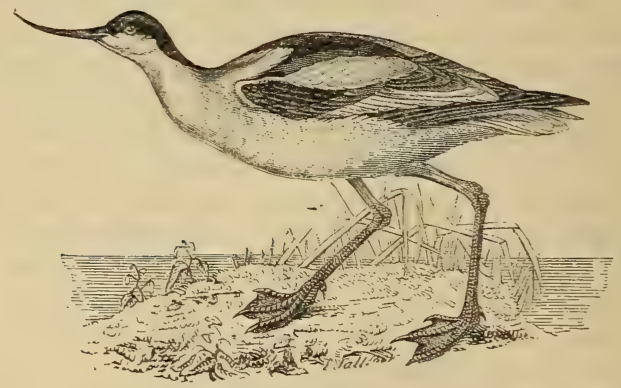

Fig. 109.-Avocet.

by flight or swimming. The nest of the Avocet is a very simple structure, generally made by placing a few blades of grass in a hole in the sand, where it lays two or three eggs, of which it is frequently robbed; for, like those of the Plover and others, its congeners, they are regarded as great delicacies by the gourmand. The flesh, however, is of little value.

The Stilt Birds (Himantopus candidus, Fig. I Io) obtain their name from the excessive length of their legs, which are also so slender and flexible that they can be bent considerably without breaking. Their feet are not so completely webbed as the species we have just mentioned; the two membranes which unite the toes are unequal in size. The bill is long, slender, and sharp, like that of the Avocet, but straight; the wings are long and pointed; the tail small. They are about the size of the Avocet, and sometimes attain the height of twenty-six inches. They possess considerable powers of flight, but walk with difficulty; on the other hand, they are much at home on 
mud or in marshes and swamps, in which they bore with their long beaks for insects, larvæ, and small molluscs, dainties to which they; are very partial.

They are dull, shy birds, leading a solitary life, except at the breeding season. At that period they assemble in great numbers, build their nests in the marshes, on little hillocks, close to one

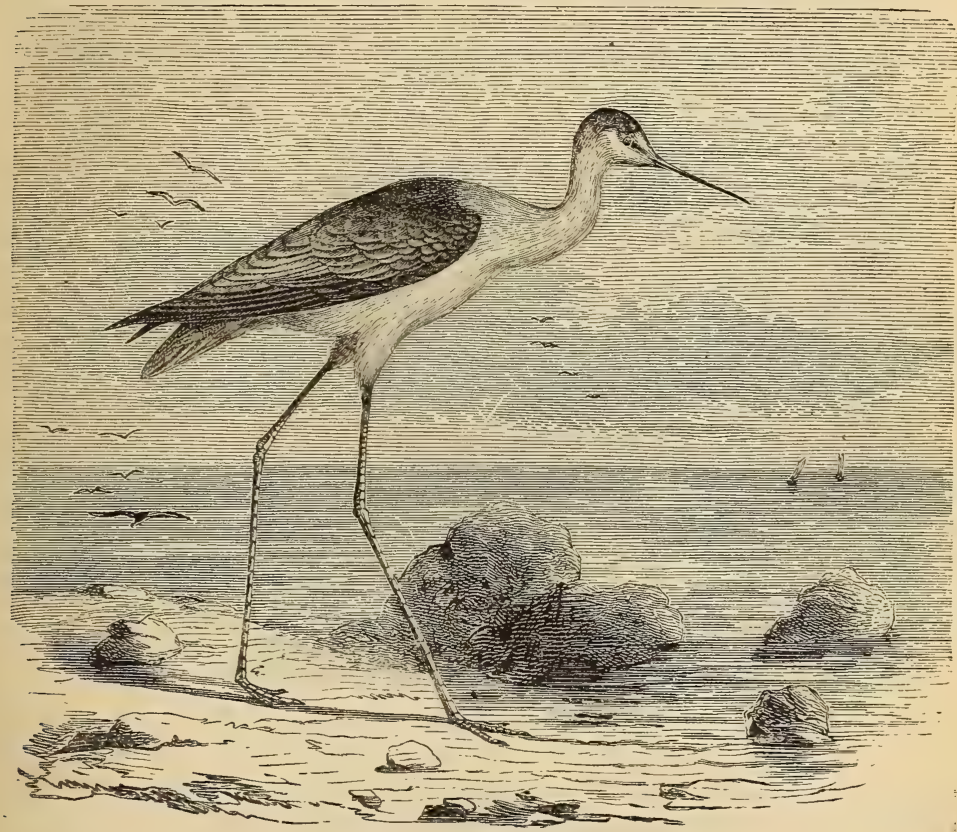

Fig. Iro.-Stilt Bird.

another, grass being the principal material employed. They lay four greenish-coloured eggs, with ash-coloured spots. The male bird watches while the females are sitting; and, at the slightest alarm, he raises a cry which startles the flock. The whole colony may then be seen on the wing, waiting for the danger to pass before settling down.

Stilt Birds are uncommon in Western Europe; they are principally to be met with in the Russian and Hungarian marshes. 
During the summer they occasionally visit the shores of the Mediterranean, but they are seldom seen on those of the Atlantic. By sportsmen they are little valued.

\section{MACRODACTYLES.}

The Birds forming the family of Macrodactyles (long-toed) are remarkable for the extreme length of their toes, which are entirely separate, or but slightly webbed; they are thus enabled to walk on

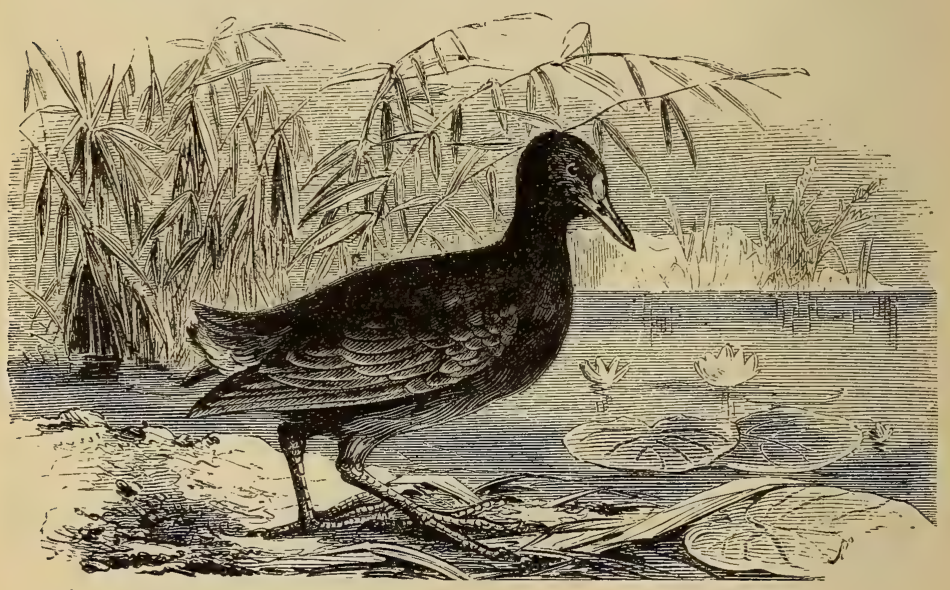

Fig inr.-Water-Hen.

the weeds growing on the surface of the water. In most instances the shortness of their wings limits their powers of flight.

This order includes the Gallinules, Rails, Coots, Pratincoles, and Screamers.

The chief characteristics of the Water Hen (Gallinula chloropus, Fig. III) are a short and strong bill, thick at the base and sharp at the end, with a prolongation of it extending up the forehead; four well-spread toes, furnished with sharp claws-the three front toes united by a small and cloven membrane. They are plentiful in some parts of France and England, their favourite haunts being marshy places and the banks of lakes or rivers, where they feed on worms, insects, molluscs, and the smaller fish. They are lively, 
graceful, and ornamental birds. During the day they secrete themselves among the reeds, but emerge from their hiding-places in the evening and morning in search of food.

Although incapable of either fast flight or rising to great elevations, the Water Hens show considerable address in escaping from the sportsman's gun. When pressed very closely, they take to their favourite element, in which they are expert swimmers and divers; under the water they go, to reappear on the surface many yards away, where they only show themselves above for a moment to breathe, avoiding flight until every cause of fear is removed.

In some countries they remain throughout the year; in others they are migratory. When the latter is the case, they travel on foot, or by swimming, and sometimes, but rarely, on the wing, following the same route, however, year after year, and always returning with constancy to the spot where they made their first nest.

The eggs are seven or eight in number. During incubation the male and temale occupy the nest alternately. Should any intruder alarm them, they never fail, before leaving the nest, to cover up their cherished treasures with grass or other material, so as to keep them warm and hidden from the voracity of their watchful enemy, the crow.

Immediately after the young are hatched they leave the nest to follow their mother, and are very soon able to supply their own wants. Their only covering at first is a scanty and coarse down; but they run rapidly, and seem almost instinctively to swim, dive, and conceal themselves at the slightest appearance of danger. Young Water Hens, however, are exposed to accident from the flooding of streams, and consequent submersion of the nests ; and it is probably by way of compensation for this that Nature has made them so prolific, for they frequently rear three broods per annum.

The Hyacinthine Gallinule (Porphyrio veterum, Fig. II2) or Sultana Fowl, is peculiarly characteristic of Macrodactyles, and might be defined as an exaggeration of the Water Hen. But its bill is thicker and more robust, the frontal plate on the forehead is more extended, the toes are longer; the habits of both are identical. Its favourite food is the seeds of the cereals, aquatic plants, and fruits; it occasionally, however, feeds on molluscs and small fishes. When eating, sometimes it stands on one foot, and uses the other as a hand in order to convey the food to its beak.

The body of this magnificent bird is of an indigo blue, the beak and feet being rose-colour. The ancients, who were acquainted with it, and were accustomed to rear it in a domesticated state, gave it 
the name of Porphyrio (purple-coloured) on account of its colour: If it could be acclimatised, it would be a valuable addition to our ornamental waters.

There are several varieties of this species, differing more or less from one another. They inhabit the warmer regions of the Old World, such as Asia Minor, Africa, and the South of Europe; it is about the size of the ordinary domestic fowl.

Rails (Rallus) are characterised by a slender, tapering, slightlyarched beak, longer than the head; elongated tarsi, terminating in

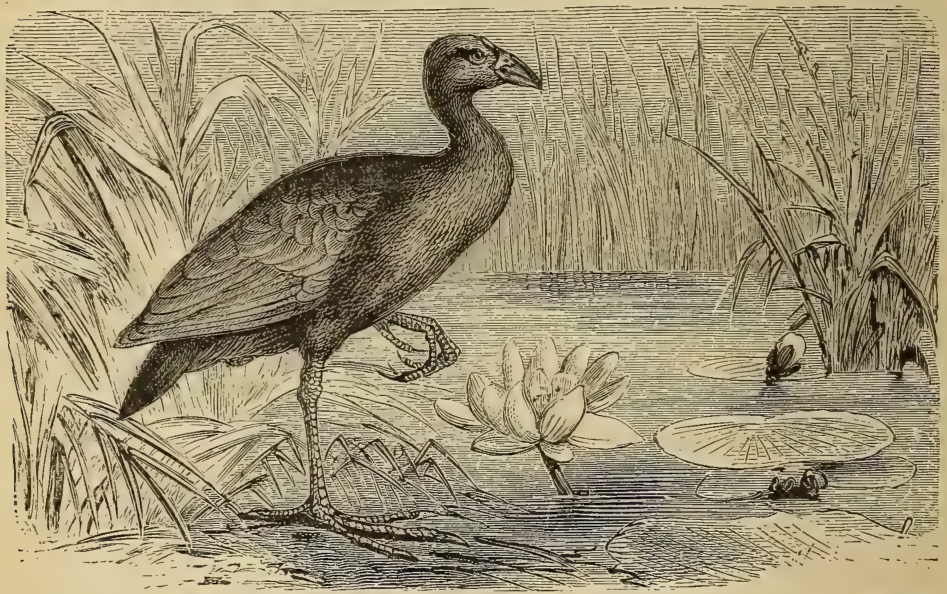

Fig. Ir 2. - Hyacinthine Gallinule.

slender toes, much compressed and completely separate, and not marginate ; wings middle-sized; tail short.

Their habits bear a strong resemblance to those of the Gallinules. Like the latter, they are timid, and hide themselves in rushes, underwood, or grass of the marshes and meadows they inhabit. They make use of the burrows hollowed out by water-rats in which to take refuge when hard pressed. Little thickets bordering brooks, and small low-lying damp meadows, are localities to which they are peculiarly partial. Their flight is heavy and slow, not elevated, but is generally in a direct line. In running, however, they are adepts, and the means they adopt for escaping their pursuers often succeed. 
Rails are not gregarious, differing in this respect from the majority of migratory birds, which generally assemble in flocks previous to undertaking their journeys.

The nest is roughly constructed either in a hedgerow or in a meadow. The females lay from six to eight eggs. The young ones run as soon as they are hatched, and grow very rapidly. Worms, insects, and shrimps, are their favourite food, but they do not reject wild corn and other seeds. Their flesh is considered delicate, and is superior to that of the Water Hen ; in the autumn it acquires an exquisite flavour in the estimation of French gourmands.

Rails, which are common in France, are vulgarly called the

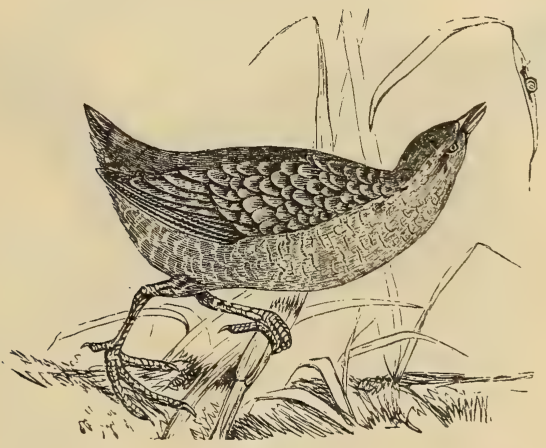

Fig. Ir 3.-Land Rail.

"king of the quails," probably from frequenting the same localities. They do not acquire their highest condition till the end of summer; this, therefore, is the proper time to kill them. Twenty species of Rails are enumerated, which are spread over the various countries of the globe. However, the characteristic features of all are nearly alike.

These remarks almost equally apply to the Land Rail (Crex pratensis, Fig. II3), and the Water Rail (Rallus aquaticus).

The Coot (Fulia) has a bill of moderate size, stout, tapering, much depressed, with a well-developed frontal plate; the toes are slender, and edged with a broad, scalloped membrane. Their plumage is glossy, soft, full, and blended, and impervious to water. They are essentially aquatic, frequenting principally lakes and marshes, some- 
times the shores of estuaries, bays, and gulfs. ${ }^{*}$ Like the Water Hen and the Rail, their life is almost nocturnal. During the daytime they secrete themselves among reeds and flags; from which they do not emerge until evening, when the demands of Nature forces them to seek their food. This consists of worms, small fishes, and the young shoots of aquatic plants. Coots but rarely traverse firm ground, where they walk with difficulty; on the other hand, they swim and dive with graceful ease. Their light is less feeble than that of the Rails; still it is far from strong.

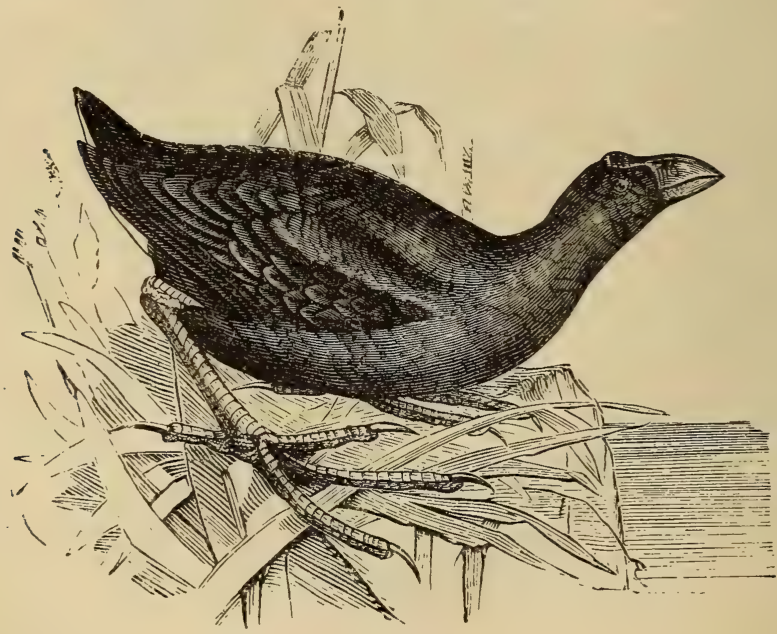

Fig. $\mathrm{II}_{4}-$ Ine Bald Coot.

Coots herd together in flocks; they make their nests on reeds doubled down on the water, and lay from eight to fourteen eggs. The young ones are able to swim as soon as they are hatched, but they often fall a prey to the marsh harrier. It sometimes happens that the whole brood is destroyed in this way: when such is the case, if early in the season, the female lays a second time.

The Coot is found in every country in Europe, in North America, in Asia, and in Africa. Its flesh, which is white and delicate in

* The southern extremity of the Chesapeake Bay (Va.), in the winter of $187 \mathbf{I}$, was covered with thousands of Coots. - Ev. 
appearance, is usually very fat, but has a disagreeable taste and marsh-like odour. Three species are known, only one of which is found in this country, namely, the Coot (Fulica atra, Fig. II4), the Foulque macroule of French naturalists, very common in the north of France and all quarters of the Old and New World; the Crested Coot (F. cristata), sometimes a visitor to the South of Europe, and

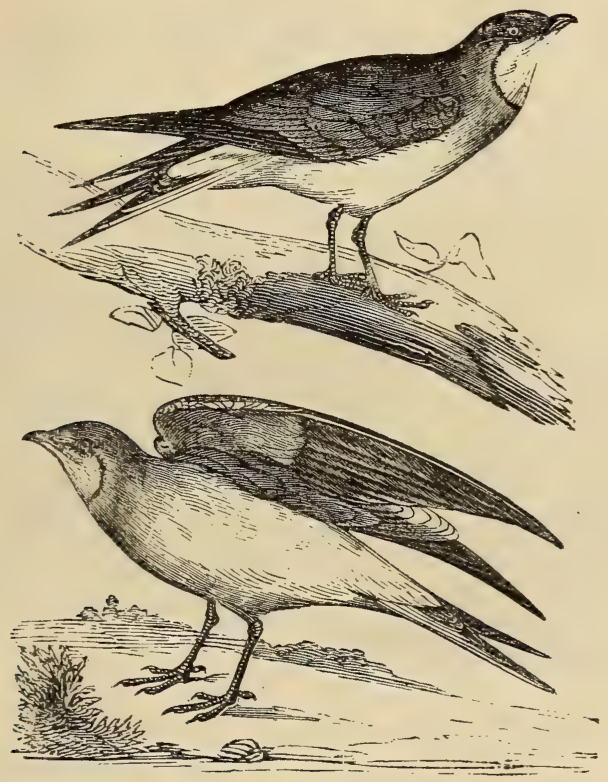

Fig. Ir5.-Pratincoles.

differing very little from the Common Coot, but distinguished from it by the red and prominent bony protuberances at the top of the frontal plate; and the Blue Coot, which is described as an inhabitant of Portugal.

The Pratincole (Glareola pratincola, Fig. I I 5) has the bill short and curved, the tarsi long and slender, the middle toe joined to the outer by a small membrane, the wings long and pointed, the tail forked. They live in flocks on the banks of the Danube, the Volga, and on the shores of the Black and Caspian Seas. They feed on 
worms, water-insects, and especially locusts, which they catch on the wing.

From the great similarity of these birds to the Swallows, many naturalists have classed them in the same order.

The Jacanas (Parra) are characterised by a straight and middlesized bill; legs armed with pointed spurs; toes furnished with long and sharp-pointed claws, and a back toe longer even than the front ones. These birds inhabit Asia, Africa, and South America. In Brazil they are called Surgeon Birds, from the resemblance the claw

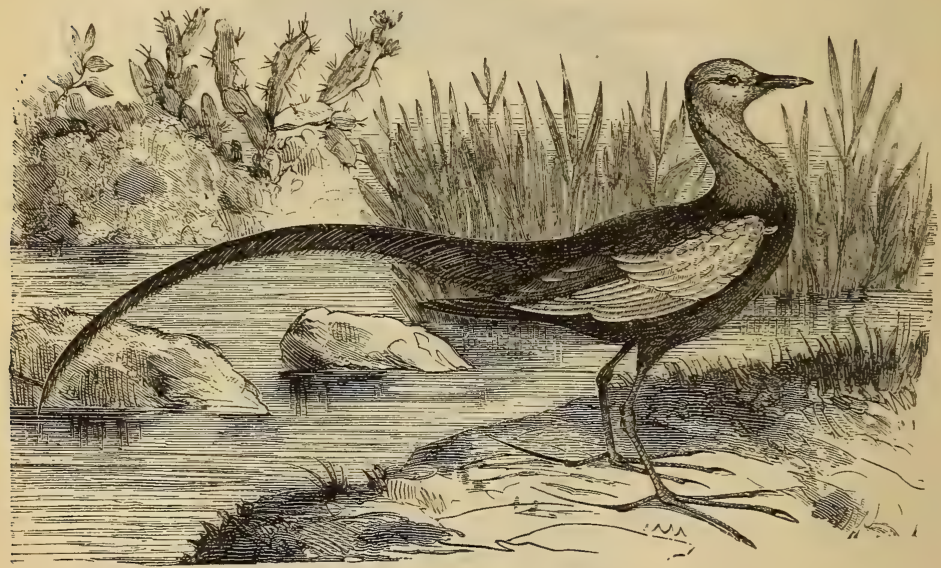

Fig. I16.-Common Jacana.

on their back toe bears to a lancet. They frequent swamps, lagoons, and marshes. They walk on the wide-spreading leaves of tropical aquatic plants with perfect ease, although they swim very imperfectly ; some naturalists, indeed, declare that they cannot swim at all, and they are probably justified in this opinion by the appearance of the bird, which seems to have few characteristics of an aquatic species. Their flight is rapid, but not very high.

The Jacanas live in pairs. They are exceedingly numerous, and perfectly fearless of man. They are restless and quarrelsome in their nature, frequently engaging in conflict with other birds, when they make good use of their spurs. They will defend their offspring with daring courage, even at the sacrifice of their lives. The male and 
the female evince the tenderest mutual attachment; once united, they part no more during life. They make their nest in a clump of flags or other aquatic plants, in which are laid four or five eggs,

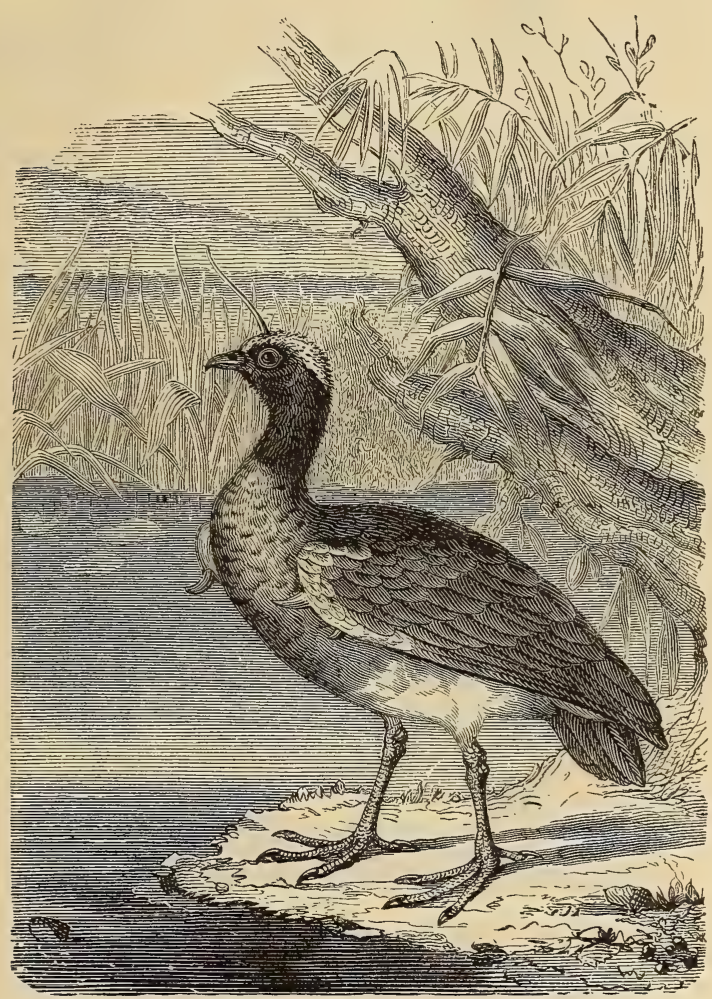

Fig. II7.-Horned Screamer.

which are sat on during the night only, the temperature produced by a tropical sun supplying the necessary warmth. As soon as hatched the young ones leave the nest, and are able to follow their parents.

The Common Jacana (Parra jacana, Fig. II6) is black, with neck and shoulders of a reddish brown, and green wing-feathers. 
The Chinese Jacana (Hydrophasianus sinensis), another species of this family, is black and white; excellent food, but very difficult to shoot on account of its wariness ; however, it is easily domesticated, when it becomes impudent and pugnacious.

The Screamers (Palmedea), which are inhabitants of South America, have the beak shorter than the head, slightly compressed,

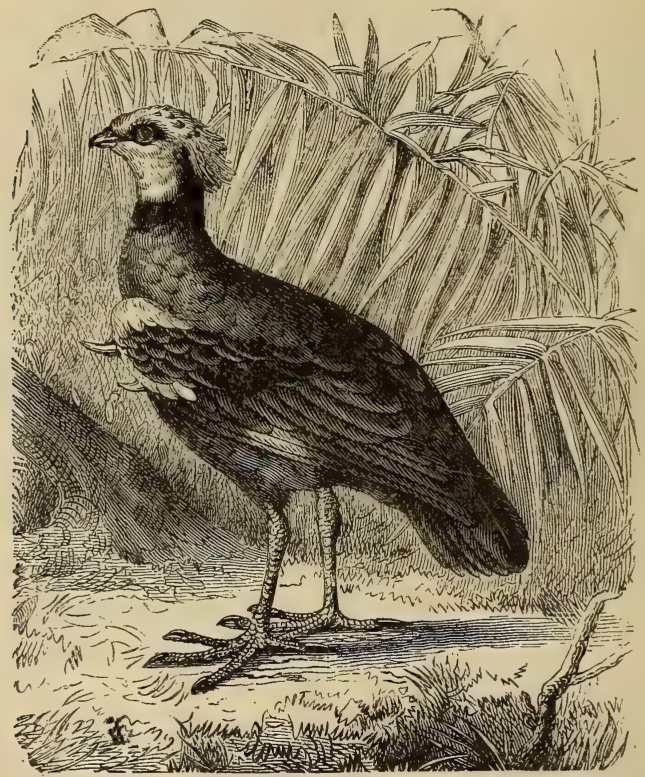

Fig. 118.-Faıthful Kamichi or Crested sicreauter.

and bent at the point; the wings are wide-spreading, and provided with strong spurs on the shoulders; the toes are separated, and furnished with long, stout, and pointed claws. Their plumage is of a blackish hue. Their size is about that of a Turkey. Their favourite haunts are moist, marshy localities, such as inundated savannahs, or the oozy banks of shallow streams. Although they do not swim, they yenture on the water in search of aquatic plants and seeds. Some naturalists, founding their belief on the presence of spurs 
with which this bird is provided, assert that it attacks small reptiles and destroys them. This is now acknowledged to be an error. These birds live isolated, in pairs; they are mild and peaceful in their nature, the breeding season is the only time when they seem at all disposed to use their weapons. At this period the cocks engage in deadly conflict to gain possession of some favourite mate. The union once formed, it is indissoluble, and only terminates with the death of one of them. It is even asserted that the survivor, deprived of its mate, exhibits signs of great affliction, lingering for days near the spot where cruel fate had severed him by death from his loved partner.

The Screamer has many points of resemblance to the Gallinaceous order in its comparatively short and thick tarsi, general make and gait, habits of life, and inoffensive nature. They are frequently domesticated, and in that state are useful assistants to man.

The Horned Screamer (Palamedea cornuta, Fig. II 7 ) is thus named on account of having on its head a horn-like excrescence, which is straight, thin, and movable, about three inches long.

The Crested Screamers ( $P$. chavaria, Fig. in 8$)$ has, instead of the horn, a crest of feathers arranged in a circle on the back of its head. It is easily tamed, and becomes very friendly with man, proving itself an active, intelligent, and devoted servant. It becomes at once the companion and protector of the other denizens of the poultry-yard-so much so, that in Brazil and Paraguay, where it is known solely as the Chaja, the inhabitants confide to its charge the care of their flocks of poultry, which it accompanies to the fields in the morning, and at nightfall conducts them back to their roosting-places. Should a bird of prey come near, the guardian spreads out its broad wings, darts upon the intruder, and soon makes it feel what a love of justice can do when aided by four stout spurs.

\section{LONGIROSTRES.}

The Birds composing this family are characterised by a long and flexible bill, which is well adapted for boring in mud and soft ground. They are indifferently shore or marsh birds. Among them are comprised the Sandpipers, Turnstones, Ruffs, Knots, Godwits, Woodcocks, Snipes, Curlews, and Ibis.

The Sandpipers (Totanus) have a long, straight, thin bill, flexible at the base, but firmer towards the point; the tarsi are slender and elongated; the wings very pointed; the feet half webbed, the back toe short, and touching the ground with the point only. They live in 
small flocks, some species frequenting marshy localities, others dry and sandy districts. They are incessantly on the move, running, swimming, and diving, all of which they perform with equal ease. Their food is chiefly worms, insects, fish-spawn, and sometimes even small fry and crustacea. Their habits are peaceable and their movements easy and graceful. They are gifted with a keen sight, for not even the smallest insect can escape their vision.

The Sandpipers are natives of the northern parts of the Old and New World; they visit France twice a year-in spring and autumn.

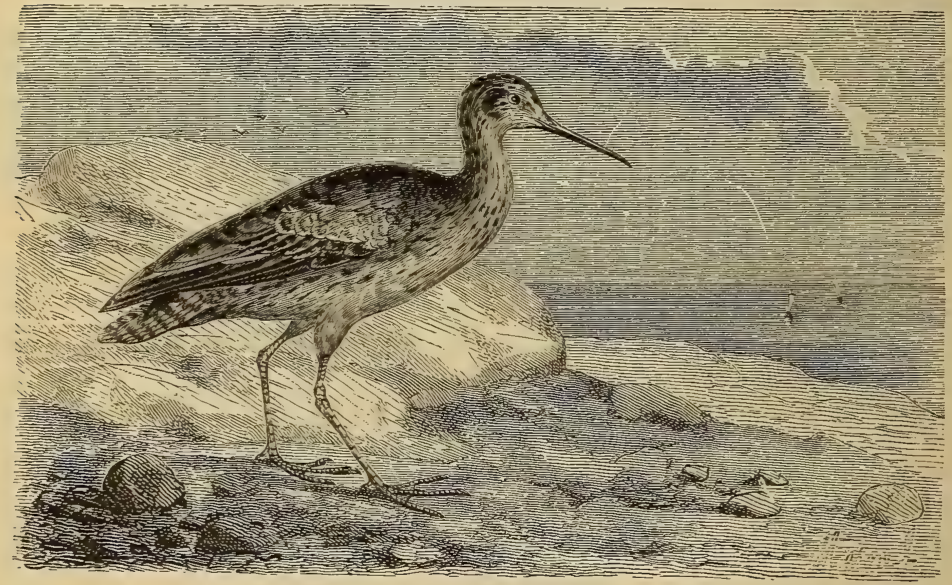

Fig. 119. -Redshank.

They breed in the north, and lay from three to five eggs. The extreme delicacy of their flesh causes them to be much sought after by epicures; they are, therefore, captured in every possible way. Extinction will probably be the result. To gratify the tastes of the gourmand and the bloodthirsty instincts of cruel men, the lovers of Nature are destined to be deprived of one of the most innocent and beautiful families of Birds.

In France seven species of Sandpipers are known, varying in size from that of the sparrow to that of the thrush. They are as follows:-The Brown Sandpiper (Totanus fuscus), the Greenshank (Totanus glottis), the Redshank (Totanus caledris, Fig. II9); the 
Wood Sandpiper (Totanus glareola), the Green Sandpiper (Totanus ochropus), the Common Sandpiper (Totanus hypoleuca). The last mentioned is the smallest, and also the most prized.

The Turnstones (Cinclus) inhabit the sea-coasts of both continents. A single known species alone has been traced over most parts of Europe, the Cape of Good Hope, and various parts of Asia, Australia, and North America. It owes its name to the peculiar method it adopts to find its food. This habit consists of lifting up the pebbles and shingles which lie spread over its domain, the sea-

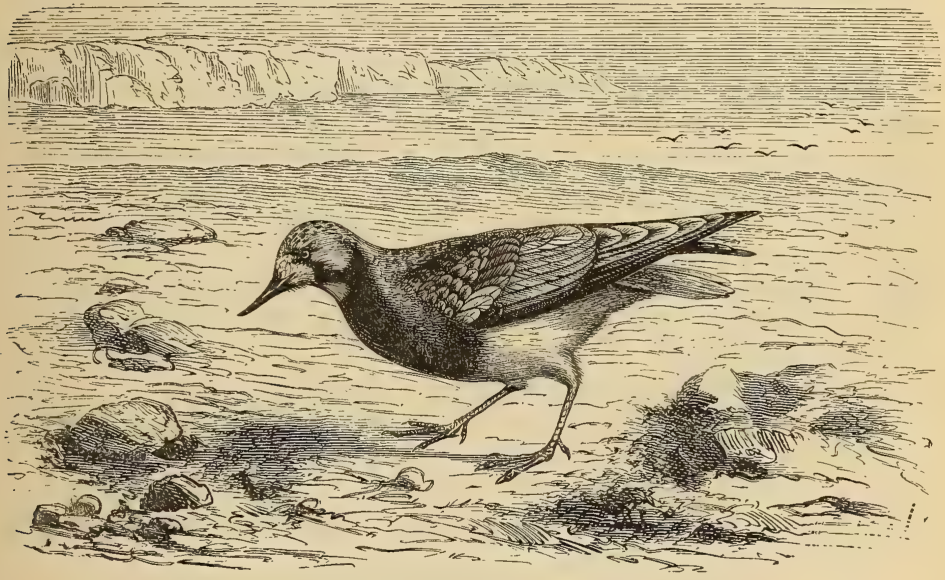

Fig. r20.-Turnstone.

shore, in order to discover the worms, crustacea, and insects concealed underneath. For this purpose it is provided with a bill of medium length, tapering, pointed, and hard, which it uses adroitly as a lever. It lives a solitary life, and does not even congregate with its own species for the purpose of migration. Only in the North, whither it repairs to breed, does it manifest any approach to sociability. The female lays three or four rather large eggs of an ashygrey colour; these are deposited in the bottom of a hole dug in the sand on the shore. The young are very precocious, for on leaving the shell they run about with their parents to seek their sustenance. The only species of this genus (Cinclus interpres, Fig. 120) is a 
bird of passage in France and England. Its flesh is good, but not equal to that of the Plover.

The Ruff (Philomachus pugnax, Plates VIII. and IX.) commends itself to the attention of the observer by the sudden metamorphosis it undergoes in May, which seems to revolutionise its entire nature. At this season he plumage of the Ruff, which has hitherto been grave and almost sombre, suffers a most brilliant transformation. On the top of its head, to the right and left, two graceful plumes come forth, which vastly improve its looks, and contribute in no small degree to the stateliness of its carriage. Brilliant hues of yellow, white, and black, arranged in a hundred ever-varying shades, combined, thus making them most attractive to the eye.

This physical transformation produces a change in the temper of the bird. Puffed up with pride, and elated at its own personal magnificence, our hero suddenly finds itself subject to the most warlike feelings, and when a rival catches its sight, without hesitation it rushes immediately to meet the stranger, who, nothing loth, charges in return at the top of his speed. With stretched-out beak and crest erect, the two adversaries impetuously close. A furious duel takes place, carried on in the sight of the feebler sex, who approve of the proceedings, possibly giving praise or blame and, by a cry at judicious moments reanimates the failing ardour of the gallant combatants. Fierce blows with the beak follow one another in quick succession, blood soon flows, and the arena is stained with gore, until at last the two weary champions roll over in the dust, and lay side by side completely exhausted. During two or three months these duels are of frequent occurrence, and cannot fail to leave numerous gaps in the ranks of the species.

In the beginning of August their rich vestments gradually disappear, and the warlike fever as rapidly abates. The Ruff now becomes a commonplace bird of peaceful habits, with no other aspiration but that of searching for worms and insects on the shores of the ocean.

The Ruff soon gets accustomed to living in captivity. In England, where they were formerly very numerous, and in Holland, where they are still probably so, Ruffs are reared and fattened for the table. They must, however, be kept in the dark during the breeding season, to prevent them from giving way to their turbulent tempers, which blaze out on the slightest excitement.

These birds inhabit the northern and temperate countries of Europe and Asia; in France they are common on the north and north-west coast of the Channel. In spring they select moist and marshy meadows for their abode, where they lay their eggs, four 



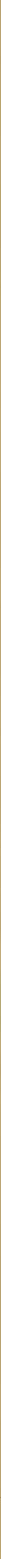




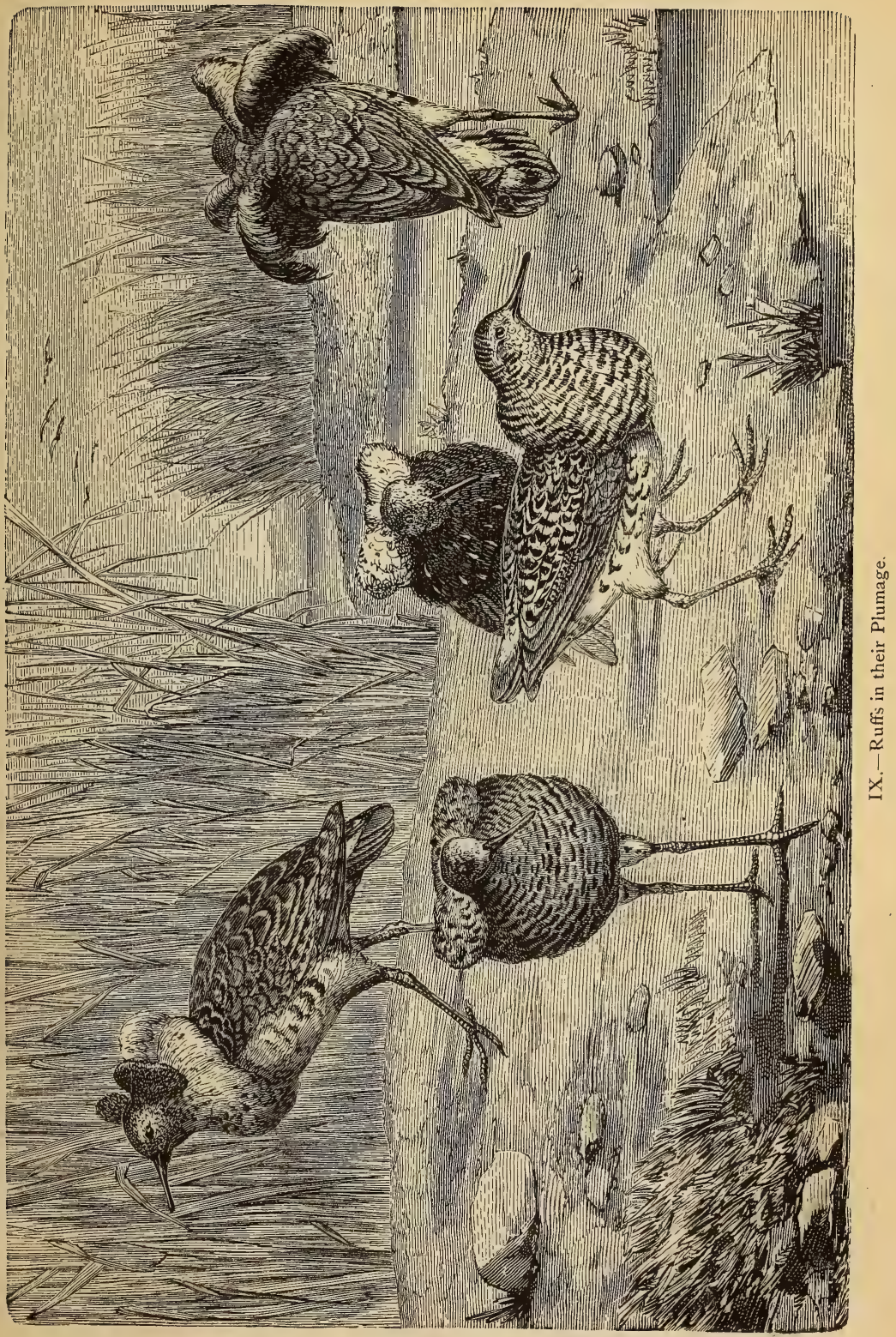



or five in number, of a greenish-grey hue, speckled with small brown spots. In the autumn they frequent the sea-shore. Their size nearly equals that of the largest of Sandpipers.

The Knots (Tringa) have a bill as long as the head; the toes divided, the back toe short; the wings pointed; plump round body. They frequent the sea-shore and salt marshes, and, except by accident, never venture far inland. They are natives of the Arctic Polar Circle, and visit our coasts in the spring and autumn. They lay their eggs, four or five in number, in their northern retreats.

The Dunlin (Tringa cinclus) and the Stint (Tringa Temminckii)

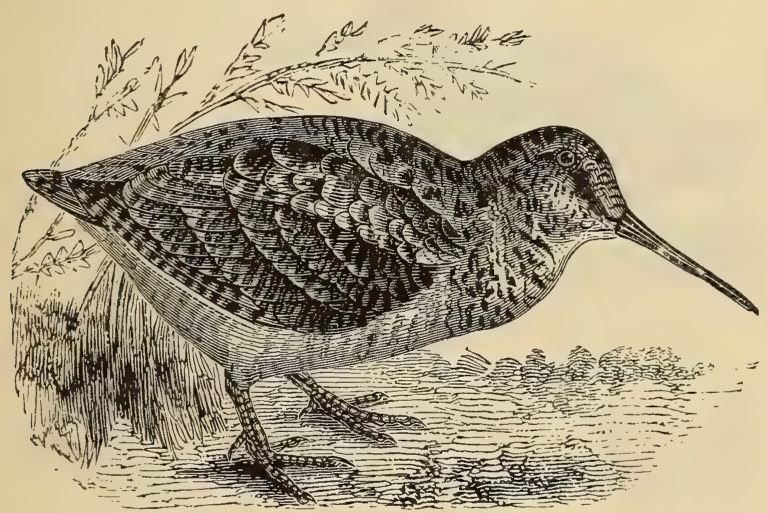

Fig 121.-The Common Wuodcock.

are species closely allied to the Sandpipers, differing but slightly in their habits and physical characteristics. In small flocks they visit all the coasts of Europe. Even an abundance of food does not suffice to keep them in the same locality; for motion seems the law of their existence.

The Woodcock (Scolopax rusticola, Fig. I 2 I) has a very long, straight, and slender bill; flattened head; and the tarsi short. They live in the woods, and do not frequent the sea-shore or river-banks. From the snipes they differ in having the body fuller, the tibiæ feathered at the joint, the tarsi shorter, the wings broader, and the bill firmer. They are also larger in size.

The Woodcock inhabits during the summer the lofty wooded mountain-ranges of Central and Northern Europe. Driven by the 
severe cold, they descend into the plains, and reach France and England about the month of November. They are shy, timid birds, and conceal themselves by day in the depths of the most retired woods. The brightness of daylight appears to dazzle them, for they do not possess full power of their visual faculties until evening, when they emerge from their retreats, to seek their sustenance of worms and grubs, in the cultivated fields, damp meadows, or vicinity of springs.

Woodcocks (Fig. I 2 2), are not all migratory, some remaining

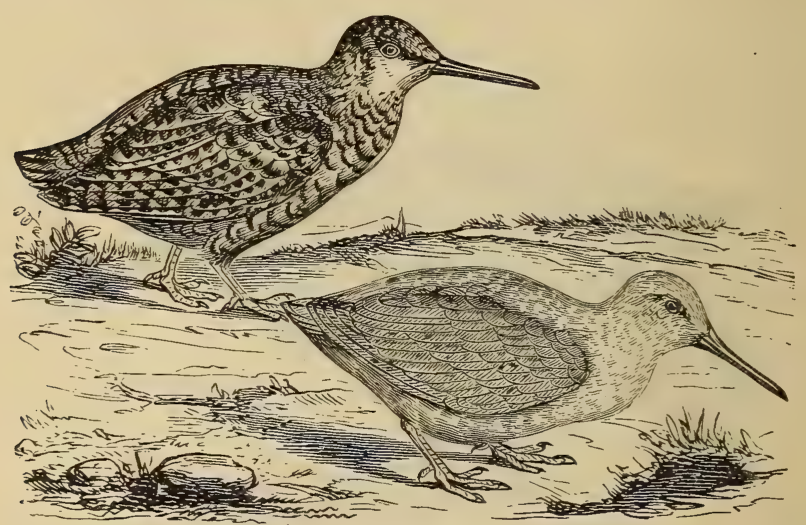

Fig. 122.-Woodcocks (White and Isabelle-coloured).

throughout the year in the neighbourhood of such springs as do not freeze. Solitary at other times, they pair in spring, building their nest on the ground with grass and roots, placing it close to the trunk of some tree (the Scotch fir by preference, it is said), or in a holly-bush. The female lays four or five oval eggs, rather larger than those of a pigeon. The young run about as soon as they are hatched; the parent birds guard them with careful solicitude, and manifest on all occasions the greatest love for their offspring. If any danger threatens, the old birds catch up their progeny, holding them under their necks by means of their beaks, and thus transfer them to a place of safety.

These birds seem to feel an affection for places they have once frequented, so love to return to them; the following fact, at least, would lead one to think so. 'A gamekeeper, having snared a Wood- 



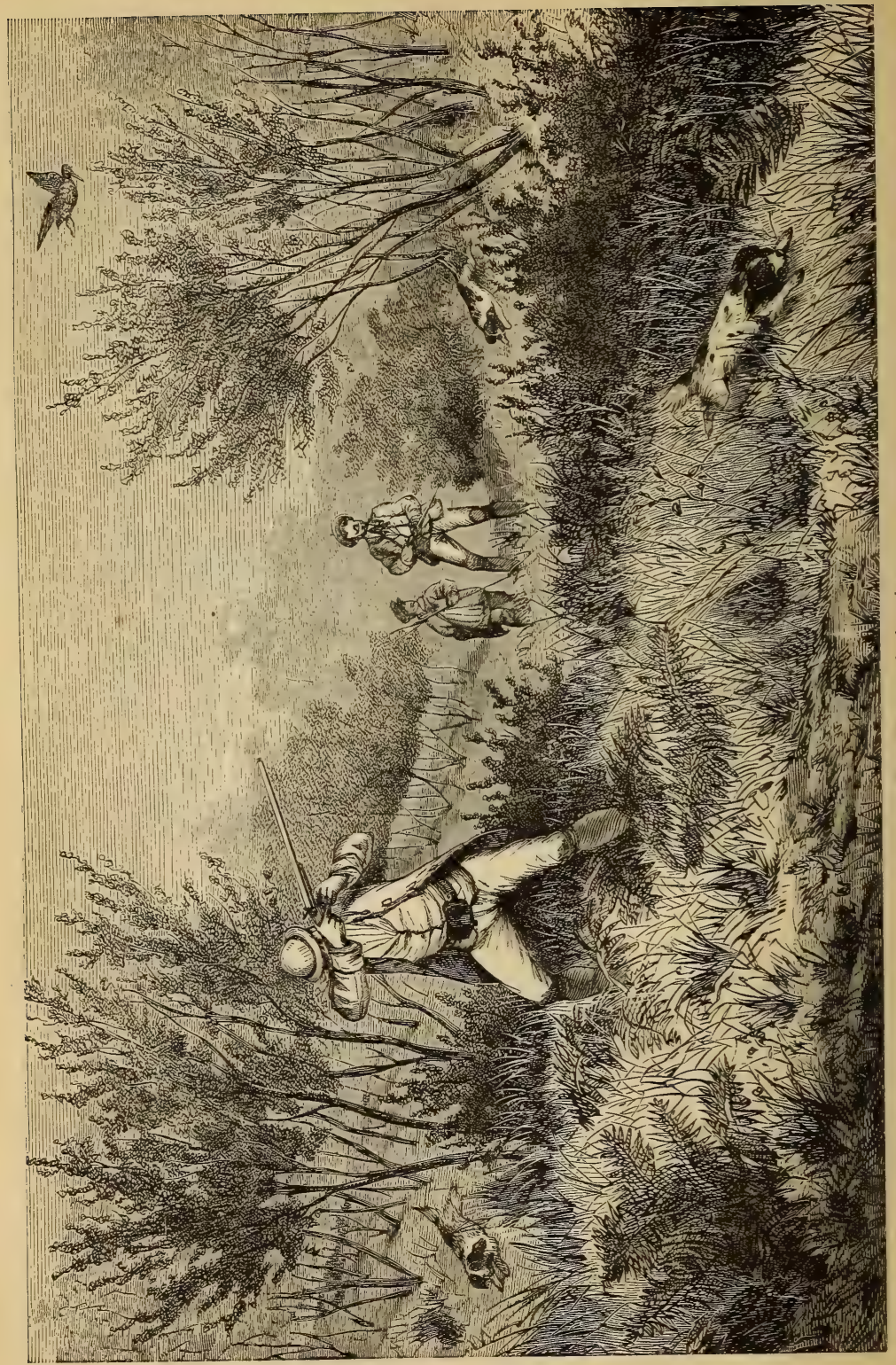


cock, gave it its liberty, after fastening a copper ring to its leg. The following year he recognised, by the help of this mark, the bird which had formerly been his captive.

During ten months of the year the Woodcock is mute; but when the early' leaves begin to bud it is gifted with a feeble call-pitt-pitt-corr!

The plumage of the Woodcock is remarkable for the harmony of its shades; it is a happy mixture of brown, russet, grey, black, and white. It is not an unusual thing to meet with Woodcocks entirely of the latter-albines of their kind. Others are arrayed in an Isabelle-coloured plumage; but white, with grey or brown mottlings, are their principal peculiarities.

The Woodcock is very clean in its habits; for it invariably plumes and dresses its feathers twice a day. At morning and evening they can be seen wending their course in rapid flight towards rivulets or springs to bore for insects, quench their thirst, or to arrange their toilette.

This Bird is found in almost all the departments of France, but principally in the Ain and the Isère. We need hardly say that they are sought after with an eagerness that no obstacle seems to discourage. One can scarcely imagine the pitch of enthusiasm some of our sportsmen possess for pursuit of the Woodcock. They will walk for ten or twelve hours in the mud, leave shreds of their garments hanging on every bush and bramble they pass, exercise all their ingenuity in manouvring and cunning, and, as a recompense for all these exertions, perhaps not get a shot. This is a short compendium of the results often enjoyed by the sportsman when in pursuit of Woodcock.

The chief difficulty in obtaining these birds is caused by the swampy densely wooded places they frequent. Motionless and mute when secreted in the thickest bushes, they emit but little scent. The dog, which ranges about in every direction, scratched and torn by thorns and briars, disheartened with such laborious and unprofitable work, discovers at last the slightest taint on the air, and "draws." As soon as the sportsman sees or knows that his dog is "pointing," he advances quietly, and, judging as well as he can of the locality of the bird, places himself in the best position to obtain a shot. (Plate X.) If he misses his aim, all his labour has been for nothing; even should the sportsman be successful in marking where the game has alighted, the same trouble has to be repeated. If ultimately the Woodcock succumbs, it will not be till it has thoroughly fatigued its persecutors.*

* From the above description of Woodcock shooting it is evident the author is not an enthusiastic sportsman.-ED. 
In Brittany, some years ago, Woodcocks were so common that the inhabitants were in the habit of catching them with nets in the following singular way:-Two men went out together at night, one carrying a lantern, the other a small net fastened at the end of a pole. They proceeded to those parts of the woods where deer had been grazing, as such localities are always favourite haunts of this bird, on account of their finding worms and insects among that quadruped's droppings. When the Woodcock was discovered, the light from the lantern was suddenly thrown on the bird, which, dazzled with its brilliancy, allowed itself to be entrapped.

A similar method to the above is practised by the negroes on the Southern plantations of the United States, with this differenceinstead of a net, only a club is used for their destruction. Often the slaughter of a successful night amounts to hundreds. The American Woodcock is scarcely as large as the European bird, but it is none the less sought after.

The Woodcock is a delicious article of food, from its exquisite flavour and piquancy; it in consequence holds the highest rank among game in the eyes of the epicure.

The Snipe much resembles the Woodcock, but is smaller, with longer tarsi. It is also different in its habits. It haunts marshes and fens, feeding on grubs-sometimes even on aquatic plants. It travels during the night as well as in the day, generally preferring stormy damp weather for performing its migrations.

The Snipe is found in all latitudes in every part of the globe. Some remain the year round in France and Ireland. They make their nests among reeds in muddy, boggy places, difficult of access to both man and beast, in which they lay four or five eggs. The young ones leave the nest as soon as hatched, and are fed by their parents for some time, the want of solidity in their bills not permitting them to bore for their own food.

The Snipe does not live so solitary a life as the Woodcock; but is occasionally seen in wisps or flocks. When flushed they utter a shrill cry, which is easily recognised. The migratory birds visit us in autumn, coming from the marshes of Poland and Hungary, whither they return again in the spring. The most common species are the Common Snipe (Scolopax gallinago, Fig. 1 23, 2), the Great Snipe, (S. major), the Jack Snipe (S. gallimula, Fig. I 23, I), Sabine Snipe (S. Sabini), and the American variety (S. Wilsonii).

The Common Snipe is no bigger than a Thrush, and has a bill longer in proportion than the Woodcock. It has on the head two longitudinal black stripes; the neck and shoulders are blackish, and 
the breast white. It is persecuted by some of the small birds of prey, such as the Merlin, the Hobby, and the Kestrel. But, among all its enemies, man is most to be dreaded, for he looks upon it as nearly equal to the Woodcock, and for this reason pursues it with the greatest perseverance. But the sportsman pays dearly for his pleasure, as he frequently contracts rheumatism at an age when most persons are still vigorous, independent of the falls sure to be encountered on the perfidious surface of the bogs and marshes which might perchance

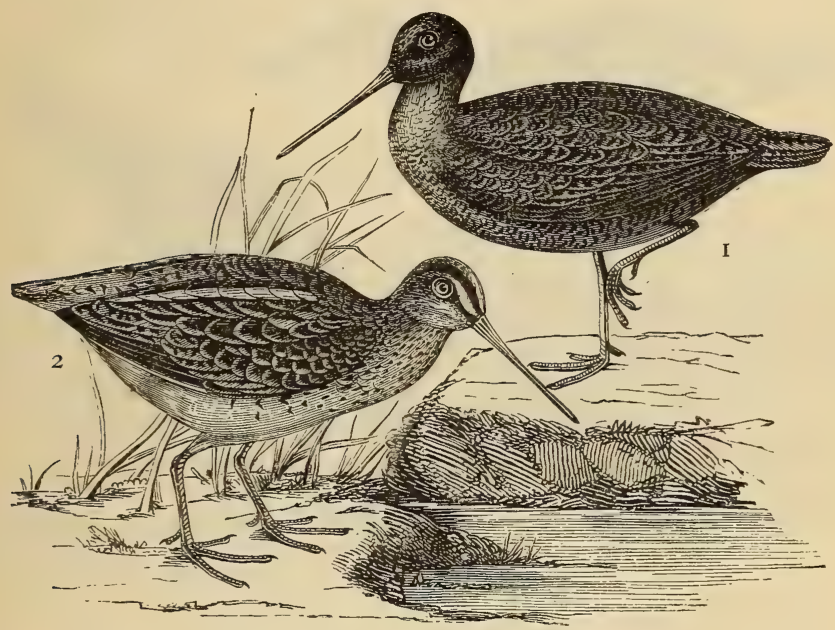

Fig. 123.-1. Jack Snipe. 2. Common Snipe.

even bury him in their muddy depths. Besides the drawback of rheumatism and the contretemps attending snipe-shooting, it is accompanied by another difficulty. Immediately on the bird flushing it makes two or three sudden twists, which often baffle even the best shots : proficiency can only be attained by long experience, aided by rapidity and steadiness of hand and eye.

The Great Snipe is about a third larger than that of which we have just been speaking.

The Jack or Deaf Snipe is thus named because it fails to notice the approach of the sportsman, and gets up literally under his feet. This is the smallest of the European species. 
Wilson's Snipe (Scolopax Wilsonii) is a native of America. In size it is the same as our Common Snipe. On the prairies of the Western continent it is found in immense numbers. It is strictly speaking migratory. The male and female differ slightly in plumage, the former having a white breast, while the latter has a brown one. As a table delicacy they cannot be surpassed.*

The Godwit (Limosa) is a beautiful bird, of slender make, with long legs. It is larger than the Woodcock, with a longer beak, this

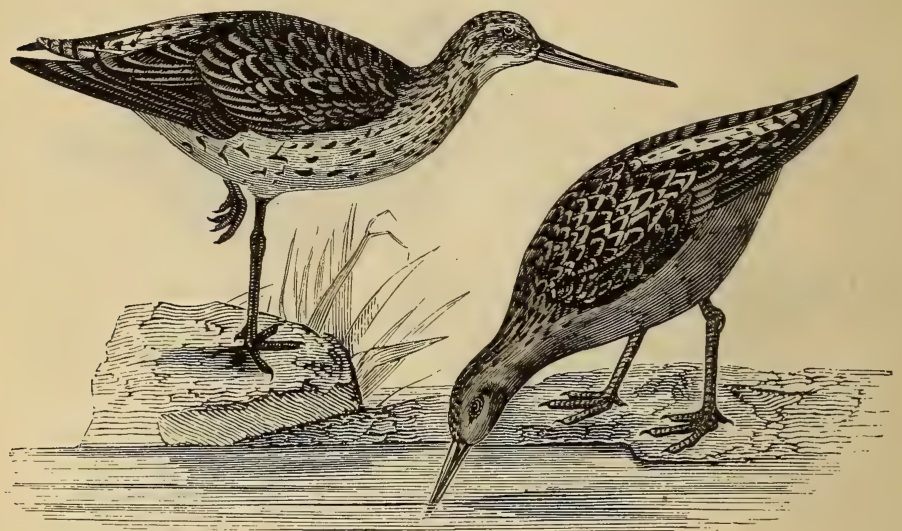

Fig. I24,-Godwits.

being twice the length of its head, and slender and tapering towards the point, which is rather depressed, and slightly curved upwards.

These birds inhabit the North of Europe, and in the autumn regularly visit France and the English coast from Cornwall to the north-east extremity of Scotland. They make their nests in meadows near the sea, among the grass and rushes, and lay four eggs, very large in proportion to the size of the parent. Their flesh is much esteemed, and, with the exception of that of the Woodcock and Snipe, is undeniably the best among the group of Waders that frequent our coast.

The male Godwit is always smaller than the female. Two species

* So numerous are these birds on the Grand Prairie (Illinois) that I have frequently killed ten dozen in one day.-ED. 
of this bird are known-the Black-tailed Godwit (Limosa agocephala, Fig. I24) and the Barred-tailed Godwit (Limosa rufa).

The Curlew (Numenius, Fig. I 25), is remarkable for the immoderate length of its bill, which is slender, curved, and round from end to end. Its wings are medium-sized, and tail short. Its plumage is a mixture of grey, russet, brown, and white. It derives its name from the plaintive melancholy cry which it utters when it takes flight.

These Birds frequent the sea-coast and the vicinity of marshes

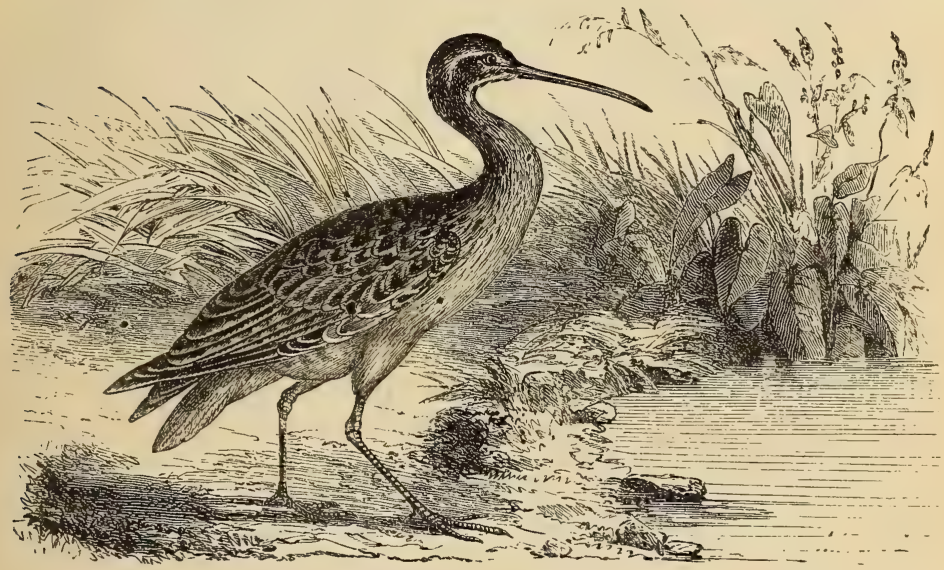

Fig. 125.-Curlew:

feeding on worms, water insects, and small molluscs. They plunge their bills into the ground, to a small portion of which they communicate a vibratory movement ; the worms, disturbed in their subter ranean dwellings, come up to the surface, and are easily preyed upon.

The gait of the Curlews, generally speaking, is grave and measured; but if disturbed previous to taking wing, they run with astonishing rapidity. They are capable of prolonged flight, but do not generally venture far into the interior of the country.* They live together in numerous flocks, except during their breeding-time, when they isolate themselves in order to build their nests, which

* At certain seasons of the year they are to be found in great numbers in the interior of North America.-ED. 
are situated in some dry place and secreted among the grass. The female lays four or five eggs. The young ones run about to seek their food as soon as they leave the shell, receiving no attention from their parents.

The Curlew is of a wild and timid nature. Nevertheless, in Senegal, they have been domesticated ; to no great advantage, it is true, as their flesh always retains a very marshy flavour.

Curlews abound all over the globe. They are very common in France, where they arrive in the month of April, leaving again in August, although sometimes they pass the winter on the coast. Of their sojourn in the British Islands the same may be said. A beautiful variety of the Curlew is found in America. In shooting them the great difficulty is to get within range. The sportsman, if well secreted, may occasionally succeed in obtaining a shot by imitating their call.

The Ibis (Ibis) has a long bill, curved in the direction of the ground, almost square at its base, and rounded towards the termination; the head and neck are bare. It has four toes; the three front ones are united at the base by a membrane; the whole length of the back toe rests upon the ground.

These Birds are inhabitants of the warm regions of Africa, Asia, and America; only one species, the Glossy Ibis, being found in Europe. They are to be met with in companies of seven or eight together, in moist and marshy grounds, and on the banks of large rivers, where they catch the worms, water-insects, and small molluscs, which form their principal food. They also crop young and tender aquatic plants. Their nature being mild and peaceable, they do not shift about with that petulance which characterises some of the Grallæ, but may be observed stationary for hours engaged digging into the mud which conceals their prey. Like nearly all other Birds of this order, they migrate every year, and undertake long journeys from one continent to another. They are monogamous ; and death alone can sever the bonds of affection and habit. They usually build their nests on lofty trees, but sometimes on the ground; the female lays two or three whitish eggs, which hatch in from twenty-five to thirty days.

There are eighteen to twenty species of the Ibis, of which three only merit our attention. These are the Sacred Ibis, the Glossy Ibis, and the Scarlet Ibis.

The Sacred Ibis (Ibis religiosa, Fig. I 26) is about the size of a fowl. Its plumage is white, with black at the extremity of the wings and on the rump. It has enjoyed celebrity from ancient times, on account of the veneration with which it was treated by the Fgyptians. For in 
their temples they set it up as a divinity, and allowed it to multiply in their cities to such an extent that, if we can believe Herodotus and Strabo, it actually impeded the traffic. Whoever killed an Ibis, even by accident, at once became the victim of a mad crowd, who stoned him pitilessly; while the dead bird was embalmed with the greatest care, and then placed in earthen pots hermetically sealed, which were ranged in special catacombs. A large number of mummies of the Ibis have been found in the necropoles of Thebes and Memphis, and several specimens of them are to be seen in the Museum of Natural History at Paris.

The Egyptian worship of the Ibis is a certain and incontestable fact. Less certain, however, is the origin of these honours. Herodotus has given an explanation, obscure enough, it is true, but which, however, was adopted by his successors, and for a long time accepted by our savants.

"The Arabians assure us," says Herodotus, "that the great veneration which the Egyptians render to the ibis

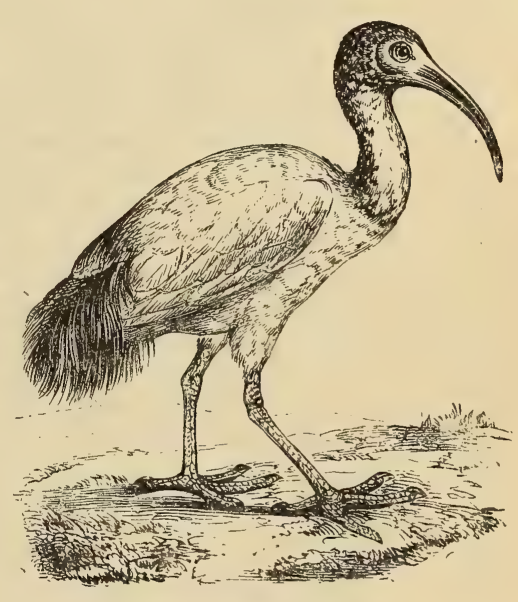

Fig. 126.-Sacred Ibis. is caused by the gratitude which they feel towards the bird for ridding the country of winged serpents."

According to tradition, these "winged serpents" came into Egypt from Arabia at the commencement of spring. They always followed the same route, and invariably passed through a certain defile, where the Ibis intercepted their passage and devoured them. Herodotus adds that, having gone to Arabia to obtain some certain information about these "winged serpents," he saw, lying on the ground near the city of Buto, "an immense quantity of bones and vertebræ unmistakably those of the winged plagues."

Since the time of Herodotus, a great many authors, probably on his authority, have reproduced this fable, and enriched it with variations more or less fanciful. Cicero, Pomponius Mela, Solinus, Ammianus, and Elian have alike done so. According to the last 
writer, the Ibis inspired the serpents with so much dread, that the very sight of its plumage was sufficient to drive them away.

In the narrative of Herodotus, as we have seen, the expression "winged serpents" is probably used for venomous ones. The translation is rather a free one. Moreover, it is the opinion of M. Bourlet, who has written a memoir on the subject, that by the term "winged serpents," Herodotus intended to describe locusts, innumerable swarms of which were wont to traverse Egypt and the adjacent countries, destroying everything as they passed. This explanation appears to us better than the former, for it is a fact that the Ibis cannot attack serpents, its bill being too weak for such a purpose.

Having quoted M. Bourlet's opinion, we may as well give that of Savigny the naturalist, whose studies on the subject have been published in the "Histoire Mythologique de l'Ibis."

"Between aridity and contagion, the two scourges which in all ages have been so dreaded by the Egyptians," says the author, "it was soon perceived that when a district was rendered fertile and healthy by pure and fresh water, it was immediately frequented by the Ibis, so that the presence of the one always indicated that of the other, just as if the two were inseparable; they therefore believed that the two had a simultaneous existence, and fancied some supernatural and secret relations existed between them. This idea, being so intimately connected with the phenomena on which their existence depended-I mean the periodical overflowing of their river-was the first motive for their veneration of the ibis, and became the basis of the homage which ultimately developed into the worship of the bird."

Thus, according to Savigny, the Ibis was venerated by the Egyptians only because it announced to them the annual overflowing of the Nile. This explanation is now generally accepted.

This Bird, the attachment of which to Egypt was formerly so great that, according to Elian, it died when taken from that country, strange to say, now is scarcely ever seen there. The cause of this probably is, that the modern Egyptians, treading under foot the ancient faith of their fathers, kill and eat the Ibis as they would any other fowl, without remembering its former rank of divinity. So, being deprived of the ancient protection which rendered Egypt so dear to it, the Ibis has almost deserted the ungrateful land of the Pharaohs. Still it occasionally pays brief visits to the Delta at the time of the rise of the Nile; but it soon takes flight into the wilds of Abyssinia, forgotten and unregretted. It is also found in Senegal and at the Cape of Good Hope. 
The Glossy Ibis (I. falcinellus), called by Herodotus, the Black Ibis, has black plumage, variegated with green on the upper part. It inhabits the north of Africa and the south of Europe. Like the first-mentioned bird, it was held sacred by the Egyptians.

The Scarlet Ibis (I. ruber) is indigenous to America, and is found principally in Guiana, where it associates in flocks at the mouths of the rivers. Its plumage is of a beautiful vermilion colour, tipped with black at the ends of the wings. It does not, however, obtain this brilliant dress till about two years old. The young are very readily tamed, and their flesh is well-tasted.

\section{CULtrirostres.}

The Cultrirostres (or knife-shaped bill) have a long, strong, and sharp-edged bill. They are generally provided with stout tarsi, and frequent the edges of marshes and banks of rivers. Many of them enjoy the faculty of being able to stand on one leg for hours together. This singular attitude is rendered possible by means of a curious mechanism, which was discovered by Duméril. The tibia, in its junction with the femur, presents a protuberant knot, which forcibly stiffens the ligaments of the knee, forming a kind of catch, similar to the spring of a knife.

The principal species of this family are-the Spoonbill, Stork, Argala, Jabiru, Boatbills, Heron, Crane, Trumpeter, and the Cariama.

The Spoonbill (Plutalea) is remarkable for the singular form of its bill, which is about four times the length of the head, straight, and flexible ; the upper mandible, about an inch and a quarter broad at the base, gradually narrowing to three-quarters of an inch, and again increases to two inches at the point, causing a resemblance to a spoon, from which it takes its name. It uses this bill for dipping into the mud and water, whence it extracts worms and small fish, on which it principally feeds. It also eats water-insects, which it catches by placing its bill half open on the surface of the water, permitting them thus to float on to the lower mandible. It lives in small companies, and frequents the sea-shore. It is easily tamed.

There are two species of them: the White Spoonbill (P. leucorodia, Fig. 127), which has a tuft on the back of its neck, and is found in most parts of Europe-it is, however, seldom met with in France, and then only in the south; and the Rose-coloured Spoonbill, a native of South America, the plumage of which possesses the most beautiful tints.

The Stork (Cicunia) has a long and straight bill, wide at the 
base, pointed, and sharp-edged; legs long and slender; tibia bare for half its length; tarsi long, compressed, reticulated; hind toe short, slightly elevated, and inserted rather high, but resting upon the ground; the tail is short. They are found in nearly all parts of the world. Some species migrate with regularity, being admirably constructed for travelling long distances; for, although their bulk seems great, their weight is comparatively small, as most of their

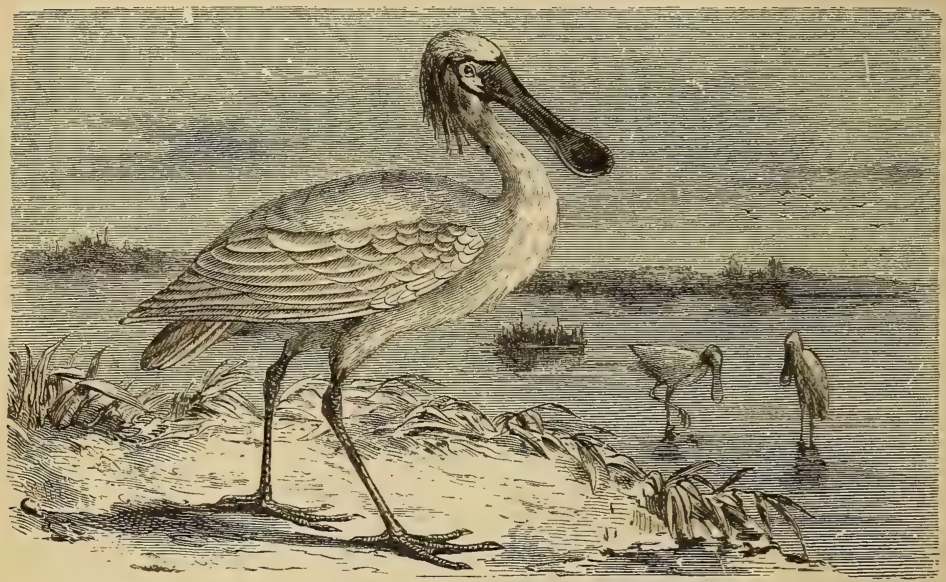

Fig. 127.-Common White Spoonbill.

bones are hollow. In their migratory journeys, which occur principally by night, they fly in continuous or angular lines.

Storks prefer moist swampy localities, as they feed principally on reptiles, batrachians, and fishes ; but small birds and mammalia, molluscs, worms, insects, even bees are not refused by them, or carrion, and other impurities. Their manner is slow and grave; they never appear in a hurry. On the wing they resemble crosses, from their manner of carrying the head and neck. They have no voice, and the only noise they make is a cracking, which results from one mandible striking against the other, and which expresses either anger or love; it is sometimes very loud, and, under favourable circumstances, may be heard as much as a league away. They lay 
from two to four eggs, their fecundity increasing in an inverse ratio to their size. The duration of their life is from fifteen to twenty years.

There are several species of Storks, the most important being the White Stork (Ciconia alba, Fig. I 28). It measures about forty inches in height; length to end of tail, forty-two inches; wings, extended, seventy-six inches; its plumage is white; the wings are fringed with black. This is the species best known in Europe. Holland and Germany are its favourite residences; and Alsace is the part of France in which they are most frequently met with. It is so rarely seen in England that there it has become almost a matter of legend. It is very common in the warm and temperate parts of Asia. In the month of August it leaves Europe to visit Africa, from whence it returns in the following spring. This migration is not caused by temperature, as the Stork can bear severe cold. No, it is a mere question of sustenance; for, feeding as it does principally upon reptiles which remain in a complete state of torpor during our winters, it is natu-

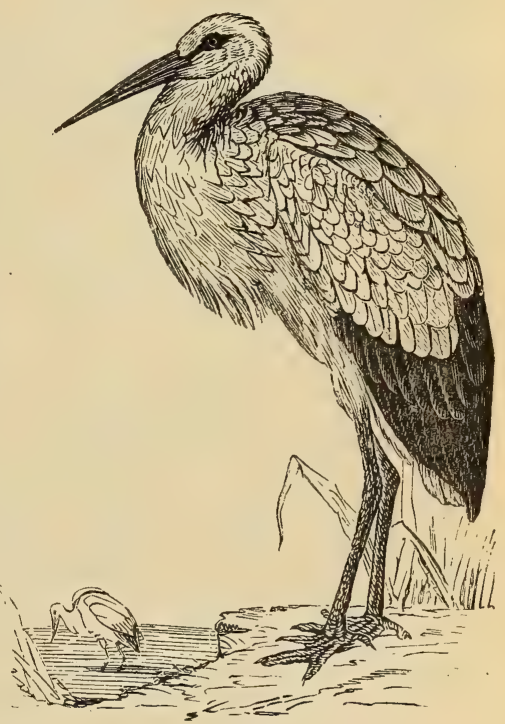

Fig. I28.-White Stork. rally compelled to seek its food elsewhere.

The Stork is of a mild nature, and is easily tamed. As it destroys a host of noxious creatures, it has become a useful helper to man, who, not ungrateful, gives it succour and protection. In ancient Egypt it was venerated on the same score as the Ibis; in Thessaly there was a law which condemned to death any one killing these birds. Even at the present day the Germans and Dutch esteem it a fortunate omen when a Stork selects their house for its home, and they even furnish it with inducements to do so by placing on their roofs a box or wheel, which forms a foundation for the bird to build a nest, which it constructs of reeds, grass, and feathers. 
When the Stork has attached itself to a place, and is kindly treated, it sometimes gives up the habit of migrating. It cannot however, quite get rid of agitation when the season for departure comes. Occasions have been known where it yielded to the appeals of its wild companions and to the desire for progeny (for in captivity it is always barren), and was allured away to join the band of travellers. But this separation is only temporary; next year the truant returns to the old house, and again takes possession of its domicile. It exhibits great pleasure in renewing acquaintance with former friends, and is not long in placing itself on a footing of familiarity with them. It frolics with the children, caresses the parents, plagues the dogs and cats-in a word, manifests a gaiety and susceptibility of affection which one would hardly expect to find in a bird generally dull and taciturn. It presents itself at the family meals, and takes its share of them. If its master tills the ground, it follows him step by step, and devours the worms which are turned up by the spade or the plough.

The Stork may certainly be taken as a model for all mothers. Its love for its progeny sometimes even approaches heroism. We will give two touching instances.

In 1536 a fire broke out in the city of Delft, in Holland. A Stork, whose nest was placed on one of the burning buildings, made at first every effort to save its young. Finally, seeing its inability to assist them, it suffered itself to be burnt with the loved ones rather than abandon them.

In 1820 , at another fire at Kelbra, in Russia, some Storks, when threatened by the flames, succeeded in saving their nest and offspring by sprinkling them with water, which they brought in their beaks. This last fact proves to what extent intelligence may be produced under the influence of parental love.

The Stork is not only a good mother, but she is also an excellent wife. The attachment which these birds show for each other when they are once paired has long procured for them a high reputation for conjugal fidelity. Thus, in the Vorarlberg ('Tyrol), a male Stork was known to have refused to migrate, passing several winters by the side of his mate, who, in consequence of a wound in her wing, was unable to fly.

We must, however, add that some lady Storks are by no means slow in consoling themselves for the loss of their husbands. A few days of mourning, as a matter of form, and their grief ends. Sprungli notes the case of one w:dowed Stork which contracted new bonds after two days. Another gave evidence of the most guilty perversity. 
The lady began by betraying the confidence of him with whom she had united her destinies; his presence had evidently become insupportable to her, and she finally killed him with the help of her accomplice.

These errors of the female render the high morality of the male bird more conspicuous. Witness the following story, related by Neander:-

A number of storks had taken up their abode in the markettown of Tangen, in Bavaria. Perfect harmony reigned in every family, and their lives were passed in happiness and freedom. Unfortunately, a female, who had been up to that time the most correct of matrons, allowed herself to be led away by the idle gallantries of a young male; this took place in the absence of her mate, who was engaged in seeking food for his tamily. This guilty liaison continued until one day the male, returning unexpectedly, became convinced of her infidelity. He did not, however, venture to take the law into his own hands. He arraigned her before a tribunal composed of all the birds at the time assembled for their autumnal migration. Having stated the facts, he demanded the severest judgment of the court against the accused. The unfaithful spouse was condemned to death by unanimous consent, and was immediately torn in pieces. As to the male bird, although now avenged, he departed to bury his sorrows in the recesses of some desert, and the place which once knew him afterwards knew him no more.

The Storks of the Levant manifest a still greater susceptibility. The inhabitants of Smyrna, who know how far the males carry their feelings of conjugal honour, make these birds the subject of rather a cruel amusement by placing Hens' eggs in the nest of the Stork. At sight of this unusual production the male allows a terrible suspicion to gnaw his heart. By the help of imagination, he persuades himself that his mate has betrayed him; and in spite of the protestations of the poor thing, he delivers her over to the other storks, who are attracted by his cries, and the innocent and unfortunate victim is peckéd to pieces.

Besides the numerous virtues that we have just stated-parental love, conjugal fidelity, chastity, and gratitude - the ancients attributed to them filial piety. They believed that these birds maintained and nourished their parents in their old age, and devoted themselves to alleviating the trials of the last years of their lives with the most tender care. Hence was derived the name of the "Pelargonian Law" (from the Greek $\pi \in \lambda \alpha \rho \gamma \partial s$, a crane), the name given by the Greeks to the law which compelled children to maintain their parents when old age had rendered them incapable of working. 
This feature in its character has not a little contributed to the universal estimation the Stork is held in.

The flesh of the Stork forms but indifferent food; it is, therefore, inexplicable why persons calling themselves sportsmen persist in shooting at them. The reprehensible mania which the French Nimrods possess of indiscriminately massacring everything which shows itself within reach of their guns is a disgrace to those who practise it, and an injury to the community at large. The result is that the Stork, meeting with nothing but ill-treatment in return for its loyal and useful services, is gradually retiring from France, and before long will have completely abandoned it.

The Black Stork (Ciconia nigra) is rather smaller than the White Stork (Ciconia alba); it is a native of eastern Europe, and is rarely seen in France. It feeds almost exclusively on fish, which it catches with much skill. It is very shy; avoids the society of man; and builds its nest in trees.

The Argala (Leptoptilos), also called the Adjutant, is characterised by its very strong and large bill, and the bareness of its neck, the lower part of which is provided with a pouch somewhat resembling a large sausage. According to Temminck, there is a notable difference between the Marabou and the Argala, the characteristic mark of the latter frequently hanging down a foot, while it is much shorter in the Marabou.

The Adjutant (Leptoptilos argala, Fig. I 29) inhabits India ; they feed on reptiles and all kinds of filth, and this fact has been the means of securing for them the goodwill of the people. In the large cities of Hindostan they are as tame as dogs, and clear the streets of every kind of garbage which litters them. At meal-times they never fail drawing themselves up in line in front of the barracks, to eat the refuse thrown to them by the soldiers : their gluttony is so great that they will swallow enormous bones. At Calcutta and Chandernagore they are protected by law, which inflicts a fine of ten guineas on any one killing one of these birds.

The long white feathers, celebrated for their delicacy and airiness, which are used in the adornment of ladies' bonnets, and known in commerce by the name of marabou feathers, come from this bird and the African Marabou (Leptoptilos marabou). Consequently, in spite of their ugliness, a good many are reared in a domestic state in order that our European fair ones may obtain their favourite decoration.

There are several other species which are allied to the Storks, and are only distinguished from them by a slightly different form of the bill. We will confine ourselves to merely naming the best known, and 
pointing out the localities they inhabit. They are as follows :-The Jabiru (Mycteria australis, Fig. I30), which is a native of Australia; the White-headed Stork (Balaniceps rex), which is found in Africa; the Bec-ouvert, which inhabits India and Africa; the Drome, which

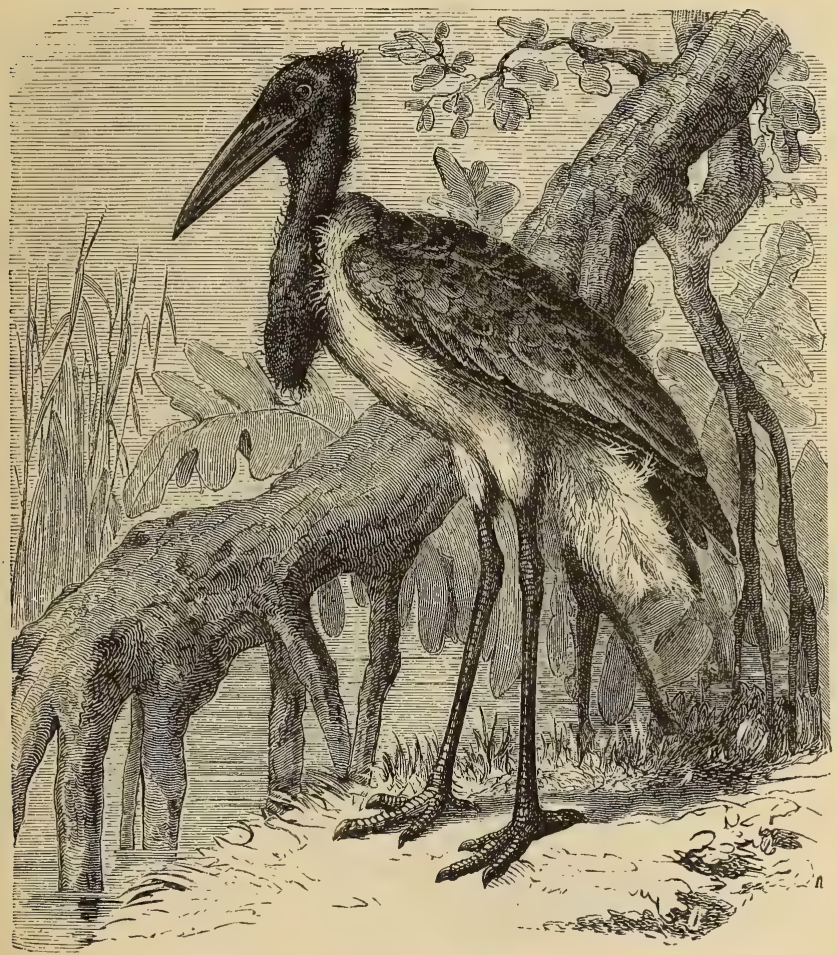

Fig. 129.-Adjutant.

is met with on the shores of the Black Sea and Senegal ; and, finally, the Tantalus, which lives in the warm regions of both the New and Old World.

Whoever has once set eyes on the Boatbill (Cancroma cochlearia, Fig. I3I) will never forget the bird, or confound it with any other. 
What, it will be asked, is there so characteristic about it? Nothing else but its bill, which certainly is the most singular implement one can well imagine. Fancy two long and wide spoons, with their

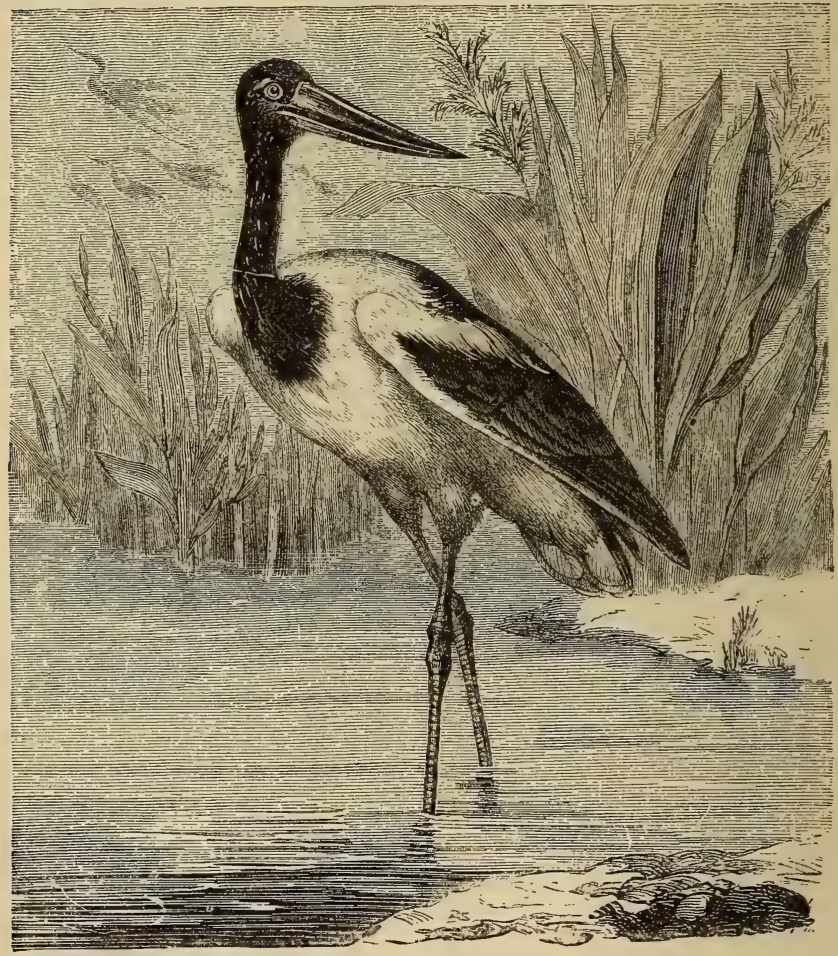

fig. 13o.-1he Jabinu.

hollow sides placed one against the other, the end of the upper spoon being furnished with two sharp teeth, and we have some idea of this extraordinary storehouse, as it may be called, for the proprietor can easily stuff into it provisions for a whole day. If we add to this that the Boatbill _ possesses a beautiful black crest which hangs down be- 
hind its head, that it is about the size of a fowl, also that it has short wings, and rests its four toes firmly on the ground, we shall then have a pretty exact portrait of our subject. This Bird inhabits the savannahs of Central America, frequenting the banks of rivers, where

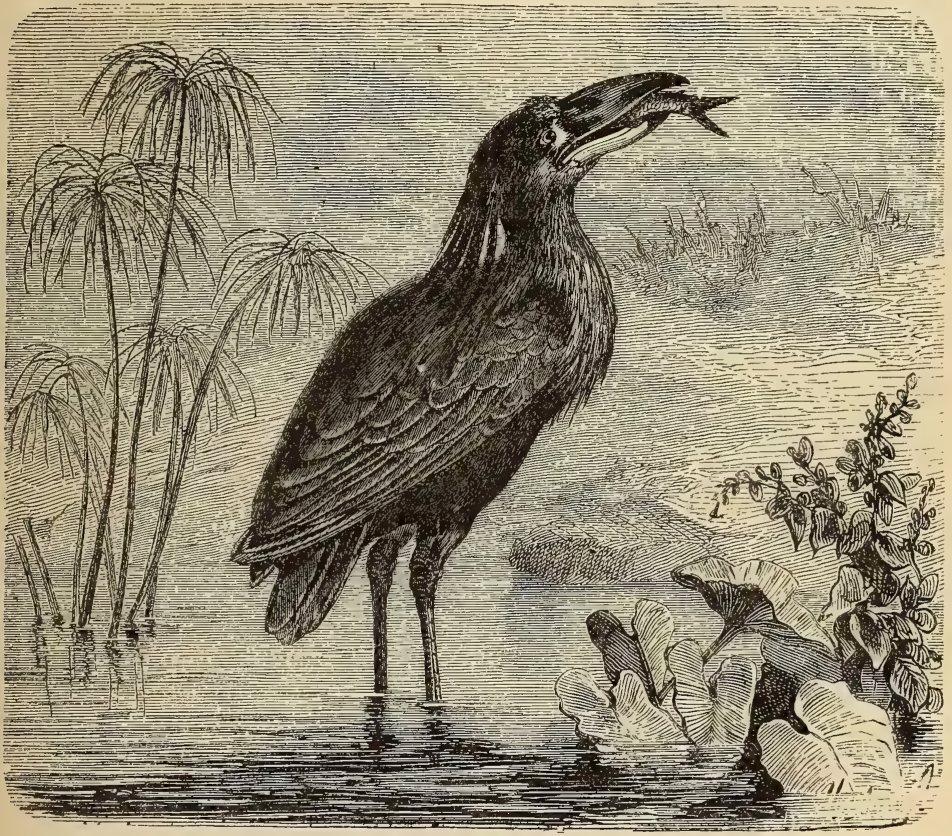

Fig. I3I. - The Boatbill.

it feeds on fish, molluscs, and sometimes crabs. It builds its nest in the thick under-brush.

The Herons (Arden), which form a genus of birds of the order of Cultrirostres, have the bill long, pointed, opening widely, and very strong; their legs are in part bare of feathers; toes long, and furnished with long claws, not excepting the back toe, the whole length of which rests upon the ground; the neck is long and slender. Further, the back of the head is adorned with a tuft of long feathers 
which fall over its shoulders like a plume, whilst those in front, which are narrow and pendent, resemble a kind of beard surrounding the base of the neck.

These Birds lead a semi-nocturnal life, and frequent the margins of lakes, marshes, and rivers, where they feed on reptiles, frogs, and fish. They are generally of a shy nature, selecting for their roost the most unfrequented portions of extensive woodlands. When in pursuit of their prey, they go into the water until it reaches half-way up their legs, and with the neck doubled down over the breast, and the head buried between the shoulders, remain immovable as statues till a fish comes within reach of them, when they suddenly shoot out their necks, as if impelled by a spring, and, with a sharp movement of the bill, impale the unfortunate victim. When their fishing is not productive they dig into the mud with their feet, to unkennel frogs and other reptiles tha: are concealed in it. If compelled by hunger, they will attack rats, wood and field mice, and if further pressed they show no repugnance to carrion. They can, however, endure abstinence for a considerable time.

Most of the Herons are endowed with great powers of flight. When compelled by unusually severe weather, they occasionally migrate, the young and the old travelling separately. Nevertheless, as they can accommodate themselves to almost any temperature, some species are stationary, and they are to be met with all the year round in countries the most dissimilar.

The principal species of Herons are the Common Heron, the Egret, the Purple Heron, the Bittern, the Night Heron, and the Nankeen Heron.

Every one knows the Common Heron (Ardea cinerea, Fig. 132), at least by reputation, if only from La Fontaine's verse :-

"Heron with the long bill, fit handle of a longer neck."

Its height is about forty inches, and it is found in nearly all parts of the globe. It is the most numerous species in France, and is the only one which builds, lays, and rears their young in company. The place selected for this community is generally a clump of lofty trees in the neighbourhood of a lake or river; on the summits of which, or in the angles formed by the branches, the Herons build their nests, which are of very simple construction-a few boughs interwoven together with smaller twigs, and without any such luxurious additions as smaller birds love to add. In these nests the females lay three or four eggs, and the males share with them the 
càres of incubation; after the eggs are hatched, he also assists in providing for the young.

When the young Herons are able to fly, they leave the nest and cease to have their wants provided for by their parents.

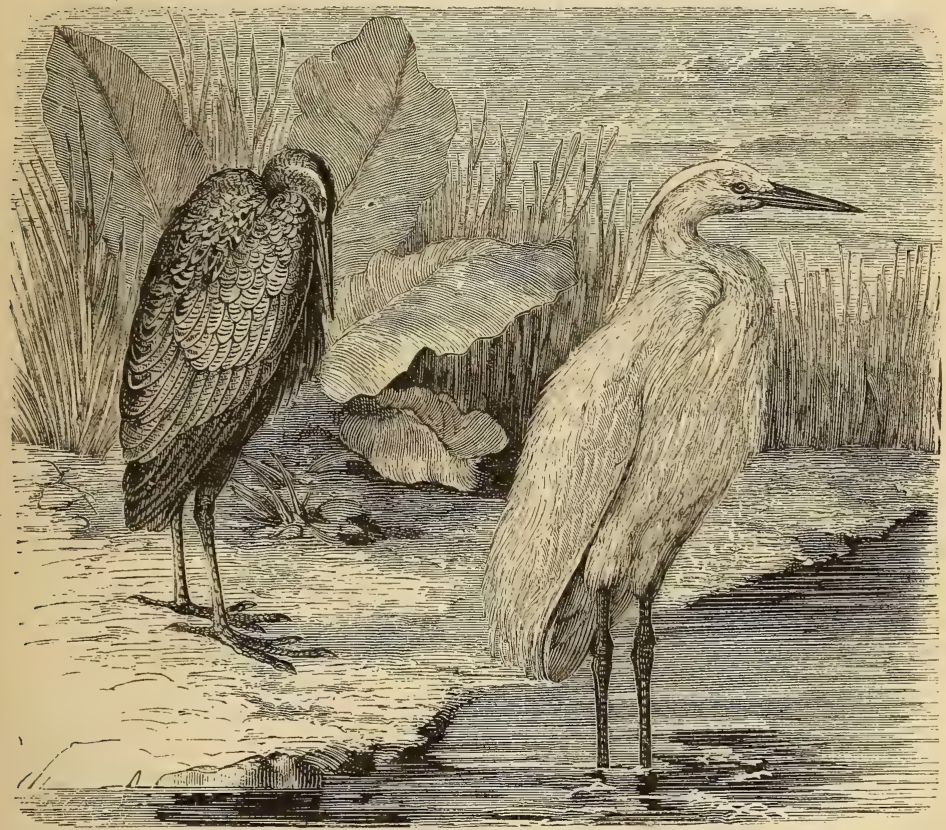

Fig. 132.-Common Heron and Egret.

About the beginning of August the time for migration has arrived, the colony, possibly then amounting to 500 or 600 individuals, prepare themselves to quit the her onry. The following year they return, and their arrival, like their departure, takes place with great regularity of date. It is remarked that the number of couples is always nearly the same as that of the nests, so that each pair readily find a resting-place; the new generation must therefore leave their progenitors to found a fresh colony. 
Heronries are becoming more and more rare. M. Toussenet states that he has met with only one in all France, that at Ecury (Marne), between Epernay and Châlons. They are not uncommon in England, where many ancient families connect them with their ancestral grandeur. Lord Warwick's heronry, on the classic Avon, still maintains seventy or eighty pairs of the noble birds.

The Heron has enemies in the Eagle, the Falcon, and the Crow. The latter combine to steal its eggs; the former to kill the parents. When the Heron finds itself pursued by a bird of prey, it endeavours to get uppermost; this plan is nearly its only means of safety. Occasionally it succeeds, for the Heron is able to attain immense altitudes. If closely assailed it makes an admirable use of its bill as a means of defence, and has been known to impale its adversary. Its usual tactics are, to wait for its enemy, lance in rest, and to allow the latter to pierce himself through by his own impetuosity. We must, however, admit that the Heron is not always so fortunate, and that oftener than not he becomes a prey to his eager adversaries, the Eagle and the Falcon.

The magnificent powers of flight possessed by the Heron, and his clever devices in defending himself, gave rise, in days gone by, to the very special regard with which it was honoured by kings and princes, who hunted them with trained Falcons. The poor Heron was doubtless not very gratified for these marks of high esteem, and it is probable that, if it could be consulted at the present day, would bless the happy obscurity in which it is now allowed to vegetate. "It costs too much to shine in the world," is the moral La Fontaine puts into the mouth of the Heron.

Although its flavour is certainly as disagreeable as possible, the flesh of the Heron was in the old time reckoned as a "royal dish," and was only served upon the tables of the great and powerful of the earth. In order to procure this supposed delicacy more easily, the idea arose of artificially arranging a certain part of the forest so as to attract the birds. Here they enjoyed all the comforts of a heronry till the moment when they were required to gratify the pleasure of their lord. We must add that the plan of taking their progeny was adopted to assist the royal treasury; for, as Pierre Belon tells us, "great people were in the habit of trading largely in the young ones, which brought considerable sums of money." Francis I. caused heronries to be established at Fontainebleau, which, as connoisseurs tell us, were everything that could be wished.

The Heron is quite susceptible of training when caught young; but it must always be little else than a bird of ornament, as the 
service it can render amounts to little or nothing. When adult at the time of capture it is aitogether intractable, entirely refusing food, and dying at the end of a few days.

The Purple Heron (Ardea purpurea) has the same habits as the one just spoken of, but it is a little smaller. It owes its name to the colour of the numerous spots which adorn its livery. It is rarely met with in France, but is pretty common at the mouths of the Danube and Volga, and the margins of some of the lakes in Tartary.

The Egret (Egretta alba, Fig. I32) is remarkable for its plumage, which is entirely of a pure white. Two varieties of it are knownthe larger, generally called the Great Egret, is about the size of the Common Heron, it is common in Eastern Europe, in the North of Africa and America, and in the Malay Archipelago; the smaller kind is known by the name of the Garzette Heron, or Little Egret, and is not larger than a Crow ; it inhabits the confines of Asia and Eastern Europe, and regularly visits the South of France.

These two species are ornamented, during the breeding season, with fine and silky feathers, which spring from the shoulders, and, spreading out over the back, fall on each side of the tail in elegant plumes. These are the adornments which European ladies value much for placing in their head-dresses.

Northern Africa presents us with a beautiful white Heron, about the size of a Pigeon, the functions of which are extremely interesting, it is called the Ox-keeper. In Morocco this bird is very common. It is in the habit of accompanying the cattle into the fields, and takes the task of relieving them from the numerous flies and insects with which they are annoyed. In France it is met with only at the mouth of the Rhône.

The Bittern (Botaurus) has both the neck and legs shorter than those of the Grey Heron; its plumage is of a rich reddish yellow, boldly variegated with dark markings. Districts intersected by marshes are the chief places of its resort; in these it keeps itself hidden, motionless, and silent, all day long among the reeds. Here, too, it makes its nest, almost on the ground, and close to the water. It does not leave its sanctuary until evening, when it will ascend on rapid wing to so great a height as to be lost to view. Its call to its mate is peculiar; for it resembles the bellowing of a bull, and can be heard more than half a league. For this reason the ancients called it bos taurus - whence, by corruption, comes the French butor.

The Bittern is a very courageous bird; it will defend itself energetically against any bird of prey, against dogs, and even man. It is 
found all over Europe. Four British species are described- $B$. stellaris, B. lentiginosus, $B$. minutus, and B. comatus.

The Crane (Grus), which forms a genus among the Cultrirostres, is characterised by a bill much longer than the head, stout, straight, tapering, compressed, and pointed, but always slightly cleft; feet

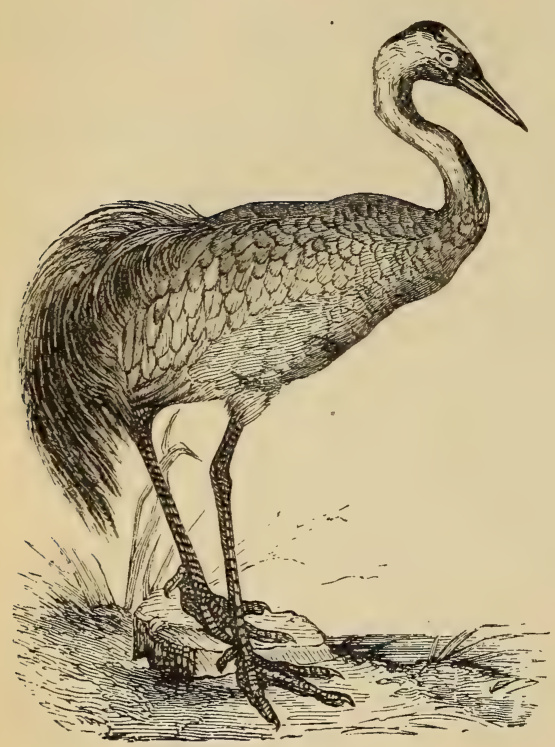

Hig. r33.-Common Crane. long; tibia bare for a fourth of its length, covered with hexagonal scales; toes, four; back toe short, which does not reach the ground: wings long and pointed. The Cranes are essentially migratory birds, and possess wonderful requisites; for, in addition to prolonged powers of flight, they enjoy the valuable faculty of being able to endure total abstinence from food for several days - a faculty which, we may remark, is common to most of the Wader tribe, though in a less degree.

There are four species described-the Common Crane the Demoiselle Crane, the Crowned Crane, and the Hooping Crane.

The Common Crane(Grus cinerea, Fig. 133) is a fine bird, attaining nearly five feet in height. With the exception of the neck, which is black, all the rest of its body is of a uniform ashygrey colour. The carriage of the bird is noble and graceful, and the feathers on its rump, which rise up in undulating clusters, add much to its elegance.

These Cranes are periodical visitors to France; they arrive in Europe in the month of April or May, passing the fine weather in more northern countries. Towards the middle of October, on the arrival of the first cold weather, they leave us in order to winter in Egypt, Abyssinia, or even Southern Asia. They travel in flocks, numbering sometimes as many as 300 or 400 birds ; generally they arrange themselves in two lines, so as to form an isosceles triangle, 
or a sort of wedge with the point in front-the most convenient formation for cleaving the air with the least amount of fatigue. From time immemorial people have been fond of saying that these birds intrust the care of their guidance to a chief, who, after having led the way for a certain time, and becoming wearied surrenders his charge to one of his companions and passes to the rear of the band, where, like a new Cincinnatus, he resumes the position of a simple citizen. The fact is, that the leaders of the two files change perhaps ten times in a minute, and the apex of the angle is occupied in succession by every crane in the flock within a very short space of time.

Cranes almost always travel at night, and halt during day-time to seek their sustenance. Sometimes, however, they push on through space, giving utterance to startling cries, which probably are intended as words of encouragement to those that are wearied from the length of the journey. When they perceive a bird of prey, or have to contend with one, they abandon their usual formation, and collect in a circular mass, so as always to present a face to the enemy.

'Cranes frequent large plains intersected with marshes and watercourses. They feed on fish, reptiles, frogs, molluscs, worms, insects, and even small mammals. Some kinds of grain have also attractions for them, and they may not unfrequently be seen invading the newlysown fields to devour the seed which the farmer has just committed to the soil.

When the breeding season arrives, they break up their social compact, and pair off for the purposes of reproduction and attending to the rearing of their young.

Their nests are but roughly constructed, and are placed on any little piece of rising ground in the midst of the marshes; in them they lay usually two eggs, the male sharing with the female the cares of incubation. Although these birds are ordinarily so timid, and are alarmed at the least appearance of danger, yet, when they have their young ones to defend they become really courageous. In this case they do not shrink from attacking man.

The Crane ought to have been the emblem of vigilance. When the flock go to sleep, with their heads hidden under their wings, one of their number is specially charged with the duty of watching over their common safety and to give alarm on the approach of danger.

When caught young they are easily tamed, and in a very short time manifest considerable familiarity with their keeper. They are, therefore, a good deal sought after in some countries, both on account of their graceful shape, and also for the sake of the vigilance which they exercise round about their home. 
These birds were well known in ancient times ; Homer, Herodotus, Aristotle, Plutarch, Elian, Pliny, and Strabo have noticed them and their migrations. Unfortunately, not content with correct observations, they have given credence to some most ridiculous fables, invented in Greece and Egypt, the classic and fertile lands of the marvellous. Thus, according to the Egyptian story, the Cranes made an expedition to the sources of the Nile to fight against the Pygmies, who were, as Aristotle says, "a race of little men, mounted on little horses, who dwelt in caves." According to Pliny, these little men were armed with arrows, and mounted on rams; they abode in the mountains of India, and came down every spring to wage war against the Cranes. The Roman naturalist fancies that they succeeded in this destructive aim, for the town of Gerania, which even in his time was ruined and deserted, was formerly, he asserts, inhabited by a race of Pygmies, who were driven out by the Cranes. In the views of modern commentators, these Pygmies were nothing but monkeys, which assemble in large troops in the forests of Africa and India, and always manifest hostility to birds.

The Greeks have also invented two stories about Cranes, which are certainly very ingenious, but result from the error of attributing too much importance to trifles. They say Cranes carry a pebble in their mouths when they cross Mount Taurus, so that they are compelled to keep mute; they thus avoid exciting the attention of the eagles inhabiting those districts, which birds are much disposed to do them mischief. In the same way, the Crane which is placed as sentinel to watch over his sleeping companions is bound to stand on one leg and carry a stone in the other claw, so that if he allows himself to be overtaken by slumber, the fall of the pebble would wake him up. It was, as we are aware, the expedient of the youthful Aristotle to hold an iron ball suspended over a metal basin in order to wake himself if he succumbed to sleep. We should ascribe too much ingenuity to the Crane in imputing to it an action of Aristotle's.

The members of this interesting feathered tribe were said to possess certain virtues. The thigh bone of a Crane imparted to him who possessed it remarkable vigour and elasticity of limb. Its brain also was a kind of love-philtre ; it transformed the ugliest man into a perfect Adonis, and won for him the favour of the fair.

It is, moreover, to the Crane that the Greeks are indebted for one of their favourite dances. Be it understood that we are now returning to plain matter of fact. The games and dances which Cranes indulge in amongst themselves are not mere idle stories; observers of our own day, well worthy of credit, have proved their authenticity. 
It is certainly true that these birds form groups in various fashions, advance one towards another, make a kind of salutation, adopt the strangest postures -in a word, indulge in pantomimes both burlesque and amusing. This is, we must confess, a curious element in their character, and has been made the most of by the Chinese, who are in the habit of teaching Cranes to dance according to all the rules of etiquette.

The ancients set a high value on the flesh of the Crane, which is, nevertheless, anything but good. The Greeks especially exhibited a great fondness for it; they used to fatten these birds after having put out their eyes or sewed up their eyelids ; this cruelty being necessary, according to their idea, to cause a proper degree of plumpness.

In the fine old days of hawking, the Crane, as well as the Heron, was honoured with the attention of the magnates of the land. In Japan, at the present day, it is reserved for the sport of the Taicoun (king), and the common people treat it with the courtesy due to such an honour.

We should certainly fall short in our traditionary lore if we failed to relate the far-famed story of the cranes of Ibycus. Ibycus of Rhegium was a lyric poet, who enjoyed some reputation in his day. On one occasion, when he was proceeding to the Olympic Games in order to contend for the poet's prize, he lost his way in a forest, and fell into the hands of two malefactors, who cruelly murdered him. Just as he was dying he cast his eyes towards heaven, and perceiving a flock of cranes passing over, he cried out, " $\mathrm{O}$, ye bird-travellers, become the avengers of Ibycus!" The next day the two robbers were quietly taking a part in the Olympic contests, when the news of the murder, which arrived during the day, excited some sorrowful emotion. All of a sudden a flight of cranes passed over the arena, uttering loud cries. "Do you see the cranes of Ibycus?" said one of the murderers to his comrade in a humorous tone. This remark, being overheard by some persons standing by, and commented upon by a thousand lips, became the ruin of the two scoundrels. At once arrested and pressed with questions, they were compelled to confess their crime, and were immediately put to death. Thus was fulfilled the dying invocation of Ibycus.

The Demoiselle Crane (Scope virgo, Fig. I34) is remarkable for two beautiful clusters of white feathers, which are suspended behind its head, and for a black pendent tuft. Its size is about the same as that of the species just described, and its shape is still more elegant. It also is gifted with great powers of mimicry. Its movements have an air of affectation and mannerism, as if it desired to attract the 
attention of the spectator; hence, in French, the name of demoiselle has been given to it. It is found in Turkey and Southern Russia, in Northern Africa, and in some parts of Asia adjacent to the latter region.

The Crested Crane (Balearica pavonina, Fig. I35) has the top of its head adorned with a tuft of feathers, which it has the power of

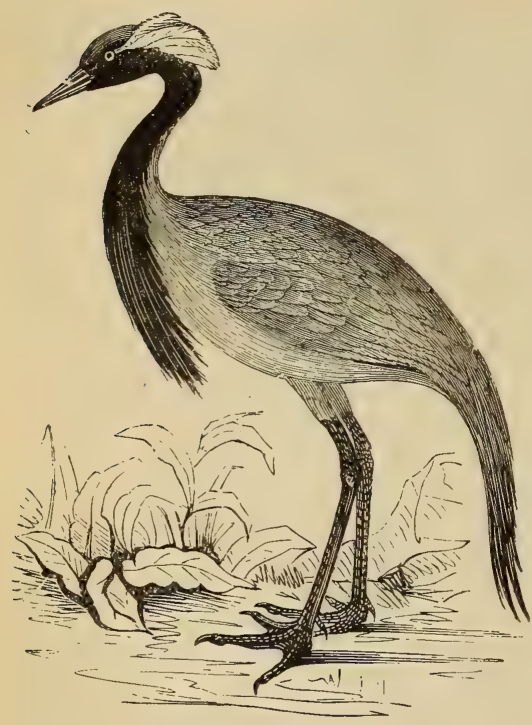

Fig. 134.-Demoiselle Crane. spreading out like a fan, so as to form a handsome adornment. Although about the height of the two sister-birds, it is more slender. Its voice is very loud. Readily becoming familiar with man, it seeks his acquaintance. Its chief habitats are the eastern and northern coasts of Africa and some of the isles in the Mediterranean: according to the ancients, it was formerly common in the Balearic Islands.

The Hooping Crane (Psophia crepitans, Latham) has a strong and tapering bill, shorter than the head; long tarsi and medium-sized toes, the back toe touching the ground at the extremity only. Its wings are short, and, in consequence, it flies with difficulty; but, to make up for this deficiency, it can run very swiftly. This bird is but little larger than a domestic fowl. It is in the habit of uttering at intervals a piercing call, which seems as if it did not proceed from the vird itself; this cry has procured for it the name it possesses. It makes its nest on the ground, in a hole scratched out at the root of a tree, and feeds on grasses, seeds, and small insects. Shyness is not one of its qualities, and it will submit to captivity without repugnance; it forms an attachment to its master, and solicits his caresses like a pet dog. The latter comparison is all the more just, as the bird renders very much the same service to man as that quadruped. This bird is entrusted with the care of the flocks when at pasture, and in the evening brings 
them back to the farm, where its activity finds plenty of scope in keeping the inmates of the poultry-yard in order.

In its wild state it inhabits the forests of Southern America. Its flesh is agreeable in flavour, and is often eaten.

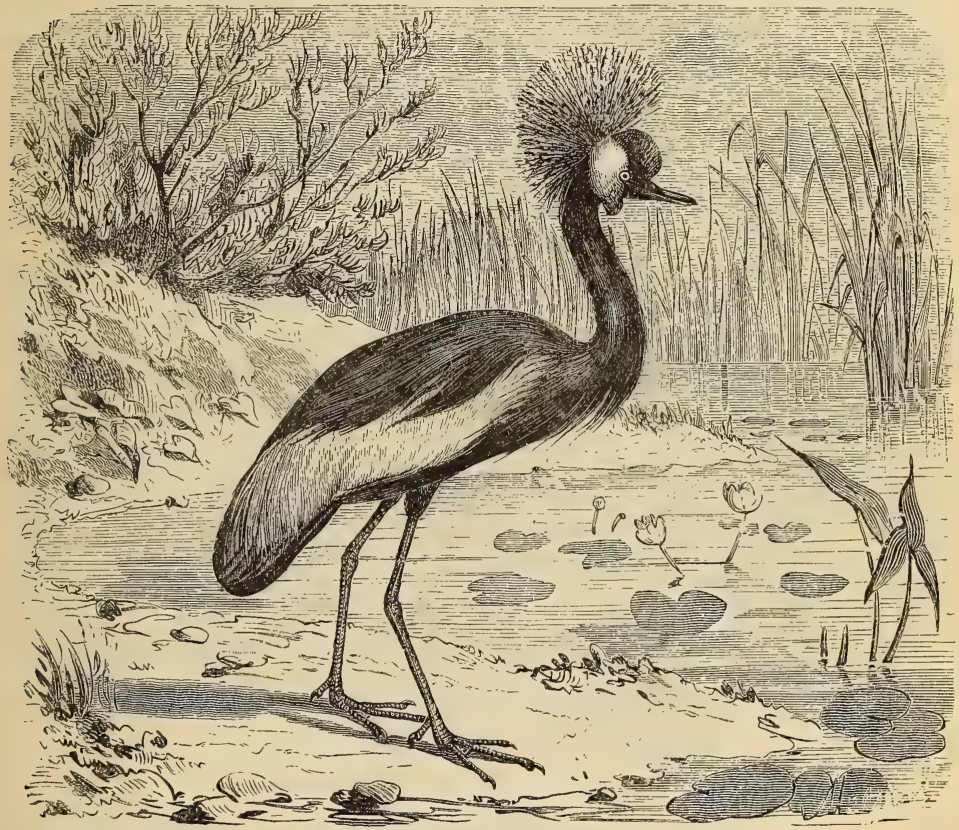

Fig. I35.-Crested Crane.

The Caurale, Figuier (Fig. 136), which forms a genus in the order we are considering, is a Bird about the size of the Partridge, with a large and fan-like tail. Its brilliant hues have obtained for it in Guinea the name of the Little Peacock or Sun Bittern. It is very wild in its nature.

\section{Pressirostres (Compressed Bills).}

The Birds which belong to the order Pressirostra are characterised by a middling-sized bill-not, however, devoid of strength- 
and a back toe which is altogether rudimentary; indeed, in some species entirely wanting. They are mostly vermivorous ; some, however, are granivorous or herbivorous. In this order a number of rather dissimilar Birds have been reckoned, some of which belong decidedly to the Wader tribe, whilst others, by their general habits, are more allied to the Gallinacea. Among them are the Goldenbreasted Trumpeter, the Cariama, the Oyster-catcher, the Plovers, the Lapwing, the Coursers, the Dotterel, and the Bustard.

The Golden-breasted Trumpeter (Psophia crepitans) is a noble bird,

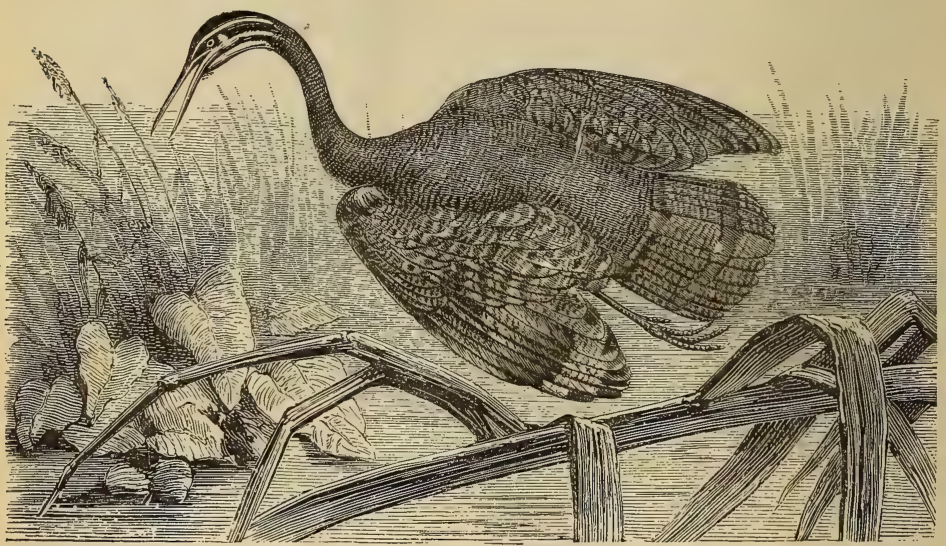

Fig. $\mathbf{1 3}_{3} 6 .-$ Sun Bittern.

covered with short glossy feathers on the head and neck, which reflect numerous golden tints, grey on the back, and black on the wings; its body is about the size of an ordinary domestic fowl, but stands much higher on its limbs. It is very easily domesticated, and evinces as great attachment to its favourites as it does antipathy to dogs and cats. It accompanies sheep to their feeding-grounds, and is even said to drive them and watch over their safety. Being able to run with great velocity, it appears in cases of danger to trust more to its legs than wings. It is a native of South America.

The Cariama (Cariama iristata, Fig. I37) has many of the same habits as the previous bird. In size it is a little larger, and is possessed of a crest whicin remains always erect. The wings are a 
darker brown than the back, which is traversed by numerous light pencillings, interspersed by diminutive jet-coloured spots. Its eyes are remarkable for their look of intelligence and vivacity. They are most easily tamed, and appear to possess a great antipathy to strife,

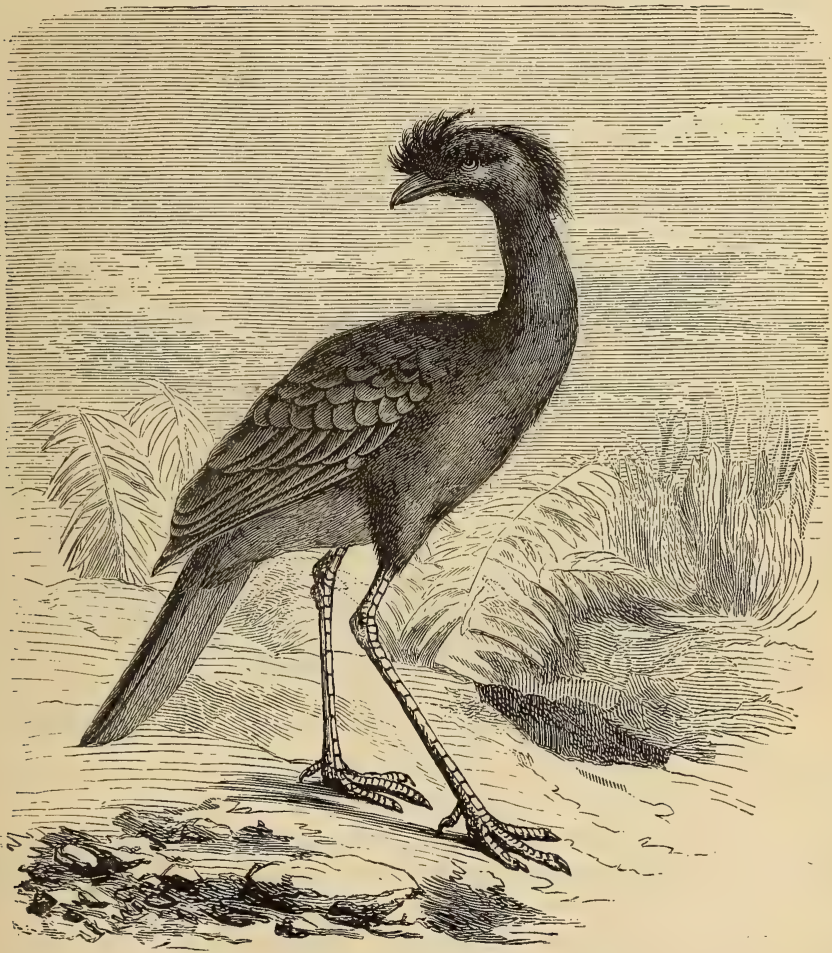

Fig. I37.-Cariama.

for it will at once separate any of the poultry who, from jealousy or - other causes, quarrel with each other. Its nest is generally upon a low bush, very rudely constructed, in which they deposit two eggs, which are pure white.

The Oyster-catchers (Hamatopus) are characterised by a long; pointed, and powerful bill, which they use like a pair of pincers for 
opening oysters, mussels, and other shell-fish left on the shore by the receding tide. Few things are more interesting than to see them hovering over the retiring water, alternately advancing and retreating with the waves. As their toes are united at the base by a web or membrane, they possess the power of resting on the water, although they do not actually swim. This they make use of by allowing themselves every now and then to be carried to some distance from the shore by the receding waves. They fly well, and can run with the greatest ease. Numerous flocks of them are found on almost every sea-coast on the globe, making the neighbourhood re-echo with their shrill cries.

In the breeding season they pair off; the female birds lay from

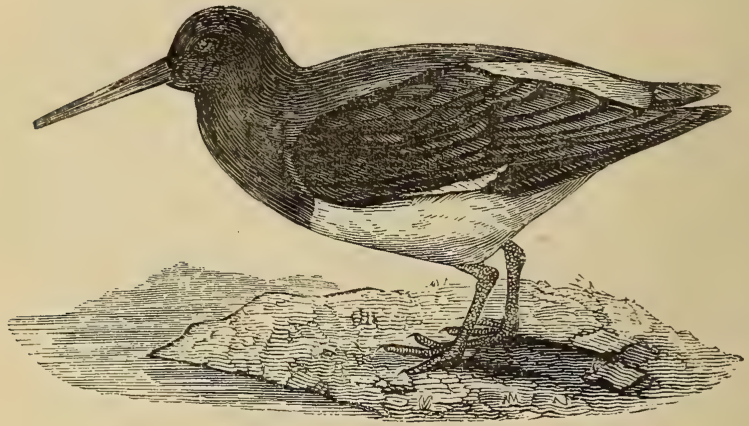

Fig. 138.-Common Oyster-catçer.

two to four eggs, either in holes carelessly scratched out on the strand, in clefts of the rocks, or even sometimes in meadows.

They assemble in considerable flocks for the purpose of migration, -if that term may be applied to the short journeys which they annually undertake.

There are three or four species of this family, only one of which, our Common Oyster-catcher (Hamatopus ostralegus, Fig. 138), is a native of Europe. The plumage of the latter is white and black, which, joined to its noisy habits, has obtained for it the nickname of Sea Magpie. Its bill and feet are of a beautiful red colour; hence the name of Hamatopus (feet the colour of blood) was given by Linnæus to the whole genus, when the other varieties of it were yet unknown. It is found at all seasons on most of our coasts. As an article of food it is not at all desirable. 
The Cream-coloured Coursers (Cursorius Gallius, Fig. I39) have slender and pointed bills, slightly bent at the end; long tarsi; no back toe ; wings much pointed ; its plumage is of a dove colour, and it is about eighteen inches in height. As its name implies, it runs with surprising rapidity. It is a native of Asia and the north of Africa, and only casually makes its appearance in Europe. Nothing is known of its habits.

The Lapwings (Vanellus) have the bill enlarged on the upper side, two-thirds of its length being filled up by the nasal channels; its

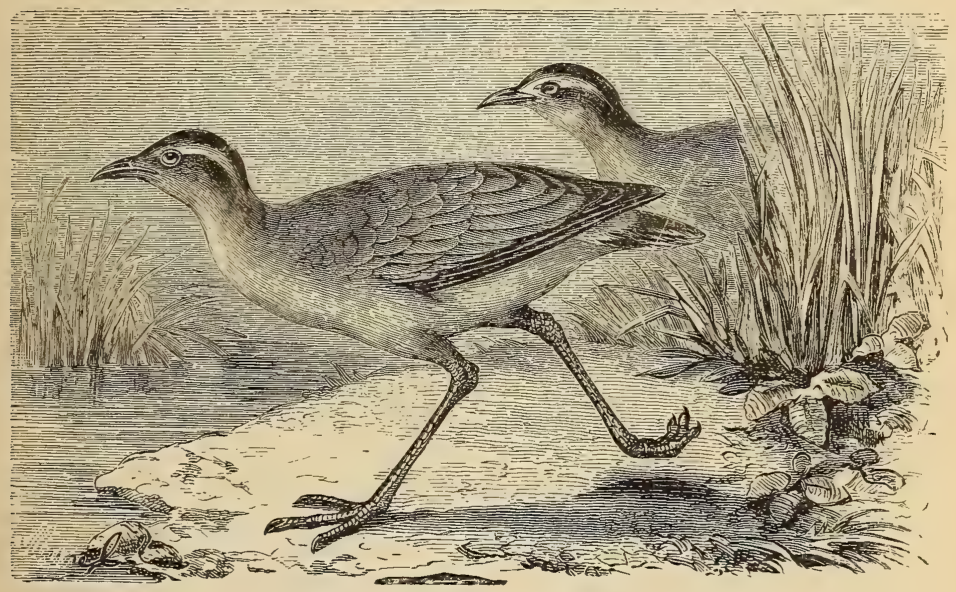

Fig. I39.-Cream-coloured Coursers.

back toe is excessively short, and wings pointed. When flying, they make a noise which is not unlike that of corn falling back on the winnowing-fan; hence their French name vanneau.

These Birds are essentially migratory, and come down from the high northern latitudes in large flocks in the beg inning of autumn, again returning thither in spring. They frequent marshes and the margins of lakes; in fact, all moist soft districts which abound in earth-worms, insects, slugs, \&c. They may often be seen settling down on fields recently ploughed, if they can there find an ample supply of worms. They are in the habit of employing a rather ingenious process to make their victims emerge from the earth. They strike the ground with their feet, and thus give the surface a slight 
s'rock, which the worm is tempted to attribute to the proximity of a mole; and consequently it hastens to the surface to escape its underground enemy, when it is immediately snapped up by the bird.

The Lapwing is a model of cleanliness. After it has been feeding on the ground for two or three hours, it washes its bill and feet; it repeats these ablutions several times in the day. In this respect the most rigid Mahommedan could scarcely find fault with it.

Lapwings live together in communities, except in the breeding season, when they separate into pairs, to devote themselves to hatching and rearing their young. The female lays three or four eggs in the most simple nest that can be imagined, placed in an exposed position on any rising ground in the marshes. These eggs are, it is said, of an exquisite flavour, and in some countries, especially Holland, a large trade is done in them.

The flesh of the Lapwing is only good eating during certain months of the year. About All Saints' Day these birds acquire their finest condition, when they are in great demand in some parts of France. In the spring they are very indifferent as food, easily explaining why the Church has allowed them to be eaten during Lent, for at that period assuredly no food could be more maigre. There is an old saying which celebrates and also exaggerates the culinary virtues of the Lapwing and its brother bird the Plover: "He who has never eaten either the plover or the lapwing does not know what game is."

The Lapwing might be ranked amongst the most useful auxiliaries of man; it destroys a prodigious quantity of worms, caterpillars, and noxious insects. After hearing this the reader might perhaps imagine that this bird has found aid and protection from mankind. Nothing of the sort; it is killed wherever and as often as possible; besides this, a limit upon its multiplication is set by stealing its eggs. We do not seem to perceive that this joyous, lively, and graceful bird longs to conclude a treaty of friendship with mankind. When will man make up his mind to understand his true interests?

There are in Europe two species of this genus, the Lapwing and the Swiss Lapwing or Squatarole.

The Lapwing (Vanellus cristatus, Fig. I40) is about the size of a pigeon; its belly is white, and its back black, with a metallic lustre. It is furnished with a crest, which coquettishly adorns the back of its head. It is tolerably abundant in France, but seems more especially partial to Holland. The Swiss Lapwing is distinguished from the last by a lighter-coloured plumage, and by the absence of the crest, it is much more rare than the former. 
The Plovers (Charadrius) have a bill closely resembling that of the Lapwing, but differ from the latter by having a back toe, which is absent altogether in the Plovers; they are, however, closely connected. Like the Lapwing, they frequent low-laying marshy lands in numerous flocks, feeding on worms and insects. They are also remarkable for the attention they pay to keeping their plumage unsoiled. Between this family and the last described exists such good

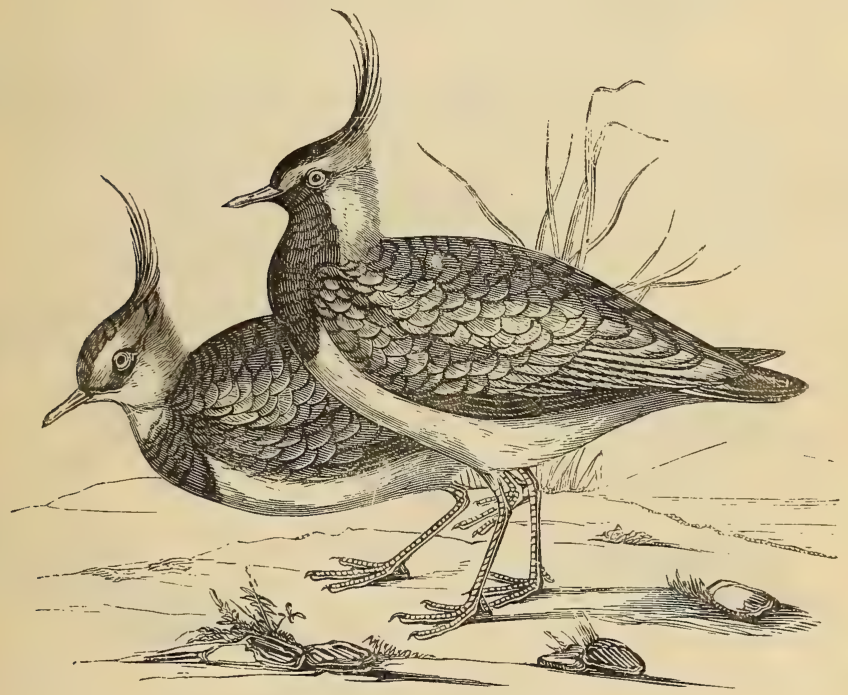

Fig. I40.-Lapwing.

feeling that they often are found teeding and even migrating together. But they do not follow out their resemblance to the Lapwings so far as to imitate them in behaving as good fathers of families, for they understand life in quite another fashion; fidelity in love is not a virtue they believe in, thus they practise polygamy.

One might well fancy that a bird of such low moraiity would not be easily affected by the misfortunes of its fellows, and that it would be endowed with no feelings but those of utter selfishness. But nothing of the sort. If you wound a Plover in company with others, the whole flock will come back to render the disabled one all the 
help they can; so if you are not a novice in field sports, you will find no great difficulty in profiting by this circumstance and so filling your game-bag.

The Plover migrates from the north of Europe to Africa, and vice vers $\hat{a}$; it thus visits France twice a year, in spring and autumn. Their appearance at these usually rainy seasons is doubtless the reason that they have obtained the generic name Pluvialis. The principal species are-the Great Plover, the Kentish Plover, the Golden Plover, the Dotterel, and the Pluvian.

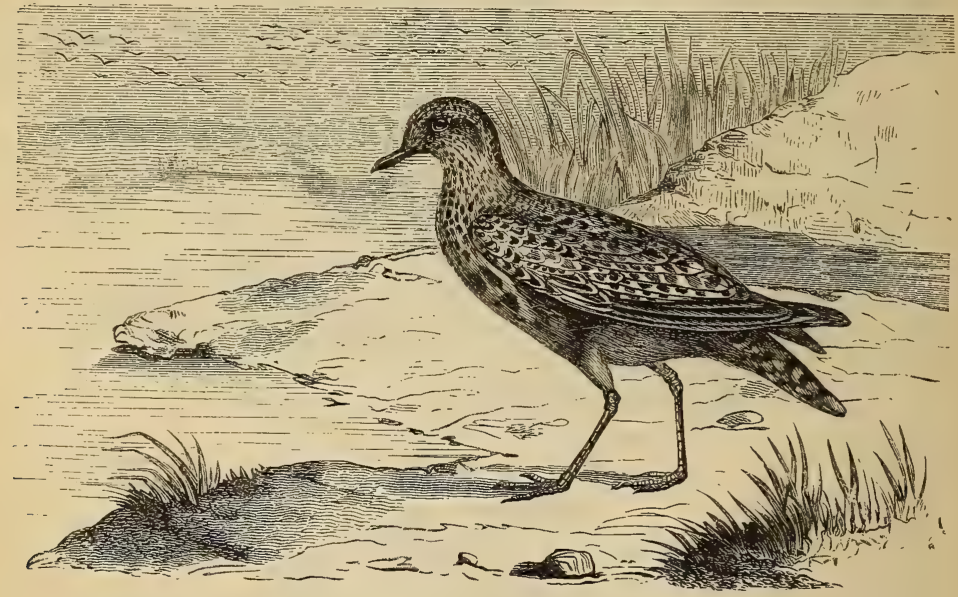

Fig. I41.-Golden Plover.

The Great Plover (Edicnemus crepitans) is about the size of a Dove ; it is very uncommon, very active, and very shy. The only chance of shooting it is in the evening, at the moment when it comes to wash itself on the edges of lakes and rivers. Its flesh is not much valued.

The Kentish Plover (Charadris cantianus) is thus named on account of its collar being divided into two parts ; it is considerably less than the last-named bird, and is found in Europe and Asia.

The Golden Plover (Charadrius pluvialis, Fig. I4I) is nearly as large as a Woodcock; the ground of its plumage is of a yellow colour, speckled over with brown spots. In winter it is always numerously 
represented in our markets: this is occasioned by the ease with which it can be either shot or netted.

The Dotterel is a little larger than a Blackbird. It visits us in March and September, and numerous flocks of these birds frequent the vast plains of France. This is the bird which seems to persist in sacrificing itself to the sportsman's gun when its companion has fallen a victim before the murderous weapon. It also shows the simplicity of believing that drunken people must be animated with the kindest feelings towards it; so much so, that it is only requisite to exhibit the outward signs of bacchanalian excitement, and the birds will be filled with a sense of false security, so that you may approach within a few yards of them.

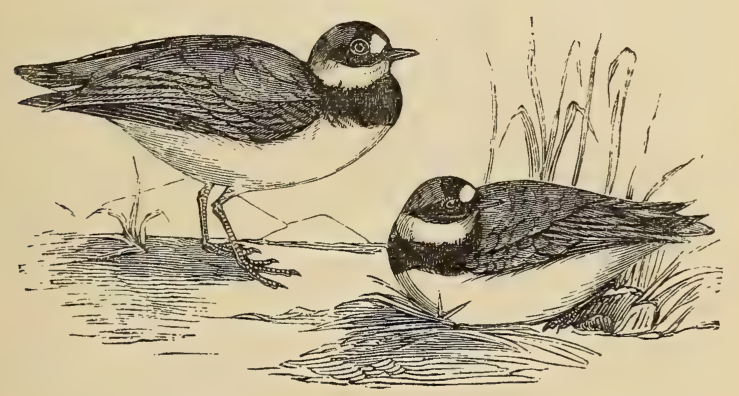

Fig. I42,-Common Dotterel.

The Dotterel has produced the reputation for the patte de Chartres : the bird's personal experience should long ago have convinced it how heavy the burden of renown sometimes proves. They have, in fact, been so much sought after, that they have been almost annihilated.

The Ringed Dotterel (Charadrius hiaticula) is about half the size of a Blackbird. It is distinguished by its black collar, and also by its extraordinarily brilliant and gold-coloured eyes. In former days this bird had the credit of being able to cure the jaundice. All that was necessary was for the sick person to look fixedly at the bird's eyes, with a firm faith in the success of the experiment; under these conditions the bird was obliging enough to relieve him of his malady. This superstitious idea has departed to join all the rest of the medical opinions of the Middle Ages.

The Common Dotterel (Charadrius morinellus, Fig. 142) much 
resembles the former bird in every respect except the position of the markings on its plumage.

The Pluvian may be considered as belonging to the Plovers, as the difference between them is insignificant. We wish to mention it on account of its curious habits, to which we previously called attention when speaking of Reptiles. This Bird is a native of Egypt and Senegal, and is on the most friendly terms with the "Crocodiles, a circumstance deserving to force itself on the meditations of philosophers. The Pluvian does the Crocodile the service of picking his teeth. This assistance rendered by the little bird to the terrible reptile of the Nile is, to say the least, interesting, and has somewhat the appearance of having inspired $\mathrm{La}$ Fontaine with his fable of the "Lion and the Mouse."

The Bustards (Otis) are allied to the Gallinacea by their short back, their thickset shape, and the general character of their habits ; but their elongated tarsi, and their legs partly bare, give them a position among the Gralle. They have short front toes, and no back ones ; they run with extreme rapidity, assisted by their wings. Their flight is heavy and awkward. They frequent dry and open plains, and make their nests on the ground. Their food consists of worms, insects, grasses, and even seeds; and they move about in large flocks. The male birds being less numerous than the females, they are generally polygamous. These birds are shy and timid, and their flesh constitutes an excellent article of food.

There are three species of the Bustard-the Great Bustard, the Little Bustard, and the Houbara Bustard.

The Great Bustard (Otis tarda) is the largest of all European birds; its weight sometimes attains to thirty-six pounds. It is yellow on the back, with black streaks, and in front it is a greyish white. The head of the male is ornamented on both sides with curled feathers, which look something like moustaches, and have obtained for it the name of the Bearded Bustard. It flies with great difficulty, and is reluctant to take wing except in cases of absolute necessity. Its eggs, two or three in number, are laid in the corn or grass; the nest is nothing more than a hole scratched out in the earth, and with scarcely any lining.

The Great Bustard was formerly very common in Champagne, which is now the only province in France in which this bird is to be met, in fact it is now so scarce that we might almost say that it has completely disappeared from French soil. Innumerable troops of them are to be seen in the steppes of Tartary and Southern Russia.

The Little Bustard (Otis tetrax, Fig. I43) is about the size of the 
Curlew, for which at a distance it might be mistaken. - It is a very handsome bird when in full plumage ; around the neck runs a wide collar of black, severed by a narrow and broad white marking. They are abundant in Morocco and in the east of Europe. Their habits are those of its predecessor.

There are other varieties of Bustard, the most remarkable of which is the Houbara, or Ruffed Bustard (Otis Denhami), distinguished by its curious plumed ruffles.

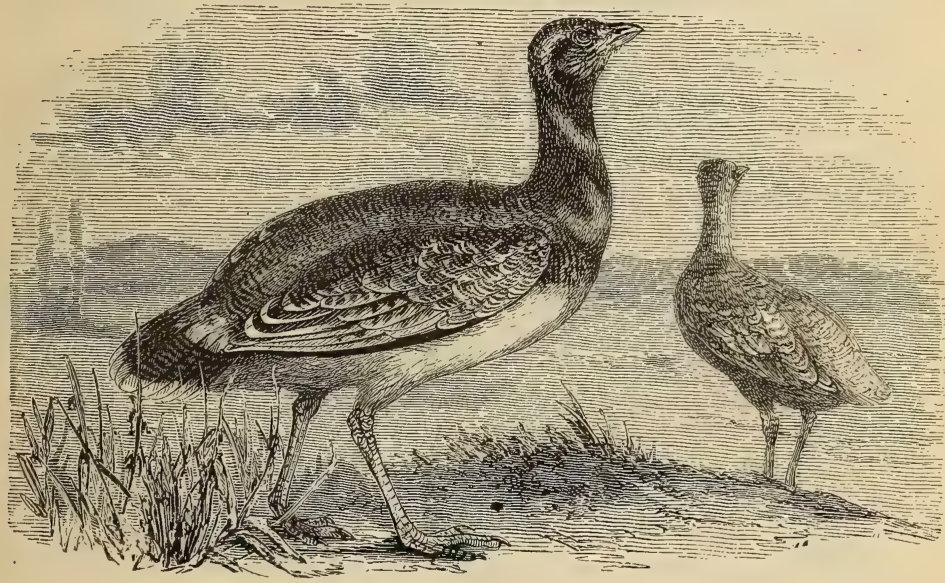

Fig. 143--Little Bustard.

\section{Brevipennes (ShORT-Winged BiRds).}

The Birds belonging to this family are distinguished from the rest of the Gralle by such decisive characteristics, that some naturalists have proposed to include them in a separate group, to be called Cursores, or runners; an arrangement which has much in its favour, although the simpler arrangement of Cuvier best suits our purpose. In certain anatomical points, and especially in their habits, the Brevipennes differ greatly from the other Grallatores. They have wings, it is true, but they are so slightly developed that they are entirely unfit for purposes of flight, and are only useful in accelerating the speed of their limbs. On the other hand, their legs are long and powerful, 
and capable of immense muscular effort, thus enabling them to run with extraordinary fleetness.

The deduction to be drawn from these facts is, that the Brevipennes are essentially land birds. This limitation of their habitat necessitated certain modifications in the sternum, which, instead of a prominent edge of bone in the centre, as in other birds, only presents one uniform breast-plate. Again, most of the Brevipennes are birds of large size, and, in certain circumstances, manifest remarkable vigour.

This group comprehends the Ostrich, Emu, Rhea, Cassowary, and the Apteryx.

The head of the Ostrich (Struthio camelus, Plate XI.) is naked and callous, with a short bill, much depressed and rounded at the point; its legs are half riaked, muscular, and fleshy; the tarsi are long and rough, terminating in two toes pointing forward, one of which is shorter than the other and has no claw; the wings are very short, and formed of soft and flexible feathers; the tail taking the form of a plume.

There is but one species of the Ostrich; it is sparsely diffused over the interior of Africa, and is rarely found in Asia except perhaps, in Arabia. It is the largest member of the Grallatores, generally measuring six feet in height, and occasionally attaining nine feet; its weight varies from twenty to a hundred pounds.

The Ostrich has been known from the most remote antiquity. It is spoken of in the sacred writings, for Moses forbade the Hebrews to eat of its flesh, as being "unclean food." The Romans, however, far from sharing the views of the Jewish legislator, considered it a great culinary luxury. In the days of the Emperors they were consumed in considerable numbers; and we read that the luxurious Heliogabalus carried his magnificence so far as to cause a dish composed of the brains of 600 ostriches to be served at a feast: this must have cost an almost incalculable sum. In former days it was a favourite dish with the tribes of Northern Africa. At the present date the Arabs content themselves with using its fat as an outward application in certain diseases, especially rheumatic affections; and they derive from it, as they say, very beneficial effects.

The natives of Africa call the Ostrich " the camel of the desert," just as the Latins denominated it Struthio camelus. There is, in fact, some likeness between them. This resemblance consists in the length of the neck and legs, in the form of the toes, and in the callosities which are found on the lower stomach of both. In some 


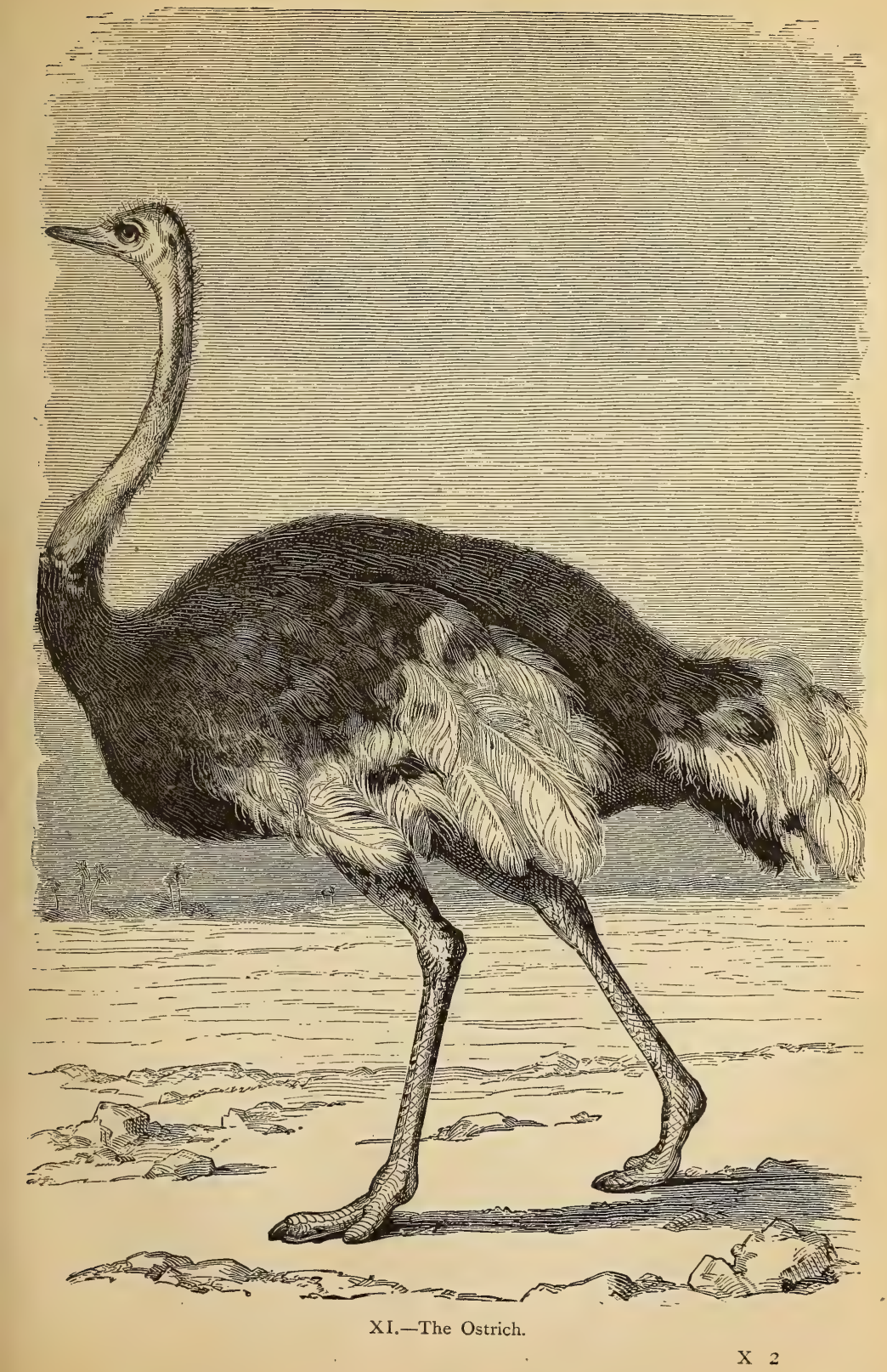



of their habits they also resemble each other; the Ostrich lies down in the same way as the camel, by first bending the knee, then leaning forward on the fleshy part of the sternum, and letting its hinder quarters sink down last of all.

An entire volume might be filled with fables recorded of the Ostrich. According to the Arabs, it is the progeny of a bird and a camel. One Arabian author states that it is aquatic : another maintains that it never drinks; some that its principal food consists of stones and bits of iron. Buffon himself asserts that it might swallow red-hot iron, provided the quantity was small. Pliny and (following him) Pierre Belon, the naturalist of the Renaissance, state that when the Ostrich is pursued it fancies itself safe if it can place its head behind a tree, believing that, as it cannot see its pursuers, they cannot see it.

That the Ostrich is extremely voracious is certain. Although the senses of sight and hearing are so highly developed that it is said to distinguish objects six miles off, and the slightest sounds excite its ear, the senses of taste and smell are very imperfect. This is the explanation given for its readiness to swallow unedible substances. In a wild state it takes into its stomach large pebbles, to increase its digestive powers ; in captivity it gorges bits of woor and metal, pieces of glass, plaster, and chalk, probably with the same object. The pieces of iron found in the body of one dissected by Cuvier "were not only worn away," says the great naturalist, "as they would likely be by trituration against other hard bodies, but they had been considerably reduced by some digestive juice, and presented all the evidence of actual corrosion."

Herbage, insects, molluscs, small reptiles, and even small mammalia, are the principal food of the wild Ostrich; when it is in a state of domesticity even young chickens are frequently devoured by it. It is capable of enduring hunger and thirst for many days - about the most useful faculty it could possess in the arid and burning deserts which it inhabits-but it is quite a mistake to suppose it never drinks, for it will travel immense distances in search of water when it has suffered a long deprivation, and will then drink with evident pleasure.

The muscular power of the Ostrich is truly surprising. If matured it can carry a man on its back; and is readily trained to be mounted like a horse, and to bear a burden. The tyrant Firmius, who reigned in Egypt in the third century, was drawn about by a team of ostriches : even now the negroes frequently use it for riding.

When it first feels the weight of its rider, the Ostrich starts at a 
slow trot; it however soon gets more animated, and stretching out its wings, takes to running with such rapidity that it seems scarcely to touch the ground. To the wild animals which range the desert it offers a successful resistance by kicking, the force of which is so great that a blow in the chest is sufficient to cause death. M. Edouard Verreaux states that he has seen a negro killed by such a blow.

Man succeeds in capturing the Ostrich only by stratagem. The Arab on his swiftest courser would fail to get near it if he did not by his intelligence supply the deficiency in his physical powers. "The legs of an ostrich running at full speed," says Dr. Livingstone, "can no more be seen than the spokes in the wheel of a vehicle drawn at a gallop." According to the same author, the Ostrich can run about thirty miles in an hour-a speed and endurance much surpassing that of the swiftest horse.

The Arabs, well acquainted with these facts, follow them for a day or two at a distance, without pressing too closely, yet sufficiently near to prevent them taking food. When they have thus starved and wearied the birds, they pursue them at full speed, taking advantage of the fact, which observation has taught them, that the ostrich never runs in a straight line, but describes a curve of greater or less extent. Availing themselves of this habit, the horsemen follow the chord of this arc, and, repeating the stratagem several times, they gradually get within reach, when, making a final dash, they rush impetuously on the harassed birds, and beat them down with their clubs, avoiding as much as possible shedding blood, as this depreciates the value of the feathers, which are the chief inducement for their pursuit.

Some tribes attain their object by a rather singular artifice. The hunter covers himself with an ostrich's skin, passing his arm up the neck of the bird so as to render the movements more natural. By the aid of this disguise, if skilfully managed, ostriches can be appro: ched sufficiently near to kill them.

The Arabs also hunt the Ostrich with dogs, which pursue it until it is completely worn out. In the breeding season, having sought and found out where the Ostriches lay their eggs, another artifice is to dig a hole within gunshot of the spot, in which a man, armed with a gun, can hide himself. The concealed enemy easily kills the male and female birds in turn, as they sit on their nest. Lastly, to lie in wait for them close by water, and shoot them when they come to quench their thirst, is often successful.

The Ostrich, which is an eminently sociable bird, may sometimes be seen in flocks of 200 or 300 , mixed up with droves of zebras, quaggas, \&c. They pair about the end of autumn. 
The nest of the Ostrich is more than three feet in diameter ; it is only a hole dug in the sand, and surrounded by a kind of rampart composed of the débris; a trench is scratched round it outside to drain off the water. Each hen bird lays from fifteen to twenty eggs, according to circumstances. The eggs weigh from two to three pounds, and are each of them equal in contents to about twenty-five hen eggs. They are of a tolerable flavour, and often a very seasonable meal to travellers, one of them being more than sufficient for the breakfast of two or three persons.

Incubation usually takes six weeks, and is shared by both male and female birds; several of the latter often lay in the same nest, and live together on the best terms, under the control of one male. Levaillant remarked four females taking turns in sitting on thirtyeight eggs laid in the same nest; they sat during the night only, the burning heat of the sun during the day being sufficient to maintain the necessary degree of warmth. $\mathrm{He}$ also observed that a certain number of the eggs were not sat upon, but were put aside to serve as nourishment for the young ones after they were hatched.

It is a strange circumstance that the cry of the Ostrich so much resembles that of the lion when in search of prey that they are often confused. Dr. Livingstone says that with all his experience he has been frequently deceived, and that only the quick ear of a native can detect the difference.

Want of affection for her progeny was long such a subject of reproach to the Ostrich that she was looked upon as the most striking example of the hard-hearted mother. Thus, the Hebrews accepted the Ostrich as the symbol of insensibility, because she left her eggs upon the sand, without troubling herself, as Job says, about the dangers to which they might be exposed. Jeremiah, too, laments over her that she is devoid of parental affection. All these accusations are quite unfounded; the Ostrich does not abandon her eggs, neither does she desert her young, although they are well covered at their birth with a thick warm down, and can from the first run about and provide for their own wants. On the contrary, she keeps them near her until they are almost full-grown, and defends them against every enemy. Mr. Cumming with his companions came suddenly one day on a dozen young ostriches no larger than full-grown grouse. "The mother," he says, "tried all she could to deceive us, just like a wild duck; first she ran away, extending her wings; then she threw herself on the ground as if she was wounded; whilst the male bird cunningly conducted the young ones in an opposite direction."

Livingstone on several occasions met with broods of young 
Ostriches led by an old male, which pretended to be lame, in order to monopolise the attention of the sportsmen.

Both the male and female birds afford one another mutual assistance, as is proved by the following fact, which was related in a report addressed to the Société d'Acclimatation:- "Si-DjelloulBen-Hamza and his brother, Si-Mohammed-Ben-Hamza, were one day hunting ostriches, and came upon the tracks of a family led by a male and two females. Si-Mohammed arrived first in sight of the birds, and firing, wounded one of the females. The male bird at once darted at him, and struck with its feet at the breast of his horse, which from fright threw its rider and ran away. The ostrich then turned upon Si-Mohammed, kicked him repeatedly, and did not quit him until he had lost all consciousness and his brother Si-Djelloul came to his assistance."

All these facts abundantly prove that the Ostrich is not so unnatural a parent as it has been thought, and at the same time give a complete denial to the accusation of stupidity which has also been made against it.

In spite of its great strength-perhaps even on account of itthe Ostrich, when unmolested, is the most peaceable creature in the world ; and owing to its inoffensive nature, it readily becomes domesticated. If captured young, it can be tamed in a very short time. General Daumas asserts that they play with the children, and frolic with the horses and dogs, \&c. In the district of Sennaar they are reared as we rear fowls; they are left to wander about as they choose, and one of them attempting to escape is a thing quite unheard of. They accompany the herds to pasture, returning to their homes at the house for meals. Kindness and caresses are sufficient to attach them to any one; but care must be taken never to strike them. They have but one fault, which arises from their voracitythey are dreadful thieves, and devour everything they can steal. The Arabs, knowing this, always look out when they are counting their money, otherwise the ostriches might snatch some of the coin.

In all ages the feathers of the Ostrich have been the object of considerable trade; the birds are hunted, and reared in a domestic state, not so much for their flesh, grease, or eggs, as for these plumes. Each bird produces about half a pound of white feathers and three pounds of black. These delicate, wavy, and flexible ornaments, so sought after by the fair sex, are found on the Ostrich's tail and wings; they have been used from time immemorial for the adornment both of man and woman. The Roman soldiers decked their helmets with them, and the Janissaries their turbans, 
when they had distinguished themselves by any glorious deed. At the present day there is a large demand for them. The plumes of the male bird are more highly valued than those of the female; and all are superior when plucked from the living bird.

Several Libyan nations in former days used the skin of the Ostrich for a cuirass, and even at the present time some Arabian tribes apply it to the same purpose. The shells of ostrich eggs, which are very hard, are also utilised; they are made into beautiful cups, which much resemble vases of ivory. The Africans annually destroy a large number of these birds; yet their race does not appear to diminish. It is a most useful creature, and too much encouragement cannot be given to the trials which have been made in Algeria and elsewhere to rear the Ostrich in flocks on an extensive scale.

The Rhea or American Ostrich (Rhea americana, Fig. I44), bears the greatest resemblance to the Ostrich, of which it is the representative in the New World; but it is only about half the size of the African bird, and has three toes in front instead of two. The colour of its plumage is a uniform grey.

This Bird (called by the Brazilians Nhandu-Guaçu) inhabits the Pampas of South America, the coolest valleys in Brazil, Chili, Peru, and Magellan's Land. There they may be seen wandering over the open plains in flocks of about thirty, in company with herds of oxen, horses, and sheep. They browse on the grass like cattle, at the same time searching for various seeds. They run nearly as swiftly as the Ostrich, so are well able, by speed, to escape the pursuit of their enemies. If a river interrupts their course, they do not hesitate to plunge into it, as they are excellent swimmers; indeed, so fond are they of water that they take pleasure in splashing and bathing in it.

The Rhea lays its eggs and incubates them in the same manner as the Ostrich. They are birds of a gentle nature, and are tamed with the greatest ease, becoming very familiar in the house, visiting the various apartments, wandering about the streets, and even into the country; but they always return to their homes before sunset.

The flesh of the adult is by no means agreeable; that of the young, on the contrary, is tender and sweet. Its skin, when properly dressed, is used for bags, purses, \&c., and their feathers serve for plumes and light dusting-brooms. We owe a knowledge of a second species of Rhea to Mr. Darwin, who has given a figure and ample descriptions of the bird and its habits in "The Voyage of the Beagle;" it has been named in consequence Rhea Darwinii. There 
is every reason for thinking that these Birds might be successfully acclimated in Europe.

The Cassowarys (Casuarius emu, Fig. I45) form a genus of birds allied to the ostrich, although they differ from it in some particulars

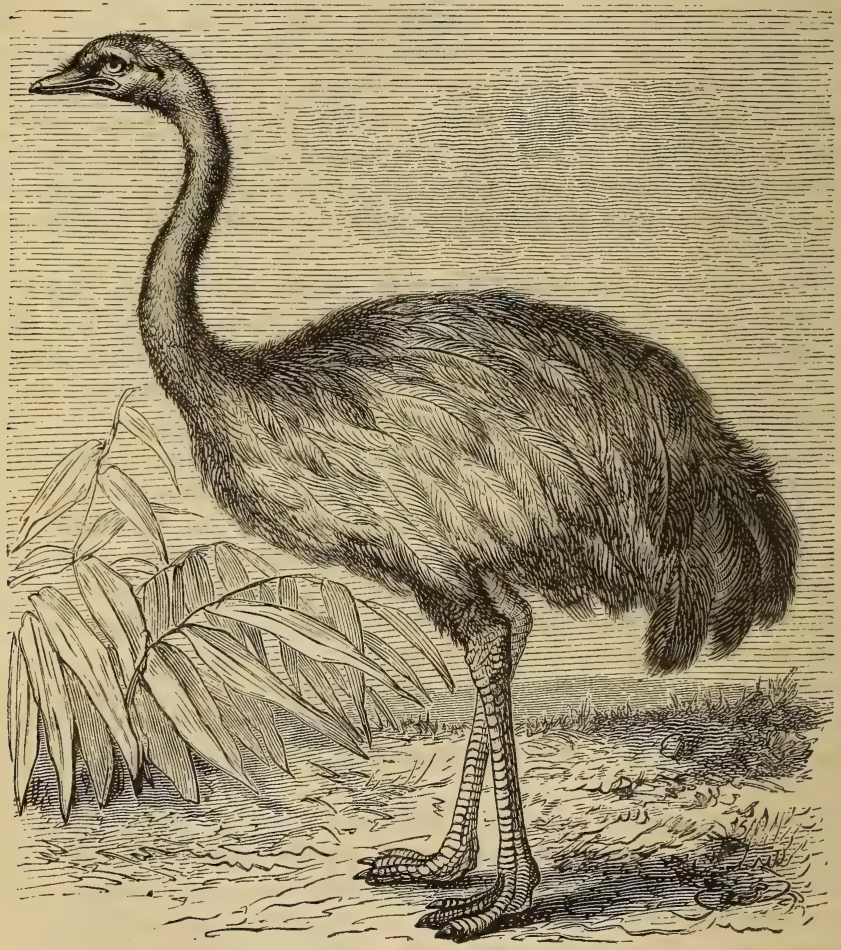

Fig. 144.-The Rhea.

- their shape is not so elegant, and their wings are even less adapted for flight ; for so short are they, that they are pefectly useless, even to assist in running. Their long blackish feathers are almost devoid of side fringes, which gives their plumage a resemblance to coarse hair; their feet are provided with three toes. This Bird was called the 
Emu by early Portuguese navigators. It is the Struthio casuarius of Linnæus, and the Casuarius galeatus of Vieillot.

The Cassowary has a kind of helmet on its head, produced by an enlargement of the bone of the skull, and covered with a horny substance. It is a massively-made bird, in size between the Ostrich and the Rhea, and is a native of the Malaccas. It is a stupid, quarrel-

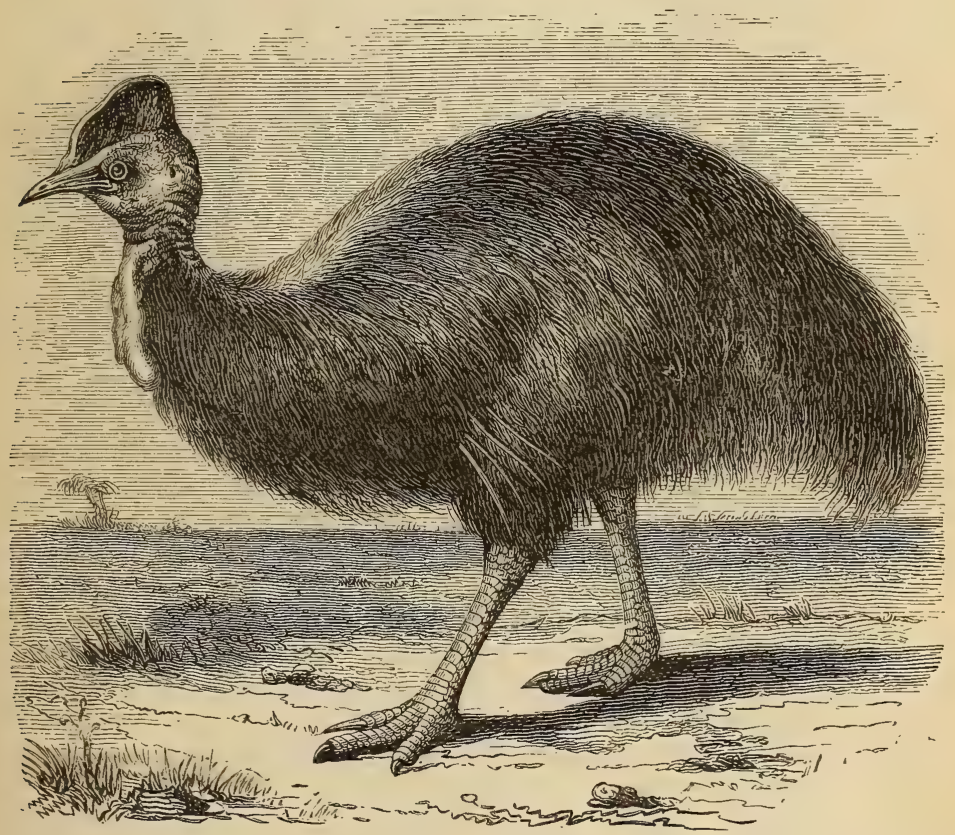

Fig. 145.-Cassowary.

some, and gluttonous creature, feeding on plants, fruits, and sometimes small animals. Possessed of considerable strength, and being wild and fierce in nature, its anger cannot be provoked without danger; for, although its wings are short, each is furnished with five pointed spines, the middle one of which is sometimes a foot long, and which are employed with adroitness as weapons of defence. Its habitual cry consists of a low grumbling, which, when the bird 
is angry, is changed into a sonorous humming noise, not unlike the sound of carriage-wheels or of distant thunder. The first bird of this species which was seen in Europe was brought from Java by the Dutch in 1597 .

The menagerie of the Museum of Natural History at Paris was in possession of a Cassowary which devoured everything that was given it-bread, fruit, vegetables, \&c., and drank seven or eight pints of water daily. In the London and the Paris Zoological Gardens there are generally several to be seen.

The Cassowary runs very swiftly, and in a way quite peculiar, for it kicks up its heels at every step. They live in pairs; and during the breeding season the male bird shows a degree of violence which renders him very formidable. The female lays three or four eggs in the dust, and sits on them alone for about a month. The young birds, when first hatched, are covered with a light down, and are without the helmet, which it acquires as it approaches maturity.

The wild nature of these birds renders them but little fitted for domestication : this is a fact not much to be deplored, as their flesh is of an unpleasant flavour, and in no other respect than as food could they be of any service to us.

The Emu (Dromains australis, Plate XII.) is distinguished from the last-named bird by its larger size, and also by the absence of the helmet, the caruncles, and the pointed spines on the wings. It inhabits the forest country of Central Australia. Being very powerful, it offers a stout resistance to dogs, with which it is hunted. It can be tamed much more easily than the last-mentioned bird, and manifests some attachment to its master. It is an excellent and useful acquisition to man, for its flesh, being of an agreeable flavour, is much esteemed. The few specimens which have been brought to Europe seem to have been readily acclimated, for they have bred afterwards.

Kiwi-kiwi or Apteryx (Apteryx australis, Fig. I46), so called from the Greek å $\pi \tau \epsilon \rho^{\prime} \nu$, "wingless," is a singular bird, bearing but little resemblance to the other members of the class. It is no larger than a domestic fowl, and combines the bill of the Woodcock with the feet of the Gallinaceous tribe. The almost complete absence of wings renders it a most remarkable creature.

The plumage of the Apteryx is a chestnut brown; it has no tail, and its mere stumps of wings are provided with strong and curved claws. It is a native of New Zealand, and keeps in the marshes, where it feeds on worms and grubs. Being nocturnal, it is seldom seen. In spite of its short legs it runs very fast, and, if overtaken, 


does not yield without an effort, using its feet, which are armed with long and sharp claws, as weapons of defence. It builds a very rough nest among the roots of marsh-growing shrubs, and lays a single egg, excessively large in proportion to the size of the producer. The natives call the bird Kizwi. They used at one time to hunt them very perseveringly, as much for their flesh as for their feathers, which they used in making mats. Now they have renounced this work,

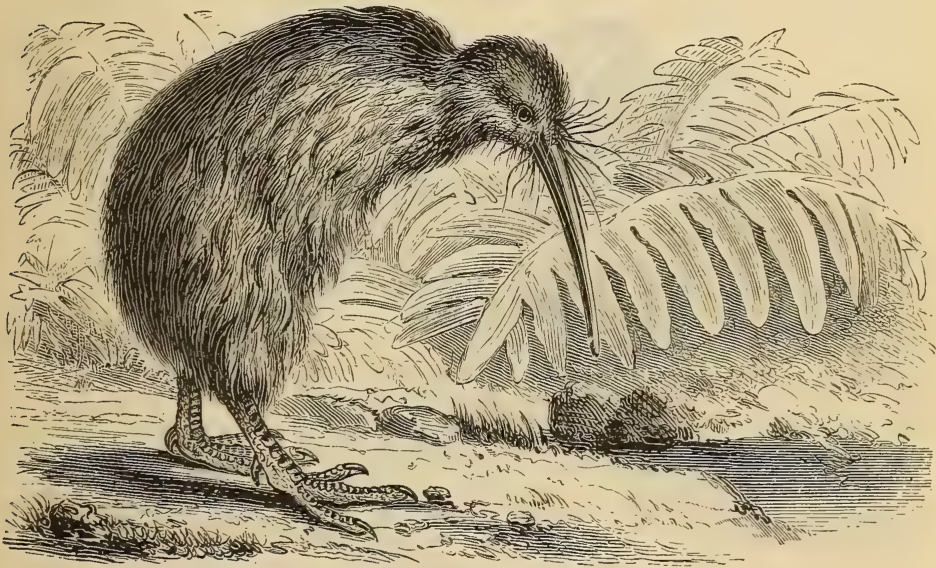

Fig. 146.-Kiwi-kiwi, or Apteryx.

the profits not compensating for the fatigue which it entailed. Day by day it is becoming more rare and difficult to procure. The Zoological Society of London has three specimens.

\section{Extinct Brevipenne.}

The order of the Brevipenna may be held to embrace some Birds which have now disappeared from the surface of the globe, but which are supposed to be contemporaneous with Man. The remains which are met with in quite modern alluvium scarcely admit of any doubt in this respect.

In the first rank of extinct birds we may place the Dodo (Didus ineptus, Fig. 147), which was indigenous to the Mauritius and the 
Isle of France, where it used to be abundant, if we may believe the testimony of the companions of Vasco de Gama, who visited there in I 497. At the end of the seventeenth century some of them still existed. Former travellers have described them; and these accounts, with skeletons and an oil painting in the British Museum, are the only information which we possess regarding them.

The Dodo was a fat and heavy bird, and weighed not less than fifty pounds. Its portly body was supported on short legs, provided

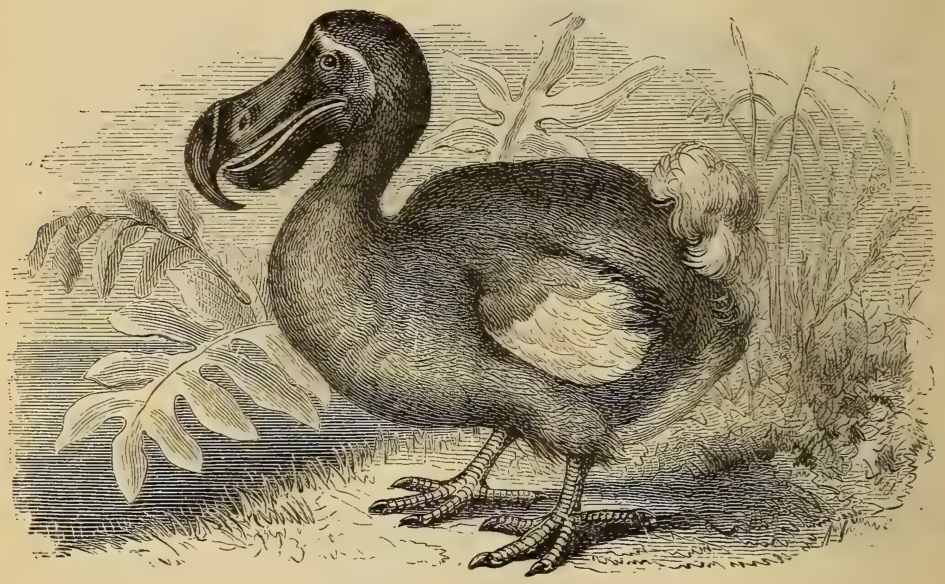

Fig. 147.-The Dodo.

with ridiculously small wings, making it equally incapable of running or flying, thus dooming the bird to rapid destruction. Lastly and principally, it had a stupid physiognomy, but little calculated to conciliate the sympathies of the observer. Its hind parts were decorated with three or four curly feathers, representing a tail, whilst in front it presented an enormous curved bill, which occupied nearly the whole of the head.

The Dodo did not even possess the merit of being useful after its death, for its flesh was disagreeable and of a bad flavour. On the whole there is not much reason to regret its extinction.

In the island of Madagascar fossil eggs and bones were found of a bird belonging to a species probably extinct, the proportions of 
which must have been truly colossal. One of these eggs was equal to at least six ostrich eggs, and its capacity more than fifteen pints. M. Isidore Geoffroy de Saint-Hilaire, who gave it the name of Epiornis, reckoned that its height could not be less than ten or twelve feet.

In 1867 , M. Joly, Professor of the Faculty of Sciences at Toulouse, published some very interesting observations on the structure and probable habits of this gigantic bird.

It cannot yet be asserted that this bird has altogether disappeared. The inhabitants of Madagascar state that, although very rare, some few representatives of it still remain. The e is an ancient tradition among this people relative to a colossal bird which could knock down an ox and then make a meal of it. This tradition, however, is deficient in anything like evidence of its truth, for an examination of the pieces of bone found proves that the Epiornis possessed neither talons to seize nor wings with which to pursue its prey ; it must, therefore, have fed chiefly upon vegetable diet.

In New Zealand also some bones have been lately brought to light, which must have belonged to a species of bird allied to the ostrich, but so superior to it in size, that it attained some thirteen feet in height. This bird has been designated the Dinornis. Some of them probably still exist in that country; at all events, its disappearance must be very recent, for the bones which were discovered still contained a large proportion of gelatine. Rumour states that a Dinornis more than thirteen feet in height was seen by two Englishmen in one of the marshy forests, but they did not venture to approach near enough to kill it. We give this tale with all due reserve, as its authenticity does not appear to be satisfactorily established. 


\section{CHAPTER V.}

\section{GALINACEOUS BIRDS.}

UNDER this name Linnæus included a large number of birds which bear considerable analogy to the Domestic Fowl, and mostly included in the Razores of Illiger.

The Gallinacex are essentially land birds, seeking their food on the surface of the soil, and frequently building their nests upon it. They delight in scratching the earth, and in rolling themselves in the dust. Walking is their habitual mode of progression, as one would at once conclude from observation of their strong legs and their short and but slightly-bent claws. Some, like the Partridge, are swift runners, having very short wings, which render their flight laboured. In this order of Birds we do not find more than two or three migratory species.

The Gallinaceæ have short arched beaks, which are generally very strong, and well adapted for crushing the husks of the seeds which, with the addition of grubs, insects, and grasses, form their principal nourishment. Their large and muscular gizzards, with thick lateral muscles, lined on the interior with a very tough coating or epithelium, are exactly fitted for digesting this kind of food. The triturating power of the Gallinaceæ is further increased by their habit of swallowing small pebbles, which facilitate the crushing of their food.

In certain species (the Domestic Fowl, Pheasant, Turkey, \&c.) the males are armed above the back toe with one or more tapering spikes (called a spur), which they use both for attack and defence. A great many of this class have their heads adorned with crests and combs of various colours. These appendages exist occasionally in the females, but with much less development than in the males.

Birds of the most brilliant plumage are to be found among the Gallinaceous tribe. The Peacock, the Argus, the Impeyan, and Common Pheasant may be said to bear the palm in splendour, and 
may worthily stand in comparison with the most gorgeous of the Passerines. This richness of colour is the characteristic of the male bird, for the females are usually of dull hues. But if the Gallinaceæ captivate the sight, they are far from affording pleasure to the ear, their voices being shrill and discordant.

Cruel, tyrannical, and quarrelsome are the characteristics of the majority of this race. They are polygamous, and the females lay a large number of eggs, which they sit upon, unassisted by the male. They are generally divided into flocks, consisting of one male, several females, and a number of young birds; but it is very rare that several families unite to live in common.

The Gallinaceæ are of all birds the most useful to man. Certain domesticated kinds stock his poultry-yard, and supply him with eggs of an exquisite flavour; nor does their utility cease here-their flesh is a popular, wholesome, and delicate food. Those known as "game birds" afford amusement to the sportsman and table delicacies for the bon vivant.

Although nearly all the Gallinaceæ were originally natives of the warm regions of Asia and America, they are now perfectly acclimated to all temperate parts of the globe.

The order of the Gallinaceæ may be divided into two great suborders, namely, the Gallinacea proper, to which the characteristics we have just enumerated specially belong; and the Columbida, which differ from them in certain details of organisation and habits, to be described hereafter.

\section{The GallinaceÆ Proper}

comprehend six families: the Tetraonida, the Perdicida, the Tinamides, the Chionida, the Megapodida, and the Phasianida.

\section{TETRAONIDE.}

The birds which compose this group are characterised as follows: tarsi completely feathered; a naked and knotty band of skin supplying the place of eyebrows; the body bulky, and the wings short. This family comprehends several species. The best known we enumerate:-The Capercaillie, Black Grouse, Cock of the Plains, Pinnated Grouse, Ruffed Grouse, Hazel Hen, Red Grouse, and Ptarmigan.

The Capercaillie (Tetrao urogallus) inhabits the pine and birch: orests of hilly northern countries. They feed upon fruits, berries: 
the buds of fir and birch trees, insects, and grubs; little, in fact, comes amiss to satisfy their appetites. Their bearing, which is proud and warlike, is supported by a robust form. Their plumage is black, spotted with white, and clouded as it were with bluish diaphanous shades. They are polygamous, and live together in families. They seek shelter in trees, both for roosting and in order to conceal themselves from their enemies.

At the first breath of spring the male birds make the woods re-echo with the loud notes with which they summon the females. For an hour every morning and evening, for over a month, this practice is continued.

The females retire into the thick brushwood to build their nests and lay their eggs; here they cevote themselves to incubation, and afterwards to rearing their offspring-cares which devolve upon them exclusively. They deposit from eight to sixteen eggs on a bed of grasses and leares roughly interwoven. The young birds run about as soon as hatched, and remain for several months with the mother, who on all occasions watches them with the tenderest solicitude.

The flesh of the Cock of the Woods is juicy, but possesses a flavour of turperitine, from the buds and leaves of the pines on which it feeds. In Scotland this species became extinct, but was restored by the Marquis of Breadalbane, who imported great numbers from Sweden. It is almost as large as a Turkey.

The Black Grouse (Tetrao tetrix, Fig. I48) is about the size of a Pheasant, and is distinguished by its tail, which in the cock is divided into two parts, composed of four lateral feathers on each side, curving outwards.

The Cock of the Plains (Tetrao artimesia), so called from its frequenting and feeding on the sage that grows in profusion on the farwestern uplands of America, is a noble bird, of handsome plumage. It is almost as large as a hen Turkey. Its numbers are rapidly diminishing.

The Pinnated Grouse (Tetrao Cupido) is a native of the prairies of the North American continent; it is the same size as the lastdescribed species, but the plumage is a light brown, occasionally ticked with white. Its call is deep and sonorous, much resembling the bellowing of a bull, and can be heard for miles in still weather. It is an excellent table bird, and affords good sport to the lovers of the gun. The Pinnated Grouse, frequently called Prairie Chicken or Hen, pair in March; they lay from twelve to fourteen eggs, and are most devoted parents. Of this species there are two stronglymarked varieties, differing in size and formation of tail. 
The Ruffed Grouse (Tetrao umbellus) is also an American bird, but differs essentially from the last mentioned in size, habits, and selection of food. The hill-sides, densely covered with evergreens or birch, are its favourite retreats; on the wing it is remarkable for its swiftness. Although not migratory, it is very erratic.

The Hazel Grouse (Bonasia curopaa, Fig. I 49) inhabits the same description of country, and has habits very similar to the last mentioned. Like them, it is suspicious and timid, and hides itself among the thick foliage of the green trees at the least appearance of danger. This bird flies awkwardly, but runs very swiftly. Its flesh,

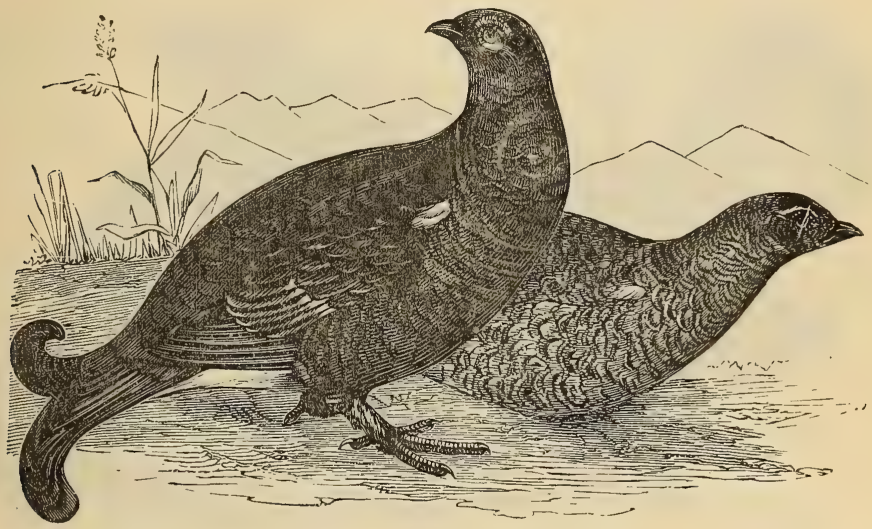

Fig. I4S.-Black Grouse.

which is both delicate and savoury, brings a high price in the market. It is not uncommon in France, being frequently met with in the departments of Vosges and Ardennes. It is about the size of a Partridge, and the prevailing colour of its plumage is a reddish brown mixed with white, or variegated with grey and brown: the male has a large black patch under the throat.

The Ptarmigans have feet much like those of a Hare, and thence is derived the name Lrgopus, which signifies " hare-foot" ( $\lambda$ ayos, hare ;

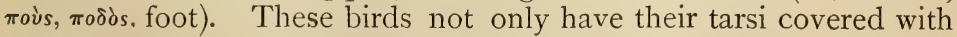
feathers, but also their toes and the soles of their feet.

The icy regions of both hemispheres, and the summits of lofty mountains, are their habitat. The snow is their favourite resting- 
place ; they delight in rolling in it, and turning it over in search of food, or forming holes in its surface, in which they pass the night, or shelter from the storm.

The colour of Ptarmigans is perfectly suited to the northern solitudes. Their winter costume is of a brilliant white, save one line of black on the head, and some tail-feathers of the same colour. In the summer, when the snow has disappeared under the scorching rays of the sun, they change their plumage, and become habited in

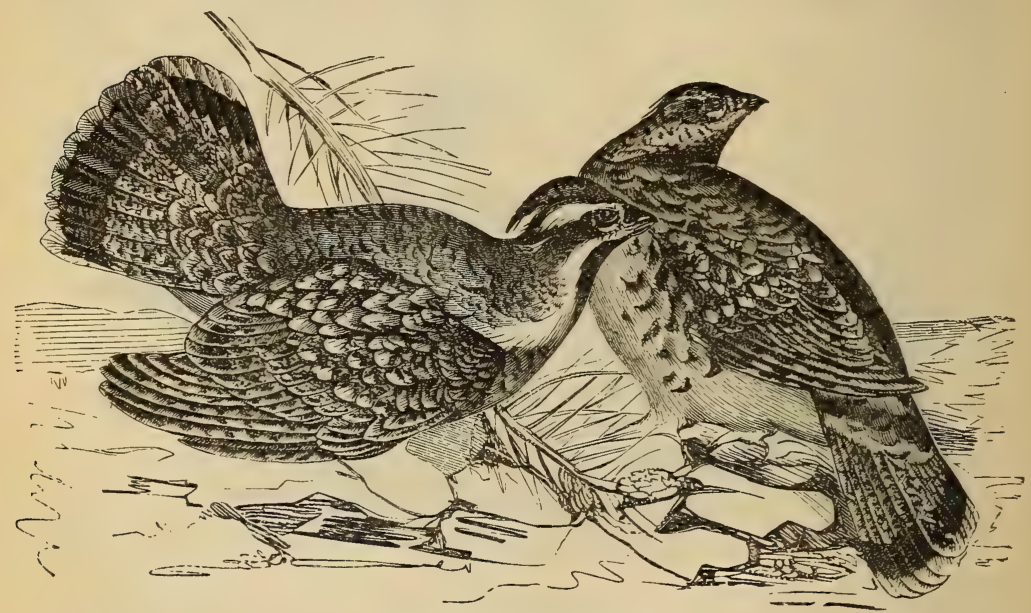

Fig. 149.-Hazel Grouse.

grey, spotted with brown. Like the Capercaillie and the Hazel Hen, they are birds of social habits, and cannot bear captivity. Their flesh is excellent and much prized. Numbers of them are sold in the markets, and considerable quantities are sent every year to England and France from Scotland, Norway, and Lapland. The two principal species are the Lagopus mutus (Fig. I50), common in the Alps, the Pyrenees, and the North of Europe and America ; and the Red Grouse (Lagopus scoticus), which is found only in Great Britain and Ireland, where it is much prized for its beauty, delicacy of flesh, and the magnificent sport it affords when killed over dogs. The 1 2 th of August, the first day of grouse-shooting, is looked forward 
to by the disciples of the gun as anxiously as the Derby-day by racing men.

\section{Perdicides.}

The distinctive features of the birds composing this family area short beak, a small head, a round and massive body, bare tarsi, with spurs more or less developed, and a middling-sized back toe. The wings are sharp, pointed, or blunt, according to the species. This family comprehends the Sand Grouse, Quail, Partridge, Colin, Francolin, and Turnix.

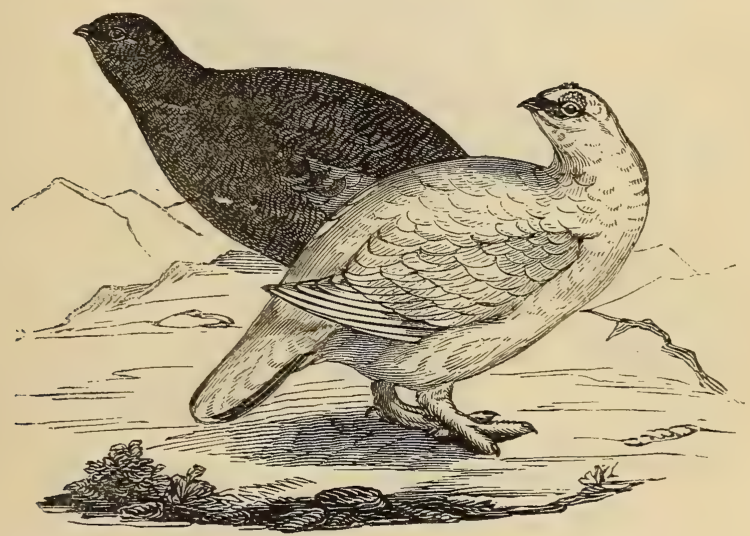

Fig. r5a-Ptarmigan (Summer and Winter Dress).

The Sand Grouse (Pterocles) are essentially birds of passage, and in consequence are provided with long and sharply-pointed wings. They resemble the Plover in their power of lofty, rapid, and sustained flight, and inhabit the arid plains of Southern Europe, Asia, and Africa.

The Pin-tail Sand Grouse (Pterocles setarius, Fig. I5I), a wellknown species, annually makes its appearance in Spain and the South of France; it is common on the steppes of Southern Russia, Tartary, and Northern Africa. Occasionally it breedsin the Pyrenees.

The Heteroclites are characterised by the total absence of the back toe. They are closely allied to the Sand Grouse, and, like them, have pointed wings, and are fond of travelling; but their flight is not 
so continuous. They inhabit the steppes of Tartary, and but rarely venture into Europe.

The Quail (Coturnix) has a small beak, a short back tce inserted rather high up, tarsi furnished with a rudimentary spur in the shape of a horny tubercle, a thick-set body, sharply-pointed middling-sized wings, and hardly any tail. There are several species of this bird, only one of which is found in Europe.

The Common Quail (Coturnix communis, Plate XIII.) is noted for its migrations. Every year in spring innumerable flocks of them

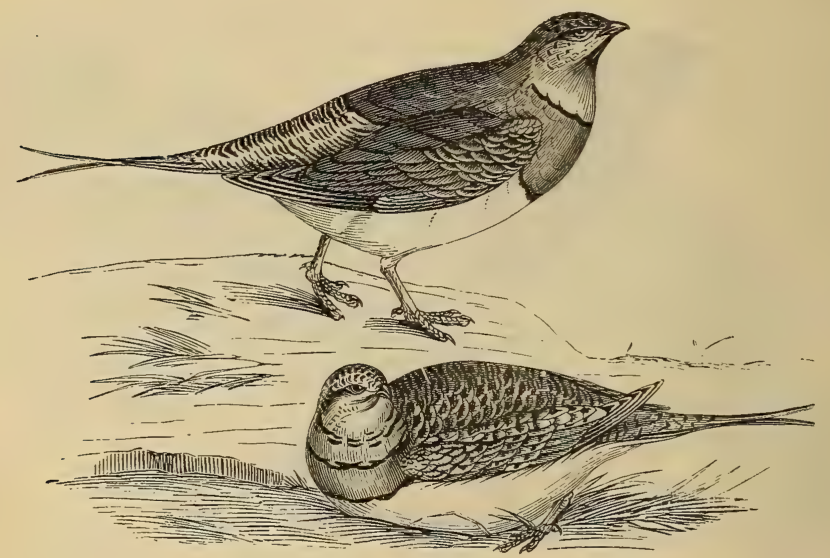

Fig. I51.-Pin-tail Sand Grouse.

leave Africa, cross the Mediterranean, and spread themselves over Europe. In the month of September they return. The instinct which impels them to migrate becomes so powerful in spring that captive Quails become very uneasy, walk up and down their cages, throw themselves against the bars with such force that they fall back stunned, not unfrequently dead.

The quarrelsome proclivities of the Quail has long been known. In the East they are regularly pitted against one another, after the manner of Game Cocks, and sums of money change hands on the issue.

The fecundity of the Quail is extraordinary: if it were otherwise the species would soon be exterminated, partly from their heavy, awkward flight, which renders them an easy prey to the sportsman's gun, 


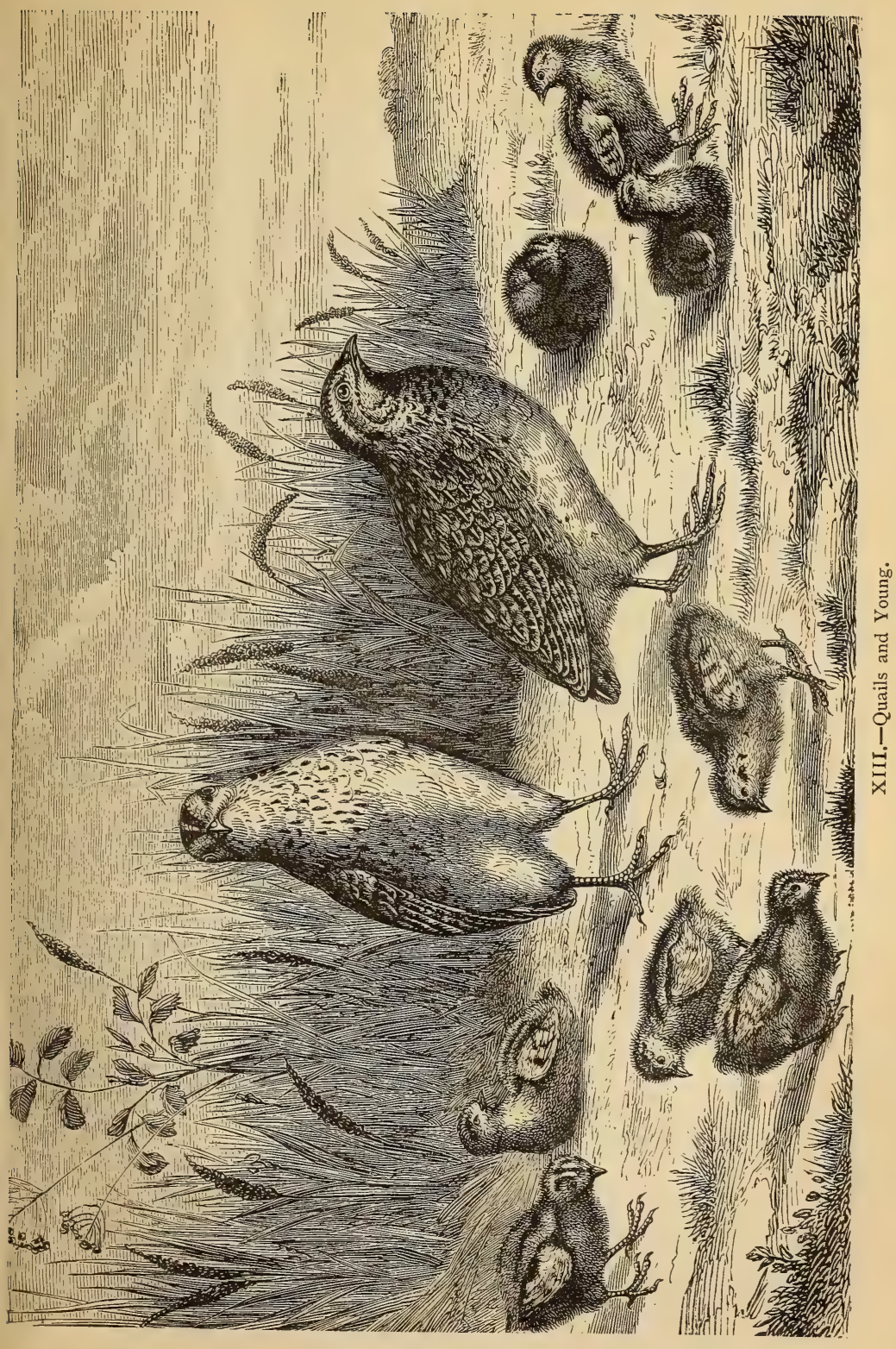



but still more from the wholesale slaughter of them which takes place in certain districts at the time of migration. The bishop of the island of Capri, situated in the Bay of Naples, receives an annual revenue of 40,000 francs ( $£ \mathrm{I}, 600$ sterling) from the duty he has imposed upon Quails taken on the island, to be sold in the markets of Naples. From this he has received the name of the "Bishop of the Quails."

On the shores of the Bosphorus, in the Morea, Crimea, and in some of the islands of the Grecian Archipelago, Quails sometimes arrive in such dense masses that, according to a popular saying, it is only necessary "to stoop to pick them up." On arrival they fall exhausted upon the ground, and the sky may almost be said to be raining birds. The inhabitants, who have been watching for them for many days, now net them in great numbers, and, having salted them, and packed them in barrels, export them to different countries.

Quails travel principally in the evening and during the night. They ascend to a tolerable height, never flying against the wind; but, on the contrary, scud before it, and are thus carried across the Mediterranean. The south winds bring them to us, and the north winds carry them back to Africa. If encountered by an adverse gale during their passage across the ocean they have not power to resist it, but fall into the waves. Thousands of them have been found drowned around the precipitous shores of the island of Malta; their strength had failed them, and, from being unable to gain sufficient elevation, they found a watery grave. Occasionally they take shelter on the decks of passing vessels.

Quails frequent plains covered with cereals, or pasture lands. They delight in rolling in the dust, and are never known to perch. Their food consists of seeds and insects. They are not sociable birds, for the sexes do not approach one another except in the breeding season, and parent and young separate as soon as the mother's care is no longer necessary for the protection of the brood. This time soon arrives, as the little things are of rapid growth. The females lav twice during the year, once in Europe and once in Africa, and each time produce from ten to fourteen eggs.

The Quail is a very swift runner, and employs this mode of locomotion to escape pursuit, unless the danger is imminent. If flushed, it flies in a straight line, keeping close to the ground. On re-alighting it shows itself a thorough master in the art of throwing dogs off their scent.

When killed at the proper time-that is to say, when it has rested after its fatiguing journey, and recovered condition-it is covered 
with a layer of fat which is unsurpassable in richness and flavour. Its flesh is sweet and delicate, and emits an odour grateful alike to the nose and palate. 'This bird ranks immediately after the Woodcock and the Snipe in the estimation of epicures.

The capture of Quails is accomplished with a net or trap, in which bait is placed; they are also shot over a dog (Plate XIV.). This last method is the only one nowadays allowed in France; and, thanks. to this restriction, the bird is destroyed on a less extensive scale than in past times, so that the species may not ultimately be exterminated. This bird is not larger than a Thrush.

The Partridge (Perdix) has a sharply re-curvate beak, a thickset body, rounded wings, and a short and drooping tail. The tarsi of the male bird are either provided with or destitute of tubercles, according to the species,

Partridges live constantly on the surface of the soil, and never perch except when they are absolutely forced to do so. They, like the Quail, run with remarkable swiftness. Their flight is rapid, but low, and does not extend to long distances.

These birds are eminently sociable, and live during the principal part of the year in flocks or coveys, composed of the parents and. the young of the last brood. They are not migratory, so seem to. attach themselves to certain localities, which they never leave except by accident or compulsion.

Partridges pair early in the year, which union does not cease. till after their parental duties are performed.

In certain species, such as the Red-legged Partridge, where the females are less numerous than the males, a great number of the latter remain single. As the cocks do not willingly resign themselves. to single blessedness, their attempts to avoid it produce frequent quarrels. These conflicts at last come to an end ; the various pairs. are united; and the unsuccessful candidates for affection, who objected to being bachelors, ultimately combine together.

At the time for laying, the hen bird makes a hole in the earth, which she lines with grass and leaves, and in it deposits her eggs, to. the number of twelve or fifteen, and sometimes even twenty or more. The season of incubation lasts about twenty days. During this time the male bird watches over his companion, and guards her from danger. When the young are hatched, paternal affection is added. to conjugal love, for the father devotes himself to the care of his children. He accompanies them in their wanderings; he teaches. them to catch grubs, finds ants' eggs, and shows himself as skilful as the mother in guarding them from attacks of their enemies. At the- 



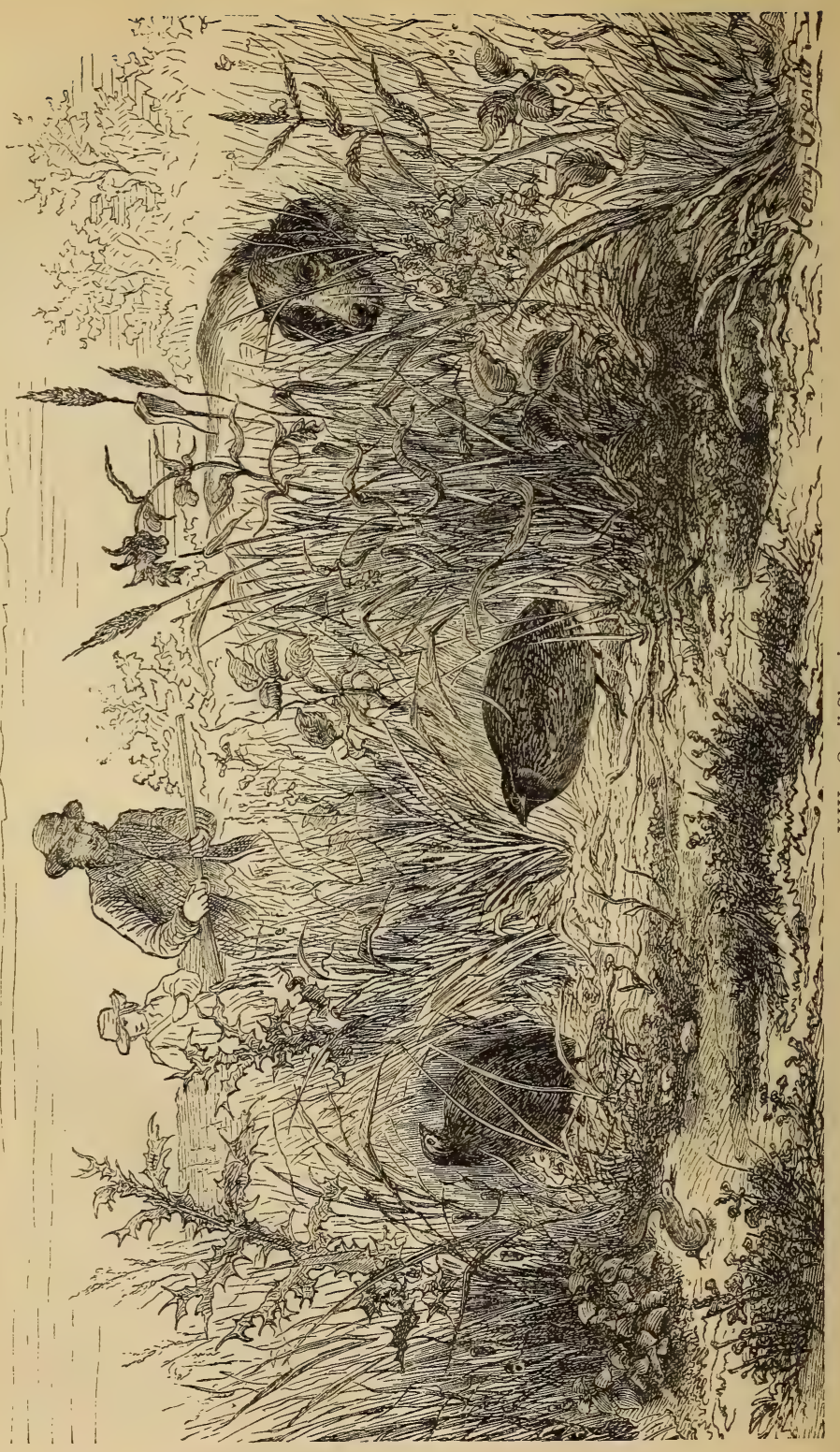




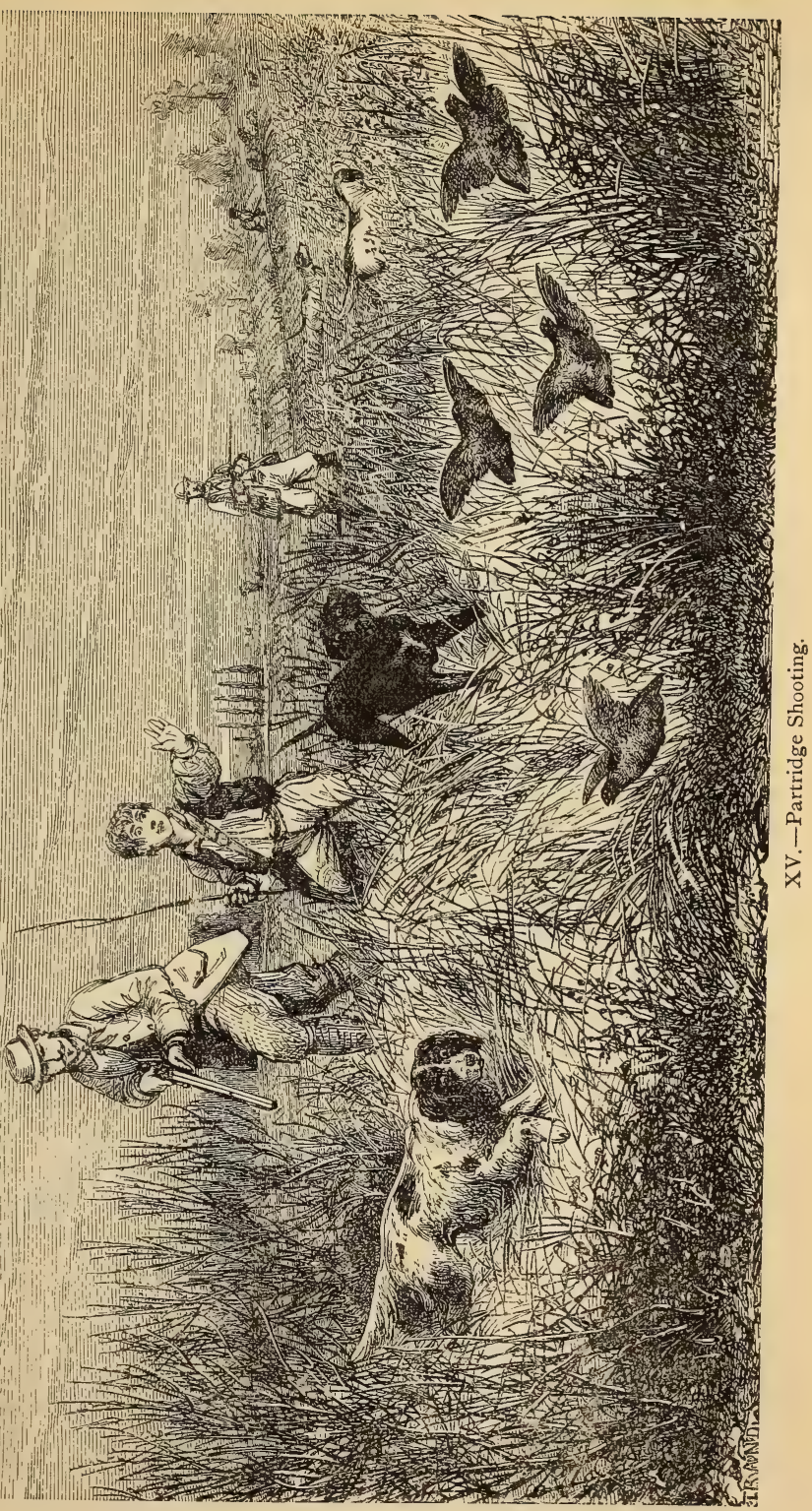



appearance of danger the male utters a cry of alarm, which warns the young ones, and enjoins them to seek concealment. Drooping his wings in order to induce the intruder to follow him, he pretends to be unable to fly. At the same time the female proceeds in another direction; and, alighting at sorne distance off, she runs back to her family, reassembles them, and leads them to a place of security, where they are soon joined by the male bird. The above is one of the ingenious stratagems by which the young brood is protected.

Some weeks after they are hatched the young Partridges are able to fly, and to provide for their own wants, but they do not now leave their parents, but continue to live with them in the closest alliance until February or March, when they pair off.

Partridges are of a shy and timid nature, which shows itself in many ways. Nor are their suspicious fears unjustifiable, when it is remembered how numerous are their foes, for foxes and birds of prey make continual and unsparing havoc amongst them : the latter especially are particularly dreaded. At the mere sight of one of the falcon tribe, a partridge is so overcome with fear as almost to be incapable of concealing itself, and it is not until the dreaded enemy is gone that it regains self-possession.

When a bird of prey unsuccessfully dashes at a partridge in cover, no power is able to make it take wing, and any one can then lay hands on it without difficulty. A partridge has even been known to prefer dying in its hiding-place from suffocation to exposing itself to the mercies of its pursuer.

The knowledge of these facts has suggested a very simple and effectual method of making partridges which are wild remain on the ground without flushing, till the sportsman is within gun-shot. This is done by frightening them with an artificial bird of prey, attached to the tail of a kite, which is flown over them.

Notwithstanding their wild nature, Partridges are susceptible of domestication, and, with care and gentleness, they may be rendered very tame. Girardin relates that a Grey Partridge, reared by a Carthusian, became so familiar that it followed its protector about like a dog. Willoughby states that an inhabitant of the county of Sussex succeeded in taming a whole covey of Partridges, and was in the habit of driving them before him like a flock of geese. Tournefort relates that formerly, in the Isle of Chio, flocks of Red-legged Partridges were reared which allowed themselves to be driven about in exactly the same way; and Sonini speaks of two Red-legged Partridges which an inhabitant of Aboukir had managed to tame. All 
these facts abundantly prove that, with a little patience, it would be possible to raise the Partridge to the dignity of a domestic farmyard fowl.

The Partridge is highly esteemed by epicures; it is also the delight of the sportsman. On account of its abundance, especially of the grey variety, it rnay be pronounced the favourite game of France. Partridge-shooting, moreover, is what is generally chosen for the education of the inexperienced shot; the dog, too, by the constant display of extraordinary sagacity, in no small degree contributes to the charm of this sport (PLATE XV).

Let us now take a rapid glance at the various species of the Partridge. The Common or Grey Partridge (Perdix cinereus, Plate XVI.) is the most numerous; it is very plentiful over the whole of Central Europe, the North of France, Belgium, Holland, and Great Britain. In these countries it frequents the districts covered with grain, green crops, and meadows. This bird is not altogether harmless to agriculture, as it is not satisfied with the ears of corn left on the surface, but scratches up the seed that has been sown. The services which it renders in destroying worms, insects, and grubs, doubtlessly compensate for these delinquencies.

The migratory Grey Partridge, a variety of smaller size, which is not known in England, is remarkable for its vagrant character, and forms a singular contrast to the stay-at-home habits of the genus generally. It makes its appearance in large flocks, at the most diverse seasons and in the most varied latitudes. Not migratory in the proper sense of the word, its journeys seem undertaken under the influence of some unknown cause, and are wanting in regularity and constancy. This bird is of a very shy nature, and is frequently met with in the East (Turkey, Syria, and Egypt) ; it is sometimes noticed in France, where it is called the Damascus Partridge.

Contrary to the Grey Partridge, the Red-legged, and those allied to it, have the tarsi provided with tubercles.

The Red-legged Partridge (Caccabis rufa, Plate XVII.) owes its name to the predominant colour of its plumage, and also to the pink shade of its beak, tarsi, and feet. Uncultivated wastes, thinly covered with heath, and undulating uplands adapted to the vine, are its favourite resorts. It is a native of Spain and Italy, all Eastern Europe, and is very common in portions of Asia and Africa. In France it is principally found in the south ; in the northern departments it is not so plentiful as the Grey Partridge.

The brush-clad mountains are its home, where it ascends in fine weather to altitudes verging on perpetual snow. It is very fond of 



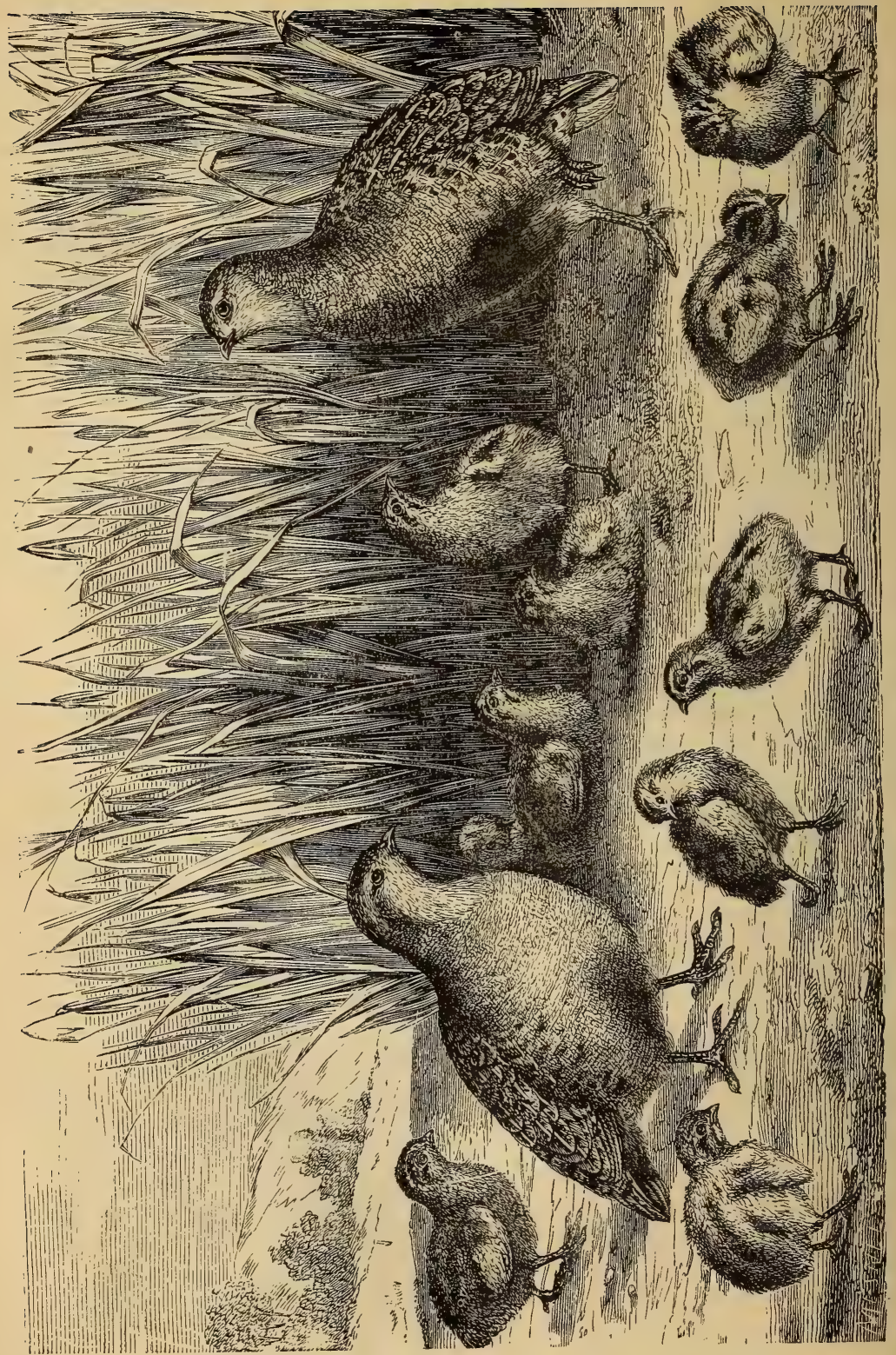

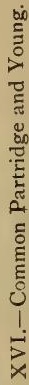




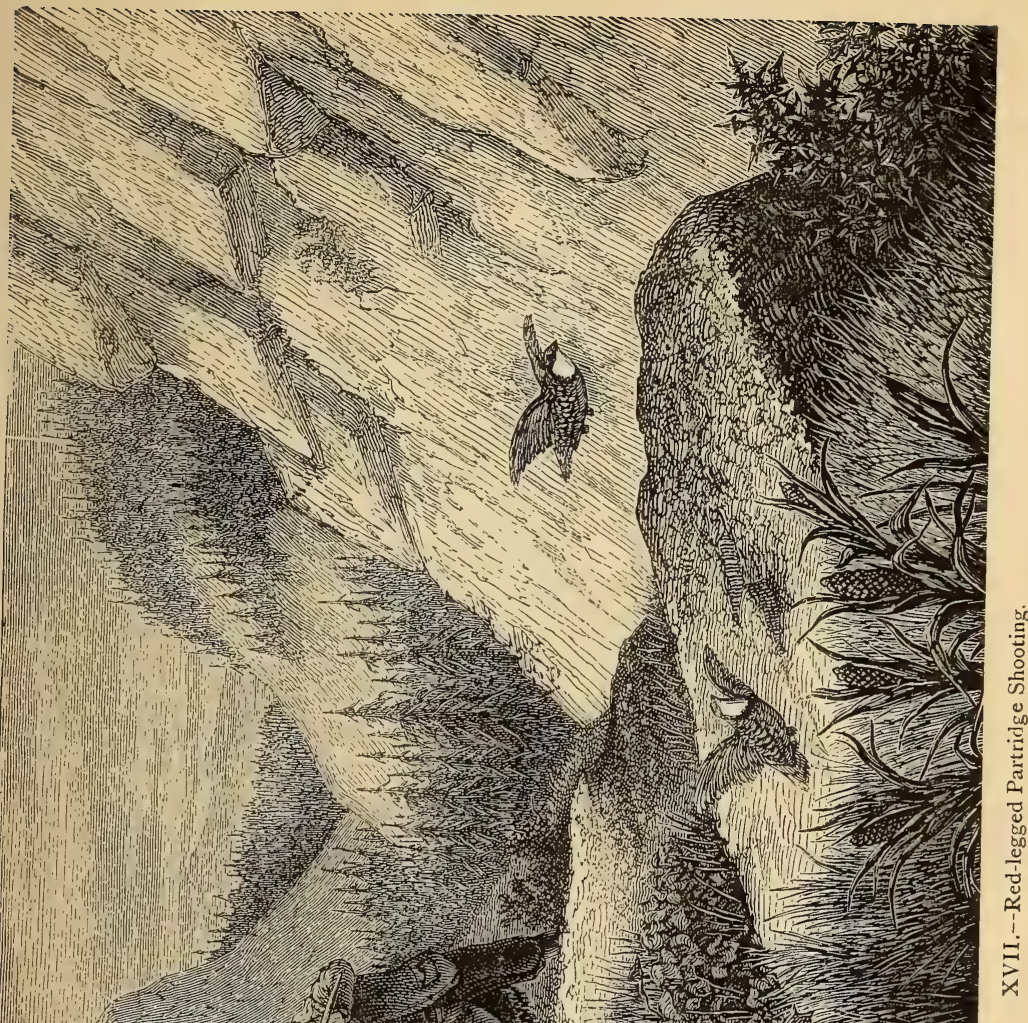

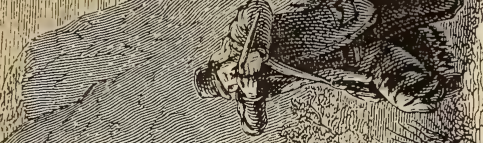

(x) (c)

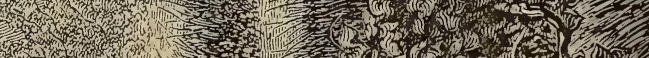
(1)

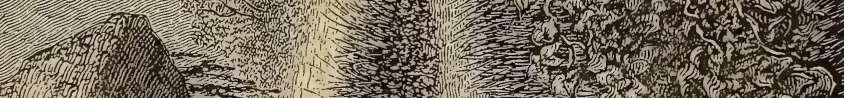
1.

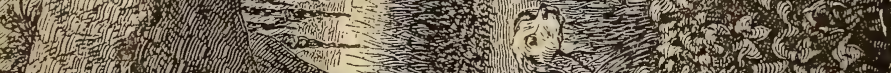
13 .

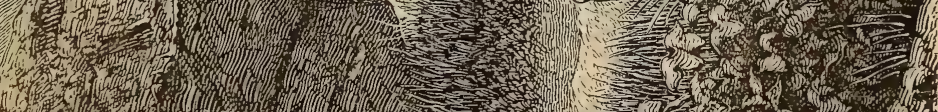

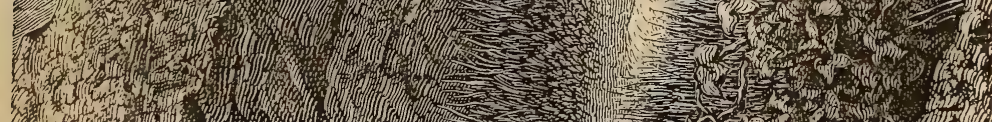

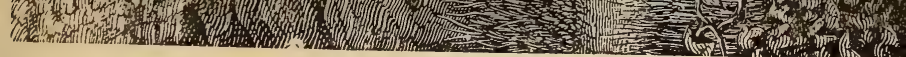



grapes and the edible variety of snails. In France, the Jura, the Upper and Lower Alps, the mountains of Auvergne, and the Pyrenees, are districts where it is most abundant.

A variety called the Gambra, which differs but little from the Red-legged Partridge, is found in Spain, Corsica, Sicily, and Calabria.

The Virginian or American Partridge (Ortyx Virginiamıs, Wilson) has a thick and convex beak, smooth tarsi, and a longer tail than the Partridge. These characteristics would hardly entitle us to make any difference as to genus, if a study of their habits had not revealed certain details which justify our doing so.

When these birds are flushed, they do not all of them fly towards. the same spot, but scatter before concealing themselves in the brushwood. Under these circumstances, if re-found, all may be killed in succession. They are more prolific than the Partridge, also less suspicious, and will readily enter snares set for them.

These birds are in the habit of making peculiar arrangements for sleeping. All the individuals of the same flock place themselves in a circle at a certain distance from each other; then walk backwards, converging towards a common centre, until they are close to one another, side to side: in this position they pass the night. By means of this precaution the flock can see in all directions, and by advancing a few steps to their front take wing without interfering with each other.

The Virginian Partridge has bred in England. Similar attempts have been made in France, but with less success, owing to a want of perseverance. It would be a very excellent addition to our game birds, as its flesh is quite delicate, and it lies well before pointers or setters.

The Californian Partridge (Ortyx Californicus, Fig. I52), is also distinguished from the Partridge proper by its vagrant habits. In this respect it resembles the Quail, but its peregrinations are irregular, and do not embrace anything like the same extent of range. This bird is a native of the western shores of North America, where it abounds. In California, during one winter, in a circuit of not more than five or six leagues, as many as I 2,000 head have been killed, without any apparent diminution of the species in the ensuing spring. On the upper ridges of the valley of the Sacramento River they are very abundant. This beautiful bird, familiarly known as the Californian Quail, is adorned with a crest, the upper portion of which points forward.

Another variety of $\operatorname{Ortyx}$, figured by Audubon, is also a resident of California, where it is called the Solitary Partridge. 
Francolins are distinguished from Partridges by a stronger and more elongated bill, by a more largely-developed tail, and by the existence in the male of one or two sharp spurs. They also differ in their habits, for they frequent wooded and marshy districts, where they subsist on berries, seeds, worms, insects, and young bulbous plants. When not feeding, they are almost constantly perched on trees, where they pass the night. These peculiarities excepted, they bear a strong resemblance to the Partridge. Their flesh is highly esteemed, the Francolin taking the first place among game birds.

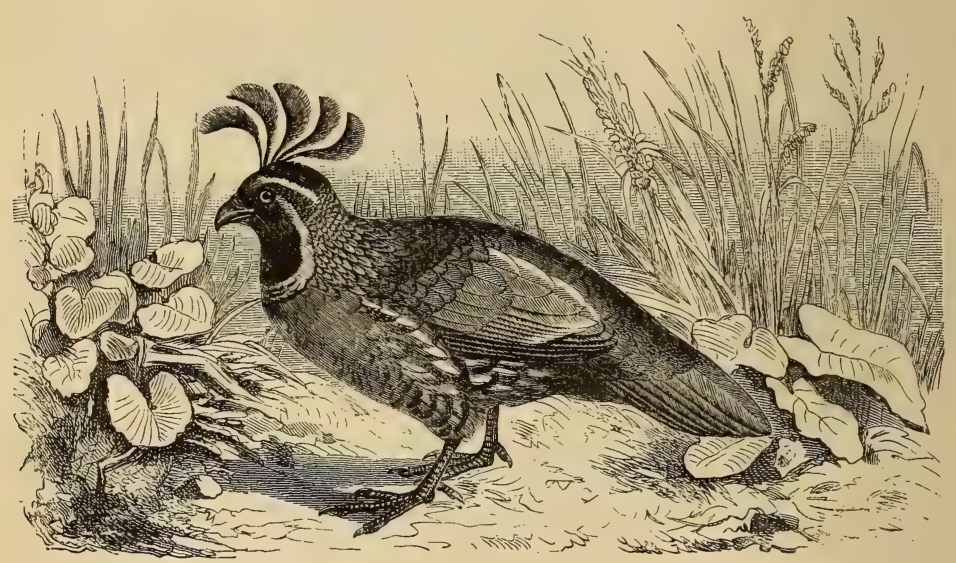

Fig. I52.-Californian Partridge.

A beautiful variety of Francolin is found in the south of China. Its favourite haunt is among the dwarf palmetto on the hill-sides. It lies well to dogs, but is so quick in flushing, and so rapid in flight, that even the best shots miss them. They are quite as large as the Grey Partridge.

Unfortunately, in Europe the Francolin is tending towards extinction, for its wild nature prevents it accommodating itself to a restricted range. It is found on the southern coasts of the Black Sea, in Sicily, and the island of Cyprus. There are other species inhabiting Africa and India, the most worthy of notice being the Sanguine Francolin (Ithag niis cruentus).

The Turnix are closely allied to the Quails; the only physical 
distinction between them is the absence of the back toe. It frequents sandy districts and plains covered with high grass. It runs very swiftly, and but rarely flies. Having alighted after being flushed, it stubbornly persists in remaining on the ground, and prefers being caught to making a fresh attempt at escape on the wing. Its flesh is excellent.

A European species, the Turnix tachydroma (rapid runner), Fig. I53, inhabits Sicily, the south of Spain, and the north of Africa.

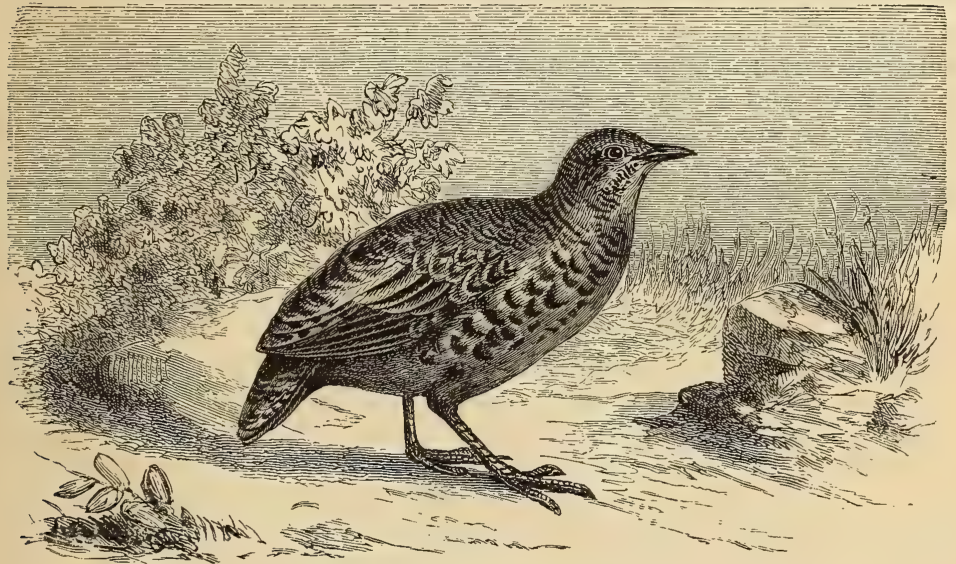

Fig. 153.-Turnix tachydroma.

\section{Tinamides.}

All the birds of this family belong to South America. They are the representatives of the Partridge on that continent. Their essential characteristics are a slender and medium-sized beak; tarsi rather long, and provided with nodosities ; the back toe either very short or altogether wanting, at all events, no use in walking can be made of it from its elevated position; the wings and tail short, the latter sometimes deficient.

This family comprises four genera, all very closely allied to one another; these are the Tinamou, the Nothures, the Rhyncotes, and the Eudromes. We shall confine our remarks to their nature and characteristics. 
These birds are naturally stupid, and cannot habituate themselves to captivity. They live in small flocks, except during the breeding season. They fly heavily, always in a straight line, and are swift runners. Some species manifest such sluggishness that they will remain the entire day without moving, and will not even take the trouble to escape from their enemies. They have the habit of rolling themselves in the dust, and frequent indifferently cultivated ground, grassy meadows, or thick woods. Except in rare instances, they sleep upon the ground. They are crepuscular-that is, they seek their food in the early mornings and evenings, and even by moonlight. Their selection of nutriment is frugivorous, granivorous, insectivorous, and vermivorous. They make their nests on the ground, and lay twice a year seven or eight eggs. Their flesh is good, and much sought after.

Tinamotis elegans may be take $\mathrm{z}$ as a representative of the order.

\section{CHIONIDE.}

The birds belonging to this family are characterised by a short, crooked, and stout bill, long and pointed wings, a middling-sized tail, and a merely rudimentary back toe. The size of the Chionides varies between the Partridge and the Pigeon. The species of Chionis, Tinochore, and Attagis are included in this family.

The Sheath-bill (Chionis alba), a good type of this genus, is remarkable for its marine habits; they frequent the sea-beach, and feed on sea-weed and animal remains. They are to be found in Australia and New Zealand. The Tinochores and the Attagis are natives of Chili and Paraguay: their habits are not known.

\section{MEGAPODINE.}

The distinctive features of this family are as follows : the bill straight and slender; the tarsi long and stout; the feet tetradactylous, and furnished with long and strong claws. This family comprises three genera: the Megapodius, Leipoa, and Talegallus.

The Megapodii are but little known. Ail that has been, ascertained is, that they inhabit marshy localities, fly but little, and run like Partridges. They lay each of their eggs in a separate hole, which is in a mound sometimes of truly gigantic size, and scraped together by the birds, there they are left to be hatched by the heat of the sun. The young birds are able to dispense with maternal assistance, and to provide for their own wants on leaving the shell. 



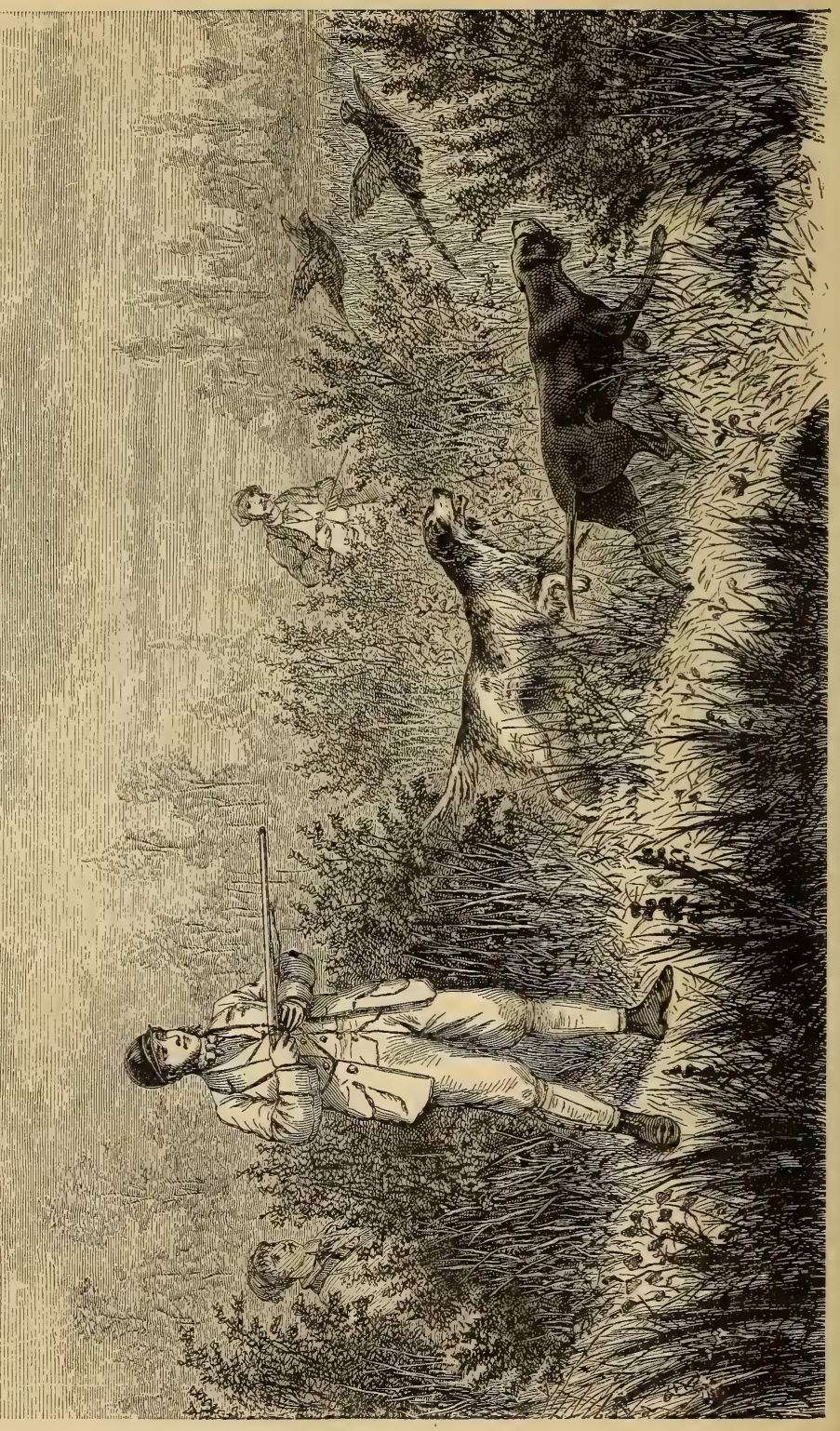

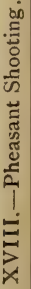


These birds inhabit Australia, the Australian Jungle Fowl (Megapodius tumulus) being the best known type.

The Leipoce bear a great resemblance to the Megapodii, and are natives of the same country, where they are familiarly called the Native Pheasant : their habits have not been studied.

The Talegalli, familiarly known as the Brush Turkeys, inhabit Australia and New Guinea. They live in low brushwood, adjacent to the sea. These birds have a curious plan in building their nests. They scrape together a large quantity of dry leaves, of which they form a conical mound five or six feet high, after the manner of the Australian Jungle Fowl, but not on so large a scale. On the top of this heap they make a hole, in which the female drops two or three eggs, one on the top of the other. The heat produced by fermentation, joined with the rays of the sun, gives sufficient warmth to hatch them.

\section{Phasianide.}

This family is divided into several genera or tribes; namely, Pheasants, Peacocks, Guinea Fowls, Turkeys, and Curassows.

The Pheasant tribe comprises not only Pheasants proper, but also the Domestic Fowls - properly the Bankiva Fowl-the Argus, Tragopans, \&c. Their characteristics are as follows: The head bare, bill stout, wings short and flight heavy, tail largely developed, plumage brilliant, sometimes gorgeous.

Although these birds were originally natives of Asia, some have been naturalised over nearly the whole face of the earth since time immemorial ; the Pheasant, however, is not so widely spread, although its range has been much increased.

The Pheasant is remarkable for the extraordinary length of its tail, the middle feathers of which in one species, Reeves's Pheasant (Phasiamus Reevesii), sometimes attain a length of seven or eight feet. It is a bird of noble and elegant form, and the males are adorned with brilliant plumage; the hens possessing a more unattractive attire. The sides of the face and round the eyes are bare and tuberculous. The stronger sex are provided with spurs (PLATE XVIII.).

There are many species of Pheasant, but there is no obvious diference in their habits; we shall therefore content ourselves with giving an account of the Common Pheasant (Phasianus Colchicus, Fig. I 54), of which there are many varieties spread through Europe.

The introduction of the Pheasant into Europe dates as far back as the expedition of the Argonauts, about I 300 B.C. The companions of Jason met with this bird on the banks of the Phasis, in 
Colchis, whence its name is derived. Struck with its beauty, they carried it back with them into Greece, whence it gradually spread over a large portion of the European continent. The Greeks, believing it to be indigenous to the banks of the Caucasian river, called it the "Bird of Phasis;" subsequently, however, it was

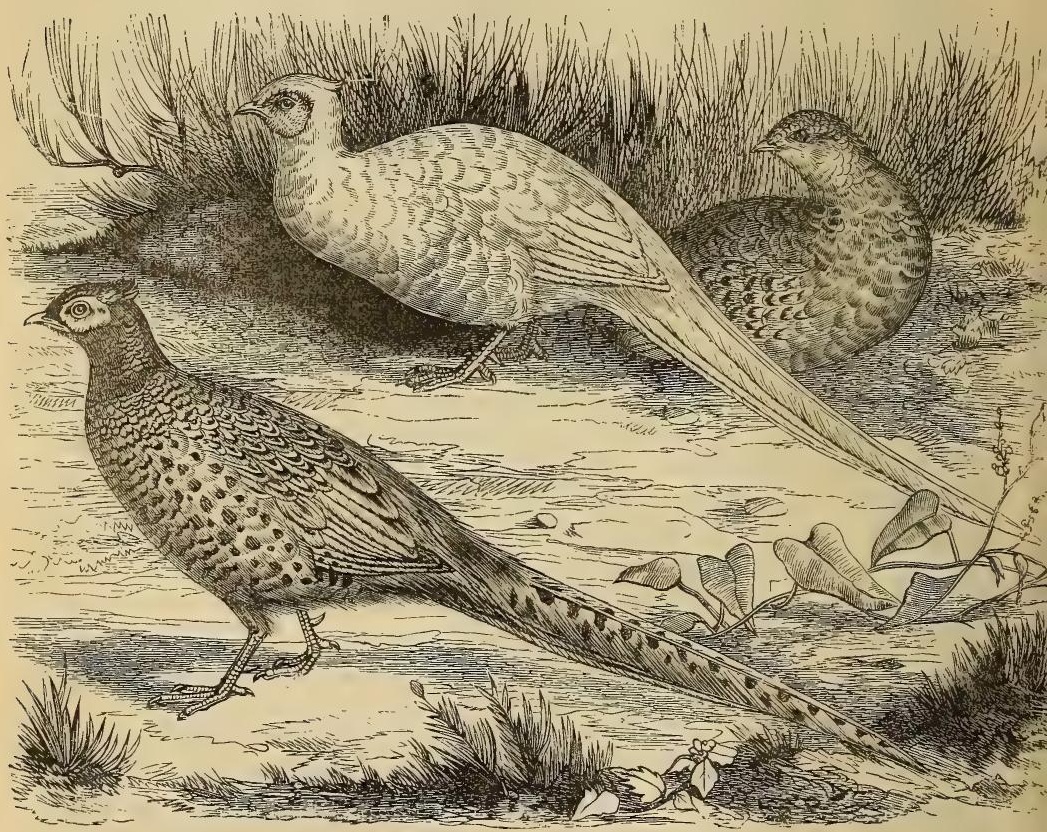

Fig. I54-Common Pheasants.

ascertained that it also inhabited the whole of the south of Asia -China, Cochin-China, Bengal, \&c.

At the present day this bird is found in France, Great Britain, Holland, Germany, and even Sweden.

Pheasants prefer wooded slopes or marshy plains. Their food is of a varied character, and is composed of grain, berries, worms, insects, and snails. They are shy and timid in their nature, taking flight at the slightest indication of danger. They live alone up to 



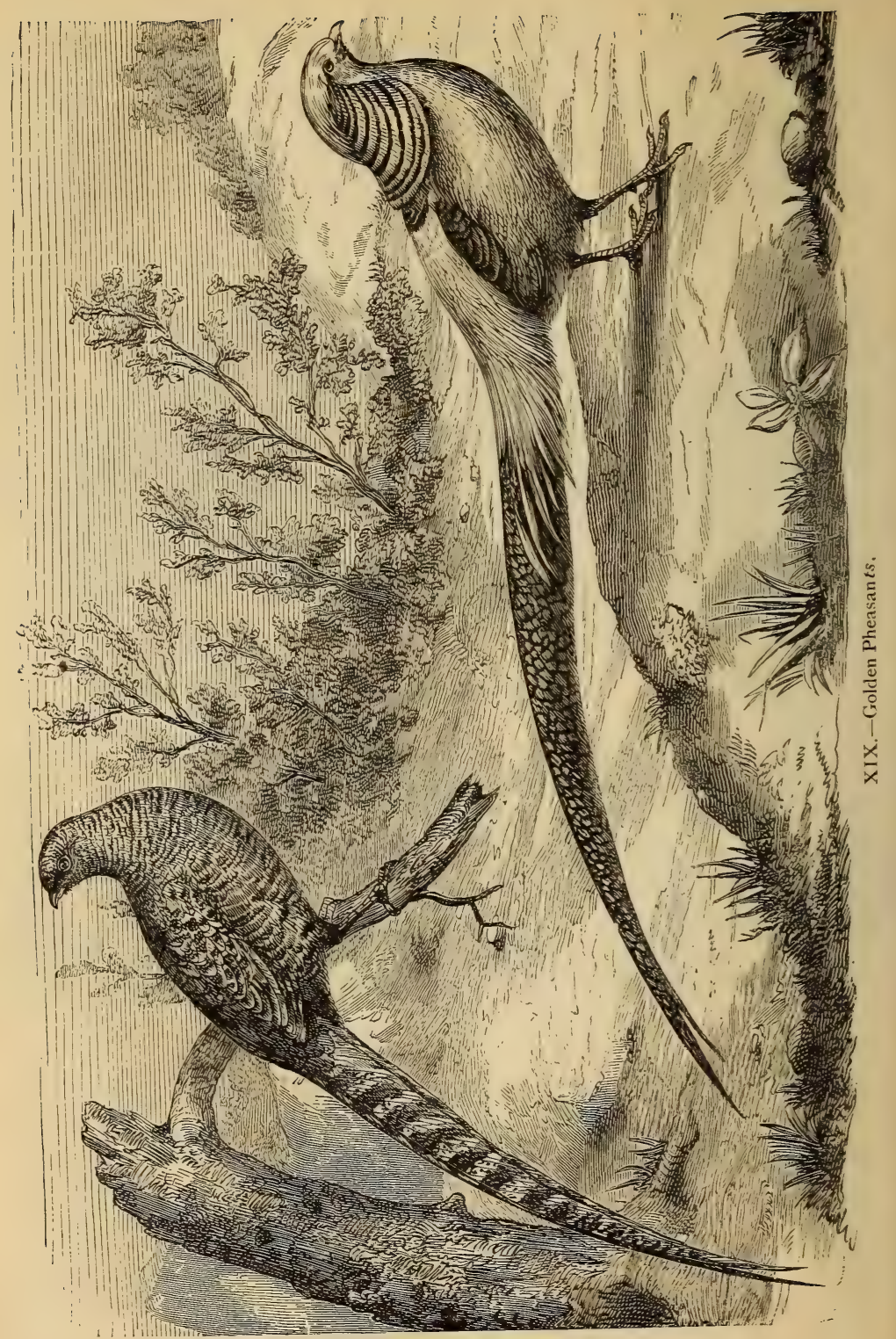


the breeding season, when the male birds select their mates, for they are polygamous. On these occasions they engage in such desperate conflicts that the weaker bird is often killed.

The hen Pheasant makes her nest on the ground, in the midst of a thicket, or in a tuft of grass, and lays from twelve to twenty eggs, which require twenty-four days to hatch.

The mother does not manifest that care and solicitude for her young which are so marked a characteristic of the majority of other birds; she does not even specially recognise her own progeny, for she pays equal attention to all the young of her race that surround her. We must not, however, expect to find much maternal love in a bird which will break her own eggs to gratify an unnatural appetite.

The Pheasant, although wary, is at times unaccountably stupid; thus it falls an easy victim to the poacher.

Although they breed in a wild state in our climate, Pheasants are principally raised in enclosures called pheasantries, where all the necessaries to existence are provided for them. As the females are bad mothers, it is not unusual for their eggs to be hatched by domestic fowls. During the first two months of existence the young pheasants require the greatest care, for they are predisposed to numerous maladies. Ants' eggs are their favourite food.

The flesh of the mature bird is very savoury, but rather dry ; and epicures consider that it ought not to be eaten till hung a long time, and become "high," a requisite considered necessary with the majority of game. There is one very curious peculiarity common to certain birds belonging to the family of which we have been speaking, and which is especially remarkable in the Pheasants-it is that when old females become unfruitful they assume the plumage of males. It is said that young Pheasants undergo the same change when deprived of their reproductive organs.

The Golden Pheasant (Phasiamus pictus, Plate XIX.) and the Silver Pheasant ( $P$. nychthemerus), are two beautiful birds, originally from China and Japan, and now naturalised to Europe. The former clothed in purple and gold; bears a golden-yellow tuft on its head; the black-and-white costume of the latter is not inferior in beauty to the preceding. Linnæus has named them Nychthemerus (the night and the day). There are also the Ring-necked or Collared Pheasant, slightly different from the Common Pheasant, which for some years has propagated rapidly in France and England.* Reeves's Pheasant, indigenous to China, where it is rather rare, and very highly prized

* This species is originally from China, where I have frequently shot them. In their native haunts they are larger than the semi-domesticated bird. - ED. 
for the beauty of its plumage and the extraordinary length of its tail-it is said that the exportation of this bird is severely interdicted : and, lastly, the beautiful Lady Amherst's Pheasant, so called because her ladyship brought the first living specimens to Europe.

The Argus (Argus giganteus. PLATE XX.) a bird with magnificent plumage, which inhabits the forests of Java and Sumatra, takes its place beside the Pheasants, from which it only differs in having the tarsi longer and unprovided with spurs, and by the extraordinary development of the secondary feathers of the wings in the male. The tail is large and round, and the two middle feathers are extremely long and straight. When seen as it struts round the female, spreading its wings and tail, this bird presents to the eye of the spectator two splendid bronze-coloured fans, upon which are sprinkled a profusion of ocellated markings much resembling eyes; it owes its name of Argus to these spots. In a state of quiescence the wings are folded on the sides, and attract little attention. Only in the male bird is this gorgeous display of colouring to be found. The Argus is very timid ; thus its habits are little known.

The $e^{z}$ general characteristics of Domestic Poultry (Gallus, Fig. 155) are as follows :-A middling-sized, curved, and strong beak; head surmounted by a fleshy, red, and denticulated crest, the lower jaw furnished with two hanging gills, equally red and fleshy; rather long tarsi, armed with sharp spurs; short, concave, and obtuse wings; tectiform tail, arched and falling in plumes, with very developed medium feathers; brilliant plumage, with metallic reflections. This description applies exclusively to male birds. Hens are not gifted with these exterior advantages ; their plumage is generally dull and unattractive, their straight and slightly-raised tails are limited to an ordinary proportion ; their crest is reduced to the most simple excrescence, and in certain species entirely disappears ; lastly, their legs are without the spur with which the male is armed.

Whatever may be the opinion adopted as to the origin of the Domestic Fowl, we know that amongst the species indigenous to Asia are the Bankiva race (Gallus Bankiva), which so nearly resembles our village chanticleer as to be often confused with it ; the Jungle Fowl (Gallus Sonnerati), inhabiting Java, Sumatra, and Hindostan; the Bronzed Cock (Gallus qneus); the Forked-tailed Cock (Gallus furcatus); and the Giant Cock or Kulm Cock, the largest species known. These are considered, not without reason, the founders of our most extensive races. The last-mentioned lives both in a wild and domestic state in Java, Sumatra, and India proper.

The Negro Cock offers a very remarkable case of contrast to the 


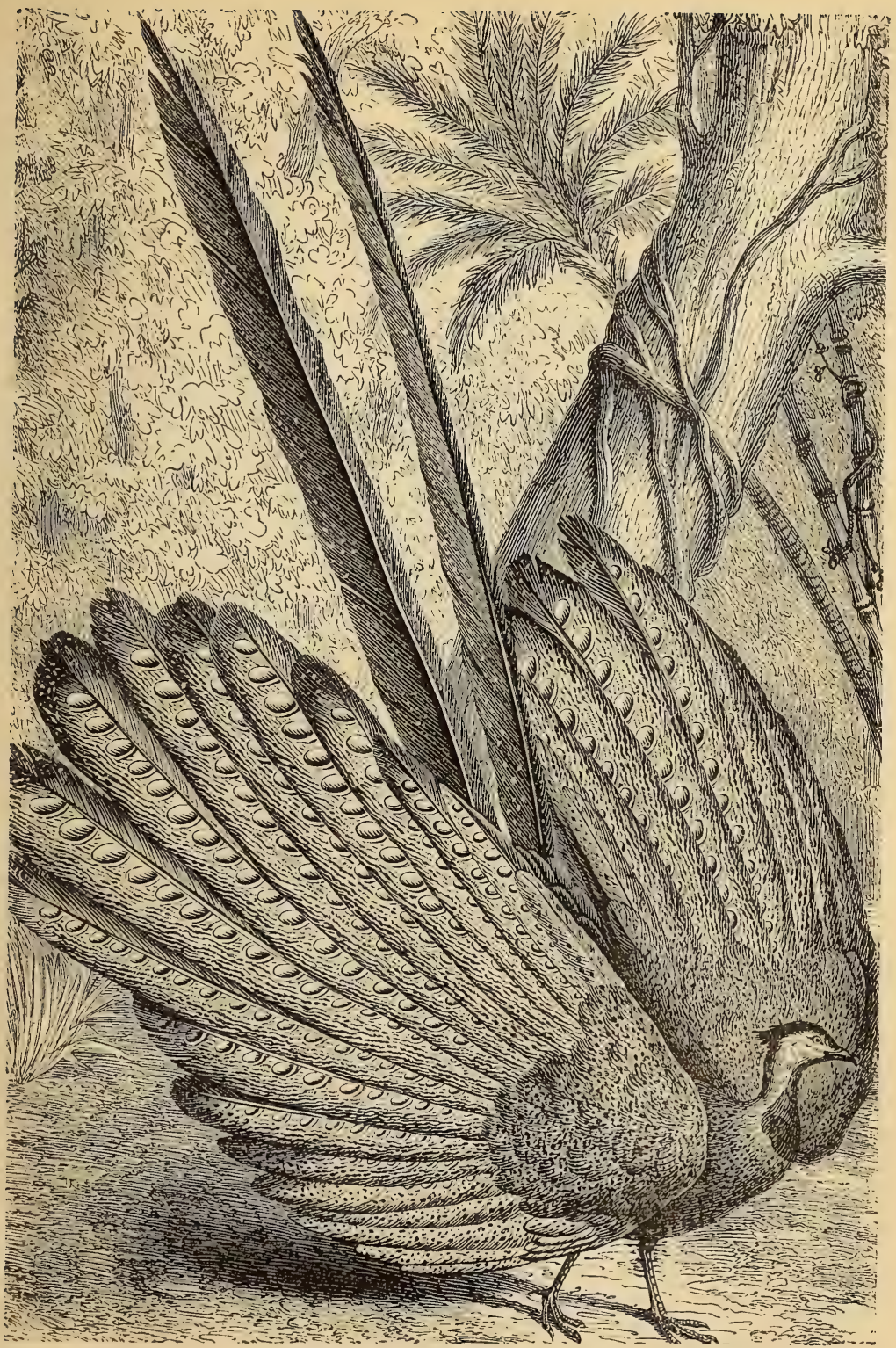

XX.-Argus. 

above-mentioned, for the crest, gills, epidermis, periosteum, and feathers of this species are black but the flesh is white. The Negro Cock, very largely spread over Belgium and Germany, still lives in freedom in the Indies. Although to the Bankiva race alone some attribute the honour of being progenitors to our domestic stock, I

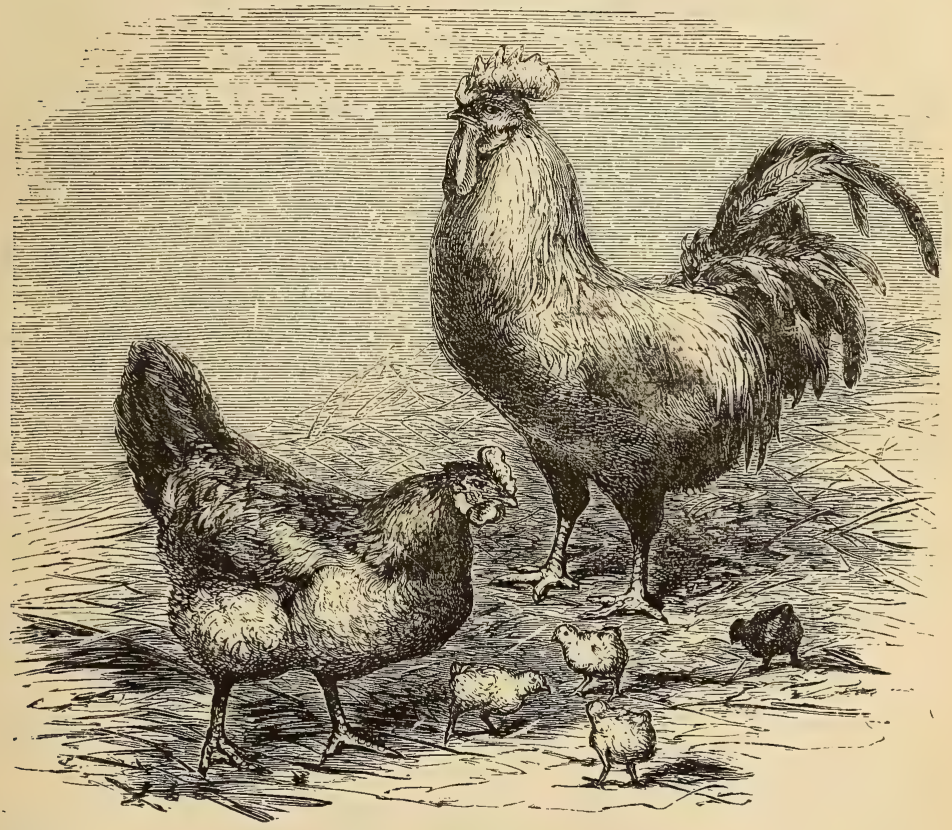

Fig. 155.-Domestic Fowls.

should be inclined to believe that in accordance with their different appearances, they have more or less of the blood of the races previously enumerated in their veins.

The male of the domestic race is thick-set and massive, but without heaviness. His upright and bold walk denotes pride. Without being an habitual runner, he moves with rapidity, but when driven to fly it is with difficulty he raises himself from the ground, as if Nature had destined him to live always by the side of man, attached to the 
earth which feeds them both. The Cock is a perfect model of a sultan; he attaches an entire seraglio to his train. His love is a curious mixture of delicate attentions and revolting brutalities. See him walking in the midst of his companions, he assumes an air at once proud and defiant. He directs his wives, protects them, watches them with restless tenderness, and if he finds a savoury morsel he unselfishly offers it to them. When the time for feeding comes, by voice he invites them to pick up the grain spread upon the ground; on the contrary at other times he is cruel and brutal both to hens and chickens. Of a jealous character, the Cock cannot suffer a rival; thus battles are inevitable when two males inhabit the same poultry-yard. With flashing eyes, head lowered, and feathers of the neck bristled, the two adversaries observe each other for a time in silence. At last the storm breaks with violence; they precipitate themselves upon each other, and fearlessly fight with both beak and spurs till the earth is reddened with their blood. These battles, which sometimes last an hour, only cease to recommence the next day, till one of the champions succumbs, or acknowledges the supremacy of the victor. The cock sometimes employs his courage and strength in more noble contests, for he does not fear to expose his life for the defence of his seraglio. Man, who knows how to utilise even the bad instincts of animals, has not failed to employ their natural combativeness in ministering to his pleasures. In olden times the Greeks delighted in cock-fights; those of Rhodes were particularly renowned for their game qualities. It is related that Themistocles, marching against the Persians, who had invaded Greece, and seeing the troops very much discouraged before the battle, recalled to them the obstinacy these birds displayed in their combats, and then added, "These animals show their courage for the pleasure of victory; but you, soldiers, you go to fight for your gods, for the tombs of your fathers, for your children, for your freedom." These words reanimated the failing ardour of the Greek troops, and the Persians were vanquished. In memory of this event the Athenians consecrated a special day in the year to cock-fighting. The Romans borrowed this pastime from the Greeks. Even in the present day cock-fighting is still in favour in various parts of the East. In Java, Sumatra, and Manilla this amusement is carried to the length of folly; the inhabitants of these countries scarcely ever travel without a favourite bird, which they carry under their arm. It is by no means rare to find gamblers betting not only their fortune, but even their wives or daughters, upon the strength and dexterity of a champion cock. In England the 



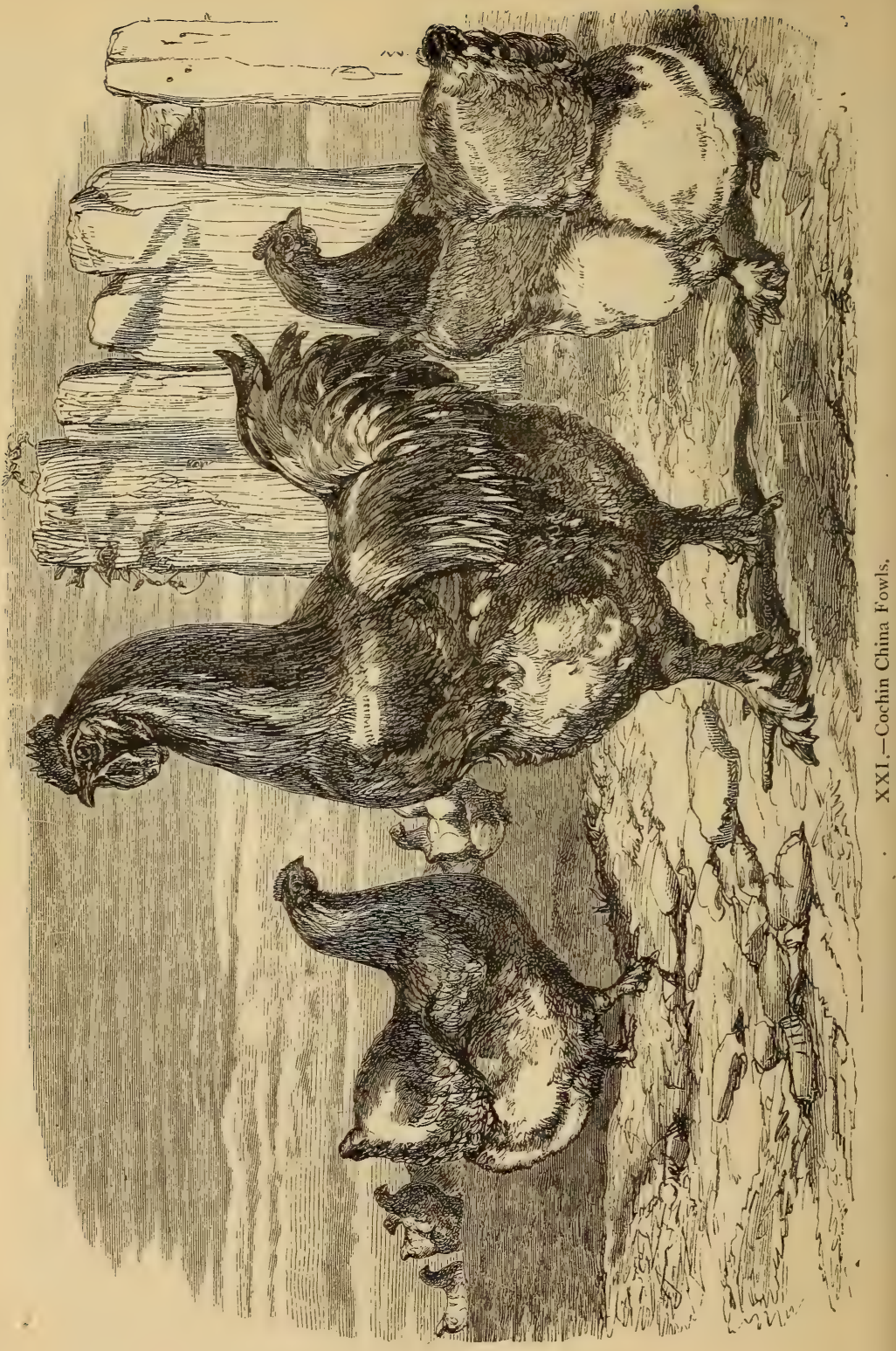


barbarous practice in former days was a favourite pastime, nor is it now entirely abandoned. Henry VIII., we read, instituted rules for the guidance of this popular sport. His example most of the English kings followed. Charles II. and James II. took it under their special protection. In the latter's reign cock-fighting was almost a science, regulated by voluminous codes, laws, and regulations, determining the circumstances of the combat, and settling the interests of the bettors. Now, however, it is almost exclusively confined to a few of the lower classes, the matches generally taking place on one or other of the few holidays at their disposal. On these occasions the crowd gathers, the bets are arranged, which sometimes rise to considerable sums. The spectators contemplate with barbarous pleasure the combat, as both adversaries, armed with artiticial spurs of pointed steel, oppose each other. When released, they attack furiously, using their steel spurs with great adroitness. The fight only terminates by the death of one of the combatants, and the victor is henceforth valued in proportion to the severity of the battle he has won. But his triumph is of short duration; the late hero is called again to do battle, the spur of a more powerful adversary strikes a vital part, and he in his turn expires in the arena. The victor, upon whom formerly so much interest rested, who excited so much admiration and such enthusiastic praises, is now in turn defeated - the former favourite of Fortune is deserted by the fickle goddess. In the poultry-yara the Game Cock is quarrelsome, and even cruel; but this may be said of poultry generally. If one of their companions is sick or wounded, all not unfrequently unite to put an end to its sufferings and life. A stranger is certain to meet with a bad reception; when first introduced to his new companions the others set on it in a body, and only cease hostilities at the end of several days, unless the Cock, who is the lord and master of the yard, takes the new arrival under his protection. Hens feed on anything that comes in their way; this renders them valuable to country-people, for they yield a profit without occasioning expense. Grain, herbs, worms, insects, carrion, rubbish of all kinds, are alike acceptable to them. (Plate XXI.)

In France Hens begin to have eggs towards the month of February, and cease about the beginning of autumn, when they moult. By giving them heating food, they can be made to lay even in winter. They generally produce an egg daily-sometimes, but rarely, two. The male exercises no influence in this respect; that is to say, Hens lay eggs without a Cock, but such eggs are clear or unfruitful. The cry of the Hen after laying is well known. 
When she has produced about twenty eggs a desire to sit is manifested: if this is permitted, twelve or fifteen eggs, placed in a basket filled with straw, are given her; uttering a peculiar clucking, and spreading her wings, she sits upon her treasures, and covers them with so much perseverance as sometimes to forget to eat or drink. During twenty-one days the eggs are maintained at a uniform temperature of about $40^{\circ}$ centigrade; at the end of that time the young chickens burst their shell. The Hen fulfils the duties of a mother with incomparable devotion and tenderness; she follows her young step by step, call them to her when they stray, and seeks nourishment for them, disregarding her own wants till theirs are satisfied. Against all dangers she warns and protects them. If a bird of prey appears, she hastens to meet it, and assumes such a menacing attitude that few will not decline the contest. The chickens rapidly develop. At the end of a month the crests of the males. show ; at six months they have acquired the vigour necessary for reproduction, females begin to lay about the same time. At the age of three months transforming the younger birds into capons and pullets is performed-names given to those deprived of their sexual organs. In this condition they are fattened, and acquire a superior flavour and delicacy of flesh. Pullets and capons, in losing the gene-rative faculty, lose also the inherent characteristics of their sex. The temper of the male becomes so subdued that he has been made to perform maternal duties when a hen has deserted her chickens to recommence laying. This is done by plucking out feathers from the capon's stomach, and then rubbing the part with nettles; the chickens, gliding under him, allay the pain which the stings have caused, and thus the bird, deriving pleasure from his wards, soon attaches himself to them. The departments of Sarthe and Ain are celebrated for the pullets there raised.

Hatching is sometimes performed by artificial incubation. In olden times the Egyptians had recourse to this means to increase the production of poultry. The method which was used and which is still employed in modern Egypt, consists in placing the eggs in a furnace maintained for twenty-one days at a uniform temperature of $40^{\circ}$ centigrade. By this means a hundred millions of fowls are annually produced in Egypt. Simple as this operation appears, it is not without difficulty, for attempts in France have never been crowned with success. In the Sunda Islands artificial incubation is accomplished by men, who, for a small salary, remain for three weeks stretched out and immovable upon eggs placed in ashes. Antiquity has bequeathed to us the story of the Empress Livia, who, being 
pregnant, and desiring a son, hatched an egg in her bosom. The egg produced a male bird; the empress, in consequence, concluded that her issue would be a son. This was realised, for she brought into the world Tiberius - rather a wicked bird, as every one knows.

The Tragopans (Ceriornis) and the Firebacks (Gallophasis) both belong to India or the Indian Archipelago, and are all remarkable for the brilliancy of their plumage. The Tragopan, which Buffon calls the Horned Pheasant, looks like a cross between the Domestic Fowl and the Pheasant, but is distinguished by two small horns which decorate the head of the male. The Firebacks live in a wild state, being as yet unknown domesticated, consequently little can be said of their habits, they probably differ but slightly from those of the pheasant.

Guinea-fowls (Numida) have remarkably small heads for their size; 'beak and neck short; the tail equally short and drooping; the tarsus very low, and destitute of spurs; body round; wings short and concave; on the head is a hard crest of a reddish blue, sometimes replaced in mature birds by a tuft ; the wattles are fleshy, and hang under the beak.

The Common Guinea-fowl (Numida meleagris, Fig. I56), has a slate-coloured plumage, covered with white spots; it is indigenous to Africa, and its introduction into Europe dates from far back, for it was done by the Greeks and Romans. The former made it an emblem of paternal affection. According to Greek writers, the sisters of Meleager felt such grief at the death of their brother that Diana, to terminate their woes, turned them into Guinea-fowls. The goddess, wishing that their plumage should bear the trace of their tears, marked it with white spots.

The Romans, who highly esteemed the flesh of these birds, propagated them with the greatest care; but after the invasion of Rome by the barbarians they disappeared from Europe; and even during the Middle Ages we cease to hear of them. The Portuguese re-discovered them in Africa on their return from the Indies, and again imported them into Europe, where they have since multiplied to a great extent. But the turbulent and quarrelsome character of these birds, and their noisy and discordant cries, are serious obstacles to their becoming favourites; they have also ceaseless quarrels with Hens and Turkeys, and although not so strong as their antagonists, they fight them fearlessly. They have been seen to attack the young of other birds, and split their skulls with a blow of their beaks. They. show great attachment to their own young, yet they occupy themselves but little with the cares of a family; consequently their progeny is 
generally brought up by Hens or Turkeys. Although bad nurses, their fecundity is very great, and when well-fed they lay as many as I 00 eggs in a year; these are much sought after, and epicures prefer them to those of the Hen. Their flesh, though good, is not so much esteemed as that of the Domestic Fowl. There are now several species known in a wild state in Africa, and in a domestic state in Europe. They are numerous in Arabia, where they are found in Iittle bands composed of a male and several females in the neighbour-

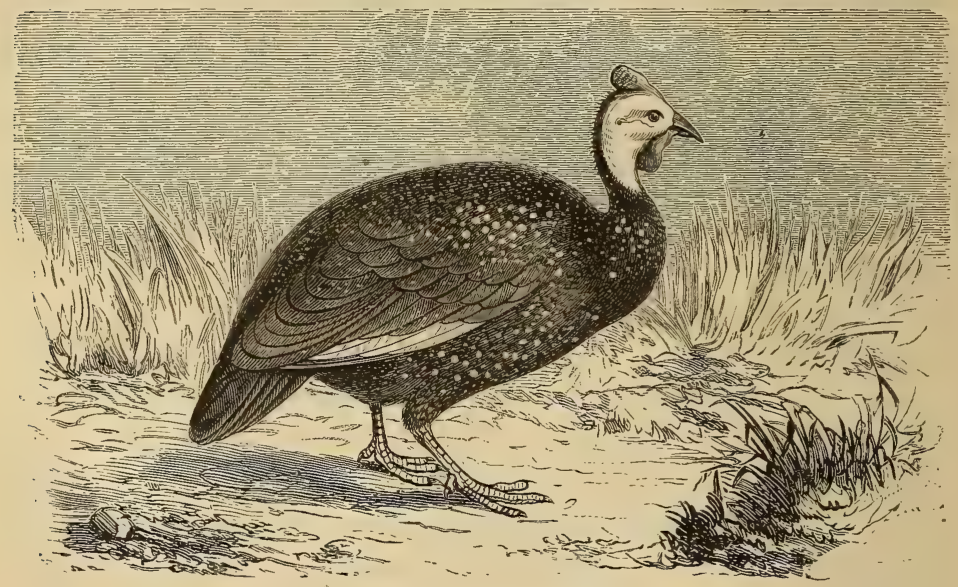

Fig. I56.-Guinea-fowl.

hood of marshes. Transported into America after the discovery of that continent, the common variety is perfectly acclimated there, and is even to be found wild in some of the vast forests and savannahs of the West Indies.

Turkeys (Meleagris gallopavo) are birds of large size, easily distinguished from other gallinacean fowls by the following characteristics :- Bare heads and necks, decorated with fleshy appendages-those of the neck, which fall under the head in front of the bird, are capable of being inflated and much enlarged under the influence of love or anger; a brush of long and straight hairs hangs at the base of the neck; the tarsi are strong, and provided with slightly-developed spurs; lastly, the tail is round, 
of moderate length, and at the will of the bird can be expanded like a fan.

The Turkey was originally imported from North America, where

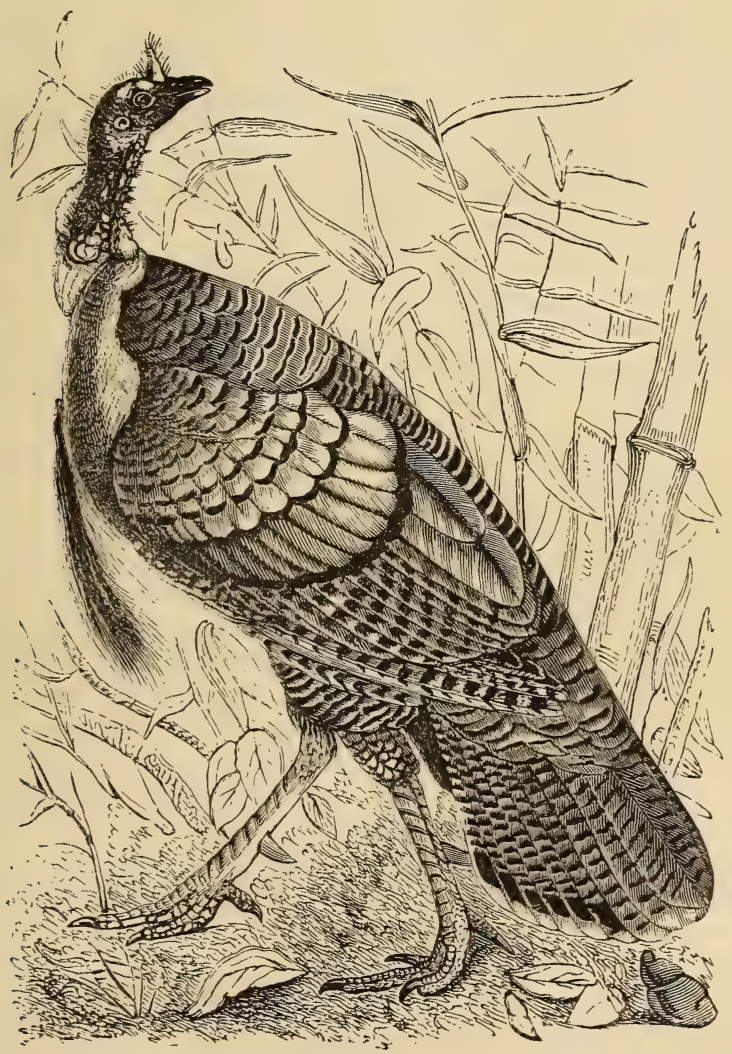

Fig. 157,-Wild Turkey.

it still lives in a wild state (Fig. I57), being frequently met with in the forests which border the Mississippi, Missouri, and Ohio rivers. The Domestic Turkey is not so handsome in plumage as is the wild, 
but the former generally much exceeds the latter in size. The colour of the Wild Turkey is brown, mixed with blue and green, giving out a diaphanous metallic brilliancy. The full-grown male bird sometimes measures over three feet, and weighs from twenty to twentyfive pounds. The American naturalist Audubon speaks of having seen one which was upwards of thirty-six.* The female is much smaller, and seldom exceeds ten pounds in weight. Her plumage cannot vie with that of the male in harmonious blending of colour. Although it does not appear constructed for the purpose, the mature bird is capable of taking considerable flights, crossing with ease in its wild state those gigantic rivers that traverse its habitat; but, as a rule, this bird only takes wing when compelled, for it runs with surprising rapidity, distancing the common cur dog with ease. It accomplishes long journeys on foot; not, however, caused by atmospheric influence, but from want of sustenance. It is generally towards the beginning of October that these migrations commence. The Turkeys then unite in groups of from ten to a hundred individuals, and seek a new abode; the males forming a separate party from the females. The necessity of protecting their young from the brutality of the old cock birds, who kill them if opportunity offers, inspires the hens with this habit. It sometimes happens that the emigrating band are stopped by a watercourse, when all evince great agitation by spreading their tails, uttering frequent gobbles, and yielding themselves to extravagant demonstrations. At the end of a day or two, after having inspected the neighbourhood, they mount upon the branches of some of the highest trees, and take wing to traverse the obstruction. Some of the young are certain to. fall into the water, but they know how to swim. When all have reached the opposite bank, they run hither and thither as if they were mad, and from their recklessness at this time it is very easy to approach and kill them. These birds pair in February or March, according to latitude; the females produce eggs six weeks afterwards; at this time the hen secretes herself, as the male would break them. The nest is an indentation in the ground, lined with soft grasses, moss, and dry leaves. When the mother leaves her eggs to seek food, she carefully covers them with reeds or grass, the better to screen them from the sight of the fox, lynx, or crow. The incubation lasts about thirty days. As the time for hatching approaches, no power can make the mother leave her nest, no peril will cause

* Near Philadelphia, Penn., a breed of Domestic Turkeys, are to be found remarkable for their size-some are said to have reached fifty pounds weight.-ED. 
her to desert her charge. On being hatched, the young Turkeys, under the protecting care of the old bird, are led to sequestered feeding-grounds, and do not leave her till the end of several months. Wild Turkeys have many formidable enemies - the most destructive being man; next the lynx and the eagle owl-they are, therefore, very wary, and when on the ground secrete themselves at the least appearance of danger; but if perched upon a tree, particularly if the weather be wet and foggy, they are less guarded, and consequently can be more easily approached by the sportsman. On a misty moonlight night American hunters take their posts under trees where ?urkeys are in the habit of roosting. Under such circumstances the flock will not attempt to escape, although numbers of their companions are being momentarily killed.* This apparent apathy is doubtless owing to want of sagacity for which, as well as for their ludicrous aspect and eccentric attitudes, Turkeys have gained a reputation for stupidity. This bird, however, sometimes gives proofs of intelligence of a high order, as the following fact, related by Audubon, proves. He had reared a Wild Turkey, which had become extremely tame, but the love of independence remained very strong in the bird, for it could not accustom itself to the pent-up life of its domestic relations. Thus, it enjoyed the greatest freedom; it went and came, passing nearly all its time in the woods, only returning to the house in the evening. At length it ceased to come home. Some time after the desertion of his pet, Audubon, whilst hunting, perceived a superb Wild Turkey, upon which he set his dog; but, to his great surprise, the bird did not fly, and the dog, instead of seizing it when it was overtaken, stopped and turned his head towards his master; greater still was the hunter's surprise when, having approached, he discovered his old pet. This bird had recognised the dog, and knew his confidence in his old friend would not be misplaced.

Turkeys feed upon herbs, grasses, fruits, and berries of every lescription; they are partial to beech and other nuts; and their liking for wheat and maize is such that they frequent the neighbourhood of cultivated fields, where they make great ravages. They also occasionally feed upon insects, frogs, and lizards. The large destructive grub familiarly known as the tobacco worm they are particularly partial to, and are consequently encouraged by tobacco planters. In a domestic state they are even known to have kllled and eaten rats. One curious peculiarity in the history of the Turkey

* In the woods on the margin of the Wabash river in Illinois I have known eighteen Wild Turkeys killed before the remainder of the flock became alarmed and took flight.-.ED. 
is its horror of red; the sight of a scarlet object tnrows it into the most comical fury. It is needless for us to vaunt the flesh of the Domestic Turkey; every one is agreed on this subject. We will only say that, from the testimony of many travellers and naturalists, the flesh of a Wild Turkey, killed in winter or spring, before laying, is far superior to that of the domestic bird, those coming from Southern Indiana and Illinois being considered by Americans as the finest. The Turkey, being indigenous to America, was naturally unknown to the ancients. The precise date of its introduction into France is not recorded. According to some, it was at the end of the fifteenth century; to others, only at the commencement of the sixteenth. Anderson affirms that the first Turkeys raised and eaten in France were served at the marriage of Charles IX., in I 570.

The Honduras or Ocellated Turkey (Meleagris ocellata) is one of the most beautiful gallinaceans; its plumage is magnificent; the tail is enamelled with large blue eyes, each of which is surrounded with a circle of brilliant yellow and purple. It inhabits the country surrounding the Bay of Honduras, Southern Mexico, and all Central America. At Regent's Park Gardens, London, is to be seen a splendid hybrid, bred between the American Wild Turkey and the Honduras species.

The family of Pavonidæ comprehends the genera Pavo cristatus (Fig. I58), Pavo Javanicus, Polyplectrons, and Lophophores. The feature which essentially distinguishes Peacocks from other Gallinaceans is the immense tail which they possess. This appendage, formed of long, large, and tufted feathers, coloured with the richest shades, is capable of being raised up like that of a Turkey. When we contemplate this magnificent ornament, in which purple and gold vie with the most varying colours of the emerald, and notice the innumerable and brilliant eyes with which it is studded; when with delight we view the bird's lofty stature, elegant shape, noble carriage, crowned with the emblem of royalty, we cannot help being struck with admiration. The Peacock was known from the earliest time; for it is mentioned in the Bible as one of the most precious products brought from Asia by King Solomon's ships. It made its first appearance in Greece after Alexander's expedition into India. Alexander, it is said, was so astonished at the sight of this bird that he forbade it to be killed under the severest penalties. For a long time they were very rare, and fetched a high price at Athens, and the people from the neighbouring towns assembled in crowds to see them. From the Greeks they passed to the Romans ; but this nation, more fond of what gratified the palate than the eye, soon made them 


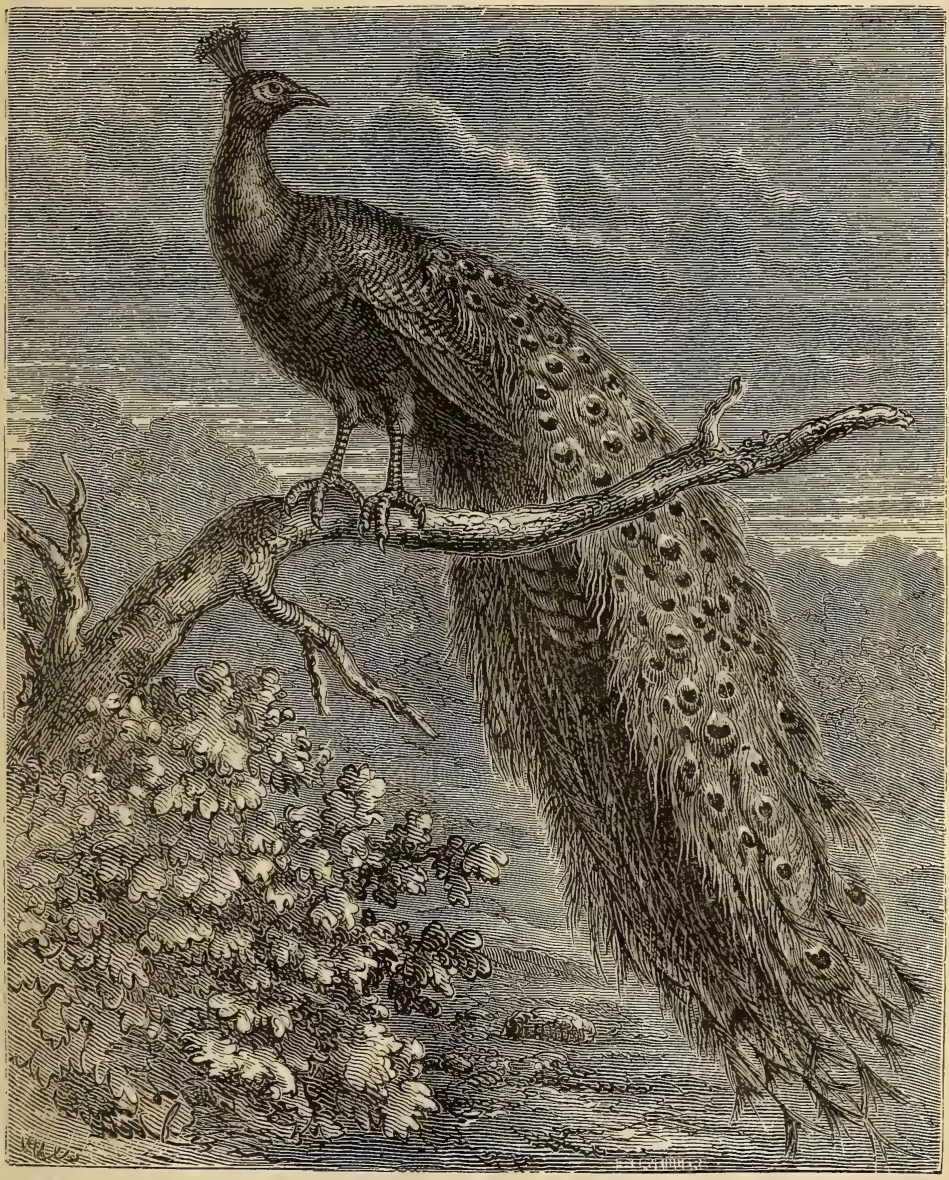

Fig. I58.-Peacock.

figure in their feasts. Peacocks consequently were rapidly propagated in the poultry-yards of the rich patricians; and some of the emperors, such as Vitellius and Heliogabalus, out of a spirit of lavish waste, 
caused dishes of the heads or brains of peacocks to be served. By degrees, however, they spread throughout the empire, and thus the Peacock has become naturalised in Europe. During several centuries its exquisite and delicate flesh was in very great favour; but the importation of the Pheasant, and later that of the Turkey, introduced rivals who have taken precedence for table honours. The Peacock is now bred principally for ornamental purposes; even when it does. make its appearance at some ceremonious repast, it is intended more to gratify the eye than the palate, for the carcase is invariably decorated with the bird's resplendent tail. The Domestic Peacock, which. is now the pride of our gardens and parks, is indigenous to India and the isles of the Eastern Archipelago, where they still live in large troops in the depths of the forests. They are so abundant in localisies that it is said the traveller, Colonel Williamson, being delayed one. day in the district of Jungleterry, counted not less than from I,200 to $\mathrm{r}, 500$. The Peacock runs with such rapidity that it often escapes pursuit by this means alone; it takes wing with difficulty, and flies slowly, though it can prolong its flight to a considerable distance. It feeds upon grain of all kinds, which it swallows without crushing. To roost for the night, it perches upon the limbs of the highest trees. In a state of domesticity it retains this fancy for elevated places, so takes pleasure in perching on the roofs of houses, even on the summits of chimneys. Elevation appears to excite it, and to endow it with a spirit of vindictiveness and destruction, for when in such situations it will scatter tiles, or tear up thatch, as the case may be, doing frequently incalculable damage. This bird also commits great ravages in cultivated fields. The Peacock at times utters deafening cries, which contrast unpleasantly with its dazzling plumage-one wishes for a more harmonious voice from such a magnificent hody. It is polygamous. At the commencement of the spring the male displays to the females all the splendour of his plumage; struts, spreads his tail, glories in his own grandeur, and receives with pleasure the admiration which his charms draw forth. His vanity at that season knows no bounds; for the adulation of his wives is not sufficient for him, but he must have eulogiums from man. Complete master in the art of showing itself, it manages the transitions of light and shade so as to be presented to the greatest advantage. At the end of August this beautiful plumage falls off, not to come forth again till the spring. It is said that the Peacock is so ashamed of having lost that which was his pride, that he afterwards shuns the sight of man. This is better explained by the fact that the time of inoulting is for it, as for all other birds, a period of sickness ; conse- 
quently it retires into solitude, to find there the calm and tranquillity which such a critical state demands. The Wild Peahen lays from twenty to thirty eggs in a hole hollowed in the ground; the domestic bird is less fruitful. To hide the nest from the searching eye of the male, which breaks the eggs whenever opportunity offers, is one of the female's first duties. Incubation lasts from twenty-seven to thirty days. The young follow their mother from their birth, and attain

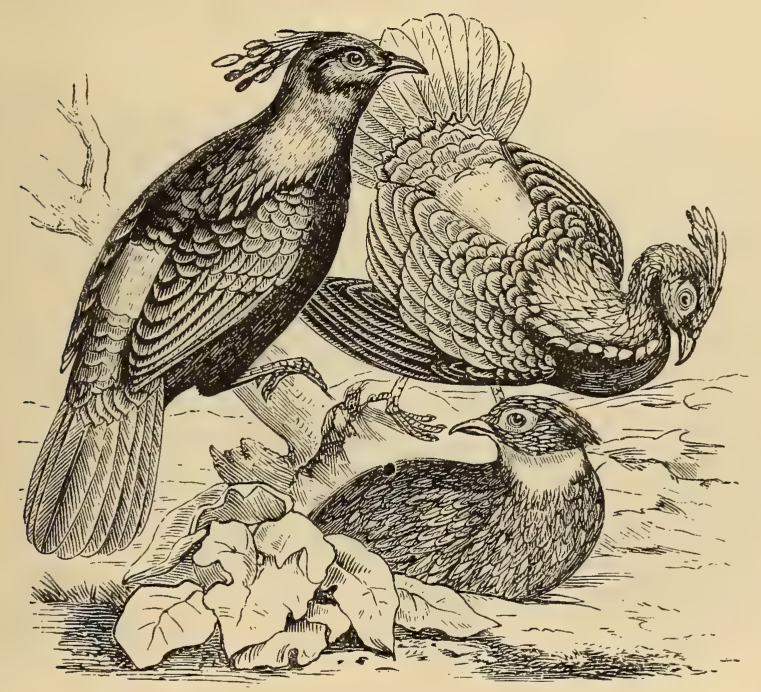

Fig. I59.-Impeyan Pheasants.

their full development in three years. The Peahen, like the Hen Pheasant and the Common Hen, adopts the plumage of the male when age has rendered her unfruitful. The Peacock lives from twenty-five to thirty years; some authors have wrongly attributed to them the longevity of a century.

Peacock Pheasants (Polyplectron) owe their name to the superabundance of spurs with which they are armed; for the males always possess two, sometimes three, on each limb. The plumage of these birds, like that of Peacocks, is sprinkled with glittering ocellations; but their tails are shorter, and not susceptible of expansion. 
There are three or four varieties known, which inhabit India, China, and the Isles of Sumatra and Borneo. Their habits have not yet been studied.

Impeyan Pheasants (Lopophorus Impeyanus, Fig. I59), are little better known than the Peacock Pheasants. They prefer cold climates, which sufficiently accounts for their predilection to the elevated ridges of the Himalayas. No one has as yet succeeded in acclimating them in Europe. This is one of the most brilliant Gallinaceans; its plumage, bedizened with the most lively colours,

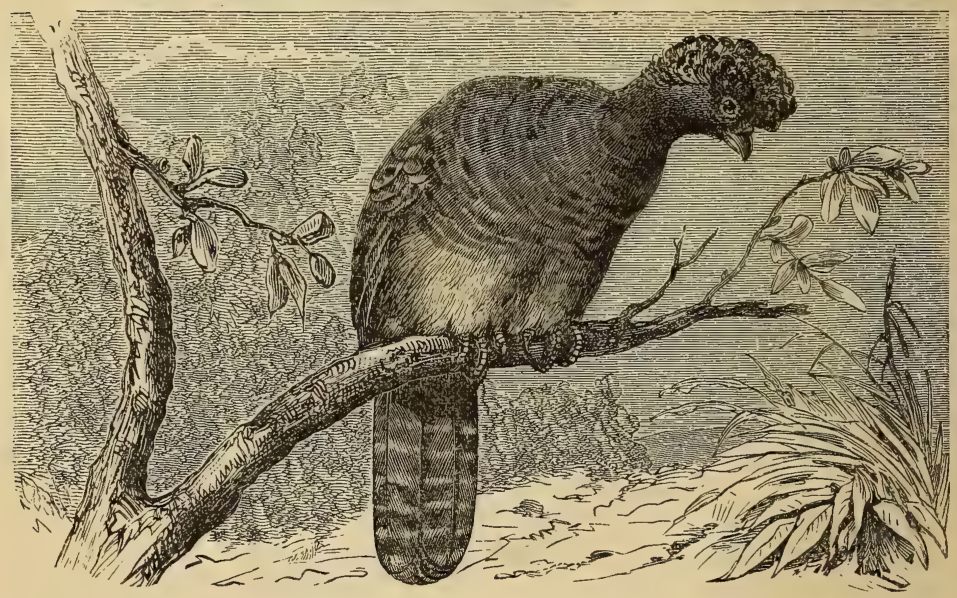

Fig. 160.-Crested Curassow.

has gained for it in India a very significant name-that of the Golden Bird.

Under the name of Alectors (from the Greek ả $\lambda \lambda^{\prime} \kappa \tau \omega \rho$ ), Cuvier has united a certain number of American birds bearing some resemblance to our Domestic Fowl, the principal of which are the Curassows, of which the crested variety (Crax alector, Fig. 160) is best known. They are analogous in form and size to a Turkey, of which they are the representatives in Central America, Guiana, and Brazil. They have a large tuft upon the head, formed of distorted and erectile feathers, and are without spurs. They live in numerous 
troops in the midst of forests, and feed upon seeds, berries, and buds. Naturally very gentle, they readily yield to captivity, when they become familiar, and evince pleasure in the caresses of their masters. Sonnini relates that he has seen them wander at liberty through the streets of Cayenne, return to their homes without hesitation, and leap upon the tables to take their food. Their flesh is exquisite, and in all respects worthy of the favour of epicures. These different qualities should cause an honourable place to be assigned them in our poultry-yards ; it is, therefore, to be regretted that the attempts to acclimate these birds made by the Empress Josephine at the commencement of this century have not been renewed.

The Pauxis (Ourax pauxi) differ but little physically from the Curassows. They have the same habits and characteristics, and easily become domesticated.

Guans (Penelope cristata) and Parraquas are two genera of birds strongly resembling each other ; they have an analogy to Pheasants, but only on account of their general forms ; they possess the confiding and peaceable nature of Curassows, but do not so willingly submit to domestication. Their flesh is delicious. They also deserve to be acclimated.

The Hoatzins, or Crested Touraco (Opisthocomus cristatus) inhabit the savannahs of Guyana. Their flesh, which exhales a strong odour-due no doubt to the vegetables on which they feed exclusively - is far from being agreeable. It has long been a disputed point whether it should be classed under the present heading or among the Passerines. The Hoatzin is almost as large as a Turkey; the head is decorated with a long flowing crest, and its bearing is imposing and handsome.

\section{COlumbide.}

The Columbida family establish a transition between real Gallinaceans and Passerines; in short, they partake of the nature of both. Whilst they approach the former in their anatomical and purely material characteristics, such as the structure of their beaks, sternum, and crops, they resemble the latter in their elegant forms, peaceable manners, and attractive habits.

Like the Passerines they are monogamists. The male and female build their nests together, and share the task of incubation and the bringing up of their progeny ; which, when released from the shell, are blind, covered with down, and unable to move about 
like young Gallinaceans. In this family there are generally two young hatched at the same time; and it is a very curious fact that there is almost always a male and a female. They do not quit the nest till they have acquired sufficient strength to use their wings and fly. During the early portion of their existence they receive no other nourishment from their parents than a sort of pap secreted in the walls of the gullet; but at the end of some days the father or mother discharges into the beaks of the young the food which they have collected. When sufficiently developed, the offspring travel with the adults in large flocks, to seek a milder climate or better feeding-ground: their migrations in the natural state occur in spring and autumn. What distinguishes them from the true Gallinaceans is that they have a thumb inserted even with the other toes, and that, consequently, they are able to perch. Their food consists principally of seeds, berries, and fruits, sometimes insects, and a peculiar little snail similar to that found in the Isle of France. Their flesh, generally good, in some species, such as the Crowned Pigeon, acquires an exquisite flavour. Thus, whether in the domestic or wild state, they occupy an important position in reference to public alimentation. Although their bodies are plump, and even present some appearance of heaviness, their flight is easy and sustained, so that Pigeons have been known to accomplish in a few hours journeys of surprising length.

We will divide the Pigeons into three families-the ColombiGallines, Colombes, and Colombars.

\section{Colombi-Gallines.}

A certain number of birds rank in this family, which, with the general forms of Pigeons, still preserve the habits of Gallinaceans; hence the mixed name of Colombi-Gallines. Thus they constantly live on the earth, build their nests there, and only take refuge upon trees to pass the night or escape from danger. They run perfectly, but fly badly, and are sedentary; lastly, some species have cephalic nudities and fleshy appendages, or long, movable feathers round the neck, like the male of the Domestic Fowl. Physically they are characterised by a slight and straight beak and by rather high tarsi. This family comprises a very large number of species spread throughout Central and South America, the isles of the Indian Ocean, and a great part of Africa. The compass of this work will not permit us to examine.all; we will merely mention the most remarkable, the Crowned Pigeon, or Goura (Goura coronata, Fig. I6I) very common in New 
Guinea and the Moluccas. The plumage of this bird is of a beautiful greyish blue; its head is ornamented with a pretty plume of straight, long, and tapering feathers ; it is about the size of a Domestic Fowl, and very highly esteemed for the qualities of its flesh; consequently the inhabitants of the above islands raise it in their poultry-yards.

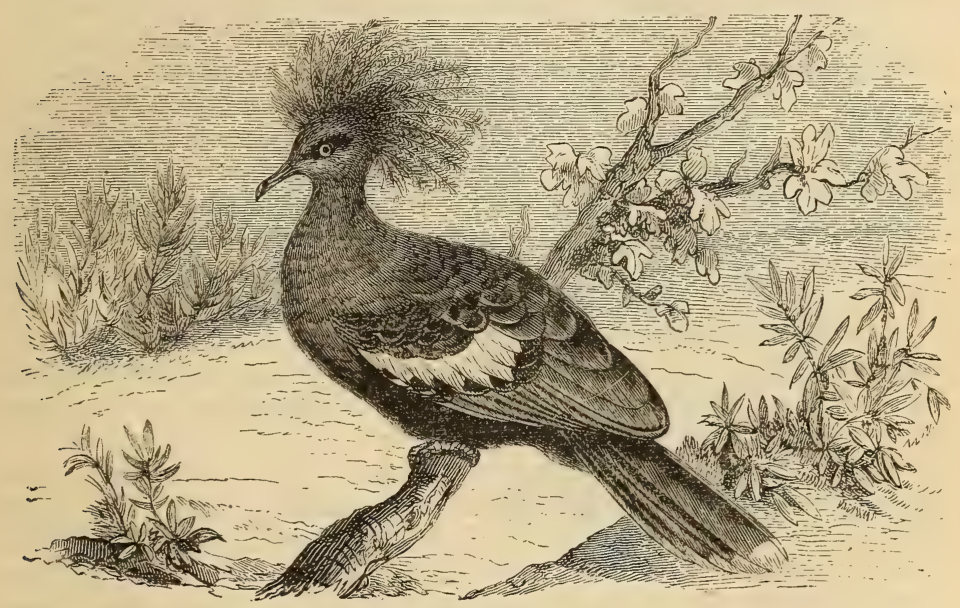

Fig. I6r.-Crowned Pigeon.

\section{Colomian.}

Colombes have slender beaks, long wings, and short tarsi. 'The principal species are the Ring-dove, Stock-dove, Rock-dove, Domestic Pigeons, Turtle-doves, and Migratory Pigeons.

The Ring-dove or Wood-guest (Columba palumbes), are the largest species of this family ; their plumage is slaty grey, with bluish, green, and rose-coloured reflections. They are spread throughout all Europe, excepting the snowy regions of the North. They are very common in France, where they arrive in numerous flocks early in March, generally departing in October or November. The Ring-doves or Cushats, as they are also called, inhabit forests, and delight among the branches of large trees. They feed upon acorns and beech-nuts, and are very partial to cherries and strawberries. With the farmers this bird is far from a favourite, for its appetite is insatiable, and it is 
alike destructive to grain in the ear or germinating. The female builds her nest in lofty trees, which is formed out of materials which the male brings her, such as little dead branches detached from trees; for the boughs which strew the ground are never used. This birthplace of the young is but a rude structure, scarcely large enough to contain them, and sometimes falls to pieces before they are able to fly ; in this case the brood retains, if possible, a position on the large branches which supported their previous dwelling. Queests, as they are frequently called, generally lay in March and August. Incubation lasts twelve days, and the progeny can take flight about two weeks afterwards. During the time of incubation and education of the young the male remains near the female, constantly cooing; as if to break the monotony of her occupation. In the wild state Ringdoves are shy and difficult of approach, but their characters become modified by domestication, or even by an independent life passed in the neighbourhood of man. Thus, taken before leaving the nest, they familiarise themselves without difficulty, and do not appear to regret having lost their liberty. They do not breed in this condition -or at least we do not know how to make them do so ; it is said that the ancients understood this art.

Ring-doves are seen in Paris which have from time immemorial chosen a domicile in the gardens of the Tuileries, Luxembourg, and Champs Elysées. They are very tame, and come almost under the feet of promenaders. Few inhabitants of the gay city have not seen at the Tuileries the charming spectacle of an old man who attracts round him numbers of wood-pigeons and sparrows, to which he distributes crumbs of bread. The confidence they show to this kind friend as an acknowledgment of his goodness is wonderful : they rest upon his shoulders, take the bread from between his fingers, and even from his mouth, and allow themselves to be caressed without manifesting the least fear : this is evidence of the possibility of taming Ring-pigeons.

Stock-doves (Columba Enas) have many traits of resemblance to Ring-pigeons, but they are smaller, justifying the name of Little Queest which is sometimes given to them; their habits are the same as those of the preceding species, except that they build their nests in the hollows of trees instead of upon the branches, as the former species do. They are very plentiful in the South of Europe and in Africa. They leave France regularly in the month of October.

Rock-pigeons (Columba livia, Fig. I62) delight in stony and arid places. They deposit their two eggs in the clefts of rocks or in ruins. They are seldom seen in Europe in a state of complete 
liberty, except upon some parts of the coasts of England, Scotland, Norway, and certain islands of the Mediterranean. They willingly sacrifice their independence to live in pigeon-houses. They are generaliy regarded as the founders of the numerous races of our Domestic Pigeons.

Domestic Pigeons, probably sprang from the Rock-doves, are of two kinds-1he Colombier Pigeons and the Aviary Pigeons. The former enjoy almost complete liberty; they traverse the country all day to seek for food, and sometimes even return to a wild state; the latter are quite tame, and the door of their habitation can be left open without danger; they go a little distance, and always return to their domicile. If Domestic Pigeons cause some harm to our crops, they amply compensate for these devastations by the services which they render to agriculture. They are equally valuable to the breeder and consumer: the former derives a certain profit from them, and tne latter an agreeable and economical article of food. To

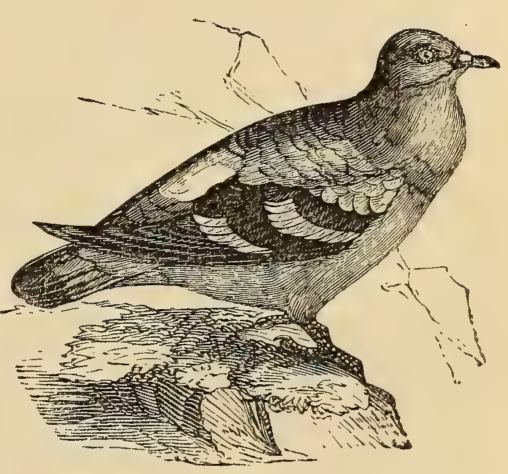

Fig. I02.-Kock-pigeon. give a sufficient idea of the resources which they supply to public alimentation, we have only to state that certain species lay as many as ten eggs a year. Further, they supply a manure which is very efficacious in improving some soils. Raising pigeons necessitates certain precautions which cannot be neglected without bad results : the greatest cleanliness is necessary in the pigeon-house or aviary; all turbulent individuals, which sow discord, and often injure the fecundity of females, must be excluded; and the races must be separated as much as possible the one from the other, in order to avoid the production of sterile varieties. Amongst the domestic species the naturalist can study at leisure the manners of Pigeons, and form an exact idea of their natures and inclinations; for he can observe them from their first steps, making their early timid endeavours to raise themselves in the air; afterwards noting at more mature age the approaches of the sexes, and their fidelity to each other through years. We will examine rapidly the principal races of Domestic Pigeons. 
The first is, as we have said, the Common House Pigeon, differing slightly from the Wild, which almost exclusively supports the population of pigeon-breeders; this is sometimes called the Blue Rock. It is only a modification of the Wild Rock-dove ; in form it is, however, more slight, while the plumage is prettier. It is one of the most fruitful species.

The Pouter Pigeon owes its name to the faculty which it possesses of inflating its crop to an immense size by the introduction of air. This peculiarity often destroys them; indeed, when feeding their young, they find so much difficulty in causing the seeds which they have swallowed to reascend into their beaks, that they contract a malady which is frequently fatal.

The Roman Pigeons, thus named because they are very common in Italy, are easily recognised from the circle of red which surrounds their eyes.

The Swift Pigeon is of smail size, its flight is light and rapid, and its fecundity very great.

The Carrier Pigeons belong to this race. They are celebrated for their attachment to their birthplace, or to the spot that contains their offspring, and for the intelligence which enables them to regain their native countries from whatever distance. 'Transport them miles from their homes, even in a well-closed basket, then give them their liberty, and they will return, without the slightest hesitation, to the place from which they were taken. This valuable faculty has long been utilised, especially in the East. The Romans made use of Pigeons as messengers. Pliny says that this means was employed by Brutus and Hirtius to concert together during the siege of a town by Mark Antony. At the siege of Leyden, in 1574, the Prince of Orange employed Carrier Pigeons to carry on a correspondence with the besieged town, which he succeeded in freeing. The Prince, to mark his acknowledgment of the services rendered by these sagacious birds, wished them to be fed with strawberries, and their bodies to be embalmed after death. We learn from Pierre Belon, the naturalist, that in his time navigators from Egypt and Cyprus took pigeons upon their galleys, and liberated them when they had arrived at the port of destination, in order to announce to their families their safe journey. In our century they have been made use of for similar purposes. The fluctuations of the Bourse were for a long time sent from Paris to Brussels by means of Carrier Pigeons.*

The Tumbler Pigeon owes its name to its curious manner of flying.

* In the late siege of Paris they were constantly used.-ED. 
It has a habit, after it has risen to a certain height, of throwing five or six somersaults.

The Wheeling Pigeon describes circles like birds of prey. It is turbulent, and ought to be banished from pigeon-houses.

The Nun Pigeon is recognised by a kind of hood formed of raised feathers, which covers the back of the head and neck, and to which it owes its name. It flies heavily, but is very familiar and very prolific.

The Fan-tailed Pigeon is remarkable for its tail, which is very large, and raised like that of the Peacock, and for the convulsive trembling which agitates it, especially at breeding-time. It thrives badly in an aviary, and is little valued, except as an object of curiosity.

There are two species of Turtle-doves, Turtur communis and Turtur risorius. The former is the smallest species of the family of Colombidæ. They are found throughout southern and temperate Europe, but are more abundant in the south. They arrive in France in spring, and depart for warmer countries at the end of summer. They build their nests in large trees in the shady and most retired parts of woods. They feed on seeds and berries. After harvest they visit stubbles of wheat or other grain ; the abundant nourishment which they there find makes their flesh extremely delicate and nutritious. Although naturally wild, the Turtle-dove is easily tamed when taken young, when it evinces great attachment.

The latter is indigenous to Africa, where it lives in a state of freedom. This is the species which, in Europe, is raised in cages and aviaries. In certain towns of Egypt, particularly Alexandria and Cairo, they are so tame that they walk in the streets, and even enter houses, fearless of the presence of occupants. They are prolific, for they lay every month, except during the moulting season. Their cooing somewhat resembles a laugh-hence the name of Laughing-dove which has been given them. The ancients made the Turtle-dove an emblem of tenderness. This honour is justified by the kind attention which the male shows the female, especially during the period of incubation.

The Migratory or Passenger Pigeon (Ectopistes migratorius, Fig. I63) is the Columba migratoria of many authors: it inhabits North America. They are remarkable for the strength and rapidity of their flight, and for the migrations which they accomplish.

The American naturalist, Audubon, says, "Pigeons have been killed in the neighbourhood of New York having their crops still full of rice, which they could not have obtained nearer than the fields of Georgia and Carolina-600 or 700 miles distant. As their digestion is sufficiently rapid to entirely decompose grain in 
the space of twelve hours, it follows that they must have travelled the above space at the rate of a mile a minute. One of these birds, if able to keep up this velocity, could visit the European continent (from America) in less than three days."

It is not for the purpose of seeking a warmer climate that they

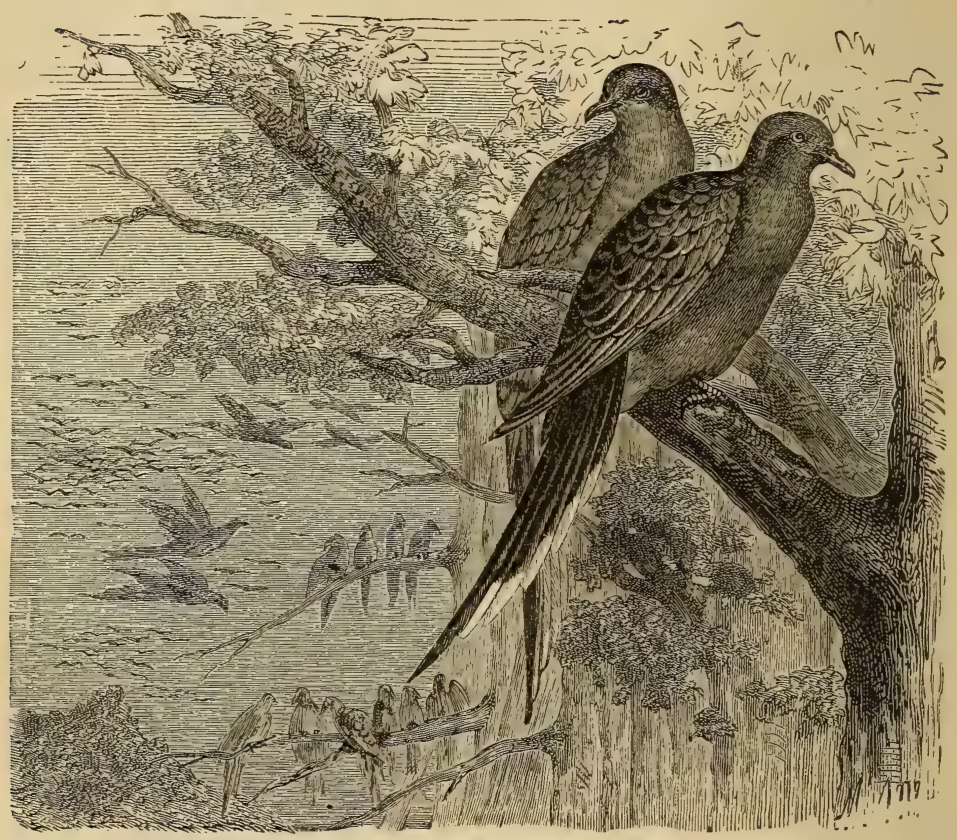

Fig. I63.-Migratory Pigeons.

undertake their journeys, but to procure food when the acorns become scarce in the woods which they inhabit. Their migrations, consequently, are irregular as to date. Looking at the innumerable and closely packed masses of passenger Pigeons which take part in these voyages confuses the mind. Audubon one day endeavoured to count the flocks which passed above him in one hour. He counted I63 in twenty minutes, but he was soon obliged to give up, the 
flights succeeded each other so rapidly. He says: "The more I advanced, the more pigeons I met. The air was literally filled with them. The daylight in full mid-day was obscured as Iy an eclipse ; the dung fell like flakes in a tall of snow ; the buzzing of their wings stunned me, and gave me a sleepy sensation." These Pigeons are endowed with very strong sight. When flying at a considerable height they can perfectly distinguish the places which will furnish them with the means of subsistence. Having found a suitable country, they a'ight, and in a few minutes completely ravage it. Large quantities of them can then be destroyed without any apparent diminution in their number. Some hours after their descent they again take to flight, to regain their nocturnal domicile, frequently twenty or thirty miles distant, where a frightful slaughter is often made amongst them. Long before the sun sets the inhabitants of surrounding counties await them with horses, carts, guns, and ammunition. Some even bring flocks of pigs, to fatten on the flesh of the pigeons which the destroyers are unable to carry away. Audubon, who assisted at one of these slaughters, has related it as follows. He says :- "Every one holds himself in readiness, with eyes directed towards the heavens. Suddenly a general cry of 'They come!' resounds. The noise which they made, although at a distance, reminded me of a strong sea-breeze amongst the cordage of a ship, the sails of which are furled. When they passed above my head I felt a current of air which astonished me. Thousands were already struck down by men armed with poles, but they continued to arrive without intermission. Fires were lit, and it was then a fantastic sight full of frightful magnificence. The birds precipitated themselves in masses, and pitched where they could, one upon the other, in large heaps like barrels. Then the branches gave way under the weight, cracked and fell, bringing to the ground and crushing the closely-packed flocks, which covered every part of the trees. It was a lamentable scene of tumult and confusion. In vain I tried to speak, or even to call the persons nearest to me. It was with difficulty that I could hear the guns fire, and I only perceived they had fired by seeing them reload their arms. Pigeons continued to come, and it was past midnight before I noticed any diminution in the number of the arrivals. The uproar continued all night. At last the day approached, the noise began to abate a little, and long before we could distinguish objects, the pigeons commenced to start in quite an opposite direction to that in which they had come in the evening. At sunrise all that were capable of flying had disappeared. Now 
it was the wolves' turn, the howls of which saluted our ears. Foxes, lynxes, cougars, bears, rats, opossums, and martens, bounding, running, climbing, pressed to the quarry, whilst eagles and falcons of different species flew down from the air to take their part of such rich booty. The sportsmen then, in their turn, entered into the midst of the dead, the dying, and the wounded. The pigeons were piled in heaps, each took what he wished, and the pigs were left to satiate themselves on the remainder."

These massacres are in nowise injurious to the existence of this species. In short, according to Audubon, the number of these Pigeons becomes doubled or quadrupled in a single year.*

\section{Colombars.}

This family, established by Levaillant, comprises some species, which belong entirely to the hot countries of Asia and Africa. These birds are characterised by thick, strong, bent beaks, which enable them to break the envelopes of the fruits which serve them for food. They fly less rapidly than birds of the Dove family, and coo in a different manner. They inhabit wcods, and build in holes in trees. Their flesh is good. The principal species are found in Abyssinia, Senegal, and the Indian Archipelago.

* In this supposition the great naturalist is wrong, for annually these birds are becoming much scarcer. In fact, in many parts of the United States, where they were abundant in his time, they are now unknown.-ED. 


\section{CHAPTER VI.}

\section{SCANSORES OR CLIMBERS.}

PEOPLE will be strangely mistaken if they imagine that all the birds which rank in this order possess the faculty of climbing. In reality it is only the privilege of some, and does not belong exclusively even, to them, for it is found in some of the Passerines. The essential characteristic of the climbers lies in this organic disposition-that the external toe, instead of being placed in front, like that in other birds, is placed behind, by the side of the thumb. For this reason the denomination of climbers has been substituted by that of Zygodactyles, which is used by Temminck, Vieillot, and others, and which has the advantage of perfectly expressing the distinctive characteristic of the order, for this word signifies fingers disposed in pairs. Thanks to the formation of their feet, the climbers can clasp the branches of trees strongly ; thus they are almost continually perched. Their flight is medium, being neither so powerful as that of the Raptores nor so light as that of the Passerines. These birds feed upon fruits or insects, according to the strength of their beaks. They chiefly inhabit warm countries, and their colours are generally brilliant. Lastly, they are all monogamists, with the exception of the Cuckoo. This order is one of the least numerous of the class of Birds. It comprehends but few families, amongst which we will mention the most familiar, such as Parrots, Toucans, Cuckoos, Woodpeckers, Jacamars, \&c.

\section{PARROTS.}

Parrots have large, strong, and round beaks; the upper mandible strongly hooked and sharp at the extremity, extending beyond the lower, which is rather deeply hollowed. The tongue, which is thick, fleshy, and movable, is terminated by a cluster of sinewy papillæ, or by a cartilaginous gland. The tarsi are very short, and the feet perfected to such a degree that they really become hards, able to seize, hold, and retain small objects. Their toes are supplied with 
strong and hooked claws, which make these birds pre-eminently climbers, with the exception of one single species-Platycercina Vigorsia, which have rather long tarsi, and straight claws, enabling them to run with some rapidity ; the Parrots, on the contrary, walk with difficulty, and with such trouble that they rarely descend to the ground, and only under pressing circumstances. Besides, they find all the necessaries of their existence on trees. They are not more favoured with regard to their flight; and we can understand that it should be so; for, living in thick woods, they only require to effect trifling changes of place, such as from one tree to another. However, some species, especially the smaller, are capable of a more prolonged and effective use of their wings. According to Levaillant, some even migrate, and travel hundreds of miles every year; but this is an exception. In general, Parrots are sedentary, and remain in the localities where reared.

Sc ciable in their dispositions, they assemble in more or less nimerois bands, and make the forests re-echo with their loud cries. To some species it is such an imperative necessity to be near each other and live in common, that they have received from naturalists the name of "inseparables." At breeding-time each couple isolate themselves for the purpose of reproduction. The male and female evince the greatest attachment to each other. The females deposit their eggs in the hollows of trees and in the crevices of rocks. The young birds are quite naked when hatched; it is not till the end of three months that they are completely covered with feathers. The parent birds wait upon them with the greatest solicitude, and become threatening when approached too closely by intruders.

Essentially frugivorous, parrots prefer the fruits of the palm, banana, and guava trees. They may be seen perched upon one foot, using the other to bear the food to their beaks, and retain it there till eaten. After they have extracted the kernel they free it from its envelope, and swallow it in particles. They often visit plantations, and cause great devastation. In a domestic state they are omnivorous. Besides seeds and grain, they eat bread, and even raw or cooked meat, and it is with manifest pleasure that they receive bones to pick; they are also very partial to sugar. It is well known that bitter almonds and parsley act upon them as violent poisons. They drink and bathe very frequently: in summer they evince the greatest desire for plunging and splashing in water. Captive Parrots will habituate themselves, if permitted, to the use of wine; it produces the same effect on them as on the human 
family, viz., excites their loquacity and gaiety. They climb in a peculiar manner, which has nothing of the abruptness displayed by other birds of the same order. This they accomplish with slow and irregular movements, helped by their beak and feet, which lend a reciprocal support. Like almost all birds of tropical regions, this family are adorned with most beautiful colours, green predominating ; sometimes red, and even blue and yellow. They have often largelydeveloped tails.

Notwithstanding their prattling, Parrots are the favourites of the human family, from their remarkable talent of imitation. They retain and repeat with great facility words which they have learned or heard by chance, and also sometimes imitate, with startling resemblance, the cries of animals, the sounds of different musical instruments, \&c.

By the words that they utter in an unexpected manner, Parrots contribute to our amusement and diversion, and quite become companions. Is it then to be wondered at that these birds have been eagerly sought since their introduction into Europe? Alexander the Great brought into Greece a parrot which he had found in India. These birds became so common in Rome at the time of the Emperors that they figured in their sumptuous repasts. They are now spread throughout Europe in a domestic state.

The species most remarkable for their mimic babbling faculties are the Grey Parrot or Jaco, a native of Africa, and the Green Parrot, from the West Indies and tropical America.

It is reported that in the sixteenth century a cardinal paid a hundred crowns for a parrot because it recited the Apostles' Creed correctly. Monsieur de la Borde relates that he has seen a parrot supply the place of chaplain to a ship, for he recited the prayer and the litany to the sailors. Levaillant heard a parrot say the Lord's Prayer lying on its back, placing together the toes of its feet as we join our hands in the act of prayer. Willoughby mentions a parrot which, when he said to him, "Laugh, parrot!" immediately burst out laughing, and cried out an instant after, "Oh, the great fool who made me laugh !" A keeper of a glass shop possessed one which, whenever he broke anything or knocked over a vase, invariably exclaimed, in tones of anger, "Awkward brute, he never does anything else!"

"We have seen a parrot," says Buffon, "which had grown old with his master, and partaken with him the infirmities "of age. Accustomed to hear little more than the words, 'I am ill,' when asked, 'How are you, parrot-how are you?' 'I am ill,' it replied in doleful tones, 'I am ill,' and, stretching itself on the hearth, 'I am ill.'" "A parrot from Guinea," says the same author, "being taught 
on the journey by an old sailor, learnt his rough voice and his cough so perfectly that he quite deceived his hearers. Although it had been given immediately after to a young person, and only heard his voice, it did not forget the lessons of its former master, and nothing was so agreeable as to hear it pass from a sweet and pleasant voice to its old hoarseness and the cough of early times."

Goldsmith relates that a parrot belonging to King Henry VIII., and always confined in a chamber bordering upon the Thames, had learnt several phrases which it heard repeated by the boatmen and passengers. One day it was let fall into the Thames, when it cried with a strong voice, "A boat! a boat! twenty pounds to save me!" A waterman immediately threw himself into the river, thinking that some one was drowning, and was much surprised to find it was only a bird. Having recognised the king's parrot, he carried it to the palace, claiming the recompense the bird had promised when in distress. The circumstance was related to Henry VIII., who laughed much, and paid it with a good grace.

The Prince Léon, son of the Emperor Basil, having been condemned to death by his father, owed his life to his parrot, which, in repeating the lamentable accents several times, "Alas! my master Léon!" ended by touching the heart of this barbarous father. M. Lemaout says :- "In a town of Normandy a butcher's wife beat her child unmercifully every day. The infant sank under the ill-treatment. The justice of man made no remonstrance, but a grey parrot which lived in the house of a rope-maker, opposite to that of the butcher, took upon itself the chastisement of this unnatural mother. It continually repeated the cries which the poor child uttered when he saw his mother rush at him with the rod in her hand-'What for? what for?' This phrase was uttered by the bird with such doleful and supplicating accents, that the indignant passers-by entered unexpectedly into the shop, and reproached the rope-maker with his barbarity. He justified himself by showing his parrot, and relating the history of his neighbour's child. After some months the woman, pursued by the accusing phrase and the murmurs of public opinion, was obliged to sell her business and leave the village."

The Marquis of Langle, in his "Travels in Spain," writes thus :"I saw at Madrid, at the English consul's, a parrot which has retained a quantity of things - an incredible number of stories and anecdotes -which it retails and articulates without hesitation. It spoke Spanish, murdered French, knew some verses of Racine, could say grace, repeat the fable of the crow, and count thirty louis. They dared scarcely hang its cage at the windows; for when it was there, and the 
weather was fine, the parrot talked ceaselessly. It said everything it knew, apostrophised all passers-by (except women), and talked politics. In pronouncing the word Gibraltar it burst out laughing. One would think it was a man who laughed."

An English gentleman bought a grey parrot in Bristol, the intelligence of which was quite extraordinary. It asked for everything it wanted, and gave orders; it sang several songs, and whistled some airs very well, beating the measure. When it made a false note it recommenced, and never committed' the mistake again. We have often, when passing through the Rue Four-des-Flammes, at Montpellier, heard a parrot which sung and articulated most distinctly the two verses of this song:-

\section{"Quand je bois du vin clairet, \\ Tout tourne, tout tourne au cabaret."}

Parrots imitate not only the word, but even the gestures of those with whom they come in contact. Scaliger knew one which repeated the songs of some young Savoyards, and imitated their dances.

These birds are more or less susceptible of education. Some, naturally peaceable, are easily tamed; others, more refractory, submit to captivity unwillingly. In general, when they are taken young, they attach themselves strongly to those who have care of them.

Parrots have a mania for using their beaks upon everything that comes in their way. When encaged against their will they utter loud cries, and sometimes turn their fury upon the bars of their prison, They have been known to pluck and even tear themselves in these paroxysms. Supplying them with a plaything is the only means of keeping them quiet under such circumstances.

These Climbers are endowed with remarkable longevity. The "Memoranda of the Academy of Sciences of Paris" mention a parrot that lived in the family of the Grand Duke of Tuscany in Florence more than i ro years. Vieillot speaks of having seen one near Bordeaux which was eighty-four years of age. The average length of their life cannot, however, be exactly ascertained.

Parrots rarely breed in Europe ; it is true they often lay, but the eggs are sterile. A few instances have been known in France where, under favourable circumstances, they have perpetuated their species. Generally all that we see in our temperate regions are brought from. countries where the majority have been taken from the nest.

The family of Parrots comprises four principal groups:- The Macaws, Parrakeets, Parrots properly speaking, and Cockatoos. 
The Macaws (Ara), the largest of the Parrots, are recognisable from their bare cheeks and long tapering tails. They inhabit South America, and are arrayed in the most brilliant colours. The principal species are the Ara or Blue and Yellow Macaw (Ara ara-

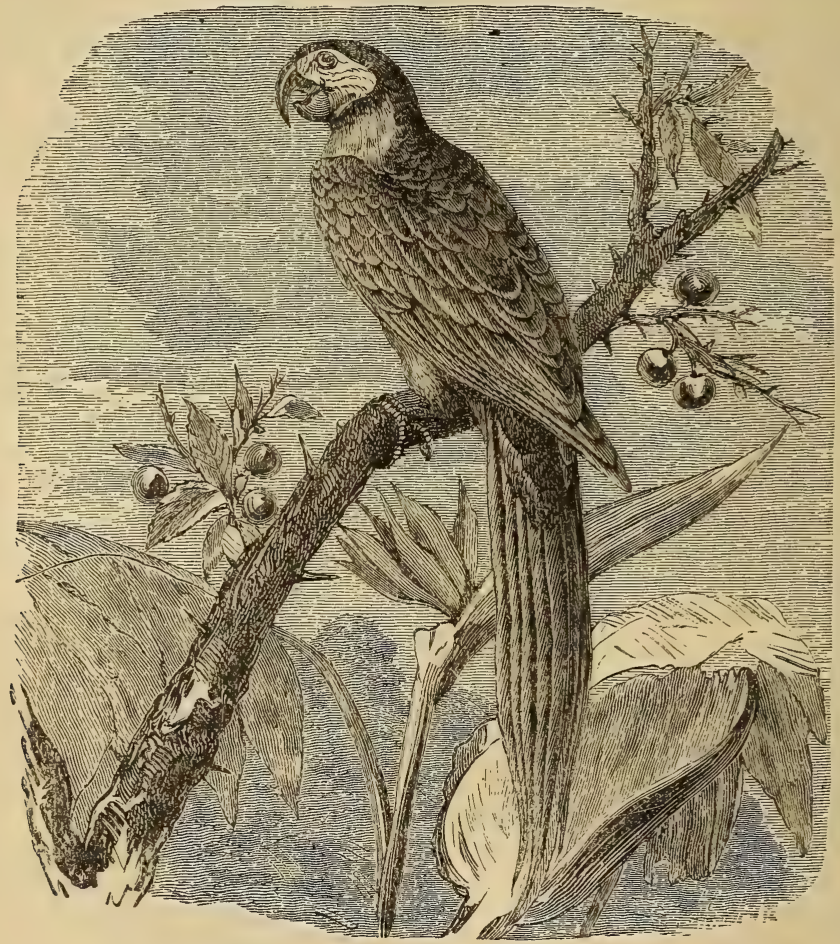

Fig. 164:-Blue and Yellow Macaw.

rauna, Fig. 164). The name Arara, by which they are known in their habitat (Brazil), describes the deafening cries which they utter. Very familiar, they tame easily, and do not abuse the liberty granted them, for they never move far from their dwelling-place, and always return to it. They like the caresses and attentions of people they know, but object to strangers. The Great Green Ara is remarkable 
for its aversion to children. This peculiarity doubtless arises from the fact that it is very jealous, and that it often sees children receive the caresses of its mistress. The Macaws have only the gift of imitation in a slight degree; they are seldom able to repeat any words, and articulate badly.

Parrakeets, much smaller than Macaws, have, like them, long

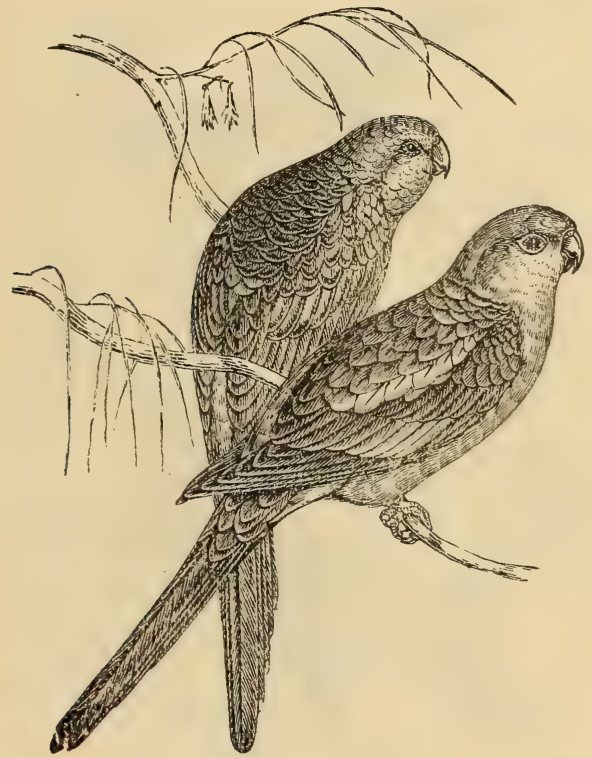

Fig. 165. - Rose Hill Parrakeet.

and tapering tails, but their cheeks are wholly or partially feathered. Some species, which resemble the preceding group by being more or less destitute of plumage round the eyes, for this reason have received the name of Macaw-parrakeets. Parrakeets are highly esteemed for their vivacity, gentleness, and the facility with which they learn to talk. Their plumage is generally of a uniform green ; sometimes it is varied with red or blue. They inhabit South America, Australia, the islands of Oceania, the Indies, Africa, and Senegal, one of the most beautiful of the family being the Rose Hll 
Parrakeet (Platyceccus eximius, Fig. I65), a native of Van Diemen's Land and New South Wales.

The Ground Parrakeet (Pezophorus formosus) which inhabits Australia, belongs to this group. These birds form a curious exception in the order of Climbers by their terrestrial habits. According to M. J. Verreaux, they never perch when pursued, but take refuge

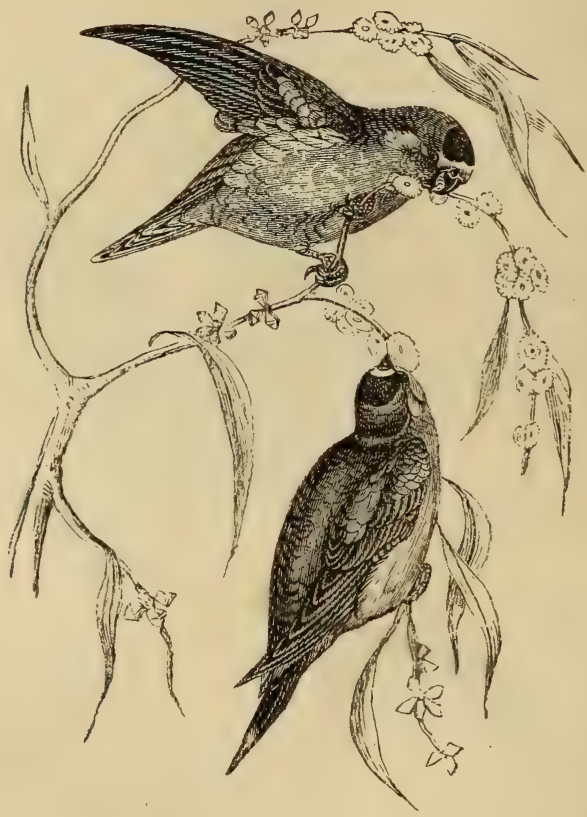

Fig. 166.-Swindern's Love-birds.

on the ground among the herbage. This pretty and highly interesting bird is frequently called by the colonists Pheasant - to its length of tail and highly game flavour this misnomer is doubtless attributable.

Love-birds, of which Psittaculu Sreinderniana (Fig. 166) is the rarest, are the smallest of this group ; their plumage varies in shades according to the climates. They are met with in America, Southern Africa, and in the islands of Oceania.

Parrots, properly speaking, are distinguished from other groups 
of the same family by their short square tails. They have feathered cheeks like Parrakeets, and their size is intermediate between them and the Aras. They are much appreciated on account of their memory, and also for their habit of repeating what they hear. Parrots are divided into several species, founded upon the size and

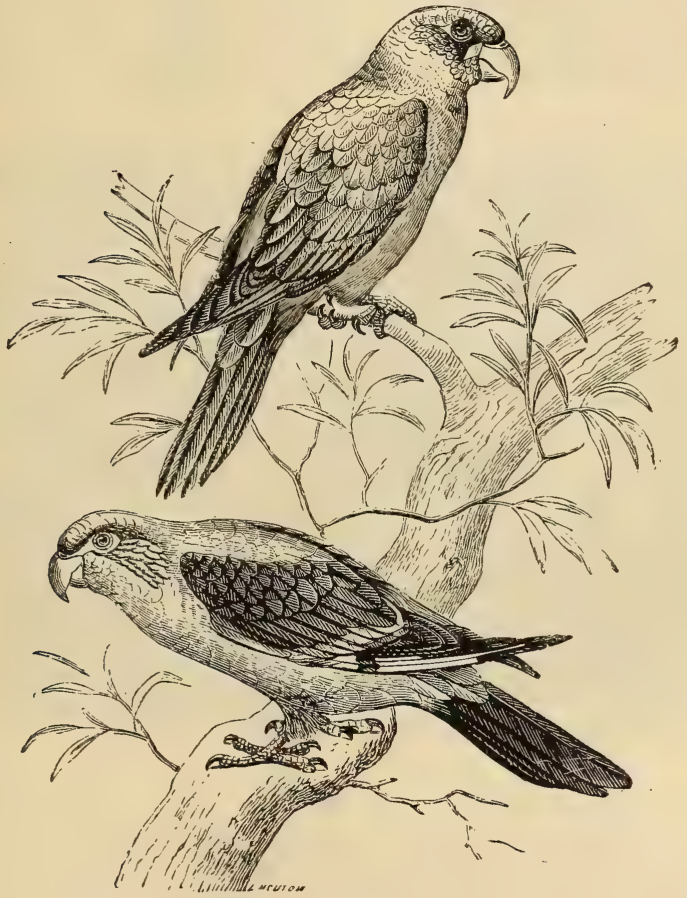

Fig. 167.-Grey Parrots.

the predominating colour of the plumage. The first of these is the Grey Parrot or Jaco (Psittacus erythacus, Fig. I67), indigenous to the west coast of Africa, to which the chief part of the anecdotes recounted in the preceding pages relate. Next come two species, the plumage of which is green : the most remarkable of these is the Amazonian Parrot (Chrysotis Amazonicus, Fig. I6.8,) and the Festive Green Parrot (Chrysotis festivus). 
Cockatoos have tails of medium length, cheeks feathered, and head surmounted by a white, yellow, or pink tuft, which they can raise and lower at will. They are the largest among the race of Parrots of the old continent. They inhabit the Indies and the isles of Oceania, and are pretty, graceful, docile, and caressing, but are indifferent talkers. One very remarkable species of this group is the Microglossum aterrimum, called by Levaillant the "Macaw with the trumpet," from the formation of its tongue, which is cylindrical and terminated by a little gland slightly hollowed at the extremity.

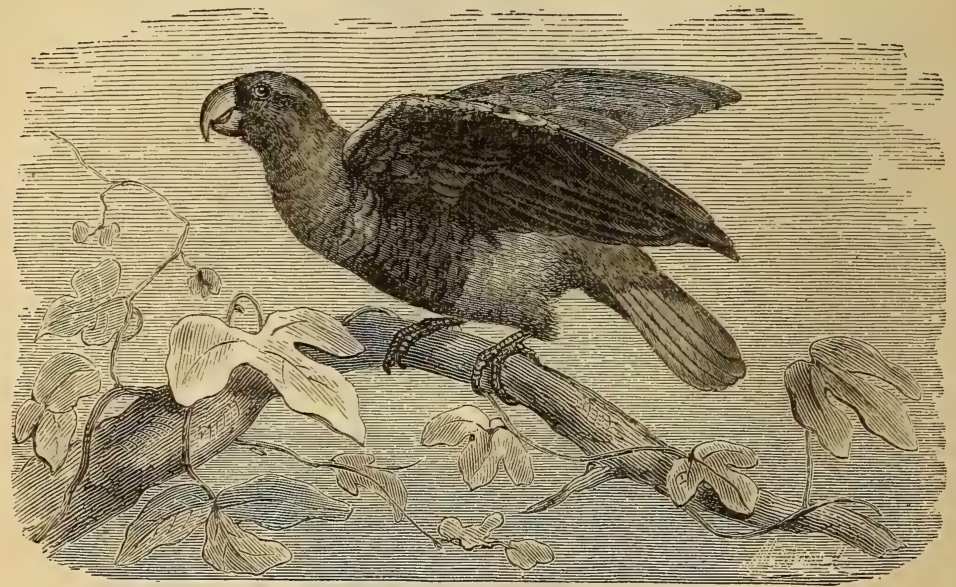

Fiz. I68. - Creen Parrct

When this bird has reduced into fragments by the help of its jaws the kernels of the fruits which form its nourishment, it seizes the preces by means of the hollow which terminates the tongue, and, having tried the flavour, projects the trumpet in front, and makes it pass to the palate, which has the function of causing it to fall into the throat. This curious mechanism was disclosed by Levaillant.

The Great White Cockatoo (Cacatua cristatus) is a remarkably handsome bird, but does not produce more admiration than Leadbeater's Cockatoo (Cacatua Leadbeateri, Fig. 169).

'Toucans.

The characteristic of the birds which compose the family of 
Toucans is their enormous beak. This is much longer than the head, is curved at its extremity, dentated at its edges, and possesses a projecting bone at the middle of the upper mandible. It is not so heavy to bear, and incommodes the movements of the birds less than might be supposed, for -it is formed of a spongy tissue, the numerous cells of which are filled with air. Thus it is very weak, and does not serve to break or even to bruise fruits, notwithstanding the idea one forms at first sight of its strength, for it is not even capable of breaking off the bark of trees, as certain authors

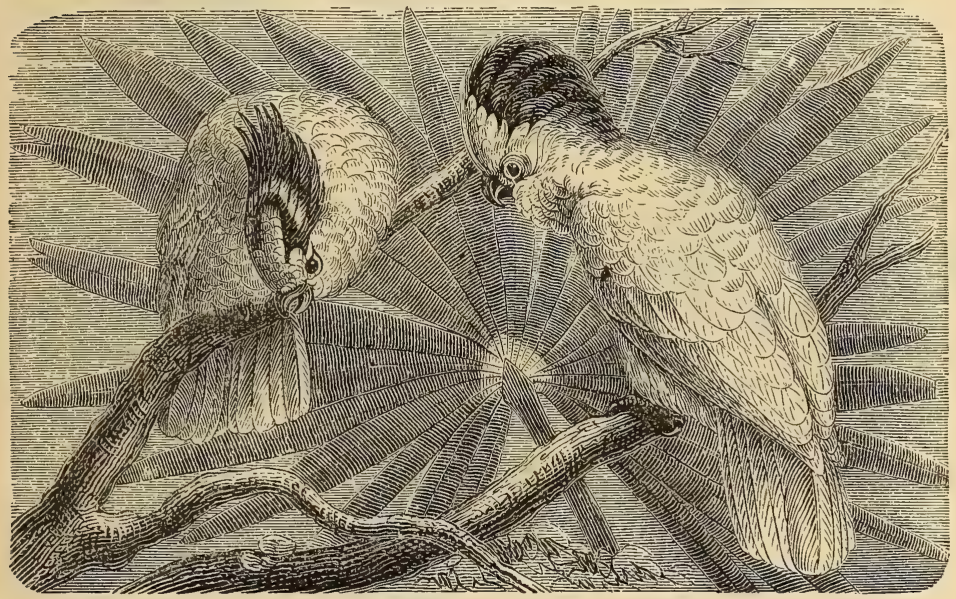

Fig. I69.-Leadbeater's Cockatoo.

have urged. This wonderful bill encloses a still more strange tongue; very straight and as long as the beak, which is covered on each side with closely-packed barbs, similar to a feather, the use of which remains to us a complete mystery. This curious instrument so struck the naturalists of Brazil, where many Toucans are found, that it furnished them with a name. In Brazilian toucan means "feather."

Toucans feed on fruits and insects ; they live in bands of from six to ten in damp places where the palm-tree flourishes, for its fruit is their favourite food. In eating they seize the fruit with the extremity of the beak, make it bounce up in the air, receive it then 
into the throat, and swallow it in one piece. If it is too large, and impossible to divide, they reject it. They are rarely seen on the ground, and although their flight is heavy and difficult, they perch on the branches of the highest trees, where they remain in ceaseless motion. Their call is a sort of whistle, frequently uttered. Very timid, they are approached with difficulty. During the breeding
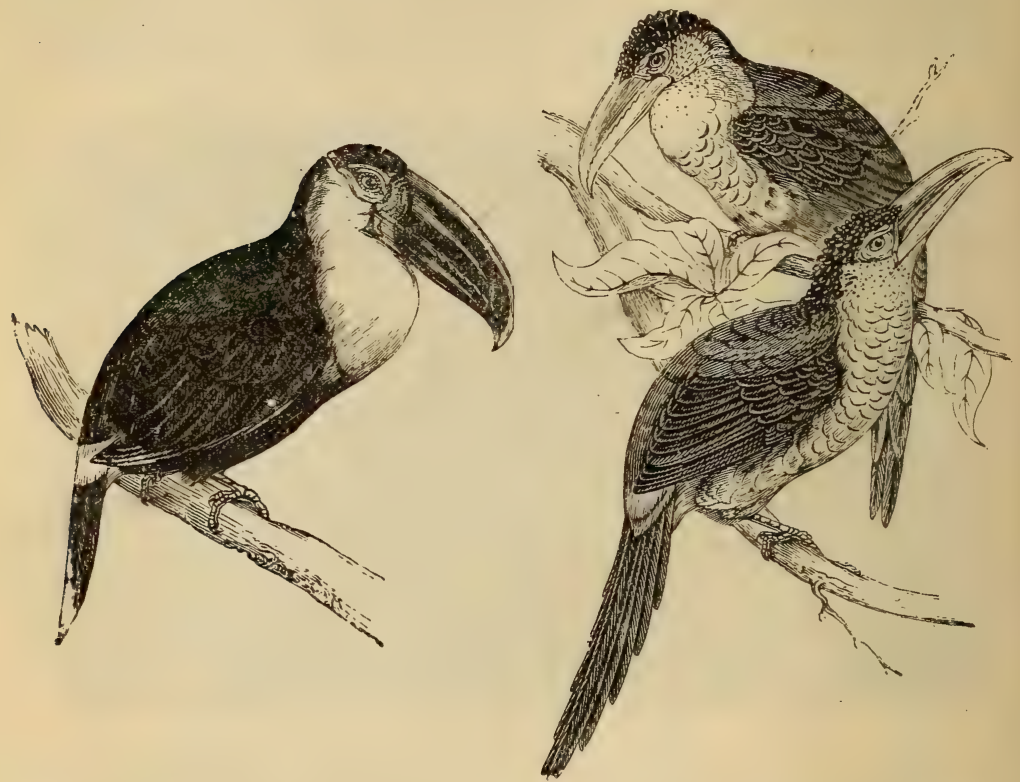

Fig. r;o-Common Toucan.

Fig. 17x.-Curl-crested Arızuri.

season they attack the weakest birds of their own race, chase them from their nests, and devour the eggs or nearly-hatched young ones. They build their nests in holes hollowed out by Woodpeckers or other birds. They all have very brilliant plumage, and inhabit Paraguay, Brazil, and Guiana.

This family is divided into Toucans properly speaking and the Aracaris. These are distinguished from the former by their much less size, more solid beak, and longer tail. The most beautiful species of the family is Cuvier's Toucan (Rhamphastos Cuvieri). The beautiful 
orange feathers which cover some of these birds are sometimes employed for ladies' adornments. This fashion has passed from Brazil and Peru into Europe, and muffs made of the throats of Toucans sell at a great price.

The Common Toucan (Rhamphastos ariel, Fig. I70) is very numerous in its habitat, and consequently best known in Europe. The Curl-crested Aracari (Pteroglossus ulocomas, Fig. I 7 I) is deserving of notice on account of its beautiful variegated plumage.

\section{Cuckoos.}

'The general characteristic of the birds ranked in this family are - slightly-curved beaks of medium dimensions, wings generally short and concave, and tapering tails. Among the Cuckoos are comprehended Honey-guides, Anis or Annos, Barbets, Trogons, and Touracos or Plaintain-eaters. Cuckoos have elegant shapes; beaks almost as long as the head, compressed, and slightly curved; the tail rather long and rounded. Unlike other birds of the same family, they have long and pointed wings. Their size is about that of the Turtle-Dove. Their flight is light and rapid, but they are unable to bear strong winds ; thus, they cannot accomplish great journeys without resting. There are a great number of known species belonging to all the countries of the old continent.

Europe only possesses one species, the Grey or European Cuckoo, which has been carefully studied, and to which what we have to say regarding this group of birds applies. Grey Cuckoos are essentially migratory. They pass the warm season in Europe, and the winter in Africa or in the warm parts of Asia. They arrive in France in the month of April, and leave it at the end of August or the beginning of September. They travel during the night, not in numerous bands; but alone, or in groups of two or three at the most. They prefer to seek their nourishment in woods, avoiding if possible the open country. Their utility cannot be doubted, as insects and caterpillars are their favourite food. They are very voracious, which accounts for the enormous capacity of their stomachs. Of a tyrannical nature, they suffer no rival of their species in the neighbourhood which they have chosen. On account of this unsociable disposition, the Grey Cuckoos, when captured after attaining maturity, are unable to accommodate themselves to confinement, so starve themselves to death.* Young birds are less restive, and gradually accustom

* More prohably starve to death, as they cannot in confinement obtain the animal food to which they have become necessitated through previous use. - ED. 
themselves to a cage; but they are always troublesome, on account of their quarrelsome habits, which prevents them from living caged with feathered companions.

Cuckoos are celebrated for the peculiar manner in which they raise their progeny. The females do not build a nest or cover their eggs, neither do they take care of their young. They lay their eggs in the nests of other birds, generally in those of little insectivorous Passerines, such as the Lark, the Robin, Hedge Sparrow, Redthroat, Nightingale, Thrush, Blackbird, and sometimes also in those of the Magpie, Turtle-Dove, and Wood Pigeon. They leave the care of hatching their eggs, even of feeding their young until they are completely developed, to these strangers. Different explanations have been imagined to justify the anomaly of the cuckoo being a hard-hearted mother. We owe to M. Florenf-Prevost the possession of certain information on this point which had long remained in obscurity. According to this naturalist, Cuckoos are polygamous, but in a reverse sense to other birds. Whilst among them males have several wives, with Cuckoos it is the females that have several husbands, because the stronger sex is much more numerous than the weaker. These ladies, as might be expected of creatures with such proclivities, have no fixed home. At the breeding-time they wander from one district to another, reside two or three days with a mate at one place, and then abandon him, according to inclination. It is at this time that the males so frequently utter the cry known to all the world, and from which the bird derives its name; it is a pleading call of love to the females, which in their turn reply by kind responsive notes. Cuckoos lay eight or ten eggs in the space of a few weeks. When an egg has been laid, the female seizes it in her beak, and carries it to the first unoccupied nest in the vicinity, and there deposits it, profiting by the absence of the proprietor, which would certainly oppose such an addition. A Red-throat has been seen to return unexpectedly, and force the stranger to retire with her burden. The next egg is placed in a neighbouring nest, but never in the same as the first. The mother is doubtlessly conscious of the unfortunate position she would place her two nurslings in if she acted otherwise, for it would certainly be impossible for two little Passerines to supply the wants of two such voracious fledglings as young Cuckoos. Pertinent to this, we will mention a fact that we have not seen stated in any work on natural history. It often happens that the female Cuckoo takes from the nest one of the eggs of the Passerine, breaks it with her beak, and scatters the shell. Thus, when the mother returns, she finds the 
same number of eggs that she left. It is from this cause one frequently sees pieces of egg-shell surrounding the nests where Cuckoos have deposited their progeny. This action on the part of the birds denotes perfect reasoning powers, and consequently real intelligence. What say the great philosophers to it, who refuse this faculty to animals? When she has thus left her eggs, the female comes several times to see that her progeny are well cared for, and does not leave the neighbourhood till she is assured that such is the case. Thus she is not quite so free from solicitude about the welfare of her young as one at first thinks. Laying her eggs at considerable intervals, she would find that to cover eggs and raise a family at the same time are incompatible, for the latter duty involves frequent absences which would destroy the eggs, to which, during incubation, an equal and constant temperature is necessary. It is not then indifference, but thought, that causes her to confide to others her maternal cares. The young Cuckoo is no sooner hatched than it employs its infant strength to get rid of the true children of the foster-parents, in order to be the only one to profit by. their attentions; so it forces itself under the frail occupants of the nest, gets them on its back-where it holds them by means of its raised wings-and precipitates them one after another from the nest. The mother, though thus cruelly treated in return for her affection, generally retains her love for this perfidious child of her adoption, and provides for all its wants until the time of its departure. Sometimes, however, she is so angry at the loss of her progeny, that she brings no nourishment to the adopted child forced upon her, and lets it die of starvation.

The European Cuckoo (Cuculus canorus, Fig. I72) we are all familiar with, the other species of this family do not visit Europe.

Honey-guides or Indicators (Indicatores) have their place next to Cuckoos. These birds inhabit the interior of Africa, India, and Borneo. They feed on insects, and especially delight in the pupæ of bees ; they employ very curious manœuvres in order to procure them, which denote perfect intelligence. When one of these birds discovers a hive, it endeavours to attract the attention of the first person it meets by frequently-repeated cries. When observed, it proceeds to fly, and leads thus for great distances till it reaches the place where the hive is, which it takes care to point out by every means in its power. Whilst the honey is being taken, the bird remains in the neighbourhood, observing all that passes, and when that is accomplished, it approaches to reap the fruits of its trouble. The bees make very little buzzing, but flutter round, trying to sting it, but its skin is impervious to their efforts: Often, however, the despoiled 
bees attack its eyes, and sometimes succeed in blinding it: the unfortunate bird, incapable of guiding itself, then perishes in sight of the place that witnessed its triumph. The Hottentots esteem Honeyguides very highly, on account of the services which they render them in revealing the abodes of bees, and they therefore scruple to kill them.

The group of Cuckoos is supplemented by several more species nearly allied to the genus Cuckoo, upon which it is useless for us to enlarge.

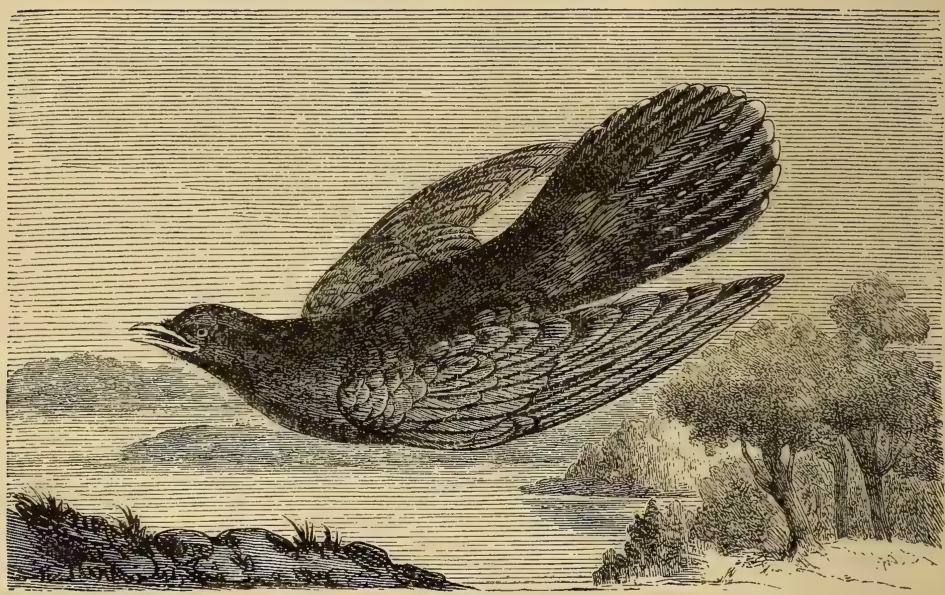

Fig. 172.-European Cuckoo.

Anis have bulky, short, very compressed beaks, surmounted by a slight and sharp crest. They inhabit the countries of Equatorial America, and live in troops of from thirty to forty in the midst of savannahs and marshes. They feed upon reptiles and insects; they are often seen to alight upon cattle to devour the insect parasites which torment them; hence comes their scientific name of Crotophaga, or eaters of insects. They are of very gentle; confiding natures, and the sight of man does not frighten them; besides, there is no advantage in killing them, for their flesh exhales a repulsive odour. Taken young, they become very familiar, and are as quick as Parrots in learning the art of speaking. They possess the instinc of sociability in the highest degree; so much so, that they do not even 
isolate themselves at pairing-times as other birds do. They build a common nest, either in the trees or bushes, in which all the females lay and sit on their eggs. This nest is sometimes diviaed by walls into a certain number of compartments, each of which belongs to a female, but generally all the eggs are mixed, and the females cover them indiscriminately. This admirable understanding does not cease after the young are hatched. These are nourished by all the mothers in common. Are not these little republics models of peace and concord? and does not man find in them salutary examples of disin-

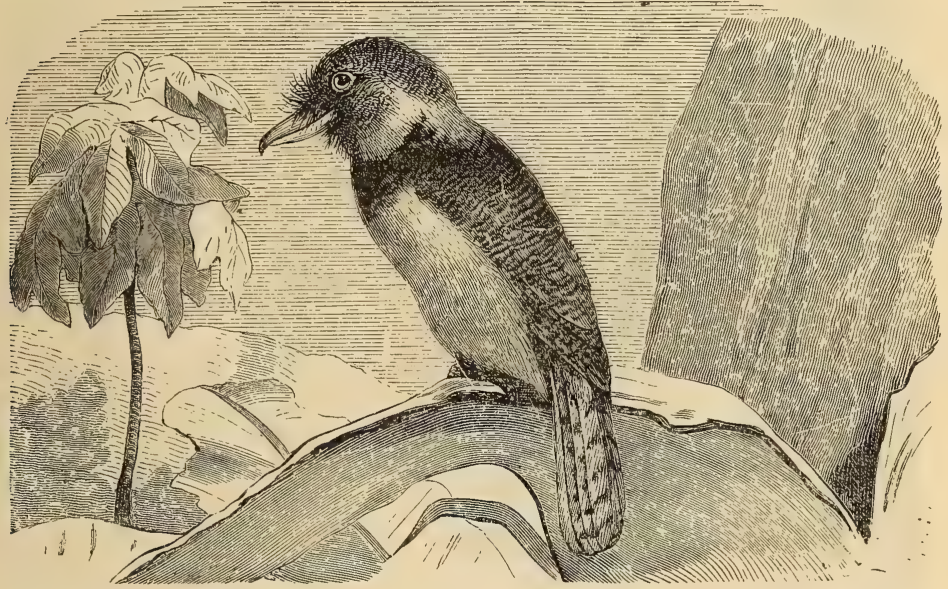

Fig. 173.-Collared Barbet.

terestedness and affection? The two principal species of the genus are the Razor-bill of Jamaica and the Savannah Blackbird of America. The former is the size of a Blackbird, the latter of a Jay.

Barbets owe their name to a number of straight hairs which they have upon their beak. They are massive in form, and their flight is heavy. Inhabiting warm countries of both continents, they conceal themselves in thick forests, either alone or in small bands. They feed on fruits, berries, and insects. Certain species even attack and devour young birds. They build in the trunks of trees. The number of eggs they lay is two, sometimes (though rarely) three. Levaillant asserts that the old and infirm Barbets are cared for and fed by those 

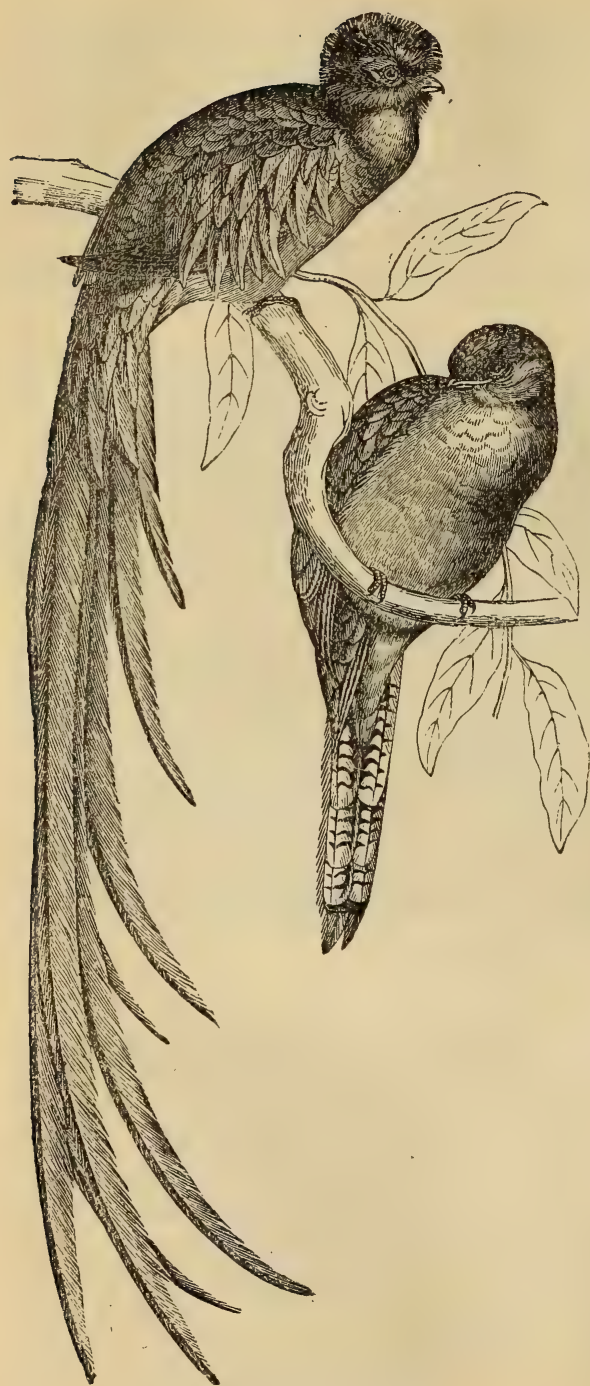

Fig. 174-Resplendent Trogons. in the enjoyment of all their vigour. $\mathrm{He}$ says that, having taken five Barbets from a nest, one of which was so old that it could not stand on its legs, and having enclosed them in a cage, "the four healthy Barbets hastened to give food to the one lying in a dying state in a corner of the cage." $\mathrm{He}$ adds that the nest from which he had taken them was filled with husks and the remains of insects, which led him to think that the old invalid had been fed a long time by these kind and thoughtful birds. If this is true, it is worthy the attention of moralists. The best known of this family is the Collared Barbet (Bucco collaris, Fig. 173). The Barbets have a curious habit of raising all their plumage till they look like a ball of feathers; from this peculiarity they have gained the name of Puffbirds.

Trogons, like Barhets, have the bases of their beaks covered with hairs. Their soft and silky plumage glitters with the most brilliant hues, and their tails are extremely long. They very strongly resemble the birds of night 
by their unsociable nature and stolid dispositions, and by the solitary lives they pass in the wildest parts of woods. Like them, also, they only go out in the morning and evening to seek the insects and caterpillars which form their principal nourishment. The presence of man does not frighten them; and this confidence ofter. leads to their death, for they are persistently pursued for their flesh, which is said to be excellent, and also for their very beautiful feathers. Their name Couroucous arises from the cry which they utter at breeding-times. They inhabit the inter-tropical regions of both continents. The most remarkable species is the Resplendent Trogon ( $\mathrm{Ca}$ lurus resplendens, Fig. I 74), indigenous to Mexico and Brazil. The plumage of this bird is of a magnificent emerald green frosted with gold ; its head is surmounted by a beautiful tuft of the same colour. The daughters of the Caciques in the New World formerly used its feathers in their adornment. At the present time creoles employ them for the same purpose. The most common species is the Cuban Trogon(Priotelus temnurus, Fig. I 75 ).

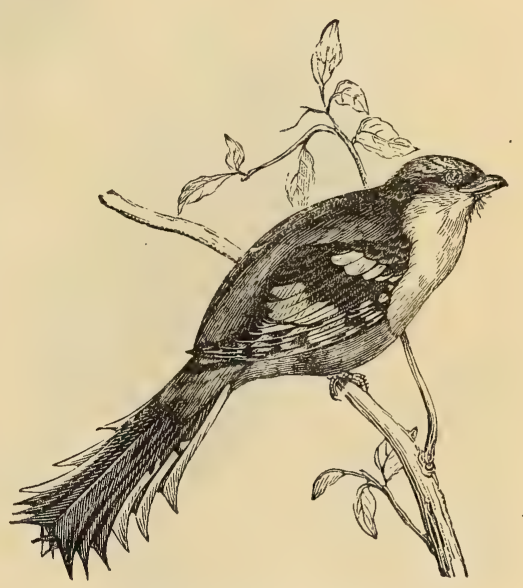

Fig. 175.-Cuban Trogon.

Turacos or Plantain-

eaters (Musophagidce), are African birds, of which the general forms bear some analogy to Curassows. They live in forests, and perch upon the highest branches of trees : their flight is heavy and awkward.

\section{WOODPECKERS.}

The Birds which compose this family are characterised by a rather long, conical, pointed beak, and by a very extensible tongue. They form two genera, Woodpeckers and Wry-necks.

Woodpeckers excel in the art of climbing, but they do not perform it in the same manner as Parrots. They accomplish their 
ascension by extending their toes, supplied with bent claws, upon the trunk of a tree, and maintain themselves hanging there; then move themselves a little farther by a sudden and jerked skip, and so on. These movements are facilitated by the disposition of the tail, formed

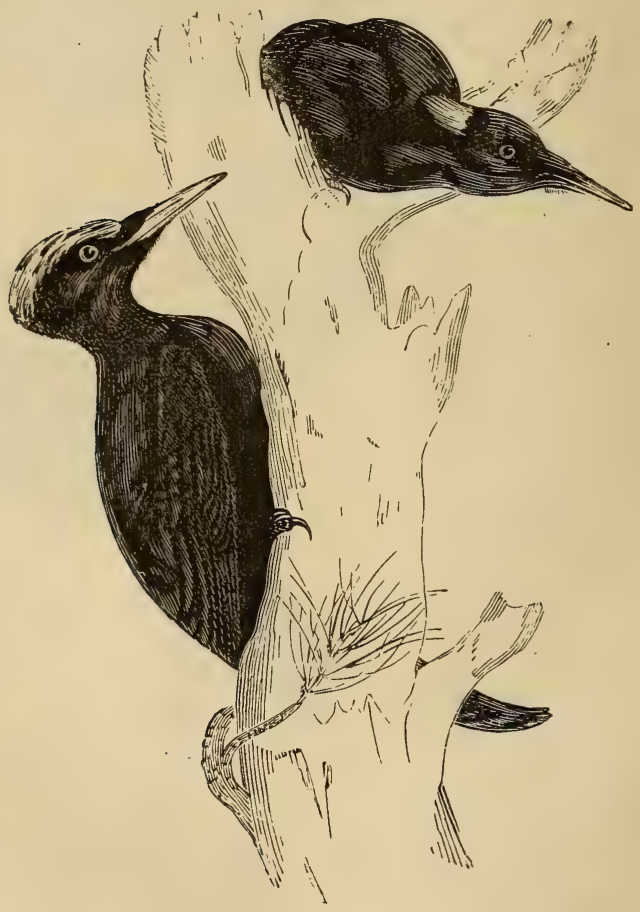

Fig. 176.-Ivory-billed Woodpeckers.

of straight resistant feathers, slightly worn away at their extremities, which, pressed against a tree, serve as a support to the bird. Thanks to this organisation, Woodpeckers traverse trees in every directiondownwards, upwards, or horizontally. Woodpeckers are of a timid and restless disposition; they live alone in the midst or on the 
borders of large forests. Insects and their larvæ form their nourishment; which they seek in the trunks and clefts of trees. Their tongue is wonderfully suited for this purpose. It is very long, and, by a peculiar mechanism, can be projected out far enough to reach objects three or four inches away. The beak is terminated by a horny point bristling with small hooks. In many species it is overlaid with a sticky humour, secreted by two voluminous glands the effect of which is to catch the insects which it touches. Whenever the bird darts this tongue into the crevices, it draws it out more or less laden with insects. If it perceives an insect that it cannot reach by means of this organ, it has recourse to its strong beak: striking the tree with redoubled blows, it cuts the bark, breaks an opening, and seizes the coveted prey. It often also taps with its beak to sound a tree, and assure itself that there is no recess in the interior which would serve as a refuge for its prey. If the trunk is hollow, it examines all parts to find an entrance to the cavity. When it has discovered it, it introduces its tongue; and if the canal is not large enough to permit it to explore the hiding-place with success, it increases the size of

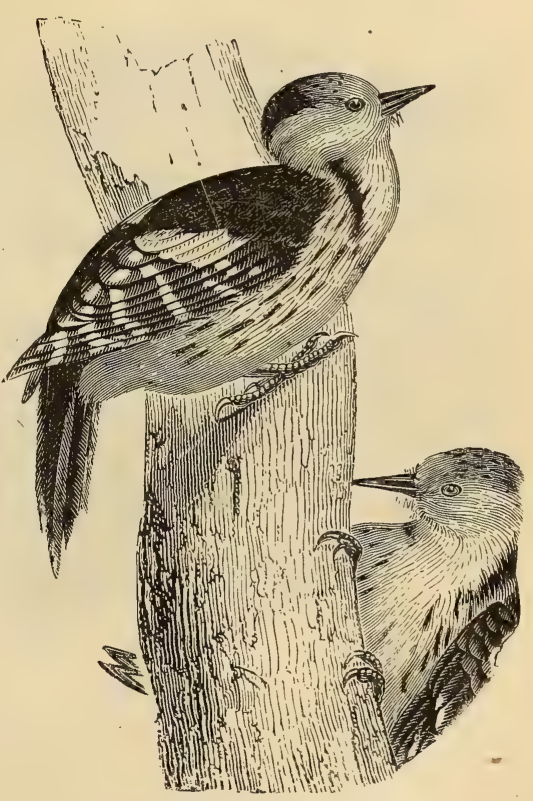

Fig. I77.-Downy Woodpeckers. the aperture. It is not only to seek for food that Woodpeckers make holes in trees, but also to form secure hiding-places for their nests. Some species, it is true, select the anfractuosities which they find, but others hollow out their resting-places according to their tastes. When such is the case, they select soft-wood trees, such as willow, aspen, \&c. The cavity which they bore to where the nest is placed is generally so oblique and so deep that perfect darkness must surround them. This is doubtless a measure of security against small mammals, especially the rodents, 
the natural enemies of their family. The female deposits her eggs upon a bed of moss or the dust of worm-eaten wood. The young birds grow slowly, and receive for a long time the care of their parents. In general they have little voice, and that disagreeable. At breeding-time they frequently employ a mode of communicating with each other peculiar to themselves: they strike the trunks of dead trees with their beaks, and these blows, which are heard at

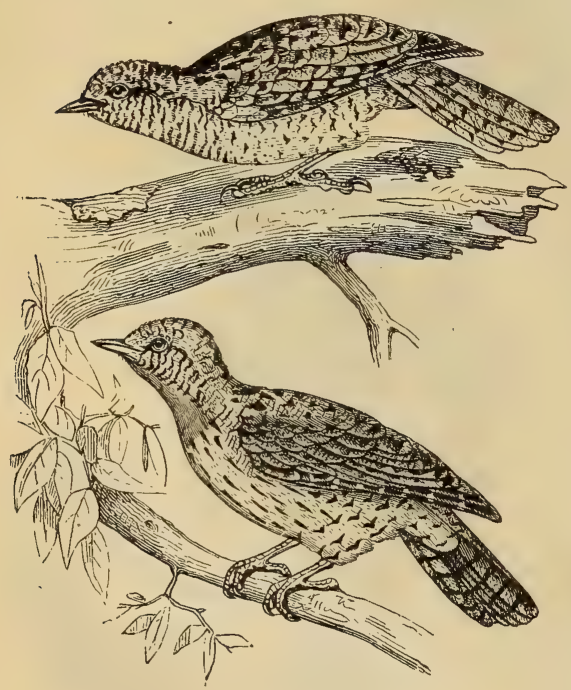

Fig. 178,-Wry-necks.

a great distance, attract all the Woodpeckers of the neighbourhood.

Woodpeckers are generally considered noxious birds, because they are supposed to injure the trees of forests and orchards, and for this reason a relentless war is made against them. They should, on the contrary, be protected; for they destroy innumerable insects, the real enemies of timber, and never touch a sound limb, for in it their food is not to be found. There are a great number of species of Woodpeckers known, which are spread over the two continents: Europe possesses eight, seven of which live in France either in a settled state or as birds of passage. The principal are the Ivory-billed Woodpecker (Campephilus principalis, Fig. I 76), a native of America ; the great Spotted Woodpecker (Picus major); and the Downy Woodpecker (Picus pubescens, Fig. I77).

Wry-necks (Yunx torquilla, Fig. 178) owe their name to the curious property they possess of being able to twist their necks in such a manner as to turn the head in all directions. They repeat this movement every instant, especially when surprised or angry. At the same time their eyes become fixed, the feathers of the head stand up, and the tail expands. Like Woodpeckers, they can hang upon trees, and sustain themselves in a vertical position for a long time. 
but they are incapable of climbing. The weakness of their beaks does not permit of their boring trees; therefore they seek their nourishment upon the ground, principally amongst the ant-hills. They lead a solitary existence, which they only relinquish at pairing-time. They possess a characteristic confidence, never in the least avoiding the presence of man, and become very familiar in captivity. They build in natural holes in trees, or in those hollowed by Woodpeckers.

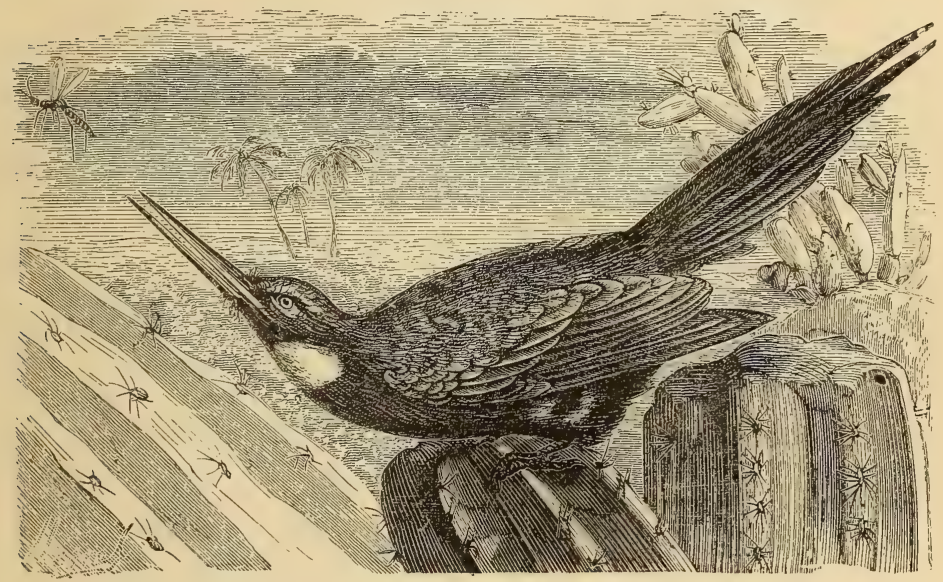

Fig. 179.-Paradise Jacamar.

Their plumage is pleasing, and their size is about that of the Lark. They inhabit all the old continent.

\section{JACAMARS.}

Jacamars inhabit equatorial America. They are characterised by long and pointed beaks, short tarsi, and short or obtuse wings. They have three or four toes, according to the species. Their habits are little known; but it is certain that they live isolated or in pairs, that they are stupid, move but little, and rarely depart from the reighbourhood where they have chosen their dwelling. All species do not frequent similar localities--as some like thick woods, others prefer 
open plains ; all, however, are insectivorous. In their manners, as well as in their physical characteristics, Jacamars appear to resemble King-fishers, of which we shall speak hereafter. The Paradise Jacamar (Galbula paradisea, Fig. I79) is a good representative of the family. 


\section{CHAPTER VII.}

\section{PASSERINES.}

The Passerines (from passer, the Latin for sparrow) form the least natural group of the Aves. Here one seeks in vain for the homogeneous characteristics which distinguish the preceding races. Indeed, it is difficult to detect the bonds which connect them together. For example, where is the link which unites the Crow to the Swallow, or the Hornbill to the Humming-bird? Nevertheless, all these winged creatures, so different externally, belong to the Passerince. It may be said that this order presents only negative characteristics, bringing together in a somewhat odd assemblage all birds which are neither web-footed, wading, gallinaceous, climbing, nor rapacious. The only physical feature common to all Passerines on which much stress can be laid, is that the outward toe is united to the middle one more or less. Their food consists of seeds, insects, and fruit. They live singly or in pairs ; they fly gracefully and easily; their walk consists of a leap ; and they build their nests and take their rest under the thick foliage of trees, or under the eaves of buildings.

In this extensive group we find most of the songsters whose melodious voices so charmingly wake the echoes of the woodlands. Some of them have even the gift of imitating the human voice, and the cries of wild animals. Many are remarkable for their brilliant plumage; others are appreciated as delicacies for the table. Man has reduced numbers of them to comparative tameness, but has altogether failed in bringing them to a domestic state.

Cuvier divides the Passerina into five great families- the Syndactyles, Temuirostres, Conirostres, Fissirostres, and Dentirostres. The first is based on the structure of the feet; the other four on the formation of the bill. But this classification is very arbitrary, as it is not always possible to assign a place to certain groups by an inspection of the beak alone. We shall, however, follow this distribution, as being that generally adopted. 


\section{SyNdACTYLES.}

The Syndactyles (having the toes united) have the external toe nearly as long as the middle one, and united to it up to the last articulation. The Birds which constitute this group have little analogy with each other, the physical character which we shall have occasion to notice being purely artificial as a means of classification. The family inciudes the Hornbills, the Fly-catchers, the King-fishers, the Bee-eaters, and the Motmots.

The Hornbills (Buceros) are remarkable for their enormous development of beak, which is long, very wide, compressed, and more or less curved and notched, and in some species surmounted by a large helmet-like protuberance. This immense beak is nevertheless very light, being cellulose, as in the Toucans. The Hornbills have in some respects the bearing of the Crow : this led Bontius to class them among the Crows, under the name of Indian Crow (Corvus indicus). They walk with difficulty, and their flight is clumsy, their favourite position being on a perch at the summit of lofty trees. Great flocks of these haunt the forests of the warmer regions of the Old World, especially Africa, India, and the Oceanic Archipelago. They build their nests in the hollows of trees. They are omnivorous, and the fruits, seeds, and insects of those regions are their principal food; yet they will not refuse flesh. In India they are domesticated, their services in destroying rats and mice being valuable. The plumage of the Hornbill is black or grey, of various shades; but there is a species described by Dr. Latham and Dr. Shaw under the name of the Crimson Hornbill, which Mr. Swainson thinks may prove to be a link between Toucans and Hornbills, and thus combine the beauty of plumage of the former with the peculiarity of form of the latter. Their flesh is delicate, especially when fed on aromatic seeds. Many. species are described, varying in size, among which the Rhinoceros Hornbill (Buceros rhinoceros, Fig. I80) is the most worthy of notice. This bird is so named from the singular protuberance with which its bill is surmounted : this is a smooth horny casque or helmet, curving upwards from the bill, somewhat resembling the horn of the rhinoceros, It is a native of India and the islands of the Indian Ocean.

The Fly-catchers (Muscicapida) are a family of insectivorous birds, many of which are British, containing, according to Temminck, the Todies (Todus), distinguished by long, broad, and very flat bills, contracting suddenly at the tip ; tail short, slender, and rounded; legs long and weak; toes short, the outer one more or less united to the middle one. T. viridis, the only species mentioned by this 
naturalist, has a bright green plumage above, whitish beneath; a scarlet throat; sides rose colour; and the tail-coverts yellow. It is a native of South America and the Antilles; and Sir Hans Sloane, under the name of Green Humming-bird, describes it as "one of the most beautiful small birds he ever saw." Mr. Browne states that

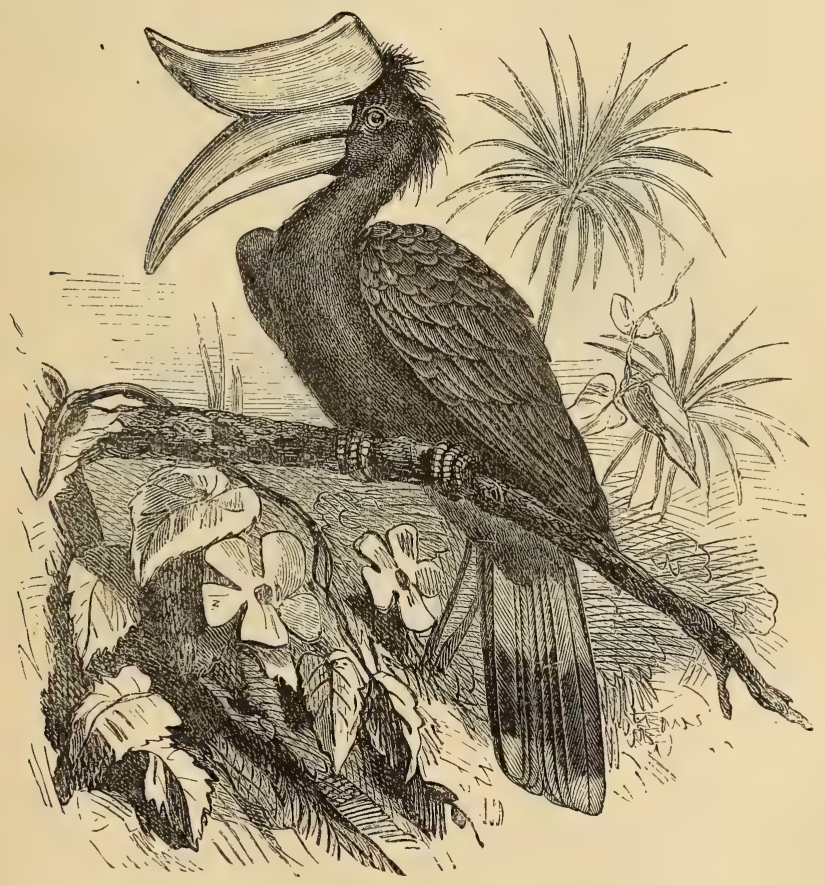

Fig. 180.-Rhinoceros Hornbill.

it is a familiar little bird, and will often let a man come within a few feet to admire it before becoming alarmed. "It keeps much about the houses in country parts," he adds, "flies slow, and probably may be easily tamed."

It lives almost entirely on the ground, feeding on insects, which it catches in the evening. It builds its nest in the crevices on river 
banks, or in the soft rocks, in which it hollows out a dwelling by means of its bill and feet.

The King-fishers (Alccdo), the Martin-fishers of some authors, form a highly interesting group, of which Alcedo ispida (Fig. I8I) is the only known species indigenous to Britain. M. Vigors finds an intimate resemblance between them and the Todies. The Kingfishers are very singular birds. Their bill is strong, straight, and angular, being of immense length compared with their size; the tip

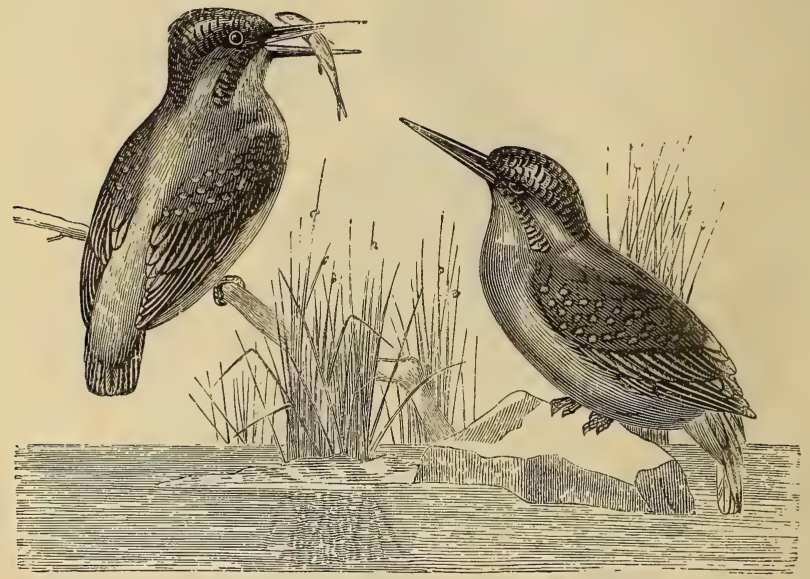

Fig. 18r.-King-fisher's.

of both mandibles acute; the commissure perfectly straight ; the head strong and elongated; wings and tail of moderate size; tarsi short, and placed far back. Those found in Great Britain have behind each eye a patch of light orange brown, succeeded by a white marking; from each corner of the mandible proceeds a line of rich blue, tinged with green; the crown of the head is deep olive green; the feathers are tipped with a verdigris shade; chin and throat with yellowish white; breast, belly, and vent with orange brown; tail a bluish green; shafts of the feathers black; and the legs a pale brick red. This beautiful bird is as interesting in manners as in appearance. Living on the banks of rivers they feed almost exclusively on fish, watching patiently from a fixed station, generally a naked itwig 
overhanging the water, or a stone projecting above the surface, for its prey: in this position it will sometimes remain for hours, absolutely immovable. When a fish comes within reach, with great rapidity the King-fisher darts upon it, seizing it in its powerful mandibles, and after destroying it by compression, or by knocking it against a stone or the trunk of a tree, swallows it head foremost. When fish are scarce it feeds upon aquatic insects, which it seizes on the wing. Its aërial movements are rapid and direct, but weakly maintained, being performed $b_{j}$ a series of quick jerking beats of the wings, close to the surface of the water: the action of the wings is so rapid as to be scarcely perceptible. The King-fisher is a bad walker, on account of the shortness of its tarsi.

This genus are all solitary in their habits, living generally in secluded places, and rarely seen even with birds of their own species, except in the pairing season. Like the Todies, they build their nests in the steep banks of rivers, either in the natural crevices, or in holes hollowed out by water-rats; and these dwelling-places are generally littered by the fragments of their food. Father and mother sit alternately, and when the young are hatched they feed them with the produce of their fishing. The bird has a shrill and piercing note, which it utters on the wing. Their flesh is very disagreeable.

The King-fisher is the Halcyon of the ancients, who attributed to it after death the power of indicating the winds. The seven days before and the seven days after the winter solstice were the Halcyon days, during which the sea remained perfectly calm that the bird might build its nest. To its dead body the attributes of turning aside thunderbolts, of giving beauty, peace, and plenty, and other absurdities, were ascribed. Fiven now, in some remote provinces in France, the dead birds are invested with the power of preserving woollen stuffs from the attack of the moth; hence they are called Moth Birds by drapers and shopkeepers. They are inhabitants of almost every region of the globe, and comprehend a great number of species, spread over Asia, Africa, and America.* Europe possesses one species not larger than a sparrow, and which is remarkable for the rich colouring of its feathers. What, indeed, can surpass the brilliancy of the King-fisher as it suddenly darts along some murmuring brook, tracing a thread of azure and emerald? Some authors separate the King-fishers, properly so called

* In China a great number of species are to be found, all robed in the most brilliant plumage, nine of which I have collected. In America I have not been so successful, its best-known species being nıout the size of a Blue Jay, and is so like that bird as sometimes to be taken for $\mathrm{i}$. by the most inexperienced. - ED. 
or river-side Birds, from the bee-eaters and other Fissirostral Birds, which, while they resemble each other in many physical characteristics, differ essentially in their habits; in short, while the one haunts the river, feeds upon its inhabitants, and nests upon its margin, the other keeps to the woods and forests, feeds upon insects, and builds in holes in trees.

The Ceyx tridactyla, inhabiting the Indian Archipelago, very closely resembles the King-fisher of Europe in its habits; it darts in short rapid flight along the surface of lakes and rivulets, emitting

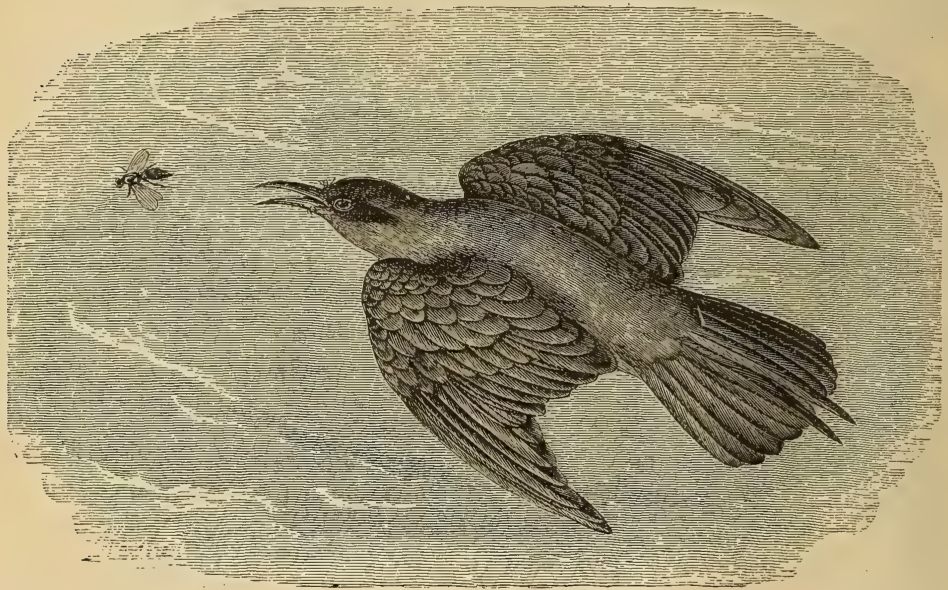

Fig. $182,-$ Common Bee-eater.

shrill discordant sounds; it perches on trees on the river banks, and feeds on small fishes and aquatic insects. Their tarsii are smooth, the inner toe wanting; in other respects its habits are those of the King-fisher.

The Bee-eaters (Meropide) have the beak long, thin, slightly curved, and pointed, the mandible having a trenchant edge ; the tarsi short; the wings long and pointed ; the tail well-developed, tapering, or forked. They are slender, graceful birds. Their cries, while they skim through the air on rapid wing, are incessant. The name of Bee-eaters they receive from their principal food, which consists of various Hymenoptera, especially bees and wasps. They seize their 
prey either on the wing, like the swallows, or secrete themselves at the entrance to a hive, and catch the inmates that enter or depart, whose stings they are skilful in avoiding. Living together in numerous flocks, they rapidly clear a district of wasps and bees.

They build their nests in the banks of rivers or rivulets, in holes which they excavate to the depth of six or seven feet. Some species are highly esteemed as table delicacies by the French.

The Bee-eaters inhabit the warmer regions of the Old World, such as Bengal, the west coast of Africa, the Cape of Good Hope,

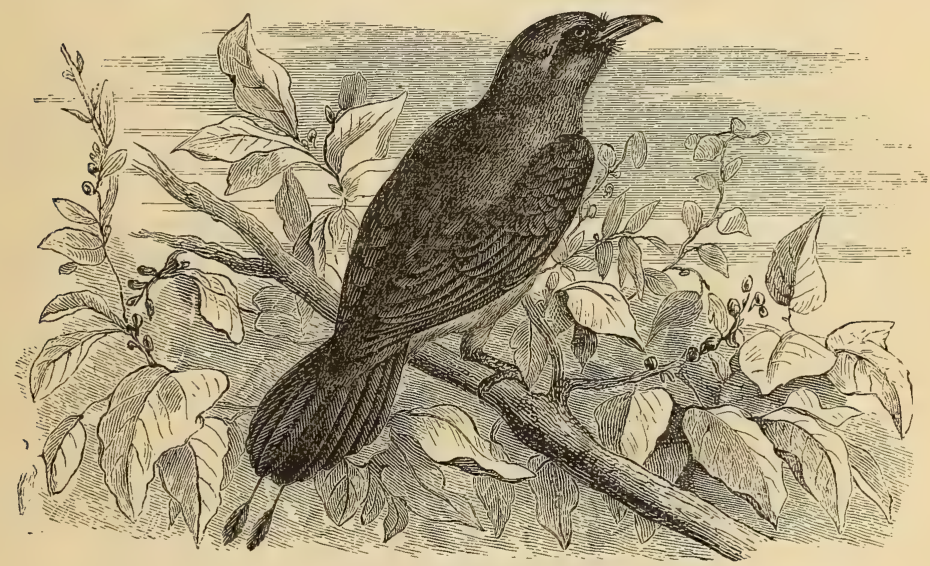

Fig. 183.-Brazilian Motmot.

Morocco, Malta. One species alone is found in Europe, the Common Bee-eater (Merops apiaster, Fig. I 82). From the coast of Africa' it migrates in small flocks into the countries skirting the northern shores of the Mediterranean. Some individuals proceed into France, Switzerland, and Germany; others spread themselves over Turkey and the southern parts of Russia. In England it is occasionally met with in Cornwall, Devonshire, and along the Hampshire coast. It has been shot in the Mull of Galloway. In France it arrives in the month of May, and remains but a short time. As a rule it rarely' ventures further north than the south of France.

The Motmots (Momotus) are birds still very imperfectly known. 
They are remarkably massive in form, heavy and slow on the wing. They are placed by systematists near the Toucans (Ramphastos), from similarity of habits, and especially from the structure of the tongue, which is in both long, and so much ciliated at the sides as to resemble a feather. The feet, however, are totally different from those of the Toucans. In the Motmots the beak is long, robust, and crenated at the edge. They are very wild, and lead an isolated life in the thick forests of South America, where they build in holes in trees. About the size of a Magpie, many of that bird's bad qualities are attributed to the Brazilian Motmot (Momotus braziliensis, Fig. I83).

\section{TENUIROSTRES.}

The Passerine Tenuirostres are characterised by a long slender beak, straight or curved, but always without indentation. They are insectivorous, and comprise the Hoopoes, Humming-birds, Creepers, and Nuthatches.

The Hoopoes (Upupa) have the beak long, slender, triangular, and slightly curved. This group, which Mr. Gray designates the Upupida, includes a number of birds whose general form presents the greatest analogy, but which possess their own peculiarities of plumage and special physiognomy. This has necessitated its subdivision into sub-families, of which the Hoopoes, the Promerops, and the Epimachii are worthy of notice.

The Hoopoes are easily recognised from the double range of plumes which form an arched crest on their head, which they have the power of raising at pleasure. These feathers are, in the Common Hoopoe, of a ruddy buff colour, tipped with black. They are solitary birds, living by preference in low grounds and humid places, where they prey on worms, insects, and terrestrial molluscs. They are migratory, and are occasionally found in the British Islands in autumn : instances have occurred of their breeding there. They take their departure for warmer regions in September. They have a light and graceful walk, and nearly pass their existence on the ground, rarely perching, and flying with visible effort. They have no song, and only utter two notes, which may be rendered by the syllables $z i$ zi, houp houp. They nest in the clefts of rocks or walls, and in holes in the trunks of trees. When captured young, they become very tame, and seem to be susceptible of great attachment to those who take care of them.

The Hoopoe (Upupa epops, Fig. I84) is found in summer as far north as Denmark and Sweden; and southward, in France and 
Italy, at Gibraltar and Ceuta, and in Egypt, where it breeds, as it probably does over northern Africa. It has been seen occasionally at Madeira, and is abundant at Trebizond, whence it

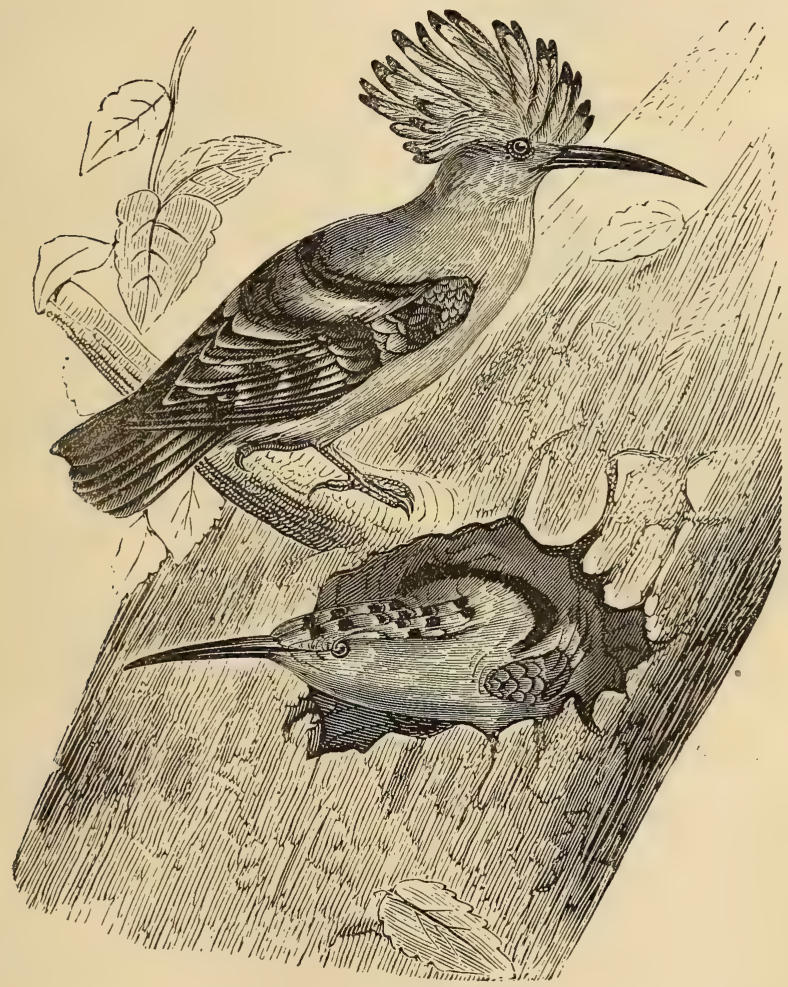

Fig. 184,-Hoopoes.

comes every year to pass the summer season in Europe. At the period of its departure from France-that is to say, in the month of September-as its flesh is very delicate in flavour, it is a choice morsel for the table. 
The Promerops are distinguished from the other Upupince by the absence of the crest, by their very long tail, and by their forked and extensible tongue. They are natives of Africa, and their habits are little known.

The Epimachus are remarkably beautiful birds. When at maturity the side-feathers develop themselves in delicate lines or elegant panicles, while their plumage, richly coloured, is brilliant with diaphanous metallic reflections.

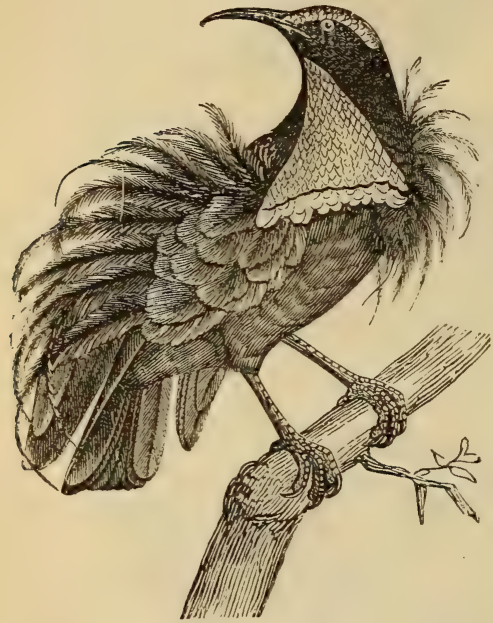

Fig. $185 .-$ Epinachus. Little is known of their habits. They are natives of Australia and New Guinea. The very remarkable species, E. multifil, has six long fillets on each side of its body. The equally striking species, $E$. magnus (Fig. I85), has the elongated side-feathers raised and curling, of a glittering steel blue, azure, and emerald green; the breast and belly lustrous with the same diaphanous tints. This bird is an inhabitant of New Guinea.

The Humming-birds (Trochilida) may be divided into those that have the beak straight, and those having the beak curved. With this slight difference, the Trochilidae and Colibri closely resemble each other. They have the same slight, elegant figure, the same brilliancy of plumage, and the same habits-describe the one, and you describe the other. We must be permitted, therefore, to treat of them together.

The Humming-birds are the most lovely of the winged race. Nature seems to have endowed them with her rarest gifts. In creating them she surpassed herself, and exhausted all the charms at her disposal ; for she imbued them with grace, elegance, rapidity of motion, magnificence of plumage, and indomitable courage. What can be more delighful than the sight of these little feathered beauties, flashing with the united fires of the ruby, the topaz, the sapphire, and the emerald, flying from flower to flower amid the richest tropical vegetation? Such are the lightness and rapidity of some of the smaller species, that the eye can scarcely follow the quick beat of 
their wings. When they hover they appear perfectly motionless, and one might fancy them suspended by an invisible thread.

Specially adapted for an aerial life, they are unceasingly in motion, searching for their food in the calyx of flowers, from which they drink the nectar with so much delicacy and address that the plant is scarcely stirred. But the juice and honey of flowers, as some authors affirm, are not their only food-such unsubstantial diet would be insufficient to sustain the prodigious activity displayed almost every moment of their existence.

The tongue of the Humming-bird is a microscopic instrument of marvellous arrangement. It is composed of two half-tubes placed one against the other, capable of opening and shutting, like a pair of pliers. Moreover, it is constantly moistened by a glutinous saliva, by which it is enabled to seize and hold insects-an arrangement not without analogy in the IVoodpeckers.

Proud of their gay colours, the Humming-birds take the greatest care to protect their plumage. They frequently dress themselves by passing their feathers through their bills. Their vivacity often amounts to petulance, and they frequently manifest belligerent propensities not to be expected in such minute creatures. Birds much larger than themselves they attack, threatening their eyes, harassing and pursuing them without intermission, and always succeeding in putting them to flight; even with their own race they frequently fight. If two males meet on the calyx of a flower, bristling with anger, and uttering their cry, they rush on each other. After the conflict is over the conqueror returns to reap the reward of his valour.

The nest of the Humming-bird (Fig. I86) is a masterpiece. It is about the size of half an apricot. The materials are brought by the male, and arranged by the female. These consist of lichens, and are most artistically interwoven, the crevices being closed up with the bird's saliva : the interior is padded with the silky fibres furnished by various plants. This pretty cradle is suspended to a leaf, sometimes to a small branch of rushes, or even to the straw roof of a hut. The hen bird lays twice a year a pair of pure white eggs, about the size of a pea.

After an incubation of six days the young are hatched; a week later they are capable of flight. During the breeding season the males are tender and demonstrative, and both parents show much affection for their progeny.

These little creatures are universally admired for their elegance and beauty, and the names given them are generally descriptive of 
their excessive minuteness. The creoles of the Antilles call them Murmurers; the Spaniards Picaflores; the Brazilians Shupaflores, or Flower-suckers ; finally, the Indians call these darlings Sunbeams. Humming-birds are much sought after-not for their flesh, which

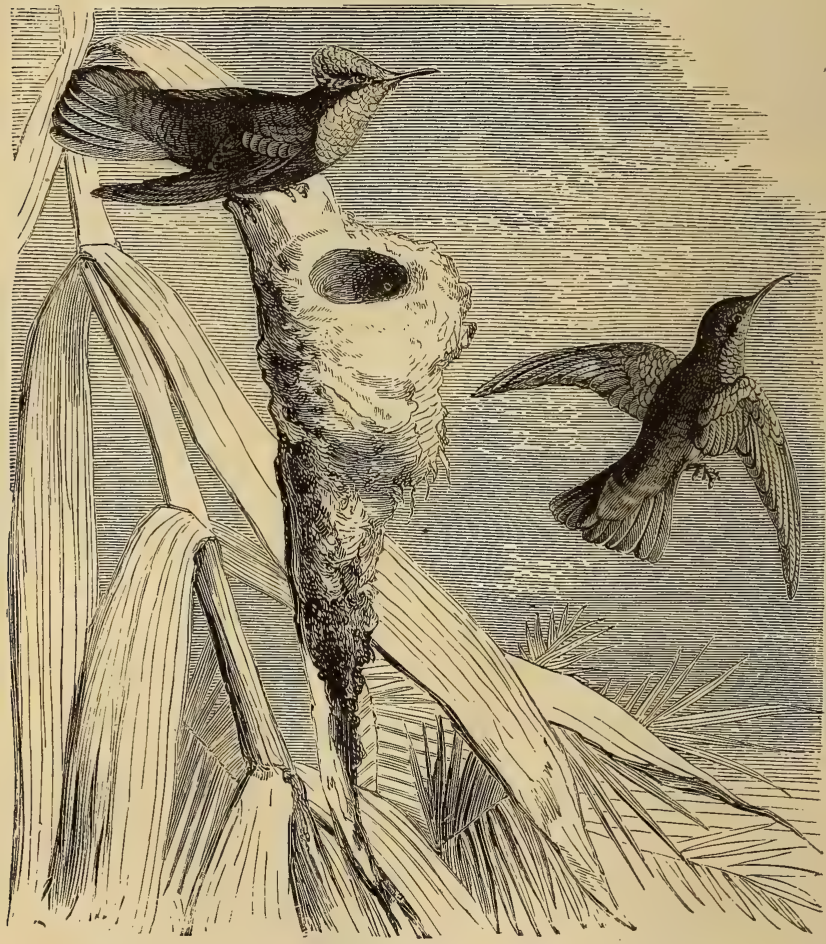

Fig. 186, - Nest of Ruby and Topaz Humming-bird.

is valueless, from its minute quantity, but for their feathers; ladies turn these to various uses, making from them collars, pendants for the ears, \&c. Some of the Indian races which have been converted to Christianity employ them to decorate the images of their favourite saints. The Mexicans and Peruvians formerly trimmed mantles with 
them. The French soldiers who shared in the Mexican expedition report that pictures made with the feathers of the Humming-bird are brilliant and effective.

Humming-birds cannot be preserved in captivity-not that they

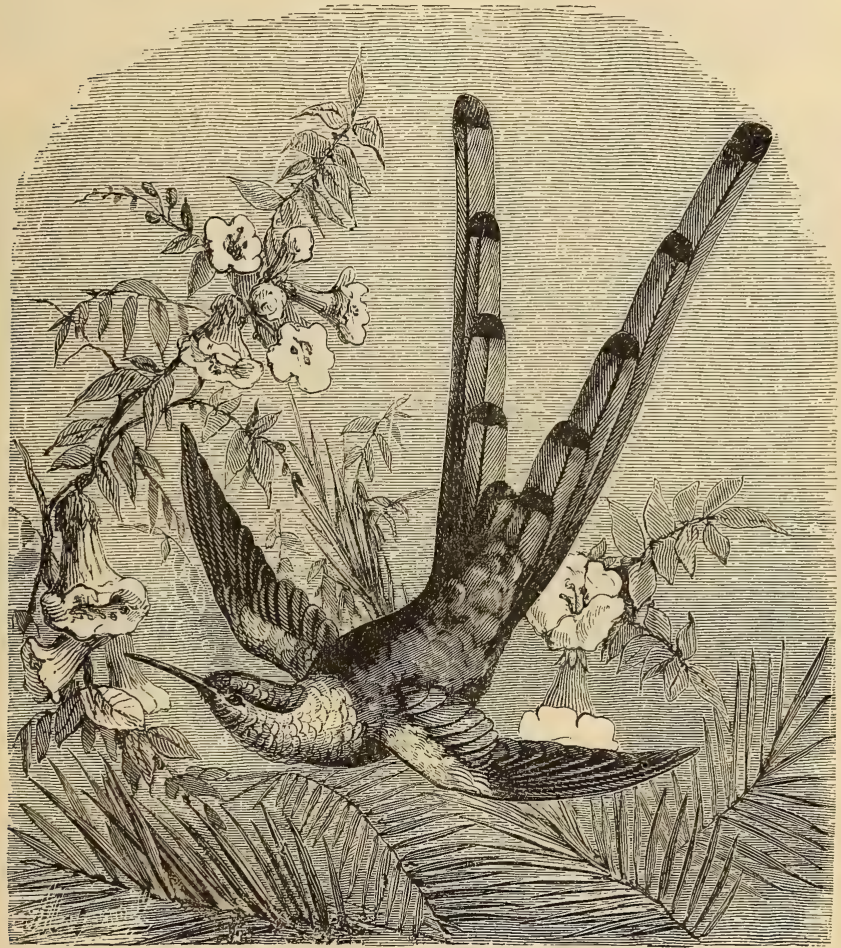

Fig. 187.-Sapho Comet.

do not become familiar and affectionate, but their extreme delicacy unfits them for restraint, for in spite of the utmost care that can be bestowed on them, they will die in a few months. In their habitat they are killed by concussion or with the sarbacane; if desired alive, they are taken with a butterfly net. 
Among the most formidable enemies of the Trochilida may be reckoned the Monster Spider (Mygale avicularia), which spins its web round their nests, and devours eggs or young; even the old birds are sometimes its victims. Humming-birds are scattered over the greater part of South and North America, even as far north as Canada ; but in Brazil and Guiana they are most abundant. At least 500 species are known. Cuvier included them in his genus Colibri. Mr. Gould has described 300 , of which he has actual specimens;

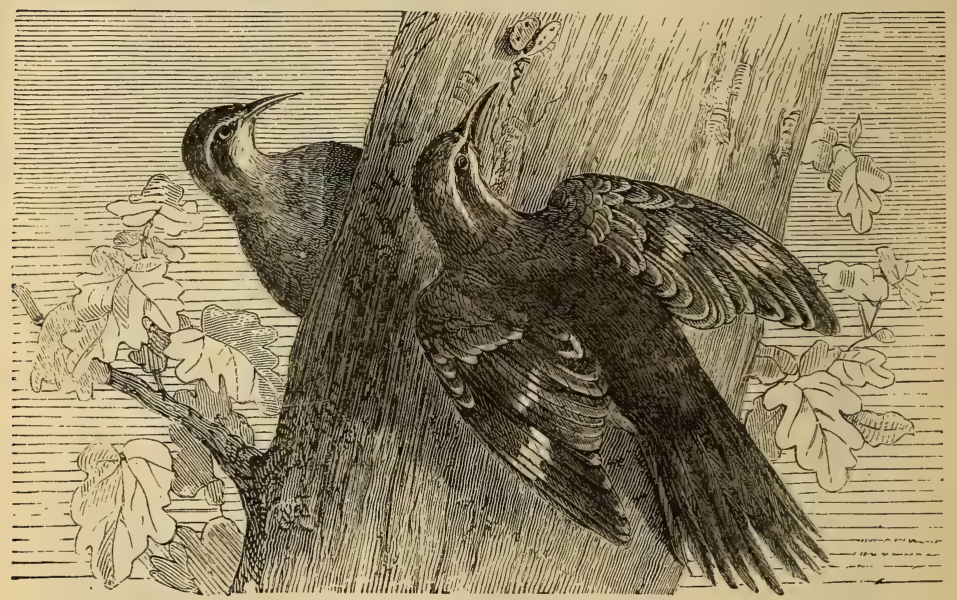

Fig. 188.-Common Tree Creepers.

these he divides into fifty-two genera. Among the more remarkable species we may note the Topaz-throated Trochilus $(T$. pella), a native of Brazil ; the Sickle-winged Humming-bird ( $T$. falcatus); the Double-crested Humming-bird (T. cornutus); Gould's Humming-bird (Ornismya Gouldii); Cora Humming-bird (Ornismya cora); the Giant Humming-bird, which attains the size of the Swallow; the Dwarf Humming-bird, whose size does not exceed that of a bee; the bar-tailed Humming-bird or Sapho Comet (Cometes sparganurus, Fig. I87), a native of Eastern Peru ; and the Racket-tailed Hummingbird, so named from the shape of its tail, which spreads out at the extremity in the form of a racket.

Climbers (Scansores), such as the Tree Creepers, are characterised 
by an arched beak and a stiff tapering tail. The family comprehends several genera and sub-genera, of which the principal are the Creepers (Certhia), properly so called, the Wall Creepers (Tichodroma), the Piculets (Picumnus), the Oven Birds (Furnarius), the Thornbills (Rhamphomicron), the Sun Birds (Nectarina), and the Nuthatches (Sitta).

The Creepers (Certhia) are small climbing birds which live and build their nests in the holes they bore in the trunks or in the natural

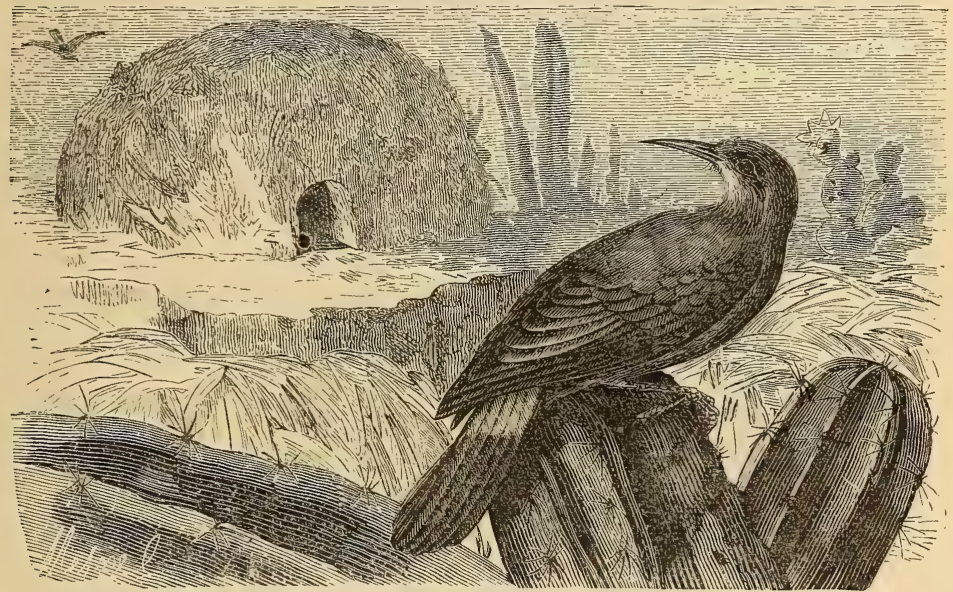

Fig. I89.-Oven Birds.

hollows of trees: the insects to be found under the bark being their food. Looking at the form of their slender beak, it is difficult to imagine how it can penetrate the hard covering of an oak, for which they exhibit a marked preference. The Common Tree Creeper (Certhia familiaris, Fig. I88) is spread over nearly every European country, and is very conimon in France. The Wall Creeper (Tichodroma murarius), called also Wall Climber (the grimpereau des murailles of French authors), owes its name to its habit of climbing the walls of dwellings. Supporting-points are not found in their tails, as in the Woodpeckers. Grasping the tree with their claws, they assist their feet by a slight movement of the wings. They feed on insects, and lead a solitary life on the mountains, only descending 
into the plains with the early frosts of winter. They are found diffused over all the south of Europe.

The Piculet (Picumnus pygmaeus) has form and habits very similar to the Creeper, but the beak is stronger and more boldly curved. They are natives of Brazil and Guiana.

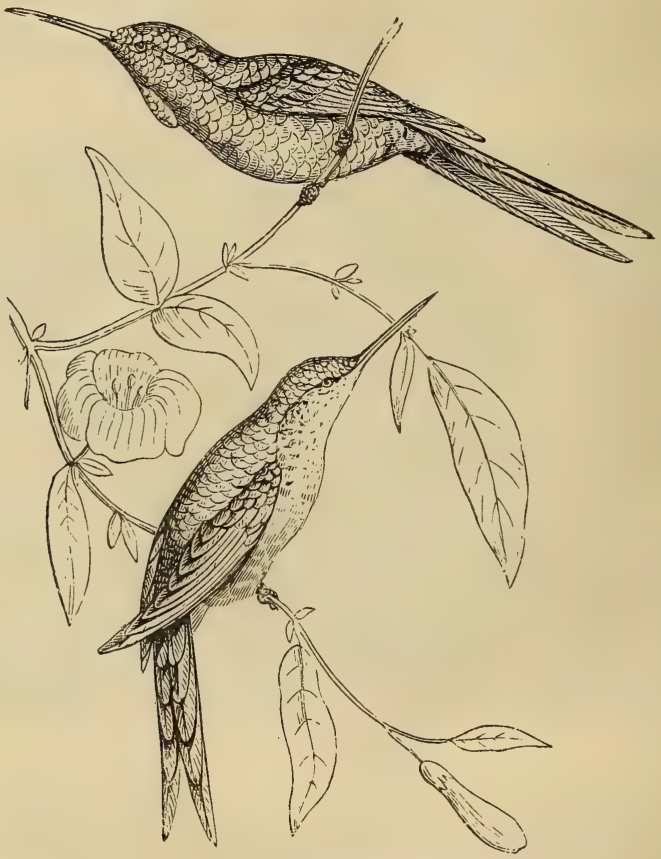

Fig. 190.-Columbian Thornbills.

The Oven Birds (Furnarius fuliginosus, Fig. I89) live singly or in pairs in the plains of Chili, Brazil, and Guiana. They feed principally on seeds, but also on insects. They take up their residence with much confidence in the neighbourhood of man's dwellings. Their nests are remarkable, being in the form of an oven, whence their name. This structure is built on trees, on palisades, or even rocks. It is remarkable for its size when compared with its architect 
and builder, for it measures not less than from twelve to fourteen inches in diameter; it is entirely formed of clay, and the interior is divided into two compartments by a partition, the outer and inner, the latter being that in which the female lays her eggs. When engaged making this birthplace for their young, the male and female alternately bring small balls of earth, out of which the edifice is constructed, and they labour so industriously that their work is sometimes finished in two days. Some species construct their nests on trees, interlacing them with spiny branches, and providing one or many openings; that of the Cinclodes is fifteen inches in diameter by twenty inches in height.

The Thornbills, of which the Columbian (Rhamphomicron heteropogon, Fig. I90) is best known of the family, are American birds; their love for saccharine substances has obtained for them their synonym. They feed on honey extracted from flowers, and the sap from the sugar-cane, the juice of which they suck through crevices in the stem. Like the Humming-birds, they have the tongue divided into two parts, by which they are enabled to seize insects, which form a part of their diet. They are small in size, and their plumage is brilliantly

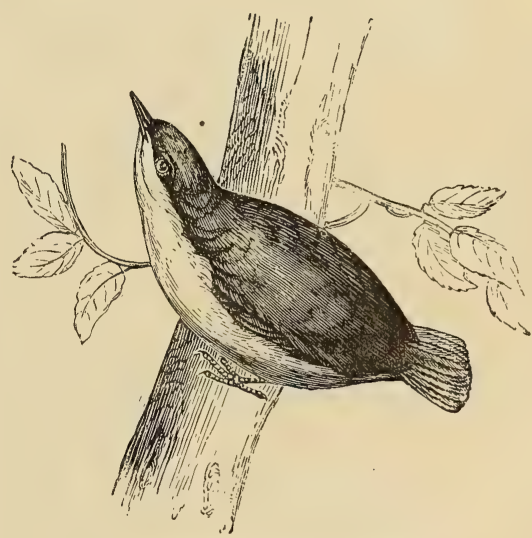

Fig. rgr - The Cimmon Nuthatch. coloured. Among the Cinny-

ridce we find the Guits-guits, ingenious little creatures, which construct a nest in the form of a horn, which is suspended from the flexible branches of a shrub : in order to protect their young from the attacks of earwigs, the opening is below.

The Sun Birds (Nectarina) have the same partiality for sugar exhibited by the last, justifying their name, which signifies "sugareater" in the Malagash tongue. They are natives of Southern Africa and India, and represent in the Old World the Humming-birds of the New. They are gay and sprightly, and decked in the most brilliant colours.

The Nuthatches (Sitta europaa, Fig. I9I) have the beak straight, 
pyramidal, and pointed, covered at the base with small feathers directed forward; the long toes are furnished with claws strong and crooked; their habitat resembles that of the Creepers. They are also found in islands of the Pacific.

\section{CONirostres.}

The Conirostral Passerince are characterised by a strong robust beak, more or less conical, and without notches. They are generally granivorous, but some species are insectivorous or carnivorous. This group includes the Birds of Paradise, Crows, Rollers, Starlings, Sparrows, Tits, and Larks.

The Birds of Paradise have the beak straight, compressed, and strong, the nostrils covered with velvety feathers. In brilliancy of colouring, and in graceful, pendent, gossamer-like plumage, they take precedence in the feathered creation.

They have a very restricted habitat, being only found in New Guinea, Ternate, and in the island of Papua, situated to the north of Australia; there they dwell in the thick forests, feeding on fruit and insects. Occasionally they are found living in solitude, but more frequently are to be met in large flocks, altering their residence with the change of the monsoon.

Their flight is very swift, and has been frequently compared by Europeans resident in the East to that of a Swallow ; in consequence, they have bestowed on the Bird of Paradise the name of Swallow of Ternate.

It is owing to the long lateral plumes, which they most perfectly control in the air, that they are so buoyant; at the same time, this unusual amount of plumage almost entirely stops their progression against a head wind.

When the Bird of Paradise was first spoken of in Europe few believed that it existed. Nor is this to be wondered at, when we recall that it was affirmed that these gorgeous birds were without legs, and hung on to the branches of trees by their long aërial plumes; that the female deposited her eggs under the feathers on the back of the male; that they passed the breeding season in Paradise; and many other stories equally absurd.

The inhabitants of Papua capture the Birds of Paradise, for their plumage is of great commercial value. The method they adopt is to place themselves in the tops of the highest trees : where, concealed, they attract the birds within reach of their blow-pipes by whistling. 
Among Birds of Paradise the most remarkable is Paradisea apoda, the Great Emerald, as it is sometimes called (Fig. I92), the throat and neck of which are of a bright emerald green, from which circumstance it has received this name, while on its sides are shaded tufts of yellow feathers, which float on the breeze, forming an elegant aërial

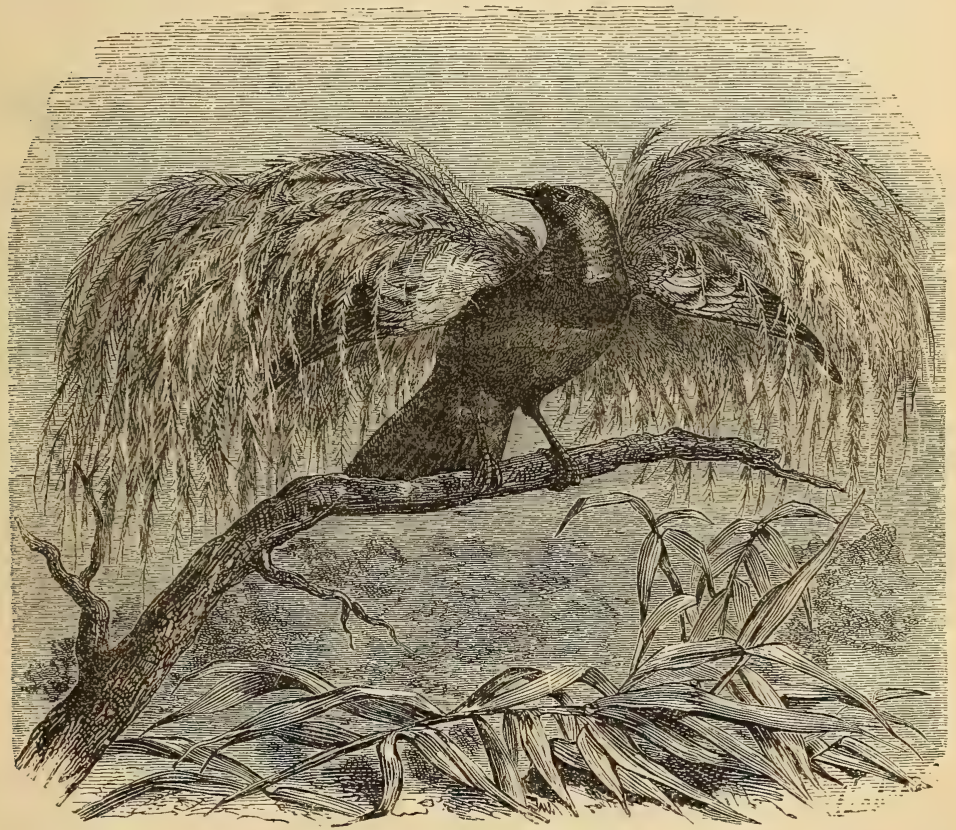

Fig. I92.-The Great Emerald.

plume, and giving the bird a meteor look as it shoots through the air. They live in flocks in the vast Papuan forests. When prepared for migration-for they change their quarters with the monsoonsthe females assemble in small flocks on the tops of the loftiest trees, and call their males, each flock of fourteen or fifteen being attended by one.

The King Bird of Paradise (Paradisea regra, Fig. 193) is a rare bird, inhabiting the Molucca Islands. Little is known of its 
habits. The beak, which is furnished at the base with small feathers pointing forward, is slender, convex, and slightly compressed at the sides. The hypochondrial feathers are broad, elongated, and truncated.

In the Superb (Paradisea superba, Fig. 194) the beak is furnished with elongated feathers, extending half its length; the feathers of the neck rising just behind the head, expand into a wing-like form.

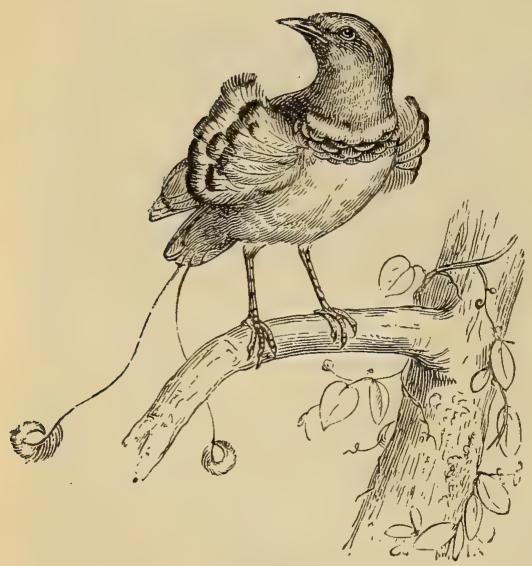

Fig. I93.--King Bird of Paradise.

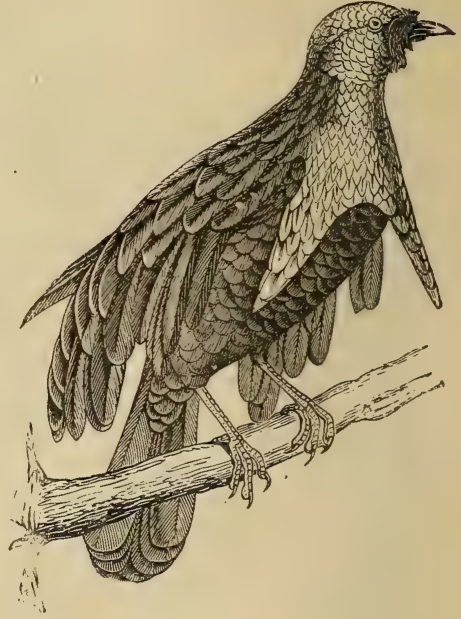

Fig. :94. - The Superb Bird of Paradise.

In the Golden Bird of Paradise (Paradisea sexsetacea, Fig. 195) the beak is furnished with short feathers for half its length, and is slender, compressed laterally, notched and curved at the tip; they have long, broad, and loose plumes covering the sides and abdominal part. It obtains the name of Sifilet, given to it by Buffon, from the three thread-like feathers on each side of the head expanding into a lancet shape at the extremity, and which form a very striking ornament.

The birds which constitute the Crows (Corvida) are characterised by a very strong beak with cutting edges, broad at the base, flattened laterally, and hooked towards the point; the nostrils covered with 
stiff feathers directed forward; also by strong claws and long pointed wings. They are divided into four groups or sub-genera-namely, the Crows properly so called, Pies, Jays, and Nutcrackers.

The genus Corvus, as limited by modern naturalists, comprehends the Raven, the Carrion Crow, the Royston or Hooded Crow, the Rook, the Jackdaw, Great-billed Crow, Philippine Crow, and Fish Crow.

All these species have in many respects the same characteristics, the same aptitude, and the same habits. With the exception of the Raven and Magpie, which live in pairs, the others reside to-

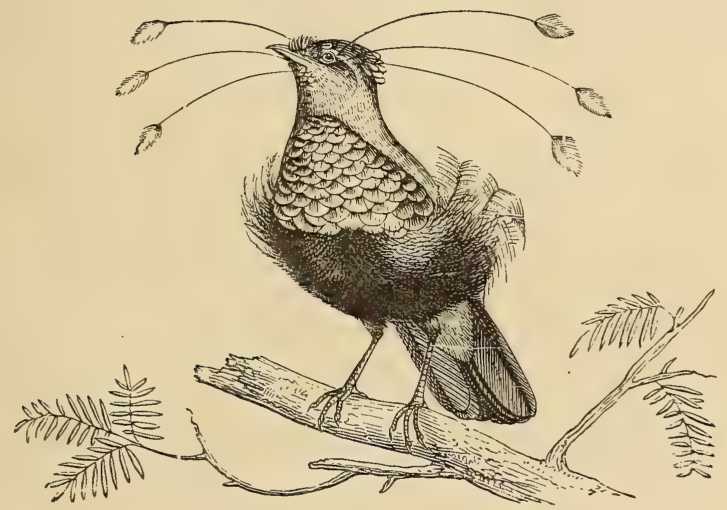

Fig. 195.-Golden Bird of Paradise.

gether in companies, whether they are in quest of their daily food or roosting for the night. They are all possessed of intelligence, cunning, mischievous habits, the gift of imitation, though in different degrees, and the same provident habit of amassing provisions in secret places. This last peculiarity in the tamed birds degenerates into a perfect mania, which leads them to carry off and hide everything that attracts or pleases their eye, especially gems and bright articles of metal. The whole group are susceptible of domestication.

The Crows, especially the Raven and the Carrion Crow, are preeminently omnivorous. Living or dead flesh, insects, eggs, fruit, seeds-nothing comes amiss to their palate. Their depredations are 
consequently enormous. Ravens, not content with levying a tribute on moles, field-mice, leverets, and young game, frequently enter poultry-yards, and without ceremony appropriate chickens, ducklings, \&c. Buffon even asserts that in certain countries they fasten upon the backs of buffaloes, and after having put out their eyes, devour them. According to Lewis, Carrion Crows attack the flocks in Scotch and Irish pastures. Lastly, all Crows delight in digging up newly-sown ground, eating with avidity the germinating seed. On this account the agricultural population are generally their bitterest enemies, destroying them when opportunity offers. In certain parts-Norway, for instance-laws were made ordering their extermination. But this policy was short-sighted: if they did harm, they also did good, by devouring grubs and larvæ, formidable foes to agriculture. How is it that men will not use their brains? that they actually destroy the animals provided by a bounteous Creator, and whose utility is most conspicuous?

The flesh of the Raven and the Carrion Crow exhales a disagreeable smell, doubtless caused by the quantities of putrid animal matter they consume; consequently, it is unfit for human food. Not so, however, with the Rook. This bird, when taken young, is not only eatable, but by some deemed a delicacy.

Crows possess a vigorous and sustained flight; they have a keen sense of smell and excellent vision. By exercising these latter qualities they become aware where food is to be obtained, and as they wing their way towards it they constantly utter their cry, as if inviting their companions to join them; this croak, as it is called, is harsh and dissonant. Their plumage being of a sombre funereal black, and their voice so unmusical, have doubtless been the reasons why they have long been considered birds of ill omen. When taken young, they are tamed with great facility, for they will neither rejoin their own race nor desert the neighbourhood where they have been kindly treated. True, they may go into the fields to seek for food, but when the increasing shadows predict the approach of night, their familiar resting-place in the house of their protector will be sought. They become much attached to those who take notice of them, and will recognise them even in a crowd. Their audacity and their malice are incredible. When they take an antipathy to any one, they immediately show it. They suffer neither cats nor dogs to approach them, but harass them incessantly, tearing from them their very food. Finally, they choose secret places, where they store up all that tempts their cupidity or excites their covetousness. They even learn to repeat words and phrases, and to imitate the cries of 
other animals. These facts are confirmed by numerous anecdotes related by naturalists of undoubted veracity.

Pliny speaks of a raven which established itself in one of the public places of Rome, and called out the name of each passer-by, from the emperor to the humblest citizen. We have all laughed heartily at the recital of an adventure which happened to an awkward horseman, who lost his seat, while a raven perched on a branch of a tree above him cried out with a solemn voice, "How silly!"

Dr. Franklin thus speaks of a raven of his acquaintance which had been brought up at a.country inn :- "It had," he says, "great recollection of persons, and knew perfectly all the coachmen, with whom it lived on the greatest intimacy. With its special friends it took certain innocent liberties, such as mounting on the top of their carriage and riding out with them until it met some other driver with which it was on terms of similarly close friendship, when it would return home." The same raven had unusual sympathy with dogs in general, and especially those which happened to be lame. These it loaded with the most delicate attentions, keeping them company, and carrying them bones to gnaw. This excessive kindness to animals which are rarely in the good graces of ravens arose from this bird having been reared along with a dog, for which it entertained such strong regard, that it attended it with unremitting assiduity when it had the misfortune to break its leg.

The same author mentions another raven which was captured in Russia, and came to be confined in the Jardin des Plantes of Paris. It recognised Dr. Monin when he stopped accidentally before its cage. It had belonged to him ten years back, and when brought before its old master it leaped upon his shoulder and covered him with caresses. The doctor reclaimed his property, and the bird was henceforth an ornament to his house near Blois, where it learnt to address the country-people as "great hogs." Dr. Franklin raised one of these birds himself, which showed wonderful powers of imitation. "He called himself Jacob. Sometimes it made such a noise at the bottom of the stairs that you could only imagine it was caused by a party of three or four children quarrelling with great violence ; at other times it would imitate the crowing of a cock, the mewing of a cat, the barking of a dog, or the sound produced by a rattle for frightening away birds from a wheat-field; then a silence would ensue ; but soon after the crying of a child of two years of age would be mimicked; 'Jacob! Jacob!' its own name, probably it would then call, repeating the cry at first in a grave tone, then with shriller intonation and more vociferously ; again another silence; but after a 
pause, a man seems to knock at the gate; if it is opened, enter Jacob, who runs about the room, and finally mounts on the table. Unfortunately, Jacob was a thief, and that was not his least faultspoons, knives, forks, even plates, disappeared, with meat, bread, salt, pieces of money, especially if new ; he carried off everything, and hid all in some secret hole or corner. A washerwoman of the neighbourhood was accustomed to dry her linen near our window, fixing the clothes on the line with pins; the bird would labour with a perseverance truly wonderful to detach these, the woman chasing him off with bitter maledictions about her fallen linen; but he would only fly over into his own garden for safety, where he would indulge in a few malicious croakings. One day I discovered, under some old timber, Jacob's hiding-place. It was full of needles, pins, and all manner of glittering objects."

$\mathrm{Mr}$. Charles Dickens was partial to keeping ravens in his youth; and has related some of his experiences in the preface to "Barnaby Rudge." He had two great originals. "The first was in the bloom of his youth when he was discovered in a humble retreat in London and given to me. He had from the first, as Sir Hugh Evans says of Anne Page, 'good gifts,' which he improved by study and attention in a most extraordinary manner. He slept in a stable-generally on horseback-and so terrified a Newfoundland dog by his preternatural sagacity, that he has been known, by the mere superiority of his genius, to walk off unmolested with the dog's dinner from before his face. He was increasing in intelligence and precocity when, in an evil hour, his stable was newly painted. He observed the workmen closely, saw that they were careful of their pigments, and immediately burned to possess some of them. On their going to dinner, he ate up all they left behind, consisting of a pound or two of white lead. Alas, this youthful indiscretion terminated in death!

"Whilst yet inconsolable for the loss, another friend of mine," adds Mr. Charles Dickens, "discovered an older and more gifted raven at a village inn, which he prevailed upon the landlord to part with for a consideration. The first act of this sage was to administer to the effects of his predecessor, by disinterring all the cheese and halfpence he had buried in the garden-a work of immense labour and research, to which he devoted all the energies of his mind. When he had achieved this task, he applied himself to the acquisition of stable language, in which he soon became such an adept that he would perch outside any window and drive imaginary horses all day long, with great skill in language. Perhaps I never saw him at 
his best, for his former master sent his duty with him, and said, ' if I wished the bird to come out very strong, to be so good as show him a drunken man ;' which I never did, having (unfortunately) none but sober people at hand. But I could hardly have respected him more, whatever the stimulating influence of this sight might have been. He had not the least respect for me, I am sorry to say, in return, or for anybody but the cook, to whom he was attached, but, I fear, only as a policeman might have been. Once I met him unexpectedly, about half a mile off, walking down the middle of the public street, attended by a pretty large crowd, and spontaneously exhibiting the whole of his accomplishments. His gravity under this trying ordeal I never can forget, nor the extraordinary gallantry with which, refusing to be brought home, he defended himself behind a pump until overpowered by numbers. 'It may have been that he was too bright a genius to live long, or it may have been that he took something pernicious into his bill, and thence into his maw-which is not improbable, seeing he new-pointed the greater part of the garden wall by digging out the mortar, broke countless squares of glass by scraping away the putty all round the frames, and tore up and swallowed in splinters the greater part of a wooden staircase of six steps as well as the landing-but after some three years he was taken ill, and died before the kitchen fire. He kept his eye to the last upon the meat as it roasted, and suddenly turned over on his back with the sepulchral cry of "Cuckoo!'"

Crows are universally diffused over the globe. The Raven (Corvus corax) and the Carrion Crow (Corvus corone) are sedentary birds, and never voluntarily abandon the place they have elected for their home. The Rook (Corvus frugilegus, Fig. 196) and the Jackdaw (Corvus monedula) are migratory in their habits, only visiting the countries of southern Europe on the approach of winter. The Royston or Hooded Crow (Corvus cornix) inhabits the lofty mountain regions of Europe, descending into the plains during winter. It is also solitary in its habits. The Senegal Crow (Corvus senegalensis) is exclusively confined to Africa. The Great-billed Crow (Corvus crassirostris) is a native of Abyssinia, the handsome Philippine Crow (Corvus sinensis) to the group of islands after which it is named, and finally the Fish Crow (Corvus ossifragus), which is about the size of a Jackdaw, is confined to America.

The Pies (Pica) are distinguished from the Crows by their shorter wings, Ionger tail, and by their variegated plumage; but for this difference, they greatly resemble the previously described. Like the Crows, they are omnivorous, but they generally avoid dead prey; 
they have the same desire, whether in the wild or domestic state, to store away provisions and hide glittering objects. Their instinctive habit of appropriating all sorts of plunder is one of the causes of their popularity. Every one has heard the true story on which the drama of The Maid and the Magpie is founded-how Ninette was accused and pronounced guilty of robbing her master, and when executed found to have been innocent, the true culprit being the pet magpie of the house.

The Magpie is a bold, impudent bird, which is easily put to flight

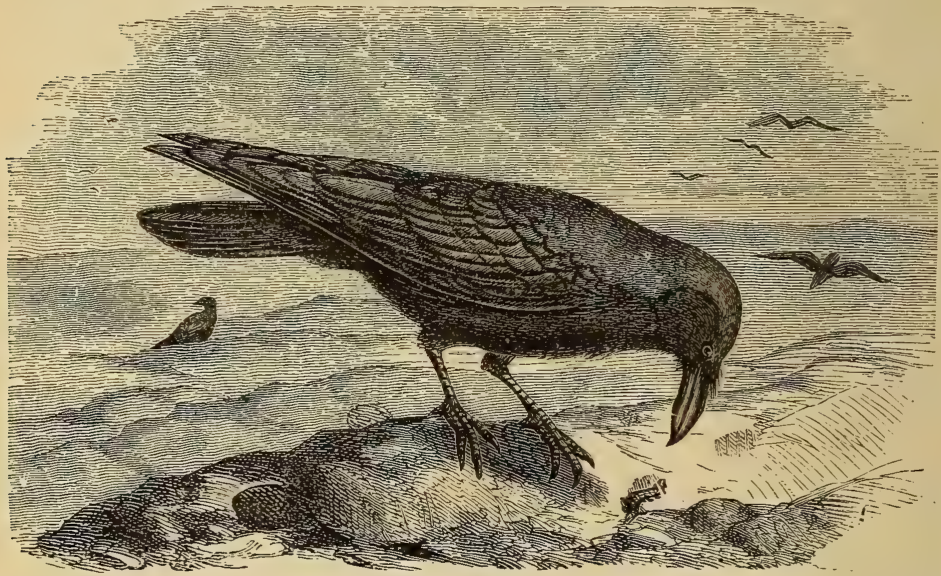

Fig. 196.-The Rook.

by man, but will fearlessly harass a dog, a fox, or any of the smaller birds of prey. Having caused one of these to retreat, it pursues the fugitive vigorously, rousing by its cries all the birds of its kind; and what with its own energy and the combined efforts of its kindred, it generally succeeds in utterly discomfiting the intruder. Its action is unceasing, its movement short and jerky; but it is heavy on the wing. It chatters incessantly : hence the proverb to "chatter like a magpie." It builds its nest of withered shrubs, dry sticks, and sand, on the highest branch of a lofty tree, which, as a structure, is remarkable for its form, size, and solidity. This fabric has many beginnings : the foundation of the last and permanent structure is laid with infinite 
precautions to avert observation. This care is taken, according to M. Nordmann, in order to mislead those who are spies on its actions; for it is in this last nest that the female deposits her eggs. If this fact were clearly established, it would show a great amount of cunning in the bird.

The Magpie lays seven eggs, which the parents hatch with care, each bird sitting alternately. They show great attachment to their progeny, and continue to afford them protection until the young are well advanced towards maturity.

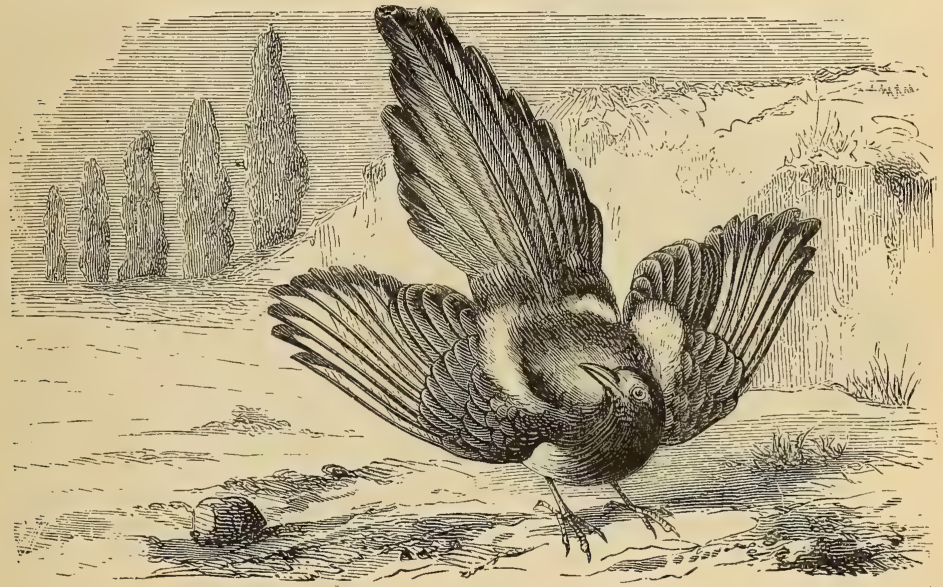

Fig. x97.-Common Magpie.

The Magpie is tamed with facility, and soon becomes familiar, assiduously following its master everywhere, and eagerly seeking his caresses, so that it is necessary sometimes to shut it up to get rid of its importunities. It readily learns to repeat a few words, "mag" being the favourite in its vocabulary. The ability to pronounce words is said to be increased by extending the soft fibrous slit which binds the lower part of the tongue to the palate. But a domesticated Magpie, draggled and mutilated, is a miserable-looking object compared with the beautiful glossy bird of the thicket.

The Common Magpie (Pica caudata, Fig. 197) abounds in all parts of the world. Cultivated valleys with natural or artificial woodlands on their slopes; low ground diversified with fields; pastures and 
moors partially covered with plantations ; fertile plains fenced in with wooded hedgerows and studded with farmhouses and cottages, are the type of landscape they prefer. In spring plumage the Magpie is a handsome bird, the feathers of the back being of velvety black, while the breast and part of the wings are pure white.

In the Brazils and Paraguay we find another species, whose whole plumage is a fine cerulean blue, with the exception of the head and throat, which are black. In China

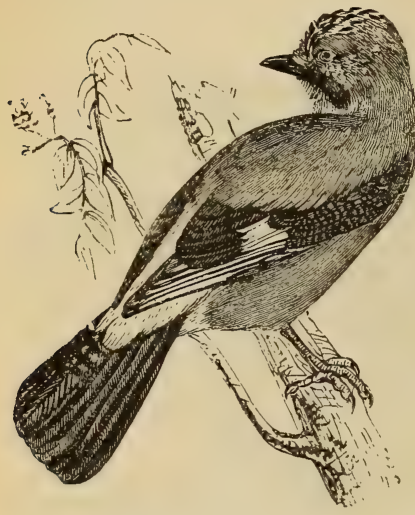

Fig. 198.-European Jay. there is also a Magpie of beautiful cobalt-blue plumage; its two centre tail feathers are very long, barred with black, and tipped with pure white; with bill and legs red. It is extremely shy, and occasionally is seen in flocks. By the inhabitants it is frequently taught to speak.

The Jays (Garrulus) have short bills, which are slightly notched at the tip; head rather large; feathers on the upper and anterior part of the head erectile when the bird is irritated; those feathers at the base of the upper mandible are stiff, with short barbs. It is not less shy than other members of the family, although it frequents gardens, where it feeds on beans and peas, of which it seems to be particularly fond. Its food, however, is not confined to fruit and vegetables, as it picks up worms, insects, the eggs of small birds, and crustacea, after the manner of crows and magpies. Naturally irascible and quarrelsome, they are nevertheless easily tamed when taken young, and soon learn to pronounce a few words. They abound in Europe and the Indies. The European Jay (Garrulus glandarius, Fig. 198) is a pretty bird of soft and blended plumage, the feathers of the fore part of the head elongated, oblong, and erectile; its general colour is a delicate brownish red tinged with grey, approaching to purple on the back. The most conspicuous trait of the plumage is the patch of ultramarine blue, banded with blackish blue, on the primary coverts.

The American variety of Jay is not quite as large as the European representative; its plumage is less brilliant. In characteristics they are much alike, being equally mischievous and dreaded by the smaller feathered denizens at the period of nesting. 
The Nutcracker (Nucifraga caryocatactes, Fig. 199) is furnished with a long, strong, and straight bill, with which it can penetrate the bark of trees when in search of insects, and open the cones of firs and pines, on the kernels of which it feeds ; failing these, it eats the hazel-nut and wild fruit, from which circumstance it derives its name. They inhabit the mountain forests of Europe and Asia, building their nests in the trunks of trees, to which they are capable of clinging, but not of climbing.

The Rollers (Coracias garrula, Fig. 200) have in their general

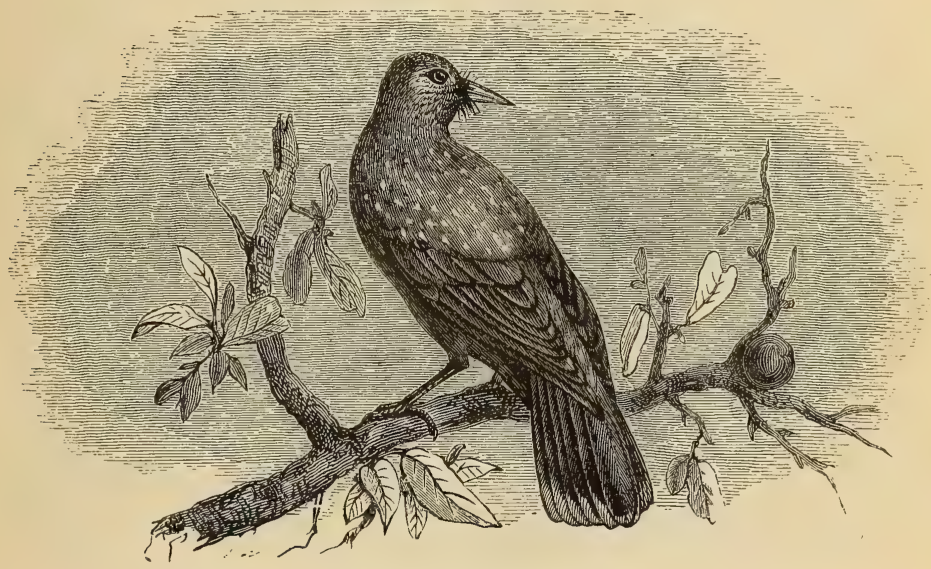

Fig. 199.-The Nutcracker.

appearance and habits considerable resemblance to the Jays ; but they differ, from the beak being more robust and the nostrils uncovered; they are also more timid, withdrawing into the thickest parts of the woods, which are their favourite haunts. When taken young from the nest it is tamable. Dr. Meyer, of Offenbach, and others, have succeeded in rearing them; but although they become so tame as to know those who attend to their wants, they never grow familiar. Their favourite food consists of insects and their larvæ, worms, and the smaller reptiles; but failing these they feed on berries, seeds, and certain roots.

The bill of the Roller is black towards the point, becoming brown at the base, with a few bristles; the irides are formed of yellow and 
brown circles; the head, neck, breast, and belly, present various shades of bluish verditer, changing to a palish green; the plumage of the upper part of the body is a brilliant azure blue on the shoulders, and reddish brown on the back; rump feathers purplish; wing primaries dark bluish black, lighter on the edge; tail feathers pale greenish blue. They abound in Europe, Africa, and Southern Asia. Although the natural habitat of the bird is oak and beech forests, M. Vieillot tells us that in Malta, where trees are scarce, the bird nests

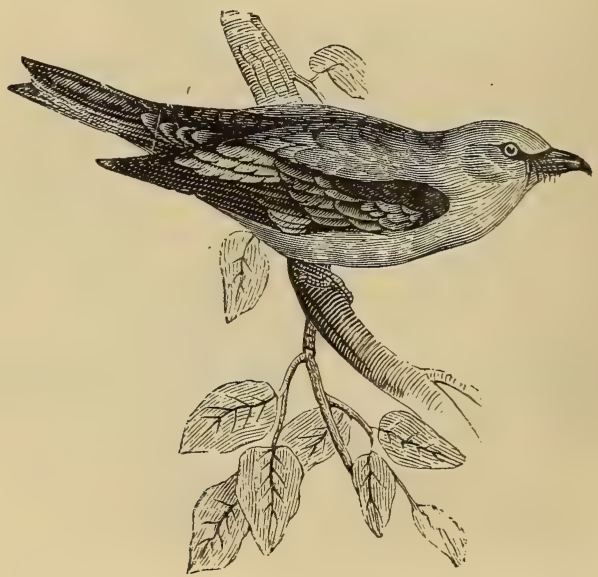

Fig. 200.-Garrulous Roller.

on the ground. In Barbary it has been observed to build on the banks of the rivers; and Pennant observes that where trees are wanting it builds its nest in clayey banks.

The Starlings (Sturnida) are characterised by a straight bill, depressed towards the point. They are remarkable for their vivacity, and grave, sombre plumage, lit up with brilliant metallic reflections of green and blue. They are sociable birds, living in numerous flocks, being, says Selby, "particularly abundant in the fenny parts of Leicestershire and Nottinghamshire, where they roost among the reeds; also at Whitefield, in Cumberland, where a spruce wood of several acres near Overwater Lake, is literally filled with them at roosting- 
time. Before retiring to rest they perform numerous manœuvres in the air, the whole colony frequently describing rapid counter-flights round a common centre. They will sometimes continue repeating the eccentric evolutions for half an hour before they finally settle for the night." Their favourite food is insects, worms, and small terrestrial molluscs, occasionally seeds and berries. They select for their nesting-places hollows of decaying trees, crevices of walls, the belfries of old churches, the ledges of roofs, and sometimes even the interior of pigeon-houses. The nest is formed of dry grass, in which

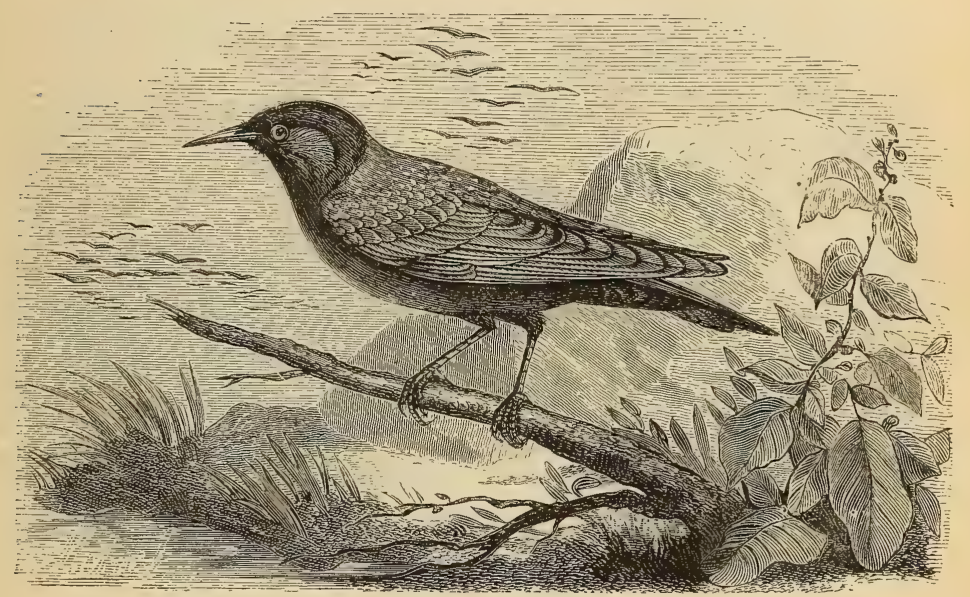

Fig. 2or.-Starling.

five light blue eggs are laid. The Starling is accused of seeking the shelter of the dovecot for the purpose of sucking the inhabitants' eggs, but this is now found to be a calumnious error. They are diffused over all quarters of the globe. There are two species described among European birds-Sturnus vulgaris, Fig. 20I (the Common Starling) and Sturnus unicolor (the Sardinian Starling), which is black, and without spots, with the anterior feathers very long, tapering, and drooping from the base of the neck. It is also found in Algeria among the rocks, where it builds. It passes the winter on the African coast of the Mediterranean, in company with the Common Starling. Its flesh is bitter, and consequently unpleasant to the taste, so when 
sought after it is on account of its docility, and for the ease with which it is taught to speak.

The Orioles (Xanthornis) have the bill broad at the base, nearly conical and pointed; the upper mandible has the dorsal line slightly arched, the ridge narrow, the sides flat and sloping. They are chiefly American birds, and have considerable resemblance in form and habit to the European starlings. Like them they are sprightly, light, and very rapid on the wing, and they live together in large

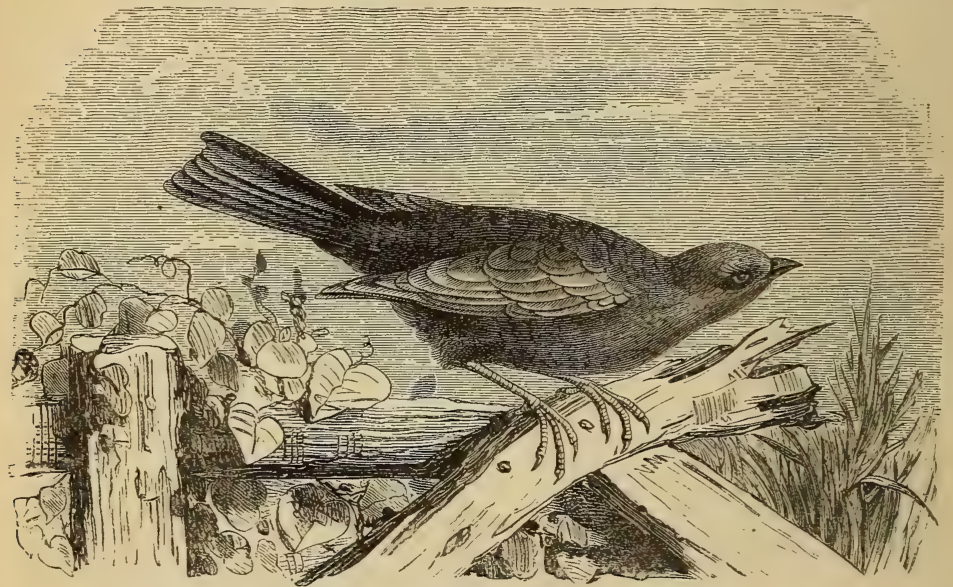

Fig. 202,-The Baltimore Oriole.

flocks throughout the year, feeding on seeds, berries, and especially insects, and frequently committing ravages on cultivated fields and orchards. Some of this genera exhibit remarkable industry and skill in the construction of their nests, particularly the Baltimore Oriole (Yphantes baltimore, Fig. 202), which, constructs a kind of purse, about a yard in length and a foot in diameter, the mouth or entrance being placed sometimes at the upper extremity, sometimes on the side. Naturalists have subdivided them into many smaller groups or genera, the most important being the one here described, and which may well be taken as an example.

The Beef-eaters (Buphagus africana, Fig. 203) owe their name to 
a singular habit they have of lighting on the backs of ruminating mammalia, and picking off the insects or extracting the larvæ of Estri which infest them-an operation which cattle submit to with great pleasure. Their food is not confined to this alone, for they feed also upon wood-bugs and locusts: hence they are likewise called Locust Hunters. They generally unite in small flocks of six or eight. They are very wild, and take flight with a sharp cry of alarm on any one approaching their haunts.

Among the congeners of the Beef-eaters may be placed the Coly

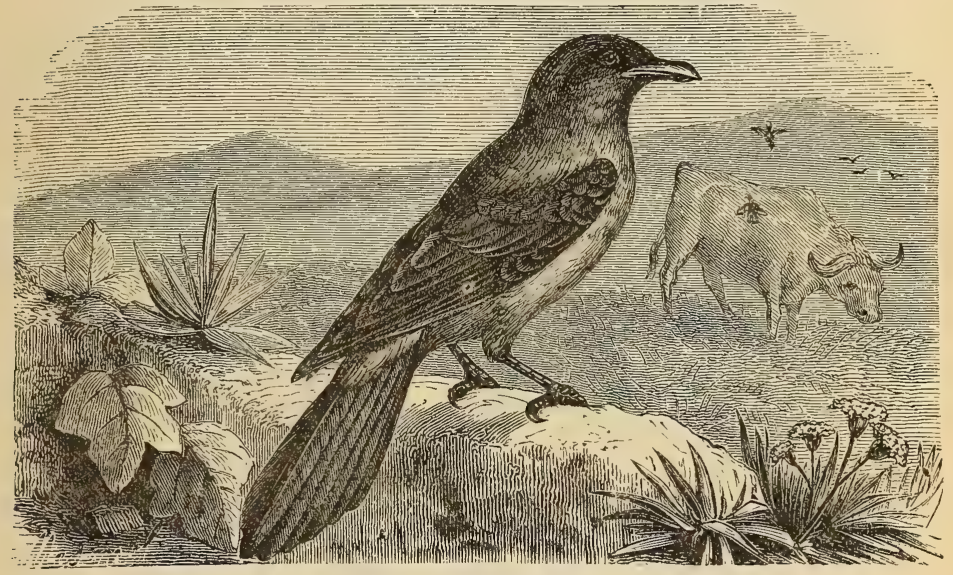

Fig. 203.-The Beef-eater.

(Colius), which, like that bird, is an inhabitant of Africa. They are small, about the size and shape of the Yellow-ammer, and have a tuft on the head. They live in flocks of from twelve to twenty, which nest in common, and feed on fruit and young birds. According to Levaillant, they creep on the branches of trees, with the head downwards; and, strange to say, even sleep in this peculiar position, pressing one against the other. Their flesh is said to be very delicate.

The Crossbills (Loxiade) are remarkable for the form of their bill, the mandibles being compressed and re-curved, crossing each other in contrary directions, the terminations being hooked, forming an 
instrument admirably adapted for dividing the scales of fir-cones so as to disclose the germs, which are favourite portions of their food. There are several species of this genus, all much resembling each other. However, Loxia curvirostris (Fig. 204) is most common. They are sometimes found near orchards, feeding on the kernels of apples, which their bills readily cut. They are said to commit great ravages among the fruit of Normandy when they pass through that

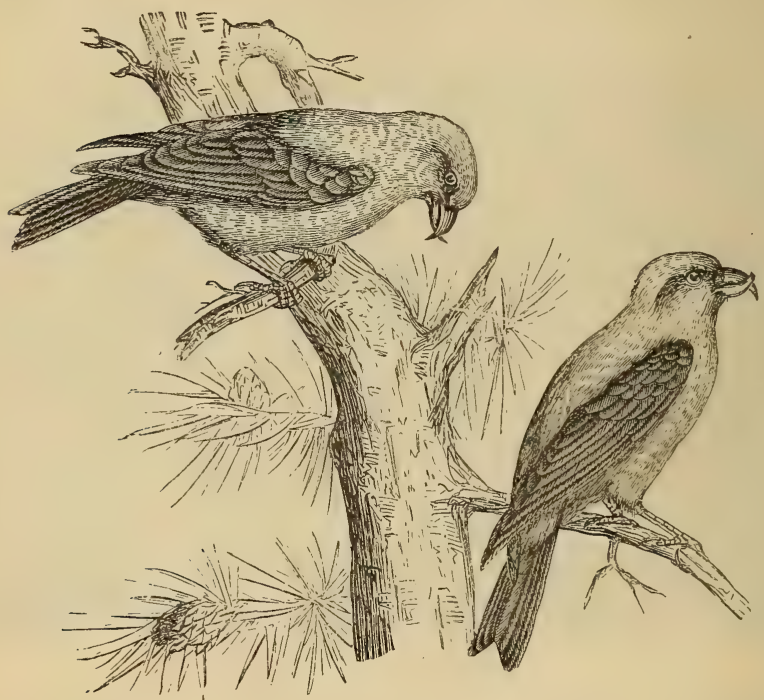

Fig. 204-Crossbills.

province, which they annually do in great flocks. This family presents a peculiarity which is almost unique among birds, that they build their nests and lay at all seasons. The Crossbills haunt the wooded mountains of the north of Europe and America.

The next are perhaps the best-characterised genus among the Passerine Conirostres. In it are included a great number of species with bills more or less thick at the base. Coming to the most remarkable of them, we have the Grosbeak (Coccothraustes vulgaris, Fig. 205), which is the type of the genus, for although not larger 
than a Thrush, it is distinguished by the possession of a bill which is about three-quarters of an inch long, not less than half an inch in thickness at the base, and of immense strength. It feeds on seeds, berries, and insects; the kernels of the hardest fruits cannot resist the powerful implement with which it is provided. Widely diffused throughout Europe, it is always met with in France, where it appears in open country or woods, according to temperature. is a quarrelsome and unsociable bird; and if placed in confinement with others, it is certain to maltreat, and perhaps kill them.

America possesses many species of this family, one having plumage of a fine rose colour.

The Bullfinches (Pyrrhula vulgaris, Fig. 206) are pretty little birds. Their cheeks, breast, and belly are a bright brick colour, shaded with orange red; round the shoulders grey, with black heads. They feed on various kinds of seeds or berries. They are easily tamed, being of a gentle, docile disposition. Their attachment to their master, and

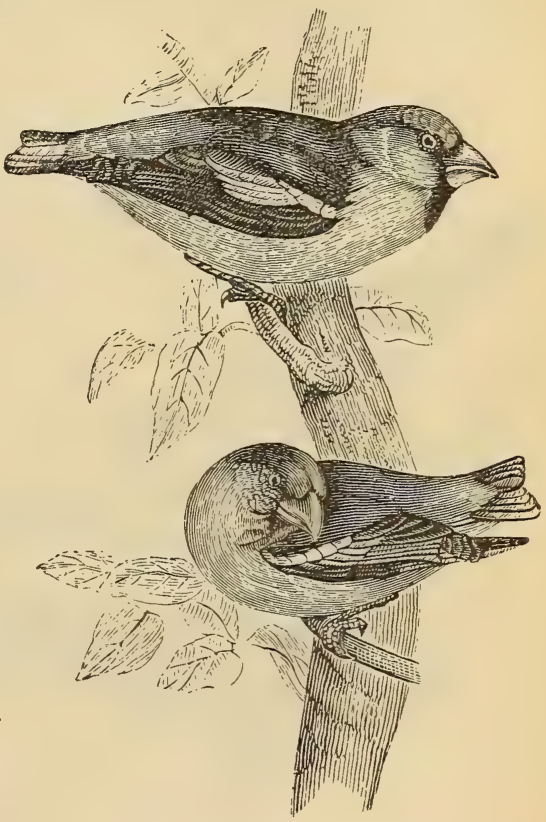

Fig. 205.-Grosbeak or Hawfinch. the ease with which they are taught to pipe, are their attractions. When in a state of freedom they construct their nests in the most inaccessible parts of thickets, usually in a black or white thorn bush. This is composed of small dry twigs, lined with fibrous roots.

The Siskin (Fringilla spinus, Fig. 207) may be mentioned among the numerous songsters which charm with their melodious notes. It is very pretty, although less richly coloured than the Goldfinch and others, its congeners. Neat and compact in form, its bill resembles that of the Goldfinch, but is more compressed, the two 
mandibles in some specimens meeting only at the base. The plumage is soft, blended, and glossy.

The House Sparrow (Passer domesticus, Fig. 208) is among the most interesting of the Passerinæ. It abounds all over Europe, from its most southern regions up to extreme north.

Every one is acquainted with this little bird-lively, pert, and

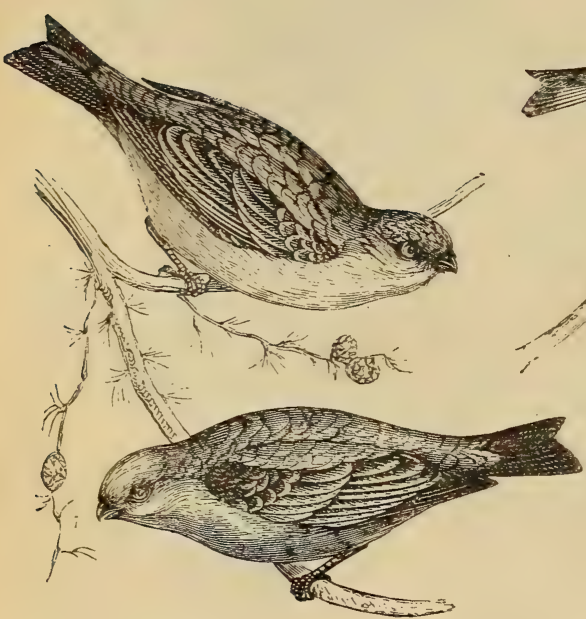

Fig. 206-Bullfinches.

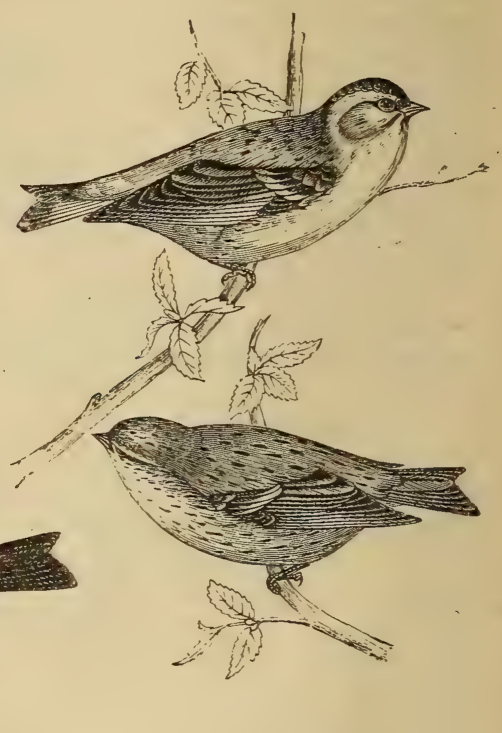

Fig. 207.-Siskin or Aberdevine.

cunning, the true gamin of the winged race. It lives in flocks in the neighbourhood of dwelling-houses, and even in the heart of large towns; it is familiar, but its familiarity is circumspect and sly. It haunts our streets and public places, but is careful to keep at a respectful distance from men and boys. It has a notion that the friendship of the great is dangerous, and its prudence counsels it to avoid intimacies which might have troublesome consequences; it is only after multitudinous proofs of good faith that the Sparrow will form an unreserved treaty of friendship with man. The sparrow 
quoted by Buffon, which not only followed its soldier-master everywhere, but would recognise him from all others in the regiment, proves they are both intelligent and capable of affection.

Sparrows are eminently sociable, seeking their food, and building their nests near each other, whether it be in crevices of walls or under the eaves of houses, in hedges or trees, or in the deserted nests of swallows, which they have the effrontery to appropriate. In their nest, which is a bulky, soft, and warm structure, lined with wool, bristles, and hair, the female deposits from four to six eggs three times a year; their fecundity is consequently very great. They are omnivorous, but prefer seeds and the larvæ of insects to all other food.

Oceans of ink have flowed to prove the ravages committed by Sparrows on corn-fields, and to demonstrate that they should be exterminated by the farmer. But it is now generally agreed that the Sparrow is a benefactor, and belongs to the list of useful birds. Have we not seen in the Palatinate that after the Sparrow was proscribed and exterminated, the inhabitants were under the neces-

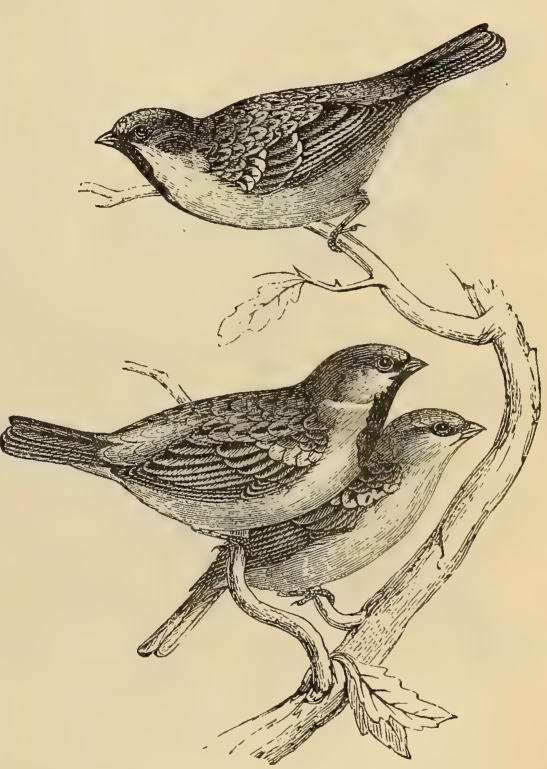

Fig. 208.- House Sparrow. sity of re-importing it in order to arrest the ravages of insects, which, in consequence of this bird's absence, had multiplied in a frightful manner?

The Goldfinch (Fringilla carduelis, Fig. 209) is the most gentle and peaceful of birds, at the same time is one of the prettiest of European races. It has the back brown, the face red, with a bright yellow spot upon each cheek; its voice is full, sweet, and harmonious; it is exceedingly docile, easily tamed and raised as a cage-bird; in the aviary it soon becomes familiar, testifying great attachment to those who take charge of it it readily learns to sing 
and perform various tricks, such as drawing up the vessel containing its food and drink, firing a miniature cannon, and other similar performances.

The Linnets (Fringilla cannabina, Fig. 2 Io) have considerable analogy to the Goldfinch. Like them, they are extremely sociable, except at the period of incubation; that duty over, the individuals begin to muster in small flocks towards the end of autumn, which

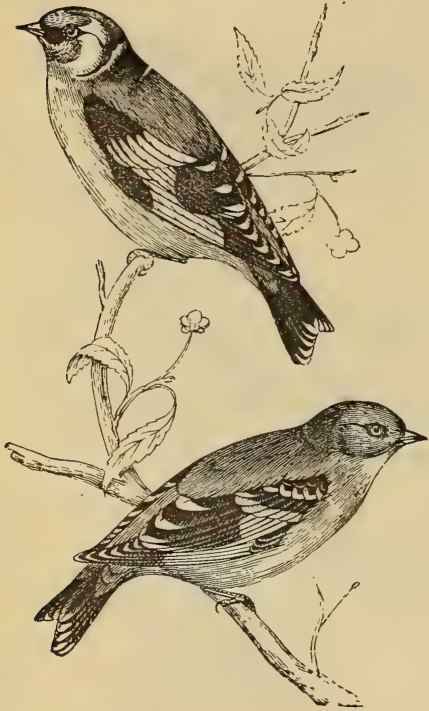

Fig. 209.-Goldfinches.

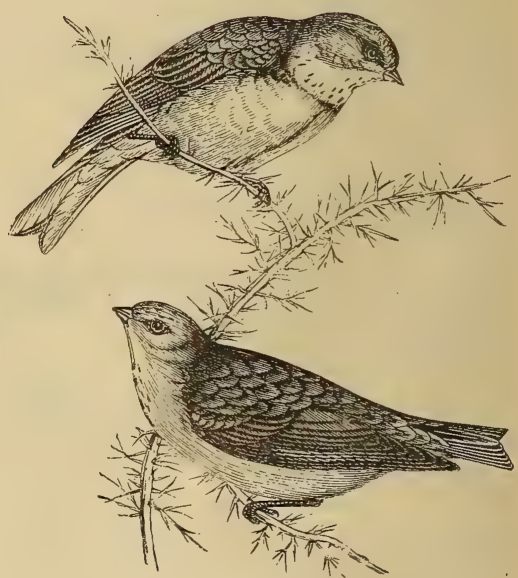

Fig. 210.-Iinnets.

increase as the winter advances, when they betake themselves in search of food to sheltered districts, or to the neighbourhood of villages and farmhouses. They associate with various other species, such as the Mountain Linnet, Green Linnet, and similar birds. The nest of the Linnet is generally placed in a bush of furze or heath. It is a neat structure, formed externally of blades of grass intermingled with moss and wool, and lined with hair of various kinds ; sometimes with thistle-down. The female lays from four to six eggs, of an oval form, bluish white colour, marked with distinct 
spots of brownish black, purplish grey, and reddish brown. Should the nest be destroyed during incubation, the pair will build again, and lay two or three sets of eggs, if needful ; but the male is said to take no part in the building or incubation, although he watches the female with great solicitude, supplying her with food during the process.

The Linnets feed principally on hemp and linseed, whence their popular name. In the winter season, in the absence of their favourite food, they eat the young buds of trees, and pick up the

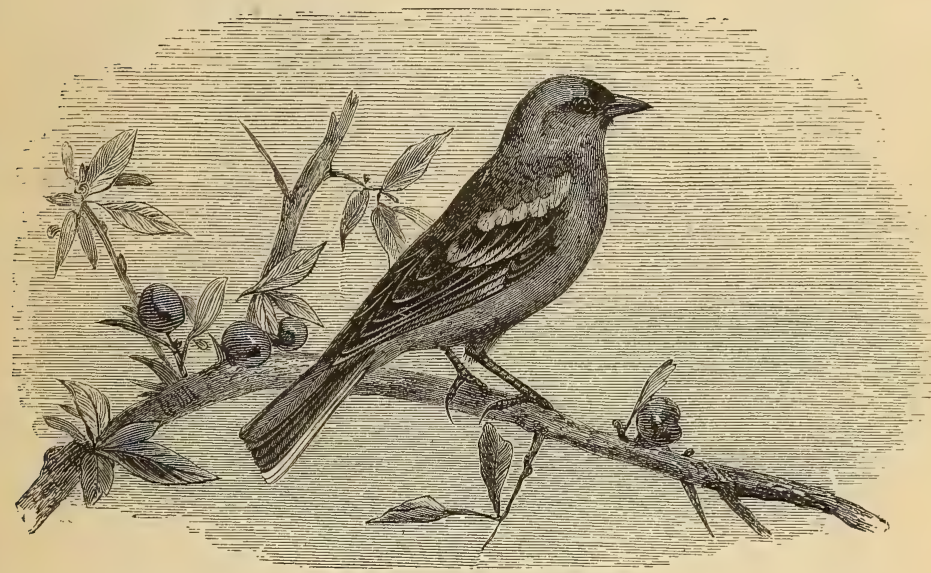

Fig. 21r. -The Chaffinch.

stray seeds about farm-yards. Their song in confinement is remarkably sweet, brilliant, and varied, but does not equal the thrilling voice of the Blackbird or Thrush. The species are numerous, both in. Europe and in America, but there is a tendency by naturalists to reduce their number, and to regard them more as varieties than entitled to the greater term of distinction.

The Chaffinch (Fringilla coelebs, Fig. $2 \mathrm{II}$ ) lives in flocks, like the Goldfinch and Linnets, except when breeding. But they differ from these members of the group in this-that their wing is less compact, and that they disperse themselves more in search of food than their congeners. Chaffinches are met with all over Europe, 
either as birds of passage or as permanent residents. They feed on various kinds of seeds and larvæ of insects, the latter of which they obtain in the early mornings of summer and autumn by searching the lower surface of the leaves of oak, ash, and other trees. They inhabit indifferently the woods, gardens, or high mountain ridges. In the early days of spring the mellow, modulated "tweet, tweet, tweet" of the Chaffinch is exceedingly pleasant to hear; but its monotony is apt to fatigue, for its eternal refrain makes it seem an affectation of gaiety, whence probably the French proverb, "gai comme un pinson."

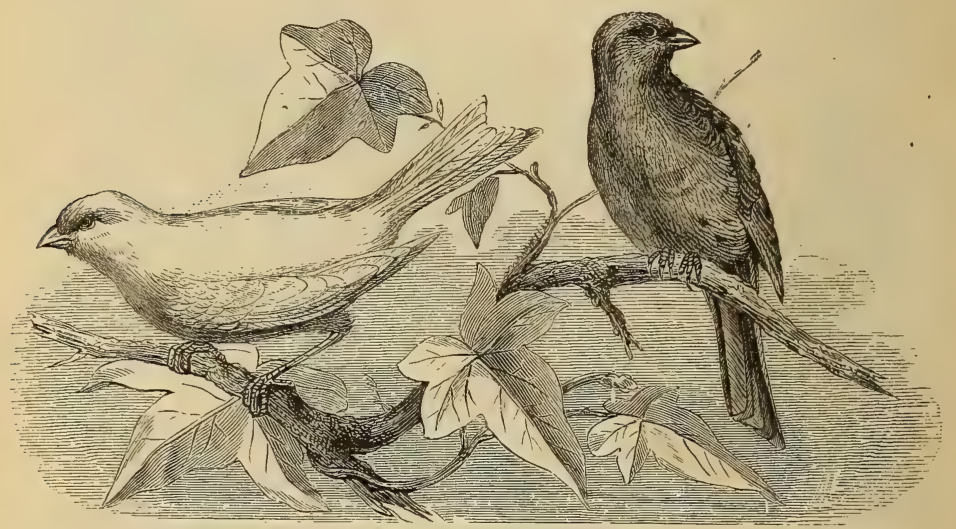

Fig. 212,-Canaries.

The Canaries (Fringilla canaria, Fig. 21 2) are only known in England and France as cage-birds, where they are recognised by their yellow plumage, more or less varied with green, although the facility with which they breed with the Linnet, Goldfinch, and others of the group, has introduced great varieties of colouring. Originally from the Canary Islands, they were first imported into Europe in the fifteenth century, and such was the charm of their song, added to their natural docility and gay plumage, that every one was eager to possess them. Buffon says, in his elegant manner, that if the Nightingale is the songster of the woods, the Canary is the chamber musician. Their race propagates, moreover, so rapidly, that the poorest can afford to possess them; for these elegant little creatures are to be found among every grade of society, pouring out their joyous melody 
in the garret of the poor seamstress with as much energy as in the gorgeous saloons of the wealthy.

There are two distinct species of the Canary, the Plain and Variegated, or as the bird-fanciers designate them, the Mealy or Spangled, and Jonquils; but between these innumerable varieties have sprung up from cross-breeding with the Goldfinch, Linnet, and Siskin. These cross-breeds are often charming songsters; but, like

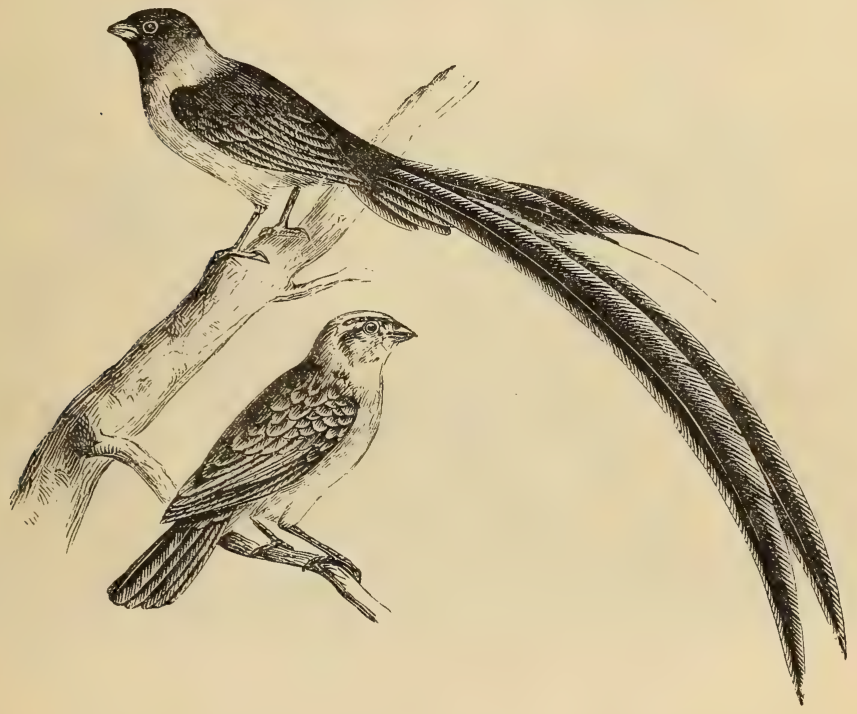

Fig, 213.-Whidah Birds.

all mules, they are completely sterile. Bechstein is of opinion that our Domestic Canary has a cross of the Siskin in it ; this belief for a long time existed, but most naturalists now are of opinion that such is not the case.

The Whidah Birds, of which the Vidua paradisea (Fig. 2I3) is the best known, are among the most remarkable of the hard-billed, seed-eating birds to which they belong. The long, drooping tailfeathers which adorn the males in the breeding season give them a very singular appearance. The upper part of their plumage is of a 
faded blackish brown, assuming a paler hue on the wings and lateral tail feathers. The whole body is tinged with this faded black, gradually narrowing as it descends to the middle of the breast; a broad, rich orange-brown collar proceeds from the back of the neck, uniting with a tinge of the same colour on the sides of the breast, this last hue passing into pale buff colour on the body, abdomen, and thighs, the under tail coverts being of the same colour as the upper onesa hue to which the bird is indebted for its popular and scientific name. The tail feathers are black; the four lateral ones on each

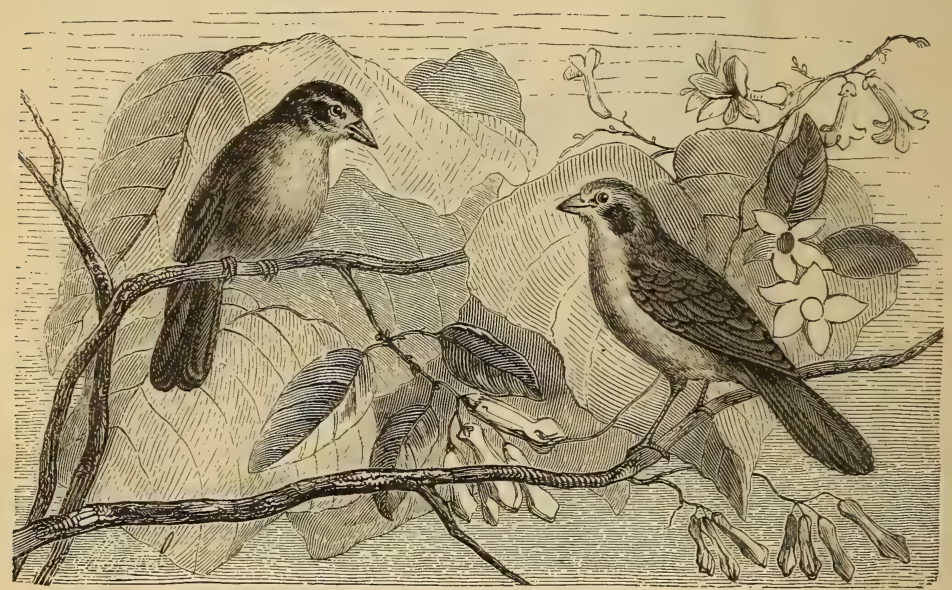

Fig. 214.-Java Sparrows.

side slightly graduated, and rather longer than the one immediately above. The next two are the long, drooping feathers, externally convex, so conspicuous in the male bird, which, in fine specimens, measure a foot in length from base, and about three-quarters of an inch in width. The body of the bird is about the size of a Canary. They are natives of South Africa and Senegal.

Near to the Whidah Birds we may place the Java Sparrow, of the Eastern Archipelago (Loxia oryzivora, Fig. 2 I4). They are eagerly sought for as pets, in consequence of their brilliant plumage and the facility with which they learn innumerable tricks.

The Weaver Birds (Ploceus, Cuvier) close the series of Fringillida. 
They live in flocks in the interior of Africa, where they feed on the cereals and the young of weaker birds. They chirp, but have no song; and they owe their name to the inimitable art which they dis. play in constructing their nests. These vary in form according to the species, and are composed of grass, rushes, and straw, suspended from the branches of a tree, the entrance being below. Sometimes they are spiral-shaped, occasionally round; in fact, they are of every imaginable outline. Mr. Swainson describes the nest of a species built on a branch projecting over a river, shaped like a chemist's retort suspended from the head, while the shank was eight or ten inches long, at the bottom of which was the entrance, all but touching the water.

Another species construct their nests in a clump under one roof or cover, each nest having a separate entrance on the under side, but not communicating with that next it. Again, a variety is said each year to attach a new nest to that of the previous year, and nothing is more picturesque than these groups of nests thus suspended to the branches of a tree.

But the most curious of birds, in respect to nidification, are the Sociable Weaver Birds (Loxia socia). These establish themselves, to the number of 500 or 600 , upon the same tree, constructing their nests under a common roof, the one backing against the other, like the cells of a bee-hive, all living together in the happiest manner.

The Buntings (Emberizida) are intimately associated with the Passerine Birds. They are characterised by a short, stout, conical bill, the upper mandible narrower than the lower, its dorsal outline nearly straight, sides convex, edges inflected, the tip acute; the lower mandible has the angle short, broad, and rounded. In the palate is a hard bony knob, to bruise the seed which forms their principal food. Their general habitat is the fields and hedges upon the margin of woods; some few species haunt the banks of rivers. They build their nests on the ground, or on low bushes, and lay four or five eggs. The young, when hatched, are blue. Their plumage is deficient in brilliancy, but their song is not without attractions. In autumn, when they leave the colder regions to go south, fattened with the rich produce of the harvest-fields, they have a rich, delicate flavour, and are then eagerly sought after for the table in France, and frequently brought to market along with larks.

The Common Bunting (Emberiza miliaria, Fig. 2 I 5 ) is best known. In winter it assembles in large flocks, and is shot in immense numbers for human food. It is destitute of song, and generally roosts on bushes. 
The Black-throated Bunting (Euspiza americana, Fig. 216) was discovered by the American ornithologist, Wilson. In many respects it resembles our Yellow-ammer. It is migratory.

The Yellow-ammer (Emberiza citrinella), is well known by its almost canary-like plumage and bold jaunty air. When this bird

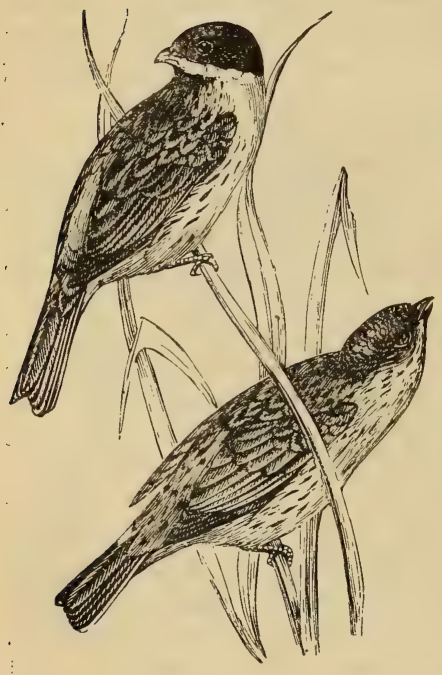

Fig. 215.-Common Bunting.

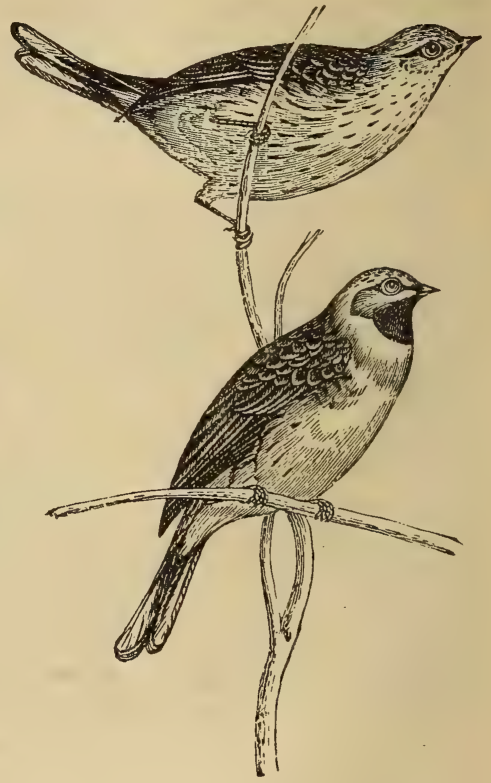

Fig. 216.-Black-throated Bunting.

becomes fat, it is supposed by some epicures to rival the celebrated Ortolan.

The Cirl Bunting (Emberiza cirlus), on the other hand, although found in Devon and Cornwall, and other parts of England, is only plentiful in the southern parts of Europe, and does not migrate into the colder regions.

The Ortolan Bunting (Emberiza hortulana, Fig. 2 I 7 ), so well known to gourmets and pot-hunters of Southern Europe, migrates periodically. They have been found in various parts of England, but 
were evidently stragglers, driven there by accidental circumstances. They abound on the northern shores of the Mediterranean, in Western Central Asia, in France, and as far north as Norway, where they are known to breed. Their favourite resorts, according to Meyer, are the borders of woods, hedges, and fields, near a water-course clothed with low willows and bushes. Although very shy, still great numbers are captured in nets, when they are kept in confinement, and crammed for the table.

The Snow Bunting (Plectrophanes niralis) rarely shows itself in

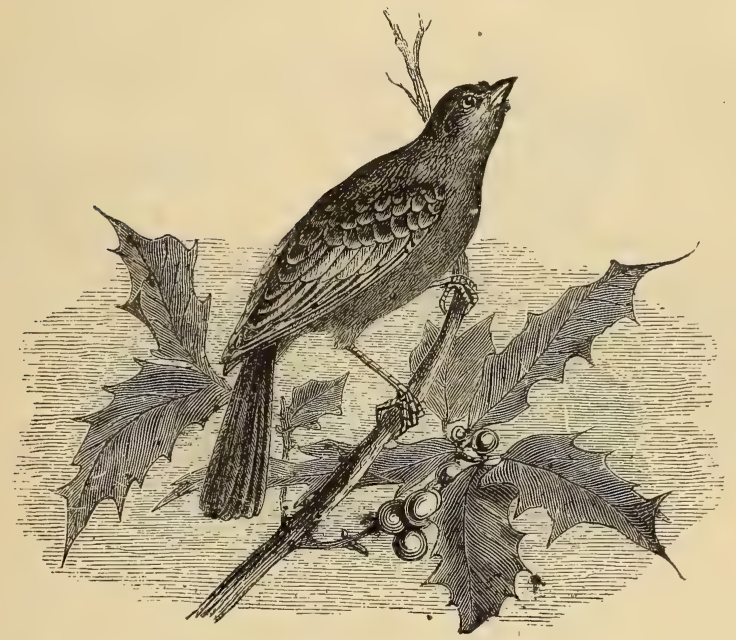

Fig. 2i 7 -The Ortolan Bunting.

France; and Montagu describes them as being rare in England; but McGillivray found them in considerable flocks all over Scotland, from the Outer Hebrides to the Lothians. On the 4th of August, I 830, being on the summit of Ben-na-muic-dhu, one of the loftiest mountains in Scotland, he observed a beautiful male flitting about in the neighbourhood of a drift of snow, and some days after, in descending from Lochnagar on a botanising expedition, he noticed a flock of eight individuals flying about among the granite rocks of a corry, evidently a family. "It is, therefore," he thinks, "very probable that it breeds on the higher Grampians.". 
The Conirostral Passerines include the family of Parida, or Tits. The Titmice, as they are sometimes called, are small birds, seldom attaining the size of the Common Sparrow. Their general form is moderately full, the head large in proportion and broadly ovate. Their bill is straight, short, and tapering, furnished with hairs at the base, but their individuality is distinguished by their specific peculiarities rather than by physiognomy. A characteristic feature is their audacity, almost approaching to impudence, and their courage, the instinctive result of their sociability. These qualities secure for them a well-defined place in the group that we have under consideration.

Who discovers the Owl during the day? Who besieges him with its clamours? Who pursues him with unintermitting blows of his bill ? Who rouses the whole tribe of small birds against the nocturnal tyrant? It is the Titmouse. Bellicose as bird can be, it gives full scope to its most warlike instincts whenever a suitable occasion presents itself, its want of physical power being compensated for by the vigour of its assault. The Tit is, indeed, the incarnation of motion; it is continually on the qui vive, skipping from branch to branch, at one moment piercing the crevices of the bark with its bill in search of food, the next hanging suspended from a branch, to which it clings with its claws, while it picks off the insects which occupy the lower surface of the leaves.

Nevertheless, it varies its food according to seasons and circumstances. It devours not only all kinds of insects, not excepting wasps and bees, but even cereals and fruits. It is even carnivorous, for it has been known to kill weak or sickly birds in order to devour them. Some species have a most unnatural partiality for grease, and eat it whenever opportunity offers. They are sociable birds, inhabiting thickets or woods, living in flocks the greater part of the year, and showing strong attachment to each other, so that a flock will suffer decimation rather than desert a wounded companion. In the spring they pair, when each couple seeks out a suitable place in which to rear their progeny.

The position of the nest varies with the species. The Great Tit (Parus major) builds in the hole of some wall, or in a cavity formed in a decayed tree; it is usually composed of moss, hair, and feathers. The Blue Tit ( $P$. caruleus) occasionally builds its nest in very insecure places. Mr. Duncan, one of Mr. McGillivray's correspondents, in a MS. note now before us, says, "In the year I $836 \mathrm{I}$ discovered the nest of a pair of Blue Tits in the shaft of a pump well, which was drenched and partly carried away every time water was 
drawn; still they persevered in building. Gladly would I have left them there, but they kept the water in a continually muddy state, and their removal became absolutely necessary." 'The Coal Tit ( $P$. ater) chooses the crevice of a wall or decayed tree. So does the Marsh Tit (P. palustris). The Crested Tit (P. cristatus, Fig. 218$)$ is a retiring little bird, provided with plumage both brilliant and beautifully blended. They are rarely seen except in the north of England, but several flocks are recorded as appearing in Scotland. They are said to breed annually in plantations near Glasgow, in the

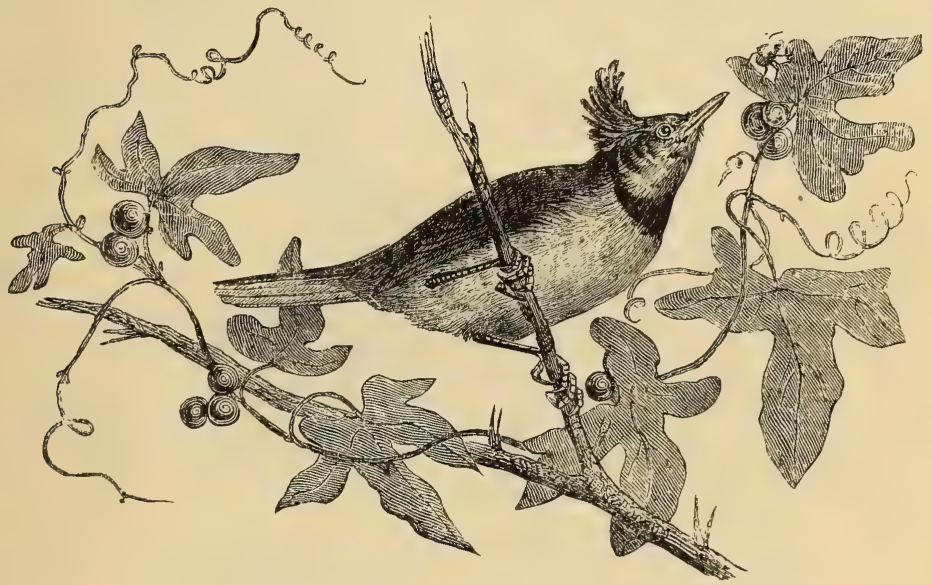

Fig. 218 -The Crested Tit.

forest of Glenmore; and near the Spey two were killed in 1836 . Some years later, at Whitefield, near Wigton, Cumberland, we found them quite abundant in a plantation bordering a small rivulet. In the north of Ireland, in autumn, they are not uncommon wherever plantations of larch trees are to be found. Their nests, according to Temminck, occur in holes of trees - the oak being preferred-in rocks, or in a deserted crow's or squirrel's nest.

The nest of the Long-tailed Tit (Parus caudatus) is, perhaps, the most skilful specimen of construction. It is oval in form, and has two openings, one for entrance, the other for exit, an arrangement which the long tail of the bird renders necessary. This singular bird -the most diminutive of our birds except the Kinglets-differs from 
the Tits in its softer and more bulky plumage and tail. Its flight is undulating and rapid; its long tail and body muffled up to the chin in dense plumage giving the observer the idea of an arrow flying through the air.

The Tits abound throughout Europe, and are also found in America; some of them remaining all the year with us, although they are all birds of passage.

The Larks (Alaudina) complete the Conirostral Passerinæ. They are distinguished by the great muscularity of the gizzard, and their elongated and slightly-curved claws, which are sometimes longer than the toe itself, strong indications of ground habits; in short, they pass their lives on the surface of great grassy plains, or soaring in the air. This family renders eminent service to agriculturists by the enormous quantity of worms, caterpillars, and grasshoppers it devours.

The Lark builds its nest in a furrow, or between two clods of earth, without skill, but with sufficient intelligence to know that it is necessary it should be concealed. It lays four or five eggs, spotted or freckled; in favourable seasons three sets of eggs in the year are sometimes hatched. The young birds break the shell after fifteen days' incubation, and are in a condition to leave their cradle at the end of fifteen more; but the mother still continues her surveillance, guides their steps, satisfies their wants, and continually hovers near them until the demands of another brood take her away, when they are abandoned to themselves, being now so fully fledged as no longer to require maternal care.

The Lark is the living emblem of happy, peaceful labour, the songster of the cultivated earth. In the early dawn the male bird rises aloft, and with soaring wings fills the air with his joyous notes, and calls the husbandman to his labour. Higher and higher he mounts, until he is lost to sight; but his voice is still heard. The song is significant ; it is the hymn of good fellowship-a call to all the dwellers of the plain.

The season of incubation over, Larks assemble in numerous flocks, having now only their food to think of ; and that being plentiful, they soon get plump and fat. In countries like France this is the signal for their destruction, for persons assemble from all quarters to make a raid on these valuable innocents, using every means to accomplish their work of death; and unless the legislature interferes in their behalf by passing laws for their preservation, it will finish probably by exterminating the race.

Taking Larks by means of a mirror is a ruse based upon the 
natural curiosity of the species, which leads it irresistibly towards any reflected light. The slaughterer places a glass, or any object that will reflect the sun's rays, in a field, concealing himself in its neighbourhood. The Larks, attracted by the light, come within reach of the destroyer, and fall around the mirror, undismayed by the fate of companions.

In this family the only species which lives in confinement is the Skylark (Alauda arvensis, Fig. 2 I9), and that only by very great care. It sings unceasingly in a cage, and even imitates the song of other birds. Larks are found all over the Old World, especially in Europe

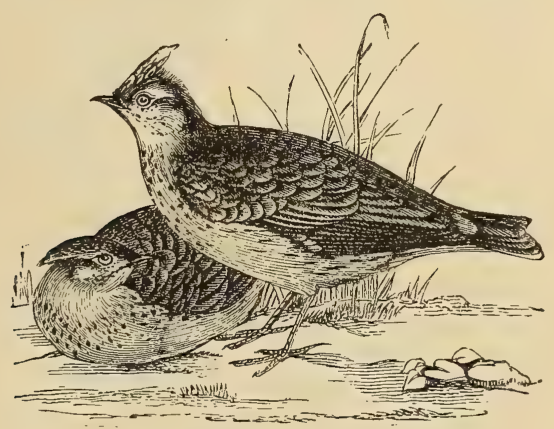

Fig. 219. - The Skylark.

and Asia. The principal species is that just mentioned, the Crested Lark (Alauda cristata) the Wood Lark (Alauda arborea), and the Shore Lark (Alauda alpestris).

The Pencilled Lark (Otocoris pencillatus) is a beautiful and but lately-discovered species. It is a native of Persia, and its habits are but little known.

\section{Fissirostres.}

The Fissirostral Passerine are characterised by a broad, short bill, flattened horizontally and slightly hooked; mandibles slightly concave; mouth very wide. They are essentially insectivorous. They comprehend three genera:- I. Swallows (Hirundo). 2. House Martins (Chelidon). 3. Sand Martins (Cotyle).

The Swallows are recognisable by their long pointed wings, forked 
tail, and excessively short tarsi. The air is the true element of these birds; they fly with a facility, lightness, and rapidity quite inconceivable ; indeed, their existence when not reposing is one eternal flight. So expert are they that they can even feed their young on the wing when the latter begin to fly. Watch them in the air, and they will be seen to rise and fall, tracing the shortest curves, crossing and interlacing each other's course, moderating their pace suddenly when at their utmost speed, in order to follow the eccentric course of some winged insect which they have doomed for their food. Such, indeed, is the rapidity of their progress that some of the species have been known to travel at the rate of thirty leagues an hour.

This wonderful power, however, is only developed at the sacrifice of another locomotive faculty, for they are bad walkers. With their short limbs, activity on their feet is impossible ; and if by chance they are placed on level ground, with difficulty they rise again on the wing. On the other hand, their sight is excellent, equal to even that of the Eagle or Falcon. According to Spallanzani, who made numerous experiments on Swallows, the Martin perceives the winged fly passing through the air at the distance of more than 120 yards.

Swallows are celebrated for their migratory journeys. In the early days of spring they reach Europe, not in flocks, but as isolated individuals or in pairs. They devote themselves almost immediately afterwards either to repairing their last year's nests, or, if these have been destroyed, to constructing new ones. Among the arrivals are many young birds of the previous year which have not had nests, and yet it is not a little extraordinary that these, after six months' absence, return with unerring certainty to the old dwelling where hatched. This fact has been too often recorded to admit of any doubt on the subject.

The form, structure, and locality of their nests vary with the species. The House Martins (Chelidon urbica, Fig. 220) build in the upper angles of the windows of some country house, under the eaves of a roof, or on the interior wall of a chimney. A chimney seems an odd place to select for such a purpose; and White of Selborne relates, not without some expressions of wonder at such a choice, that near the middle of May one of these little birds began to form her nest about five or six feet down a chimney adjoining the kitchen fire. Their nests consist of a crust or shell of mud mixed with straw, and lined with fine grass and feathers. Other species, sometimes in vast numbers, establish themselves in the hollows of dead trees. Audubon estimated at the incredible number of i I, 000 the quantity of swallows which had taken up their dwelling 


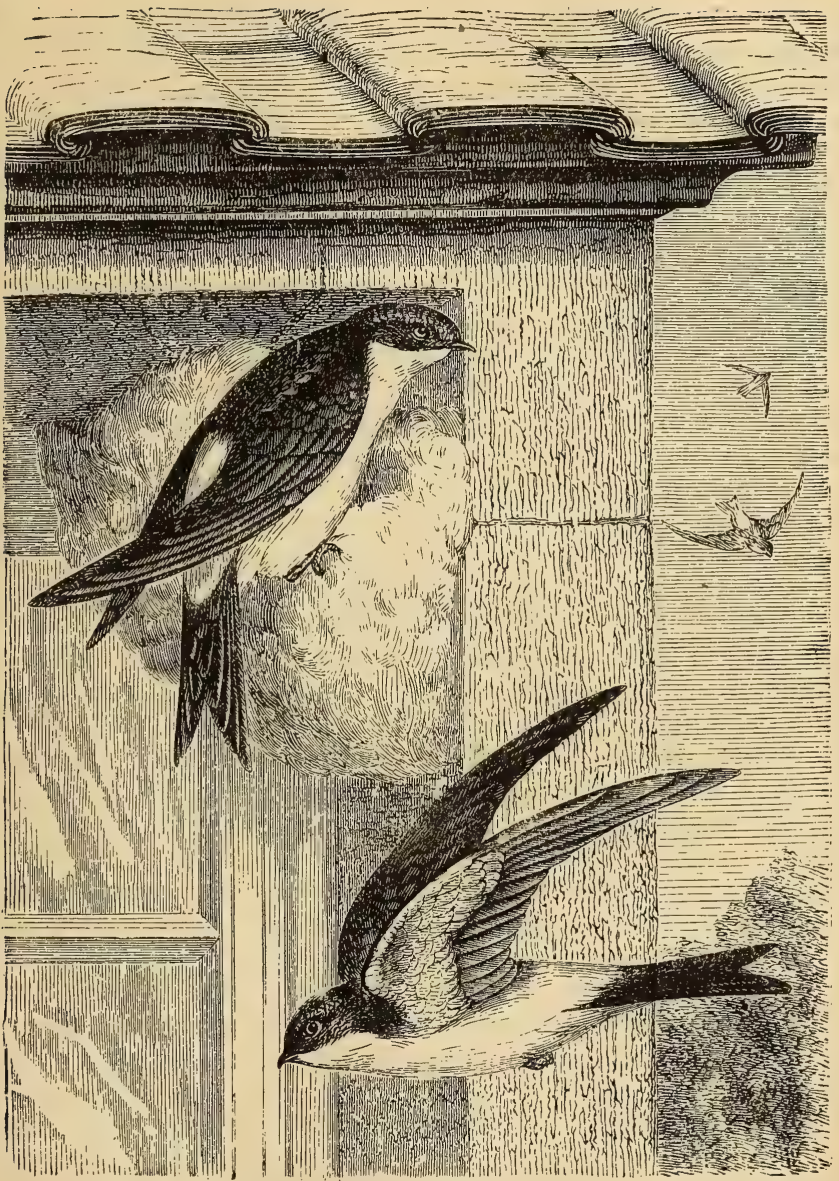

Fig. 220.-House Martins.

in a sycamore tree (familiarly known there as a button-wood) near Louisvillein Kentucky, United States. These trees grow to an immense size and are generally hollow. Some of this family prefer rocks or caverns, and excavate in steep escarpments a gallery from two to 
three feet in depth, at the extremity of which they place their nest. Sometimes the nursery of their young is formed of twigs torn by the bird from the dead branches of trees, and bound together by a viscous liquid which flows from its mouth.

When, after a month's labour, the Swallows have finished their dwellings, the female deposits from four to six eggs. Incubation commences, and continues from twelve to fifteen days, during which the male bird exhibits intense interest in the proceedings, carrying food continually to his mate, and passing the night in her immediate vicinity, twittering and chirping all day long to cheer the mother at her task. Two or three times in the season they thus raise a family.

From the time when the little ones are hatched the parent birds attend them with all the care their feebleness demands, and often exhibit remarkable proofs of affection. When the young Swallows feel strong enough to try their wings, the old ones tenderly guide them on their first attempts at flight, and teach them how pursuit of insects in the air is successfully performed. Boerhaave quotes an instance where a Swallow, returning from some distant excursion, found the house in which it had built its nest in flames. It did not hesitate an instant to dash into the fire to try and save its young.

Swallows generally prefer the proximity of a lake or river, the surface of water being always the rendezvous of crowds of insects, among which they reap a plentiful harvest. Extremely sociable, they assemble in large flocks, and appear to be bound together by strong attachment, for they aid each other in trying circumstances.

"I have seen an unfortunate swallow," says Dupont de Nemours, "which had, I know not how, entangled its foot in a long thread, one end of which was attached to the roof of the College of the Four Nations; its strength was exhausted, and it hung uttering painful cries at the end of the line, endeavouring to release itself occasionally by futile attempts at flight. All the swallows between the Tuileries and the Pont Neuf, and perhaps for a much greater distance, were assembled around the unfortunate bird, to the number of many thousands, forming a perfect cloud. All that came flew past, giving a peck of their bills to the fatal thread; these blows, being frequently repeated, and always directed at the same spot, were finally successful, for in half an hour the line was cut and the captive set at liberty."

Another fact, related by the great naturalist Linnæus, proves how strong is the spirit of brotherhood with these birds. When some swallows returned in spring to take possession of their nests, a certain 
number of them were found occupied by sparrows. One of the more legitimate proprietors, thus despoiled of his property, endeavoured by every possible means to recover possession, but all was unavailing. Under these circumstances the assistance of its companions was demanded. The whole assembly proceeded to besiege the intruder. It resisted, intrenching itself in its fort, and in revenge the ousted swallows brought mud in their bills, and actually walled up the entrance to the citadel and entombed the interloper in his cell. The truth of this account, which is repeated by many naturalists, has been denied; but Mr. McGillivray, than whom we have no more reliable author, records three well-authenticated similar instances.

Swallows generally leave us in the month of September in order to seek a milder climate, and one providing more abundant food. Some time before their departure their cries are incessant, and great agitation is seen in their ranks; ultimately they assemble in some elevated place, as if to hold council and deliberate over their journey, and fix the date of their departure ; finally, a day is decided on, which, when it arrives, all the swallows of the neighbourhood mass at a rendezvous, and after certain evolutions, intended, no doubt, to determine the route, they advance in one mass towards the shores of the Mediterranean, whence they pass into Africa. Although they are of all birds the strongest on the wing and best adapted for a long journey, they cannot accomplish this without rest if adverse winds should arise. Ships passing are frequently boarded by stragglers which alight on the rigging; and both at Gibraltar and Tangiers large flocks are occasionally seen to arrive in a state of great exhaustion. Those stragglers which, through weakness or the duties of maternity are prevented from joining the great flocks, depart some days later in smaller parties. Occasionally however a few individuals seem to remain with us all the year round, contriving to survive the most severe winters, which has given rise to the supposition that the Swallow has the power of hibernating, or of remaining in a state of torpor during the winter, and returning to animation in the spring. This much-controverted point has now been consigned to the mythical legends to which it belongs.

Swallows have in all ages possessed the sympathies of mankind, some of the ancients regarding them as sacred birds; nor are they ungrateful for the good feeling they excite. The services they render in destroying vast quantities of noxious insects, not to speak of their gentle habits, mutual attachment to each other, and the happy presage they bring with them of spring's advent, contribute to make them welcome visitors. "Nevertheless, instances do occur where 
these proper sentiments yield to the love of destruction-where their innocent confidence is rewarded by death.

The greater number of this genus have the breast and belly white, and the upper parts of the body black, tinted with reflected blue or peach colour. The White Collared Swift (Cypselus cayanensis, Fig.

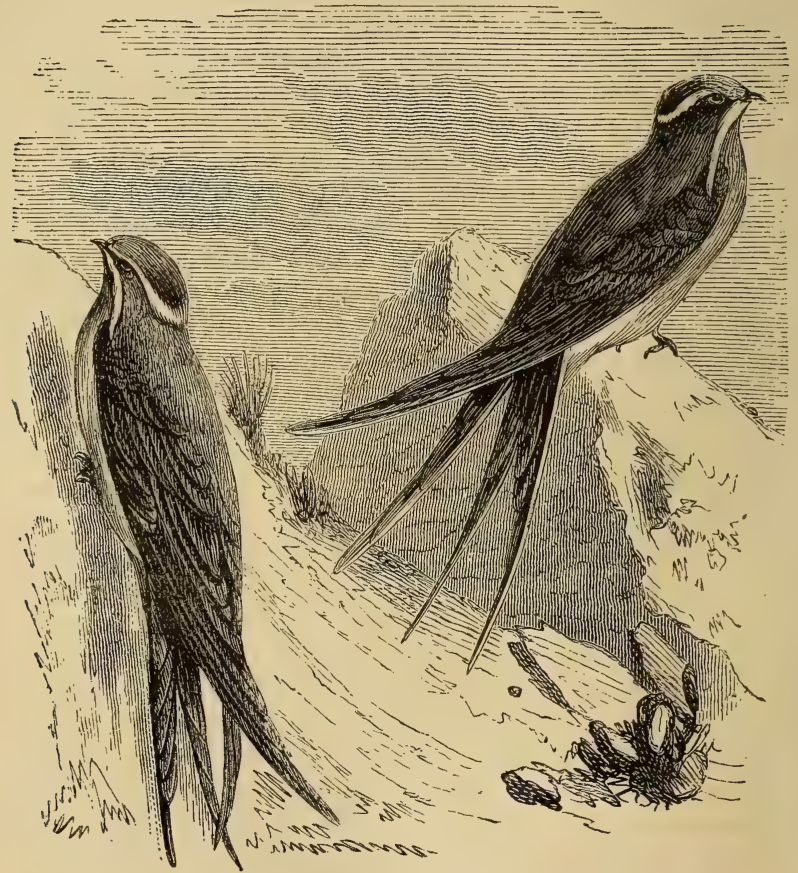

Fig. 221.-The White Collared Swift.

$22 \mathrm{I})$, a South American species, scarcely follows this description, it having two white line marks diverging from the bill. There are about sixty species spread over the globe, of which six only are natives of Europe.

This family are familiarly known as Swifts, Swallows, House Martins, and Sand Martins. Of these the Swift(Cypselus apus, Fig. 222 ), 
the Alpine Swift (Cypselus melba, Fig. 223), the Swallow (Hirundo rustica), Sand Martin (Cotila reparia), and the House Martin (Chelidon urbica, Fig. 220) are best known to residents of Europe.

Among the foreign species the Esculent Swallow (Collocalia nidifica, Fig. 224) may be mentioned, so famous over the world for its edible

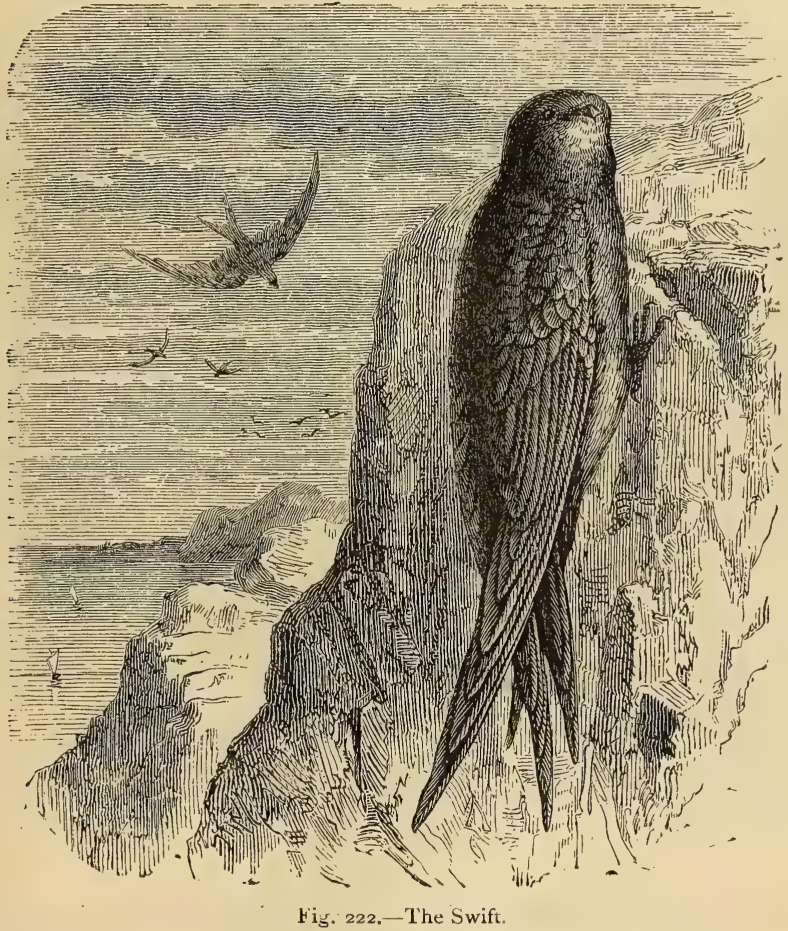

nest. This bird inhabits the rocks and caverns of the sea-shore in Sumatra and Java. The plant called fucus, which abounds in these regions, is metamorphosed in the bird's stomach, and is afterwards disgorged and made use of to fabricate the walls of its nest. The fucus thus devoured forms the nutritive substance so eagerly sought after by the Eastern gourmet. The consumption of the nest 
of the Esculent or Salagane in China, in spite of its high price, is very considerable. From the days of Buffon there have been exported from the coast of Cochin China 4,000,000 of them annually; and the proprietors of one cavern in the island of Java receive annually 50,000 florins for rent alone.

The distinctive features of the Goatsuckers (Caprimulgus) are a

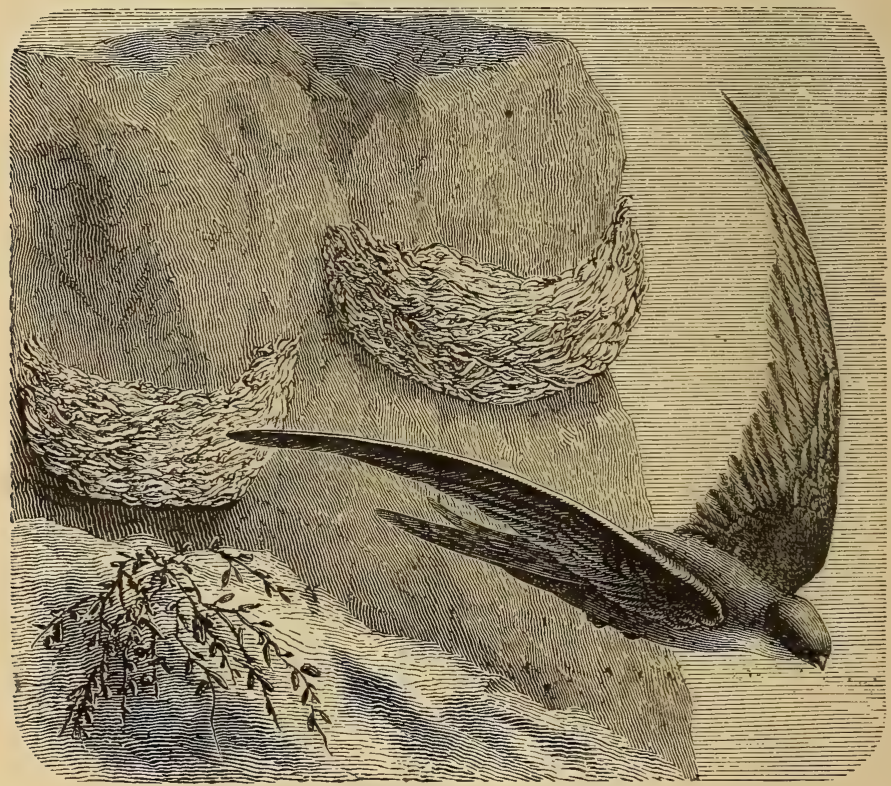

Fig. 223.-Alpine Swift.

short, much-depressed bill; the body small in proportion to the plumage; the neck short; the head large, broad, and depressed; the eyes very large and broad; the feet very small; tarsi partially feathered; toes four, the lower surface broad and flattened, the anterior toes connected by basal membranes ; claws moderate, arched, and compressed. The plumage is full, soft, downy, and blended, like the owl's; the wings have the second and third quills longest; tail long and rounded. Almost all the species have strong bristles 
around the base of the upper mandible, and some have the feathers of the face radiated, like those of the owls.

The Goatsuckers are not sociable birds, living generally in pairs, sleeping during the day, issuing from their nest with the setting sun, or possibly earlier in gloomy weather, to chase the crepuscular and

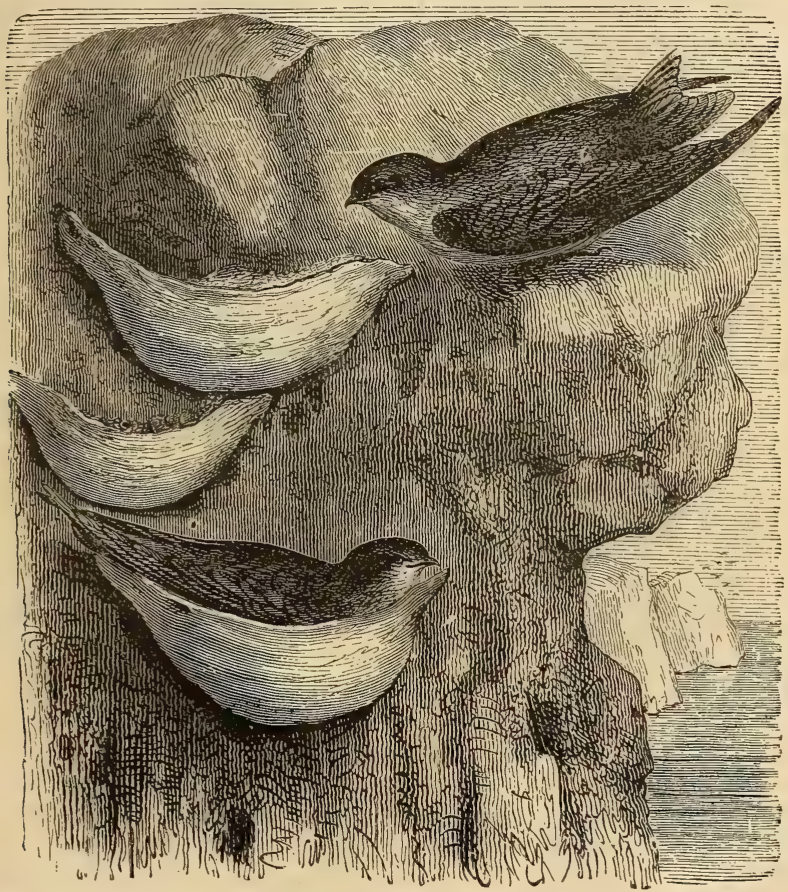

Fig. 224. - Nest of the Esculent Swallow.

nocturnal insects on which they feed. They move silently, and with great rapidity. Some authors say that when on the wing they keep the mouth open; but this is not supported by facts, and is opposed to reason. The insects they principally devour are moths, dragonflies, beetles, crickets, cockchafers, and mosquitoes. Their usefulness therefore is nearly equal to that of the Swallow. As they get 
very plump and fat in the autumn, they fall a sacrifice to the gunner; and in their turn are eaten by gourmets greater than themselves. They are migratory birds, travelling only during the night. They are readily distinguished by the bristles at the base of the bill, and by the claws of the middle toe, which is toothed. The object of this toothed appendage has been the subject of speculation. Some writers fond of the marvellous even surmise that it is intended to comb and smooth the head-feathers. Mr. Vigors is of opinion that it may be useful as a further power of prehension, citing, in support

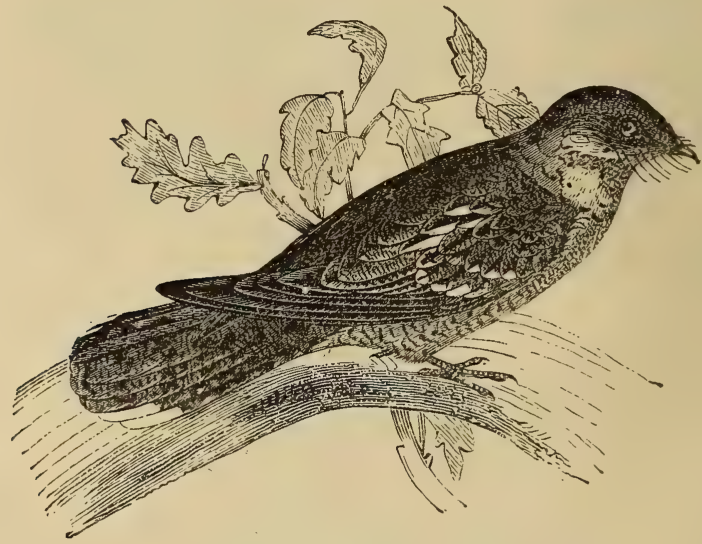

Fig. 225.-The Night.jar.

of his view, the family of the Ardeida among the wading birds, which exhibit an analogous construction in the middle nail.

Throughout Europe, Asia, Africa, America, and Australia the Goatsuckers are diffused, and naturalists have divided them into several sub-genera, such as Podargus, represented by Podarous humeralis of the Gold River, and Podargus javanensis, the Chabbawonno of Java, and the Guacharo Bird, Steatornis villot of Humboldt and Bonpland.

'The typical species of Caprimulgus is the Night-jar. (C. europaus, Fig. 225): It is rather larger than a Thrush; and Montagu states that he observed on one occasion a flock of eight or ten on the wing together, in the dusk of the evening, skimming over 
the surface of the ground, after the manner of Swallows in pursuit of insects. Its nest is of the simplest kind, for it deposits its eggs on the bare ground, or upon a few dry leaves. These eggs, in number only two, are hatched by the female in fourteen days.

The Common Night-jar is chiefly found on furzy commons, wild bushy heaths, and broken hilly ground in the neighbourhood of thickets and woods. During the day it lies concealed in the scrub, issuing forth in the balmy. summer evenings to pursue its insect prey on the wing.

On the prairies of North America, especially those intersected by sloughs, dozens of these birds may be seen at the hour of sunset, their swift, powerful, and graceful flight being worthy of the greatest admiration. They are there called Bull Bats, and are often accused by the ignorant of the crime of sucking milk from cows-about as probable as snakes being guilty of the same offence; yet there are hundreds who believe in such impossibilities.

The Night-jar is a bird of evil omen in the estimation of our rural population; such it has been considered since the days of Aristotle, and possibly even further back. The reverse should be the case, for the benefit it confers by clearing the air of noxious insects is incalculable.

The Guacharos (Steatornis caripensis) are singular birds, with more of the Hawk than Goatsucker in their appearance. They were first described by MM. Humboldt and Bonpland as being found in the interior of a vast Columbian cavern-the Grotto of Caripe. Their hooked bill and general aspect are more robust than the Night-jars. They inhabit in thousands the deep recesses of the caverns of the Cumana Chain, hanging to the walls by their pointed claws. In these caves, which they only leave during the night, they build their nests. Unlike their congeners, they feed only on grain and seeds. The Indians of Caripe enter these sombre domains from time to time, and make raids upon their ranks, for they are deservedly esteemed as great delicacies.

\section{DentiRostres.}

The Passerine Dentirostres are characterised by a bill more or less strong, compressed on each side of the point. They feed on berries and insects, and comprehend numerous genera, including the Manakins, Cock of the Rock, Warblers, Lyres, Orioles, Honey-eaters, Dippers, Thrushes, Tanagers, the Rollers, Chatterers, Fly-catchers, and Butcher Birds.

M. Lesson thinks the Muscicapida should consist of the genera 
Tyrannus, Monacha, Eurylaimus, Platyrhynchus, Todus, Myiagra, Muscicapa, Alectrurus, Drymophila, Formicivora, Rhipidura, Seisura, Psophodes, and Euicurus. Of these, Eurylaimus have a very large, depressed, and cleft bill. They are of more elegant form than plumage ; for their colouring is devoid of brilliant tints. They live a retiring life in marshes, and upon the banks of lakes and rivers, feeding upon the worms and insects which abound in such localities. They are about the size of the Thrush, and they inhabit the isles of Oceania.

The Manakins (Piprince), have the bill rather short; the upper mandible much curved, and pierced with large nostrils; the feet longish, slender, and weak; the external toes reverted towards the middle. These birds are natives of South America, and are gifted with brilliant plumage.

The Cock of the Rock (Rupicola) is remarkable for the lively and delicate shades of the colour of its plumage, and for a graceful crest which decorates its crown. It prefers sombre localities, and retires into clefts and caverns when pursued. It is very wild, and only issues from its hiding-place in search of the fruits which form its food. Under the most favourable circumstances these birds are difficult to approach, taking flight at the slightest appearance of danger. Their name comes from their size, and also from their habit of scratching up the earth, and flapping their wings like the Domestic Cock. They are natives of South America and Malaya. The best-known species, Rupicola aurantia, is a native of Guiana; its plumage is bright orange, and the crest is formed by two rows of feathers, so arranged as to form a semicircle.

The warblers (Sylviana) are readily recognised by their short, slender, and tapering bill, constituting a numerous series of birds, among which we recognise many of our most familiar garden and field favourites.

All these are of small size, and have the singular property of imparting a vibratory motion to their tails. They are denizens of our woods, thickets, and gardens, where they fill the air with their melody. They are generally migratory, arriving in the spring, and departing at the fall of the leaf. Living, except in autumn, almost exclusively on insects and their larvæ, they render in this respect eminent services to man ; but it is a curious fact that at that period these birds cease to be insectivorous, and feed on fruits-principally figs and grapes, whence the name of bec-figues applied to them in the South of France. By gourmets they are most eagerly sought after for their flesh, which is considered most delicate. 
Wárblers prefer a partially enclosed country, sloping hill-sides; or the banks of rivers clothed with trees and shrubs, for their haunts.

In the first rank of the Warblers stands the Nightingale (Philomela luscinia, Fig. 226), celebrated all over the world for its song, which is superior, without any doubt, to that of all other birds. In size it is somewhat greater than the Garden Warbler, which it resembles in its sober attire. Many have been the attempts made to describe this far-

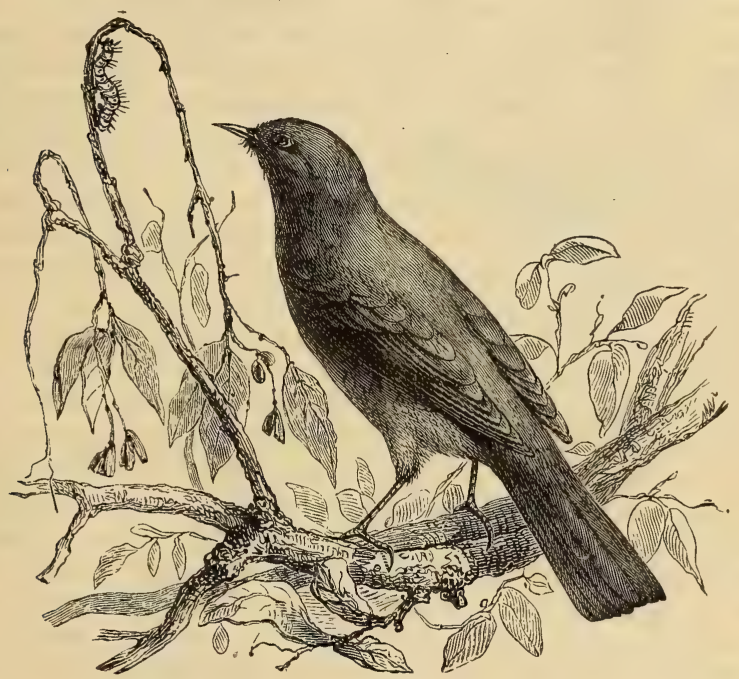

Fig. 226.-The Nightingale.

famed bird. Naturally shy, the Nightingale retires into the closest and most sheltered places, rarely exposing itself to opservation. Brushwood and thickets, wych-elms and evergreen trees, growing on th2 banks of some retired watercourse, are its favourite dwelling. It is among these that it establishes its nest, built without care, at irregular heights, and sometimes even on the ground. The Nightingale possesses this peculiarity - that it sings not only during the day, but also in the night; but let any alarming noise approach its retreat, and it stops instantly. It seems to love solitude above all things. Audubon, the American naturalist, has described some of the distinctive charac- 
teristics of the bird with a few graphic touches. He has left his downy couch, and sallied forth to watch the eventful moment when Nature arises, fresh, blooming, and full of renovated vigour. In his wanderings he comes upon a Nightingale. "In the midst of a thicket," he says, "I now see a solitary bird, humble in its attire, and of most modest mien, peeping at me with a caution so uncommon, and yet so inviting, that I feel tempted to seek its acquaintance. With care I approach the feathered stranger. Its form is somewhat elongated, yet not incompact; its eyes are large, and of peculiar mildness ; it stands rather high, on a pair of light flesh-coloured and, as it were, transparent legs ; its wings, which are of moderate length, droop, and seem at intervals to tremble: and, as it moves from one twig to another, I see it hops, or leaps, and does not walk step by step, like many other birds. Its colour is a dull brownish olive, but the hind part of the back and the tail are of a richer tint, though corresponding with the general hue. At this moment it flies lightly to the ground, hops a few steps, picks up a grub, and returns to its former station."

"The Nightingale," says McGillivray, "which in summer is spread over the greater part of the Continent, extending its migrations to Sweden and the temperate parts of Russia, arrives in the South of England about the middle of April, or a few days later, should the weather be severe. The females, according to various observers, come from a week to ten days after the males. Individuals settle in the southern counties, including part of Devonshire, in the eastern and midland districts, as far north as York and Carlisle; but none are to be seen in Cornwall, Wales, or the north-western parts of England, although it is found much farther north on the Continent." It is alleged that the migration of the Nightingale does not extend into Scotland. Mr. Duncan, one of Mr. McGillivray's most reliable correspondents, states that a pair of Nightingales arrived in Calder Wood, in $\mathrm{W}^{\top}$ est Lothian, in the early part of the summer of $\mathrm{r} 826$. "Before and about midnight, when the full moon shone bright and clear, the warble of the male was first heard; it soon attracted a number of admiring listeners, who hastened to the spot. The owner of the wood was anxious to preserve them, thinking they might breed; but, in spite of his care, the male was shot, upon which the female left the wood." In France they arrive singly, and depart. alone about the middle of August, on their return journey to Africa or Asia.

The Sedge Warbler (Salicaria phragmites) is a delicate, lively little bird, haunting the margins of streams and pools overgrown with 
weeds, sedges, and other aquatic plants, in the midst of which it seeks its food, and nestles so secretly that it very frequently eludes observation. Mr. McGillivray found a nest of this species on the marshy borders of Duddingston Loch, near Edinburgh. It was placed in the midst of a large clump of Solanum dulcamara, supported by the branches, and so hidden that he only found it after cutting off a great number of flowering twigs. This nest was composed of leaves, grasses, and other slender plants, loosely but neatly put together.

The Fan-tailed Warbler (Salicaria cesticola, Fig. 227) closely resembles the preceding. Its song is loud, cheerful, and much diversified, night being generally selected for the display of its vocal powers. Its nest is composed of blades and stalks of grasses, lined with finer plants and hair; is of a conical form, with the apex downwards; in depth from four to five inches externally, and three in the interior, and as much in breadth at the top; and is fastened to the stalks of several reeds, in a most ingenious way, some distance

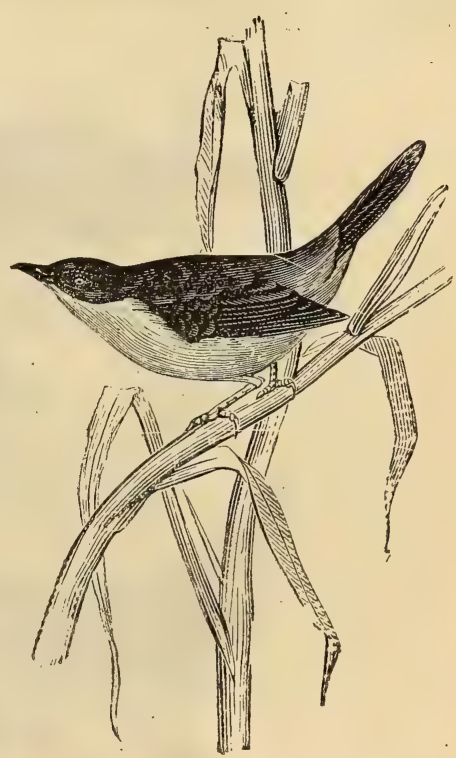

Fig. 227.-The Fan-tailed Warbler. above the ground-an arrangement giving security to the eggs, which are of a brown colour, spotted with dark olive, and usually marked with one or two blackish, irregular lines.

The charming petite Grasshopper Warbler (Calamodyta locustclla) is well worthy of remembrance, although its visits to us annually do not extend over three months. It has a peculiar power of ventriloquism in its voice, which would induce the listener to its silvery note to believe that the producer was close at hand, although in reality a hundred yards off.

The Tailor Bird, known to French writers as la fauvette couturiere, is most curious in respect to the manner in which it builds its nest. Aided by bill and claws, it stretches out into a thread fibres gathered 
from the trees ; selecting broad resistant leaves, it drills 'them with its bill, sews them together with the cotton which it has prepared, and in this manner constructs a bag which serves the purpose of completely hiding its nest from the observation of enemies. This species belongs to India and the islands of the Indian Ocean, and is unknown in Europe.

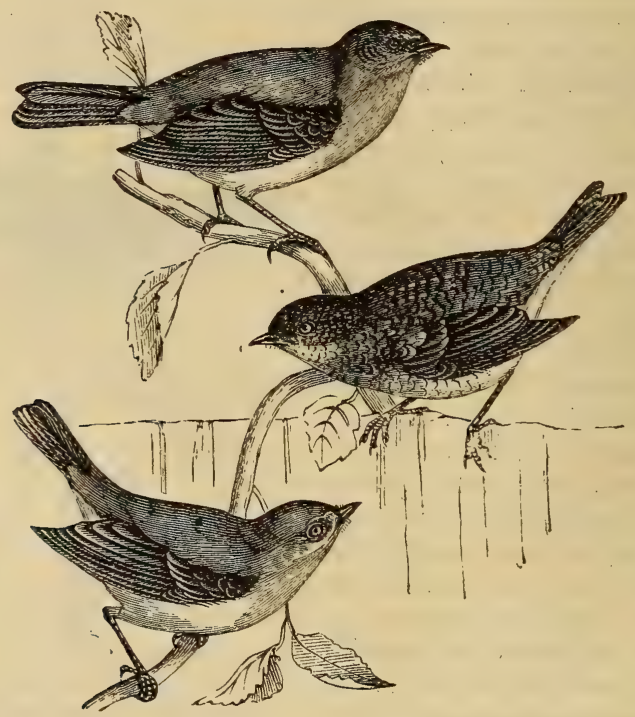

Fig. 228.-The Robin or Redbreast.

The Robin or Redbreast (Erythacus rubecula, Fig. 228), is to familiar a friend to require description. It is lively, pert, pugnacious, cheerful, and a universal favourite. In April the Robin betakes itself to the woods and thickets, where it rears its brood. On the approach of winter it returns to civilised life, when, we are informed by a French author, it constitutes excellent game! No doubt it is edible; but where is the consumer of such to be found? Not in the British Islands; we hope.

The Wrens (Regulus) are the smallest of European birds. The Golden-crested Wren(Regulus iristatus) inhabits the woods and thickets 
of the cold and temperate regions of the earth, where, among the twigs, with great agility it searches for insects, on which it feeds. While thus occupied it emits a single shrill feeble note, too often accepted by heartless boys as a tell-tale of its whereabouts.

The Fire.crested Wren (Regulus ignicapillus, Fig. 229) so much

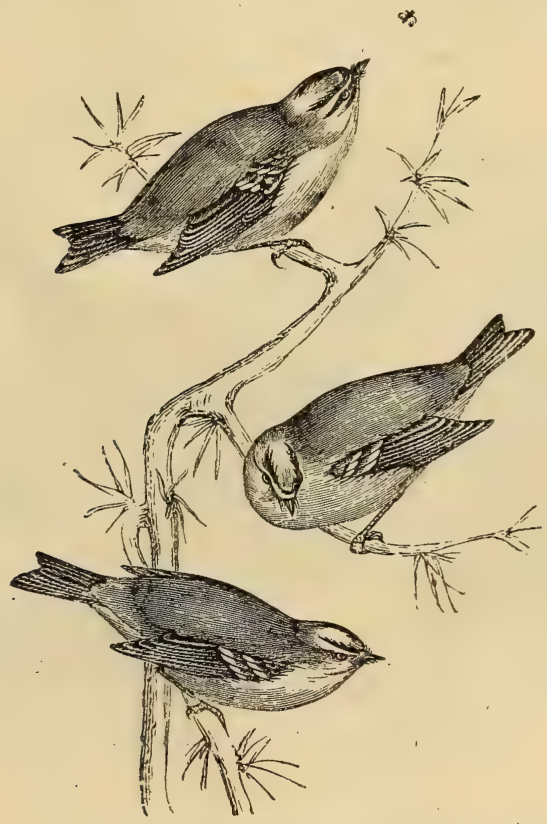

Fig: 229--Fire-crested Wrens.

resembles the last-mentioned that they are frequently confused. However, it is much rarer and of more brilliant plumage.

The Common Wren (Troglodytes vulgaris, Fig. 230) is widely diffused over Europe, from the Baltic to the southern parts of Italy, and from Trebizond to the west coast of Ireland: Like the Robin, it has become, in a sense, a sacred bird, and very few will harm the familiar little creature. Its nest is found in all kinds of situations; a favourite one being under the turfed summit of a stone wall skirting a brook; 
or on the edge of a wood or shrubbery. It is an elegant structure, oval in form, and dome-shaped, with the entrance at the side, the materials varying with the locality; but the lining generally is soft; downy feathers.

The Willow Wren (Sylvia trochilus, Fig. 23I) is a delicate, active little bird, pretty generally diffused. It is of retiring and unobtrusive manners, its favourite haunt being among the willows and osiers which skirt some sluggish stream. While flitting about in such

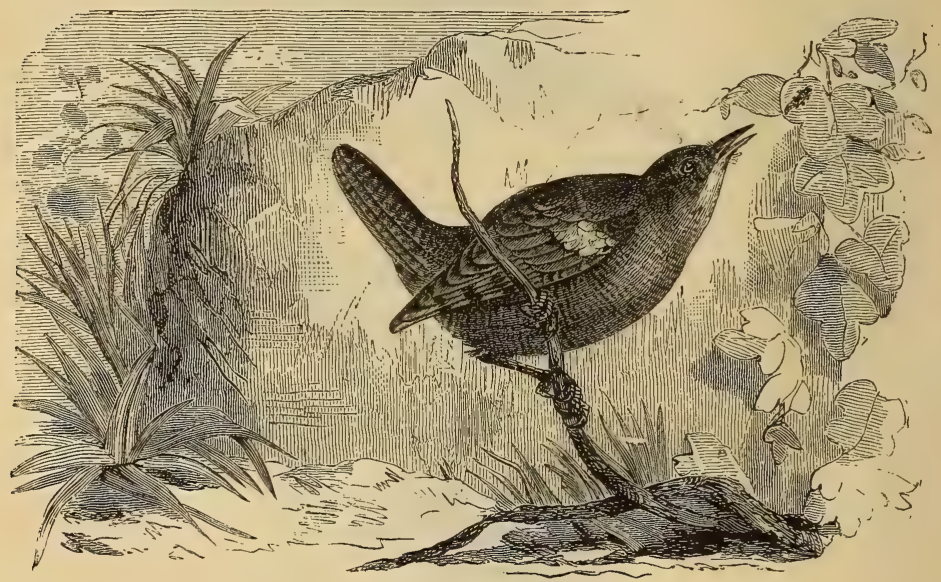

Fig. 230.-The Common Wren.

localities it emits a small chirping noise; but during the months of May and June it is often heard chanting a soft, mellow, and very pleasing song. In autumn great numbers of them may be seen gliding among the fruit-trees and bushes. Its colour is an olive green of deeper or less intensity, with canary-coloured breast, gradually becoming whiter as it reaches the stomach. It possesses a very sweet song, and is migratory.

The Stone-chat (Pratincola rubicola, Fig. 232) has the head and throat black in the male, the breast brownish red, the sides of the neck white, a white spot on the wings, the upper parts brownish black, and the feathers edged with brownish red. In the female the 
head and upper parts are streaked with brownish red, the throat yellowish grey, the breast dull brownish red, a white spot on the wings, and the upper tail coverts yellowish red. "In April," says McGillivray, "it forms its nest, generally under some furze bush, or other shrub, or among rank grass; it is formed of stems and blades of grasses, intermixed with moss, and lined with fine straws,

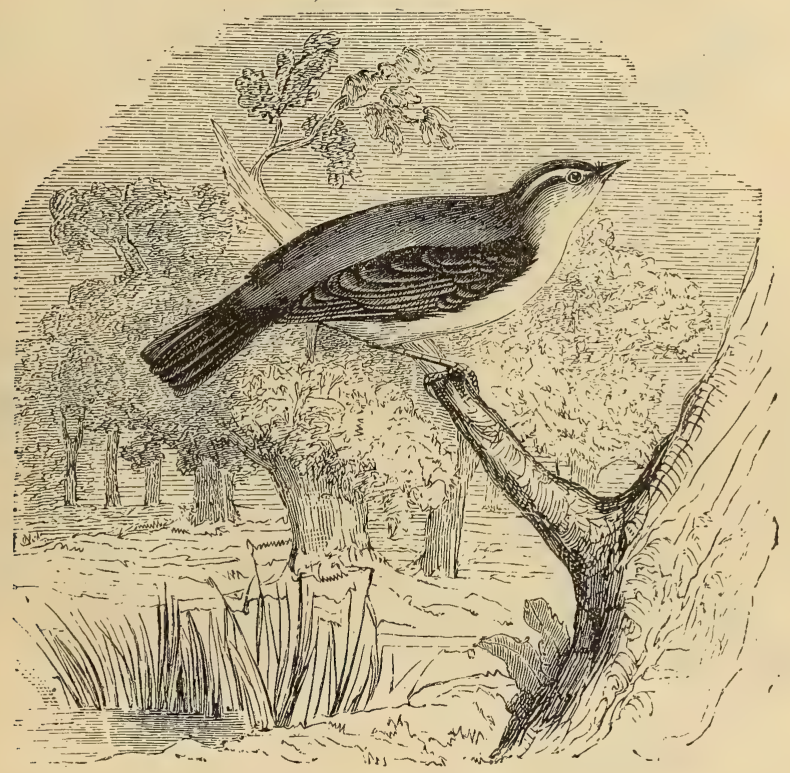

Fig. 23r., The Willow Wren.

fibrous roots, hair, and wool, as well as feathers. These birds manifest intense anxiety should any one approach their nest, fluttering and flitting about, and incessantly emitting their sharp, snapping note, while endeavouring to lead the intruder off in pursuit of themselves." Very much like the preceding in habits, and differing but slightly in appearance, is the Whin-chat (Pratincola rubetra). It, however, is migratory, which its predecessor is not.

The Wagtails (Motacilla) are remarkable for their slender, elegant form; the neck of moderate length; the head ovate, small, and 
narrow,; plumage soft and blended; the wings long, broad, and pointed; tail long, straight, slender, consisting of twelve weak, narrow feathers. The Wagtails are intimately allied to the Pipits, and resemble them in many of their habits, differing chiefly in the lengthened tail and shorter claws. Both are remarkable for the vibratory motion of their body while standing or walking, which their long tail renders a conspicuous feature.

The Pied Wagtail (Motacilla Yarrellii, Fig. 233), which is generally distributed in England, seems until lately to have been confused

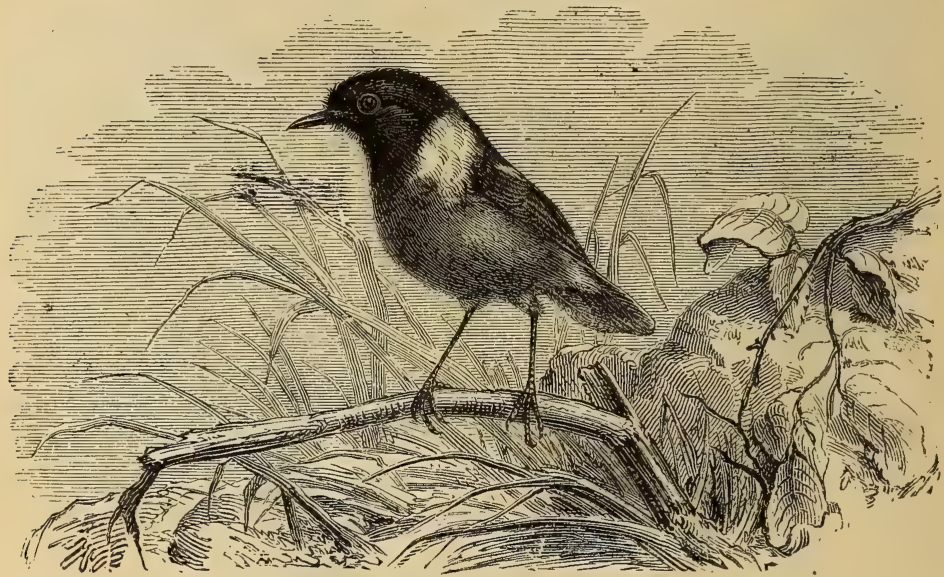

Fig. 232 - The Stone-chat.

with the White Wagtail (Motacilla alba). In form and proportion the two species closely resemble each other, the Pied Wagtail being the smaller. Mr. Gould states, in the "Magazine of Natural History," that while preparing his work on the bircls of Europe he was surprised to find that the sprightly Pied Wagtail, so common in our island at all seasons, could not be referred to any described species, and that its habitat was limited to the British Islands, Norway, and Sweden. The true Motacilla alba of Linnæus, on the other hand, is abundant in France, particularly in the neighbourhood of Calais, but has never been discovered on the opposite Kentish coast.

The Quaketails (Motacilla flava, Fig. 234) form the transition 


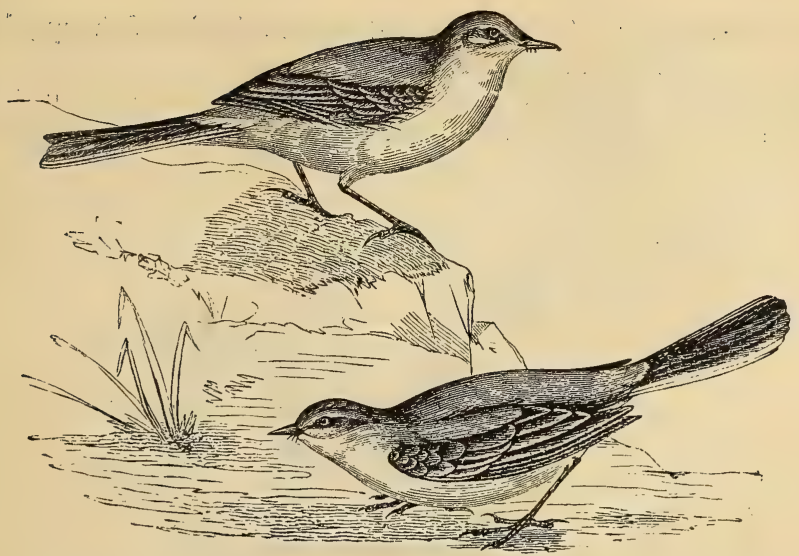

Fig. 233 - The Pied Wagtail.

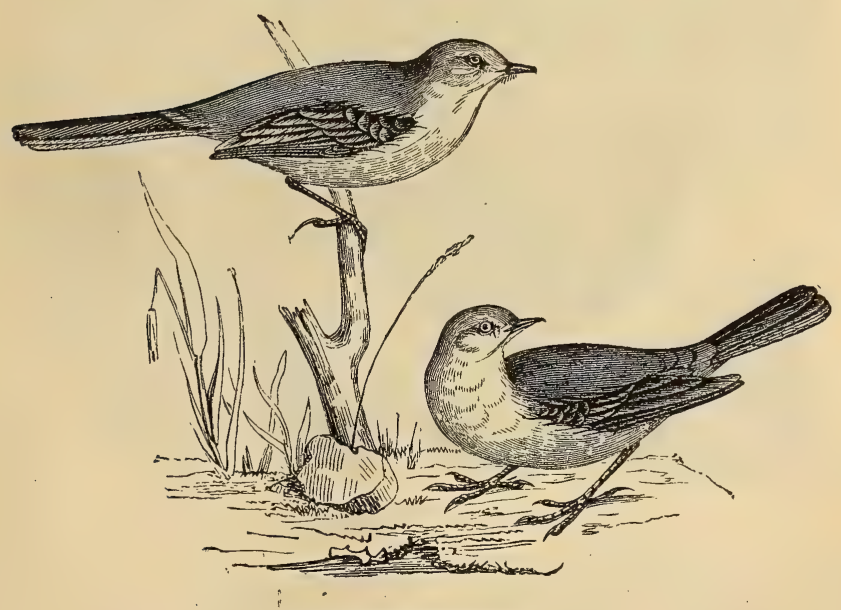

Fig. 234. - Quaketails,

from the Pipits to the Wagtails, but incline more to the latter. They are the bergeronnettes of French authors. The claw on the hind toe, which is long, and greatly resembles that of the Larks, distinguishes 
them from Wagtails. They are said to follow flocks of sheep; hence the name given them in France.

The Titlarks, or Pipits (Anthus), the farlouses of French writers, approach the Larks by the same characteristics which distinguish the

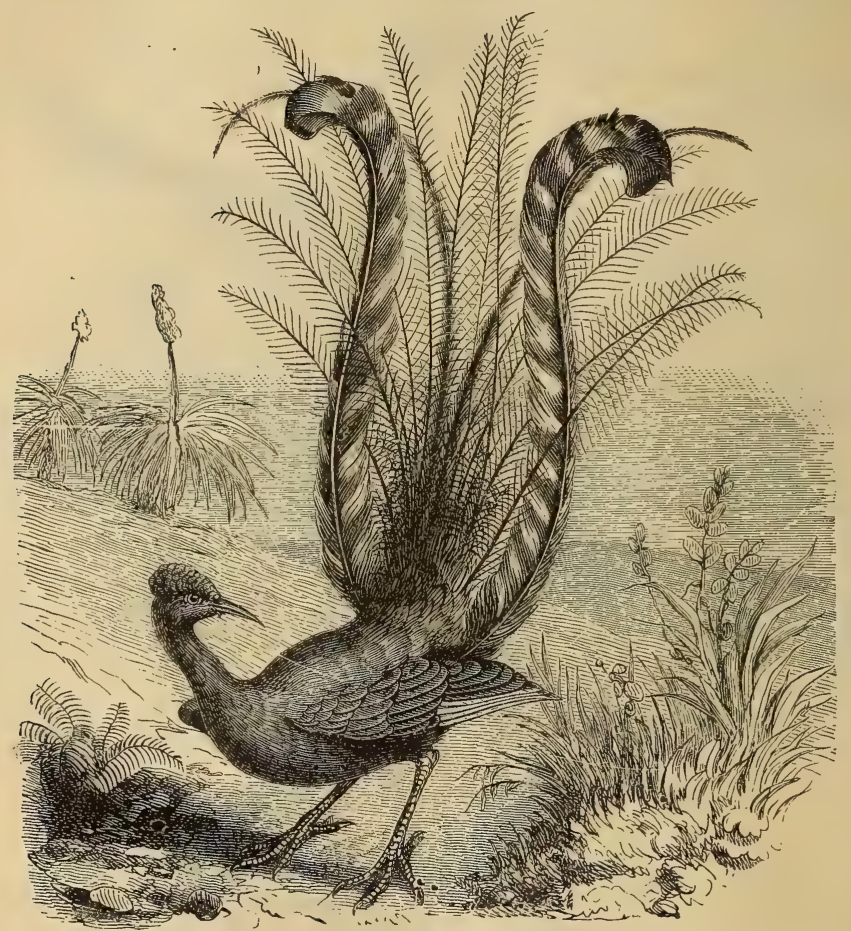

Fig. 235-- The Lyre Bird.

Quaketails, and might be confounded with them were it not for their compressed bill. 'They feed on autumnal fruits. Anthus arboreus (the Tree Pipit), A. pratensis (the Meadow Pipit), A. aquaticus (the Rock Pipit), and $A$. Ricardi (Richard's Pipit), are the British species. The Lyre-tail (Manura superba, Fig. 235) is a bird of New South Wales, about the size of a Common Fowl, and has been classed by 
some naturalists among Gallinaceous Birds; but Temminck places it in his Insectivorous order, among the Thrushes, and between Cuculus and Pitta. Cuvier places it among the Passerines. Vigors places it in the order Rasores, and in the family of the Cracida. This curious bird has a long compressed bill, triangular at the base. It owes its name to the peculiar disposition of its tail, which in the male has the exact form of a lyre. The singular development of the feathers of the tail is its chief attraction, for the plumage is dull and sombre in

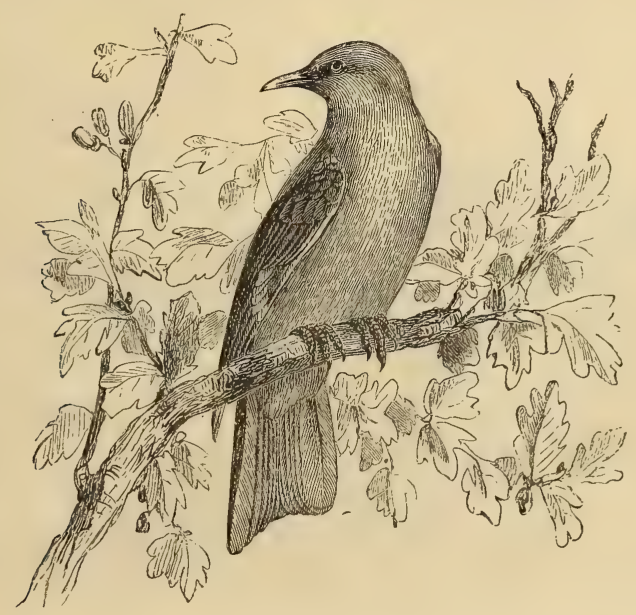

Fig. 236 - The Golden Oriole.

colour. It inhabits forests; builds its nest in trees, a short distance from the grouni ; and feeds upon worms and insects, which it seeks for under the dried leaves on the surface of the soil. Its song is described as not unpleasant.

The Orioles (Oriolus) have the bill long, stout, nearly straight, rather broad at the base, the dorsal line arched, and the tarsi very short. They are found in all the warmer parts of the Old World and in the islands of Oceania. Their plumage is richly coloured, shades of yellow and black blending in great variety.

The Golden Oriole (Oriolus galbula, Fig. 236) is about the size of the Blackbird, which it much resembles in form. The plumage is of a bright yellow; the feathers are oblong, with disunited barbs; 
those on the fore part of the head very short. The wings, when closed, reach to within an inch of the end of the tail; hence its flight is easy and sustained; while the form of its feet is equally well adapted for hopping on the ground and perching among the branches. It is a shy, solitary bird, and is approached with great difficulty. In the countries where it is a constant visitor it arrives in May, and departs in August; but while it arrives singly, on its return migration it travels in parties composed of families. It frequents by preference the borders of woods on the banks of watercourses; especially where

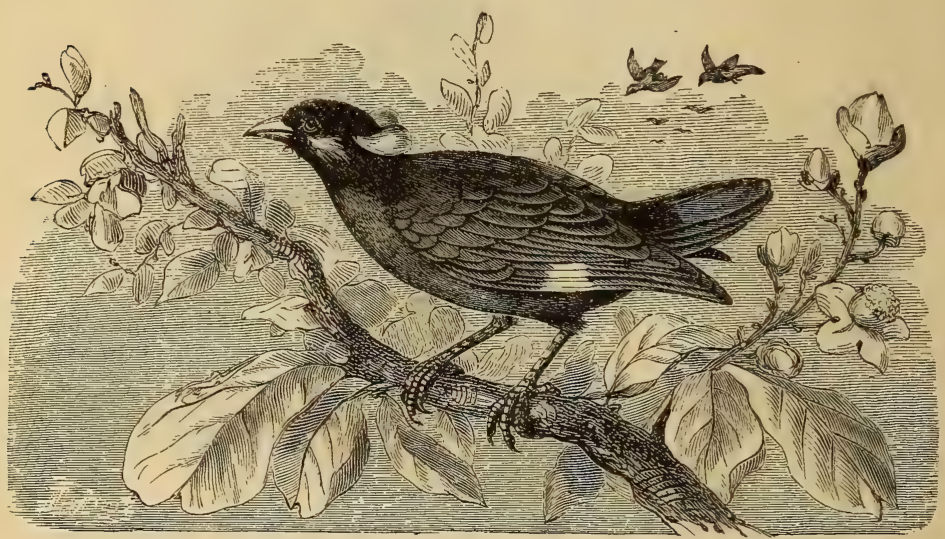

Fig. 237.-The Mino Bird.

large trees, such as oaks and poplars, are to be found, in which it builds its nest. The bird is common in the South of France. It lays from four to six eggs, and during incubation feeds on the larræ of insects and caterpillars, and is especially fond of such fruits as mulberries, cherries, and figs. This gives a delicious flavour to their flesh, which causes it to be much sought after. The Oriole will not live in confinement.

The Mino (Gracula musica, Fig. 237) has been assigned to various families. Swainson places it among the Sturnida, Gray in the sub family of Graculina, under the family of Corida. However, we prefer to put it here. They are sought after by the Orientals in consequence of their impudent and amusing habits, and the facility 
with which they imitate, like Parrots, short phrases, and even airs. Their song is very melodious.

The Minos have a bill analogous to that of the Orioles; but their general form and habits approximate more to the Starlings. They are eminently social in their habits, searching for their food and roosting in large flocks. Their natural disposition being peaceful, lively, and confiding, they appear to prefer the vicinity of man's residence, and the cultivated fields that surround his dwelling. They frequently attend upon flocks of sheep, to feed upon the insects that infest the skins of these ruminants. In countries where locusts abound, they are of great service to man by feeding upon them.

The Isle of Bourbon was at one time so infested with Locusts that it threatened to become uninhabitable. The idea was entertained of introducing some Minos, and these birds multiplied so fast that in a few years the pests had disappeared. Unfortunately, the services of the Minos had to be paid for dearly, for they showed a penchant for fruit, and made great havoc among the cherries, mulberries, \&c. When insects became scarce they even attacked the cereals and other crops.

These birds readily habituate themselves to a cage, and in a short time become as tame as Starlings. Like these birds, too, they possess the talent of remembering and repeating words and various cries. They inhabit Africa and Asia. In their migrations they sometimes visit the southern countries of Europe ; but they are rarely seen in France.

The Honey-eaters (Meliphagide) are sprightly, graceful birds, peculiar to Australia and the neighbouring islands. Their plumage is in general brilliant, and ornamented with tufts and collars. The voice of some species is very melodious, but little or nothing is known of their habits.

We now come to the Ring Ouzel (Turdus torquatus), which is called in France merle rose, because it combines the shape of the Blackbird with, particularly in the young birds, a red colouring over the breast.

They are migratory, and arrive in England about April, and leave in early autumn. They are so shy, that, although frequently seen, it is only for a moment. Their flight is remarkably swift, and their voice is clear and melodious.

The Dipper (Hydrobates cinclus, Fig. 238) has a straight and slender bill; large and stout toes, furnished with strong and hooked claws; and short wings and tail. The decidedly aquatic habits of these birds form a curious exception to the rest of the Passerine 
order. They live constantly on the edge of the water, or in the water itself, hunting for the insects which constitute their food. Although their toes are not webbed, they may often be noticed diving and moving about under water, by extending their wings and using them as fins. They are frequently to be observed flying along streams, and catching the winged insects skimming over the surface of the water. They live a solitary life, except during the pairing season, and frequent by preference the banks of mountain streams,

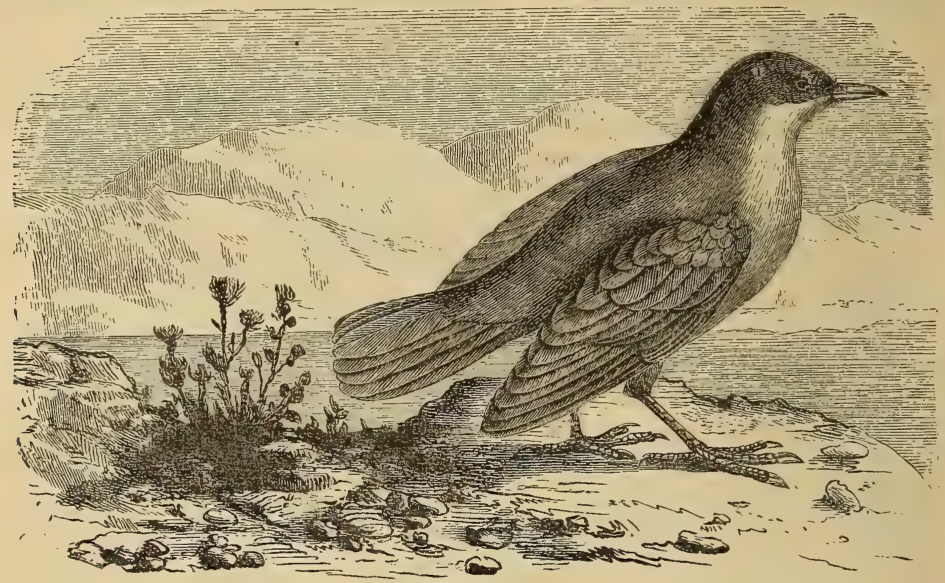

Fig. 238.-The Dipper.

especially such rocky and precipitous countries as the Alps, Pyrenees, and other mountain chains in the south, west, and north of Europe. It is met with in Great Britain and France.

The Hermit Thrushes(Turdus solitarius, Fig. 239) are distinguished from the other Dentirostral Passerines by their long and slender tarsi. They are natives of America, and are principally to be found in the midst of the vast forests that margin the Mississippi. Their food is indifferently vegetable or insectivorous. They fly heavily, but in running and hopping they are very adroit. They lay their eggs on the ground, on a bed of dry leaves, which are always well secreted among grass and brush. They have two broods each season. Their eggs, which are marked with blackish-brown splotches, are generally five 
in number. Their song is very low, plaintive, and sweet. They are wild and shy, and dash their heads against the bars when they are shut up in a cage. Their flesh is appreciated for the table.

The Merulide genus is characterised by a flattened, curved, and slightly denticulated bill, and is one of the most numerous of the family, embracing no less than 150 species spread plentifully over the whole surface of the globe.

Birds of this genus are, generally speaking, migratory, and travel in more or less numerous flocks. They feed on berries, fruits, and insects, and are endowed with harmonious powers of song. They

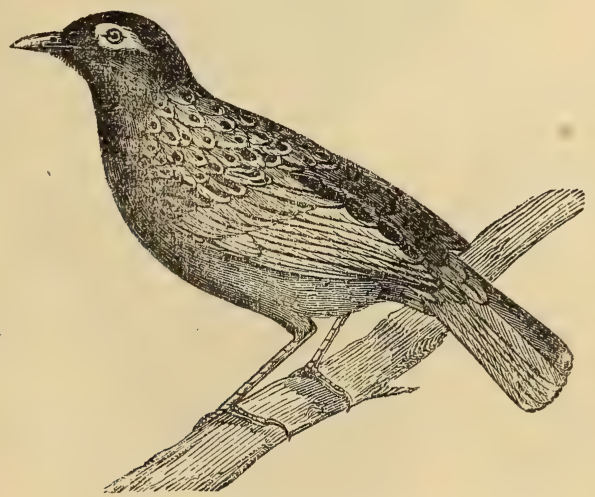

Fig. 239.-The Hermit Thrush.

have been divided into two great sections, the division being based upon the particular arrangement of their colours. First, all such as have the plumage of a uniform colour; secondly, those whose plumage is marked with small dark spots on the breast.

The principal species of the first section are the Blackbirds and the Polyglot Thrush.

The Common Blackbird (Turdus merula, Fig. 240) is so called on account of the plumage in the male bird, which is of a uniform black colour. It delights in localities covered with groves and thickets situated in the vicinity of water. When a sufficiency of food is to be found it seldom leaves the district it has frequented. In nearly all the countries of the European continent it is to be met with the entire year. These kirds appear to be more numerous in 
winter than in summer. The foliage being off the trees then, renders it more easy to detect them, thus accounting for their apparent increase.

The Blackbird is timid and cunning by nature, and shows extreme caution in approaching any object of suspicion. It rarely allows itself to be surprised by man, except when its voracity and greedi-

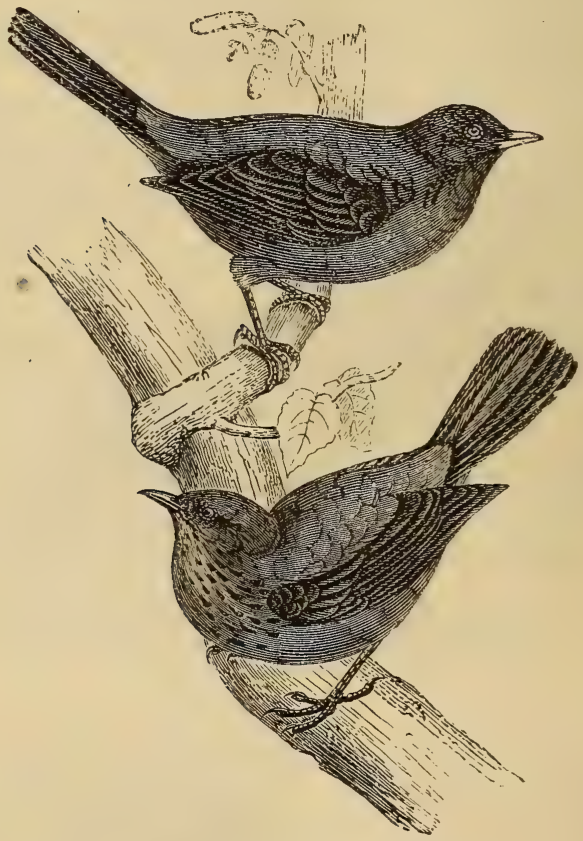

Fig. 240.-The Common Blackbird.

ness lead it into danger; but still, notwithstanding its shyness, it is disposed to frequent public and private gardens, and the vicinity of habitations. When taken young it easily becomes accustomed to captivity.

It builds its nest at a short distance from the ground, on trees or bushes, the female bird only participating in the labour of building. She lays from four to six eggs. 
In the South of Europe this species is much sought after, on account of the exquisite flavour which its flesh acquires from living on myrtle and juniper berries.

The Ring Blackbird (Merula torquata) differs from the kind we have just noticed in being of larger size, and in evincing a predilection for mountainous countries. It sings very agreeably, and in France is found on the high summits of the Vosges, the Alps, and the Pyrenees.

The Solitary Blackbird (merle bleu of the French) is remarkable

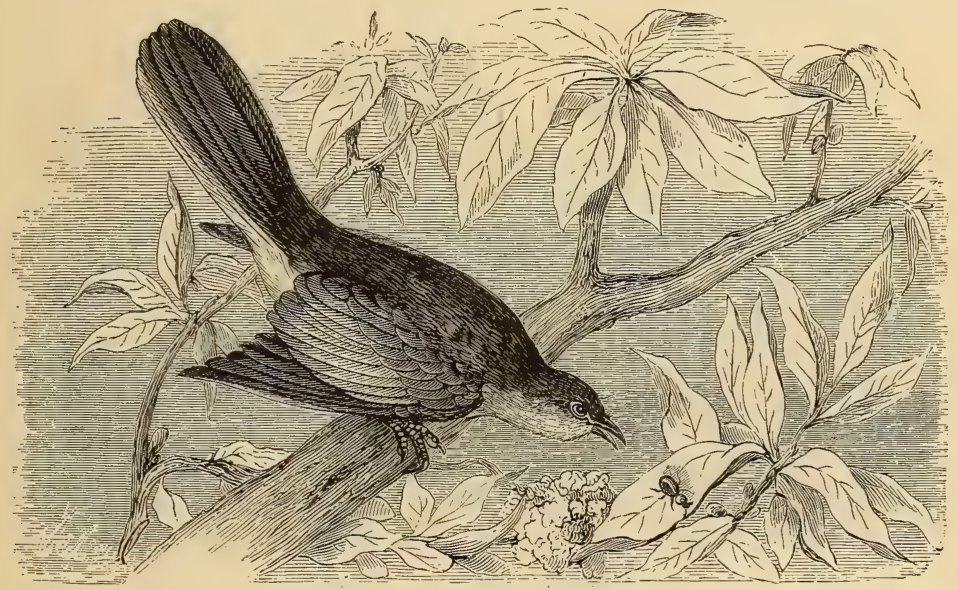

Fig. ${ }_{2}+$. - The Mocking-bird.

for the deep blue colour of its plumage. It frequents the same regions as the bird last described, and its habits are nearly the same, but it is wilder in its nature, and its song is even still more charming, We read in the chronicles of his time that Francis I. was never weary of listening to the strains of one he possessed. This bird is common in the South of Europe, and the whole of the Levant, and when it is tamed acquires considerable value.

Of all the various species of the Merulida the one which is unquestionably the most favoured, as regards its vocal powers, is the Mocking-bird, or Polyglot Thrush (Mimus polyglottus, Fig. 24I), native of North America, and chiefly of the Southern States. Its notes are so melodious that the conscientious Audubon does not 
hesitate to rank them far above those of the Nightingale. In addition to this, it possesses the wonderful faculty of imitating the songs of other birds, and even the cries of the mammals which make their abode near it. For this reason the Indians call it the "bird with four hundred tongues." Being protected by the inhabitants of Louisiana, it does not seem to dread the presence of man, and builds its nest with the utmost publicity in the vicinity of dwellings. When it is captured before leaving the nest it becomes very tame.

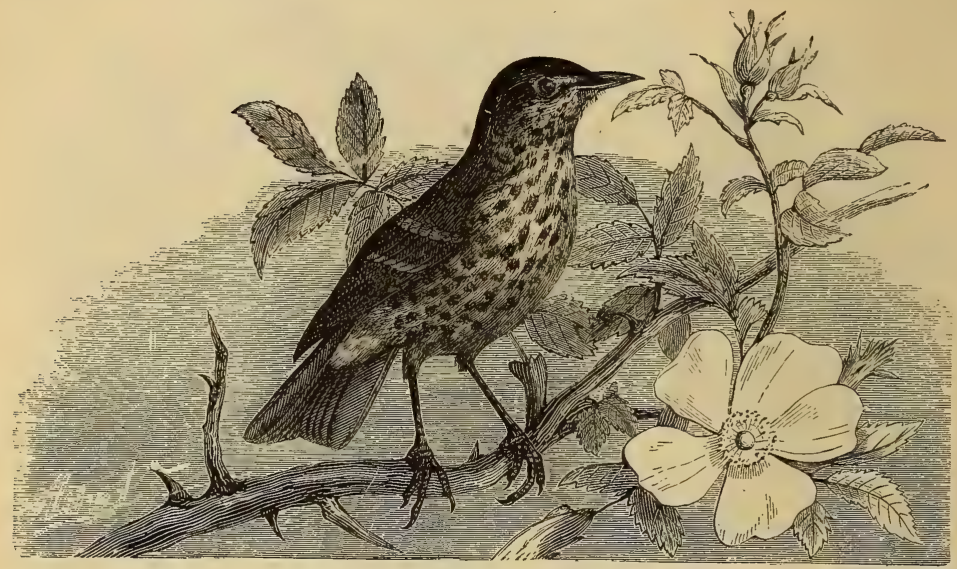

Fig. 2+2, - The Song Thrush.

The principal species of the Merulida, with freckled breasts, are the Song Thrush, the Redwing, the Mistletoe, and the Fieldfare.

The Song Thrush, Mavis of the Scotch (Turdus musicus, Fig. 242), has enjoyed, from ancient times, great reputation, not, as we might have preferred, for its vocal powers, but for the delicacy of its flesh. The Romans appreciated these birds to such a degree that they were in the habitof fattening them by thousands in immense aviaries, cleverly combining the privation of light with a suitable temperature. Nowadays Thrushes are not fattened artificially, because they take very good care to fatten themselves in their autumnal wanderings, for they gorge themselves to such an extent with grapes, figs, and olives, and other fruits peculiar to southern countries, that they attain an incredible state of obesity, causing them to be sought after with avidity, to 
gratify the fastidious palate of the gourmand. It is even said that thrushes intoxicate themselves among the vines, which has given rise to the French proverb, "As drunk as a thrush," in speaking of a man who has been indulging too freely in wine. But this is absurd; although the Thrush may be unable in the autumn to fly away with its usual agility, the only cause is its increased weight.

The Redwing (Turdus iliacus) shares both the good qualities and defects of the Song Thrush, and is likewise much esteemed by epicures. The two other species, Missal Thrush (Turdus viscivorus) and the

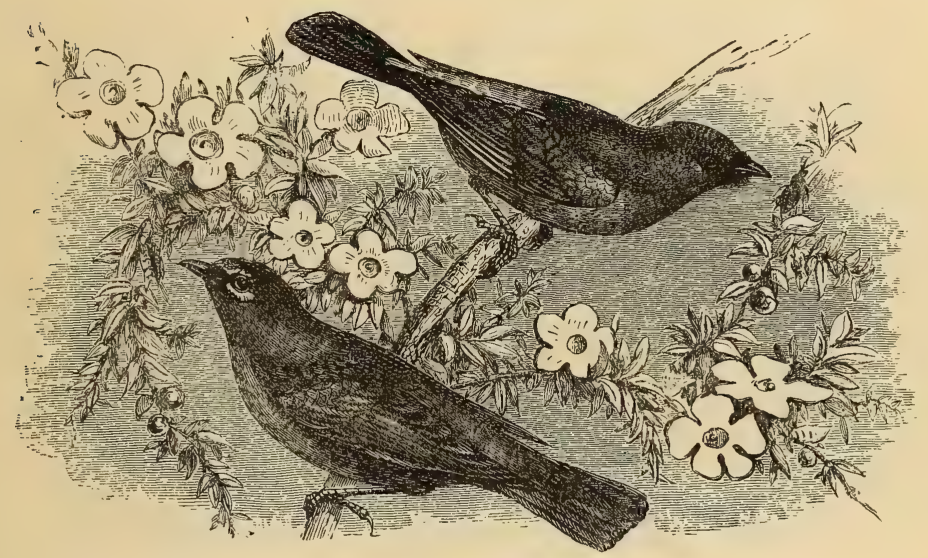

Fig. 243.-Scarlet Tanagers.

Fieldfare (Turdus pilaris), are of less importance in an edible point of view. They are all natives of Europe, and visit the centre and south of France.

The Tanagrine group form a genus of birds peculiar to the hot regions of America. They are remarkable for having a bill which is tapering and triangular at the base, and for the brilliant colours of their plumage. They are allied by their habits to the Warblers and the Sparrow. They are lively, constantly in motion, and but seldom settle on the ground. In general life they resort among trees and bushes to collect berries, seeds, and insects. According to the species, they live either solitarily, in families, or in flocks. Some kinds of them have an agreeable song; among these are the Organist Tanagers. 
Tiose which are most richly endowed, as regards the splendour of their dress, are the Scarlet Tanagers (Ianagra rubra, Fig. 243).

The Grosbeak Tanager (Tanagra magna) is remarkable for the sociability of its nature, for, with the help of its companions, it is in the habit of building on the top of a palm tree a vast construction, divided into a certain number of compartments, which are portioned out to so many couples, to hold their nests and young broods.

The Dicrurus (Dicrurus macrocercus, Fig. 244) resembles a Crow in shape and a Blackbird in size. They have a carinated beak, pretty

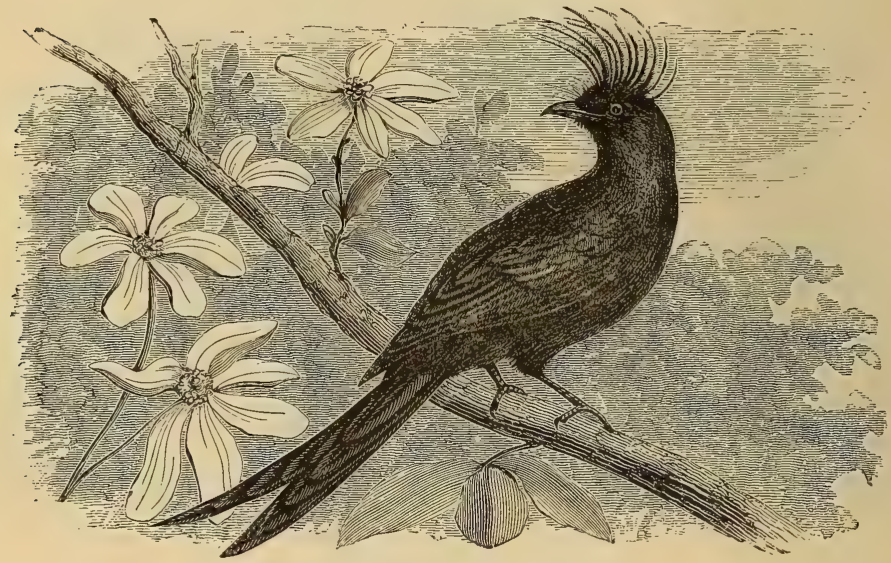

Fig. 244.- The Dicrurus.

strongly curved, and a forked tail. The ground of their plumage is black, with a green or blue metallic reflection. They live in small flocks in the forests of India. They are great destroyers of bees. The better to accomplish this, they post themselves, at morning and evening, at the skirts of a wood, on a tree which is dead or bare of leaves, and watch for these insects as they leave or regain their retreats. When they attack their prey, they fly down from their post of observation, and from their great activity make terrible massacre of the unfortunates.

Their turbulent and noisy nature, and their black funereal appearance, has been the means of gaining for them the name of Devil Birds. Their flesh is of no value; but some species are said to sing 
not unpleasingly. In one species the two outside feathers of the tail are long filaments, terminating in square-pointed feathers.

The genus Cotinga is characterised by a short, flattened, curved, and stout bill. It embraces, according to several authorities, as sub-genera the Manakins (a species of which has been previously described in p. 5 I4), Rollers, and Chatterers.

The Golden-winged Manakin (Pipra chrysoptera, Fig. 245), the most beautiful species, is a bird about the size of a Thrush; it inhabits Brazil and Guiana, and is remarkable, during the pairing

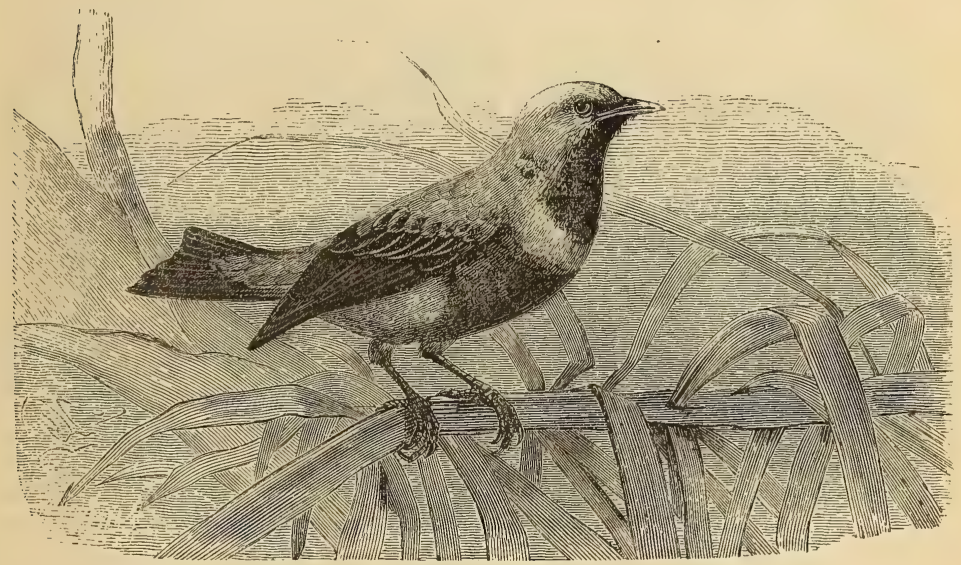

Fig. 245.-The Golden-winged Manakin.

season, for its brilliant and variegated plumage. It frequents damp localities in the midst of great forests, and its food consists of seeds, fruit, and insects. It is very shy in its nature, and cannot habituate itself to captivity. Its rich colours alone cause it to be admired, for its voice is by no means melodious, and its flesh is too bitter for human food.

The Rollers (Coracias) owe their name to their habit of moving stones and sticks, under which they find their principal sustenance; but they also feed on flies and the larvæ of insects. They differ from the preceding families in their habitat and the colour of their plumage. The former are only met with in America; and the latter are 
found in Africa, the Indian archipelago, and occasionally southern Europe.

The Chatterers (Ampelide) are sociable birds, living together in flocks the whole of the year, except during the breeding season. They feed on buds, berries, and insects ; they even catch flies on the wing. They are, nevertheless, extremely indolent, and do not move about more than is necessary to satisfy the requirements of appetite. The greater part of their time they remain hid in the recesses of

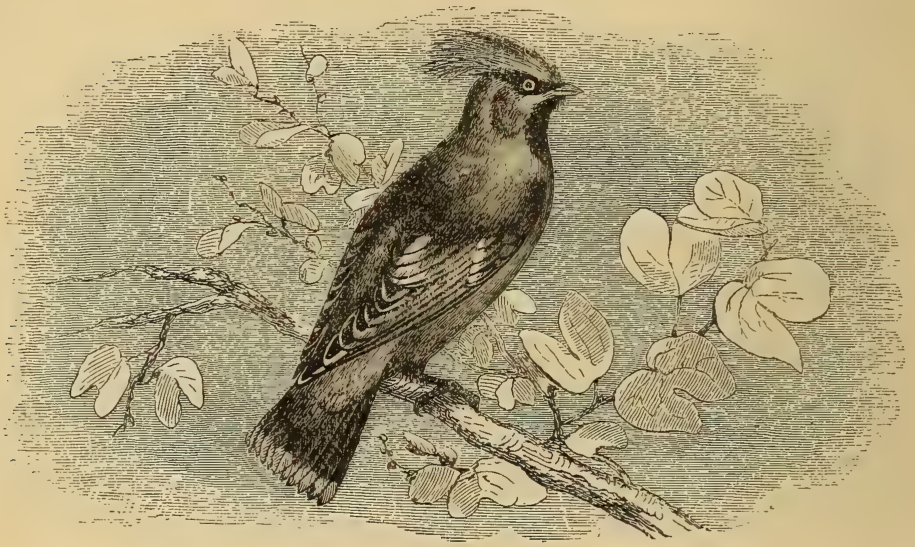

Fig. 246.-Bohemian Waxwing.

woods, and are rarely seen; they settle rarely on the ground, for their gait is awkward and constrained. Not endowed, properly speaking, with any powers of song, their only utterance is a feeble twittering, which in some species is very prolonged. The Bohemian Waxwing is noisy at all seasons ; and this is probably the origin of the name Chatterer, which is given to the whole genus. They are tamed with great facility, and, as they are adorned with brilliant plumage, they are often reared in cages. These birds are found in Europe and North America.

The European species (Ampelis garrulus, Fig. 246) breeds in northern countries, and migrates to Germany at the approach of 
winter. It is rarely met with in France. It is a very pretty bird, and is easily domesticated.

The American species, familiarly known as the Cedar Bird ( $\mathrm{Am}$ pelis cedrorum), very much resembles the former in plumage and habits, but is not so large.

The birds belonging to the Fly-catcher genus (Muscicapida) have a flattened and hooked bill, furnished with a projecting edge, and with stiff hair at the base. They are divided into Fly-catchers proper, Tyrants, and Eurylaimince.

The Fly-catcher proper feeds on insects, which it"catches on the wing with a vivacity and agility which are extraordinary. It sometimes adds to its fare caterpillars and ants, but it never settles on the ground except when in pursuit of prey. They are birds of taciturn and solitary habits, frequenting alone the depths of forests, or the margin of sluggish streams. They are silent even during the pairing season, and are rather negligent in their mode of building, taking no care to hide their nests from the view of their enemies. According to the species, they build either on trees and bushes, or in the crevices of

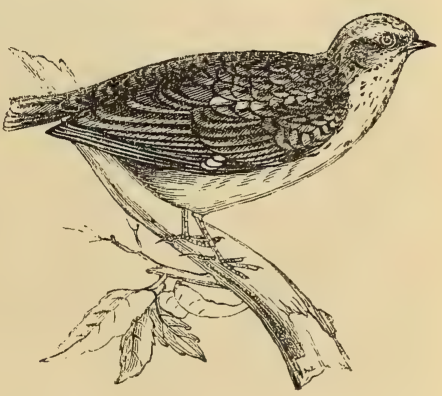

Fig. 247.-The Spotted Fly-catcher. walls, rocks, or under the eaves of roofs. In Europe, the female bird lays from three to six eggs once a year, but is more prolific in other parts of the world.

The Fly-catchers are not larger than the Warblers. They are birds of passage, and various species of them are spread over the whole surface of the globe. Some are natives of Europe, among which we will name the Spotted Fly-catcher (Muscicapa grisola, Fig. 247), and the Pied Fly-catcher (Muscicapa atricapilla). The latter bird is very fond of fruit; and in the South of France it is killed for the delicacy of its flesh.

The Royal Great Crests or King Tody (Eurylaimus serilophus, Fig. 248) are birds of the same size and with the same habits as the Flycatchers proper. They differ in nothing but their plumage, which is much more brilliant, their more fully developed tail, and the beautiful tufts which adorn their heads. They are natives of tropical America. The species mentioned may serve as a type, on account of a mag- 
nificent red tuft, edged with black, which spreads out round its head, and resembles a splendid diadem. Other species are found in India and Africa.

The Tyrants (Tyrannus) owe their name to their courageous, audacious, and quarrelsome character, which leads them to attack birds more powerful than themselves, such as some of the smaller birds of prey, and even the White-headed Eagle. It must be added, too, that they more often than not succeed in forcing these robbers

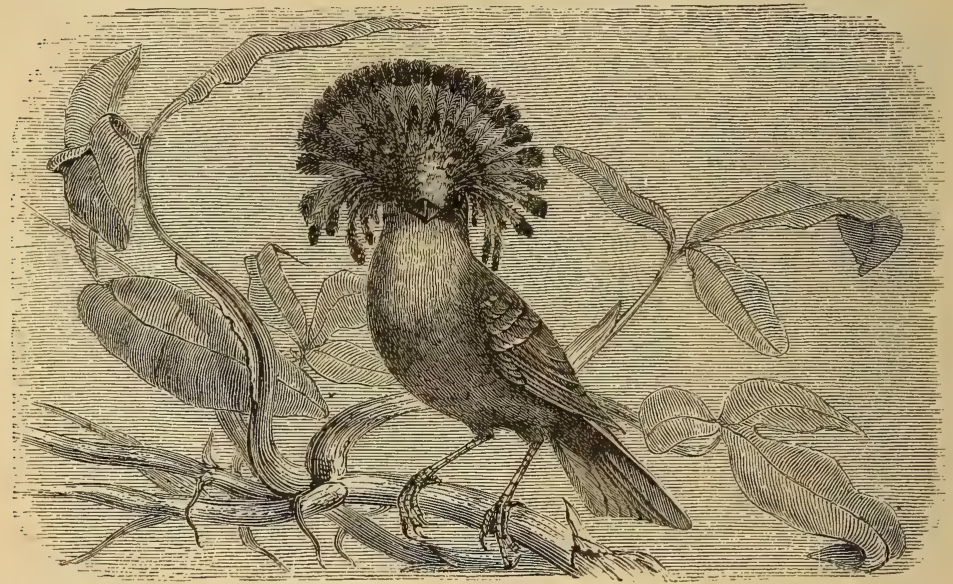

Fig. 248.-King Tody.

to quit the neighbourhood in which the Tyrant's young brood is reposing. They feed on insects, small reptiles, and sometimes on very small fish. The King Bird of the United States (Tyrannus intrepidus) is a well-known type. But the Forked-tailed Fly-catchers (Melvulus tyranmus, Fig. 249), found in South America only, and principally in Brazil and Guiana, are the most attractive.

The Umbrella Bird (Cephalopterus ornatus, Fig. 250) has some resemblance to Crows, both in size and plumage. Their name, which in Greek signifies "winged-head," is given them on account of a wide crest which spreads out above their head like a parasol. Added to this the front of the neck is bare, but the lower part is furnished, with a thick tuft of feathers, which hang down over the breast. 
These birds are natives of the forests of Brazil which margin on rivers. Little or nothing is known as to their habits. The wide shape of the bill would suggest that they feed chiefly on berries and fruit.

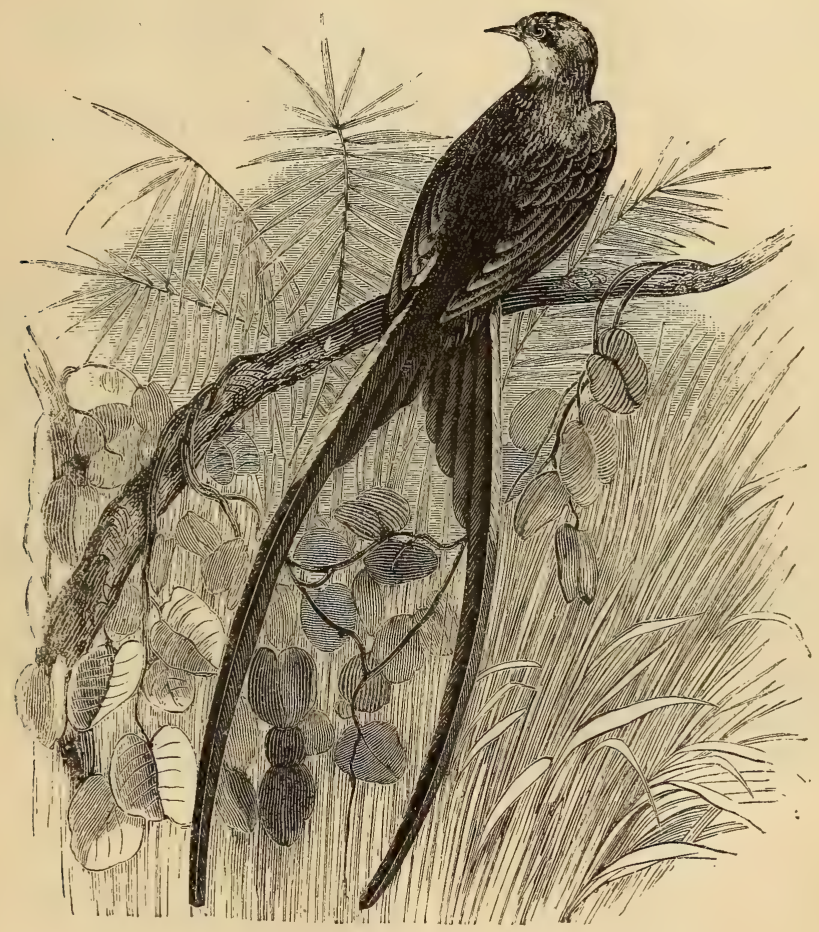

Fig. 249.-The Forked-tail Fly-catcher.

The Shrike genus concludes the Passerine order. It comprises a certain number of birds with tapering or flattened bills, more or less hooked at the point, and deeply indented. In their quarrelsome nature, and in their partiality for flesh they resemble the Rapacious order. Among them are classed the Great Grey Shrike, the Redbacked Shrike, the Woodchat Shrike, the Pied Crow Shrike, and the Piping Crow Shrike. 
The Shrikes proper possess the instinct of destruction in the very highest degree. They delight in shedding blood and in spreading death wherever they go ; indeed, their evil disposition has become proverbial. Not satisfied with killing with a view of satisfying the lawful needs of hunger, they sacrifice, as if for mere pleasure, insects, birds, and small mammals. They afterwards impale them upon the thorns of bushes and hedges.

But still we must not condemn these birds with too great a degree of severity. No doubt there is cruelty in their actions; but, first

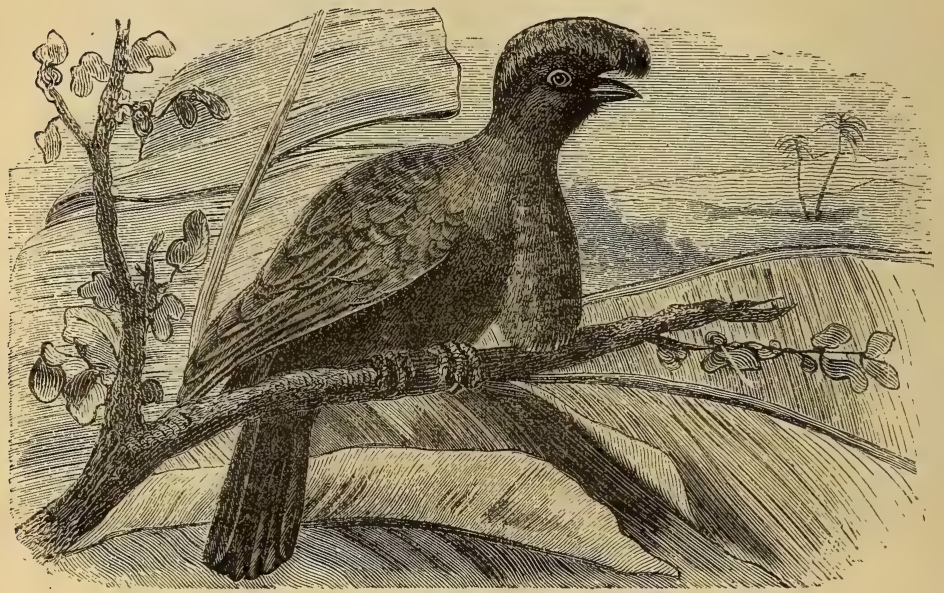

Fig. 250.-Umbrella Bird.

and foremost, we are bound to recognise the foresight which they show. These victims are stored as a supply in time of need. It is a mistake to think that all creatures which they attack are smaller than themselves. Although not large, they are not afraid of ravens or magpies, and even birds of prey, particularly if called upon to defend their young.

Shrikes generally inhabit extensive woods. During the day they perch upon the top branches of trees, from which they pounce upon their prey. They fly rather indifferently, but hover with great ease. Their twittering is continual, and some of their melodies are not entirely devoid of charm. They are remarkable for their talent of 
imitation, and mimic the songs of other birds with such exactness as to deceive the most experienced ear. Some even go so far as to assert that they use this faculty to capture small birds.

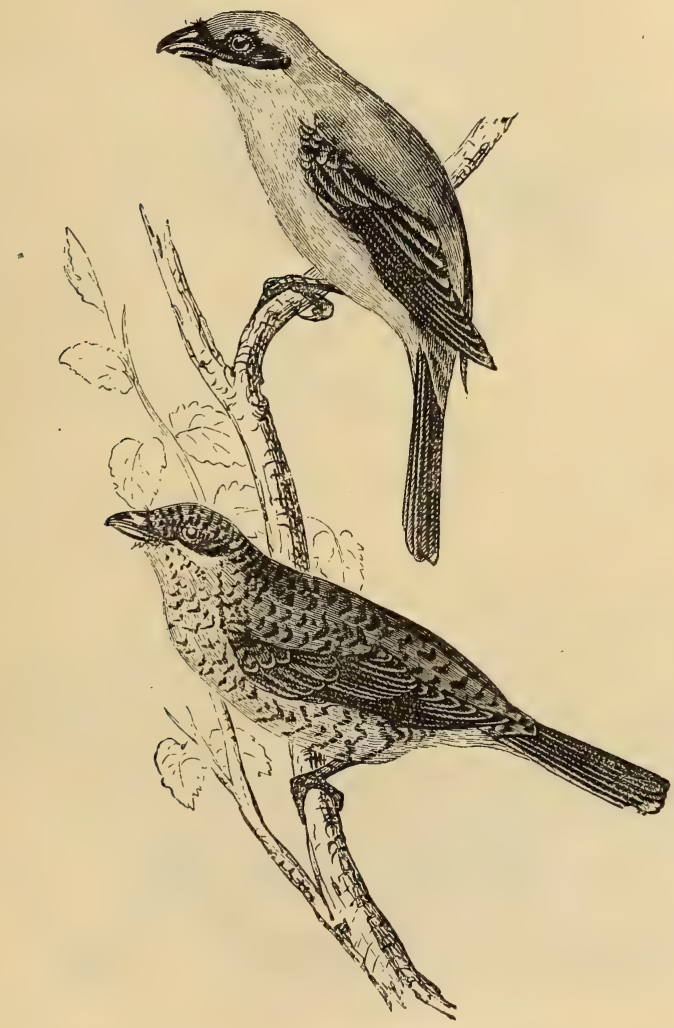

Fig. 25 I.-The Great Grey Shrike.

They migrate every year, and at the time of their journey are much sought after for the table; for their flesh, being covered with abundant layers of fat, is very rich. It is a curious fact that, in spite of their cross-grained nature, they are very easily tamed. They cannot, however, accommodate themselves to close captivity, their active 


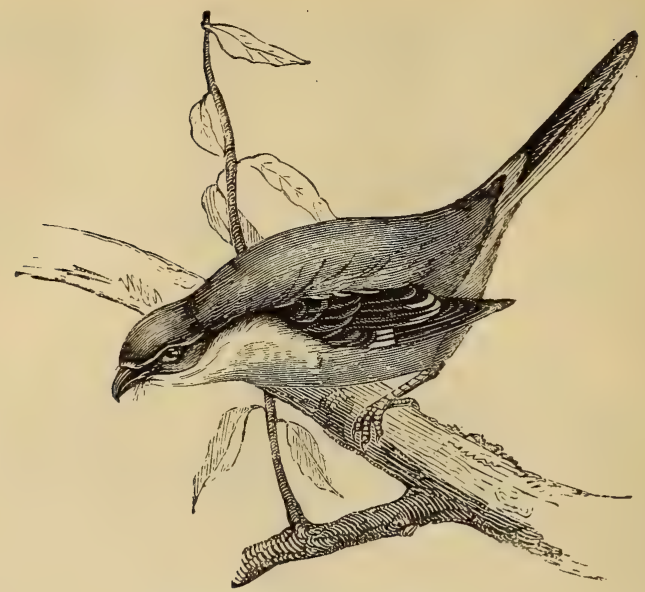

Fig. 252. The-Red-backed Shrike

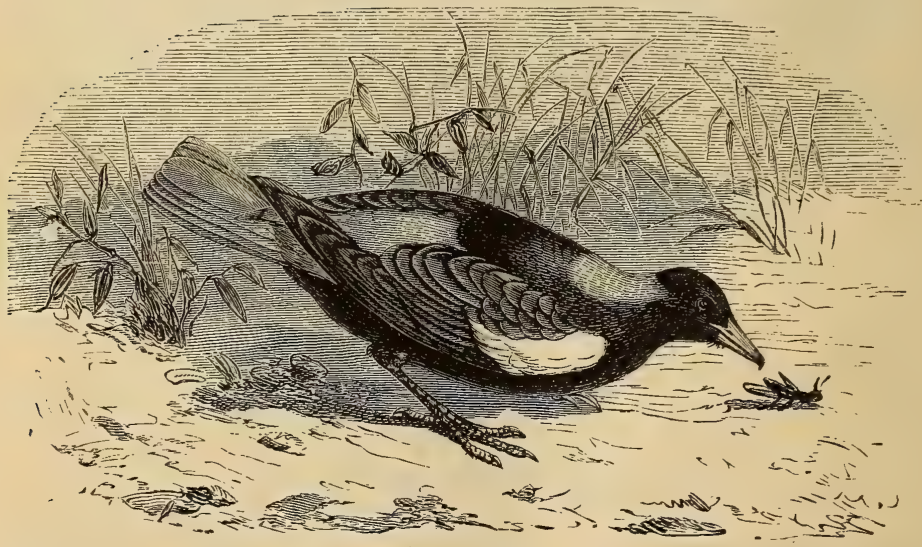

Fig. 253.-The Piping Crow Shrike.

natures requiring a more extended field of action; such, for instance, as a large aviary affords. When kept in a place of this kind they 
become very friendly, and appear to be capable of great affection for their master.

Shrikes are common in all parts of the globe. Seven species are known in Europe, the principal of which are the Great Grey Shrike (Lanius excubitor, Fig. 25I), the Red-backed Shrike (Enneoctonus collurio, Fig. 252), and the Woodchat Shrike (Enneoctonus rufus) are known in England. In France these birds are rare, except in the southern departments.

The Falcon Shrikes are sometimes called Swallow Shrikes, because they fly with great ease, and pursue insects on the wing. Their habits, however, differ but little from those of the true Shrike. They are natives of Africa, India, and the Southern Archipelago.

The Pied Crow Shrike (Strepera graculina) bear a still greater similarity to the Shrike proper. Their habits of life are altogether the same; but they are found only in Australia.

Lastly, the Piping Crow Shrike (Gymnortrina tibicen, Fig. 253) belongs to New South Wales, and holds an intermediate place between the Shrike and the Crow, the latter of which it resembles in its gait, size, and plumage. In its habits it is clamorous, turbulent, and omnivorous. It may be readily recognised by its long bill. 


\section{CHAPTER VIII.}

\section{RAPTORES, OR BIRDS OF PREY.}

THE Raptores enjoy a greater amount of public notoriety than almost any other birds, although they are of little or no service to us, and possess infinitely fewer claims on our interest than a multitude of other winged creatures. The audacity and courage by which several species are distinguished, the marvellous stories to which their exploits have given rise, and the superstitious terror caused by their appearance may help to explain the reason of this notoriety. Poets and novel-writers, in order to characterise their heroes, often inspire them with the qualities or defects of some of the rapacious birds. They have made the eagle a type of nobility, strength, and valour; the vulture the incarnation of cowardice and unclean gluttony. The owl, with its staring aspect and noiseless flight, has been made a bird of ill omen; its doleful hoot echoing through the shades of night, over the house of sickness, being regarded as an infallible prediction of death. These superstitions have had considerable influence upon popular imagination, and have thus passed into habitual use in conversation.

The Rapacious order is characterised by a very strong, hooked, and sharp-edged bill, which is furnished at its base with a membrane called the cere-it is generally of a yellow colour, and upon it the nostrils open; strong legs, covered with feathers; four toes, three in front and one behind, which are usually very flexible, and provided with crooked and retractile talons, often possessed of great strength. Their powers of vision are very great, and they are marvellously organised for flight, their long and vigorous wings enabling them to hover in the highest regions of the air, and to travel over immense distances in an incredibly short space of time.

Their generic name sufficiently indicates that they live by plunder and blood-shedding. They correspond, in the class of birds, with the carnivora among mammalia: Like them, they live on animals, either 
dead or living; like them, too, they possess the strength and cunning which are necessary to secure their victims.

With her ever-admirable foresight Nature has wisely limited the reproduction of these destructive creatures-the largest only lay two eggs a year; the others, on an average, five or six. It is a singular thing that the female is often nearly a third bigger than the male; hence the name of " tarsel," given to the latter in certain species.

The Raptores present none of the graces and are totally deficient of the charming powers of song possessed by other races of birds, for their sole utterance consists either of harsh cries or strange and plaintive modulations. Their plumage is nearly always of a sad and monotonous appearance. Destruction is the sole object of their existence ; they are the terror of all the rest of the feathered creation, among which they every day nake numerous victims. They live alone, or in couples, in the most deserted localities, their gathering together in flocks being exceptional, and then it is to devour putrid carrion. They are of a despotic and combative temperament, and will not suffer any rivals in their neighbourhood. They practise absolutism in its strictest form, and reign as lords and masters in the districts which they choose for their territory.

The Raptores are met with over the whole surface of the globe; the larger species inhabit lofty mountains, or seek a hiding-place in the face of inaccessible and solitary cliffs.

This order is divided into two sub-orders, the Nocturnal and the Diurnal. This division is a very rational one, for it is founded on dissimilarity of habits, which is owing to a difference of organisation.

\section{Nocturnal Birds of Prey.}

Norturnal birds of prey are distinguished by large staring eyes, directed straight in front, and surrounded by a circle of slender and stiff feathers, which, by their radiation round the face, form a nearly complete disc, to which the name of fucial disc has been given; by the large development of their head; by very short bills, devoid of cere, which is replaced by a plain skin covered with hairs; by tarsi feathered down to the claws; by the mobility of the outside toe, which can be turned either forwards or backwards ; by very strong, sharp, and retractile claws ; by abundant and soft plumage ; and by tails which are generally short.

But the original characteristic of these birds, and that which has contributed to their union in one group, is their inability to bear the light of mid-day, and the faculty they possess of being able to see in 
twilight, owing to the pupils of their eyes having enormous powers of dilatation. They consequently remain hidden in their retreats while the sun is high, and do not begin to hunt until the luminary has approached the horizon, when they are able to distinguish with surprising clearness the creatures on which they prey.

We are not, however, bound to believe that these birds can see in the midst of perfect darkness. When the night is thoroughly obscure they become subject to the law common to all. They manifest the greatest amount of activity when the moon diffuses her light over the earth; for then they revel in their destructive instincts, levying a heavy tax on all weaker animal life. The epithet of "nocturnal," which is applied to them, is, therefore, not strictly accurate, and must not be taken literally.

Owing to the large cavities existing in their skulls, which communicate with the internal ear, and increase the capacity of this organ, the Raptores have the sense of hearing strongly developed,

Their plumage is streaked with diversely-arranged markings, and is as soft and delicate as the down of fledglings. These peculiarities are probably owing to the special conditions of their existence. Constantly deprived as they are of the rays of the sun, the action of which upon colour of plumage cannot be doubted, they are not arrayed in those splendid hues which clothe diurnal birds of tropical regions.

Owing to the structure and nature of their feathers, nocturnal birds of prey fly without noise. Thus they are enabled to pounce unawares on their victims, seizing them before they have any idea of necessity for escape. When they capture prey, it is at once devoured; an easy matter, on account of the enormous expansion of their bills. Their stomach afterwards separates the indigestible parts, such as bones, hair, and feathers, and when these are rolled together in the shape of a ball or pellet, they are ejected by vomiting. Diurnal birds of prey which subsist on living animals also possess this peculiarity.

With the exception of the Barn Owl, all nocturnal birds of prey lay eggs of a spherical shape. They live in couples, only assembling in flocks at the epoch of migration; they never, however, hunt in common. They do not build any nest, but deposit their eggs in cavities in old trunks of trees or ruined habitations. They exhale a disagreeable foetid smell, which no doubt is produced from their diet being exclusively animal.

Unless forced, none of the members of this sub-order come out of their roosting-places during day. When compelled by circum- 
stances to do so, they are assailed by all the Passerines of the neighbourhood, which resent their intrusion, and avenge the oppression exercised over them during the night. When thus attacked a nocturnal bird places itself in the strangest postures, ruffles up its feathers, and balances its head with a stupid look, and expresses its indignation by making a cracking sound with its bill. It does not, however, try to defend itself, and passively receives the blows of its feathered enemies. The natural antipathy of small birds for their nocturnal destroyers has been taken advantage of for their capture. The fowler imitates the voice of an owl, the birds flock together and perch on the trees or bushes in the vicinity suspected to shelter one, where twigs covered with birdlime have been abundantly scattered. This operation must take place about an hour before sunset, if later it would not be successful. This way of catching birds was in use in the days of antiquity, for Aristotle has given us a description of it.

In consequence of the peculiarities of the Owl, it has given rise to more fables and prejudices than any living creature. Although inoffensive in general, and even useful-for they destroy a large quantity of rats and mice-in the rural districts nocturnal birds of prey have occasioned so much superstition and terror, that they have been hunted down with the utmost animosity.

On account of the calm and grave attitude which distinguishes the Owl, giving it the air of a philosopher meditating on the problems of life, the Greeks dedicated it to Minerva.

Mr. Swainson divides Owls into three groups-namely, Typical Owls, Horned Owls, and Hawk Owls ; for simplicity and brevity we prefer making only two families-namely, those with horns and those without.

\section{HORNED OWLS.}

Horned owls are distinguished by two tufts or horns of feathers placed on each side of their head. They are subdivided into many species, five of which-the Great Dwl, Virginian Eared Owl, the Long-eared Owls, Short-eared Owls, and Scops-eared Owl, we will mention.

The Great Owl (Bubo maximus, Fig. 254) is the most remarkable of the family on account of its size and strength. Its height is on an average two feet, and it is justly acknowledged as the king of nocturnal birds. Its bill and claws are of a black colour, very strong and hooked. Its plumage is russet, variegated with black spots and brown stripes; its wings, when extended, are not less than five feet 
across. Its eyes are large and fixed, with black pupils surrounded with yellow. It bears light with less inconvenience than the other nocturnal birds, and therefore goes out sooner in the evening and returns home later in the morning. This bird makes its home among the clefts of rocks on mountain sides, rarely leaving elevated ground

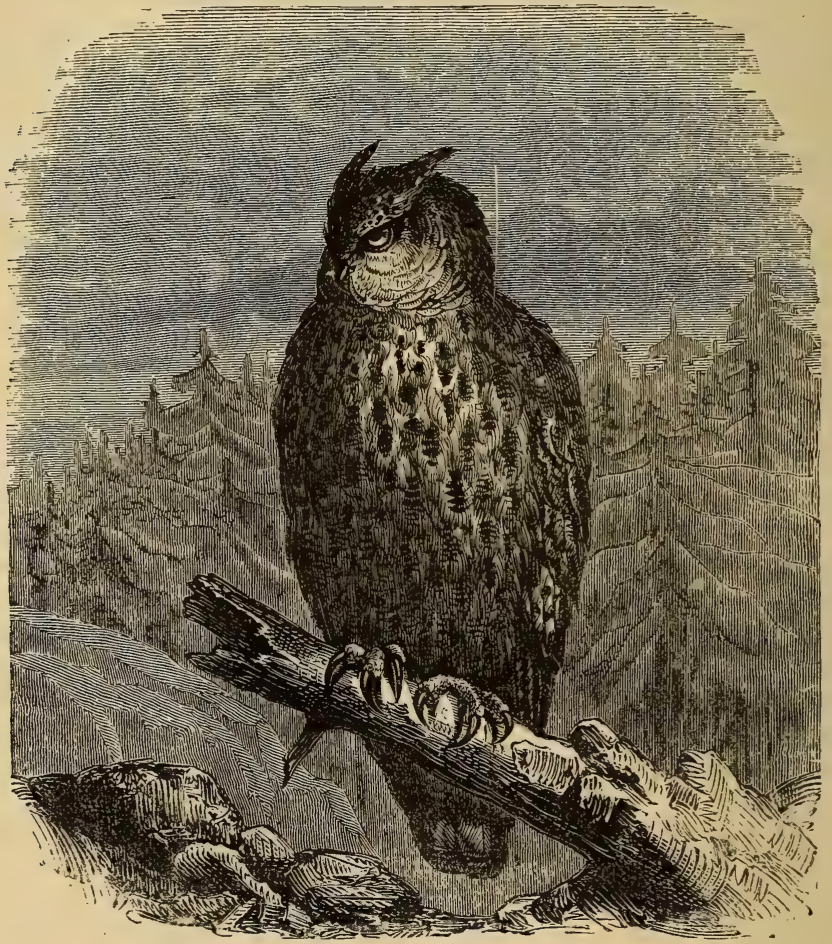

Fig. 254.-Grcat Owl.

to descend into the plain, even when hunting. Its cry, huibou, houhou, bouhou, ouhou, re-echoing in the silence of night, is a source of terror to the rest of the feathered creation. It feeds also upon hares, rabbits, moles, rats, and mice. When rearing its young, which are very voracious, it even devours toads, frogs, and small reptiles. 
The Great $\mathrm{Cwl}$ is very courageous, and often fights with the Tawny Eagle, not unfrequently becoming victor in such contests. The fight is sometimes so severe that it terminates in the death of both combatants.

M. Bailly relates that he was told by reliable witnesses that an Eagle and Great Owl, which were fighting together in the mountains of Savoy, drove their claws so deep into one another's flesh that the belligerents could not withdraw them, so both died on the scene of action. In a similar fight near Zurich a Great Owl, which was the conqueror, was so fastened to its adversary that even after both fell to the ground it was unable to disengage its talons, and in consequence was taken alive.

When wounded so as to be unable to fly, if attacked by dogs, the Great Owl will sell its life dearly; for, turning upon its back, with open claws and menacing bill, it fights its enemies as long as possessed of life.

In spite of this combative disposition, the Great Owl easily becomes tame; even learns its name, and comes at the call of its master. Perfect liberty may then be safely allowed it, as it will remain in the neighbourhood of its home, seldom failing to return at meal-times. Frisch relates that he twice kept birds of this kind, and that they lived for a considerable time; he fed them on ox-flesh. They would sometimes swallow as many as five mice without stopping, having first broken their bones with blows from their bills. In case of necessity they would eat fish. Some hours after taking their food, they ejected the bones and hair of their victims. Instances have been known, however, in which this Owl would not submit to confinement.

The Great Owl is possessed of the strongest attachment to its young. M. Cronstedt, a Swiss gentleman, lived for several years on a farm situated at the foot of a mountain, on the top of which a couple of Great Owls build their nest. The servants caught and shut up in a hen-house one of the young birds, which thirst for rapine had doubtless impelled prematurely to leave the maternal abode; the next morning they were surprised to find at the door of the henhouse a freshly-killed partridge. The idea was that the parent birds, attracted by the cries of the young owl, had thus provided for its sustenance: the same thing occurred fourteen days running. $M$. Cronstedt, wishing to have ocular proof, watched during several nights, in order to surprise the hen bird in this act of maternal love. But he failed, probably because the bird, thanks to its powerful vision, took an opportunity to leave her offspring's provisions at a 
moment when his attention was diverted. These parental attentions ceased in the month of August, when the young bird became capable of providing for itself.

The Great Owl, which is common in Switzerland and Italy, inhabits also Asia. It is not often met with in France, except in the eastern and southern departments, where it rarely remains during winter.

A variety of this species is very common in Egypt, and is sometimes seen in the south of Sardinia and Sicily.

The Virginian Eared Owl (Bubo virginianus, Fig. 255) inhabits North America. This bird is nearly the size of the Great Owl of Europe. It is distinguished from the latter by a different arrangement of the feathered projections on its head, which, instead of starting from the ears, take their rise close above the bill. This bird feeds on young Gallinaceæ, which it boldly carries off from the very midst of the poultry-yards ; to the Turkey it is especially destructive. When other food fails, it feeds on dead fish. If caught when young it is easily tamed, but as it gets mature its bloodthirsty instincts become so powerful that it ultimately proves a most expensive pet.

The Long-eared Owl (Otus vulgaris) is more sociable than most nocturnal birds of prey, and is often met with in the north of France and England. Its habitat is not confined, for it is to be found in Asia, Africa, and America. It is not large, for it seldom exceeds fifteen inches in length; nevertheless, it is possessed of great courage, and attacks successfully birds and mammals of considerable size. Its appetite appears insatiable. The general colour varies from pale to dark brown, marked with dark pencillings. Any nest, even that of the squirrel, suits its fancy, in which it lays four or five white eggs. Although so bloodthirsty, it is easily tamed.

The Short-eared Owl (Otus brachyotus) is about a foot in .height. The horns of this species are much shorter than those of the Longeared Owl. Its length is about fifteen inches; in its plumage russet predominates, shaded with grey and brown. It has a blackish bill and claws, and beautiful yellow eyes. It inhabits hollows in rocks or dead trees, and old ruined houses, and sometimes instals itself in nests left vacant by Magpies, Ravens, and Buzzards. It is much less timid than the Long-eared Owl, and does not possess a protracted flight.

This Owl being very fond of mice, which form its principal food, all that is requisite to attract it to a snare is to imitate the cry of those rodents. It also feeds on moles, and, in cases of emergency, even on frogs, toads, leverets, and young rabbits. Its nest has been 
found in a rabbit-hole. This bird displays much courage in the defence of its young when it thinks them in danger, and does not then fear even to attack man. Its cry consists of a kind of low moaning clow, cloud, which it frequently utters during the night. It is easily

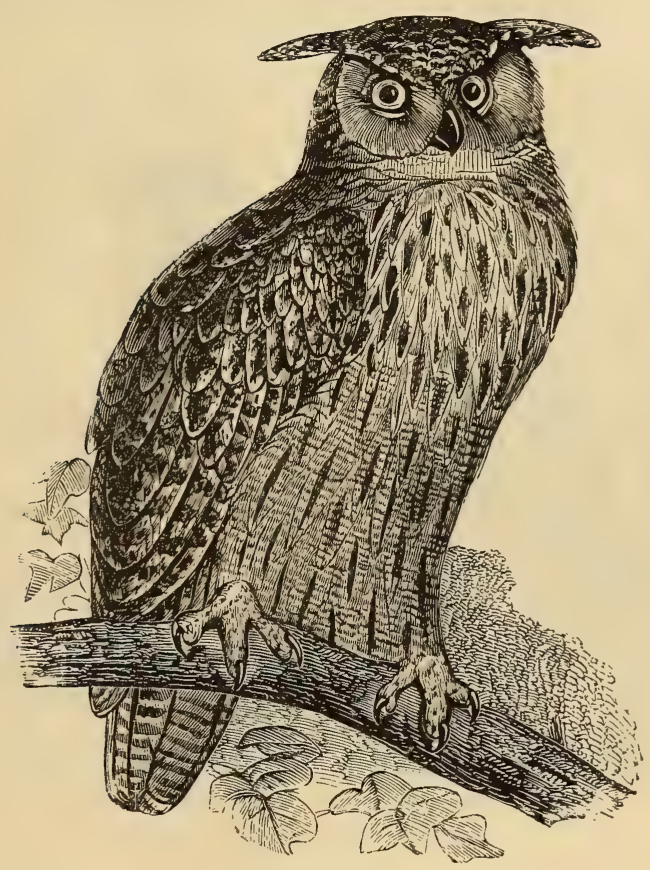

Fig. 255.-The Virginian Eared Owl.

tamed if taken young; but if old when caught, it persistently refuses food.

The Scops-eared Owl (Ephialtes scops, Fig. 256) is remarkable for its diminutive size, which does not exceed that of a Thrush, and for its horns, which are perfectly rudimentary and formed of a single feather. Its plumage, which is beautifully shaded with russet, grey, and black, is more pleasing than that of the preceding species. 
These Owls are more sociable than larger ones, and assemble in flocks in autumn and spring to migrate into warmer climates; they depart after the Swallows, and get to their destination soon after. They are of great service to the agriculturist in destroying field-mice. "At times when this scourge was prevalent," says Buffon, "small Horned Owls have been known to arrive in numbers, and wage such a

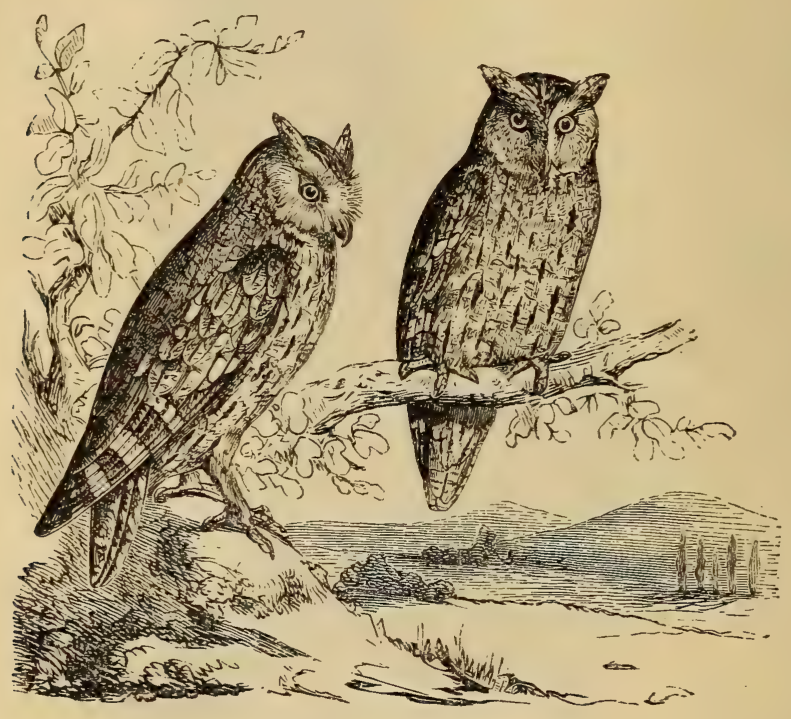

Fig. 256.-The Scops-eared Owl.

successful warfare against the field-mice, that in a few days the ground was cleared of them."

Dale, an English author, mentions another example of the utility of the Scops. In 580 such a large quantity of mice appeared in the plains near South Minster that all the plants were gnawed off by the reots. Soon after, a number of small Horned Owls came in flocks, and destroyed the mice.

When pressed by hunger, the Scops is not above eating fish. It may then be seen hovering over ponds and rivers, and seizing them 
when on the surface with remarkable dexterity. Bats and large insects also are its prey.

It is difficult to kill or catch the Scops, although they travel in numerous companies, for they do not begin their journey until the evening, a short time before night closes in, and secrete themselves in the woods during the day. When they find a place favourable to their habits of life, such as a plain intersected by marshes and small woods, there they remain for two or three days. In the evening they have a strange habit of following people passing through their haunts. Sometimes they precede them, hopping from tree to tree, and uttering low plaintive cries, frequently fluttering round almost sufficiently close to touch them. The Scops is easily tamed, and becomes very familiar, it is consequently in much request in Savoy for the purpose of bird-catching. It perfectly recognises the voice of whoever feeds it, and, although at liberty, will not abandon the house of its master, except when the season of migration arrives, when it would be useless to attempt to detain it; kindness and caresses are then all in vain. So, unless the precaution of shutting it up be taken, it rejoins its companions, and accompanies them, perhaps to Africa or Asia.

There is a variety of this bird, named Scops asio, which is found on the shores of the Ohio and Mississippi, in North America. It is very gentle, and allows itself to be caressed when taken without attempting to bite or scratch. Audubon relates that he carried one of these birds from New York to Philadelphia; he kept it in his pocket during the whole journey, accustomed it to eat out of his hand, and it never attempted to escape.

Several other species of Horned Owls are scattered over the two continents. The most interesting is the exotic species called Choliba, which the inhabitants of Brazil and Paraguay rear in their dwellings to destroy rats and mice.

\section{HoRnless Owls.}

The family of Hornless Owls is distinguished from the horned group by the absence of projecting feathers on their heads. Many species are comprehended in this family, the principal of which are the Little or Sparrow Owls, burrowing Owls, Brown or Tawny Owl, White Barn or Screech Owls, Hawk or Canada Owls, Ural Owls, and Snow Owls.

Sparrow Owls are of small size; their facial disc is incomplete; the tarsi are elongated; the claws bare or slighty hairy; their tails short and square. There are numerous varieties, of which we shall only notice the principal. 
The Common Sparrow Owl (Athene passerina), which is very numerous in France, and, in fact, through the whole of Europe, is about the size of a Thrush. It inhabits old ruins and quarries, but never lives in the hollows of trees ; therefore it rarely makes its abode in the woods. Its nature is much less nocturnal than that of its congeners, and it is often seen pursuing small birds in broad daylight, though probably with but little success. Its general food consists of mice, which it tears in pieces before eating, as it is unable to swallow them whole. It also very skilfully plucks the feathers from birds which become its victims. In winter, when the snow is on the ground, it devours the filth deposited in the farm-yards. Like the Scops, it delights in following persons who pass its retreat, especially at the break of dawn. When flying it utters a cry, poopoo, poopoo! which it substitutes, when perched, for a sound very like the voice of a young Frenchman saying, aime, heme, esme! Buffon relates a curious anecdote on this subject:- " I was sleeping in an old tower of the Château of Montbard, when a little before daybreak, at three o'clock in the morning, a sparrow owl came and perched on the window-seat of my chamber, and woke me by its cry of heme, cdme. As I listened to this voice, which seemed to me all the more singular as it was so near, I heard one of my servants, who was sleeping in a room above, open his window, and, deceived by the well-articulated sound of edme, answer the bird: "Who is down there? My name is not Edme, but Peter.' The servant actually believed that it was a man calling, so much did the voice of the owl resemble that of a human being, and so distinctly did it articulate the word."

The fowlers of Tessin employ the Sparrow Owl for enticing birds into their nets. If taken when young it is easily tamed, and shows itself capable of affection. M. Bailly possessed one which exhibited much pleasure when rubbed on the breast, back, or head, remaining during the operation perfectly immovable, either on its chest or on its back.

In Northern Italy this bird is reared in captivity; it feeds on mice, and even eats fruit and polenta. M. Gérard relates that he reared a Sparrow Owl, which became so tame that it willingly allowed itself to be caressed. It destroyed a great many insects, and ate everything that was given it, but showed such a very decided preference for raw meat that it sometimes, without letting go its hold, hung suspended to a morsel of intestine for more than ten minutes. It was on the best of terms with the cat of the house ; and they were often found lying close together in the same basket. The dog was never able to gain the bird's affections; and a raven, which lived in 
the house by the same right as the owl, was cordially hated by it. It showed much irritation at the sight of other birds, even if they were only stuffed ones ; and when able to obtain possession of them, carried them into a corner, and plucked off their feathers at leisure. It also delighted in rolling in the dust.

Another diminutive species, 'Tengmalm's Owl (Nyctate funerea), inhabits the northern part of the two continents, and sometimes ventures as far south as Germany. Its plumage, which is ashcoloured above, below the chest is dazzling white, marked with spots. It has a white stripe round the front of its neck.

The Pampas Sparrow Owl is found in South America, and is no bigger than a Thrush. This bird, though so small, has stronglydeveloped bloodthirsty instincts; for it slips under the wings of poultry, and kills them by tearing open their sides.

Buffon classes with this species a variety which inhabits the Cape of Good Hope, and is endowed with magnificent plumage, red and black partly mixed with grey. The colonists tame it, and use it to keep their houses clear of mice.

The Burrowing Owl (Athene cunicularia) derives its name from the place in which it makes its nest. This bird is about the size of a pigeon, and frequents the immense plains or pampas of South America and the prairies of North America. However, it does not itself dig the burrows, but simply takes possession of those belonging to the prairie dog, with which it lives on the most amicable terms.

Burrowing Owls are not solely nocturnal, for they love the light of day, and seek their food even when the sun is vertical. It is a curious circumstance, this bird living in association with beings with which it has no natural tie. Captain Francis Head, an English traveller, gives the following description of such a commonwealth :-

"Towards the evening the prairie dogs keep outside their burrows, with a serious look on their faces, like grave and reflective philosophers or moralists. During the day the entrance to their subterranean burrow is guarded by two owls, which never quit their post. While the travellers were galloping over the plain the owls continued their duty as sentries, looking them full in the face, and one after the other shaking their venerable heads in a way which was most ludicrous on account of its solemnity. When the horsemen came near them the two sentinels lost much of their dignified look, and darted hurriedly into the burrows."

This Owl feeds on mice, reptiles, and insects, It is gentle, and 
may be easily tamed, and is sometimes kept for the purpose of destroying vermin.

The first of the next group, which have a complete facial disc and short tarsi feathered down to the claws, is the Brown or Tawny Owl (Surnium aluco). It is commonly called the Wood Owl. Its cry, hoo-00-00! which resembles the howling of a wolf, caused the Romans to call it Ulula, from ululare, to howl.

The Tawny Owl has a large head, and is about fourteen inches in height. It inhabits the woods during the summer, where it conceals itself in the thickest bushes or the old trunks of trees. It remains hidden all day, only going out in the morning and evening to hunt small birds and field mice, its favourite prey. In the winter it approaches human habitations, and even ventures into barns to catch rats and mice; but it retires to its hiding-place as soon as day begins to dawn.

At the beginning of autumn, the education of its young ones being completed, this bird takes up its abode in swamps, where it can catch frogs and reptiles, to which it is very partial. During that season woodcock shooters often flush them.

Like many individuals of the same family, the Barn Owl will lay its eggs in strange nests, such as those of Ravens, Magpies, and Buzzards. The young ones are very voracious. Before they are strong enough to stand upon their feet they will support themselves on their stomachs, and, holding their prey in their claws, tear it to pieces with their bills; when they become stronger, they stand on one leg, and use the other to convey food to their mouths. A proof of the determined courage of these birds is given in the Field, wherein a pair attacked a cat that had approached their nest, and ultimately destroyed the intruder.

This owl is easily tamed, when it learns perfectly to know its master, and will call to him for fond by uttering low cries. It is found scattered all over Europe, and frequently in Scotland.

The Barn Owl, also known by the name of White or Screech Owl (Strix flammea, Fig. 257), is found over a great portion of Europe, but in France it is rare. There are several varieties of this bird; the one best known in England has the following characteristics:Its plumage is agreeably variegated with yellow, white, grey, and brown, and is more pleasing than that of any of the other nocturnals. The eggs, which are elliptical, are generally five in number, sometimes six or seven, and are deposited in holes in walls, deserted buildings, or hollows in rocks and old trees; but the bird does not take the trouble to line these places with grass or leaves. It is but 
seldom it takes possession of the nests of other birds, although stories are told of its driving away the Martins from their retreats, and installing itself therein, having first considerately devoured the young.

Children, women, and even men who are silly enough to believe in ghosts and sorcerers, look upon the barn owl as a bird of ill omen, and as a messenger of death. All these prejudices are really very foolish, for few birds are of more service. They destroy a vast quantity of vermin which are injurious to agriculture, and therefore have a good claim to protection. When the owl has young ones to feed, rats and mice are exterminated without either truce or mercy. As rapidly as they can be caught they are carried to the nest ; and each of the pellets of bone and hair which are thrown up from its stomach is composed of at least six or seven skeletons. Dr. Franklin collected, in the space of sixteen months, a whole bushel measure of these pellets, all proceeding from a couple of Barn Owls.

Farmers are in error when they accuse the Barn Owl of destroying

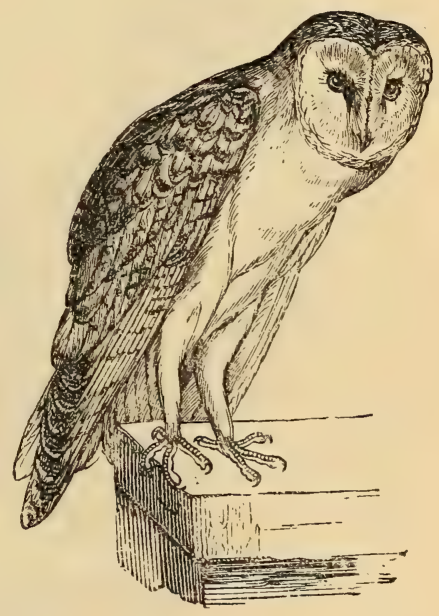

Fig. 257--Barn Owl. their pigeons' eggs. The real culprits are the rats. When an Owl makes its appearance in the vicinity of a dovecot, the proper course of conduct is to give it a kind reception and to protect it, for its only object in coming is to obtain shelter for a time, and, during its stay, to destroy rats or mice, the real scourges of the pigeon-house.

When the Barn Owl finds a deficiency of food it has recourse to fishing. It may then be seen hovering over water to capture fish which are floating upon the surface.

The Chinese and Tartars pay special reverence to this owl, in memory of a fact which well deserves to be recorded. Gengis Khan, the founder of their empire, having been put to flight by his enemies, was one day compelled to take refuge in a wood, when an owl came and perched in the thicket in which he had hidden himself; this was the sole cause of his escaping the pursuit of his foes; for those who 
were searching for him very naturally omitted to explore the bushes in which he was concealed, thinking that it was impossible that a covert should at the same time shelter both an owl and a man. Thus, thanks to the intervention of the bird, Gengis Khan was saved from his pursuers. In memory of this event the Chinese were in the habit

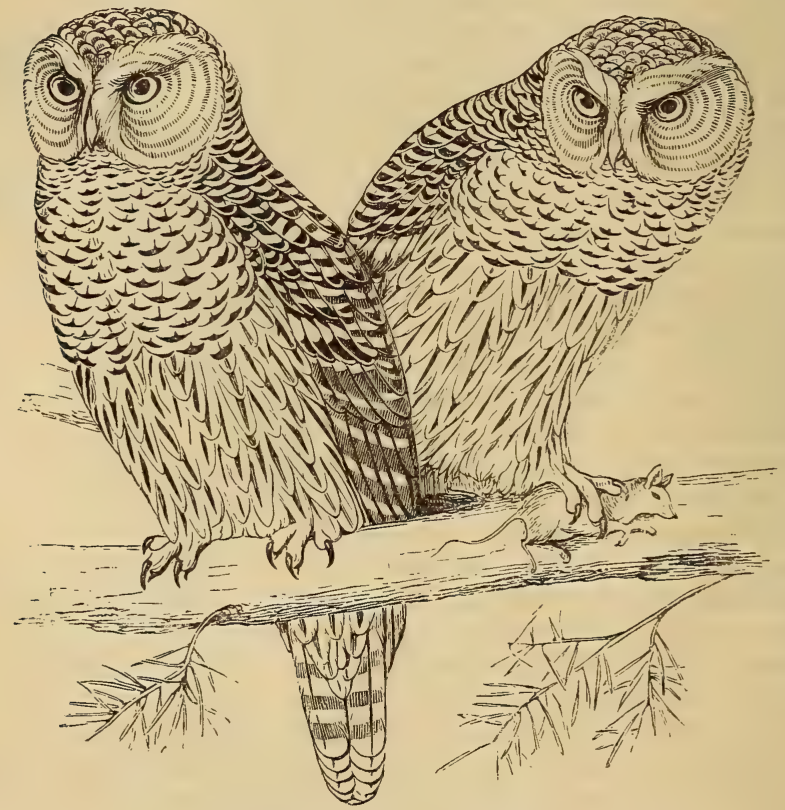

Fig. 258.-The Hawk or Canada Owl.

of wearing on their heads an owl's feather. Certain tribes of the Calmucs have an idol representing an owl.

The Hawk Owl (Surnia ulula, Fig. 258), well known in North America, especially in Canada, appears casually in the north of Europe, and is common in Siberia. Its plumage is of a greyishbrown colour. It feeds on hares, rabbits, rats, mice, reptiles, and birds; it is about fifteen inches high. Audubon often had an opportunity of studying its peculiarities. 
"Its cry," says he, "is wach, waahha, which one is tempted to compare with the affected laugh of a votary of fashion. Often in my distant excursions, when encamped under the trees, and roasting a slice of venison or squirrel by means of a wooden spit, I have been greeted with the laughter of this nocturnal disturber. It stopped at a few paces from me, exposing its whole body to the gleam of my fire, and looking at me in such an odd way, that had I not feared to make a fool of myself in my own eyes, I should have politely invited him to come and partake of my supper. This bird visits Louisiana, and is met with in all the most isolated woods, even in open day. If it appears likely to rain, it laughs louder than ever; its waah, waahha, penetrates into the most remote recesses of the woods, and its comrades answer it in strange and discordant tones; one might almost think that the owl nation was celebrating some extraordinary fête."

Audubon adds that when you approach one of these birds it thoroughly scrutinises you, assuming at the same time the most grotesque attitudes. If any one fires at it and misses, it flies away, but stops at a little distance and utters its mocking cry.

The name Hawk Owls has been given to this genus, as it serves as a transition from the nocturnal to the diurnal birds of prey. In fact, although by their general shape and physical conformation they evidently belong to the former, they are also connected with the latter by their habits and mode of hunting, which are very like those of the Sparrow Hawk; hence their name. They are easily recognised by their long and tapering tail, and by their free and bold gait. They form a very characteristic group, and the species, which are four in number, present but little diversity.

The White Owl (Nicteivea), sometimes called the Harfang, can be tamed; but it must not be closely confined. It requires both air and space to move about at will. Under these conditions it constitutes a useful auxiliary to the farmer, and will advantageously take the place of several cats, for it possesses great strength and equal courage; but if it is kept in a cage it refuses food, and dies after a few days' captivity.

The White Owl may be found in all parts of Europe, Asia, and North America. Its plumage is a brilliant white, with some black spots on the head. This colour is well suited to the nature of the places in which it lives, for it sometimes inhabits the most desolate solitudes to the north of America: Newfoundland, Hudson's Bay, Greenland, Iceland, and the neighbouring islands. Thanks to its colour, which harmonises so perfectly with all around, it is enabled 
to traverse almost unseen the immense deserts of snow, and thus has great facilities for surprising its prey, which consists of Hazel Hens, Ptarmigan, Grouse, Hares, and Rabbits. Owing to its abundant plumage and thick down, it is capable of braving the inclemency of a climate that would be fatal to any creature less amply protected.

The fact is attested by the statement of Captain Parry, of Arcticregion celebrity, that this bird frequently dies of starvation. Sometimes it shows so much audacity and greediness that it is impossible to entertain any doubt on the subject of its hunger, as it will pounce on the game shot by the sportsman, totally disregarding human presence.

The Caparacoch Owl, called by Buffon the Great Canadian Sparrow Owl, measures about fifteen inches. In summer it feeds upon small rodents and insects ; in winter on Ptarmigan, which it accompanies in their migrations from the South to the North. It will sometimes pounce down on the game which is killed by the sportsman, and, if care is not taken, will carry it off. It is a native of the Arctic regions, especially those of America. Sometimes it penetrates as far as Germany, but rarely makes its appearance in France.

The Ural Owls have the same habits as the Harfang, only their geographical distribution is less extended. Naturalists regard them as one of the rarest of European Owls. As their names indicate, they are peculiar to certain countries. They have not the dazzling whiteness of the Harfang $\mathrm{Owl}$; and this is the characteristic which specially distinguishes them.

We may class in the same genus two exotic species discovered by Levaillant. These are the Choucou, which is a native of Africa, and the Huhul Owl of Guiana, which hunts its prey in open day.

\section{Diurnal Bikds of Prey.}

All that we previously remarked, when commencing the consideration of this order, as to the general characteristics which distinguish birds of prey, applies more particularly to the nocturnal portion of them. We shall not repeat here what we have alrearly stated, but only add a few words, the better to specify the diurnal division of the order.

The diurnal birds of prey have their eyes placed at the sides of the head, and the toes completely bare. They vary in size from those the spread of whose wings is scarcely twelve inches to such as stretch their pinions over a space ef four or five yards. They lay their eggs, which are generally of an oval shape, in rude nests called "aeries." 
The diurnal section of the Rapacious order is divided into three families: the Falcons, the Vultures, and the Serpent-eaters.

\section{FALCONIDE.}

The Falcon tribe have a very strong and comparatively short beak, which is generally curved from the base, with denticulated or scalloped edges; the head and neck covered with feathers; the talons very powerful, and furnished with retractile nails-not, indeed, in the same manner as cats, which have the power of withdrawing. or sheathing theirs within the integuments, but by a conformation which gives the bird of prey the power of elevating its claws at pleasure.

These are the birds of prey par excellence. They feed for the most part on living animals; there are, however, some which, when other means of sustenance fail, devour putrefied flesh. Their flight is very rapid, and they ascend to immense altitudes. They are seldom to be seen on the ground; if they settle there it is but to seize their prey, which accomplished, they without delay take wing to their aerie. They lay at the utmost three or four eggs. Their plumage alters considerably during their early years; to such an extent, indeed, does this occur, that the young and the adult birds have often been taken for two distinct species. This fact has not a little contributed to confuse students of ornithology.

This family is a very numerous one, comprising no less than nine genera ; namely, Eagles, Sea-eagles, Harpy Eagles, Caracara Eagles, Hawks, Goshawks, Kites, Harriers, and Buzzards.

The Eagle genus is characterised as follows :-The bill scalloped, but not toothed, and presenting a straight portion at the base; the nostrils elliptical and transverse ; the tarsi short, and feathered down to the toes; the wings long; and the tail rounded.

Buffon has sketched a portrait of the Eagle, but his picture is by no means a model of accuracy :-

"The Eagle," he says, "both physically and morally, presents several points of harmony with the Lion. In the first place, in strength, and consequently in an empire over other birds, as the Lion over beasts. In magnanimity ; for he, too, disdains small creatures, and despises their insults. The Eagle will for a long time bear with the troublesome cries of the Crow and the Magpie ere he makes up his mind to punish them with death. Added to this, he covets no good things that he has not conquered for himself, and no other prey than that of his own catching. In temperance; for he scarcely ever eats the whole of his victim, and, like the Lion, leaves the fragments 
for other creatures. However great may be his hunger, he will never feed upon dead carcases. Again, like the Lion, he lives a solitary. life, inhabiting a desert, into which he allows no other bird to enter, and in which he himself must be the sole hunter; for two pairs of Eagles in the same mountain district are perhaps a rarer sight than two families of Lions in the same part of a forest. They keep at a sufficient distance from one another, so that the space allotted to them should furnish each an ample subsistence; and the extent of their demesne is regulated by its productiveness. The Eagle has a flashing eye like the Lion, and is nearly of the same colour; has claws of a similar shape, a breath equally rank, and a cry equally frightful. Both seem as if they were made for combat and the pursuit of prey; both are alike inimical to companionship, alike ferocious, alike proud, and difficult to tame."

Buffon has much overrated the character of the Eagle ; it will be well to reduce it to somewhat more just proportions. Agreeing with the immortal naturalist, we admit that the Eagle is endowed with no common amount of strength. With regard to its magnanimity we must be allowed to entertain a doubt. As a matter of fact, the Eagle always attacks animals which are unable to resist it; if it disdains small birds, it is because they can easily evade its pursuit, and after all, there would be but little profit gained if they were caught. As to its moderation, it is easily proved to have no existence save in the imagination of the distinguished naturalist. On the contrary, the Eagle is voracious; it never leaves its prey until it is completely surfeited, and then only because it is unable to carry away the remainder. So far from despising dead carcases, it will readily feed upon them, even when it is not compelled by need, for it will gorge itself on carrion to such an extent that through surfeit it frequently becomes incapable of avoiding its enemies. Its honesty, too, is a fact not better established, for the Fish Eagle pursues birds that are weaker than itself, and, in defiance of all justice, takes from them the booty which they have acquired through labour.

By. a kind of rhetorical metaphor the Eagle has been proclaimed "the king of birds." If the possession of strength, and the abuse which is made of it, constitute the attributes of royalty, the Eagle has an unquestionable right to the title; but if with the kingly rank we connect the ideas of courage and nobility, it would never do to place the crown on the Eagle's head.

The ancients were inspired with a juster sentiment in making the Eagle the symbol of victory. The Assyrians, the Persians, and the Romans placed an Eagle with outspread wings on the top of their 
standards ; and even in modern times we find a representation of this bird filling the same emblematic post in the armies of several European nations. Some, as Austria, instead of one Eagle, adopt two as their allusive emblazonry.

In consequence of the Eagle mounting up to such prodigious heights the ancients looked upon it as the bird of Jupiter and the messenger of the gods. When Jove, after the withdrawal of Hebe, came down to earth to seek for another cup-bearer, he changed himself into an Eagle, and it was under this shape he carried off Ganymede.

But we must leave mythology and symbols, and turn our attention to a matter-of-fact description of the great bird of prey.

In the Eagle the sense of vision is developed to its very highest excellence. Contemplate him hovering majestically among the clouds, and you will be struck with admiration. By an imperceptible motion of his wings he maintains this prodigious height without fatigue. Perceiving a Hazel Hen on the heath below, he folds his wings, and in a few seconds drops down to within a short distance of the ground; then, with his legs stiffened, he swoops upon his prey, seizes his victim, and carries it away to some adjacent mountain.

The great strength of the muscles which work the wings of this bird (Fig. 259) will explain the power and long duration of its flight.

The Eagle is endowed with such an enormous amount of muscular force, that it contends successfully against the most powerful winds. Raymond, the naturalist, who has been styled "the painter of the Pyrenees," relates that, having reached the summit of Mont Perdu, the loftiest peak of that range, he perceived an eagle pass over him at surprising speed, although it was flying against a gale of wind.

If to the weight of the body of the Eagle we add that of the victim which it clutches in its talons ; if we consider that this victim is often borne by it to considerable distances, and that the Eagle will thus cross the chain of the Alps; if we also reflect that the prey is not unfrequently a chamois or a sheep, we shall be enabled to form some idea of its strength and muscular power.

The size of the Eagle varies according to the race, but all attain imposing dimensions. The female of the Golden Eagle measures three feet nine inches from the tip of the beak to the points of the feet, and the spread of its wings is nearly ten feet. In the Imperial Eagle the spread of the wings is only six feet, and in the small Marine Eagle four feet four inches.

It has been stated that the Eagle can travel sixty-five feet in a second, which would give a speed of forty-four miles an hour; but 
Naumann positively contradicts this assertion. It is at all events a matter of certainty that the flight of this bird is very rapid. An Eagle. has been noticed circling over a hare in a field, and hemming it in, so that the victim was unable to escape on either side, always finding its enemy in front.

The Eagle builds its nest in the clefts of the most inaccessible rocks, or on their edge, that its brood may be safe from danger or surprise. This nest is nothing but a floor, made of sticks placed carelessly side by side, bound together with some pliable branches, and lined with leaves, reeds, and heather. However, its solidity is sufficient to resist for years the decay caused by time, and to bear

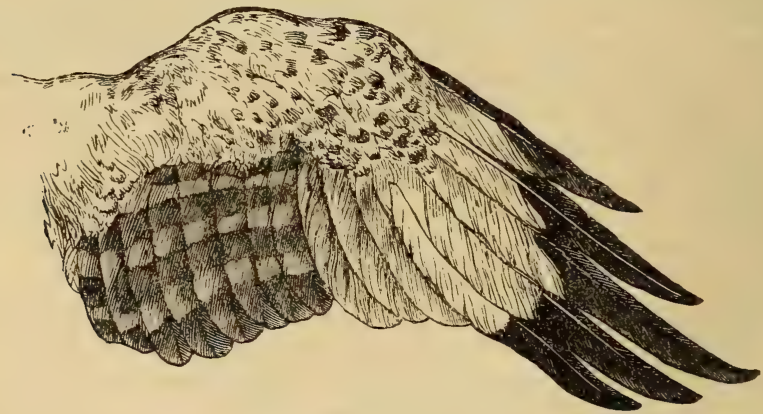

Fig. 259.-Wing of an Eagle.

the load of four or five birds, weighing combined from seventy to eighty pounds, with the provisions brought for their sustenance. Some eagles' nests have an area of as much as five feet square. The number of eggs laid is generally two or three, rarely four. Incubation requires thirty days.

Their young being very voracious, the parent birds are compelled to hunt with great assiduity. Nevertheless, should scarcity occur, the brood do not suffer in proportion, for Nature has endowed them with the faculty of supporting abstinence for many days. This peculiarity they possess in common with all birds of prey. Buffon mentions an Eagle which, having been taken in a trap, passed five weeks without anything to eat, and did not appear enfeebled until the last eight days. An English author states that for twenty-one days a tame Eagle was not fed, and that the bird appeared to have suffered little from its protracted fast. 
When the young are large enough to provide for their wants they are driven from the paternal home; when they proceed to an unoccupied district of country, of which they take possession.

The Eagle is, as we have before said, endowed with immense muscular vigour ; it is, therefore, able to carry off prey of considerable size. In the mountains in which chamois are abundant they are the principal objects of the eagle's pursuit, and it employs various stratagems to get these animals into its power; for the bird will not venture to make its attack in front, as the chamois is well able to bid it defiance with its horns, provided its rear is protected.

It is stated that a blow from an Eagle's wing will deprive a kid of life ; it is not therefore surprising that its strength enables it to carry off young children.

Many for a long period have refused to give credence to this fact; but the evidence of persons who are worthy of all confidence will not allow of any doubt being raised on the subject. We will, however, mention a few instances.

In the Canton of Vaud two little girls, one three years old and the other five, were playing together in a meadow. An Eagle swooped down upon the eldest, and carried her off. All that immediately afterwards could be found upon a most active search was a shoe and stocking belonging to the child. Two months having elapsed, a shepherd discovered the remains of the little victim, horribly mutilated, and lying upon a rock half a league from the meadow from which she was taken.

In the Isle of Skye, in Scotland, a woman left her child in a field. An Eagle carried off the little one in its talons, and crossing over a broad lake, laid it upon a rock. Fortunately the robber was perceived by some shepherds, who came up in time to succour the infant.

In Sweden a babe was carried away under somewhat similar circumstances. The mother, who was only a short distance off, heard the shrieks of the poor little thing; but it was impossible for her to rescue it. It was borne out of her sight, and the wretched woman went mad with grief.

In the Canton of Geneva a boy of ten years old, who was robbing an Eagle's nest, was seized by one of the birds, and borne to a point 600 yards from the spot. He was rescued by his companions without having suffered further injury than some severe wounds inflicted by the bird's talons.

In the Faroe Isles an Eagle flew away with a child (which its mother had left for a few moments), and bore it off to its aerie. Maternal love inspired the unfortunate woman with such a degree 
of strength as to enable her to reach the nest; but, alas! to find her child lifeless.

Near New York, in America, a lad of seven years of age was attacked in a harvest field by an Eagle, while the labourers were absent for their mid-day meal. The boy having avoided the first shock, the Eagle persevered in its onslaught; but he waited for it bravely, and gave the bird a vigorous blow under the left wing with a sickle, which killed it. When the stomach of this Eagle was opened it was found entirely devoid of food. The bird was, therefore, in a famished state, and consequently enfeebled. Its persistent boldness is thus explained, and also the ease with which it was mastered.

We must, however, confess that cases of children being carried nway by Eagles are rare, for they generally avoid the vicinity of man, feeling unable to cope with them successfully. The chief objects of their attacks are newly-born lambs, which they frequently take in spite of the shouts of the shepherd and the proximity of his dogs. Sometimes they devote their attention to young calves; they do not, however, attempt to transport them to their aerie, but feed on them where slaughtered.

A considerable amount of ingenuity has been displayed by some men in turning to account the habit which Eagles have of storing up a quantity of provisions in their nests for the sustenance of their young. A peasant in Ireland kept himself and the whole of his family for an entire season by robbing the eaglets in a neighbouring aerie of the stores of food which were brought to them by the parent birds. In order to prolong this singular means of livelihood, report says, he endeavoured to delay the moment when the young ones would be driven forth, adopting the artifice of cutting their wings to render it impossible for them to fly.

Eagles are very suspicious, and it is consequently difficult to get within gunshot of them. The mountaineers of the Pyrenees suffer much from the ravages they make among their flocks, and for this reason brave many dangers to prevent their increase.

"This pursuit," says M. Gérard, "is carried on by two men; one of the hunters is armed with a double-barrelled carbine, the other with an iron pike several feet long. At the first indication of daybreak the hunters reach the mountain-peak where the Eagle has his aerie, just at the time that the old birds are away seeking food. The first stands on the summit of the rock, and, carbine in hand, waits the arrival of the Eagle. The other makes his way down to the nest, climbing from cleft to cleft by means of cords. With a bold hand the eaglets are grasped, still too young to oppose resistance. The 
parents, hearing the cries of their young, swoop down furiously, and fall upon the intrepid mountaineer, who beats them off with thrusts of his pike, whilst his companion waits a favourable opportunity to deliver his fire, which generally terminates the contest."

The Eagle has been taken in snares; but if the instrument is not fastened down securely to the ground, the bird will tear it up and bear it off. Meisner relates that an Eagle, having been caught by the foot in a fox's trap, struggled with such effect that it wrenched up the trap, and carried it away to the other side of the mountain, although the instrument weighed nearly nine pounds.

The Scotch employ a peculiar method for capturing Eagles. In a narrow space, bounded by four tolerably high walls, they throw down pieces of raw meat. The Eagles settle to devour it. When completely gorged they become too heavy to fly, and endeavour to make their way out through an opening at the foot of the walls, where they are caught and held fast by a running noose, which is placed in front of the exit.

The Eagle is remarkable for its longevity; but this cannot be accurately determined. Klein mentions an instance of one of these birds which lived in captivity in Vienna for 104 years; he also speaks of a pair of Eagles in Forfarshire, in Scotland, which inhabited the same aerie for such a length of time that the oldest inhabitants remembered them from childhood.

If captured young, Eagles are susceptible of a certain amount of education; but there always remains a tinge of ferocity in their nature, which renders them gloomy and sullen. When taken old they are absolutely untamable. In captivity they adapt their appetite to circumstances, and will even devour their own race. When nothing better is to be obtained, serpents, lizards, and, according to Buffon, bread are acceptable food to them.

Although the Eagle is so irascible by nature, it has sometimes given proofs of gentleness truly astonishing. We may instance the bird which lived in 1807 in the Jardin des Plantes, in Paris, which was captured in the forest of Fontainebleau. One of its feet was broken in the trap in which it was taken, and in consequence it was compelled to submit to a most painful operation, which it underwent with exemplary calmness and courage. Fully three months elapsed before it was cured, and afterwards it became so familiar with its keeper that it allowed itself to be caressed by him, and on his retiring for the night the bird roosted by his couch.

The ancient falconers of the East were not in the habit of making use of the Eagle; its want of docility and its great weight rendered. 
it but little adapted to their purpose. Thus they rather unceremoniously class the Eagle among the ignoble birds.

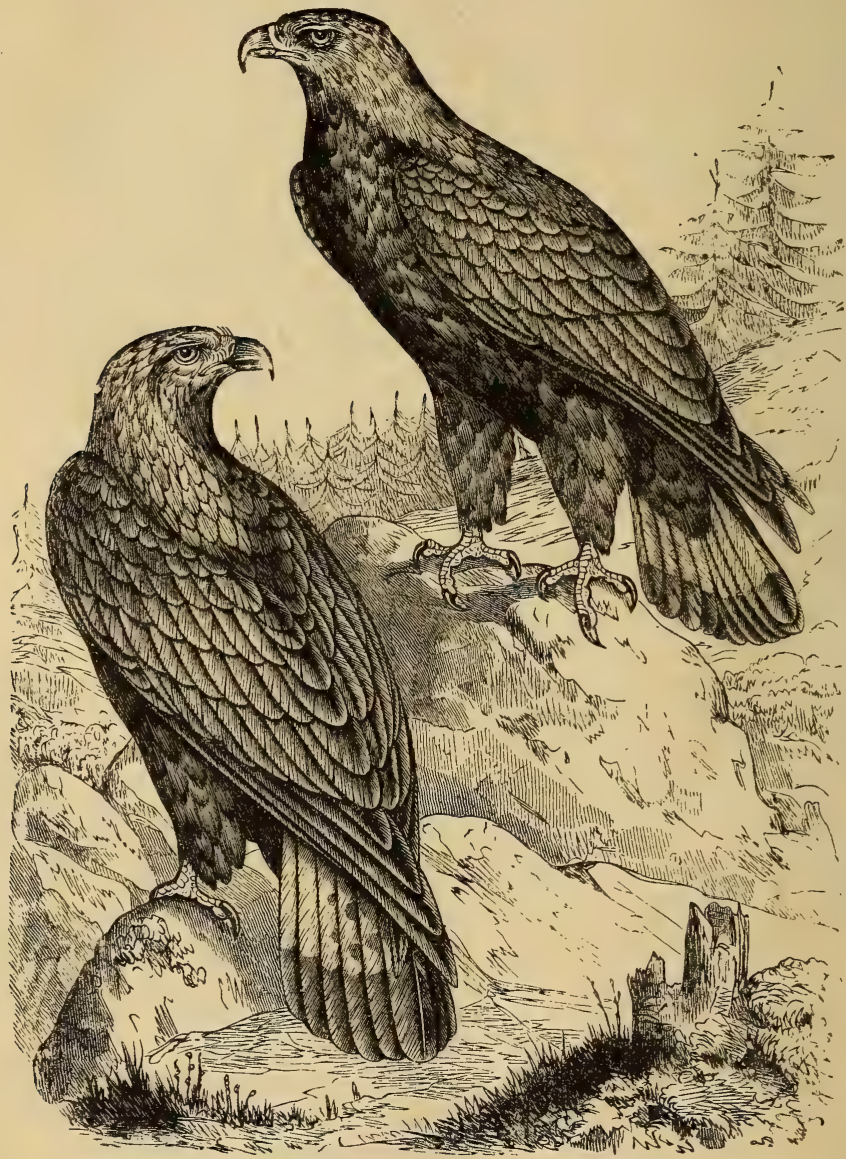

Fig 260.-Giolden Eay' es.

The Tartars, however, are in the habit of using an Eagle indigenous to Central Asia to assist in taking the hare, tox, antelope, and 
wolf. As this bird is weighty, they do not hold it on the fist, but place it in front of their horse's saddle. This species, called the Bere-

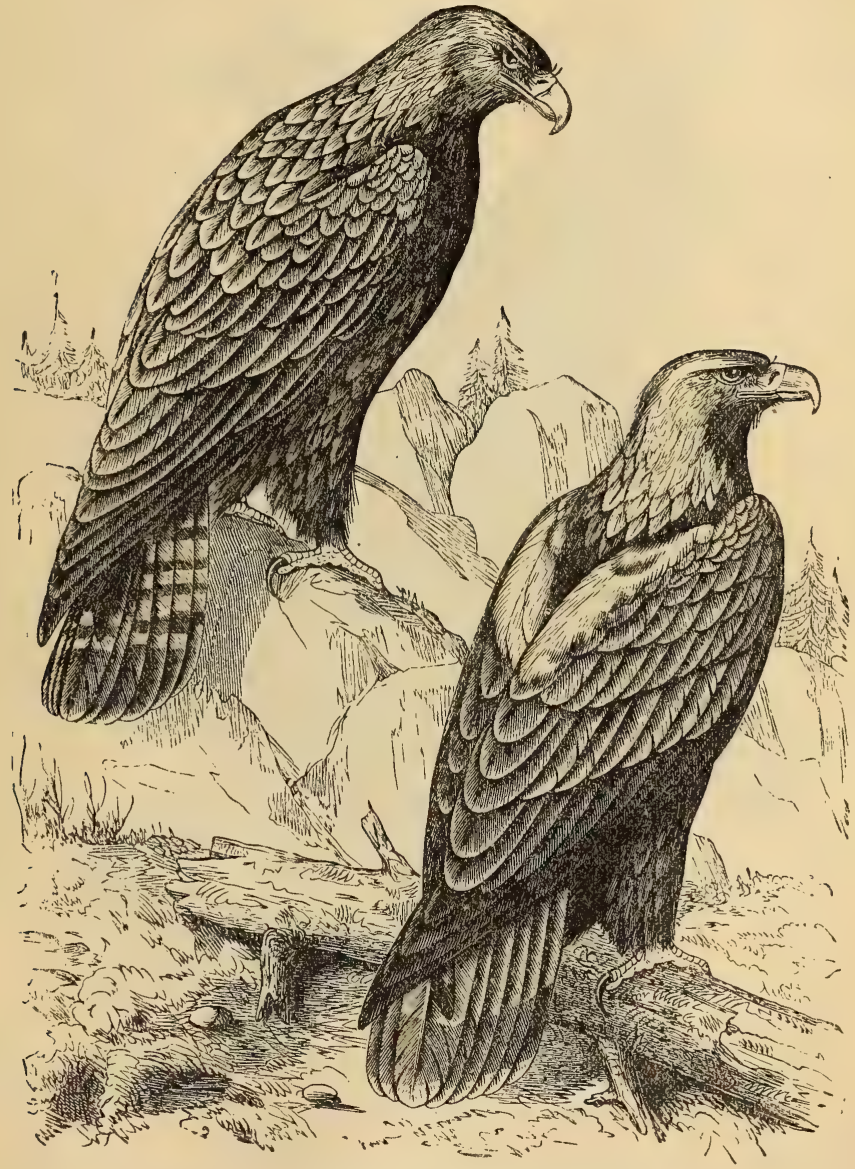

Fig. 26r.-Imperial Eag'es.

coot, which is scarcely known by Europeans, is of great power and courage. A well-known traveller describes a scene he witnessed on 
the steppes of Tartary, where a pair of them attacked and killed a brace of wolves with the greatest apparent ease.

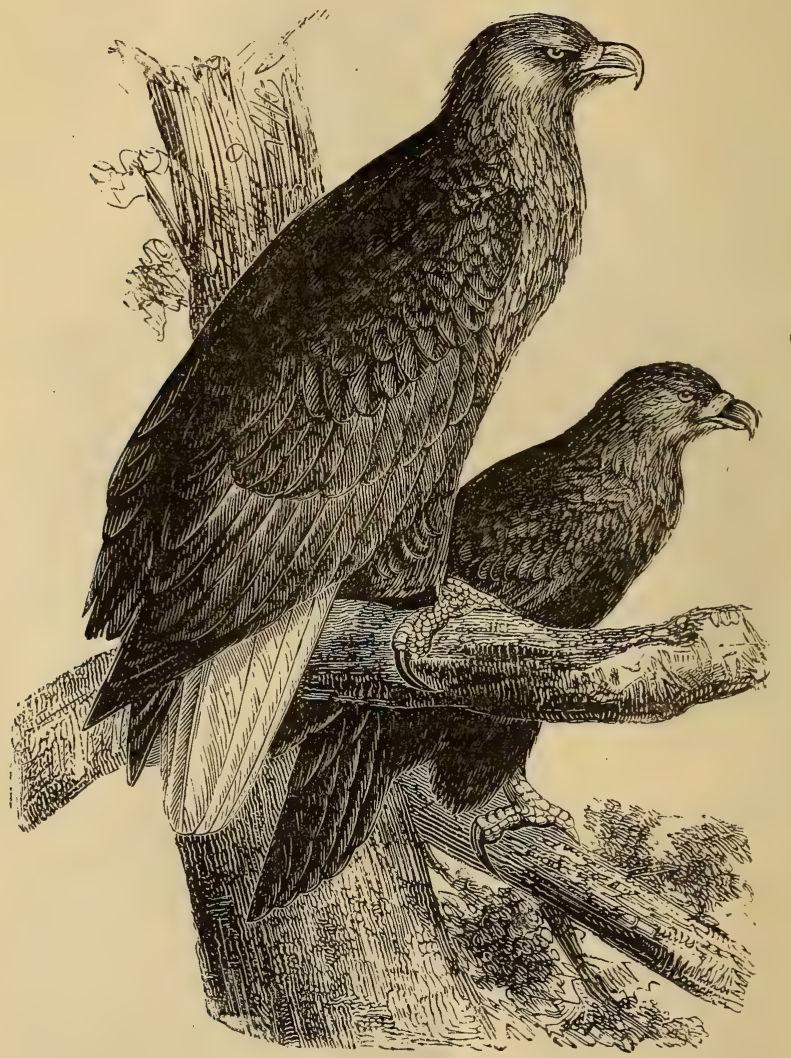

Fig. 262.-European Sea Eagles.

The Eagle is cosmopolitan, and may be found in all parts of the globe. There are numerous species, the principal of which we shall merely make mention of, because the habits of all are so exceedingly similar. 
The synonyms here given are those used in the classification of the British Museum. The Royal-Eagle (Fig. 260), called also the Golden Eagle (Aquila chrysactos), attains a greater size than any other; it is a native of the north and east of Europe. The Imperial Eagle (A. mogilnik, Fig. 26r) is found in the east and south of Europe, and also in North Africa. The Bold Eagle $(A$. audax $)$.

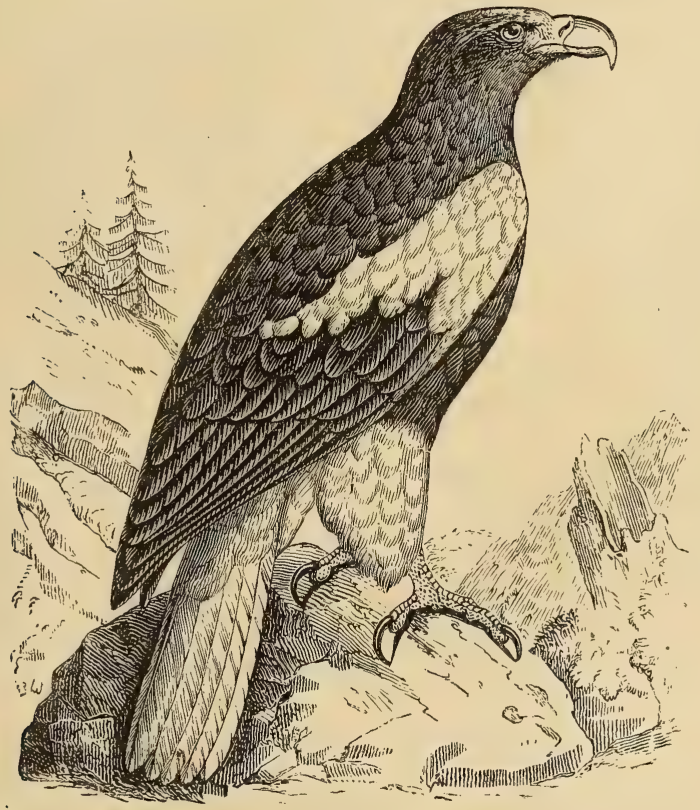

Fig. 263.-Bald or White-headed Eagle.

Bonelli's Eagle (A. Bonellii) inhabits southern Europe, particularly Greece. The Tawny Eagle (A.ncerioides) is to be met with in all the mountainous and woody countries of Europe. The Booted Fagle $(A$. pennata $)$ lives in the east and south of Europe, and occasionally makes its appearance in France. Reinwardt's Eagle (A. malayensis) is found in the Malay peninsula and islands; and the Martial Eagle (Spizotus bellicosus) is a species peculiar to South Africa, and of which Levaillant was the first to point out the peculiar characteristics. 
The diurnal birds of prey belonging to the order of Sea or Fishing Eagles are distinguished from Eagles proper by their tarsi, which are feathered only in the upper part, as well as by their feeding principally on marine animals.

\section{Sea Eagles.}

Their name, Pygargus, which is derived from the Greek, means "white-tail." They generally frequent the sea-shore, where they feed on fish and aquatic birds; and they occasionally pursue small mammals, and even devour putrefied flesh. Their claws are very powerful, and the strength of their vision is so great, that they can see their aquatic prey swimming under the surface of the water. The rapidity with which they descend through the air when striking at their quarry is so wonderful, that many have compared it to lightning. They even venture to attack the seal, but as they cannot lift their victim, they cling to its back, forcing it on shore by means of their wings. But this excess of boldness has been known to be fatal to them ; large seals are strong enough to dive and drag their foe under water, where the eagle meets with a miserable death; for, having buried its claws deeply in its quarry, it is often impossible for it to disengage itself.

Sea Eagles hunt in the night as well as day. They attack seabirds weaker than themselves, and take from them their food. They are indefatigable in pursuit of Vultures, which they make disgorge, and afterwards appropriate the results. Audubon observed, on the shores of the Mississippi, a Sea Eagle pursuing a Vulture which had just swallowed some intestine. Part of this protruded from the Vulture's bill ; the Sea Eagle seized it, and forced the original possessor to give it up.

The Sea Eagle of Europe (Haliatus albicilla, Fig. 262) lives in the coldest regions of the North. It is common in Sweden and Norway, where it builds. Its aerie is about two yards wide, and is generally situated in the forests bordering on the sea or great lakes. It visits the French coasts in the autumn, following flocks of geese which are migrating to the south; and it is again seen in the spring, on its return to the high latitudes. In Russia the special conditions of existence somewhat modify the habits of this bird, where, living in the midst of the vast steppes, it feeds, not on fish, for that is unprocurable, but on small quadrupeds, birds, and carrion. This bird nearly attains to the size of the Golden Eagle.

The Bald or White-headed Eagle (Haliatus leucocephalus, Fig. 263) is a native of North America. It builds its nest on the summit of 
the highest trees. Its flight is as powerful as that of the Golden Eag.e, and its strength and adroitness are even greater.

This Eagle is represented on the flag of the United States. The illustrious Franklin with sorrow regretted the selection his nation had made.

"It is a bird of low and evil nature," wrote Franklin, in one of his letters; "it does not know how to gain its livelihood honestly. Added to this, it is nothing but a cowardly rogue. The little Wren, which is not so large as a sparrow, resolutely attacks it, and drives it from its haunts! Thus, in no point of view is it a suitable emblem for a brave and honourable nation."

The varieties of this family are numerous on the North American continent, but the distinctions are not sufficiently great to deserve particular notice. Those from other portions of the globe most worthy of attention are the Marine Eagle (Pandion ichthyaëtus), which inhabits Java; the Piscivorous Sea Eagle (Cuncuma vocifer); the Caffir Sea Eagle, discovered in Africa by Levaillant ; the Sea Eagle of Mace (C. Macei); and the Pondicherry Eagle, called by some the Sea Eagle of India, which inhabits India and Bengal, where the bird is an object of veneration among the Brahmins, being consecrated to Vishnu.

We shall class with the same genus the Osprey (Pandion halicetus), which, although different from Sea Eagles in certain details of organisation, is, however, allied to them by its aquatic habits. It prefers the neighbourhood of lakes and rivers to the sea-shore. It is frequently mistaken for the Sea Fagle. Wild fowl and carrion are sometimes its food, but fish forms the principal portion of its diet. It does not always enjoy the fruit of its labour, for the Sea Eagle frequently forces it to abandon its prey, which, if dropped in the air, will be adroitly re-seized by the robber in its descent.

The old naturalists, Aldrovandus, Gesner, Klein, and Linnæus, s.nctioned a singular error concerning the organisation of this bird. From the fact that it sometimes dives into the water to catch fish, they imagined that it had one foot webbed for swimming, and the other furnished with prehensile claws for seizing prey. The River Osprey is about a third smaller than the Sea Eagle. It is found all over Europe, but especially in Germany, Switzerland, and the east of France, and also in the Canadas and United States.

The birds which form part of the genus Morphnus (Cuvier) occupy a middle position between Eagles and Hawks, of which we shall speak further on. They are characterised by a full and rounded tail, comparatively short wings, and the existence of a tuft 
on the back of the head. This latter feature, although general, is not, however, common to all the species.

These birds inhabit the forests of Africa and South America. They are admirably organised for strife and slaughter, and are the terror of all animal life in their neighbourhood.

The Huppart (Falco occipitalis), thus named on account of its huppe, or tuft, which is about six inches long, is a native of Africa, and feeds on hares, ducks, and partridges. It also pursues crows, for which it feels a deadly hatred, as these birds sometimes league together to deprive it of its prey, and even to devour its brood. It will not suffer any rival in its domain, but accords protection to small birds which come near to its nest to seek a shelter from the attacks of inferior birds of prey.

The Brazilian Eagle or Urubitinga (Morphnus Urubitinga), inhabits Brazil and Guiana; it is eminently wild and taciturn, and builds its nest in the vicinity of marshes. It feeds on birds, small mammals, reptiles, and even fish.

The Harpy or Crested Eagle (Harpyia destructor, Fig. 264), is the model species of the genus. It is the most formidable of the genus Morphnus, for it is larger, measuring nearly five feet from the extremity of the head to that of the tail ; its bill is more than two inches in length; and its claws and toes are longer and more robust than the fingers of a man. It is rumoured that the Harpy does not fear to attack carnivora of large size, and even men. Two or three blows from its bill are sufficient to break its victim's skull. In order to render these assertions worthy of belief they should be confirmed by those who have enjoyed opportunities for observation.

Be this as it may, there is no doubt that Harpies are endowed with extraordinary strength. D'Orbigny relates that at the time of an exploring expedition on the banks of the Rio Securia, in Bolivia, he met with a Harpy of large size. The Indians who accompanied him pursued it, pierced it with two arrows, and gave it numerous blows on the head. At length, thinking it was dead, they plucked off the greater part of its feathers, and even the down also, placing it afterwards in their canoe. What was the surprise of the naturalist when the bird, recovered from its stupefaction, darted upon him, and, burying its claws in his arm, inflicted most dangerous wounds! The interference of the Indians was necessary in order to rid him of his antagonist.

The Harpy inhabits the great forests situated on the banks of the rivers of South America. Its food consists of agoutis, fawns, sloths; and especially monkeys. 
The Indians, who highly estimate warlike qualities, hold this bird in great respect. Its tail and wing feathers they use to adorn themselves with on state occasions.

The Jean le Blanc Eagle (Circatus gallicus), so called because its

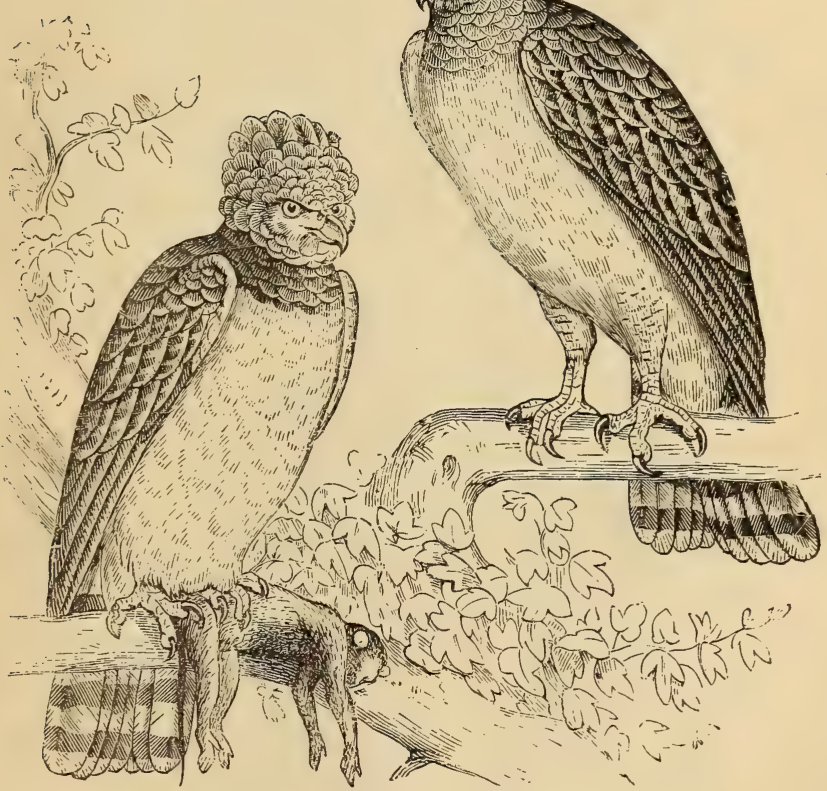

Fig. 264.-The Harpy or Crested Eagle.

plumage is principally white, has points of similarity to the Eagle, the Sea Eagle, and the River Osprey. It is two feet in height, and its spread of wings is five feet. It is very common all over Europe, except England, and is only too well known to the villagers on whose poultry-yards it frequently levies heavy tax. It also feeds on moles, field-mice, reptiles, adders, and sometimes insects. It bears captivity 
very well. Buffon reared one which became tolerably familiar, but never showed the least affection for those who tended it.

Falcons properly so called (from falx, a reaping-hook) are marvellously organised for rapine, and realise the ideal of a bird of prey. They have a short bill, bent from the base, with a very strong tooth on each side of the upper mandible, with which an indentation corresponds in the lower portion. The wings of this bird are long and pointed, causing its flight to be at once powerful, rapid, and agile. Its tarsi are short, and its claws hooked and sharp. When we add to all this a most remarkable power of vision, enormous strength, and undaunted courage, it will easily be understood that these birds inspire terror wherever they go. 'They feed only on living prey-birds or small mammals. They always hunt on the wing. They assemble in flocks at the time of migration to follow the birds of passage. At other times they live in solitary couples, and build their nest, according to the locality, in woods, cliffs, holes in quarries, or in ruined habitations, and sometimes even in the interior of towns. They lay from two to four eggs.

We shall divide the falcons into two groups: those that have tails longer than their wings, and those which have wings as long and sometimes longer than the tail.

The group of Gyrfalcons or Jerfalcons comprehends the Gyrfalcons proper, the Lanner Falcon, and the Peregrine.

The Egyptians venerated the Falcon, and to this circumstance the name of Gyrfalcon must be attributed, as it is a corruption of hierofalco, or Sacred Falcon.

The Gyrfalcon (Falco gyrfalco, Fig. 265) is the most powerful of the Falcon tribe. In strength, although hardly two feet in height, it rivals the Eagle itself. Its colour varies with its age. When young it is of a beautiful brown tint, but becomes almost white with age. It inhabits the Arctic regions, where it feeds on large birds, principally Gallinaceæ or Palmipedes.

Three varieties of this species are known, all very similar to each other: the White Falcon, called by Buffon the White Gyrfalcon of the North, which inhabits the extreme north of the two continents; the Falco islandicus, or Gyrfalcon of Iceland, peculiar to that country; and the Gyrfalcon of Norway, which is found in Scandinavia, and sometimes appears in Germany, Holland, and France.

The first two of these are very docile, and consequently were eagerly sought after by falconers, who used them for pursuing the Heron, Crane, and Stork. An ancient Danish law, which was repealed in $175^{8}$, forbade, under pain of death, the destruction of these birds.

The Lanner Falcon (Falco lanarius, Fig. 266) is about the same size 
as the White Gyrfalcon; it is found in Hungुary, Russia, Styria, and Greece, where it makes its appearance after the arrival of the birds of passage. It is also easily trained for hawking.

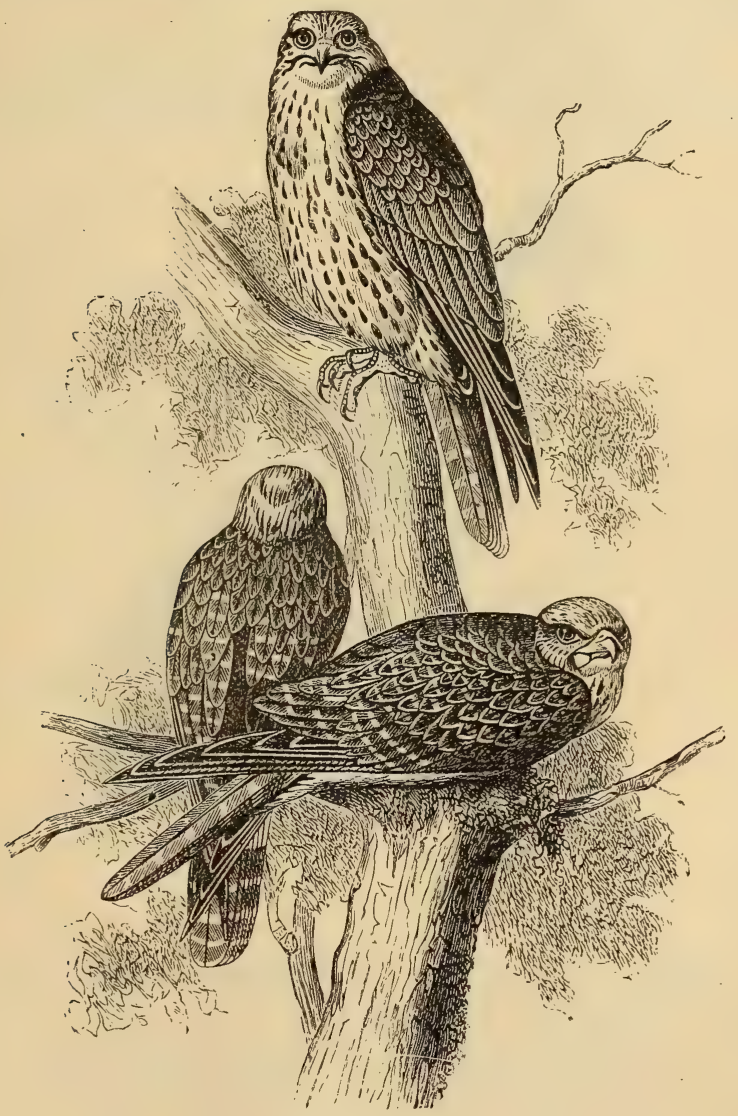

Fig. 265.-Jerfalcons.

In the first rank of Falcons proper must be mentioned the Peregrine Falcon (Falco peregrinus), often designated by the names of the Common Falcon and the Passenger Falcon. As its name 
sufficiently indicates, it is a bird of passage. It is common in the centre and north of Western Europe, as well as in the islands of the Mediterranean. It also inhabits North America, where it is frequently called the Chicken-eater.

The flight of the Peregrine Falcon is wonderfully rapid. One of these birds having escaped from the falconry of Henri II., it is said that it performed the whole distance from Fontainebleau to Malta in one day, over 300 leagues. It hovers in the air with graceful

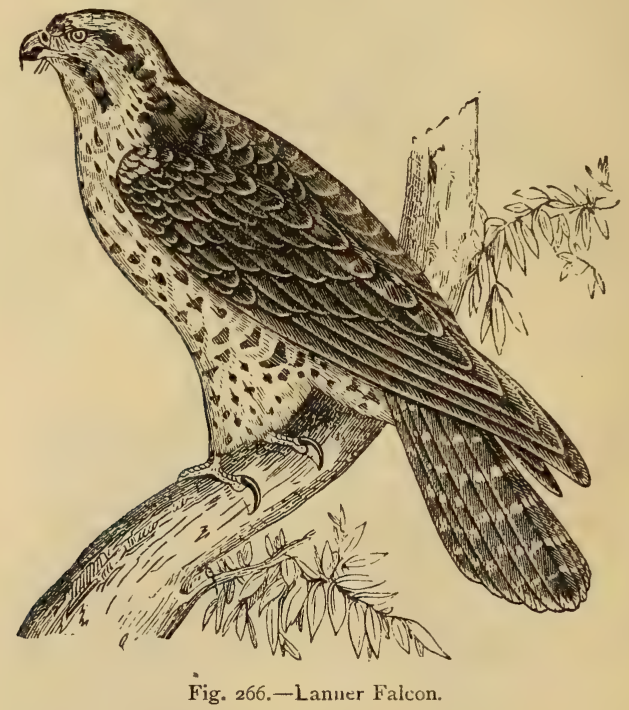

facility, and when it marks a victim, swoops upon it with extraordinary rapidity, courage, and ferocity.

The falcon feeds principally on aquatic birds, pigeons, partridges, and larks. So great is its courage that it has been known to pursue the latter into the nets of the bird-catcher. If compelled, it will eat dead fish, as was observed by Audubon on the banks of the Mississippi; but this latter circumstance is excessively rare. This bird possesses little dread of man, for it sometimes has the audacity to pounce upon the game which the sportsman has killed, and not unfrequently succeeds in carrying it off. One of these birds estab- 
lished itself some years ago on the towers of Notre Dame in Paris, and every day captured several of the tame pigeons which fly at liberty in the city. This continued for a month, and was only put a stop to by the proprietors of the pigeons keeping their pets shut up. Thus deprived of its means of existence, the Falcon soon disappeared.

Notwithstanding the magnificent powers of flight of the Peregrine

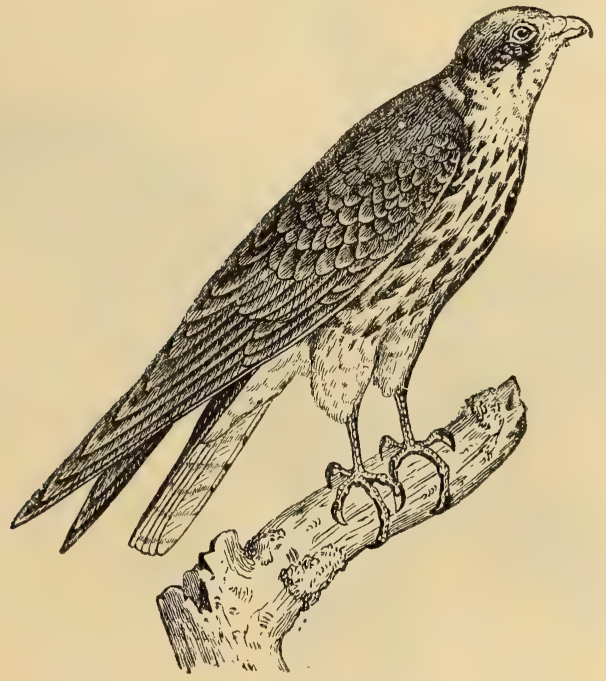

Fig. 267. - The Hobby.

Falcon, it is not always successful in its forays. Naumann narrates that he saw a Pigeon pursued by one of these destroyers throw itself into a lake, dive down, and shortly after emerge in another part, thus baffling its enemy. When a Pigeon is harassed by a Falcon it endeavours to mount above its enemy; if it succeeds in this it is saved, for the Falcon becomes fatigued, and gives up the pursuit.

Ravens are inveterate enemies of the Peregrine Falcon. They have frequent fights, in which the former sometimes prove the conquerors. A Raven has been known to break the skull of a Falcon with a blow of its bill. 
The Falcon is gifted with a more remarkable degree of longevity than even the Eagle. It is reported that in 1797 , at the Cape of Good Hope, a Falcon was caught which showed no signs of decrepitude, and which had on a golden collar with an inscription stating that in 16 Io it belonged to James I., King of England; it was therefore over 187 years old.

The parent birds exhibit the greatest attachment to their young until they are able to provide for themselves: when that stage of maturity arrives they are driven forth.

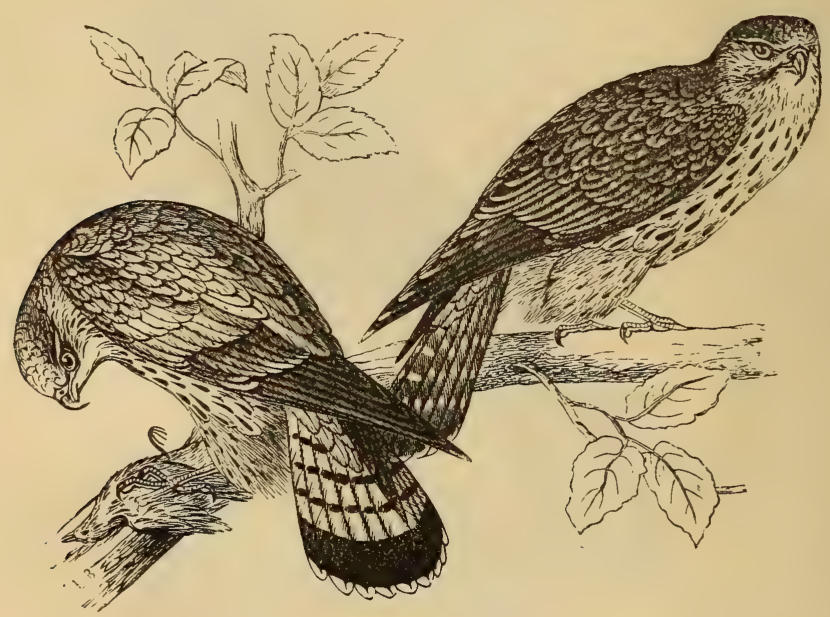

Fig. 268.-Merlins.

The Peregrine Falcon is found among the cliffs of Normandy.

There are other species of Falcons smaller than the preceding. They are only distinguished from them by their size; their habits are identical, except that they prey on smaller birds, such as quails, larks, swallows, and sometimes insects. These species are: the Hobby (Hypotriorchis subbuteo, Fig. 267), which is found all over Europe, and also in Africa-it is about a foot in height; the Merlin (Hypotriorchis asalon, Fig. 268), which is not much larger than a Thrush, and in summer inhabits the north and in winter the south of Europe ; the Kestrel (Tininunculies alaudarius, Fig. 269), which owes its name to its sharp cry-it is thirteen inches in height, and is 
common in the centre of Europe ; lastly, the Bengal Falcon (Terax carulescens), which is a native of India and Java-this is the smallest of all birds of prey. Several other varieties of Falcon, which do not present any remarkable peculiarity, are met with both in Africa and America.

The name of Falcon is still associated with the sport of hawking or falconry, of which we are about to speak.

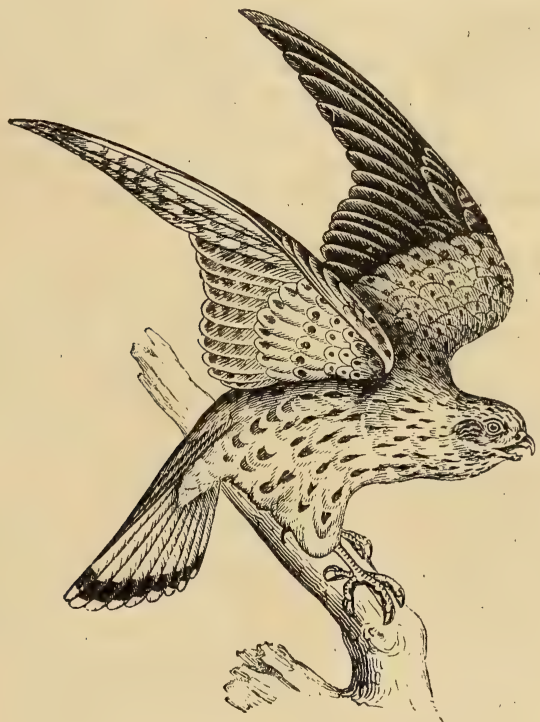

Fig. 269.-Kestrel.

Falconry, the art of training or flying hawks to take other birds, was formerly held in high esteem in the various countries of Europe. After having been for centuries the delight of kings and nobles, in consequence of the invention of fire-arms it fell into disuse. The Arabs and other Asiatic nations practise it at the present day. This sport may be traced back to a very remote period, for Aristotle, and subsequently Pliny, make mention of it. Falconry was introduced. into Europe about the fourth century of our era, and was at its greatest repute in the Middle Ages and during the Renaissance. All 
the nobility, from the monarch to the lowest courtier, were passionately fond of hawking - the name specially applied to it. Sovereigns and noblemen expended princely sums upon it. The gift of a few fine falcons was considered a magnificent present. The kings of France solemnly received twelve falcons every year from the grand-master of the Order of St. John of Jerusalem. They were entrusted on their voyage to a French knight, to whom the monarch accorded, under the name of a present, a sum of $£ 3,000$, and the expenses of his journey.

Gentlemen, and even ladies, of the Middle Ages, seldom made their appearance in public without a falcon on their wrists; and this example was followed by bishops and abbots-they entered the churches supporting their favourite birds, depositing them on the steps of the altar during mass. Noblemen on public ceremonies proudly held their falcons in one hand and the hilt of their sword in the other.

Louis XIII. was devoted to falconry. Daily he went hawking before going to church; and his favourite, Albert de Luynes, owed his fortune to his great skill in this science. Charles d'Arcussia of Capri, Lord of Esparron, published, in I6r5, a "Treatise on Falconry," in which it is stated that the Baron de la Chastaigneraie, chief falconer of France under Louis XIII., purchased his office at a cost of 5,000 crowns. He had the direction of 140 birds, which required the assistance of a staff of 100 men for their care.

This kind of sport has almost totally disappeared; a revival of it in England and Germany took place, but only with moderate success. For this purpose a society, called the "Hawking Club," meets together annually in a dependency of the royal castle of Loo, under the presidency of the King of the Netherlands, to hawk herons. From 100 to 200 of these birds in the space of two months have been taken; but this is only a feeble resuscitation of an institution which once flourished in great grandeur.

Falcons were formerly divided into birds of the noble and inferior grades. The former comprehended the gyrfalcon, the falcon, the hobby, the merlin, and the kestrel; the latter, the goshawk, and sparrow-hawk.

The falcons destined for training must be captured young. Those that have been providing their own food, and have nearly reached maturity, are taken with a lure, which is generally a pigeon. Young birds which have just left the nest are called eyases; when rather more mature, branchers; that is to say, birds about three months old, strong enough to hop from branch to branch, but incapable of flying 
or providing for their own subsistence. The latter are preferable to all others, as they are not so young as to require the care necessary to the eyas, and are yet not old enough to have become intractable.

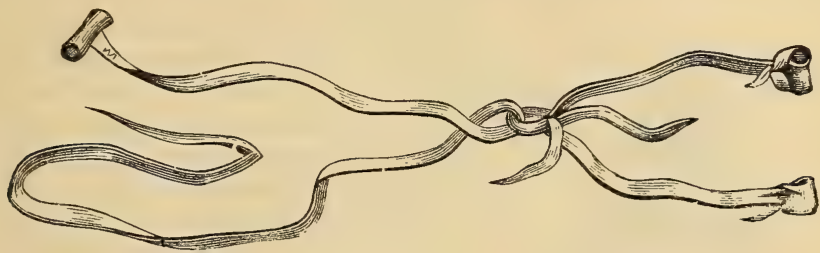

Fig. 270.-Bewits.

At a year old it would be nearly useless to attempt their education; they are then called haggards.

The Falcon being naturally wild, violent, and alike insensible to caresses and chastisements, it can only be tamed by privations, such as want of light, sleep, and food, and also by constantly being cared for by the same person. This is the foundation of the method which the falconer practises.

Supposing that a brancher has been caught, its legs are first made fast in the shackles, or bezerits (Fig. 270), made of straps of supple leather, terminated by bells. Then the falconer, his hand covered with a glove, takes the falcon on his wrist, and carries it about night and day, without allowing it rest. If the pupil is intractable, refuses to submit, and tries to use its bill, the tamer plunges its head into cold water, and thus produces stupor in the bird. Afterwards the head is covered with a hood

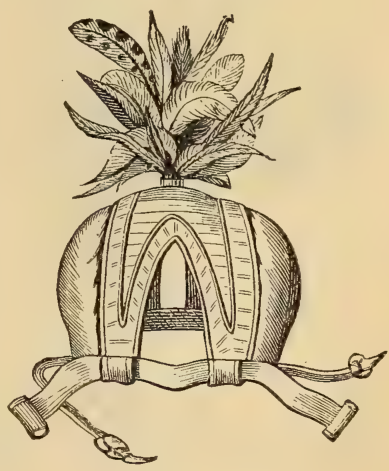

Fig. 271.-Hood. (Fig. 27I), which keeps it in complete darkness. After three days and nights of this treatment, rarely more, the bird becomes to a certain extent docile. The falconer then accustoms it to take its food quietly; this is presented in the hand, while at the same time a peculiar noise is made, which it learns to recognise as a call. In the meantime it is carried about in frequented places, so as to become 
familiarised with strangers, horses, and dogs, which are to be at some future date its companions in the chase. When an obstinate bird is dealt with its appetite is excited, so as to render it more dependent; with this view it is made

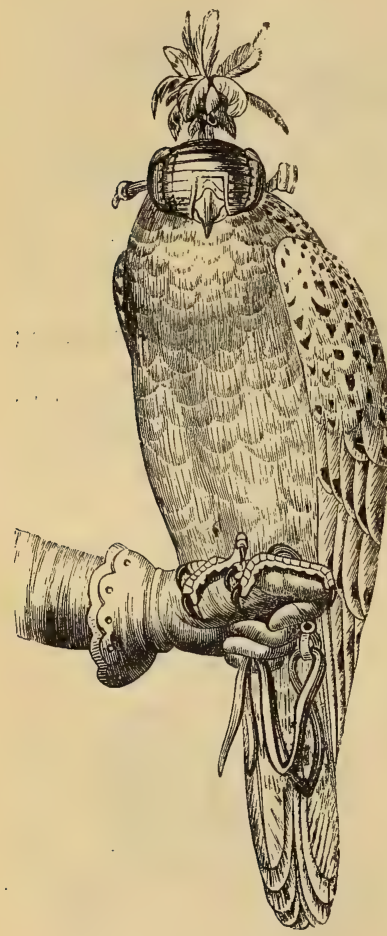

Fig. 272.-Dressed Falcon. to swallow small pellets of tow mixed up with garlic and wormwood. These pellets have the effect of increasing its hunger; and the pleasure which it afterwards experiences in eating tends. to attach it more closely to the individual who feeds it.

In a general way, after five or six days of restraint the falcon is tamed, and the falconer can then proceed with the training, to which the former practices are nothing but preliminaries.

The bird is taken into a garden, and taught to hop up on the hand when called; a piece of meat is shown, to entice it, which is not given to the bird until the requisite manœuvre is properly executed. The meat is then fastened to a lure, or decoy, and the same course is adopted, the bird being attached to

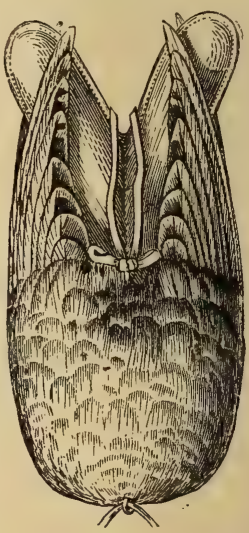

Fig. 273.-The Lure. the end of a string

from ten to forty yards in length. The lure (Fig. 273) is a flat piece of wood, covered on both sides with the wings and feet of a pigeon. The falcon is uncovered, and the lure is shown to it at a short distance off, and at the same time a call is given. If the bird swoops upon the lure it is allowed to take the meat which is attached to it. The distance is progressively increased, and the falcon is recompensed for. its docility on each occasion. When, at the full length of the string, 
it will obey the call, a great point is gained, for it fully recognises the lure, and knows that the meat attached will become its own on returning to its master. Then the falconer no longer fears it becoming free, for he well knows he can reclaim it ; that is, make it settle down upon his fist, even when the bird is flying in the air.

Afterwards it is introduced to living game by letting it fly at tied pigeons ; and, lastly, its education is completed by habituating it to swoop on the special game which it is intended to chase.

Supposing partridge be the game it is destined for pursuing in the first place, the pigeon's wings on the lure are replaced by those of the partridge, and then the falcon is let fly in succession, first at partridges tied to a string, and then at liberated birds. When it binds its prey well, and shows itself obedient, it is employed on wild game.

Birds of prey used to be educated for taking the kite, the heron, the crow, the magpie, the hare, partridges, quails, and pheasants; also wild ducks and other aquatic birds.

The pursuit of the kite, the heron, the crow, and the magpie, the profit of which was absolutely nothing, was looked upon as a sport fit for princes, and was carried on by means of the falcon and gyrfalcon. But the chase of other birds, in which the inducement was a prey fit for food, was considered the sport of an esquire ; and for this were used the hobby (hobereau, French), the merlin, the kestrel, the goshawk, and the sparrow-hawk. Hence comes the nickname of hobereau applied to French country gentlemen; "because," as Lacurne de Sainte-Palaye says, "they wish to show an appearance of more property than they really possess ; and not being able to keep falcons, which cost too much in their purchase and food, they hawk with hobbies, which are readily procured, and also provide partridges and quails for their kitchens."

The most noble cast, but also the rarest, was that at the kite. We have already mentioned, when speaking of nocturnal birds of prey, how at one time they were in the habit of alluring this bird by means of a great (long-eared) owl, dressed out with a fox's brush. Some stratagem of this kind was obliged to be used in order to get near the kite, which flies at heights altogether inaccessible to the best falcon. When the kite came within range a falcon was let $f y$, and then a most interesting conflict took place between the two birds. The kite, harassed by its enemy, and, in spite of its turns and twists and numberless feints, unable to escape him, generally in the end fell into the clutches of its foe.

The cast at a heron generally presented fewer incidents. This 
bird, from not being gifted with the same powers of wing, was unavoidably overtaken with much greater ease, although, when not
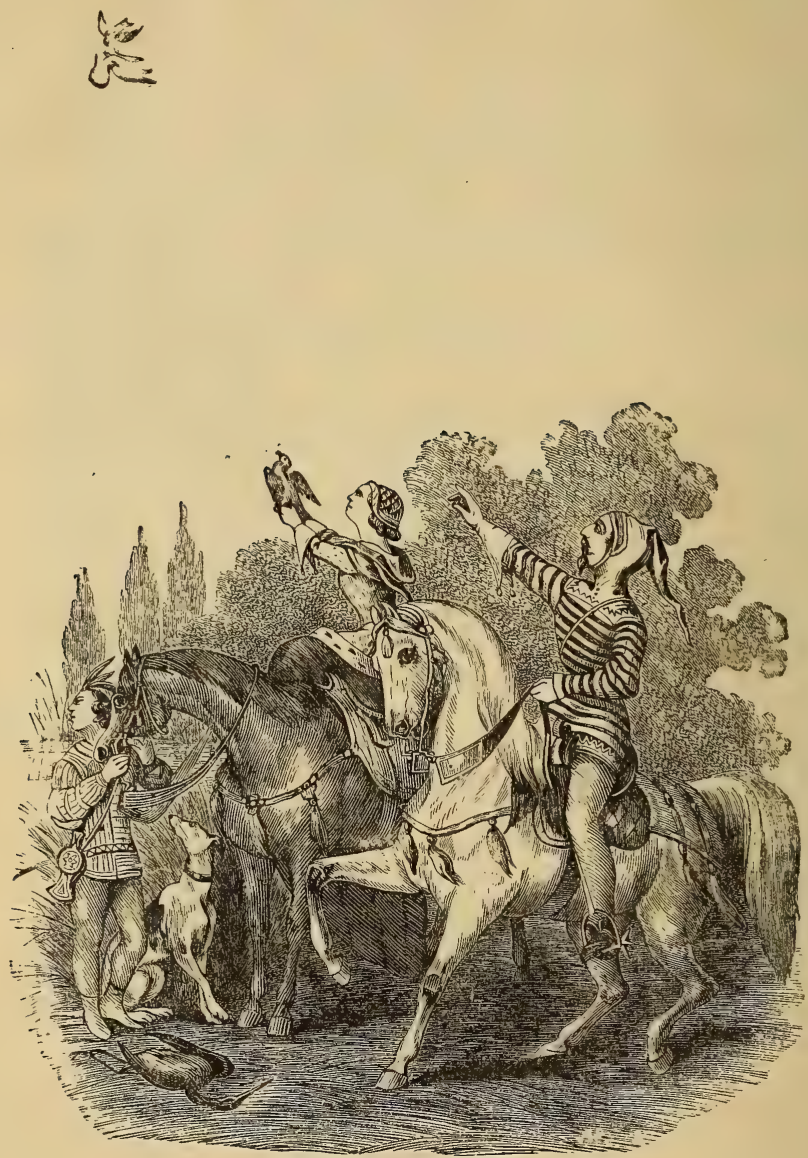

Fig. 274.-Heron Hawking.

overloaded with food, it occasionally managed to escape. Still it always defended itself with energy, and the blows of its formidable bill were often fatal to its pursuer. In heron hawking (Fig. 274) 
a dog was required to flush the game, and three falcons to capture it : the duty of the first was to make the quarry rise, of the second to follow it, and of the third to clutch it. We shall quote from an ancient author of a "Treatise on Falconry" the account of a cast at a heron; the description will well explain the details of this kind of sport.

"Now riding fast, we soon came by the side of the meadows adjoining the warren, where the 'markers' of $M$. de Ligné discovered three herons, and at once came to tell him of it. Making up his mind to attack them, the Sieur de Ligné did me the favour of giving me a white gyrfalcon, named 'La Perle,' to let fly; he himself took another, called 'Le Gentilhomme,' and one of his people took a third, named 'Le Pinson.' When the herons heard us approach they became alarmed, and took wing while we were yet some distance off; seeing this, we let fly the birds, which were some time before they perceived the quarry. At last one of the hawks caught sight of them, and went in pursuit. The two others immediately followed with so much ardour and speed that in a very short time they had all reached the herons, and were attacking one, which defended itself; but it was so roughly treated that it could not make much resistance, and was soon taken. Whilst the falcons were having their pleasure with it (that is, whilst the quarry was being given them), the other herons, frightened at seeing their companion so badly treated, kept on rising in the direction of the sun, hoping to shelter themselves in its glare. But they were descried; M. de Ligné told me of this, saying, 'I can see the two herons up above still rising. I give you one as your share.' On which, seeing them at such an immense height, I replied that the falcons would have great difficulty in getting at them. Then he let fly his bird, we doing likewise, and they all vied with one another in soaring upwards, using such diligence that soon we saw them almost as high up as one of the herons. Having first made an effort, and got above their prey, they commenced to deal it such a shower of blows that it seemed stupefied, and flew down to gain the shelter of the woods. We rode forward to bring the hounds to the assistance of the falcons, and were just in time; for the heron had thrown itself into a thicket, in which we captured it alive, although taken from the mouth of one of the dogs. Giving this bird to the falcons, we mounted our horses again to let fly after another."

The casts at the crow and magpie were also productive of sport. These birds would try at first to escape by means of speed, and then, recognising the uselessness of their efforts, they afterwards took 
refuge in a tree, from which the falconers had much trouble to drive them, so great was their terror for their pursuers.

For field and river sport the falcon is not let fly direct from the fist; that is, the falcon does not attack immediately on leaving the hand-it is throu'n up, or, in common parlance, is let fly, before the game flushes. The falcon hovers for some time, and then stoops down on the prey which the dogs have forced to take wing. In order to escape its persecutor the wild duck often returns to the water; from this the dogs again force it to take wing. The hare is hunted in much the same way.

Hawking is even nowadays held in high repute by the Arabs in the north of Africa and in Asia. In the Sahara they train their birds to hunt the antelope.

In Persia and Turkestan the falcon is not trained, as it used to be in Europe, for some special game, but accustomed to stoop at all kinds of prey. Hunting the antelope with hawks is a diversion much esteemed among these nations. The plan adopted is as follows :-

"The Persians," says Thévenot, the traveller, "provide stuffed gazelles, on the noses of which they always place the food for their falcons, and never feed them anywhere else. After they have been thus trained they take them out into the open country, and when they see a gazelle they let fiy two of these birds, one of which darts down on the nose of the gazelle, and fastens on to it with its talons. The gazelle stops short, and shakes himself to get rid of the bird; but the latter keeps his place for some time by means of flapping his wings, thus preventing the gazelle from running fast, and even from seeing where it is going. When at last, with some "trouble, the gazelle disengages itself from its pursuer, the other falcon, which is flying near, takes the place of the one thrown off; the latter, in its turn, again resumes the assault when its companion has fallen. The birds thus hinder the running of the gazelle, so that the dogs easily overtake it."

In Egypt the falcon is trained for this kind of sport by taking it young, limiting the quantity of its food, and then frequently bringing it into the presence of sheep, when, being in a famished state, the bird unhesitatingly darts on them.

Hawking is also held in esteem in India, both by the natives and European residents. It is no rare thing to see young ladies reviving all the customs of the Middle Ages, and penetrating into the jungles mounted on elephants, accompanied by their falcons, which are flown at the charming blue antelope.

In China and Japan hawking is also very popular : in the course 
of a day's journey it is not uncommon to meet persons pursuing this sport. *

The birds which form the next family differ from the previous in having no teeth in the upper mandible of the bill; their tarsi, also, are longer, and their wings shorter. Their flight, too, is both

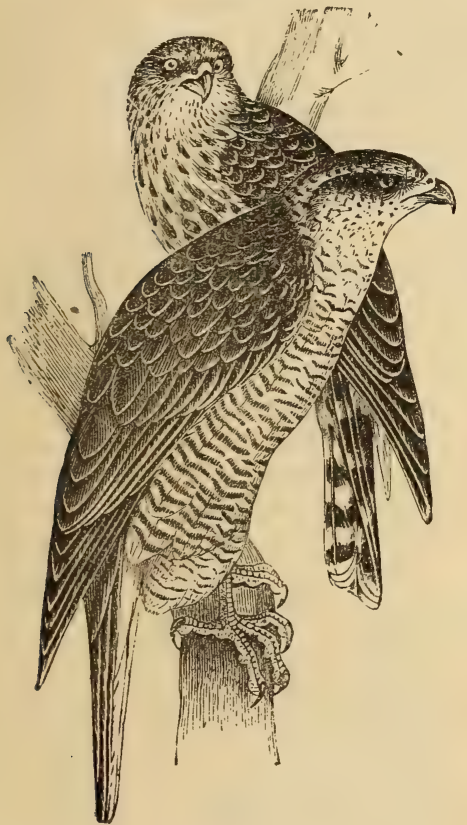

Fig. 275.-Goshawks.

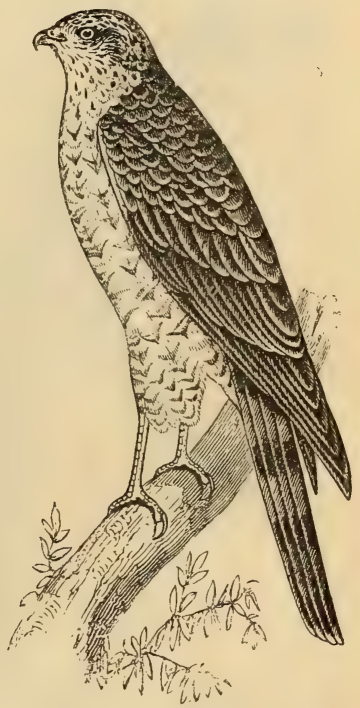

Fig. 276.-Common Sparrow-hawk.

less high and less rapid than that of the falcons proper. They are found in all parts of the globe, presenting some slight modifications, due to the influence of climate. They generally feed on small birds and reptiles, and exceptionally on very small mammals. They are divided into Goshawks and Sparrow-hawks.

There are various species of the Goshawk, one only of which, the Common Goshawk, is a native of Europe-all are characterised by very strong tarsi.

* On the plains about Tein Sin I have encountered two or three parties of hawkers in a day.-ED. 
The Common Goshawk (Astur palumbarius, Fig. 275) is by no means rare in France and England. In summer it frequents the oak and beech woods which cover the mountain sides, and sometimes ventures near habitations to carry off fowls and pigeons. At the commencement of autumn it descends into the plains, making its roosting place on the skirts of some extensive wood, from which it darts out upon partridges, grouse, or young leverets, which form its principal

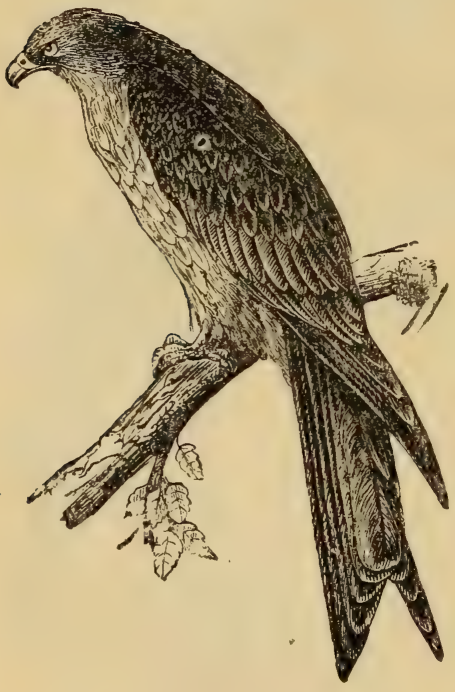

Fig. 277.-The Common Kite. food. It pursues larks with such ardour that it often falls into the snares set by fowlers for these birds; but it will never attempt to get free from the trap until it has satiated its sanguinary appetite. When hunting it skims over the ground and bushes, carefully inspecting each. Should it perceive a victim, it approaches with caution until within striking distance, when it suddenly darts upon its prey with unerring precision. This bird is as large as the Gyrfalcon, but, although equal in cunning and address, is possessed of less courage.

The Goshawk is difficult to tame; its ferocious nature is not subdued by captivity. In I850, a young one four months old, kept in the Botanical Garden of the Natural History Society of Savoy, killed with its claws and bill a Kite the same age as itself, which had been its companion for fifteen days. The young savage tore its victim to pieces, and fed on the carcase, although it had not the least necessity for food, being abundantly cared for.

The Common Goshawk is also found in the north of Africa. Two other species are known in North America.

The Sparrow-hawks are distinguished from the preceding birds by the slenderness of their tarsi. The Common Sparrow-hawk (Accepiter nisus, Fig. 276) is found all over Europe. In France it is a constant resident. Although smaller, it has much the same habits as the Goshawk, but is bolder, and will carry off partridges, or other small 
game, under the very nose of sportsmen or gamekeepers. It will even attack and devour fowls and chickens in the poultry-yard, and so absorbed does it become in the enjoyment of its feast that a person may not unfrequently get sufficiently near to capture it. In the plains where game is abundant, Sparrow-hawks are very destructive, and, consequently, are seldom spared when within gunshot.

In captivity it will become gentle and tame. Dr. Franklin mentions an instance of one of these birds, belonging to a friend of his, which lived with two pigeons. This bird had succeeded in gaining the affection of all who knew it, and was, it is said, as playful as a kitten.

Africa possesses two species of Sparrow-hawk : the Dwarf Sparrowhawk (A. minullus), which does not exceed the Blackbird in size. As intrepid, although not so strong, as its European brother, it often ventures to attack Kites and Buzzards, and, by its agility, harasses them with impunity. The Chanting Falcon (Melierax musicus), which is about the size of the Goshawk, sings in the vicinity of the female during the season of incubation. It is the only musician among birds of the Rapacious order, and therefore has a claim to honourable mention.

Both the Goshawks and the Sparrow-hawks were employed in hawking in days of old, but their relative value was much inferior to that of the Falcon.

The birds which belong to the Kite genus (Milnus) are characterised as follows:-Beak curved from the base, and not toothed; tarsi short, slender, and feathered on the upper part; wings very long; tail long, and more or less forked; colour generally brown. Several species are known, but their characteristics are identical.

The Common Kite (Milvus regalis, Fig. 277), thus named on account of affording amusement for princes, who hunted it with the falcon, and even the sparrow-hawk, measures two feet in height, the spread of its wings being not less than five feet. Of all the Falcon tribe this bird is gifted with the most graceful, rapid, and sustained powers of flight. It is so incessantly on the wing, that it appears scarcely to require rest. Love for soaring through space must be the cause of this activity, as it never pursues its prey, but descends upon it with incredible velocity from the prodigious heights at which it may be hovering, and, seizing it in its claws, bears it to some adjacent tree to be devoured. Its food consists of leverets, moles, rats, field-mice, reptiles, and fish-the latter it catches on the surface of the water. It builds its nest on lofty trees, rarely on rocks. It is a constant resident in some parts of France, and is met with in nearly all countries of Europe. 
The Black Kite (Milvus niger) is very common in Russia, and has a particular penchant for fish. It is not, however, above assisting vultures to devour carrion, and may be seen hovering over the cities of Russia to pick up the fragments which are thrown into the streets. In autumn these Kites assemble in flocks, and, crossing the Black Sea, proceed to winter in Egypt, where they are so tame that they perch on the window-sills of the houses. In the spring they return to Europe.

The Parasite Kite (Milvus agyptius) is thus named by Levaillant because its whole system of life seems to be at the expense of man, either by devastating his poultry-yards or robbing with extraordinary impudence travellers encamped in the open air. This celebrated naturalist relates that whenever he made a halt some of these birds came and perched on his wagon for the purpose of stealing.

"At Cairo," says Dr. Petit, in the account of his travels to Abyssinia, "I one day saw a kite snatch suddenly from the hands of an Arab woman a piece of bread and cheese at the very moment she was raising it to her mouth. At Chizé, in Abyssinia, another kite carried away, from under the very nose of my dog, which was guarding it, a portion of a sheep just killed. The same thing took place .several times in view of my servants."

The same authority adds that these birds sometimes assemble in innumerable flocks; he having seen thousands hovering over an Egyptian village.

The Swallow-tailed Kite (Elanoides furcatus) is remarkable for its deeply-forked tail, which it perceptibly uses as a rudder to guide it in flying; in its flight it describes the most elegant curves, hence the name Forked-tail Pilot, which is sometimes given it. Essentially migratory, they may be seen in spring and autumn proceeding north or south. Snakes, lizards, and frogs are their usual food.

The Mississippi Kite (Ictinia mississippiensis), another American species. It is a remarkably handsome and powerful bird; nevertheless is said to feed only on insects.

The bills and claws of Kites are weak in comparison with their size; they therefore wisely avoid coming in collision with birds of prey better armed than themselves. This has been sufficient to give them the character of cowardice.

Kites are easily tamed, and if taken young they will soon become familiar.

Buzzards (Buteo) have long wings, a large head, and a rather squat figure ; their tarsi are short, or of medium size; and the beak curved from the base; in appearance they are heavy and deficient of grace. 
They do not chase their prey when it is on the wing, but secrete themselves, where they wait until a victim passes within reach. When thus occupied, they will remain for several hours in the most complete immobility, presenting an air of lethargy which has become proverbial. This stupid look is owing to their nonchalant and apathetic attitude, and also to the weakness of their eyes, which are affected by strong light.

They generally build their nests on the loftiest trees, occasionally in thickets of brushwood growing among rocks. When frost occurs they visit farm-yards and make forays upon poultry. If pressed by hunger, they become excessively bold. Their general food consists of small birds, rodents, serpents, insects, and sometimes corn. They are éasily tamed. M. Degland mentions one which lived in perfect good fellowship with a sporting dog, and even went so far as to share its food. Buffon also speaks of another which was so attached to its master that it could not be happy unless in his company; it was present at all his meals, when it would caress him with its head and bill; and, although this bird always enjoyed the most complete liberty, every evening it returned to roost on the window-sill. One day when its master was riding on horseback, it followed him for more than two leagues, hovering over him in the air.

Mr. Yarrell relates of these birds, which are much attached to their progeny, that in the town of Uxbridge a Buzzard kept in a domestic state having manifested a desire for building, the means were furnished, and two hen eggs placed under her. The young chickens were hatched, and reared as if they had been her own. On another occasion, in order to save her the trouble of sitting, some chickens just hatching were placed in her nest; these she killed, evidently feeling that she was not allied to them by any maternal tie.

The principal species are the Common Buzzard (Buteo vulgaris, Fig. 278), which is found all over Europe-it was until lately very common in England; the Honey Buzzard (Pernis apivorus), a native of Eastern Europe-this bird is partial to bees, wasps, and their larvæ, of which its food principally consists, it will also eat grain, and, in a domestic state, fruit ; and the Rough-legged Buzzard (Archibuteo lagopus), so called on account of the feathers which cover its tarsi down to the toes, it is a native of Europe, Africa, and North America. Ptarmigans are their favourite food, so cold climates are their principal habitat.

The birds which belong to the Harrier genus are characterised by long and slender tarsi, covered with feathers on the upper portion only, and also by a sort of collar formed of closely-planted feathers, 
which surrounds the neck and extends on each side to the ears. Marshy plains, and woods situated in the vicinity of rivers, are their most frequent resorts. They build their nests on the ground, or close to it in the brushwood, and in this respect differ from most of the Falcon family. When searching for their prey they skim over the ground, and take it by surprise ; if the attacked is fortunate enough to avoid the Harrier's onset it is safe from pursuit. In Europe the

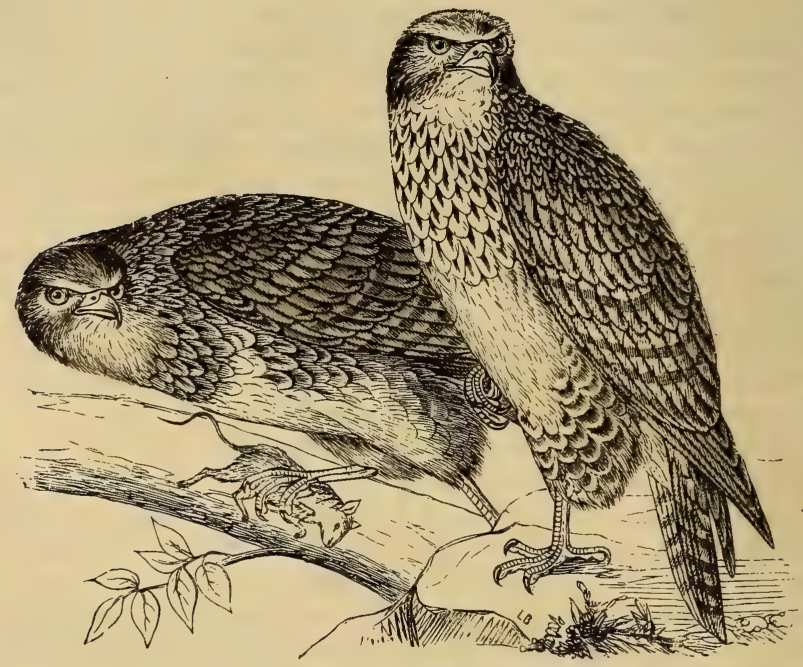

Fig. 278.-Common Buzzards.

best-known species of this family are the Hen Harrier (Circus cyaneus, Fig. 279), and the Marsh Harrier (Circus cruginosus):

The former bird is about seventeen inches high; it inhabits all. the countries of Europe, and feeds on serpents, rodents, and frogs. When it succeeds in making its way into pigeon-houses or poultryyards it commits great havoc.

The latter feeds principally on game, to which it is extremely destructive. Game preservers consequently are their bitterest enemies. Their flight is not swift except when pouncing on their prey, which is done with great certainty and velocity.

The other species we will mention are the Frog-eating Harrier 
(Circus ranivorus), which is a native of South Africa, where it feeds principally on frogs and fish; the Pale-chested Harrier and Jardine's Harrier (C. Swainsonii and C. Jardinii); and the Ash-coloured Harrier ( $C$. cinerescens), which is met with in the extreme south of America. The latter has great powers of flight, and is always in motion, never halting except to seize its prey; it is very wild, and can only be approached when feeding.

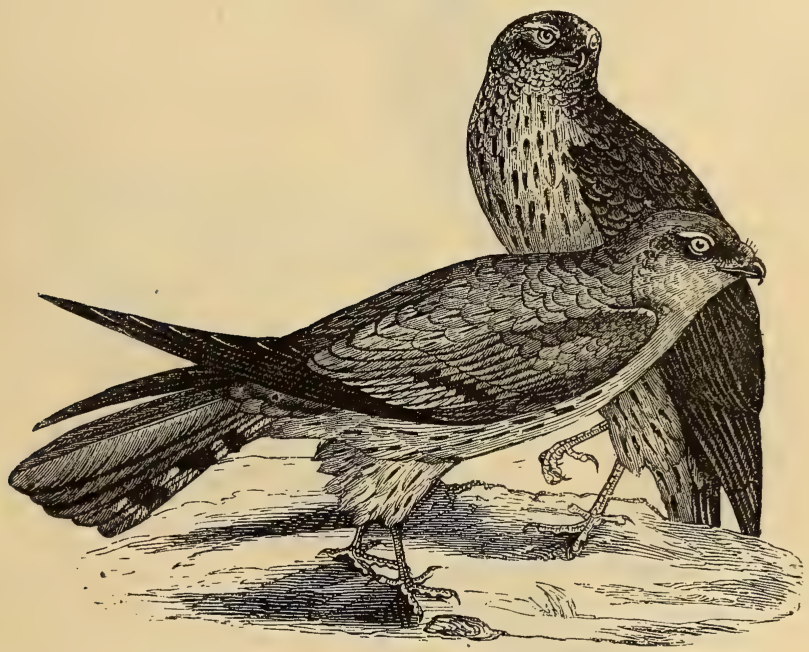

Fig. 279.-Hen Harrier.

The Caracaras are a race of birds which form a link between the Falcon and the Vulture families. They have, like the latter, the projecting crop, goggle eyes, head partly bare of feathers, toes long, especially the middle one, and the claws but slightly crooked. They show a decided taste for putrid carrion. However, they do not feed exclusively on it, for when opportunity offers they capture mammals, young birds, reptiles, molluscs, grasshoppers, and even worms. These birds are essentially pedestrians; the slight curvature of their claws renders this easy, and it is not an unfrequent thing to see them walk at a slow pace for considerable distances.

Their name is derived from the cry which they utter. They are 
peculiar to South America, in which they are found in every latitude and at all altitudes. They present, however, differences according to the region which they inhabit. Each species fixes itself in a zone, which becomes its special place of habitation. Thus the Brazilian Caracara is met with everywhere, from the coldest districts to the hottest countries, but only at a slight altitude, and in

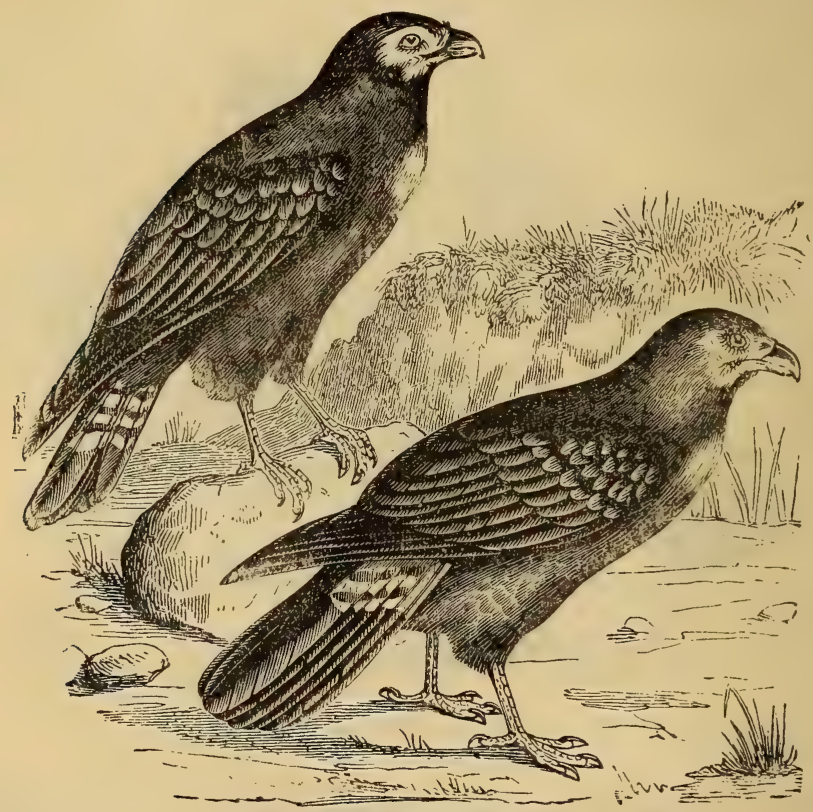

Fig. 280. - The Black Caracara.

company with the Chimango Caracara (Milvago chimango), whilst the summits of the Andes are inhabited by the Long-winged Caracara ( $M$. megalopterus) ; and the Chimachima Caracara ( $M$. chimachima) inhabits the burning plains between the tropics.

The Caracaras, especially the common species and the Chimango, are distinguished from the other Falconides by an excessive amount of sociability: everywhere they seek out the vicinity of man. But we should be labouring under a mistake if we supposed that affec- 
tion had any share in this alliance; for self-interest is the sole motive which impels them to act thus. It is to feed at his expense, to devour the fragments of his meals, kill his domestic fowls, or take possession of the pieces of meat which are hung in the sun to dry. This bird, however, is useful, for it most efficiently performs the duties of scavenger.

The Caracara will craftily follow the sportsman, and steal away game that is not quickly bagged. It also accompanies travellers across the vast pampas to prey on the carcases of the worn-out beasts of burden. It will even attack horses and mules which are galled by the pack-saddle, fastening greedily on their wounds, and would actually devour them alive if the quadrupeds had not the sagacity to dislodge them by rolling on the ground. It will also take up its abode near flocks of sheep, and if it can evade the watchfulness of the shepherd, will destroy the newly-born lamb.

Having confidence in its own strength, the Caracara frequently pursues other birds, especially vultures and gulls, which it forces to disgorge their food. It will even engage in sanguinary conflicts with its own species for the possession of prey. Contrary to the habit of most birds in a state of freedom, it remains constantly paired, without, however, having more than one or two broods a year. The Caracara lays two eggs; the nest is generally placed on the ground among brushwood.

Besides the four species we have mentioned there is also the Caracara funebris (Fig. 280), thus named on account of its plumage, which is almost entirely black. This bird is still more of a plunderer than the preceding species, and is a native of the shores of Tierra del Fuego, the Falkland Isles, Van Diemen's Land, New Zealand, \&c.

\section{VULTURES.}

The Vultures (Vulturida) form a well-marked order, which is readily distinguished from the Falcons by the following characteristics : A beak almost entirely straight, and curved only at its extremity; the head and neck generally devoid of feathers; small and staring eyes; head small; tarsi generally bare; toes short and slightly curved; weak claws; and wings very long. They are also distinguished from holding themselves in a horizontal position, whether walking or at rest; whereas the Falcons stand erect, and present a noble bearing. Vultures probably adopt their attitude on account of the length of their wings, which even in a stooping position sweep the ground, and would drag much more but for this precaution. 
Lastly, they are specially characterised by their partiality for putrid flesh, which almost forms their exclusive nutriment, as it is only rarely they attack living prey.

When a Vulture has glutted itself, its crop, swelled by the food which it has devoured, forms a voluminous projection in front of the neck; a fetid humour oozes from its nostrils, and it remains sunk in a state of stupid torpor until the food is digested.

They fly heavily, but mount aloft to great altitudes. Their powers of vision are extraordinary. Should a carcase be left on the plain, they immediately see it and drop down, turning over and over in their hurry to arrive at the scene of the anticipated banquet. It has been supposed by some that their olfactory organs are so acute as to smell, at great distances, the emanations which escape from bodies in a state of decomposition, and thus to account for their prompt attendance. Latterly, however, certain observers have opposed this theory ; according to their ideas the Vulture tribe owe this wonderful facility to their sight, not to scent. This explanation, however, has not as yet been rendered altogether clear. We therefore think it prudent to abstain from pronouncing an absolute judgment on the point, and will content ourselves by admitting that both sight and smell concur in producing the result : these two senses may either exercise an equal power, or one of them may predominate over the other.

The Vultures exhale a putrid odour, which is owing to the peculiar nature of their nutriment ; it is, therefore, impossible for their flesh to be in any way utilised as food. This family comprises four principal genera : the Gypaëtus, the Sarcoramphii, the Cathariste, and the Neophronies.

The Lämmergeyer (Gypaëtus barbatus) form, as their name indicates, an intermediate genus between the Eagles and the Vultures. Although they have small and goggle eyes, not very strong talons, and a projecting crop during the digestion of their meals, they are allied to the Eagles in virtue of their feathered tarsi, as well as by their head and neck; they also show a preference for living prey, which they attack with readiness. We will complete their portrait by stating that they have a very strong beak, enlarged towards the point.

The Bearded Griffon is the celebrated Lämmergeyer, described by Buffon under the name of the Golden Vulture. It owes its name to a tuft of stiff hair which is under the beak : the loftiest mountains of Furope, Asia, and Africa are its habitat. Its aerie, which is of considerable dimensions, is built amongst the most inaccessible rocks. On the old continent it is the largest of all the birds of 
prey, and sometimes reaches five feet in length. Its spread of wing generally measures nine or ten feet. Sometimes these limits are exceeded, for one was killed during the French expedition to Egypt, in the presence of Monge and Bertholet, which measured upwards of fourteen feet.

The Lämmergeyer is endowed with wonderful strength of body and powers of flight; it is not therefore surprising that it attacks animals of considerable size, such as calves, lambs, deer, chamois, \&c., and that it succeeds in overpowering them. Like the Eagle, it is reported to perpetrate the following ruse, one almost telling of reasoning powers. Waiting until its victim stands isolated on the edge of a precipice, it flies suddenly against the poor creature, beats it with its wings, and forces it to fall over into the abyss below, where it descends to feed on the mangled carcase.

It has been asserted that it sometimes ventures to employ this manœuvre against the chamois-hunter, to make him lose his equilibrium in difficult passes. But in spite of all the wonderful stories told, it cannot be admitted that it is capable of carrying off lambs or children, for the weakness of its claws will not support a prey of weight; it is therefore obliged to rend its victims in pieces, and devour them where killed.

Although it cannot carry off children, it is nevertheless true that it sometimes attacks them, as the two following facts will prove.

In ISIg two children were devoured by Lämmergeyers in the environs of Saxe-Gotha, which induced the Government to set a price on the heads of these birds. M. Crespon, in his "Ornithologie du Gard," relates the second fact:-

"For many years," says he, "I was in possession of a living Griffon which exhibited no very great courage towards some other large birds of prey which were kept with it, but it was different as regarded children, upon whom it attempted to spring, spreading out its wings as if it wished to strike them. Latterly, I let this bird run about free in my garden. Watching for a moment when no one saw it, it darted upon one of my nieces, two years and a half old, and, having seized her by the top of her shoulders, threw her down to the ground. Fortunately her cries warned us of the danger she was in, and I hastened to her rescue, and found that the child had suffered no other injury but fright and the tearing of her dress."

This bird shows great courage in defence of its offspring. Joseph Scherrer, a chamois-hunter, having first killed the male parent, climbed to an aerie to obtain the young, and had to engage in such a furious encounter with the female that it was with immense difficulty 
he saved himself by shooting her, and then not before he had received some severe wounds.

They live in pairs, and a number are rarely seen together. This is common to all animals which Nature has endowed with a great amount of physical strength, for it is the weak only which practise the maxim, "Union is strength."

These birds were once far more plentiful in Europe than now. The reason of this is the great havoc which was made among them in the last century. Even at the present day pursuit of them is encouraged by the grant of a reward to the person who kills one. This and the number of eggs they lay being limited (two), there is but little cause for surprise that the species is very sensibly diminishing.

In the birds which belong to the Sarcoramphus family the base of the bill is furnished with a ring of feathers, and the bill itself is surmounted with a thick and scalloped fleshy crest; from this peculiarity of organisation they derive their name, the signification of Sarcoramphus being "fleshy-billed."

Vulture.

This genus comprises but two species, the Condor and the King

The Condor, from the word Cuntur, in the Peruvian language (Sarcoramphus gryphus, Fig. 281), commonly called the Great Vulture of the Andes, is the most remarkable species of the Vulture family, both for its size and strength, and also for the vast extent of the stretch of its wings. Its plumage is of a dark blue, approaching to black ; its collar, which occupies only the back and sides of the neck, is formed of a dazzling white down. Its crest, bevelled off at the edge, is cartilaginous in its nature, and of a bluish colour, and extends down the side of the neck in two fleshy strings. Lastly, the male has two fleshy appendages under the lower mandible, level with the collar. The wings are as long as the tail, their whole development being ten or twelve feet. The length of the bird from the point of the bill to the tip of the tail is on an average about four feet.

The chief habitat of the Condor is the western slope of the chain of the Andes, Bolivia, Peru, and Chili ; it frequents all the different altitudes, from the burning sands of the sea-coast to the ice-bound solitudes of perpetual snow. Humboldt and Bonpland, when exploring the Andes, repeatedly noticed Condors close round them when at a height of I 5,700 feet above the level of the sea. D'Orbigny saw them as high up as the summit of Illimani; and he likewise met with them on the coasts of Peru and Patagonia, seeking their food among the various débris which the waves had thrown upon the shore, proving that they can support variations of temperature which man 
would be unable to bear; in fact, at a height of 19,000 feet the air becomes so rarefied, and the cold so intense, that no human

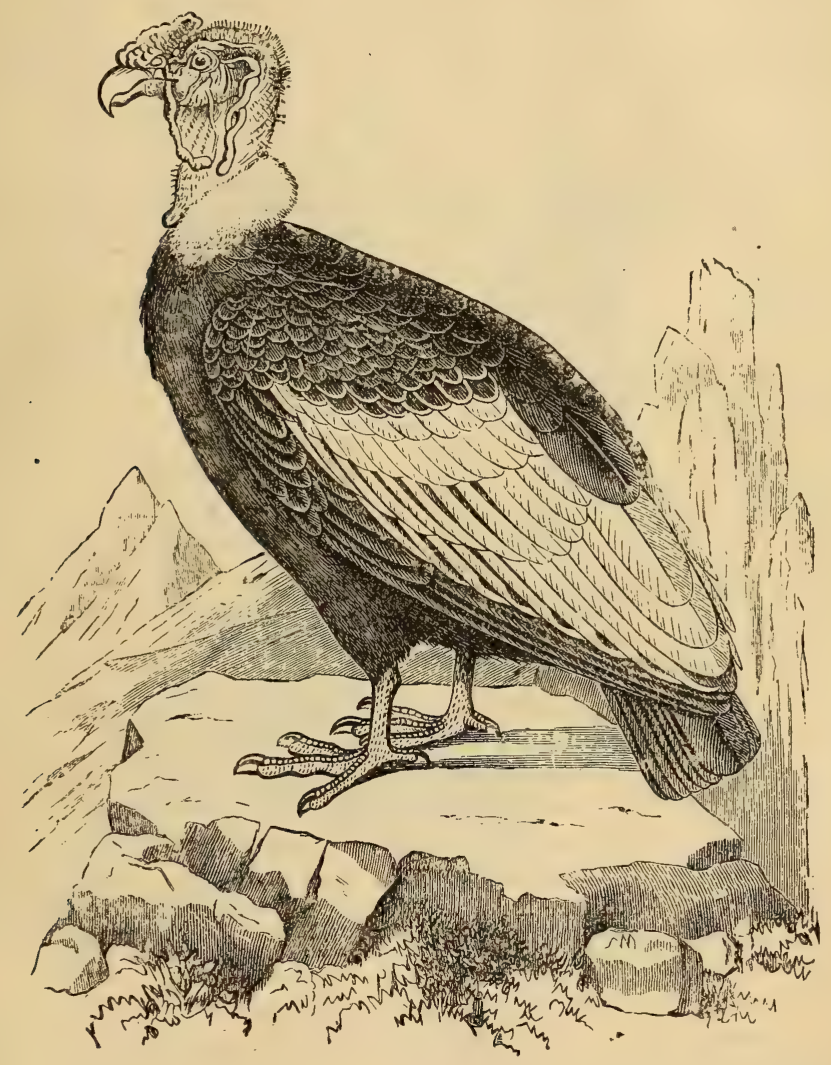

Fig. 28 r. -1 he Contor.

being would be able to exist for any length of time subject to their influence.

The Condor passes the night at great elevations, perched on a crag. As soon as the rising sun gilds the peaks of the mountains 
it raises its neck, hitherto buried between its shoulders, and shaking its wide wings, launches into space. The impetus of its own weight at first carries it downwards, but soon recovering itself, it traverses the aërial space with majestic ease and grandeur. Almost imperceptible movements of the wings are sufficient to carry it in every direction; at one moment it is skimming over the surface of the ground, now it is up in the clouds, 3,000 feet above. The Condor's power. of vision is so great that it commands a view of the plain beneath from the greatest altitudes, and although it is no longer visible to denizens of earth, their slightest movements cannot escape its piercing sight. When it views prey, partly folding its wings, it descends with the rapidity of lightning.

Although endowed with such powerful means of action, the Condor never attacks living animals unless they are helpless from age or enfeebled by disease. The stories of some travellers concerning the boldness of this bird are not founded on fact. It is inaccurate to state that the Condor will attack a man, as a child of ten years old, armed with a stick, has been known to put it to flight. It has been asserted that this bird will carry off lambs, young llamas, and even children, but this statement will not hold good when subjected to examination; for the Condor, like all the vulture tribe, has short toes and non-retractile claws, it is therefore radically impossible for it to clutch and carry prey of any considerable weight.

It is, however, a fact beyond all question that the Condor is in the habit of prowling round flocks of sheep and cows; and, like the Caracara, will fall upon and devour newly-born animals. It accompanies the caravans which cross the plains of South America, and when an unfortunate pack animal, worn out with fatigue and privation, sinks down exhausted, totally unable to proceed on the journey, it becomes the prey of these winged banditti, which often commence their meal before life has left the exhausted body. M. de Castelnau, who has studied the Condor in the Andes, writes with regard to this subject :- -

"Travellers, who have sunk down upon the ground when utterly worn-out with fatigue and suffering, have been known to be attacked, and finally torn to pieces, by these ferocious birds, which pluck strips of flesh off their victims, having first disabled them with blows of the wing. The unfortunates may resist for a time, but ere long a few blood-stained fragments are all that remain to announce to the passer-by the horrible death suffered by those who preceded him on these dangerous paths."

The Condor possesses extraordinary tenacity of life. Humboldt 
relates that he found it impossible to strangle one, and that he was compelled to shoot it to put an end to its existence.

When the Condor is gorged with food it becomes very heavy,

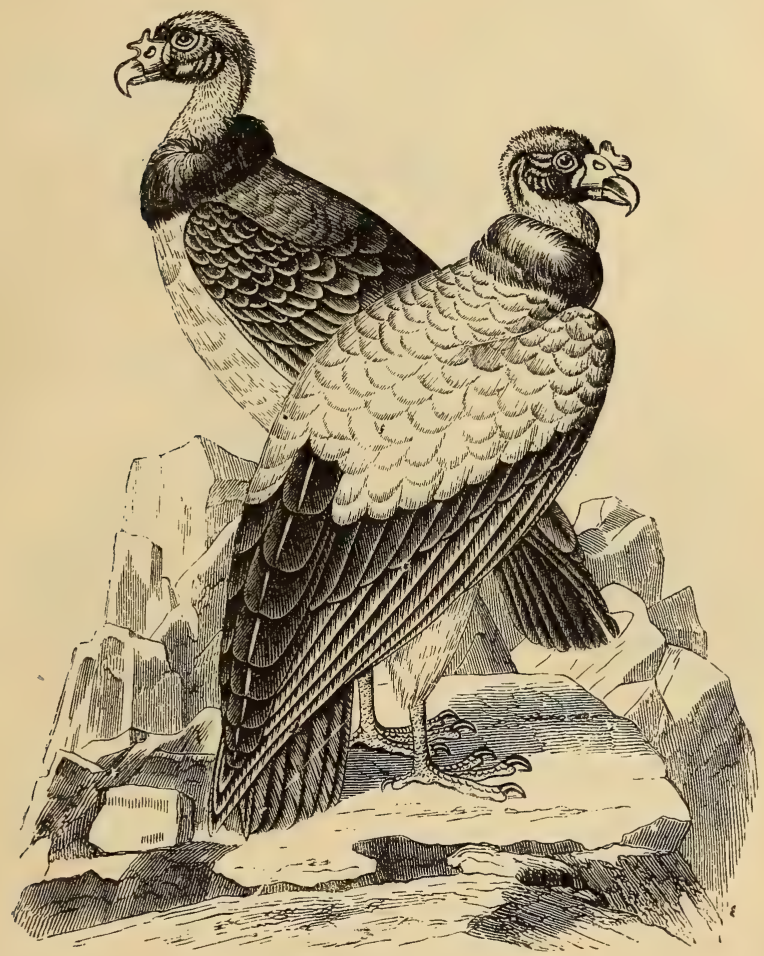

Fig. 282. - King Vultures.

and unwilling to fly. The Indians, who are well aware of this peculiarity, take advantage of it to destroy the robber thus:Carrion is placed in full view to entice the Condors. When the birds have thoroughly surfeited themselves they are hunted on horseback and entangled with lassoes, to be finally beaten to death with clubs. 
Condors do not assemble in flocks except when devouring an animal of great size. The hen bird lays a couple of eggs in a crevice on the mountains or cliffs; nest-building they entirely disregard. The rearing of the young requires several months; the parent birds feed them by disgorging into their bills the food which they have stored in their crops. All the Vulture tribe do the same.

The Condor is tamed with difficulty; captivity seems only to increase its savage nature. Humboldt kept one at Quito for eight days, and he states that to approach it was always dangerous.

The King Vulture (Sarcoramphus papa, Fig. 282) is distinguished from the Condor by the collar or ruff which surrounds the neck being slate colour, and also by its orange crest, situated on the top of the bill. Instead of confining itself to arid and barren localities, it frequents plains and wooded hills, and nests in the hollows of old trees. Its habits are, however, very much the same as those of the condor. It has been named the King of the Vultures because the other species dread it, as it appropriates their prey. It is found in Mexico, Guiana, Peru, Brazil, and Paraguay, and occasionally in Florida, doubtless its most northern habitat. In this species the female has a crest as well as the male.

The genus Catharta has a long and elongated bill ; the head and neck bare; the nostrils oblong and pierced through; the wings obtuse, and reaching a little beyond the tail. There are three species : the Urubu and the Turkey Buzzard, natives of America, and the Alpine Vulture, or Pharaoh's Hen of Bruce, peculiar to the Old World.

The Urubu (Vultur atratus, Fig. 283), is the size of a small Turkey. Its plumage, of a brilliant black, gives it a somewhat dismal look, which is amply justified by its disgusting habits. This bird is of a sociable nature, and is always met with in numerous flocks. Like all birds which subsist on decomposed animal matter, it is the constant guest of man, and accompanies him in all his wanderings through its habitat. In nearly all the large towns of South America it has acquired rights of citizenship, where it may be seen almost in a domestic state, and multiplying under the protection of the laws. In Peru the inhabitants are interdicted from killing a Urubu under penalty of ten pounds. The same prohibition exists in Jamaica.

This will easily be understood when it is explained that in these countries the Urubus perform the whole duty of cleansing the public streets from all kinds of filth and garbage, which, under the influence of a tropical sun, would certainly infect the air and engender continual epidemics. These birds, officiating as public scavengers, 
preserve the general health, and are therefore placed under the protection of the laws, in spite of their unpleasant aspect and their unclean odour.

"The familiarity and tameness of the Urubus," says Alcide D'Orbigny, "are extreme. At the time of the distributions of $m$ cat

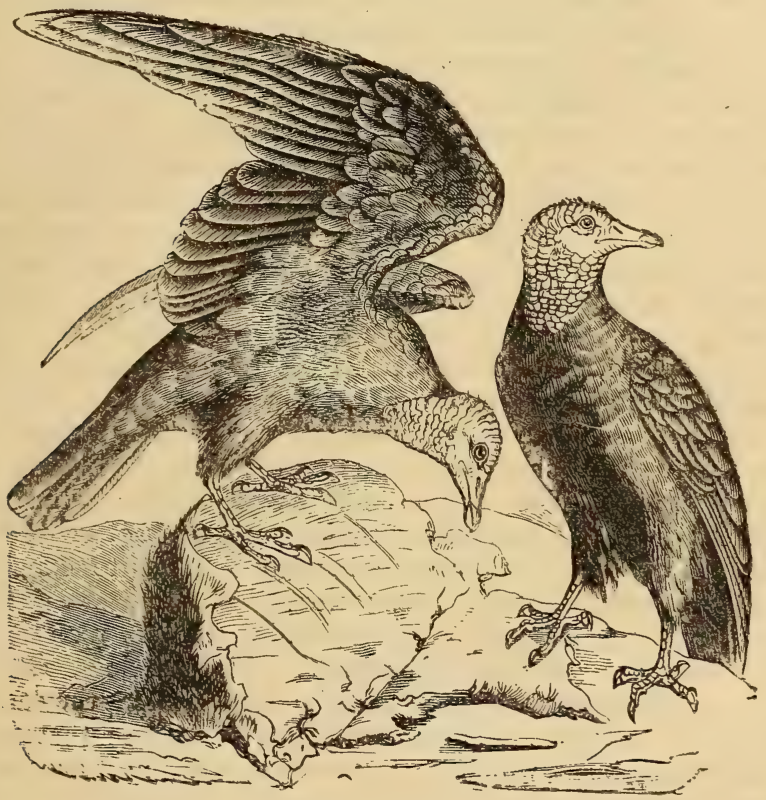

Fig. 283.-Urubus.

made to the Indians in the province of Mojos I have known them snatch away the pieces as soon as the men had received them., $A_{\text {t }}$ one of these periodical distributions at Concepcion de Mojos, an Indian told me beforehand that I should see the most impudent bird possible, which was well known to the inhabitants by having lost a foot. It was not long, in fact, before we saw it come up, and it certainly showed all the qualities that had been attributed to it. I was told," says he, "that it was perfectly aware of the time of the distribution, which took place every fifteen days in each mission. 
And true enough, for happening to be present the following week at a similar performance at the mission of Magdalena, distant twenty leagues from Concepcion, I heard the Indians cry out, and soon recognised the lame Urubu, just arrived. The cur's of the two missions informed me that this bird never failed to be present on the fixed days at both places. This fact would seem to indicate a very high degree of instinct in the Urubu, combined with memory."

According as it inhabits country or town; the Urubu passes the night on branches of trees or roofs of houses. As soon as it is light in the morning it proceeds to search for food; and, describing wide circles in the air, explores the neighbourhood. If it perceives a carcase, it pitches on it, and, from the power with which its beak is furnished, soon effects an opening through the hide into the intestines. But its movements have been watched by others, and soon thousands arrive to take part in the putrid banquet. Contests and fights, wrangling and struggling, in which the strongest is triumphant, then arise. In an incredibly short time the carcase is devoured, and nothing remains but a skeleton, the bones of which are cleaned as thoroughly as if done by an anatomist. The Urubus afterwards perch in the neighbourhood, and with their necks drawn back between their shoulders, and their wings extended, rapidly digest their food. The Urubus, like most of the Vulture family, spread their wings out for hours, although in a state of repose. The cause of this habit is that the attitude permits them to exhale from their bodies a kind of greasy perspiration.

In spite of the services which this bird renders man it is still regarded with the greatest repugnance. Nevertheless, D'Orbigny states that he has seen some completely tamed, and that they appeared susceptible of affection. This naturalist also relates that a creole had one of these birds, which he had reared, and that it accompanied its master wherever he went. At one time its master having fallen ill, the bird became very sad; but finding one day that the window of the sick-room was left open, it flew in, and came close to the invalid, manifesting by its caresses the joy it felt at seeing him again.

The Turkey Buzzard (Vultur aura) is a native of the same hemisphere as the preceding species, but is more addicted to temperate climates. It is met with as far north as the shores of the great chain of lakes which sever Upper Canada from the United States. It is the same size as the Urubu, and its habits of life are nearly identical. Like the Urubu, too, it is protected by the laws. In Peru, for instance, any one who kills an Aura is punished by a fine of fifty piastres; in Cuba, the culprit is excommunicated. They are capable 
of standing a great amount of cold : when snow covers the ground in the great stock-raising State of Illinois they may be seen congregated in numbers wherever carrion is to be found.

The Alpine Vulture (Percnopterus) is to the Old World what the Urubu and the Turkey Buzzard are to the New. It is very common in Greece, Turkey, Egypt, and Arabia. In Constantinople and other Eastern cities it performs the duty of the scavenger by removing all the putrid matter which the carelessness and apathy of the inhabitants allow to remain in the streets. A great amount of respect is consequently paid them; and although the law inflicts no penalty for killing them, they nevertheless enjoy the most perfect security in the midst of the Mussulman population.

These birds were well known to the ancients, who gave them the name of Percnopterus on account of the colour of their wings. The Egyptians classed them among sacred birds, and often represented them on their monuments as religious symbols. Flocks of them are in the habit of following caravans across the desert; and, as they invariably accompany the pilgrims in their journey to Mecca every year, some devout Mussulmen have bequeathed money sufficient to feed numbers of these birds which manifest such fidelity to the faith of Islam.

They are about the size of a Domestic Fowl; hence they obtain the name of Pharaoh's Chickens, by which they are designated in Egypt. Although they do not manifest much inclination for living prey, they will sometimes attack small mammals which are incapable of defence or flight. The Crow is an adversary whose superiority they never fail to acknowledge, and rarely dare to resist.

The Pondicherry Vulture (Vultur ponticerianus), the Indian Vulture (Vultur indicus), and Kolbe's Vulture (Vultur Kolbii), are also deserving of notice; the two former are found principally in Hindostan, the latter in different parts of Africa as well as Java.

The Vultures properly so called (Vultur, Cuv.) have the head and neck bare, the latter being surrounded at its base by a ruff or collar of feathers; the nostrils round or oval; the tarsi bare or feathered on the upper portion; the middle toe very long ; the wings pointed, and almost hanging down to the ground. Their flight, although powerful, is slow and heavy ; they take wing with difficulty, and this fact has procured for them their name of Vuitur (volatus tardus, slow flight). Preferring putrid meat, they feed but little on flesh in a fresh state, although they do not absolutely refuse it; they consequently seldom attack living animals.

Buffon has branded the Vulture with a stigma of infamy which 
will always cast an odium on its name. "Vultures," says he, "are actuated by nothing but a degraded instinct of gluttony and greediness. They will never contend with the living if they can glut their appetites on the dead. The Eagle attacks its enemies or its victims face to face; it pursues them, fights them, and seizes them by its

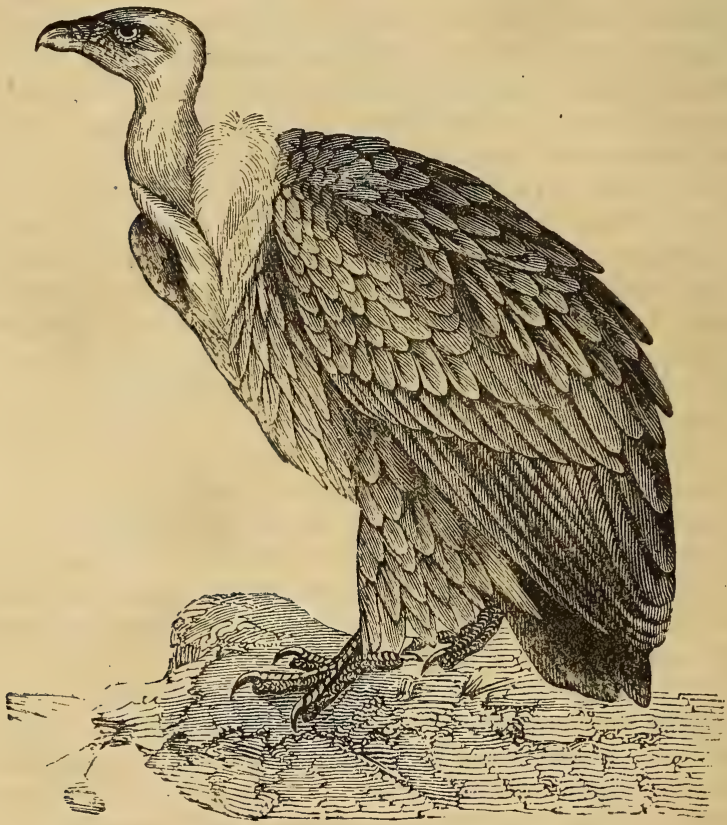

Fig. 284.-The Fulvous Vulture.

own individual prowess. Vultures, on the contrary, however slight may be the resistance which they anticipate, combine in flocks like cowardly assassins, and are rather thieves than warriors-birds of carnage rather than birds of prey ; for these are the only birds which are so madly devoted to carrion that they pick the very bones of a decaying carcase. Corruption and infection seem to attract instead of repelling them." Further on, too, he adds, "In comparing 
birds with quadrupeds, the Vulture seems to combine the strength and the cruelty of the tiger with the cowardice and gluttony of the, jackal.".

This fanciful naturalist has, however, been unjust to the Vulture. In depicting it in such very dark colours, his desire seems to be to contrast it with the Eagle, which he had represented as the highest type of courage and nobility; and he has evidently yielded to the temptation to make the contrast between the two birds as striking as possible. The idea of this antithesis must, in fact, have led Buffon's mind astray, as he was often more fond of figure than fact. The Vulture seeks after carrion because it prefers it ; and its not attacking living animals, like the rest of the family, is caused by the fact that it is neither armed nor organised for strife. It obeys the irresistible and ordained instincts of Nature, and to its doing so we have no right to attribute false motives. In the present day it is really time to have done with all these time-worn rhetorical fancies which are in continual and complete variance with the results of science and observation.

The Vulture genus comprises several species, all of which belong to the Old World.

The Fulvous Vulture (Gyps fulvus, Fig. 284), the size of which is about equal to that of the Goose, is a native more especially of the south and south-east of Europe. It is common in the Pyrenees, Alps, Sardinia, Greece, Hungary, Italy, and Spain ; it is rarely seen in France. It makes its nest in the crevice of some inaccessible rock. When pressed by hunger it shows no fear in attacking living animals; it is thus an object of dread among the shepherds along the sea-coast of the Mediterranean. It is easily tamed when caught young. Of this fact M. Nordmann gives us an instance:-

"A lady residing at Taganrog," says he, "was in possession of one of these vultures, which was in the habit every morning of leaving its home and resorting to the fresh-meat market, where the bird was well known and usually fed. If it so happened that it was refused its daily pittance, it was always well able to get hold of it by some cunning or other; and then, after the larceny was committed, the bird would take itself off to the roof of some neighbouring house, so as to consume its plunder in peace, and safe from any attack. This bird would often cross the Sea of Azoff, and visit the city of the same name, situated opposite Taganrog; and, after having spent the day there, would come back at night to the house of its mistress." 
There is a variety of the above bird rather larger than the one just noticed. It is common in the Alps, Pyrenees, the Tyrol, the Greek Archipelago, and also in the south of Spain, in Egypt, and a great part of Africa. In autumn it leaves the temperate regions to winter in warmer climes. M. Degland and M. Bouteille mention various instances of courage shown by it, wherein it repelled dogs wishing to participate of its food. Another bird of the same kind, having flown away from its master's house, grievously: wounded two

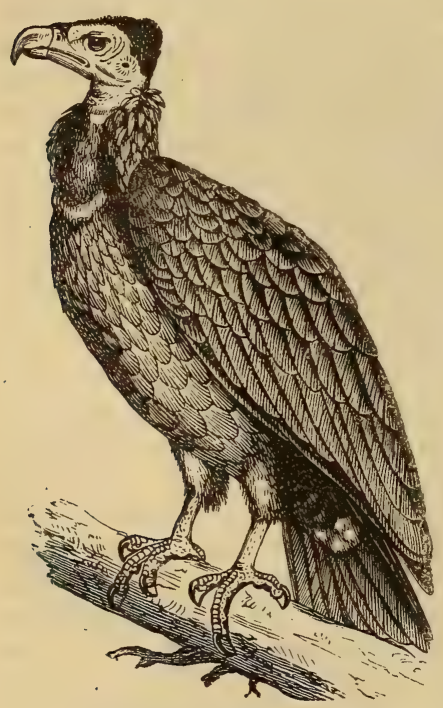

Fig. 285.--Pondicherry Vulture. men who endeavoured to catch it. The shepherds fear it even more than the preceding.

The Sociable Vulture (Otogyps auricularis) is a native of the lofty mountain regions of Africa. It has a tleshy crest, which, taking its rise close to each ear, extends down the neck; from this it derives its Latin specific name. Levaillant, who often observed it in Africa, was several times a witness of its voracity. One day he had killed a couple of buffaloes, and, after having had them cut up, caused the quarters of meat to be hung to dry in the sun; they were soon assailed by a flock of these Vultures, which carried away the pieces of flesh in spite of the numerous gunshots with which they were greeted. On another occasion, having killed three zebras at some distance from his camp, he went to find a wagon to carry them home; on his return he found nothing but the bones remaining, round which hundreds of Vultures were hovering.

The Pondicherry Vulture (Otogyps calvus, Fig. 285) is a well known Indian bird: it is scarcely as large as the one previously described, but in habits of life they are very similar.

Lastly, the Chinese Vulture (Vultur leuconotus), which is about the size of a Turkey, is of a dirty brownish black on the body, and white about the shoulders; it is very common in the southern portions of the Celestial Empire. 
The Serpent-eaters (Gypogeranus).

This family comprehends but one single species, the Secretary Bird, which in its organisation seems allied to the Waders.

The Secretary Bird (Serpentarius secretarius, Fig. 286) has a

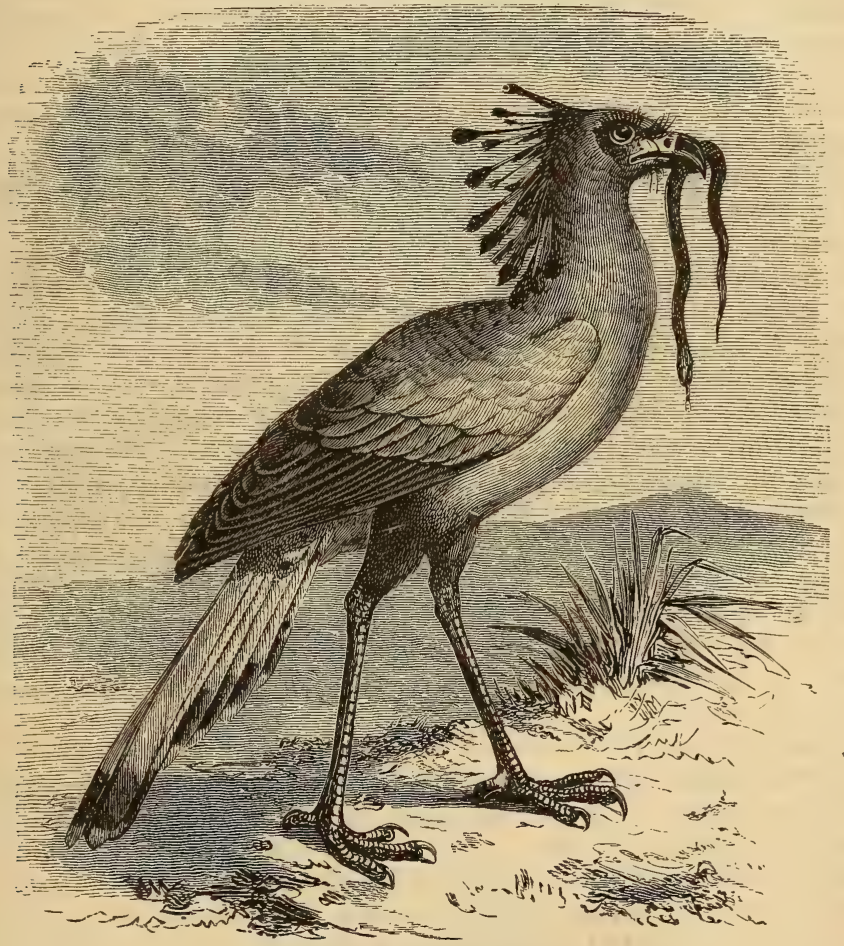

Fig. 236.-Secretary Bird.

widely-opening bill, very crooked and very powerful; a projecting superciliary arch; tarsi very long, and covered, as well as the toes, with large and hard scales; the tail is tapering, and the two middle feathers are longer than the others; the wings, which are short and provided with bony protuberances, form most destructive weapons, 
which the bird uses with much skill to disable the various snakes of which its food principally consists. It has on its head a tuft of long feathers, which can be raised at will. This has been the origin of its name, in allusion to the custom that clerks had of placing their pen behind their ear in the days when goose-quills were used for writing. Its toes are short, and its claws blunt and well-adapted for walking. It consequently runs very rapidìy hence it sometimes obtains the name of Messenger Bird.

A contest between a Secretary Bird and a serpent is a most curious sight. The reptile, when attacked suddenly, stops and rears itself up, swelling its neck and showing anger by shrill hissings.

"At this instant," says Levaillant, "the bird of prey, spreading one of his wings, holds it in front of him, and covers both his legs as well as the lower part of his body with it as if with a buckler. The reptile makes a spring at his enemy; the bird makes a bound, and, spurning the serpent with his wing, retreats again, jumping about in every direction in a mode which to a spectator appears highly grotesque. He soon returns to the combat, ever presenting to the venomous tooth of his adversary nothing but the end of his well-protected wing; and whilst the latter is fruitlessly expending its poison by biting the callous feathers, the bird is inflicting vigorous blows with his other wing. At last the reptile, stunned and wavering, rolls at full length in the dust; the bird then cleverly catches hold of it, and throws it several times up into the air, until, the victim becoming exhausted and powerless, the bird crushes its skull with his sharp-pointed bill. The serpent is then swallowed whole by its conqueror, unless it is too big, in which case it is first torn in pieces."

The Secretary Bird does not feed exclusively on serpents ; it also consumes lizards, tortoises, and even insects ; its voracity is extreme, and it possesses a power of digestion which is really surprising. Levaillant killed one, the stomach of which contained twenty-one small tortoises (still whole); eleven lizards, each eight or nine inches long; three serpents, of a length varying from two to two and a half feet; a perfect heap of grasshoppers and other insects ; asd, lastly, a great pellet of various remains which it had not been ab.e to assimilate, and which would have ultimately been vomited up.

These birds are natives of the arid plains of South Africa. They pair about the month of July, the male birds having first engaged in sanguinary conflicts for the choice of their mates. Their nest, which is flat and lined on the inside with down and feathers, is constructed in the thickest bushes, or on the loftiest trees, in which two or three 
eggs, of a white hue spotted with red, are laid. 'The young ones are very late in quitting the parental home; for they do not leave it till they have acquired full development. Nearly four months elapse before they are able to stand firmly and run about with complete freedom.

The Secretary Bird is much appreciated at the Cape of Good Hope, on account of the services it renders in destroying venomous reptiles. As it is easily tamed if captured when young, the colonists have made a domestic bird of it, and use it to protect their poultry against the incursions of serpents and rats. With the inhabitants of the poultry-yard it is always on good terms, even to quelling the quarrels which spring up among the Gallinaceæ around it. But it must be told that it is necessary to see that it is sufficiently fed, for otherwise it will not hesitate to help itself occasionally to a chicken.

In 1832 the Secretary Bird was introduced into the French West Indies, particularly Guadaloupe and Martinique, on purpose to make war upon the Trigonocephalus, or Rattlesnake, a dangerous reptile swarming in those countries, which we mentioned in a previous portion of this work. The introduction of the Secretary Bird into the Antilles proved to be a real benefit. In order to be convinced of this it is only necessary to read the interesting work on this question published a few years ago by M. Rufz de Lavison, who was for a long time an inhabitant of the French West Indies previous to his becoming director of the Jardin Zoologique d'Acclimatation in Paris. 



\section{N D E X.}

THE ITALICS ARE ILLUSTRATIONS.

Aboma, The, 56.

$$
\text { The, } 58 .
$$

Adder, Common, 86.

Fangs and Tongue of an, 88.

Adders, Common, 85.

$$
\text { , Death, } 64 \text {. }
$$

,? Puff, 83.

Adjutant, 33I.

Agami, or Hooping Crane, The, 338, 342.

Albatross, Black-browed or Sooty, 290.

, Common, 290.

, Common, $29 \mathrm{I}$.

,Y Yellow and Black-beaked, 290.

Alectors, 420.

Alligator, 140.

Alligators, 138 .

Ameivas, The, 105.

Amphibia, or Batrachians, 7 .

, Antiquity of, 17 .

," Characteristics of, $\mathbf{3} 4$.

, Distribution of, I 7 .

," Intelligence of, I3.

, Structural Distinctions of, 8.

Anaconda, The, 6 o.

$$
\text { , Boa, The, } 59 .
$$

Anatomy, Internal, of Birds, 177.

Anis, 446.

Anoles, II9.

Apteryx, or Kiwi-kiwi, The, 364.

Aracari, Curl-crested, 442.

Aracaris, The, 442.

Archeopteryx lithographicus, 3.

Argala, The, or Adjutant, 330.

Argus, The, 397, 402.

Asp, The, 70 .

Auk, 203.

Avocet, 294.
Avocet, The, 294.

Baltimore Orioles, The, 486.

Bankiva Fowl, The, 397.

Barbet, Collared, 447.

Barbets, 447.

Basilisk, The, I 8 .

" Hooded, The. II9.

Bec-ouvert, The, 331.

Bee-Eaters, The, 460.

Beef-Eater, The, 487.

", The Common, 460 .

Beef-Eaters, The, 486.

Bernicle, White-fronted, 249.

Bewits, 583.

Bird, Frigate, 258.

" Secretary, 6ir.

"Stilt, 294.

,, Tropic. 26r.

", Weaver, 496.

", , Republican or Sociable, 497.

,' Widow, or Whidah Finch, 495.

Bird of Paradise, Golden, 475.

,

King, 474 .

Birds, Anatomy of, 166.

Superb, 474.

, Beak or Bill of, 173 .

, Classification of, 190.

, Digestive Organs of, 176.

", Longevity of, 187.

, Nests of, 181.

" Plumage of, 170.

,, Powers of Sight of, 177,178 .

"Reproduction of, $\mathbf{1} 8 \mathbf{I}$.

,Utility of, I89.

,, Vocal Organs of, 179.

Bittern, Sun, 344. 
Bittern, The, 337 .

Blackbird, Common, 529.

$$
\text { , Common, } 530 .
$$

, $\quad$ Ring, 53I.

Blindworm, 97.

Solitary, 531.

Blunt-Heads, or Amblycephalidæ, The, $5 \mathrm{I}$.

Boas, The, 36, 51 , 56.

Boatbill, The, 325, 331.

Brevipennæ, 353 .

$$
\text { The, } 333 \text {. }
$$

Buffon's Skua, 286.

Bullfinches, The, 489.

Bullfinches, 490.

Bungarus, 7I.

Bunting, Black-throated, 498.

" Common, 498.

", Ortolan, 499.

Buntings, The, 497 .

, The Cirl, 498.

, The Ortolan, 498.

", The Reed, or Black-throated, 498.

The Snow, 499.

Bustard, The, 352.

, The Great, 352.

., Little, 353.

Buzzards, 592.

$\begin{array}{ll}, & \text { Common, 593. } \\ , & \text { Common, 594. } \\ , & \text { Foney, 593. } \\ , & \text { Foot of, r 73. } \\ \text { Rough-legged, 593. }\end{array}$

Caimans, The, 138.

Canaries, 494.

Canary, The, 494.

Capercaillie, or Cock of the Woods, The, $37 \mathrm{r}$.

Caracaras, Black, 596.

" The, 595 .

", , Brazilian, or South American, 596.

, , Chimachima, 596.

, , Chimango, 596.

, " $\quad$ Funebris, 597.

Cariama, 345 ".

,, Long-winged, 596.

Cariama, The, 325, 344.

Cassicus, The, or Piping-Crow Shrike, 543.
Cassowary, The, 362 .

," The, 363 .

Cathartes, The, 604.

Foot of, 173 .

Caurale, The, 343 .

Cephalopterus ornatus, or Umbrella Bird, 538.

Ceyx Meninting, or Tridactyla, 460.

Chaffinch, The, 493. , The, 493.

Chameleon, Common, I28.

Chameleons, The, I26.

Chat-stone, The, 520.

Chatterers, The, 536 .

Chelonians, or Shielded Reptiles, 142.

Chinidæ, The, 371, 394.

Cobra di capella, 69.

Cobras, The, 65.

Cock of the Plains, 371, 372.

$$
\text { , , Rock, 513, 514. }
$$

," , Woods, 372.

Cockatoo, Leadbeater's, 44I.

Cockatoos, 440.

Colibri, 464 .

Colin, Californian, 391.

, Solitary, 39r.

, Virginian, 391.

Columbars, 430.

Columbi-Gallines, 422 .

Columbidæ, 421 .

Condor, The, 60I.

" The, 600 .

Conirostres, 455, 472.

Coots, 296, 300 .

" Bald, 300 .

", Bald, 300.

", Blue, 30r.

", Crested, 30I.

,, Foot of, 173 .

Cormorant, The, 266.

$$
\text { ", The, } 267 .
$$

Cotinga, The, or Coracina, 535 .

Coturnix, The, or Turnix, 392.

Coursers, Cream-coloured, 347 .

Crane, The, 325,338 .

" Ash-coloured, 338.

," Bill of, $\mathbf{1 7 5}$.

, Common, 338 .

, Crested or Crowned, 338, 342.

" Crested, 343. 
Crane, Demoiselle, 338, 34I.

,' Demoiselle, 342.

", Hooping, 338, 342.

Creepers, The, 469.

Crested Screamer, 304.

Crocodiles, I 30.

True, 132.

Crop" and Digestive Organs, 176.

Crossbill, The, 487 .

Crossbills, 488.

Crows, 474.

," Carrion, 475, 479.

Cuckoos, 443 .

Royston, 479.

$$
\begin{array}{ll}
, & \text { Bill of, r775. } \\
, & \text { European, } 446 . \\
\text { Grey, 443. }
\end{array}
$$

Cultrirostres, 325 .

Curassow, Crested, 420.

Curassow, The, 321, 394, 420.

Curlew, The, 305 .

Curlere, $32 \mathrm{I}$.

Darter, The, 263.

Darters, The, 263.

Dentirostres, 455, 513 .

Dicrurus, The, 534 .

Dinornis, The, 369.

Dipper, The, 528.

Divers, Arctic, 195.

,, Black-throated, 198.

", Great Northern, 195.

", Great Northern, 196.

," Imbrius, 195.

", Red-throated, 198.

Dodo, The, 368.

," The, 367 .

Domestic Forels, 405.

Dotterel; Common, 35 r.

The Ringed, 35 r.

Dove, Ring, The, or Laughing, 423, 427 .

The Turtle, 423, 427.

Drome, The, 331 .

Drongos, The, or Dicrurus, 534 .

Duck-shooting, Open, 221.

" Eider, 230.

, Velvet, 235.

Ducks, Wild, 2r4.

Dunlin, The, $3 \mathbf{1} 3$.

Eagles, Bonelli's, 571 .
Eagles, Bald, $57 \mathrm{r}$.

, Bill of, I74.

, Booted, $57 \mathbf{I}$.

", Golden, 568.

," Harpy or Crested, 575.

, Imperial, 57 I.

, Imperial, 569.

,, Martial, 57I.

,, Reinwardt's, 571.

, Royal, 57 I.

,, Tawny, 57I.

", White-bellied, or Jean le Blanc, 575.

White-headed, Foot of, 173 .

", Wing of, 168, 564 .

,, Sea, 572 .

,, , American, 572.

,, ,, Caffir, 573 .

,, ,, European, 572.

,, , Indian, 573 .

,, , European, 570.

,, ,, Mace's, 573.

,, , Marine, 573.

,, , $\quad$ Piscivorous, 573.

,, ,, Pondicherry, 573.

Egret, The, 335.

,, The, 334, 337.

Elodians, or Marsh Tortoises, 147.

Emerald, The Great, 473.

Emu, The, 364 .

The Great, 473 .

Emydes, The, 148, 149.

Epimachus, The, 464 .

Epimachus, 464.

Epiornis, The, 369.

Falco urubitinga, or Brazilian Eagle, 574.

Falcon, Chanting, The, 591.

Falcons, Bengal, $38 \mathrm{r}$.

, Dressed, 584.

, Lanner, 576.

" Lanner, 578.

", Peregrine, 577.

Fauvette Couturière, La, 517.

Fer-de-lance, The, 74.

Fer-de-lance, The, 73.

Fissirostres, 455,503 .

Flamingo, The, 256 .

Flamingoes, 258.

Fly-catcher, Forked-tail, The, 539.

„,. : Spotted, The, 537. 
Flycatcher, The, 456, 537 .

Francolins, African and Indian, 392.

Frigate Bird, 259.

Chinese, 392.

Frogs, 18 .

, Common, 22.

," Development of Young of, 20.

,Edible, 19.

, Green, or Edible, I8, 22.

," Green-tree, 22.

", Green-tree, 23.

" Habits of Life of, I9.

,- Skeleton of, $\mathbf{I} 2$.

Furnarius, The, or Oven Bird, 470.

Gallinaceous Birds, 370.

Gallus, or Cock, 402.

, Bankiva, 402.

," Bronzed, 402.

," Common, 402 .

", Fork-tailed, 402.

, Kulm, 402.

,, Negro, 402.

Gangas, The, or Sand Grouse, 375 .

Gannet, 265.

Gannets, The, 264.

Garrot, Golden-eyed, The, 226.

Gavials, The, 137 .

Gecko, Wall, i25.

Geckos, The, I24.

Gelinotte, The, or Hazel Grouse, 372.

Glaræola, The, or Pratincole, 301.

Goatsuckers, 5 I0.

Godwit, The, 320 .

Godwit, 320.

Goldfinch, The, 49I.

Goldfinches, 492 .

$$
\text { Nest of, } 163 .
$$

Goosander, The, 240.

Goose, The, 242.

$$
\begin{aligned}
& \text {," , Bean, } 248 . \\
& \text { ", ,, Bernicle, 248. } \\
& \text {, , , White Bellied, } \\
& \text { ", } \quad \text {, Bill of, 175. } \\
& \text { ", ", Domestic, } 246 . \\
& \text {," ," Wild, } 242 .
\end{aligned}
$$

Goshawk, The, 589.

Goshawks, 589.

Grallatores, or Wading Birds, I9I, 292.
Grebes, 202,

" Castanean, or Great Crested, 203.

Crested, 204.

," Crested, 204.

Griffon, The, or Gypaëtus, 598.

," ," Bearded, 598.

Grosbeak or Hawfinch, 489.

Grosbeak, The, 488.

Grouse, Black, 37I, 372.

, Black, 373.

" Pinnated, 371, 372.

,, Hazel, 374.

,, Pin-tail Sand, 376 .

, Red, 37I, 374.

, Ruffed, 371, 372.

Guacharos, The, 513 .

Guillemots, 205.

Guillemots, The, 205.

Guinea Fowl, 4I2.

Guinea Fowls, 397.

Gulls, The, and Allied Species, 282.

", Black-backed, 284.

", Great black-backed, $2 \& 2$.

", Grey, 284.

", Herring, 284.

", Large White Winged, 284.

,, Laughing, 285.

Gyrfalcons, 576 .

$$
\begin{array}{ll}
, & \text { Iceland, } 576 . \\
, & \text { Norway, } 576 . \\
\text { White, } 576 .
\end{array}
$$

Harpy, The, 574 .

Harrier, Hen, 595.

Harriers, 593.

, Ash-coloured, 595.

, Frog-eating, 594.

", Hen, 594.

, Jardine's, 595.

Moor, or Marsh, 594.

,, Pale-chested, 595.

Heron, Common, 335.

Heron-hawking, 586.

Herons, 325, 333 .

,, Common, 334 .

, Night, 334 .

, $\quad$ Purple, 334, 337.

, White, 337.

Heteroclites, The, 375 .

Hoatzins, The, 421 .

Hobby, Tie, 579. 
Hobby, The, 580 .

Hocco, or Curassow, The, 321, 394, 420.

Homopodes, The, 147.

Honey-Sucker, The, or Honey-Eater, 527.

Hood, 583 .

Hoopoes, 463 .

The, 462.

Hornbill, Rhinoceros, 457.

Hornbills, or Calaos, 456 .

Rhinoceros, 456 .

House Sparrow, The, 490 .

Humming-Bird, Nest of, I82, 466.

Huppart, The, 574.

Birds, 188, 464.

Hyacinthine gallinule, 298.

Ibis, The, 305, 322 .

", Glossy, 325 .

,, Sacred, 322.

, Sacred, 323.

," Scarlet, 325.

Jguana, Common, IIo.

Iguanas, I09.

Impeyan Pheasants, 420.

Indicators or Honey-guides, 445.

Jabiru, The, 325, 331 .

, . The, 332.

Gacamar, Paradise, 453.

Jacamars, 453.

Facana, Common, 302.

Jacanas, The, 302 .

Jacares, 138 .

Jackdaw, The, 479 .

Jararaca, The, or Callophis Braziliensis, 75.

Java Sparrow, The, 496.

Fay, European, $48 \mathbf{1}$.

Jays, The, 482 .

Ferfalions, 577.

Jungle Fowl, The, 402 .

Kamichi or Screamers, 304.

", Faithful, 304.

," Faithful or Crested, 305.

", Horned, 305.

" Wing of, 169

Kestrel, The, 580 .

Kestrel, $58 \mathrm{r}$.

King Bird of Paradise, 473.
Kingfishers, 458.

Kingfishers, $45^{8}$.

Kinglet, Nest of, 182.

King Tody, 538.

Kinixys, The Genus, I 47 .

Kites, American, 592.

,, Black, 592.

, Common, 591.

,Common, 590.

, Parasite, 592.

Kittiwake, 285.

," The, 283,285 .

,, Grey, 285.

Kiwi-kizei, or Apteryx, 367.

Knot, The, 305, 313.

Lapwings, 349.

Laridæ, The, 277 .

Larks, 502.

,, Crested, 503.

Linnets, 492.

Linnets, 492.

Lizards, Distribution and Division of, $92,93$.

, Flying, I22.

," Flying, 123.

", Green, I03.

,, Green, I03.

," Grey, I02.

,, Ocellated, I03.

", Ocellated, 103.

, Order of-Saurians, 92.

Longipennes, The, 277.

Longirostres, 305.

Love-birds, Swindern's, 438.

Lure, The, 584 .

Lyre Bird, 524.

Lyre-tail, The, 524 .

Macaw, Blue and Yellow, 436.

,' The, 436 .

Macrodactyles, 296.

Magpies, 480.

, Brazilian, 482.

", Chinese, 482.

, Common, 48I.

Mallard, 2 I4.

Common, $48 \mathrm{r}$.

," The, 213.

Manakin, The Golden-winged, 535.

Manakins, The, 5I4, 535 . 
Marabou, The, 330.

Martins, House, 505.

Megapodidæ, The, 371, 394:

Merlin, The, 580 .

Merlins, 580 .

Mino, The, 526. Bird, The, 526.

Mocking Bird, 'The, 53I.

Motmot, Brazilian, 46I.

Motmots, 46r.

Natatores, or Swimming Birds, I9I, 193.

Neck covert, 172 .

Newts, $3 \mathbf{I}$.

Nightingale, The, II8, 515.

Nightingale, 515.

Night-jar, 512 .

Noddy, The, 28r.

Nutcracker, The, 483 .

Nutcracker, 483 .

Nuthatch, Common, 47 I.

Nuthatches, The, $47 \mathrm{I}$.

Ombrette, The, or White-headed Stork, 33I.

Oricon, The, or Pondicherry Vulture, 6 Io.

Orioles, 486, 525 .

, Baltimore, 787.

," Golden, 525.

,, Golden, 525 .

Osprey, The, 573.

Orvet, or Blindworm, The, 96.

Ostrich, The, 354 .

Ouzel, Rose-coloured, 527.

Water, or Dipper, 527.

Oven-birds, 469.

Owls, 547 .

$$
\begin{aligned}
& \text {,, Barn, } 557 . \\
& \text {," Nest of, I83. } \\
& \text {, Barn, } 556 \text {. } \\
& \text {, Burrowing, } 553 . \\
& \text {,, Canada, } 553 \text {. } \\
& \text {," Caparacoch, 56o. } \\
& \text {,, Great, } 547 . \\
& \text {,, Great, } 548 . \\
& \text {,, Harfang, } 560 . \\
& \text {," Hawk, or Canada, } 55^{8} . \\
& \text { „, Hawk, 553. } 558 . \\
& \text { " Horned, } 547 \text {. }
\end{aligned}
$$

Owls, Hornless, 553.

," Lapland, or Ura', 560.

, Scops-eared, 552.

", Scops-eared, 55 I.

", Short-eared, 550 .

," Tawny, 556 .

,U Ural, 553.

, Virginian, 550 .

,, Virginian Eared, 55 I.

," White, 559.

Oyster-catchers, Common, 346.

,

The, 345 .

Palmidactyles, 293.

Paradise, Birds of, 472.

, King Bird of, 473 .

Parrakeets, 437 .

Parrakeets, Rose Hill, 437.

Parrots, 43I.

Parrots, Green, 433, 439.

," Green, 440.

," Grey, 433, 439.

," Grey, 439.

," Tabuan, or King's, or Ground

Parrakeets, 438 .

Parraquas and Guans, 421 .

Partridges, Grey, 385, 386.

, Californian, 392.

,, Red-legged, 380, 386.

,, Rock, or Gambra, 39I.

Passerines, 455.

Pauxis, The, $42 \mathrm{r}$.

Peacock, 4I 7 .

Peacocks, Domestic, 418.

Pelicans, 270.

$$
\text { Wild, 419. }
$$

, Brown, 272, 275.

," Crested, 272.

, Crested, 273.

" Spectacled, 272, 276.

,, White, 272, 274.

Penelopes, or Guans, 421 .

Penguins, 199.

Penguin, King, 200.

," Wing of, 169.

Percnopterus, The, 607 .

Perdicides, 371, 375 .

Petrels, The, 287 .

" Capped, 288.

," Fork-tailed, 288.

," Fulmar, 288.

", Fulmar, 289. 
Petrels, Stormy, 288.

Wilson's, 288.

Phasianidæ, The, 371, $=97$.

Pheasant, Foot of, 173 .

Pheasants, 397.

$\begin{array}{ll}, & \text { Common, 398. } \\ , & \text { Common, 397. } \\ , & \text { Golden, 40I. } \\ \text {,", } & \text { Impeyan, 420. } \\ \text { Impeyan, 419. } & \text { Lady Amherst's, } 402 . \\ , \quad & \text { Reeve's, 397, 40I. } \\ , \quad & \text { Ring-necked, 40I. } \\ \text {, Silver, 40I. }\end{array}$

Picumnus, The, or Piculet, 470.

Pigeons (Colombes), 422.

Carrier, 426.

", Common Domestic, 423, 424.

, Crowned, 423.

", Fan-tailed, 427.

", Lungs of, 168.

," Migratory, 428.

," Nun, 427 .

, Passenger, 427.

, $\quad$ Pouter, 426.

, Respiratory organs of, 167 .

,, Ring or Wood, 423.

, Roman, 426.

," Swift, 426 .

", Tumbler, 426.

", Wheeling, 427.

", Wild Rock, 424.

Pintados, The, or Guinea Fowl, 4II.

Pintailed Sand Grouse, The, 375 .

Pipits or Titlarks, 524.

Pleuroderes, The, I49.

Plovers, 349.

,, Golden, 350.

," Golden, 350.

, Great Land, 350.

", Kentish, 350 .

Plumes, I $7 \mathbf{I}$.

Plumules, 172.

Pluvian, The, $350,352$.

Pochard, The, 227.

Pochard, 227.

Polyplectrons, 4I9.

Potamians, or River Tortoises, 150.

Pratincoles, $30 \mathrm{I}$.

Pressirostres, 343 .

Promerops, 464 .

Ptarmigan, 375.
Ptarmigans, 373 .

", Common, 374.

Puff Adder, Horned, 83.

Puffins, or Shear-waters, 288.

, Brown, 288.

", English, 288.

,, Grey, 288.

Pythonidæ, or Pythons, 36, 37, 51, 54.

Pyxis, The Genus, 147 .

Quails, 375, 376.

Quaketail, The, 522 .

Quaketails, 523.

Rail, Land, 299.

Rails, 296, 298.

Raptores, or Birds of Prey, 192, 544.

," $\quad, \quad$ Diurnal, 560 .

Rattlesnake, Northern, 78 .

Raven, The, 479.

Redshank, 306.

Redwing, The, 533 .

Reptiles, Ophidian, or True Snakes, 35.

Rhea, The, 362.

Rhea, The, or American Ostrich, $36 \mathrm{I}$.

Rissas, 285.

Robin or Kedbreast, 518.

Robin, The, 518 .

Rock-pigeon, 425.

Rollers, The, $483,535$.

Rook, The, 480 .

," The, 479.

Ruff, The, 305, 308.

Runners, 347 .

Salamanders, Aquatic, or Newts, 30.

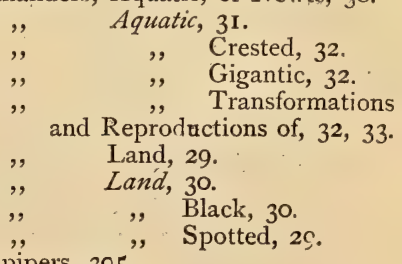

Sandpipers, 305 .

$$
\text { ," Brown, } 306 .
$$


Sandpipers, Common, 307.

," Green, 307.

,, Greenshank, 306.

,, Redshank, 306.

," Wood, 307.

Sapho Comet, 467.

Sarcoramphi, 600.

Scansores, or Climbers, I9I, 43I.

Scissors-bill, $28 \mathrm{I}$.

Scissors-bills, 28I.

$$
282 \text {." }
$$

Scoter, 236.

, Black, 236.

," Great-billed, or Surf Duck, 239.

Screamer, Crested, 304.

, Horned, 303.

Secretary Bird, 6I I.

Seps tridactylus, 95.

Serpent-Eaters, 6 I I.

Shaft, I7I.

Shag, The, or Green Cormorant, 269.

Shear-Waters, 288.

Shieldrake, The, 229.

, $\quad$ The, 230.

Shoveller, The, 228.

$$
\text { The, } 228 .
$$

Shrike, Great Grey, 541.

", Piping Crow, 542.

, Red-backed, 542.

Shrikes, 539.

, $\quad$ Pied Crow, 543.

Siflits, 474.

Piping Crow, 543 .

Siskin, 490.

, The, 489.

Skua, The, 285 .

, Buffon's, 287.

, Common, 287.

, Parasite, 287.

,, Pomerine, 287.

Skylark, 503.

Smew, The, 24I.

Smerv, 242.

Snakes, 38 .

$\begin{array}{ll}\text {, } & \text { Black, 45. } \\ \text {, } & \text { Blind, 42. } \\ \text {, } & \text { Carrowing, 39. } \\ \text {," } & \text { Copperhead, 76. } \\ \text { ", } & \text { Coral, 42. } \\ \text {, } & \text { Desert, 47. }\end{array}$

Snakes, Diamond, 54 .

Fresh-water, 39.

Guinea Rock, 57.

Green and Yellow, 47.

Ground, 39.

Innocuous, 4I.

Natal Rock, 55 .

Rat, 45 .

Rattle, 76, 77 .

Ringed, 45 .

Ringed, 46.

Rock, 55 .

,, Guinea, 56.

, Natal, 55, 56.

,, Royal, 55 .

Sea, 37, 40, 63 .

Shield-tail, 43 .

Tree, 39 .

Viperine, 48.

" $, " 47,73$.

Snipe, 305, 318.

" Common, 319.

, , 318.

, Great, 318, 319.

", fack, 3 I9.

", Jack, 318, 319.

,, Wilson's, 320.

Sociable or Republican Birds, Nests of, 184.

Solan Goose, 265.

Soui-Mangas, The, or Sun Birds, 471.

Sparrow, Hedge, Nest of, 182.

," House, 491.

Sparrow, Java, 496.

553 .

, , Pampas, 555.

", ", Small, 554.

Sparrow Haze, Common, 589.

, Hawks, 589.

,, , , Common, 590.

Spoonbills, 325 .

Dwarf, 591 .

, Common White, 326.

," Rose-Coloured, 325 .

Starling, 485 .

White, 325.

Starlings, 484 .

,, Common, 485.

Stiit" Bird, 295.

Sardinian, 485 .

Stint, The, 313. 
Slone-Chat, The, 522.

Storks, 325 .

The, 520 .

, Black, 329.

," White, 327.

," White, 330.

," White-headed, or Ombrette, $33 I$.

Sucriers or Cinnyridæ, 47I.

Superb, The, 474.

Swallow, 503. , Esculent, Nest of, $5 \mathrm{I}$ I.

, 509.

Swan, The, 250.

, Black, 255.

, Black, 256 .

,, Mute and Whistling, $25 \mathrm{I}$.

," Skeleton of, $\mathbf{1} 66$.

," Whooping, 252.

Swift, The, 509.

, Alpine, 5 Io.

,White-collared, 508.

Syndactyles, 455,456 .

Tadpole, Development of, $2 \mathbf{I}$.

Tail Covert, 172.

Tailor Bird, Nest of, I84.

Tanagers, 534 .

Scarlet, 533 .

Tanagarine Group, The, 533 .

Tantalus, The, 33 I.

Teal, Common, 233.

Teal, Common, The, 233.

Tenuirostres, 455,462 .

Tern, The, 279.

Tern, 278.

, Arctic, 28r.

, Caspian, 28I.

," Little, or Lesser, 28I.

, Roseate, 28I.

", Sandwich, 28I.

, Sooty, 28r.

Tetraonidæ, The, 37 I.

Thalassians, or Sea Tortoises, 156 .

Thornbills, Columbian, 470.

$$
\text { Hermit, } 229 .
$$

Thrush, Polyglot, 529, 53 I.

," Solitary, or Hermit, 528 .

, Song, 532.

, Song, 53I.

Tic-polonga, The, 82 .
Tinamides, The, 371, 393.

Tit, Crested, 50 I.

Tits, 500.

,, Great, 500.

,, Long-tailed, 5or.

Toads, 23.

, Common, 24.

, Natterjack, 24.

, Surinam, 26.

,, Surinam, 26.

Tortoises, 144.

, Box, 149.

", Elephantine, I45, I47.

, Greek, 145, 146.

," Land, I42, I44, 145.

,, Margined, I45, I46.

,, Moorish, 146.

,, Moorish, I45.

,, Mud, I48.

, Mud, I42, I49.

, Sea, or Turtles, I44.

, Green, I6I, I62.

," Hawk's-bill, I62.

, Leather-back, I63.

," Loggerhead, I63.

Toucan, Bill of, $\mathbf{1 7 4}$.

, Common, 442 .

Toucans, 44I.

,, Proper, 44I, 443.

Tragopans, The, 4II.

Tree Creepers, Common, 468.

Trimeresurus, 75 .

Trionyx, The, I42, I48, $15 \mathrm{I}$.

Trogons, 448.

, Cuban, 449.

", Mexican, 449.

", Resplendent, 448.

,, Resplendent, 449.

Tropic Bird, 262.

Tube, I7 I.

Turkey Buzzard, The, 606.

Turkeys, 4I 2 .

," Domestic, $4 \mathrm{r} 6$.

," Ocellated, or Honduras, 416.

," Wild, 4r 3 .

, Wild, 4I3.

Turnix Tachydroma, 393.

, Tachydroma, 393.

Turnstone, The, 305, 307.

Turnstone, 307.

Turtle, Egyptian River, I52.

, Green, 158. 
Turtle, Hawk's Bill, 162.

"Leathery, 164.

", Loggerhead, I63.

,, Skeleton of, I 5.

Tyrants, The, 538 .

Ular Saward, The, 54.

Umbrella Bird, 540.

Urubu, The, 604 .

Urubus, 605 .

Vanjas, or Pied Crow Shrike, 543.

Vipers, Pit, 73.

Vocal Apparatus, Contracted and Distended, I 79.

Vulture, Chinese, 6 ro.

" Common or Alpine, 607.

," Fulvous, 608.

,, King, 604 .

, King, 603.

," Kolbe's, 6o7.

," Pondicherry, 607.

,, Pondicherry, 6ı.

,. Sociable, 6ro.

", Yellow, 609.

Vultures, 597.

Wagtails, $52 \mathrm{I}$.

$$
\begin{array}{ll}
, & \text { Pied, } 523 . \\
& \text { Pied, } 522 .
\end{array}
$$

Warblers, 5 I4.

, Fan-tailed, 517 .

,, Night, 517.

, Sedge, 516.

Water Hen, 296.

", Hens, 296.

", , Common, 296.

,, , Yurple or Sultana Fowl, 297.

Waxwing, Bohemian, 536.

Web, I $7 \mathbf{I}$.

Whidah Birds, 495.

Whidah Birds, 495.

Woodcock, The, 305, 313 .

Woodcocks, 3 I 4. Common, 313.

Woodpeckers, 449.

Wrens, 518.

Downy, 45 I.

$$
\text { , Ivory-billed, } 450 \text {. }
$$$$
\text { owny, 45 I. }
$$

, Common, 520.

, European, 519.

,, Fire-crested, 5 I9.

," Golden-crested, 518.

," Nest of, $\mathbf{1} 8 \mathbf{2}$.

,, Willow, $52 \mathrm{r}$.

,, Wood or Willow, 520.

Wry-necks, $45^{2}$.

Wry-necks, $45^{2}$.

Yellow-ammer, The, 498.

THE END. 



SMITHSONIAN INSTITUTION LIBRARIES 